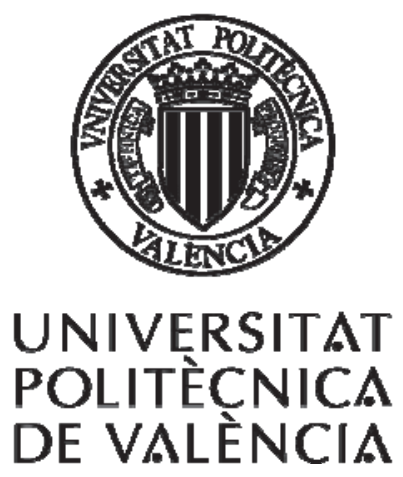

\title{
DISEÑO DE REDES DE DISTRIBUCIÓN DE AGUA MEDIANTE ALGORITMOS EVOLUTIVOS. ANÁLISIS DE EFICIENCIA.
}

\author{
TESIS DOCTORAL \\ DEPARTAMENTO DE INGENIERÍA HIDRÁULICA Y MEDIO \\ AMBIENTE
}

Autor: Daniel Mora Melia

Director: Pedro L. Iglesias Rey

Julio 2012 
Agradecimientos:

A mis padres, por educarme en la constancia y el trabajo

A Cristina, por todo su apoyo, aún en los peores momentos A mi director, por toda su ayuda y comprensión A mis compañeros, por hacer el día a día mejor A Heber Pimentel, por acogerme durante mi estancia en el LEHNS 


\section{Resumen}

Los modelos utilizados en el diseño de redes hidráulicas pueden ser muy variados, en función del objetivo que se pretende abordar. Este trabajo se centra fundamentalmente en el dimensionado hidráulico de redes de distribución de agua, de modo que se cumplan una serie de requerimientos de servicio, entre los que se incluyen condiciones mínimas de presión, velocidad, etc.

El diseño de redes de distribución de agua es un problema de difícil resolución. El mayor problema radica en la elección de los diámetros como variables de decisión; puesto que en este caso las restricciones son funciones implícitas de estos mismos diámetros, el espacio de soluciones se convierte en no convexo y la función objetivo en multimodal. En este punto, los métodos tradicionales basados en técnicas matemáticas quedan limitados a la localización de mínimos locales de la función objetivo, que depende del punto de inicio del proceso de convergencia.

Es por ello que tradicionalmente el diseño, ampliación o rehabilitación de redes de distribución de agua se ha basado en la experiencia ingenieril. Sin embargo, durante las tres últimas décadas numerosos investigadores han centrado sus esfuerzos en desarrollar metodologías de optimización que pudieran aplicarse al diseño de redes de distribución de agua.

La aplicación de técnicas heurísticas de optimización permite una búsqueda más allá de mínimos locales, que generalmente amplía el campo de búsqueda, y por tanto, la capacidad de obtener mejores soluciones. Dentro de este tipo de técnicas, los algoritmos evolutivos son métodos de búsqueda de soluciones basados en los principios naturales de la evolución.

Las distintas técnicas evolutivas son numerosas y en la bibliografía es posible encontrar multitud de modelos de optimización aplicados al diseño de RDA mediante estas técnicas, pero no existen criterios válidos de comparación entre ellas más allá del coste mínimo de diseño obtenido para una determinada red. Dentro de este grupo se encuentran metodologías como los algoritmos genéticos (AG), Particle Swarm Optimization (PSO), Harmony Search (HS), etc.

El objetivo es minimizar los costes de inversión necesarios para la implantación de un determinado sistema, partiendo de la situación topológica de la red, la demanda en cada nudo de consumo y unos requerimientos de presión mínima en los nudos. La metodología propuesta desarrolla una codificación alfanumérica en lugar de la tradicional formulación binaria. Del mismo modo se analiza la posibilidad de optimizar los distintos parámetros de ajuste asociados a cada una de las metodologías planteadas. 
Esta tesis compara los resultados obtenidos por algunas de estas técnicas aplicadas al diseño óptimo de redes de agua. Así, a partir de las simulaciones realizadas, la tesis se centra en cómo mejorar los resultados obtenidos, para lo que se realiza un análisis estadístico no sólo de los resultados obtenidos por cada uno de los modelos de optimización, sino también de la influencia que ejerce el ajuste de los distintos parámetros de cada técnica en el buen hacer de la misma.

Para ello se define un índice de eficiencia del algoritmo que permite relacionar la calidad de la solución obtenida con el esfuerzo computacional que realiza un determinado algoritmo hasta encontrar la solución de diseño definitiva. La eficiencia es un nuevo concepto en la aplicación de métodos heurísticos a la resolución de problemas complejos. En este caso, se representa la relación entre calidad de la solución y velocidad de resolución del algoritmo.

El índice de eficiencia (E) da una idea de la calidad de la simulación realizada, de modo que cuanto mayor es este número mejor es la relación entre calidad de la solución y recursos empleados para obtenerla. Este índice de eficiencia representa una forma neutra de comparar los algoritmos de optimización en base a distintos criterios. 


\section{Resum}

Els models utilitzats en el disseny de xarxes hidràuliques poden ser molt variats, en funció de l'objectiu que es pretén abordar. Aquest treball se centra fonamentalment en el dimensionat hidràulic de xarxes de distribució d'aigua, de manera que es complisquen una sèrie de requeriments de servici, entre els que s'inclouen condicions mínimes de pressió, velocitat, etc.

El disseny de xarxes de distribució d'aigua és un problema de difícil resolució. La major complicació radica en l'elecció dels diàmetres com a variables de decisió; ja que en este cas les restriccions són funcions implícites d'estos mateixos diàmetres, l'espai de solucions es convertix en no convex i la funció objectiu en multimodal. En este punt, els mètodes tradicionals basats en tècniques matemàtiques queden limitats a la localització de mínims locals de la funció objectiu, que depén del punt d'inici del procés de convergència.

És per això que tradicionalment el disseny, ampliació o rehabilitació de xarxes de distribució d'aigua s'ha basat en l'experiència ingenieril. No obstant això, durant les tres últimes dècades nombrosos investigadors han centrat els seus esforços a desenrotllar metodologies d'optimització que pogueren aplicar-se al disseny de xarxes de distribució d'aigua.

L'aplicació de tècniques heurístiques d'optimització permet una busca més enllà de mínims locals, que generalment amplia el camp de busca, i per tant, la capacitat d'obtindre millors solucions. Dins d'este tipus de tècniques, els algoritmes evolutius són mètodes de busca de solucions basats en els principis naturals de l'evolució.

Les distintes tècniques evolutives són nombroses i en la bibliografia és possible trobar multitud de models d'optimització aplicats al disseny de RDA per mitjà d'estes tècniques, però no hi ha criteris vàlids de comparació entre elles més enllà del cost mínim de disseny obtingut per una determinada xarxa. Dins d'este grup es troben metodologies com els algoritmes genètics (AG) , Particle Swarm Optimization (PSO), Harmony Search (HS), etc.

L'objectiu és minimitzar els costos d'inversió necessaris per a la implantació d'un determinat sistema, partint de la situació topològica de la xarxa, la demanda en cada nuc de consum i uns requeriments de pressió mínima en els nucs. La metodologia proposada desenrotlla una codificació alfanumèrica en compte de la tradicional formulació binària. De la mateixa manera s'analitza la possibilitat d'optimitzar els distints paràmetres d'ajust associats a cada una de les metodologies plantejades.

Esta tesi compara els resultats obtinguts per algunes d'estes tècniques aplicades al disseny òptim de xarxes d'aigua. Així, a partir de les simulacions realitzades, la tesi se centra en com millorar els resultats obtinguts, per al que es realitza una anàlisi estadística no sols dels 
resultats obtinguts per cada un dels models d'optimització, sinó també de la influència que exercix l'ajust dels distints paràmetres de cada tècnica en el bon fer de la mateixa.

Per això es definix un índex d'eficiència de l'algoritme que permet relacionar la qualitat de la solució obtinguda amb l'esforç computacional que realitza un determinat algoritme fins a trobar la solució de disseny definitiva. L'eficiència és un nou concepte en l'aplicació de mètodes heurístics a la resolució de problemes complexos. En este cas, es representa la relació entre qualitat de la solució i velocitat de resolució de l'algoritme

L'índex d'eficiència (E) dóna una idea de la qualitat de la simulació realitzada, de manera que quant major és este número millor és la relació entre qualitat de la solució i recursos empleats per a obtindre. Este índex d'eficiència representa una forma neutra de comparar els algoritmes d'optimització basant-se en distints criteris. 


\begin{abstract}
The models used in the design of water distribution networks networks can be quite varied, depending on the objective to be attained. This Ph. Degree focuses primarily on hydraulic sizing water distribution networks, so as to meet certain service requirements, including minimum conditions of pressure, velocity, etc.
\end{abstract}

The design of water distribution networks is extremely complex. It is well-known that when the diameters of the conductions are chosen as decision variables, the restrictions are implied functions of these variables of decision, so the space's region of solutions is a no convex type and the objective function becomes multimodal. At this point, traditional methods based on mathematical techniques are limited to the location of local minima of the objective function, which depends on the starting point of convergence.

Traditionally, water distribution network design, upgrade, or rehabilitation has been based on engineering judgement. Howewer, in the last three decades a significant amount of research has focused on the optimal design of water distribution networks.

The application of heuristic techniques of optimization allows the search beyond these local minimums, which generally ample the field search and with it the capacity to obtain better solutions. The evolutionary algorithms are methods of search of solutions that are based in the natural beginning of the evolution.

The different evolutionary techniques are numerous. In the literature one can find many optimization models applied to the design of water distribution networks using these techniques. Regrettably, there are no valid criteria for comparing them beyond the minimum cost design for a given network obtained. Inside the evolutionary algorithms, we can find Genetic Algorithms (GA), Particle Swarm Optimization (PSO), Harmony Search and so on

The aim is to minimize the necessary costs of investment for the implantation of a certain system, starting from the topological layout and the demands and requirements of pressure in the nodes. The proposed method develops a code based on the use of numerical particles instead of binary particles. It is also introduced the optimization of the different parameters associated with each methodology.

This doctoral thesis compares the results obtained by some of these techniques applied to optimal design of water networks. Thus, from simulations, the thesis focuses on how to improve the results, for which statistical analysis is performed not only on the results obtained by each of the optimization models, but also the influence adjusting the various parameters of each technique in the good work of it. 
In order to do this, we define an efficiency ratio of the algorithm that allows us to relate the quality of the solution obtained with the computational effort that performs an algorithm to find the final solution. Efficiency is a new concept in the application of heuristic methods to solve complex problems. In this case, it represents the relationship between solution quality and speed of resolution of the algorithm

The efficiency (E) gives an idea of the quality of the simulation performed, so that the greater this number the better the relationship between solution quality and resources used to obtain it. This efficiency rating is a neutral to compare optimization algorithms based on different criteria. 


\section{Resumo}

Os modelos utilizados no dimensionamento de redes hidráulicas podem ser muito variados, dependendo do objetivo a ser abordado. Este trabalho é focado primariamente na dimensionamento hidráulico redes de distribuição de água, a respeitar uma série de requisitos de serviço, que incluem condições mínimas de pressão, de velocidade, etc.

O dimensionamento de redes de distribuição de água é um problema difícil. O principal problema reside na escolha dos diâmetros como variáveis de decisão, uma vez que neste caso os constrangimentos são funções implícitos do mesmo diâmetro, o espaço solução torna-se não-convexa ea função objectivo em multimodal. Neste ponto, os métodos tradicionais baseados em técnicas matemáticas são limitados para a localização de mínimos locais da função objectivo, a qual depende do ponto de partida de convergência.

É por isso que o projeto de expansão, ou a reabilitação de redes de distribuição de água foi baseado na experiência de engenharia. No entanto, durante as últimas três décadas, muitos pesquisadores têm focado seus esforços no desenvolvimento de metodologias de otimização que poderiam ser aplicados ao dimensionamento de redes de distribuição de água.

A utilização de heurísticas de otimização permite uma busca para além mínimos locais, que geralmente estende o campo de pesquisa, e, portanto, a capacidade de obter as melhores soluções. Dentro de tais técnicas, algoritmos evolucionários são métodos de busca de soluções baseados nos princípios da evolução natural.

As diferentes técnicas evolutivas são numerosos e da literatura é possível encontrar muitos modelos de otimização aplicados ao projeto de RDA com esses métodos, mas não há critérios válidos para compará-los além do projeto custo mínimo obtido para uma determinada rede. Dentro deste grupo são metodologias, tais como Algoritmos Genéticos (GA), Particle Swarm Optimization (PSO), Harmony Search (HS), etc.

O objectivo é o de minimizar os custos de investimento necessários para implementar um sistema em particular, com base na situação de rede topológica, a demanda em cada nó de consumo e requisitos mínimos de pressão nos nós. A metodologia proposta desenvolve um código alfanumérico em vez de a formulação binário tradicional. Assim como analisar a possibilidade de optimizar os vários parâmetros associados com cada conjunto de metodologias.

Esta tesis compara los resultados obtenidos por algunas de estas técnicas aplicadas al diseño óptimo de redes de agua. Así, a partir de las simulaciones realizadas, la tesis se centra en cómo mejorar los resultados obtenidos, para lo que se realiza un análisis estadístico no sólo de los resultados obtenidos por cada uno de los modelos de optimización, sino también de la 
influencia que ejerce el ajuste de los distintos parámetros de cada técnica en el buen hacer de la misma.

Esta tese compara o desempenho de algumas dessas técnicas aplicadas ao projeto otimizado de redes de água. Assim, a partir das simulações, a tese concentra-se em forma de melhorar os resultados, para que a análise estatística é realizada não só os resultados para cada um dos modelos de optimização, mas também a influência ajustar os vários parâmetros de cada técnica.

Para este fim, definir uma taxa de eficiência do algoritmo que se relaciona com a qualidade da solução obtida com o esforço computacional que executa um algoritmo para encontrar a solução de dimensionamento final. Eficiência é um novo conceito na aplicação de métodos heurísticos para resolver problemas complexos. Neste caso, é a relação de qualidade solução e velocidade de resolução do algoritmo.

O índice de eficiência (E) dá uma ideia da qualidade da simulação realizada, de modo que quanto maior for o número, melhor a relação entre a qualidade da solução e meios utilizados para a obter. Este índice de eficiência é uma forma neutra de comparar os algoritmos de otimização com base em critérios diferentes. 


\section{ÍNDICE}

1. INTRODUCCIÓN.

1.1 Justificación 1

1.1.1 Clasificación de las redes de distribución de agua

1.1.2 Estados de carga

1.2 Necesidad de la tesis 7

1.3 Objetivos 9

1.4 Estructura de la tesis 10

2. ESTADO DEL ARTE EN LA OPTIMIZACIÓN DEL DISEÑO DE REDES DE DISTRIBUCIÓN DE AGUA

2.1 Introducción al diseño de redes de agua. 13

2.2 Fundamentos de diseño. 14

2.2.1 Ecuaciones y variables de naturaleza hidráulica

2.1.2 Variables de tipo económico

2.3 Técnicas de diseño. 21

2.3.1 Técnicas de tipo funcional

2.3.1.1 Aplicación de criterios de velocidad admisible

2.3.1.2 Aplicación del criterio de pendiente uniforme

2.3.1.3 Dimensionado de redes malladas 
2.3.2 Técnicas de diseño económico

2.3.2.1 Programación lineal

2.3.2.2 Programación no lineal

2.3.2.3 Programación dinámica

2.3.2.4 Técnicas heurísticas

2.3.2.4.1 Algoritmos Genéticos ( $A G)$

2.3.2.4.2 Simulated Annealing (SA)

2.3.2.4.3 Particle Swarm Optimization (PSO)

2.3.2.4.4 Shuffled Frog Leaping Algorithm (SFLA)

2.3.2.4.5 Harmony Search (HS)

3. MODELOS HEURÍSITICOS DE OPTIMIZACIÓN.

3.1 Introducción. . .47

3.2 Modelo de optimización Algoritmo Pseudogenético (APG). 50

3.2.1 Operadores genéticos

3.2.1.1 Proceso de reproducción

3.2.1.2 Proceso de cruce

3.2.1.3 Proceso de mutación

3.3 Modelo de optimización Harmony Search (HS). 60

3.3.1 Operadores HS

3.4 Modelo Particle Swarm Optimization modificado (PSO). 64

3.4.1 Operadores PSO

3.4.1.1 Población del algoritmo (№ de partículas)

3.4.1.2 Velocidad máxima $\left(\mathrm{V}_{\mathrm{lim}}\right)$ 
3.4.1.3 Constantes de aceleración $\left(C_{1}\right.$ y $\left.C_{2}\right)$

3.4.1.4 Factor de inercia (w)

3.4.1.5 Probabilidad de despiste $\left(P_{\text {desp }}\right)$

3.5 Modelo de optimización Simulated Annealing (SA)

3.5.1 Parámetros de optimización

3.5.1.1 Temperatura ( $\mathrm{T})$

3.5.1.2 Velocidad de enfriamiento

3.6 Modelo de optimización Shuffled Frog Leaping Algorithm (SFLA).. 76 3.6.1 Operadores algoritmo SFL

3.6.1.1 Parámetros relativos a la población del algoritmo $(\mathrm{m}$ y $n)$

3.6.1.2 Parámetros relativos a la naturaleza de los saltos evolutivos (N, Q y $\mathrm{C})$

4. CASOS DE ESTUDIO Y RESULTADOS

4.1 Introducción 83

4.2 Red de Hanoi. 84

4.3 Red de Nueva York. 89

4.4 Red R-9 de Joao Pessoa 94

4.5 Red de Go-Yang. 99

5. ANÁLISIS ESTADÍSTICO DE SOLUCIONES. 103

5.1 Introducción 103

5.2 Análisis de parámetros... 104

5.2.1 Ajuste de parámetros Algoritmo Pseudogenético (APG)

5.2.1.1 Red de Hanoi 
5.2.1.2 Red de Nueva York

5.2.1.3 Red R-9 de Joao Pessoa

5.2.1.4 Red de Go-Yang

5.2.2 Ajuste de parámetros Algoritmo PSO modificado

5.2.2.1 Red de Hanoi

5.2.2.2 Red de Nueva York

5.2.2.3 Red R-9 de Joao Pessoa

5.2.2.4 Red de Go-Yang

5.2.3 Ajuste de parámetros Harmony Search

5.2.3.1 Red de Hanoi

5.2.3.2 Red de Nueva York

5.2.3.3 Red R-9 de Joao Pessoa

5.2.3.4 Red de Go-Yang

5.2.4 Ajuste de parámetros Algoritmo SFL

5.2.4.1 Red de Hanoi

5.2.4.2 Red de Nueva York

5.2.4.3 Red R-9 de Joao Pessoa

5.2.4.4 Red de Go-Yang

5.3 Análisis de población del algoritmo. 175

5.3.1 Ajuste de población Algoritmo Pseudogenético

5.3.1.1 Red de Hanoi

5.3.1.2 Red de Nueva York

5.3.1.3 Red R-9 de Joao Pessoa

5.3.1.4 Red de Go-Yang 
5.3.2 Ajuste de población del algoritmo PSO modificado

5.3.2.1 Red de Hanoi

5.3.2.2 Red de Nueva York

5.3.2.3 Red R-9 de Joao Pessoa

5.3.2.4 Red de Go-Yang

5.3.3 Ajuste de población del algoritmo HS

5.3.3.1 Red de Hanoi

5.3.3.2 Red de Nueva York

5.3.3.3 Red R-9 de Joao Pessoa

5.3.3.4 Red de Go-Yang

5.3.4 Ajuste de población del algoritmo SFL

5.3.4.1 Red de Hanoi

5.3.4.2 Red de Nueva York

5.3.4.3 Red R-9 de Joao Pessoa

5.3.4.4 Red de Go-Yang

5.4 Análisis de la velocidad de cálculo en los modelos de optimización desarrollados.. 221

5.4.1 Influencia de los parámetros en la velocidad de cálculo del APG

5.4.2 Influencia de los parámetros en la velocidad de cálculo del algoritmo PSO modificado

5.4.3 Influencia de los parámetros en la velocidad de cálculo del algoritmo HS

5.4.4 Influencia de los parámetros en la velocidad de cálculo del algoritmo SFL 
5.5.1 Análisis de parámetros

5.5.2 Análisis del tamaño de población

5.5.3 Análisis de velocidad del algoritmo

6. EFICIENCIA DE LOS MODELOS DE OPTIMIZACIÓN..

6.1 Introducción

6.2 Eficiencia de los modelos de optimización en la red de Hanoi

6.2.1 Algoritmo Pseudogenético

6.2.2 Algoritmo PSO modificado

6.2.3 Algoritmo HS

6.2.4 Algoritmo SFL

6.3 Eficiencia de los modelos de optimización en la red de Nueva York

6.3.1 Algoritmo Pseudogenético

6.3.2 Algoritmo PSO modificado

6.3.3 Algoritmo HS

6.3.4 Algoritmo SFL

6.4 Eficiencia de los modelos de optimización en la red R-9 de Joao Pessoa.

6.4.1 Algoritmo Pseudogenético

6.4.2 Algoritmo PSO modificado

6.4.3 Algoritmo HS

6.4.4 Algoritmo SFL 
6.5 Eficiencia de los modelos de optimización en la red de Go-Yang.... 304

6.5.1 Algoritmo Pseudogenético

6.5.2 Algoritmo PSO modificado

6.5.3 Algoritmo HS

6.5.4 Algoritmo SFL

6.6 Aplicaciones basadas en el análisis de eficiencia.

6.6.1. Aplicación a la ampliación de una red de trazado real

6.6.2 Aplicación a la fiabilidad de una red de distribución

6.6.2.1 Red de Hanoi

6.6.2.2 Red de Nueva York

6.6.2.3 Red R-9 de Joao Pessoa

6.6.2.4 Red de Go-Yang

7. CONCLUSIONES Y DESARROLLOS FUTUROS

7.1 Conclusiones

7.1.1 Algoritmo Pseudogenético (APG)

7.1.2 Algoritmo PSO

7.1.3 Algoritmo SFL

7.1.4 Algoritmo HS

7.2 Desarrollos futuros 358

BIBLIOGRAFÍA 363

ANEXO. CONCLUSIONS AND FUTURE DEVELOPMENTS. 371

ANEXO. CONCLUSÕES E DESENVOLVIMENTOS FUTUROS 


\section{INTRODUCCIÓN}

\subsection{Justificación}

Una red de distribución de agua (RDA) no es más que una serie de componentes que, conectados de modo adecuado entre sí, suministran la cantidad de agua demandada a la presión establecida. Estos componentes son tuberías, válvulas, bombas, depósitos, etc. Para que esta definición sea efectiva, es necesario determinar las dimensiones de los componentes de la red. Así, el establecimiento de los diámetros idóneos de los conductos que integran cualquier sistema de distribución de agua no es un problema directo y determinado, como tampoco lo es el resto de elementos que la componen.

Con todo esto, el problema de diseño óptimo de redes de agua está sin resolver de una forma completamente satisfactoria, y ello es en parte debido a la gran diversidad de factores que afecta al problema.

Por este motivo los modelos de diseño no se han introducido aún con la misma fuerza que los modelos de análisis, debido probablemente a limitaciones como:

- El número de modelos de demanda que pueden manejar.

- El tamaño de la red.

- El tipo de componentes que pueden ser dimensionados.

- La incorporación o no de una aproximación al diseño fiable de la red.

- La dificultad para entender la metodología matemática en la cual se basan.

De igual manera, el diseño de una red de distribución puede presentar multitud de variables y circunstancias, que imposibilitan la definición de una metodología de diseño de redes que pueda considerarse de aplicación general en todos los casos. El proceso de diseño que debe seguirse en cada caso está condicionado a las características de la red objeto de estudio.

\subsubsection{Clasificación de las redes de distribución de agua}

Es posible realizar distintas clasificaciones de las redes de agua en base al tipo de diseño que se requiera realizar en cada caso. La clasificación más sencilla que se puede realizar en redes 
de distribución de agua divide a éstas en dos grandes grupos, como son las redes ramificadas y las redes malladas

Sin atender a razones hidráulicas, una red ramificada tiene un aspecto arbóreo, puesto que se ramifica desde la alimentación (depósito, bomba, etc) hasta los puntos de consumo. Por el contrario, las redes malladas tienen un aspecto reticular, con circuitos cerrados de tuberías.

Desde un punto de vista hidráulico, las redes ramificadas permiten determinar los caudales que circulan por las tuberías a partir de los consumos de la red. No es necesario en este caso conocer las características de la propia tubería. Por el contrario, en el caso de una red mallada, la distribución de caudales depende de las características hidráulicas de las propias tuberías, por lo que los datos de consumo no proporcionan suficiente información para poder calcular los caudales.

Las diferencias conceptuales entre ambos tipos de redes justifican la utilización de un tipo de red u otra según el caso. Así, aplicando cualquier método de optimización considerando tan sólo factores económicos, el resultado es que la implantación de una red ramificada siempre es más económica que una red mallada.

Por el contrario, las redes malladas son mejores desde el punto de vista de la seguridad en el suministro, puesto que la rotura de una conducción en una red mallada no implica que el suministro quede interrumpido. Si el diseño de la red mallada es adecuado, el sistema es redundante, por lo que se puede mantener el servicio al usuario sin interrupciones por reparación. Evidentemente, esta redundancia provoca que un sistema mallado tenga mayor capacidad de transporte de la que es estrictamente necesaria, lo que provoca una subida en el coste de la red.

El diseño de sistemas mallados reviste mayor complejidad que el de sistemas ramificados, puesto que es necesario conocer el caudal que circula por una tubería para determinar su diámetro. Del mismo modo, dicho caudal es función del diámetro de la propia tubería y del resto de diámetros, razón por la que el problema de diseño en redes malladas no es de resolución trivial.

La necesidad de redundancia es difícil de cuantificar económicamente, pero parece fácil imaginar que los perjuicios provocados por una falta de suministro son grandes, por lo que resulta necesario introducir en la formulación del problema de diseño algún tipo de restricción que asegure el buen funcionamiento de la configuración mallada, lo que se conoce como condición de redundancia, y consiste en establecer rutas alternativas para la conducción del agua a cualquier nudo de consumo, de modo que ante un escenario de fallo siempre existan alternativas, que garanticen tanto la llegada como la capacidad de transporte para un determinado punto de consumo. 
Para cumplir la condición de redundancia es necesario contemplar todos los posibles escenarios de fallo, por lo que en la formulación del problema es necesario incluir todas y cada una de las configuraciones que resulten de posibles roturas de tubería en la red. Cuando el número de tuberías en la red resulta mayor de 10 o 15 esta forma de proceder resulta complicada sin ayuda de software especializado, por lo que varios autores han definido restricciones adicionales en el problema de diseño que representen, de modo indirecto, el mantenimiento de la condición de redundancia sin necesidad de recurrir a la descripción exhaustiva de todos los casos posibles. Algunas posibilidades son:

- Evitar la eliminación de tuberías en el proceso de dimensionado. Para ello es posible establecer restricciones sobre el valor mínimo de alguna variable hidráulica de la tubería, como pueda ser imponer un diámetro mínimo de tubería (Alperovits y Shamir, 1977), un valor mínimo de caudal circulante, etc.

- Establecer que cada nudo de consumo deba estar conectado por medio de al menos dos tuberías (Goulter y Morgan, 1985). Exigir un mayor número de conexiones podría llevar a un mallado excesivo e innecesario.

Esta última posibilidad se conoce como condición de redundancia local, si bien no asegura la redundancia de toda la red. En la figura 1.1 se observa que una rotura en la tubería 9 dejaría sin servicio a los nudos situados en la subred de la parte derecha, pese a cumplir la condición de redundancia local.

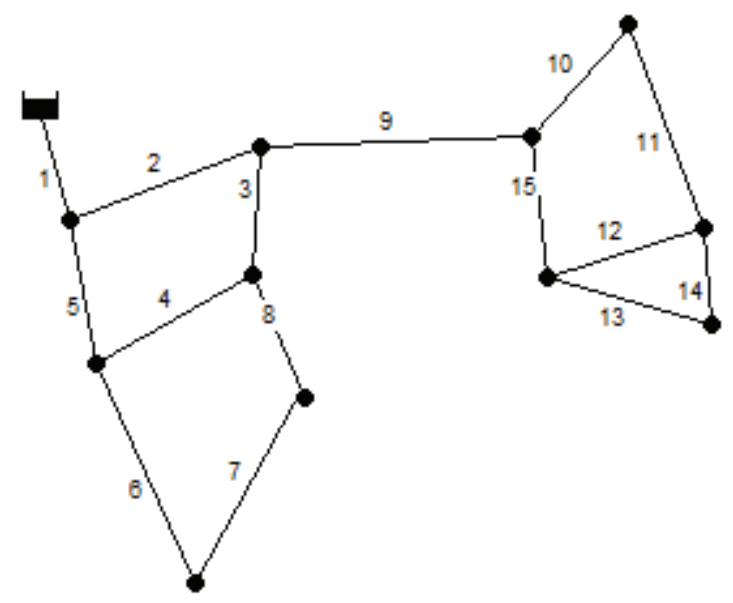

Figura 1.1. Condición de redundancia local

Otra opción es ampliar el criterio anterior, de modo que se establezca un número mínimo de conexiones por sector. De este modo, cualquier zona de la red está alimentada por un mínimo de dos tuberías, con lo que se asegura la redundancia total. La figura 1.2 muestra el 
ejemplo anterior, al que se le ha añadido la tubería 16 , con lo que ahora se cumple la condición de redundancia en toda la red

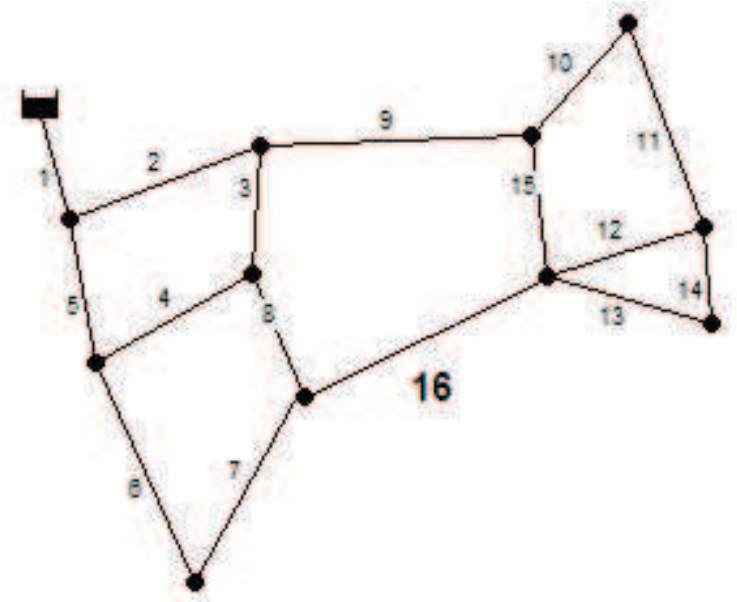

Figura 1.2. Condición de redundancia en toda la red

Normalmente se utilizan redes ramificadas en casos donde el prejuicio derivado de una interrupción temporal en el servicio no es considerable, como pueden ser las redes de riego o industrial. En el caso del abastecimiento en ciudades la configuración más adecuada es la mallada.

Independientemente de si el caso de estudio es ramificado o mallado, existen otras consideraciones de interés que conviene conocer cuando se pretende abordar el diseño de una red de distribución.

Así, cuando se diseña una red de distribución de agua es posible diferenciar claramente dos etapas. La primera de ellas es la referente al proceso de distribución en planta, cuya optimización está orientada a disminuir los costes de inversión y operación, mientras que la parte del diseño comprende el dimensionamiento de los elementos de la red. Si la distribución en planta de la red está predeterminada, el problema de diseño se limita, en el caso de las tuberías, a escoger los diámetros más apropiados. El verdadero problema surge cuando dicha distribución en planta no está predeterminada y es necesario combinar ambas etapas. En este caso, el trazado definitivo del sistema, que serviría de base al dimensionamiento del mismo es también una incógnita, con lo que el problema adquiere una complejidad inusitada.

Otra posible clasificación para los distintos problemas de diseño diferenciaría entre redes de nueva implantación y redes de ampliación para una red ya existente. Actualmente, cuando se habla de implantación de una nueva red casi siempre se refiere a redes de riego, nuevas urbanizaciones o redes industriales, puesto que la mayoría de las poblaciones ya cuentan con 
su propia red de abastecimiento de agua. Por su parte, el diseño de ampliaciones y mejoras de una red existente suele estar asociado a redes de distribución urbanas, ya sea por insuficiencia de la red actual por el crecimiento de la población o por el deterioro de las condiciones de la red producido por el paso del tiempo.

\subsubsection{Estados de carga}

En el diseño de redes de distribución de agua es importante considerar la situación operacional para la que se está diseñando. Normalmente, en ingeniería hidráulica se diseña para que el sistema sea capaz de funcionar en la situación más desfavorable que se pueda plantear, de modo que si es capaz de funcionar en esas condiciones se puede afirmar de manera implicita que también lo hará en el resto de escenarios posible.

Si consideramos un caso sencillo, como pueda ser el de una tubería de impulsión diseñada para trasegar un caudal máximo, la situación más desfavorable del sistema trasiega precisamente ese valor máximo de caudal. Si el sistema es capaz de solventar esa situación más desfavorable, obviamente podrá trasegar también caudales menores.

En el caso de la presión de trabajo de la tubería resulta necesario calcular el golpe de ariete provocado por la parada brusca de las bombas impulsoras. Existen dos tipos de situaciones más desfavorables: una estacionaria (máximo caudal) para determinar la capacidad hidráulica y otra transitoria para estimar la resistencia mecánica de la tubería.

Es difícil decidir cuál es la situación más desfavorable en una red de distribución, puesto que son multitud las condiciones operativas en las que trabaja una determinada red. No obstante, se consideran "patrones" de funcionamiento que permiten representar adecuadamente el conjunto de situaciones más desfavorables que pueden encontrarse en el funcionamiento de la red.

El patrón de funcionamiento describe las demandas de caudal en los nudos más los correspondientes valores de la presión de servicio. A estos datos es a lo que se conoce como estado de carga de la red. La formulación del problema de diseño será más precisa y fiable cuantos más estados de carga representativos sean introducidos. Obviamente, esto complica el modelo y su solución.

En ocasiones es posible aglutinar la información de varios estados de carga en uno sólo. La figura 1.3 muestra un problema de dimensionado donde un depósito abastece dos zonas cuyas demandas en régimen normal son $\mathrm{Q}_{1}$ y $\mathrm{Q}_{2}$ (caso a). Además, el sistema debe poder hacer frente a ciertas demandas de emergencia (caudales de incendio, por ejemplo) $\mathrm{Q}_{\mathrm{e} 1}$ y $\mathrm{Q}_{\mathrm{e} 2}$, que se suponen no simultáneas (casos b y c). Toda la información de los casos a, b y c queda condensada en la representación $d$. Si el sistema es diseñado para ésta última representación responderá adecuadamente en los casos a, b y c. 


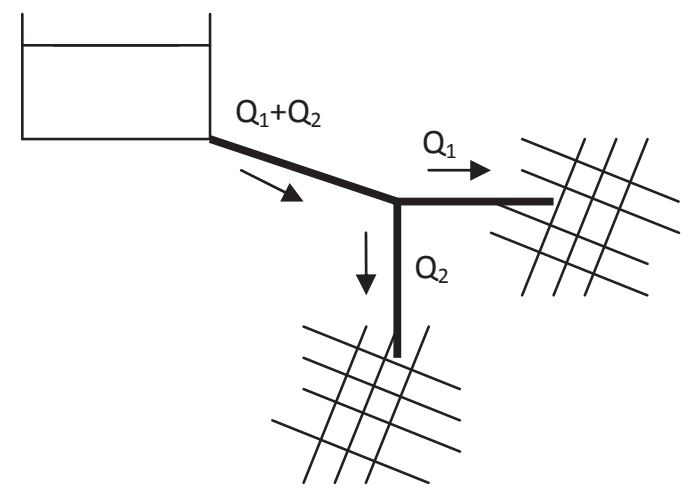

Caso a)

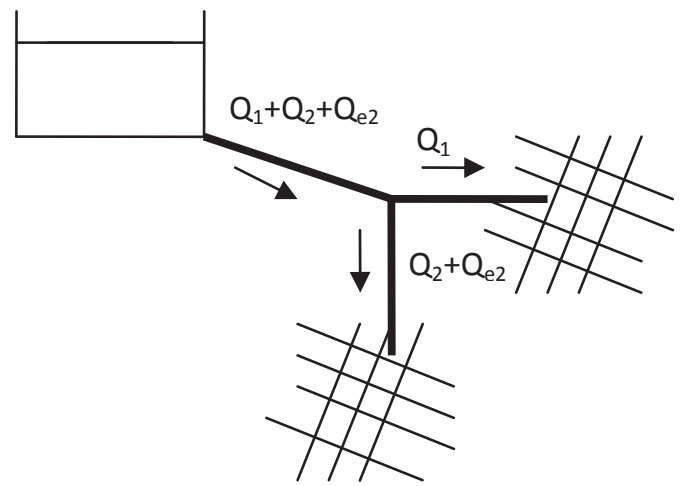

Caso c)

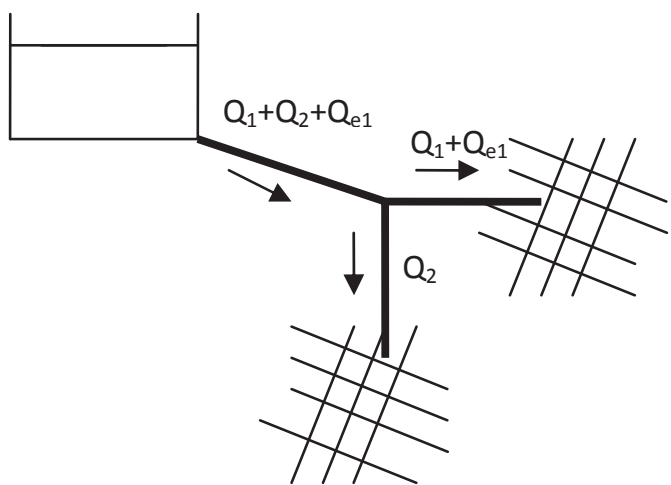

Caso b)

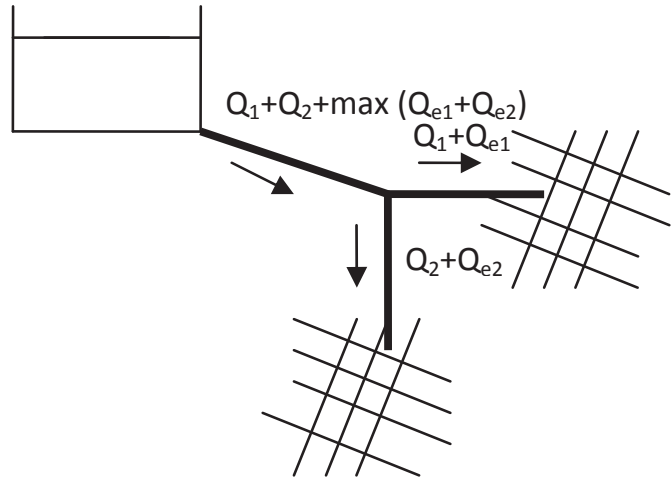

Caso d)

Figura 1.3. Ejemplo distintos estados de carga

Hay que tener en cuenta que los caudales resultantes en las tuberías A, B y C no verifican la ecuación de continuidad, ya que:

$$
Q_{1}+Q_{2}+\max \left(Q_{e 1}, Q_{e 2}\right) \leq Q_{1}+Q_{2}+Q_{e 1}+Q_{e 2}
$$

No es éste un hecho relevante cara a la validez de la representación, puesto que en la etapa de diseño no se busca una situación real, sino una representación operativa adecuada, sin importar que sea ficticia. Esta representación simplemente tiene que agrupar un conjunto de situaciones más desfavorables, a las que el sistema debe poder responder.

La representación mediante criterios probabilísticos de los caudales de diseño o la aplicación de criterios de simultaneidad son ejemplos de agrupar información en un solo patrón. Los 
siguientes puntos enumeran el conjunto de datos previos que son necesarios para acometer el diseño de una red de distribución:

- Necesidades de caudal: distribución espacial y temporal.

- Necesidades de presión.

- Trazados de conducciones.

- Características y situación de los elementos de inyección y almacenamiento.

- Topografía del terreno.

- Diámetro de las conducciones.

- Materiales de las conducciones.

- Velocidades de circulación permitidas y aconsejables

Si existe compatibilidad entre los distintos requisitos de diseño existirán multitud de configuraciones posibles que verifiquen estas premisas. Es entonces cuando entra en juego el concepto de solución más económica. Desde un punto de vista económico, la solución óptima es aquella que representa el menor coste conjunto de explotación e inversión, debiendo cumplir en cualquier caso las restricciones de consumos y presión requerida.

\subsection{Necesidad de la tesis}

La información disponible en la literatura acerca del diseño de redes de agua es abundante, pero aún hoy en día, las especiales características del problema de diseño hacen que no esté completamente resuelto de forma satisfactoria, debido a la gran cantidad de factores que afectan al mismo.

Cuando se pretende abordar el diseño de una RDA es conveniente seguir ciertas recomendaciones dadas en la literatura. Así, Gessler (1985) propone una serie de condiciones que deben cumplir los programas de optimización de redes, y que se deben tener en cuenta en el desarrollo cualquier herramienta de diseño de redes de agua. Tales condiciones son:

- Los diámetros de las tuberías se deben tratar como variables discretas, puesto que los diámetros estándar disponibles para su implantación en la solución final constituyen un diámetro discreto y finito.

- El modelo de optimización debe garantizar al menos una buena aproximación al óptimo global para unas restricciones dadas. 
- El procedimiento de optimización debe poder garantizar que la solución cumple los requisitos para más de un estado de carga.

- Es necesario tener la posibilidad de cambiar el diámetro de las tuberías en determinados puntos de la instalación diseñada.

- Es deseable que el algoritmo proporcione una lista de alternativas en lugar de una única solución.

Numerosos investigadores han diseñado aplicaciones en lo que a métodos de diseño de redes de agua se refiere, planteándose los costes de la red como la función a optimizar. En esta área, la utilización de algoritmos heurísticos para la resolución de problemas de diseño permite una mejor exploración del espacio de soluciones que la ofrecida por los métodos clásicos.

En este sentido la mayoría de las metodologías evolutivas desarrolladas en esta tesis han sido ya aplicadas con cierto éxito a distintos problemas de diseño, pero no se han establecido criterios que permitan comparar el buen hacer de un algoritmo frente a otro. Así, la mayoría de los trabajos que pueden encontrarse en la literatura muestran la mejor solución obtenida, pero no profundizan en otros aspectos de interés, como puede ser la influencia de los distintos parámetros susceptibles de ajuste que tiene cada método, la repetibilidad que se obtiene de la solución o el coste computacional requerido para alcanzarla. Esta tesis muestra un estudio detallado acerca de cada uno de los algoritmos estudiados, desarrollando patrones que permiten la comparación de unos algoritmos con otros, a fin de determinar cuál es la metodología más adecuada en la resolución de redes de agua.

Actualmente, todo el conocimiento sobre el comportamiento de un algoritmo heurístico aplicado al diseño de redes de agua consiste en seguir ciertas pautas cuando se realiza el modelo de optimización y tratar de obtener la mejor solución posible mediante un método que podría calificarse como de prueba y error. Así, no hay trabajos que profundicen sobre la configuración adecuada que deben tener los operadores asociados a cada técnica de optimización, o trabajos que comparen distintos algoritmos de optimización de algún otro modo que no sea la obtención de una mínima solución de diseño. 


\subsection{Objetivos}

La presente tesis pretende avanzar lo suficiente en el conocimiento de las técnicas heurísticas como para reducir en lo posible el factor aleatorio que inevitablemente acompaña a las mismas cuando se realiza una simulación, aportando la configuración más adecuada para cada metodología, de modo que se maximice la eficacia de este tipo de técnicas de optimización en el diseño de redes de agua.

Asimismo, se define el concepto de eficiencia de un algoritmo como un operador matemático que permite la comparación de distintas técnicas heurísticas, no sólo teniendo en cuenta la solución final de diseño obtenida, sino también los recursos computacionales empleados para llegar a ella. Esta aportación permitirá la elección del algoritmo de optimización más adecuado en función de las necesidades de diseño requeridas.

Todos los modelos de optimización utilizados en esta tesis están basados en la aplicación de distintas técnicas heurísticas, para lo que se han desarrollado herramientas informáticas que se apoyan en el programa de análisis para redes de abastecimiento EPANET (Rossman, 1997).

Cabe destacar que la metodología propuesta no incluye otras problemáticas de las redes de agua, como pueda ser el trazado de la misma, la calidad del agua suministrada, la operación de los sistemas de distribución existentes o la optimización de la altura de bombeo.

Este objetivo de carácter general puede concretarse en una serie de objetivos mucho más específicos, que son detallados a continuación:

- Realizar una revisión lo más detallada posible acerca de las investigaciones realizadas hasta la fecha relativas a la optimización de técnicas de diseño en redes de agua, ya sea mediante metodologías funcionales o mediante otro tipo de técnicas de diseño, entre las que se incluyen los algoritmos heurísticos.

- Estudio de las técnicas de optimización más adecuadas dentro de la familia de los algoritmos heurísticos. En este sentido, criterios como la robustez del algoritmo, así como la facilidad para abordar el problema de diseño de redes de agua solventando los inconvenientes que presentan otras técnicas ya aplicadas a este problema serán considerados.

- Establecimiento de modelos matemáticos de optimización de carácter general, que pueden ser aplicados al diseño de redes de agua y adaptados a distintas técnicas de optimización heurísticas. En este sentido, la definición de la función objetivo que se va a utilizar adquiere vital importancia. 
- Implementación de los distintos modelos de optimización en una herramienta que permita el diseño de redes de agua. Así, cada uno de estos modelos incluye un módulo de simulación hidráulica en régimen permanente que permite un análisis dinámico y un modulo de optimización basado en una de las técnicas evolutivas estudiadas. Uno de los principales objetivos del trabajo es la comparación de los distintos modelos de optimización entre sí, a fin de determinar cuál puede ser más adecuado en su aplicación al diseño de redes de agua.

- Evaluación de la bondad de los distintos modelos desarrollados aplicándolos a un conjunto de ejemplos. Algunos de estos ejemplos han sido tomados de la bibliografía especializada y otros surgen fruto de la colaboración con otros investigadores.

- Definición del ajuste más adecuado de los distintos operadores de diseño para cada una de las técnicas de optimización que ensaya este trabajo. Para ello se realiza un análisis estadístico en profundidad, no sólo considerando el coste mínimo de diseño, sino también otros factores, como pueda ser la obtención de buenas soluciones o el número de iteraciones que realiza el algoritmo hasta encontrar la solución final de diseño.

- Creación de un índice de eficiencia que permita la comparación entre las distintas técnicas heurísticas considerando tanto criterios de calidad de la solución, que miden la bondad de la solución obtenida como criterios de velocidad, que consideran el tiempo de cálculo a través del número de evaluaciones de la función objetivo realizadas hasta encontrar la solución final. Este tipo de operador permitirá la elección de una técnica u otra en función tanto de los objetivos del problema como del propio problema en sí.

Las conclusiones derivadas del análisis de eficiencia son utilizadas para el estudio de nuevos problemas de optimización más complejos, que permiten alcanzar una serie de objetivos secundarios derivados del trabajo realizado.

En este sentido, aprovechando la optimización realizad en el buen hacer de los distintos algoritmos se ha formulado una aproximación a la fiabilidad de una red de distribución. Dada la dificultad de definición e interpretación matemática en su forma completa, se limita el estudio a la fiabilidad de las tuberías en cuanto a la rotura de las mismas. Es necesario considerar que el objetivo alcanzado es una aproximación, pues de acuerdo con Goulter (1995), no existen todavía medidas viables para evaluar la fiabilidad de una red de distribución, ni se ha llegado a acuerdos que definan lo que se considera un grado aceptable de fiabilidad. 


\subsection{Estructura de la tesis}

En términos generales, esta tesis puede dividirse en dos bloques bien diferenciados. De este modo, lo que se podría considerar como primer bloque realiza, a modo introductorio, una revisión del estado del arte acerca del diseño óptimo en redes de distribución de agua. A continuación, se plantean distintos modelos de optimización basados en algoritmos evolutivos, aplicados en este caso al dimensionado óptimo de redes de agua. Los distintos modelos que desarrolla este trabajo son utilizados para resolver distintas redes de agua, comparando los resultados obtenidos con otras metodologías y autores.

En un segundo bloque, el trabajo se centra en cómo mejorar los resultados obtenidos por los modelos de optimización planteados, para lo que se realiza un análisis estadístico profundo no sólo de los resultados obtenidos por cada metodología, sino también de la influencia que tienen los ajustes realizados en los parámetros de cada técnica en los resultados finales. Ésta es, en líneas generales, la estructura que presenta este trabajo, aunque las siguientes líneas repasan con mayor detalle el método de trabajo seguido.

Así, el capítulo 1, del cual forman parte estas líneas, realiza una introducción acerca del dimensionado de redes de agua, acercando al lector a la complejidad del problema, y justificando la necesidad de este trabajo. Del mismo modo, se trata de definir cuales son los objetivos que se pretenden conseguir en esta tesis y los medios que se van a utilizar para llegar a ellos.

En el capítulo 2 se trata de ofrecer una visión global acerca de la gran cantidad de factores de los que depende el problema de diseño óptimo de redes de agua, lo que hace que sea un problema aún no resuelto de forma completamente satisfactoria en la realidad. A lo largo del capítulo se realiza una revisión exhaustiva del estado del arte hasta el momento actual, concluyendo la síntesis con una ligera definición de los algoritmos heurísticos, situándolos cronológicamente y repasando algunos de los trabajos que se han presentado hasta la fecha.

Es en el capítulo 3 donde se analizan con profundidad las distintas metodologías heurísticas con las que se trabaja en esta tesis, presentando con detalle los distintos modelos de optimización desarrollados, así como las particularidades introducidas en cada uno de ellos, que tienen como objetivo mejorar a otros existentes en la literatura.

El capitulo 4 aplica los distintos algoritmos de optimización a la resolución de distintas redes de ejemplo. Así, este capítulo define por completo los distintos problemas de optimización que se van a abordar y muestra los resultados de diseño obtenidos tanto por técnicas más clásicas como por los modelos de optimización desarrollados, comparando los resultados obtenidos en cada caso. Todos los ejemplos de aplicación planteados son de variable discreta 
(tuberías), aunque la versatilidad de este tipo de técnicas permite adaptar la metodología seguida a la resolución de problemas de variable continua.

En este punto quedaría cerrado lo que se podría considerar un primer bloque del trabajo, puesto que a partir de aquí los esfuerzos se concentran en cómo mejorar las metodologías empleadas, aplicando para ello análisis estadístico. Así, el capítulo 5 analiza la influencia que tienen los distintos parámetros de ajuste de cada algoritmo en los resultados de diseño obtenidos. De este modo, se plantean distintos análisis independientes que relacionan el ajuste de parámetros con la obtención de la mejor solución posible o con la velocidad con la que resuelve el algoritmo.

Todas las conclusiones tomadas acerca de la influencia de los distintos parámetros en los resultados de diseño y en la velocidad de convergencia tienen su puesta en común en el capítulo 6, que relaciona todos los análisis anteriores en lo que se denomina eficiencia del algoritmo, definida como una herramienta matemática que permite relacionar la calidad de la solución obtenida con el esfuerzo computacional que realiza un determinado algoritmo heurístico. Las conclusiones de este capítulo permiten establecer el mejor modo de trabajo para cada una de las metodologías desarrolladas, a la vez que permite comparar los distintos modelos de optimización entre sí.

El análisis de eficiencia resulta de utilidad en la resolución de nuevos problemas de optimización, puesto que nos permite utilizar una buena configuración en cada modelo de optimización desechando de inicio malos ajustes para los distintos parámetros. En este sentido, el último apartado del capítulo 6 adapta la formulación de los distintos algoritmos a la resolución de un problema de ampliación de una red de distribución de agua y a la consideración de criterios de fiabilidad por rotura en el diseño.

Finalmente, el capítulo 7 resume los principales logros alcanzados en esta investigación, planteando las directrices a seguir en desarrollos posteriores, con el objeto de mejorar en la medida de lo posible la optimización de redes de agua con técnicas heurísticas. 


\section{ESTADO DEL ARTE EN LA OPTIMIZACIÓN DEL DISEÑO DE REDES DE DISTRIBUCIÓN DE}

AGUA

\subsection{Introducción al diseño de redes de agua}

Los conceptos de análisis y diseño son conceptualmente diferentes en la ingeniería hidráulica. Así, cuando se realiza el análisis de una red el problema consiste en conocer el estado hidráulico de dicha red para unas condiciones de funcionamiento determinadas, es decir, determinar las alturas piezométricas de los nudos desconocidos, así como los valores de caudal que circula por las tuberías. En el caso del diseño de redes, el objetivo es obtener la configuración del sistema de conducciones y sus dimensiones para conseguir un estado hidráulico determinado.

Los modelos utilizados en el diseño de redes hidráulicas pueden ser muy variados, en función de la orientación final del diseño. Este trabajo se centra fundamentalmente en el dimensionado hidráulico de una red, de modo que dicha red cumpla unas determinadas condiciones de servicio, entre las que se incluyen cumplir determinados criterios de presión en la red, velocidad, etc.

En una línea de trabajo distinta, es posible diseñar estrategias de operación, que se orientan a otros objetivos, como puede ser dotar al sistema de una mayor fiabilidad u optimizar los costes energéticos. Del mismo modo, también es posible el diseño de sistemas de protección, con el fin de proteger al sistema ante fenómenos transitorios.

Sea cual sea el modelo de diseño utilizado el objetivo es obtener la estrategia más adecuada para conseguir un determinado estado hidráulico de la red. Así, en el caso de diseñar elementos de protección contra el golpe de ariete se utilizan modelos que trabajan en régimen transitorio. Sin embargo, si se trata de diseñar una estrategia de operación en el sistema es necesaria la utilización de un modelo que contemple la evolución de las distintas variables hidráulicas en el tiempo. 
En el caso de mayor interés para el desarrollo de este trabajo, que es el dimensionado hidráulico de una red, se utilizan habitualmente modelos de régimen permanente, puesto que se trata de que el sistema funcione incluso en las condiciones más críticas de servicio. En términos rigurosos, considerar una situación de régimen permanente en un sistema de distribución de agua no deja de ser una situación teórica. No obstante, cuando las variaciones de caudal y presión son pequeñas no conduce a demasiados errores el despreciarlas y considerar como permanentes las situaciones de funcionamiento en que los valores medios en el tiempo de estas cantidades se mantienen constantes.

La red de distribución está constituida por una gran cantidad de elementos, entre los que se pueden encontrar tuberías, bombas, válvulas, elementos de protección contra incendios, etc. Entre todos los elementos que pueden formar parte de una red de distribución de agua destacan las tuberías como elemento principal. Desde un punto de vista funcional, la tubería permite el transporte del agua por su interior, mientras que el resto de componentes realizan un trabajo auxiliar de esta función, ya sea de regulación, control, medida, etc. Del mismo modo, si atendemos a factores económicos, la partida presupuestaria destinada a la instalación de tuberías conforma la inversión más importante en una red de distribución. De hecho, a nivel de proyecto, es habitual presupuestar el resto de elementos auxiliares como un porcentaje del costo total de tuberías.

\subsection{Fundamentos de diseño}

En el diseño óptimo de redes de distribución intervienen tanto variables de naturaleza hidráulica como variables de naturaleza económica. En este apartado se trata de relacionar ambos con el objetivo de tener una perspectiva global del problema de diseño.

\subsubsection{Ecuaciones y variables de naturaleza hidráulica}

Desde un punto de vista hidráulico, una red de distribución se interpreta como un conjunto de elementos hidráulicos utilizados para distribuir agua en una zona determinada. Entre los elementos de una red, distinguimos dos principales elementos, a los que denominamos de forma genérica Líneas, y que se encuentran conectados entre sí por sus extremos, a los que denominaremos Nudos.

A cada línea es posible asociarle una ecuación constitutiva, que permite caracterizar el comportamiento global de los elementos que constituyen la línea, es decir, una relación entre el caudal circulante y la diferencia de alturas piezométricas entre ambos extremos de la línea. Las líneas pueden ser de varios tipos, presentando cada una de ellas distintas particularidades. Así, distinguimos entre: 
- Tuberías

- Válvulas de regulación

- Válvulas de retención

- Válvulas automáticas

- Bombas

Por su parte, los nudos constituyen el punto de unión entre varias líneas y pueden ser agrupados en los siguientes tipos

- Nudos fuente: Puntos de la red que reciben un aporte externo de caudal.

- Nudos de consumo: Puntos de la red en el que se realiza una extracción de caudal.

- Nudos de conexión: Puntos de la red donde no existe ningún tipo de aportación o extracción del caudal, o lo que es lo mismo, sólo existe una transferencia de caudal entre dos o más líneas

- Nudos de presión. Son nudos en los que conocemos el valor de la presión, siendo nuestra incógnita el caudal que entra/sale a través de ellos.

Las líneas quedan caracterizadas hidráulicamente por una serie de variables. Por ejemplo, en el caso de las tuberías, las cuatro variables hidráulicas fundamentales son: velocidad v, caudal $\mathrm{Q}$, diámetro $\mathrm{D}$ y perdida de carga $\mathrm{h}_{\mathrm{f}}$. Estas cuatro variables quedan relacionadas por dos ecuaciones básicas en ingeniería hidráulica:

a) Ecuación de continuidad

$$
Q=\frac{\pi \cdot D^{2}}{4} \cdot v
$$

b) Ecuaciones de pérdidas

$$
\begin{gathered}
h_{f}=\frac{8 \cdot f \cdot L}{\pi^{2} \cdot g \cdot D^{5}} \cdot Q^{2} \\
h_{f}=w \cdot \frac{L}{C^{a} D^{b}} Q^{a}
\end{gathered}
$$

La ecuación de continuidad se plantea como la relación $Q=f(v, D)$ para el caso de conductos de sección circular (2.1). En el caso de la ecuación de pérdidas no existe una única formulación, ya que son numerosos los autores que han dado correlaciones para el cálculo de 
las perdidas en una tubería. En este trabajo se consideran de interés dos de estas correlaciones, como son la ecuación de Darcy-Weisbach (2.2) y la ecuación de Hazen-Williams (2.3).

La ecuación de Darcy-Weisbach resulta de interés por su consistencia dimensional y por ser la fórmula más utilizada en nuestro entorno. Considerando un régimen de circulación del agua turbulento es posible obtener el factor de fricción $f$ (adimensional), siendo variadas las formas existentes para el cálculo de dicho factor. Así, diversos autores han dado correlaciones para el cálculo de f, aunque probablemente la más popular de todas ellas sea la fórmula de Colebrook:

$$
\frac{1}{\sqrt{f}}=-2 \log _{10}\left[\frac{\varepsilon / D}{3,7}+\frac{2,51}{\operatorname{Re} \sqrt{f}}\right]
$$

La principal dificultad que plantea la fórmula de Colebrook-White es la necesidad de utilizar cálculo iterativo para obtener el factor de fricción. Por esta razón se han propuesto diversas fórmulas que permiten calcular el valor de $f$ de modo directo. Entre ellas cabe destacar la fórmula de Swamee y Jain (1976), una de las más utilizadas en la actualidad. El hecho de emplear una expresión u otra para el cálculo de las pérdidas no resta generalidad a la problemática de diseño presentada.

$$
f=\frac{0.25}{\left[\log _{10}\left(\frac{5.74}{\mathrm{Re}^{0.9}}+\frac{\varepsilon_{r}}{3.7}\right)\right]^{2}}
$$

Si se aplica el problema de diseño a una única tubería, como pueda ser una tubería de impulsión o de gravedad, el caudal a trasegar $Q$ suele ser dato de partida, de modo que introduciendo una restricción más, el problema queda totalmente resuelto. Desde un punto de vista funcional, la indeterminación puede ser resuelta especificando una pérdida de carga admisible, una velocidad recomendada o un diámetro normalizado. No obstante, lo más aconsejable es introducir criterios económicos con el fin de abaratar el coste de la instalación.

En el caso de conducciones formadas por varias tuberías en serie, el caudal Q que atraviesa cada una de las tuberías queda definido como la suma de consumos en los nudos ubicados aguas debajo de la misma. En otras ocasiones, el caudal de diseño viene determinado por criterios probabilísticos (redes de riego, redes de incendio, etc). Del mismo modo que en el ejemplo anterior es posible aplicar criterios de tipo funcional para el dimensionado de cada tubería, como puede ser especificar una presión mínima de servicio para todos los nudos, una velocidad de circulación óptima, etc. 
En conducciones malladas, la determinación del caudal que atraviesa una tubería no es inmediata aunque estén especificados los consumos. En este caso será necesario introducir nuevas condiciones de ligadura, referidas a principios de conservación. Así, la primera ley establece que la suma algebraica de caudales en cualquier nudo debe ser nula, es decir, que la suma de lo que entra debe ser igual a la suma de lo que sale. La segunda ley establece que las pérdidas de carga, sumadas algebraicamente para todas las líneas de cualquier malla, debe ser asimismo nula.

La primera ley proporciona tantas ecuaciones como número de nudos $\mathrm{N}$, pero como debe verificarse el equilibrio en los consumos exteriores. Una de esas ecuaciones es ligada, por lo que el número de ecuaciones linealmente independientes es de N-1. Por su parte, la segunda ley proporciona tantas ecuaciones como número de mallas independientes se puedan definir en la red, que denotamos por $\mathrm{M}$.

En una red mallada, siempre es posible encontrar un subconjunto de líneas que aún constituyendo una red ramificada, une entre sí a todos los nudos de la red. Dicha red ramificada, que en teoría de grafos es conocida como árbol de la red, tiene tantas líneas como nudos menos uno, es decir N-1. El subconjunto de líneas que completa la red mallada se conoce con el nombre de coárbol y estará constituido por L-(N-1) = L-N+1 líneas, siendo L el número total de líneas de la red. En el árbol de la red no existe ninguna malla, por lo que la adición de nuevas líneas de coárbol implica la aparición de nuevas mallas.

Se obtiene un total de ecuaciones de malla igual al número de líneas que posea el coárbol, de donde se deduce la relación (2.6), válida para todo tipo de red:

$$
\mathrm{L}=\mathrm{M}+\mathrm{N}-1
$$

La conclusión es que las dos leyes de conservación representan una ecuación más por cada línea, es decir, hay cuatro incógnitas y tan sólo 3 ecuaciones para resolverlas. La cuarta ecuación necesaria para poder estimar los diámetros ha sido objeto de hipótesis basadas nuevamente en estimación previa de caudales, limitación de velocidades o simplemente se han fijado los diámetros en base a la experiencia.

Las $\mathrm{N}$ relaciones que proporciona la primera ley de conservación son intercambiables por cualquier otro criterio que permita establecer los caudales de diseño que circulan por las tuberías, como pueda ser la aplicación de criterios probabilísticos o de simultaneidad.

Además de las relaciones que ligan entre si las variables hidráulicas del problema de diseño, es posible plantear restricciones de tipo funcional sobre dichas variables, como por ejemplo:

- Restricciones de velocidad 
La velocidad de circulación del agua deberá ser lo suficientemente alta para evitar estancamientos en la tubería, que provocaría problemas de depósito en las paredes, así como otros de tipo sanitario. Del mismo modo, la velocidad máxima de circulación también estará limitada a un valor, por encima del cual, se considera que aparecerán problemas de erosión en la tubería, además de aumentar la posibilidad de que se produzca el golpe de ariete. Pese a que son varios los factores que intervienen en el rango adecuado de velocidad, es posible generalizar los límites adecuados entre 0.5 y 2.5 metros/segundo.

- Restricciones sobre la presión en los nudos de consumo

Se establece un rango de presiones aceptable para los nudos de consumo en función del uso que va a tener la red y de la instalación existente aguas abajo del punto de consumo. En el caso de redes de distribución de agua potable se estima un valor promedio entre 2.5 y 4 $\mathrm{kg} / \mathrm{cm}^{2}$ en acometidas, con valores mínimos de $1 \mathrm{~kg} / \mathrm{cm}^{2}$ y máximos de $6 \mathrm{~kg} / \mathrm{cm}^{2}$.

- Restricciones en el material y tamaño de las tuberías

Es habitual establecer un diámetro mínimo de tubería, así como acudir a gamas de diámetro comercial no muy numerosas, con el objetivo de reducir stock y evitar problemas de suministro. También existen condicionantes de tipo constructivo que pueden aconsejar la utilización de unos materiales en detrimento de otros.

\subsubsection{Variables de tipo económico}

En los costes que podemos asociar a la implantación de una red de distribución, es posible distinguir en primera instancia los que se conocen como costes de construcción (o costes fijos) y costes de explotación (o costes variables). Los primeros son los relativos a la propia construcción de la red, mientras que los segundos son los asociados al uso del sistema. Cabe destacar el coste imputable a las tuberías en cuanto a los costes de construcción y el coste energético en cuanto a los costes de explotación. La siguiente tabla muestra esta clasificación de un modo más detallado:

\begin{tabular}{|c|c|c|}
\hline & TUBERÍAS & \\
\hline \multirow{4}{*}{$\begin{array}{c}\text { COSTES DE CONSTRUCCIÓN } \\
\text { (Costes fijos) }\end{array}$} & Accesorios & $\begin{array}{c}\text { Acoplamientos, Anclajes, } \\
\text { Juntas, Valvuleria }\end{array}$ \\
\cline { 2 - 3 } & Obra civil & $\begin{array}{c}\text { Excavación, Relleno, } \\
\text { Asentamiento, Depósitos }\end{array}$ \\
\cline { 2 - 3 } & Instalaciones & $\begin{array}{c}\text { Estaciones bombeo, Sistemas } \\
\text { de control y regulación. } \\
\text { Seguridad }\end{array}$ \\
\hline
\end{tabular}




\begin{tabular}{|c|c|}
\hline \multirow{2}{*}{$\begin{array}{c}\text { COSTES DE OPERACIÓN } \\
\text { (Costes variables) }\end{array}$} & Energéticos \\
\cline { 2 - 2 } & Mantenimiento \\
\cline { 2 - 2 } & Personal \\
\hline
\end{tabular}

Tabla 2.1. Parámetros de estudio en cada técnica de optimización

El problema del dimensionado económico queda reducido a minimizar la suma de los costes de construcción y explotación, teniendo en cuenta que el problema está sujeto a una serie de restricciones que hay que cumplir.

Cuando se pretende llevar a cabo el diseño económico de una red hidráulica es necesario realizar una primera estimación acerca del coste de los elementos que intervienen, o más concretamente, de las funciones de coste asociadas a dichos elementos. Siguiendo las descripciones de Orth, una función de coste se ve sometida a tres posibles tipos de influencia: Funcional, sistemática y aleatoria.

La influencia funcional determina la estructura de la función mientras que las influencias sistemática y aleatoria no modifican la estructura de dicha función, aunque sí que intervienen en el valor de sus coeficientes. Por ejemplo, si tenemos en cuenta la función de coste para una tubería, el material de la misma o el tipo de moneda son factores sistemáticos, mientras que la fluctuación del mercado es un factor de tipo aleatorio. En las siguientes líneas se entra en detalle en las funciones de coste de distintos elementos de la red:

- Coste asociado a las tuberías

El coste completo de construcción de una tubería incluye tanto su adquisición como el transporte y la instalación de ésta. La expresión general que puede utilizarse es:

$$
C_{C}=\left(A_{1}+A_{2} \cdot D^{a}\right) L \quad ; \quad 1 \leq a \leq 2
$$

donde $D$ representa el diámetro de la conducción y $L$ la longitud. $A_{1}$ y $A_{2}$ representan constantes características de la tubería, que pueden depender del material de construcción, la presión de trabajo, etc. Todo el término que queda incluido entre paréntesis hace referencia al coste de construcción de la tubería por metro (coste unitario)

- Coste asociado al bombeo

El parámetro más significativo en el coste de una estación de bombeo (EB) es la potencia instalada W. El coste de bombeo es un claro ejemplo de economía de escala, puesto que el coste de construcción por kilovatio $(\mathrm{kW})$ es decreciente con la potencia total instalada. La expresión tipo que evalúa el coste de bombeo se puede aproximar a:

$$
C_{C}=A_{1}+A_{2} W^{a} \quad ; \quad 0<a \leq 1
$$


donde $W$ es la potencia total instalada, mientras que $A_{1}$ y $A_{2}$ representan coeficientes de ajuste. El coste total de bombeo consta de dos partes bien diferenciadas, como son por un lado los costes asociados a mantenimiento y conservación del equipo, y por otro, los asociados a la facturación eléctrica anual. Este último representa un coste muy superior y puede expresarse como:

$$
C_{O}=A_{3} W+A_{4} W_{m} t_{m}
$$

donde $W$ es la potencia instalada, $W_{m}$ la potencia media consumida $(k W)$ y $t_{m}$ el tiempo medio de utilización anual en horas/año. $A_{4}$ representa el coste del kWh, mientras que $A_{3}$ representa el coste anual del kW instalado. $A_{3}$ también puede incluir otros costes de operación, proporcionales a la potencia instalada.

\section{- Costes totales}

Para obtener el coste total del sistema es necesario tener en cuenta tanto la inversión inicial en la construcción como los costes de operación derivados del uso habitual de la instalación. Como la inversión inicial en la construcción del sistema es un gasto fijo y los gastos de operación son variables en el tiempo surge la necesidad de expresar todos los costes implicados en base a una única referencia temporal, para lo que se pueden aplicar distintas opciones, como son:

a) Trabajar con cantidades totales, es decir, con el total de la inversión y el total de gastos de operación durante la vida útil del proyecto

b) Referir los costes de inversión a un término anual (amortización). De este forma es posible comparar distintas alternativas de proyecto y escoger aquella que presenta un menor coste total del dueto inversión + operación.

Los costes de construcción se refieren a unidades monetarias (um), mientras que los costes de explotación se refieren en unidades monetarias (um/año) por año. Esta conversión a um/año se consigue multiplicando por el llamado factor de amortización y las anualidades conseguidas representan, desde un punto de vista técnico, el coste anual que supone el mantenimiento de un determinado sistema durante toda la vida útil del mismo.

El hecho de considerar la inflación no modifica el planteamiento, siempre que se suponga que la tasa inflacionaria es la misma para los costes energéticos y las tuberías, lo que permite que se mantenga la relación entre los costes energéticos y los de amortización de las tuberías, que es en definitiva lo que condiciona la solución.

Las dos opciones son perfectamente válidas a efectos de diseño económico del sistema, aunque la mayoría de autores optan por referir los costes a una base temporal anual, como se 
hace con la mayoría de inversiones a medio y largo plazo. No obstante, el valor del dinero cambia con el tiempo y las leyes de la economía dictan que una cierta cantidad de dinero en un momento presente tiene menos valor que esa misma cantidad en un instante futuro.

\subsection{Técnicas de diseño}

Los primeros métodos de diseño que surgieron tan sólo tenían en cuenta el balance hidráulico de la red, y su principal objetivo era cumplir las condiciones impuestas por las ecuaciones de conservación de masa y energía. Estos primeros intentos de diseño de redes de distribución no introducen ningún criterio de diseño que permita la minimización de costes de implantación de la red.

A este tipo de métodos se les conoce como métodos funcionales de diseño y se basan estrictamente en parámetros hidráulicos. Quizás el más representativo de todos ellos por su importancia es el método de Hardy-Cross (1936). Si bien los métodos funcionales no están basados en ningún criterio económico, no se puede discutir la importancia que han tenido estos métodos de cara al desarrollo de otros métodos que mejoraran el diseño de redes de distribución.

Con el desarrollo de sistemas computacionales y por tanto, de herramientas matemáticas de las que no se disponía con anterioridad se hace posible la introducción de nuevas metodologías de diseño de redes, mucho más complejas que las conocidas hasta la fecha y que tienen en cuenta factores económicos.

En apariencia, la complejidad de los algoritmos de cálculo utilizados en las técnicas de diseño económico pueden dar lugar a pensar que las soluciones que obtienen son netamente mejores que las que proporcionan los métodos funcionales. Sin embargo, las diferencias entre unos métodos y otros se manifiestan sobretodo en las redes de mayor tamaño, puesto que existiendo mayor número de combinaciones, el resultado de un dimensionado económico supone un ahorro importante en la inversión dedicada a la instalación de tuberías.

De esta manera, en sistemas pequeños o que no revistan mucha complejidad, la diferencia entre métodos funcionales y económicos no es tan significativa, debido a la reducción del número de combinaciones posible. En estos casos es posible utilizar métodos funcionales, puesto que el orden de magnitud de los diámetros utilizados (entre 60 y $300 \mathrm{~mm}$ ) hace que la diferencia de costes entre dos consecutivos de la serie comercial adoptada no sea excesiva.

Cuando se tratan redes de un tamaño mayor, las ventajas de los métodos de optimización respecto a los métodos clásicos son tan acentuadas que hoy en día estos últimos están siendo descartados. La aplicación ingenieril del diseño realizado mediante métodos clásicos tenía utilidad cuando no existía la posibilidad de realizar cálculos complejos con ordenadores, pero 
las posibilidades que ofrece hoy en día la informática posibilita el desarrollo de nuevas técnicas de optimización que hace años eran inviables.

Dentro de los métodos de optimización podemos situar la aplicación de técnicas heurísticas al diseño de redes de agua. Tal como se ha mencionado, la resolución óptima del diseño de sistemas de distribución de agua resulta en ocasiones extremadamente compleja, debido a que cuando se escogen como variables de decisión los diámetros de las conducciones, las restricciones son funciones implícitas de dichas variables de decisión. En estas condiciones la región del espacio de posibles soluciones es de tipo no convexo y la función objetivo se vuelve multimodal.

Las siguientes líneas recogen con detalle gran parte de las técnicas aquí nombradas, prestando especial interés a las técnicas heurísticas que estudia este trabajo.

\subsubsection{Técnicas de tipo funcional}

En el caso de las técnicas de tipo funcional, la indeterminación del problema de dimensionado se puede resolver mediante criterios basados en parámetros hidráulicos, fijando por ejemplo una velocidad recomendada o la pérdida de carga admisible.

El diseño y posterior comprobación del sistema se realiza de diferente manera en el caso de redes malladas y ramificadas. En los siguientes apartados se describen con amplitud algunas de las técnicas más populares de diseño funcional.

\subsubsection{Aplicación de criterios de velocidad admisible}

Una de las posibilidades más sencillas en el dimensionamiento de redes ramificadas consiste fijar criterios de velocidad. En este caso, el tamaño de las tuberías de la red debe ser tal que no se sobrepase un valor máximo de velocidad (criterio de velocidad máxima) o resultar en torno a un valor recomendado (criterio de velocidad recomendable).

De este modo, se pretende dimensionar una determinada red atendiendo a criterios en los que la velocidad no debe superar un determinado valor. Para ello lo lógico es disponer de una determinada gama de diámetros comerciales $\left(D^{1}<D^{2}<\ldots<D^{n}\right)$, cada uno de los cuales podrá trasegar un caudal máximo tal que:

$$
q_{\max }^{i}=\frac{\pi \cdot\left[D^{i}\right]^{2}}{4} v_{\max }
$$

donde $q_{\max }$ es el máximo caudal que puede trasegar un determinado diámetro $D^{i}$ considerando la velocidad máxima fijada de antemano $\left(\mathrm{v}_{\max }\right)$.

Así, para cada línea de la red se seleccionará el menor diámetro que permita trasegar el caudal estipulado. Obviamente, la condición impuesta sobre la velocidad no garantiza que el 
caudal vaya a llegar a los nudos de consumo a la presión mínima requerida. Es por ello que se hace necesario calcular las presiones obtenidas en la red y comprobar que son adecuadas. En caso de que las presiones en los nudos resulten insuficientes los diámetros de algunas de las líneas deberán ser corregidos.

Esta técnica funcional asume que el valor de velocidad máxima a considerar es el mismo para todas las tuberías. No obstante, otros autores proponen utilizar distintos valores de $v_{\max }$ dependiendo del diámetro de la tubería, de modo que, en general, el límite de velocidad máxima crece con el diámetro. En este sentido, la fórmula de Mougnie expresa la velocidad máxima en diseño en función del diámetro:

$$
v_{\max }=1,5(D+0,05)^{1 / 2}
$$

Utilizar la fórmula de Mougnie no modifica el procedimiento, ya que cada uno de los posibles diámetros comerciales da lugar a un valor de velocidad máxima, y consecuentemente, a un caudal máximo q:

$$
v_{\max }^{i}=1,5 \sqrt{D^{i}+0,05} \Rightarrow q_{\max }^{i}=\frac{\pi \cdot D^{i}}{4} v_{\max }^{i}
$$

\subsubsection{Aplicación del criterio de pendiente uniforme}

El método de diseño de pendiente uniforme consiste en dimensionar las tuberías de una red intentando mantener la misma pendiente hidráulica en todas ellas. Por ejemplo, utilizando la expresión de Darcy, es posible obtener el diámetro de una tubería i que trasiega un determinado caudal qi para que el valor de la pendiente hidráulica resultante sea j (valor de referencia), de modo que:

$$
j^{*}=\frac{8 \cdot f_{i} \cdot q_{i}^{2}}{\pi^{2} \cdot g \cdot D_{i}^{5}} \rightarrow \quad D_{i}=\sqrt[5]{\frac{8 \cdot f_{i} \cdot q_{i}^{2}}{\pi^{2} \cdot g \cdot j^{*}}}
$$

El problema está en seleccionar el conjunto de tuberías a dimensionar, así como el valor de la pendiente hidráulica de referencia que se va a considerar. Al estar tratando con redes ramificadas, el dimensionado se efectúa siguiendo una secuencia de trayectos de tubería, comenzando por el trayecto que une la cabecera de la red con el nudo crítico. El nudo crítico representa el nudo más exigente respecto a la presión mínima de servicio que se debe mantener.

Se llamará pendiente hidráulica mínima disponible $j_{\text {disp,i }}$ del trayecto que une la cabecera con el nudo i al valor: 


$$
j_{\text {disp }, i}=\frac{h_{f} \text { admisible }(0 \rightarrow i)}{\sum_{j \in S_{i}} L_{j}}=\frac{H_{0}-H_{\min , i}}{\sum_{j \in S_{i}} L_{j}}=\frac{H_{0}-\left(z_{i}+\frac{P_{\min , i}}{\gamma}\right)}{\sum_{j \in S_{i}} L_{j}}
$$

donde $\mathrm{H}_{0}$ es la altura piezométrica en cabecera, $\mathrm{z}_{\mathrm{i}}$ la cota del nudo i y $P_{\min } / \gamma$ la presión mínima de servicio en el nudo i.

El nudo crítico será el que presente un menor valor de la pendiente hidráulica disponible, y el trayecto crítico será el formado por las conducciones que van desde la cabecera al nudo crítico.

Una vez establecida la pendiente hidráulica disponible en cada trayecto se calcula el diámetro teórico que se ajusta al valor de dicha pendiente, utilizando para ello la expresión (2.13). El diámetro obtenido de esta forma difícilmente corresponderá a una gama comercial, por lo que será necesario tomar el diámetro comercial inmediatamente superior o inferior al obtenido de modo teórico. Elegir el diámetro comercial inmediatamente superior garantiza que todas las presiones van a estar por encima de la presión mínima, aunque como contrapartida aumentará ligeramente el coste de la solución. En cualquier caso, si en los nudos del trayecto crítico se presentan deficiencias de presión será necesario corregirlas aumentando algún diámetro.

Otras opciones son considerar el diámetro comercial más cercano (criterio de proximidad) o incluso dimensionar la línea con dos diámetros comerciales (los inmediatos superior e inferior al obtenido) de modo que se produzca la misma pérdida de carga que en el diámetro teórico calculado.

Una vez dimensionadas todas las tuberías del trayecto crítico se está en disposición de conocer las alturas piezométricas en los nudos que pertenecen a dicho trayecto. Para dimensionar el resto de las tuberías se sigue aplicando el criterio anterior, seleccionando siempre cada trayecto y nudo crítico.

Si la alimentación se realizase con algún grupo de bombeo cuya altura sea necesario determinar, el problema está en que no es posible tomar como referencia ningún valor de pendiente hidráulica disponible, puesto que la altura piezométrica en la cabecera está por determinar. En este caso, se toma un valor de pendiente hidráulica como referencia, por ejemplo $j^{*}=0,005+0,010 \mathrm{mca} / \mathrm{m}=5+10 \mathrm{mca} / \mathrm{km}$. El nudo crítico corresponderá con el que necesite una mayor altura de bombeo considerando este valor de referencia para la pendiente hidráulica $j^{*}$ : 


$$
\text { Nudo crítico si : } H_{b}^{(c)}=\max \left[H_{b}^{(i)}\right] \operatorname{con} H_{b}^{(i)}=z_{i}+\frac{P_{\min , i}}{\nu}+j^{*} \sum_{k \in S_{i}} L_{k}-z_{0}
$$

donde $z_{0}$ es la cota de aspiración de la bomba, $z_{i}$ es la cota del nudo $\mathrm{i}, \mathrm{P}_{\min } / \gamma$ es la presión mínima de servicio y $S_{i}$ representa el trayecto comprendido entre la cabecera y el nudo i.

\subsubsection{Dimensionado de redes malladas}

En los apartados previos se han descrito métodos funcionales de diseño basados en el conocimiento previo de los caudales que circulan por la red. Tanto el método basado en criterios de velocidad máxima como el método de la pendiente uniforme requieren del caudal circulante por la red para poder ser aplicados, puesto que en caso contrario no es posible el cálculo de los diámetros.

Esto supone una complicación añadida en el diseño de redes malladas, puesto que de inicio no es posible conocer los caudales circulantes en este tipo de redes. Una posibilidad en el diseño de redes malladas es suponer unos caudales circulantes, de modo que se asimile la red mallada a una red ramificada, puesto que a efectos de dimensionado la única diferencia entre ambas tipologías es el conocimiento de los caudales circulantes.

Un modo sencillo de determinar unos caudales de diseño que permitan dimensionar la red es realizar cortes en nudos concretos de la red, de modo que, sin perder ninguna de las líneas, la red se convierta en ramificada. Evidentemente, el funcionamiento hidráulico de la nueva red no es el mismo que el de la red mallada de origen, por lo que para conseguir, en la medida de lo posible, un equilibrio en las presiones, se recomienda realizar los cortes de modo que los posibles trayectos para alimentar el nudo tengan una longitud semejante.

El caudal de consumo de los nudos donde se realiza el corte se reparte entre las líneas que confluyen al mismo. Una vez diseñado el sistema se comprueba el funcionamiento, puesto que al ser una red mallada, los caudales circulantes por cada una de las conducciones serán distintos. Si las presiones resultantes en la red mallada no cumplen los valores mínimos exigidos será necesario modificar determinados diámetros hasta conseguir que toda la red cumpla los requerimientos de presión.

La figura 2.1 muestra una red con tres mallas básicas, a la que se efectúan tres cortes a fin de conseguir una tipología de red ramificada: 

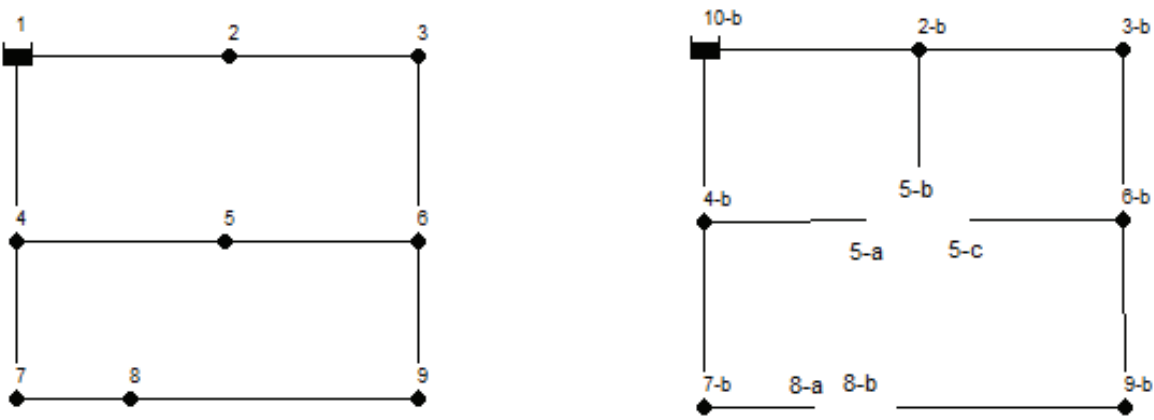

Figura 2.1. Dimensionado de redes malladas mediante cortes en la red

No todos los posibles cortes son capaces de abrir la malla. En este caso, los cortes se realizan en los nudos 8 y 5, lo que da lugar a a la aparición de nudos ficticios, que reciben el nombre de $8 a, 8 b, 5 a, 5 b$ y $5 c$. El caudal del nudo original se reparte entre los nuevos nudos ficticios, ya sea de modo equitativo o de otro modo, en función de la longitud de los ramales que llegan a cada uno de ellos.

Este modo de proceder permite el dimensionado de redes malladas, asemejándolas a las redes ramificadas. Sin embargo, esto presenta dos problemas. El primero de ellos es de tipo operativo, puesto que se debe restituir la conectividad en los cortes para comprobar el funcionamiento real de la red como mallada. Atendiendo al ejemplo de la figura 2.1, la restitución implica unir de nuevo los nudos ficticios, de modo que, como la presión en tales nudos deberá ser la misma, los caudales circulantes (y las consiguientes pérdidas de carga) pueden verse alterados.

El segundo problema afecta al planteamiento, puesto que al asemejar la red a una tipología ramificada se deja de lado el motivo fundamental de utilizar redes malladas, es decir, la fiabilidad del sistema. Obviamente, si se produjera una rotura en la red diseñada con esta metodología, el sistema no sería capaz de alcanzar la presión mínima de servicio en todos los nudos.

Sobre esta segunda cuestión es posible actuar de varias formas. Una opción consiste en asignar el caudal completo del nudo a cada uno de los nudos ficticios producidos al realizar el corte, en lugar de distribuir dicho caudal. A efectos prácticos, se está considerando la posible factura de alguna de las líneas conectadas a dichos nudos ficticios. De todos modos, esta no es una solución especialmente aconsejable, puesto que por ejemplo en el nudo 5 se está considerando que se producen dos roturas simultáneas, lo que es bastante improbable. Además no se considera la posible rotura del resto de líneas que no acaban en nudos ficticios. 
Otra alternativa factible para adaptar el dimensionado de redes malladas es eliminar líneas completas en lugar de producir cortes en los nudos. De esta forma se abren las mallas, generando lo que se llama árbol de red, consistente en una red de tipo ramificado pero con capacidad para entregar los caudales consumidos en los nudos de la red. El esquema de este tipo de operación se aprecia en la figura 2.2:
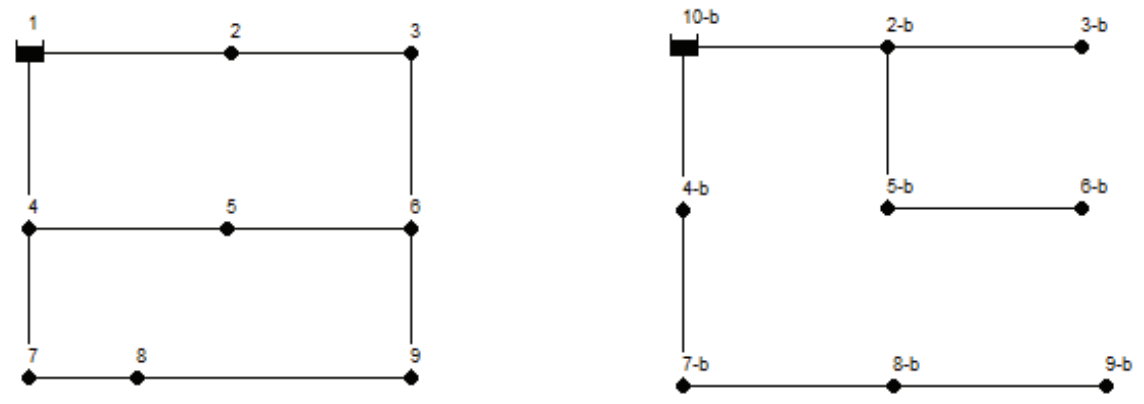

Figura 2.2. Red mallada original y árbol resultante.

En la figura 2.2 se eliminan las líneas 4-5, 3-6 y 6-9, de modo que se obtiene una configuración ramificada que alcanza a todos los nudos de la red (árbol). Una vez se complete el dimensionado del árbol se completará de nuevo la red mallada, asignando a las líneas que habían sido cortadas el diámetro menor de las que estén en contacto con ellas. Normalmente, esto será suficiente para conseguir un funcionamiento fiable de la red bajo escenario de rotura, aunque será necesaria la comprobación de funcionamiento de la red mallada.

La única forma de diseñar una red mallada de modo que quede asegurado el correcto funcionamiento de la misma ante cualquier rotura es plantear tantos estados de carga como posibles roturas en tuberías, aunque obviamente esto resulta utópico en redes de tamaño considerable. Es por ello que se proponen métodos alternativos, utilizando artificios que permitan simplificar el problema.

\subsubsection{Técnicas de diseño económico}

El desarrollo de métodos de diseño basados en criterios económicos no tuvo especial relevancia hasta la década de 1940, coincidiendo en el tiempo con el desarrollo urbanístico en las grandes ciudades. Previamente a estos años apenas se había trabajado con métodos de optimización numérica de varias variables y es con el desarrollo de los sistemas computacionales cuando se abre un nuevo campo de estudio en el diseño de redes de agua. 
Las técnicas de diseño económico no sólo utilizan criterios basados en parámetros hidráulicos, sino que además introducen criterios económicos que permiten optimizar el diseño de redes de agua. En las siguientes líneas se repasan algunas de estas metodologías.

\subsubsection{Programación lineal}

Los modelos de Programación Lineal (PL) consideran que las variables de decisión tienen un comportamiento lineal, tanto en la función objetivo como en las restricciones del problema. La PL es una herramienta muy utilizada en la investigación operativa, ya que facilita los cálculos y, en general permite una buena aproximación de la realidad. El método Simplex, creado por el matemático americano George Dantzig (1947) es probablemente el más popular entre los métodos de programación lineal.

Todo problema de PL posee una interpretación geométrica, puesto que el espacio de soluciones posible de un problema lineal con n-variables de decisión es un poliedro ndimensional, acotado por las restricciones del problema, que deben ser lineales. Dichas restricciones pueden ser representadas como hiperplanos. La función objetivo también es lineal y queda representada por hiperplanos paralelos, asociados a diferentes valores. Si existe una solución óptima del problema, ésta se localizará en uno de los vértices del poliedro

Entre las distintas metodologías que se han desarrollado en los últimos años para el diseño óptimo de redes de distribución de agua, las técnicas basadas en la programación lineal forman uno de los grupos más importantes. Entre las distintas técnicas utilizadas, la denominada Gradiente de Programación Lineal (GPL) es una de las que ha tenido un avance más significativo.

El método GPL descompone el problema de optimización en dos etapas. En la primera de ellas se consideran como fijas algunas variables, mientras que el resto se utiliza en el proceso de PL. La segunda etapa del método trata de mejorar la solución obtenida en la primera etapa, y para ello realiza un proceso de búsqueda donde modifica el valor de las variables que eran fijas en la primera etapa. Ambas etapas se repiten hasta obtener una reducción en los costes de diseño de la red.

La técnica de optimización GLP fue propuesta originalmente por Alperovits y Shamir (1977). A partir de una topología de red ya dada, plantean el problema de determinación de diámetros de manera continua, descomponiendo el problema no lineal original en dos subproblemas, uno lineal y otro no lineal, que son solucionados alternativa e iterativamente hasta encontrar un óptimo. El problema lineal es solucionado mediante Programación lineal y el no lineal con gradiente. Al asumir como constantes y conocidos los caudales que circulan por las líneas, la red puede ser calculada mediante técnicas de programación lineal, utilizando una metodología semejante a la empleada por Karmeli et al (1968). Dicho método está basado en la consideración de que, en la solución final, cada línea de la red estará constituida por una o 
más tuberías de diámetro normalizado, y la longitud de cada una de estas sub-líneas es tomada como variable de decisión.

Este planteamiento proporciona directamente los diámetros normalizados que deben constituir las líneas de la red. Los diámetros que pueden formar parte de la red reciben el nombre de diámetros candidato. El número de diámetros candidato que es posible tomar en cada caso queda a elección del usuario y de las necesidades de cada caso. Un posible criterio de selección es elegir un rango de diámetros basado en la máxima y mínima pérdida de carga unitaria que se está dispuesto a permitir.

Hay que tener en cuenta, no obstante, que el número de variables del problema de PL aumenta proporcionalmente al número de diámetros que consideremos. Por otro lado, si el rango de diámetros candidato es demasiado pequeño no es posible asegurar que la solución obtenida sea la óptima a menos que se calculen varios problemas sucesivos de PL.

La segunda etapa del método utiliza la solución óptima de la etapa anterior para determinar el Gradiente de la función objetivo (GFO). Alperovits y Shamir (1977) sugieren la utilización de un algoritmo de busca simple de gradiente para:

- Determinar la dirección en que el GFO debe modificar el caudal de cada línea.

- Definir el incremento de caudal fijo que debe tener cada línea de la red.

Modificados los caudales se resuelve nuevamente el problema inicial con el objetivo de encontrar soluciones para el problema con un coste menor. Dicho procedimiento se repite hasta que el método sea incapaz de encontrar soluciones mejores.

Numerosos investigadores han propuesto modificaciones al método, tratando de encontrar alternativas que mejoren la propuesta de Alperovits y Shamir. En este sentido Quindry et al (1979) realizan una corrección matemática a la expresión del GFO propuesto por Alperovits y Shamir, considerando una interacción entre tuberías que pertenecen a distintas líneas de la red.

Fujiwara et al. (1987) realizaron todas las derivadas de las expresiones de GFO, proponiendo el uso del método de Quasi-Newton para determinar la dirección del flujo y un método de busca lineal para determinar el incremento de caudal que se producirá en cada línea. Fujiwara et al observaron que la solución final del problema era bastante sensible al incremento de caudal que da inicialmente el usuario. Esto ocurre por la existencia de muchos óptimos locales que se encuentran próximo entre si. Como solución a este problema Fujiwara et al. propone la utilización de distintos valores de incremento de caudal antes de aceptar una solución como definitiva. 
En otros estudios realizados, distintos investigadores han tratado de estudiar la influencia que tiene el camino elegido por el flujo. Goulter y Coals (1986) afirman que el resultado final de diseño depende del camino escogido entre fuente (depósito o bomba) y nudos. En este sentido tampoco hay unanimidad, puesto que este trabajo se ve rebatido por Kessler y Shamir (1989), que presentan un problema en forma de matriz donde demuestran que la solución final es independiente del camino escogido.

\subsubsection{Programación no lineal}

Un modelo de programación no lineal (PNL) trata de resolver un sistema de igualdades y desigualdades sujetas a un conjunto de restricciones, donde dichas restricciones pueden ser lineales o no lineales. El objetivo final del método es maximizar o minimizar una función objetivo.

La principal característica de este tipo de programación es que no tiene un único algoritmo que se aplique a la resolución de todos sus problemas. De este modo, dependiendo de la naturaleza de la función objetivo es posible aplicar un tipo de resolución u otro. Así, si la función objetivo es cóncava o convexa, y el conjunto de restricciones es convexo, el problema puede ser resuelto utilizando el método general de Optimización convexa.

Si el problema es no convexo existe una gran variedad de métodos para resolver el problema. Así, un posible método de resolución utiliza formulaciones especiales de programación lineal. Otra opción implica la utilización de técnicas conocidas como ramificación y poda, etc.

El mayor problema de este tipo de optimización reside en la imposibilidad de garantizar que la solución obtenida es realmente la mejor posible. Esto quiere decir que en numerosas ocasiones se alcanzan óptimos locales en lugar del óptimo global, siendo éste un dato inherente a la naturaleza no lineal del problema.

En el campo hidráulico son numerosas las aplicaciones realizadas para el diseño óptimo de redes de agua. Así, existen algunos paquetes de optimización para diseño óptimo de redes malladas, entre los que se puede citar MINOS (Murtagh y Saunders, 1987), GINO (Liebman et al, 1986) y GAMS (Brook et al, 1988). Todos estos paquetes utilizan la técnica del Gradiente Reducido Generalizado (Abadie y Carpentier, 1969). A partir de estos paquetes de optimización varios investigadores han desarrollado aplicaciones de optimización no lineal para el problema de diseño de redes de abastecimiento de agua (Lansey y Mays, 1989; Lansey et al, 1989; Duan et al, 1990)

El-Baharawy y Smith (1985) aplican MINOS al problema de dimensionado de redes de distribución de agua. Su modelo se compone de tres etapas: la primera de ellas define el problema a partir de los datos disponibles, en la segunda etapa ocurre el proceso de optimización propiamente dicho y en la tercera etapa se realiza el proceso de normalización 
de diámetros, para ajustarlos a una gama comercial. Este modelo de distribución permite simular las distintas partes que componen una red de distribución de agua, como pueden ser bombas, depósitos, válvulas de maniobra, válvulas reductoras, etc. El-Baharawy y Smith aplican con éxito su metodología en problemas como la localización óptima de un sistema auxiliar de bombas, la altura óptima de operación, etc.

Su et al (1987) utilizan la programación no lineal para la optimización de redes malladas. En su trabajo, además de las restricciones físicas del problema (ecuación de continuidad, presión mínima requerida, etc) también se añadieron restricciones relacionadas con la fiabilidad del sistema. Según los autores, la fiabilidad es la probabilidad de realizar una tarea, dentro de ciertos límites, en un determinado intervalo de tiempo. La fiabilidad, relacionada con los sistemas de distribución de agua indica la capacidad que tiene el sistema para suministrar la cantidad de agua demandada a la presión mínima requerida. Para el estudio de la fiabilidad Sue et al desarrollan un método que determina la probabilidad de fallo de los distintos componentes de la red de distribución.

Sue et al basaron su modelo de optimización en la técnica de los Gradientes Reducidos Generalizados (GRG). El programa de simulación KYPIPE (Wood, 1980) fue utilizado en cada iteración del problema para calcular la presión en todos los puntos del sistema. De modo paralelo se utilizó otro modelo para simular la fiabilidad del sistema. Este modelo define la fiabilidad como la probabilidad de mantener la presión del sistema en todos los puntos del sistema, contemplando el escenario de rotura de alguna tubería, que quedaría fuera de servicio temporalmente. Este modelo tan sólo incluye la posibilidad de fallo en tuberías, no contemplando otros elementos del sistema como bombas, válvulas, depósitos, etc.

Lansey et al. (1989) estudiaron los parámetros de incertidumbre del problema de diseño óptimo de redes, puesto que los sistemas de abastecimiento de agua son proyectados para ser utilizados durante mucho tiempo. Lansey et al. consideran que la imposibilidad de conocer cuanto va a crecer la población, así como el desconocimiento de futuros patrones de consumo son grandes incertidumbres del problema. Otro parámetro de incertidumbre del sistema es el estado de conservación del sistema, ya que éste se ve afectado por la corrosión y por la incrustación de sustancia en los tubos. Este cambio en la conservación del sistema trata de verse reflejado en el coeficiente de rugosidad de los tubos. Como el impacto de los distintos procesos que ejercen su influencia en el sistema es desconocido se plantea una incertidumbre acerca de qué valores de rugosidad pueden ser los más adecuados en cada caso. Lansey et al. plantean una restricción de probabilidades que convierte el problema probabilístico en determinístico. En dichas restricciones se especifica la capacidad del sistema para satisfacer las demandas y presiones en los nudos.

Lancey y Mays (1989) utilizan la programación no lineal para realizar un diseño óptimo de redes de agua. Ellos agregaron el programa KYPIPE (Wood, 1980) a su modelo, para asegurar 
que tanto la ecuación de continuidad como la de energía son cumplidas. El método GRG se utiliza para encontrar una solución óptima y un método Lagrangiano se emplea para incluir las restricciones en el modelo. Duan et al (1990) realizan mejoras en este modelo, incluyendo la posibilidad de introducir otros elementos en el sistema, como bombas o depósitos. Este modelo se divide en 3 fases: La primera fase (problema principal) identifica el número y localización de estanques y depósitos utilizando métodos de enumeración exhaustiva. En la segunda fase (subproblema) se utiliza GRG para realizar la optimización de los tubos, teniendo en cuenta la salida de bombas y depósitos especificados en el problema principal. La tercera etapa es un bucle dentro del subproblema que sirve para garantizar que se cumplen la ecuación de continuidad, así como las condiciones de presión mínima en cada nudo.

Silva (1997) aplicó la PNL al diseño de redes ramificadas. El problema se resuelve en dos etapas. En la primera etapa se considera como variables de decisión la cota de cabecera y los diámetros continuos de los tubos. En la segunda etapa se adoptan diámetros discretos, dentro de la gama comercial disponible, y se utilizan como variables de decisión el tamaño de los tubos y la cota de cabecera. El trabajo verifica que, para redes ramificadas, la PNL presenta resultados semejantes a los obtenidos por PL (Karmeli et al, 1968).

Cirilo (1997) propone un modelo de optimización de redes malladas que resuelve el problema sin necesidad de utilizar otro programa que realice el balance de caudales en la red. Este modelo utiliza como variables de decisión los caudales circulantes y los diámetros de las tuberías. La pretensión de este modelo no es conseguir una gran minimización de los costes, pero sí una determinación de diámetros mínimos y máximos caudales que estén dentro de los límites impuestos por las restricciones.

Gomes y Formiga (2001) proponen una metodología llamada PNL2000. Esta metodología utiliza el modelo matemático de programación no lineal y se divide en dos etapas. La primera de ellas realiza un pre-dimensionado del sistema, donde los diámetros, los caudales y la altura manométrica de alimentación son variables que deben ser determinadas en el proceso de optimización. Posteriormente, con los resultados obtenidos en esta primera etapa se ejecuta la segunda, donde se ajusta la solución obtenida inicialmente. En esta segunda etapa del método los diámetros obtenidos en la primera etapa se redondean a diámetros comerciales, puesto que en la primera etapa del método el resultado viene dado por diámetros continuos.

El proceso de optimización del método PNL2000 utiliza el Gradiente Reducido Generalizado (GRG2) desarrollado por Lasdon et al (1984). Todo el modelo de programación no lineal, a partir de GRG2, puede ser implementado en la herramienta Solver de Excel.

\subsubsection{Programación dinámica}

Matemáticamente, el término programación dinámica se refiere a la utilización de subproblemas superpuestos y sub-estructuras óptimas, con el fin de encontrar la solución de un 
problema de optimización en un menor espacio de tiempo. En la aplicación de la programación dinámica al diseño de redes de agua se repasan en las siguientes líneas algunas contribuciones de interés.

Monbaliu et al (1990) proponen una técnica de gradiente de búsqueda, donde una vez fijada una gama de diámetros comerciales de trabajo, todos las tuberías de la red comienzan el proceso de optimización con el diámetro mínimo disponible. Se recurre entonces a un programa de análisis de redes para determinar la presión en todos los nudos de la red. Si el sistema cumple la presión mínima en todos los nudos el proceso de optimización ha acabado, si por el contrario no se cumplen los criterios de presión mínima se aumenta el diámetro de la tubería con mayor pérdida de carga hasta el inmediatamente superior. El proceso de iteración se repite una y otra vez hasta que los límites de presión mínima se cumplen.

Leal y Gomes (1997) proponen una metodología semejante, con la salvedad de que en esta metodología no se utiliza la pérdida de carga como parámetro que determine qué tubería debe ser aumentada. En este método se tiene en cuenta el incremento de coste que se produce en un determinado tramo al aumentar al diámetro inmediatamente superior, relacionando dicho coste con la disminución de pérdida de carga que se produce. A esta relación se le llama Gradiente de Cambio (Granados, 1990). La utilización del Gradiente de Cambio sólo es posible en redes ramificadas, por lo que es necesario transformar la red mallada, utilizando un método de seccionamiento similar al método de Seccionamiento Ficticio (Leal, 1995). Leal utiliza el programa REDES (1995) para el realizar el dimensionado de la red ramificada obtenida. El balance de la red se realiza por aplicación del método de HardyCross, donde en cada iteración se verifica si el sistema cumple las restricciones de energía y continuidad características de las redes malladas.

Gomes et al (2009) desarrollan otro modelo de optimización llamado LENHSNET, que se introduce en el código fuente del programa de análisis de redes EPANET (Rossman, 1997). LENHSNET es un algoritmo iterativo basado en programación dinámica, que optimiza el diseño de redes a agua a presión, y que permite incluir en el diseño elementos como bombas o depósitos. LENHSNET ha sido el método de programación dinámica elegido para comparar los resultados obtenidos con las distintas técnicas heurísticas estudiadas, por lo que se describe de modo más detallado su funcionamiento en líneas sucesivas.

\section{- Método LENHSNET}

El método LENHSNET ha sido desarrollado por el Laboratorio de Eficiencia Energetica e Hidráulica de la Universidad de Paraiba, en Joao Pessoa, Brasil. El método queda integrado como plugin dentro del programa de análisis de redes EPANET y proporciona como respuesta los diámetros de todas las tuberías de la red, así como la cota piezométrica de impulsión, de modo que se alcance la mejor solución económica posible para el problema de optimización. 
Dicha solución comprende una parte asociada a la instalación (diámetro de los tubos) y una parte asociada a la explotación (coste energético de bombeo).

El proceso iterativo LENHSNET parte de una solución inicial, donde todos los diámetros de la red tienen el valor mínimo dentro de la gama elegida para el cálculo. Normalmente, esta solución inicial no es una solución factible para el sistema, puesto que las pérdidas de carga en los tubos son elevadas, con lo que el sistema se ve incapaz de cumplir las restricciones de presión.

Se inicia entonces un proceso iterativo donde en cada paso del proceso se obtiene una nueva solución, a partir de incrementar algún diámetro de la solución anterior. El proceso iterativo termina cuando la red cumple las restricciones hidráulicas impuestas en el proyecto.

El algoritmo de optimización se asocia a un simulador hidráulico, en este caso EPANET, cuya función es proporcionar en cada paso del proceso iterativo el valor numérico de las variables de la red (caudales, velocidades, perdidas de carga, etc.).

El método calcula el estado hidráulico de la red en cada iteración, seleccionando el nudo más desfavorable (nudo donde la presión es menor). Una vez detectado el nudo más desfavorable se inicia un proceso de optimización de la red, basado en obtener la mayor ganancia posible de presión (disminución de pérdidas de carga) con el menor coste posible.

Cada iteración del método analiza tantas posibilidades como tuberías tiene la red de distribución que se quiere diseñar, aunque a efectos prácticos tan sólo cambia el diámetro de una tubería en cada paso del proceso de optimización. El diámetro de la tubería seleccionada pasa a ser el inmediatamente superior de la gama definida y la elección se realiza según criterios de ganancia de presión con el menor aumento posible de coste de la red. El conductor modificado será el que proporcione el mayor "gradiente de coste" en el nudo más desfavorable de la red. El gradiente $G_{p}$ viene dado por la ecuación 2.14, que representa el alivio de pérdida de carga en la red que proporciona el cambio realizado.

$$
G_{p}=\frac{P_{2}-P_{1}}{\Delta p}
$$

donde:

$\mathrm{G}_{\mathrm{p}}$ es el gradiente de coste, en unidades monetarias por mca de alivio de pérdida de carga (um/mca).

$\mathrm{P}_{1}$ es el coste de la tubería con el diámetro actual, en um.

$\mathrm{P}_{2}$ es el coste de la tubería con el diámetro inmediatamente superior al actual, en um. 
$\Delta p$ es la ganancia de presión en el nudo más desfavorable que se produce con el cambio de diámetro, en mca.

En cada paso iterativo se calculan " $n$ " gradientes de presión, correspondientes a las " $n$ " configuraciones distintas que se producen en los " $n$ " tramos de la red al aumentar cada tramo en una unidad. El gradiente de coste óptimo $\mathrm{G}_{\mathrm{p}}{ }^{*}$ será el menor de todos los calculados y determinará cuál es la tubería que aumenta de diámetro en cada iteración.

$\mathrm{G}_{\mathrm{p}}{ }^{*}$ se calcula en cada iteración del algoritmo, para lo cual se debe calcular el gradiente de todos los tramos en relación al nudo más desfavorable. Definido el gradiente de coste óptimo, la red asume una nueva configuración, donde el tramo cuyo gradiente era óptimo pasa a tener el diámetro inmediatamente superior en la gama. Esta última configuración será la configuración de partida en la siguiente iteración. El proceso iterativo sigue esta metodología hasta encontrar la solución final, de coste óptimo, para la red de distribución diseñada.

El método trabaja con dos alternativas de diseño, que determinan las condiciones de convergencia o parada del proceso iterativo de optimización. En la primera de ellas, el sistema trabaja con un depósito de altura conocida, cuya cota de origen es fija y conocida. En este caso, el coste del sistema depende única y exclusivamente del coste de implantación de las tuberías.

En este caso, la condición de parada del algoritmo se ejecuta cuando la presión del nudo más desfavorable iguala o supera el valor de presión mínima que se requiere en la red. Cuando el proceso iterativo finaliza, normalmente queda un exceso de presión en el nudo más desfavorable, que puede intentar reajustarse para disminuir el coste del sistema. En este caso, el método ofrece la posibilidad de dividir la última tubería modificada en dos tramos, uno con el último diámetro calculado y el otro con el inmediatamente inferior, de modo que la pérdida de carga aumenta hasta ajustar la presión sobrante hasta el valor mínimo requerido. La principal ventaja de esta operación es el tramo que queda diseñado con un diámetro algo inferior, y por tanto, más barato.

En la segunda alternativa, el agua se impulsa a la red a través de un sistema de bombeo. En este caso, los costes del sistema se componen por un lado del coste de implantación de las tuberías y por otro del coste energético que supone el sistema de bombeo.

En este escenario, la cota de origen es una variable de decisión más en el proceso de optimización y el proceso de optimización también depende del coste de presurización del agua, que se considera mediante la variable "gradiente energético". El gradiente energético representa el coste anual de bombeo de un determinado caudal a una determinada presión. Esta variable viene dada en unidades monetarias/metro de elevación y queda representada por la ecuación 2.15: 


$$
G_{e}=W_{m} \cdot t \cdot N_{b} \cdot F a
$$

donde:

$\mathrm{G}_{\mathrm{e}}$ es el gradiente energético anual, actualizado, en um $/ \mathrm{m}$;

$\mathrm{W}_{\mathrm{m}}$ es la potencia requerida por la bomba, por metro de altura (potencia unitaria), en $\mathrm{kW} / \mathrm{m}$; t es la tarifa energética, en um/kWh;

$\mathrm{Nb}$ es el número de horas de bombeo anual;

Fa es el factor de actualización, o factor de valor presente, que viene dado por la ecuación 2.16:

$$
F a=\left[\frac{(1+e)^{n}-(1+i)^{n}}{(1+e)-(1+i)}\right] \times\left[\frac{1}{(1+i)^{n}}\right]
$$

donde:

i es la tasa de interés anual, en modo decimal;

n es el número de años correspondiente a la vida útil del proyecto;

e es el aumento del coste de la energía, en modo decimal.

La potencia requerida $\mathrm{W}$ por metro de altura, en $\mathrm{kW} / \mathrm{m}$, viene dada por la ecuación 2.17 , donde $Q$ es el caudal del sistema en $\mathrm{m}^{3} / \mathrm{s}$ y $\eta$ es el rendimiento esperado del conjunto motorbomba.

$$
W=\frac{9,81 \times Q}{\eta}
$$

En la configuración inicial de la red todos los diámetros asumen el valor del mínimo diámetro de la gama. Del mismo modo, el valor de la cota de bombeo en la configuración inicial es cero. Se ejecuta una primera simulación con estos valores por defecto, de modo que quede identificado el nudo más desfavorable, de forma análoga a como se procedía cuando la cota piezométrica en el origen era fija.

A partir de la primera solución obtenida, el proceso iterativo sigue la misma metodología descrita para un dimensionamiento con una cota de origen fija. Al final de cada iteración en el proceso de optimización se compara el gradiente de coste óptimo encontrado $G_{p}{ }^{*}$ con el gradiente energético $G_{e}$ calculado. En el caso de que $G_{p}{ }^{*}$ sea inferior a $G_{e}$ el coste necesario 
para disminuir las pérdidas de energía en la red - y por tanto aumentar la presión en el nudo más desfavorable - será inferior al coste energético necesario para aumentar la carga de la red. En este último caso, la modificación del sistema que se producirá será la modificación de diámetro (el menor gradiente de coste).

El proceso iterativo seguirá aumentando el tamaño de los diámetros hasta que se produzca un valor de $\mathrm{G}_{\mathrm{p}}{ }^{*}$ que iguales o supere el valor de $\mathrm{G}_{\mathrm{e}}$. Con esta condición, el proceso iterativo alcanza su condición de parada y la configuración de diámetros en los tramos de la red será definitiva.

Una vez obtenida la solución de diámetros que da la última iteración es necesario determinar el valor de la cota y altura piezométrica en el nudo de origen de la red. Para ello, LEHNSNET suma el valor de la presión en el nudo más desfavorable -en módulo- al valor de presión mínima establecido para todos los nudos de la red. El valor obtenido corresponde a la cota piezométrica definitiva en el origen y se incorporará al fichero de EPANET en el punto de alimentación correspondiente. Tras este ajuste, la red se simula una última vez, de modo que todas las variables de estado quedan actualizadas.

El coste definitivo de diseño que da LENHSNET es igual a la suma del coste de instalación de las tuberías y el coste de la energía de bombeo. El coste de instalación de tuberías se calcula en base a los diámetros de la última iteración, multiplicando el coste unitario de cada uno de ellos por la longitud de tubería instalada. Para el cálculo de los costes energéticos se debe conocer la cota manométrica en el origen, que el programa obtiene restando la cota del terreno a la cota piezométrica. De este modo, el coste de la energía será el valor de la cota manométrica multiplicada por el gradiente energético $\mathrm{G}_{\mathrm{e}}$ previamente calculado.

\subsubsection{Técnicas heurísticas}

La palabra "heurística" deriva del griego heuriskein, que significa "encontrar" o "descubrir". El significado del término ha variado históricamente e incluso algunos autores han definido el término como antónimo de algorítmico. En este sentido Newell et al (1962) definen el término como:

"A un proceso que puede resolver un cierto problema, pero que no ofrece ninguna garantía de lograrlo se le denomina una heurística para ese problema"

Actualmente, el término suele utilizarse como adjetivo, refiriéndose a cualquier técnica que mejore el desempeño en promedio de la solución de un problema, aunque no mejore el desempeño en el peor caso. Una definición más precisa y adecuada es la que proporciona Reed (1967): 
"Una heurística es una técnica que busca soluciones buenas (es decir, casi óptimas) a un costo computacional razonable, aunque sin garantizar factibilidad u optimalidad de las mismas. En algunos casos, ni siquiera puede determinar que tan cerca del óptimo se encuentra una solución factible en particular"

Existen multitud de problemas que no pueden resolverse utilizando un algoritmo que requiera tiempo polinomial, es más, en muchas aplicaciones prácticas ni siquiera se puede decir que exista una solución eficiente. De este modo, cuando se quieren resolver problemas de búsqueda tan grandes como puede ser el diseño de una red de distribución de agua, las técnicas clásicas de búsqueda y optimización pueden resultar insuficientes, y es aquí donde la heurística juega su papel.

La aplicación de técnicas heurísticas en procesos de optimización permite la búsqueda de posibles soluciones más allá de mínimos locales, lo que amplía en muchas ocasiones el campo de búsqueda, y por tanto, la capacidad de obtener buenas soluciones. Dentro de las técnicas heurísticas se encuentra un grupo de particular interés, como es el de los algoritmos evolutivos. Los algoritmos evolutivos presentan diferencias respecto a las técnicas tradicionales de búsqueda y optimización, entre las que se destacan:

- Utilización de una población de soluciones potenciales en lugar de un único individuo, lo que hace estas técnicas menos sensibles a quedar atrapadas en máximos y mínimos locales.

- Utilizan operadores probabilísticos, mientras que las técnicas tradicionales utilizan operadores determinísticos. Es importante reseñar que el hecho de que una técnica evolutiva utilice operadores probabilísticos no implica que opere de manera análoga a una técnica de búsqueda aleatoria.

- No necesitan conocimiento específico acerca del problema que van a resolver.

Los principios de estas técnicas evolutivas datan de principios de los años 1930s, donde la evolución natural comienza a ser vista como un proceso de aprendizaje por el hombre. Así, W.D. Cannon (1963), en su libro "The Wisdom of the Body" manifiesta que el proceso evolutivo es algo similar al aprendizaje por ensayo y error que se da en los seres humanos. Ya a finales del año 1950, el biólogo Alexander S.Fraser publicó una serie de trabajos sobre la evolución de sistemas biológicos en una computadora digital. El trabajo de Fraser incluye, entre otras cosas, el uso de una representación binaria, un operador de cruce probabilístico, una población de padres que se reproducía y el empleo de mecanismos de selección. El trabajo de más de 10 años de Fraser queda resumido en su libro "Computer models in Genetics" y puede considerarse como un anticipo de las técnicas evolutivas que se desarrollarían años después. 
El término "computación evolutiva" engloba una serie de técnicas inspiradas en los principios de la teoría Neo-Darwiniana de la evolución natural. En términos generales, todas estas técnicas tienen una serie de principios comunes, independientemente del proceso en el que puedan estar inspiradas. De este modo, puntos comunes en todas las técnicas evolutivas son:

- Existencia de una estructura de datos utilizada para almacenar un "individuo"

- Existencia de operaciones que afecten a los individuos

- Una función de aptitud que nos indica lo buena o mala que es la solución obtenida respecto a las demás.

- Un mecanismo de selección que implemente un criterio de supervivencia en el algoritmo, permitiendo reproducirse tan sólo a los más aptos, tal como postula Darwin.

La mayoría de estas técnicas son susceptibles de ser aplicadas en infinidad de campos, dada la versatilidad que presentan. Este trabajo aplica algunos de estos métodos al diseño óptimo de redes de distribución de agua. Dado que las técnicas basadas en este tipo de metodología son numerosas, éste trabajo solo profundiza en las que se estudian en el mismo.

La aplicación de técnicas heurísticas de optimización permite la búsqueda más allá de los mínimos locales, lo que amplia en muchas ocasiones el campo de búsqueda dentro del espacio de soluciones de un determinado problema. y por tanto, la capacidad de obtener mejores soluciones. Existe una gran variedad de distintas técnicas de búsqueda de soluciones, algunas de las cuales se enumeran a continuación, respetando el nombre original anglosajón:

- Hill Climbing

- Simulated Annealing (en adelante SA)

- Quantum Annealing

- Tabu Search Beam Search

- Genetic Algorithms (en adelante AG)

- Particle Swarm Optimization (en adelante PSO)

- Ant Colony

- Estrategic Evolution

- Differential Evolution 
- Harmony Search (en adelante HS)

- Shuffled Frog Leaping Algorithm (en adelante SFLA)

- Etc,

Cada una de estas técnicas es susceptible de ser aplicada en infinidad de campos donde se requiere un proceso de optimización. Este trabajo aplica cinco de estas metodologías al diseño óptimo de redes de agua, estableciendo criterios de comparación entre las mismas, a fin de determinar las ventajas e inconvenientes que puedan asociarse a cada una de ellas. Obviamente, el número de técnicas evolutivas es mucho mayor, pero existen suficientes referencias en la literatura que justifican el empleo de las metodologías elegidas frente a otras en el diseño de redes de agua.

De este modo, la aplicación desarrollada incluye modelos de optimización para los Algoritmos Genéticos (AG), Particle Swarm Optimization (PSO), Simulated Annealing (SA), Harmony Search (HS) y Shuffled Frog Leaping Algorithm (SFLA).

\subsection{Algoritmos Genéticos (AG)}

Entre las técnicas heurísticas, AG es una de las de mayor importancia, siendo aplicada en todo tipo de problemas de optimización. Los Algoritmos Genéticos nacen del interés de John Holland en resolver problemas de aprendizaje de máquina. Dicho interés se materializó a principios de la década de 1960, donde Holland estudia los procesos lógicos involucrados en la adaptación. Inspirado por otros estudios de la época como los autómatas celulares y las redes neuronales, Holland se percata de que el uso de reglas simples puede generar comportamientos flexibles y decide investigar la evolución de estos comportamientos en sistemas complejos.

Holland publica su trabajo en el año 1975, donde da a conocer su sistema bajo el nombre de "Plan reproductivo genético", aunque posteriormente se popularizó bajo el nombre de "Algoritmo Genético". Por aquel entonces, David Goldberg entra en contacto con Holland y empieza a estudiar sus métodos. Goldberg era un ingeniero industrial que trabajaba en diseño de tuberías, y fue uno de los primeros que trató de aplicar los algoritmos genéticos a problemas industriales. Pese a que Holland trató de disuadirle, ya que pensaba que el problema era excesivamente complicado como para aplicar AG, Goldberg consiguió su propósito, escribiendo un AG en un ordenador personal Apple II. Esta y otras aplicaciones creadas por estudiantes de Holland convirtieron a los algoritmos genéticos en un campo con base suficiente como para celebrar en 1985 la International Conference on Genetic Algorithms (ICGA'85), evento que sigue celebrándose bianualmente.

Aunque la concepción original del método estaba orientada al diseño de aprendizaje de máquina, lo cierto es que el método ha resultado excelente para los procesos de 
optimización, lo que la convierte en uno de los métodos más populares de optimización en la actualidad. Como nota anecdótica, cabe destacar que en 1999 se concede por primera vez en la historia una patente a un invento no realizado directamente por un ser humano, y fue a un algoritmo genético.

En el campo de la ingeniería hidráulica, numerosos investigadores han diseñado diversas aplicaciones que aprovechan las características de los algoritmos evolutivos para la resolución de distintos problemas, planteándose los costes de construcción, los costes de operación o incluso ambos como las funciones a optimizar. Son destacables en este sentido aplicaciones dedicadas al reemplazamiento de tuberías principales en sistemas de distribución de agua (Engelhard, 1999), la optimización de sistemas de distribución (Farmani, 1999) o la rehabilitación en sistemas de distribución (Halhal, 1999).

En redes de saneamiento, el desarrollo de métodos de optimización ha sido bastante menor, existiendo menor cantidad de bibliografía disponible. No obstante, cabe destacar los distintos trabajos de M.H Afshar (2006), donde aplica AG al diseño de redes de saneamiento. Es en esta temática donde se hace más complicado el encontrar redes de referencia que permitan comparar resultados entre distintos investigadores, si bien algunos de ellos toman como referencia la red propuesta por Larry W, Mays (1975).

La bibliografía existente acerca de AG y sus distintas aplicaciones es tan extensa que conviene centrar la búsqueda en el verdadero objetivo de este trabajo, que es la aplicación de distintos algoritmos al diseño optimo de redes de distribución, tomando como función de optimización el coste de instalación de los conductos cuando se deben cumplir una serie de restricciones de presión, velocidad y/o caudal.

En este campo son muchos los investigadores que han aplicado AG y otros métodos sobre una serie de redes de referencia o "benchmarking", como puede ser la red de Alperovits (1977), la red de Hanoi (1990) o la red de los túneles de Nueva York (1969). Son destacables en este sentido trabajos como los de Alperovits y Shamir (1977), Fujiwara y Khang (1990) y Murphy et al (1993). Mención especial merece la labor de Dragan Savic (1997), cuyo trabajo con AG se ve culminado con la creación de "Optimal Solutions", empresa asociada a "Ewan Associates" en un ejemplo a seguir en la vinculación entre universidad e industria.

La mayoría de investigadores con intereses en este novedoso campo programan sus propios algoritmos, introduciendo pequeñas modificaciones que permitan mejorar el resultado de anteriores estudios, ya sea obteniendo una solución de menor coste, reduciendo el tiempo de cálculo o incorporando nuevas características que permitan estudios más complejos, como puede ser la consideración de criterios de fiabilidad en redes de distribución (Prasad, 2004), la disposición óptima del flujo en estaciones de medición (Zhang, 2009) o la programación óptima de sistemas de bombeo en sistemas de distribución (Wang, 2009) 
Del mismo modo, algunos investigadores programan algoritmos híbridos, que tratan de mejorar las características de un AG clásico. En este sentido, Van Zyl (2004) estudia el proceso de optimización de un sistema de bombeo utilizando un AG combinado con la estrategia de búsqueda hillclimber, que permite mejorar la búsqueda de óptimos locales.

Siguiendo con los algoritmos híbridos, es destacable el trabajo de Keedwell (2004), que utiliza un método heurístico basado en autómatas celulares locales para conseguir una población inicial del algoritmo genético que no sea totalmente aleatoria, de modo que las iteraciones posteriores del algoritmo se encuentran ya más cercanas de la solución final.

Por último, cabe destacar que son abundantes las aplicaciones creadas en base a los algoritmos genéticos para la resolución de todo tipo de problemas de optimización. Algunas de estas aplicaciones son gratuitas y otras permiten la descarga de versiones de prueba que permiten evaluar la calidad del programa antes de comprarlo. Entre estos últimos se encuentra OptiGA, desarrollado en visual Basic y que permite adaptar el algoritmo genético al problema de optimización requerido, entre los que se encuentra el diseño óptimo de redes de agua. OptiGA y otros pequeños programas de optimización aplicados al diseño de redes de agua pueden encontrarse en la página web www.optiwater.com.

\subsection{Simulated Annealing (SA)}

Las distintas metodologías que surgen de los algoritmos genéticos pueden considerarse pioneras en la aplicación de técnicas heurísticas a los procesos de optimización, pero las enormes posibilidades que ofrecen este tipo de técnicas respecto a otras más clásicas provocaron el desarrollo de nuevas técnicas. En un orden cronológico dentro de los distintos algoritmos que aplica este trabajo al diseño de redes de agua, el siguiente foco de interés se establecería en la técnica de optimización conocida como Simulated Annealing (SA), dada a conocer por S. Kirkpatrick, C.D Gelatt y M.P Vecchi en 1983. En este caso, el proceso de optimización toma el nombre del proceso industrial de enfriamiento de cristales y es una adaptación del Algoritmo Metropolis-Hastings (Metropolis et al, 1953).

El algoritmo SA es una de las técnicas metaheurísticas más clásicas. Su simplicidad y buenos resultados en una amplia gama de problemas de optimización combinatoria la han convertido en una herramienta muy popular, con cientos de aplicaciones en campos muy variados. Es un algoritmo probabilístico de búsqueda local, que permite movimientos ascendentes con el fin de evitar quedar atrapado prematuramente en un óptimo local.

A menudo se suele decir que es fácil conseguir que SA funcione, si bien es difícil que funcione bien. Esto es debido a que no es propiamente un algoritmo, sino una estrategia heurística que necesita de varias decisiones para que quede totalmente configurado, teniendo estas decisiones gran influencia en la calidad de las soluciones para el problema de optimización. 
La idea de utilizar los algoritmos de recocido simulado como método de optimización nace a principios de la década de 1980, cuando publicaciones independientes de Kirkpatrick et al (1983) sobre diseño de circuitos de integración a gran escala (VLSI circuits), y Cerny (1985) para el problema del vendedor viajero (TSP) muestran como este proceso puede ser aplicado a problemas de optimización, asociando conceptos clave del proceso original de simulación, con elementos de optimización combinatoria según se indica en la siguiente tabla:

\begin{tabular}{|c|c|}
\hline SIMULACIÓN TERMODINÁMICA & OPTIMIZACIÓN COMBINATORIA \\
\hline Estados del sistema & Soluciones factibles \\
\hline Energía & Coste \\
\hline Cambio de estado & Solución en el entorno \\
\hline Temperatura & Parámetro de control \\
\hline Estado congelado & Solución heurística \\
\hline
\end{tabular}

Tabla 2.2. Relación entre elementos de simulación termodinámica y elementos de optimización combinatoria

En el campo de la ingeniería hidráulica varios autores han aplicado con éxito SA al diseño de redes de agua a presión. Así, Cunha y Sousa (1999) analizan la influencia de los distintos parámetros del modelo SA en la calidad de las simulaciones. En el mismo sentido, Reca et al (2008) incluyen SA entre las técnicas heurísticas disponibles en la herramienta de diseño MENOME, orientada al diseño de redes de agua a presión.

\subsection{Particle Swarm Optimization (PSO)}

Continuando con el repaso cronológico que sitúa las distintas metodologías que trata este trabajo, J.Kennedy y R.Eberhart (1995) presentan una técnica de optimización basada en el comportamiento social que tienen las bandadas de pájaros en los procesos migratorios, cuando buscan lugares más calidos donde poder alimentarse. Esta técnica de optimización, llamada Particle Swarm Optimization (PSO), adquiere rápidamente popularidad entre los investigadores y son numerosos los trabajos existentes en la bibliografía acerca de este algoritmo.

Uno de los motivos por los que el algoritmo PSO resulta tan popular es porque permite un ajuste bastante estándar de los parámetros siguiendo unas directrices básicas existentes en la bibliografía. Esto permite implementar el algoritmo sin muchas dificultades, lo que facilita el trabajo del investigador.

De este modo, una configuración relativamente estándar del algoritmo permite trabajar con una gran variedad de aplicaciones, entre las que se incluyen todo tipo de problemas de optimización, en áreas tan diversas como problemas multi-objetivo, modelización de sistemas biológicos, aplicaciones robóticas, toma de decisiones, y por supuesto diseño óptimo de redes de agua. 
Inicialmente PSO fue propuesto para la optimización en espacios continuos, siendo relativamente escaso hasta el momento el trabajo aportado para su aplicación en espacios discretos. En el diseño óptimo de redes de agua, cuando se trata de dimensionar una serie de tuberías, es mucho más práctico trabajar en espacios discretos, puesto que la instalación se hace según una serie de diámetros comerciales disponibles. Es por ello que la aplicación diseñada aplica el algoritmo PSO al espacio discreto, siguiendo el modelo que da Jin et al (2006).

De un modo más específico relacionado con las redes de distribución, el algoritmo PSO ha sido aplicado con éxito tanto en problemas de diseño óptimo como en problemas relacionados con la localización óptima de sistemas de protección contra transitorios. En este sentido, Jung (2006) aplica con éxito GA y PSO como métodos de optimización para la posición, tamaño y número de dispositivos hidráulicos de protección en sistemas de distribución.

\subsection{Shuffled Frog Leaping Algorithm (SFLA)}

La versatilidad que ofrecen los algoritmos evolutivos en la resolución de todo tipo de procesos de optimización es tal que incluso pueden desarrollarse técnicas híbridas que combinen las mejores características de distintas técnicas. Una de las más recientes la dan a conocer Eusuff y Lansey (2000), bajo el nombre de Shuffled Frog Leaping Algorithm (SFLA). SFLA tiene un funcionamiento similar al resto de técnicas evolutivas, tratando de encontrar una solución óptima para un determinado problema a partir de la evolución de una población inicial aleatoria. Para ello realiza una búsqueda heurística que combina elementos de otros métodos de optimización, de modo que la búsqueda local realizada por SFL está basada en el algoritmo PSO, mientras que el intercambio global de información tiene su origen en una técnica conocida como Shuffled Complex Evolution (SCE).

Tras el primer trabajo presentado en el año 2000, Eusuff y Lansey han publicado distintos trabajos de aplicación de SFLA a problemas matemáticos complejos, como pueden ser funciones no derivables, diseño de RDA, gestión de proyectos, etc. Dentro del campo de estudio en el que se enmarca esta tesis el trabajo de más interés es el publicado en 2003, donde Eusuff y Lansey aplican el algoritmo SFL al diseño óptimo de distintas redes de agua ampliamente conocidas, como pueden ser la red de Hanoi, la red de Alperovits y Shamir o la red de Nueva York.

\subsection{Harmony Search (HS)}

La última técnica de optimización que incluye este trabajo es también la más reciente de todas ellas, y la evolución propuesta trata de imitar el proceso de improvisación que realiza una orquesta en la composición de una melodía que podríamos considerar perfecta. Geem publicó las bases de la técnica de optimización Harmony Search (HS) en el año 2001. En los 
últimos años, Geem ha presentado distintos trabajos que utilizan esta técnica aplicada a todo tipo de problemas de optimización relacionados con las redes de distribución, como pueden ser el proceso de diseño óptimo de redes (Geem, 2006) o la optimización de sistemas de bombeo (Geem, 2009).

Pese a la relativa juventud del algoritmo HS, algunos investigadores ya han realizado diversas propuestas que modifican el algoritmo tratando de mejorar sus prestaciones. Así, la técnica original HS fija de modo invariable la probabilidad de que se produzca un ajuste, así como el valor del ancho de banda (bw) en el que se tiene que mover la variable de decisión. Mahdavi et al. (2007) proponen una variación del algoritmo original llamada IHS (Improved Harmony Search), donde la principal diferencia radica en el tratamiento de los parámetros de ajuste de los que dispone HS y del ancho de banda en el que se mueve bw.

Uno de estos parámetros de ajuste se conoce como Pitch Adjustment Rate (en adelante PAR) y tiene ciertas semejanzas con la mutación genética. Así, Mahdavi propone incrementar el PAR y disminuir bw conforme el proceso de optimización avanza. Para ello propone las siguientes expresiones:

$$
P A R(g n)=P A R_{\min }+\frac{\left(P A R_{\max }-P A R_{\min }\right)}{N I} \cdot g n
$$

donde NI representa el número de vectores solución que ya se han generado, gn es el número de generaciones y $\mathrm{PAR}_{\max } / \mathrm{PAR}_{\min }$ representan los valores máximo y mínimo de probabilidad de ajuste. Del mismo modo:

$$
b w(g n)=b w_{\max } \cdot \exp (c \cdot g n) \quad \text { con } c=\frac{\ln \left(b w_{\text {min }} / b w_{\text {max }}\right)}{N I}
$$

donde bw(gn) es el valor del ancho de banda en una determinada generación y bw $w_{\min } / b w_{\max }$ son los valores mínimo y máximo en los que puede oscilar el ancho de banda.

El disminuir el valor del ancho de banda parece razonable, puesto que conforme se está más cerca de la solución final, puede ayudar a realizar un ajuste más fino de esta. Sin embargo, el encontrar los valores adecuados $b_{w_{\min }} / \mathrm{bw}_{\max }$ se convierte en un nuevo problema. La filosofía aplicada es similar a la que emplean las redes neuronales en el llamado factor de aprendizaje.

Omran y Mahdavi (2008) presentan otra modificación al algoritmo original, basada en el concepto de la inteligencia que propone la técnica de optimización PSO. Esta variación recibe el nombre de Global-best Harmony Search y su característica principal es que elimina el ancho de banda cuando es necesario realizar un ajuste según PAR. Esta técnica realiza el ajuste 
sustituyendo directamente la variable de decisión que debe ajustar por el mejor valor disponible en la memoria del algoritmo $\left(x_{x}^{\text {best }}\right)$.

En lo sucesivo, este trabajo estudia con detalle la aplicación de cada una de estas técnicas al diseño óptimo de redes de agua, planteando el problema de optimización en todas ellas y realizando, en la mayoría de los casos, modificaciones a la formulación original del algoritmo, en aras de mejorar su aplicación en el problema planteado. 


\section{MODELOS HEURÍSTICOS DE OPTIMIZACIÓN}

\subsection{Introducción}

Tradicionalmente, este tipo de técnicas se ha formulado en variables binarias. La cadena binaria que contiene la solución del problema recibe un nombre u otro en función del tipo de técnica que se utiliza. Cada cadena binaria contiene bloques de bits que codifican una sola variable del problema y al valor dentro de cada posición del bloque se le llama alelo (de valor cero o uno).

Este tipo de codificación binaria se ha dado sobretodo en los AG. La formulación tradicional de $A G$ en variables binarias es debida en especial al trabajo pionero de Holland, que en su libro da una justificación teórica para utilizar codificaciones binarias. Según Holland, el alfabeto binario es el que ofrece el mayor número de esquemas posibles por bit, lo que favorece la diversidad e incrementa la probabilidad de que se formen buenos "bloques constructores" en cada generación, lo que mejora el desempeño del AG.

No obstante, los argumentos de Holland son rebatibles cuando se trata de resolver ciertos problemas del mundo real. Por ejemplo, en el caso que nos ocupa, si tratamos de optimizar una red de distribución de 50 tuberías, con una gama amplia de diámetros, el mapeo de números reales a binarios generará cadenas extremadamente largas, con lo que el AG tendrá muchos más problemas para producir resultados aceptables.

Otro problema relativo al uso de la codificación binaria es que no mapea adecuadamente el espacio de búsqueda con el espacio de representación. Un ejemplo de ello es la codificación en binario de los números 5 y 6 , que son adyacentes en el espacio de búsqueda. No obstante, si se realiza su representación en números binarios son el 101 y el 110, que difieren en dos bits en el espacio de representación. A este fenómeno se le conoce con el nombre de Risco de Hamming y conduce a los investigadores a proponer representaciones alternativas donde la propiedad de adyacencia pueda preservarse en los espacios de búsqueda y solución.

El código Gray es una de estas técnicas de representación donde dos valores consecutivos difieren solamente en uno de sus dígitos. Dicho código se construye por entero a partir del código binario a través de un proceso reflejante, aplicando la función lógica a sus bits 
consecutivos de derecha a izquierda. Por ejemplo, dado el número 1001 en binario la codificación Gray resultante sería: $1 \oplus 0=1,0 \oplus 0=0,0 \oplus 1=1$, siendo el número Gray resultante 1101, ya que el último bit de la izquierda permanece igual. Algunos investigadores han demostrado de modo empírico que la utilización de códigos de Gray mejora los resultados obtenidos por los Algoritmos Genéticos, ya que no sólo elimina los riscos de Hamming, sino que además altera el número de óptimos locales en el espacio de búsqueda, así como el tamaño de buenas regiones de búsqueda.

En el método que se propone para diseño de redes de distribución de agua, cada una de las variables de decisión (diámetros de las tuberías) puede tener un rango de soluciones posibles diferentes, lo que se representa mediante una variable alfanumérica. La figura 3.1 muestra la analogía entre la representación binaria y la alfanumérica que se propone en el algoritmo utilizado.

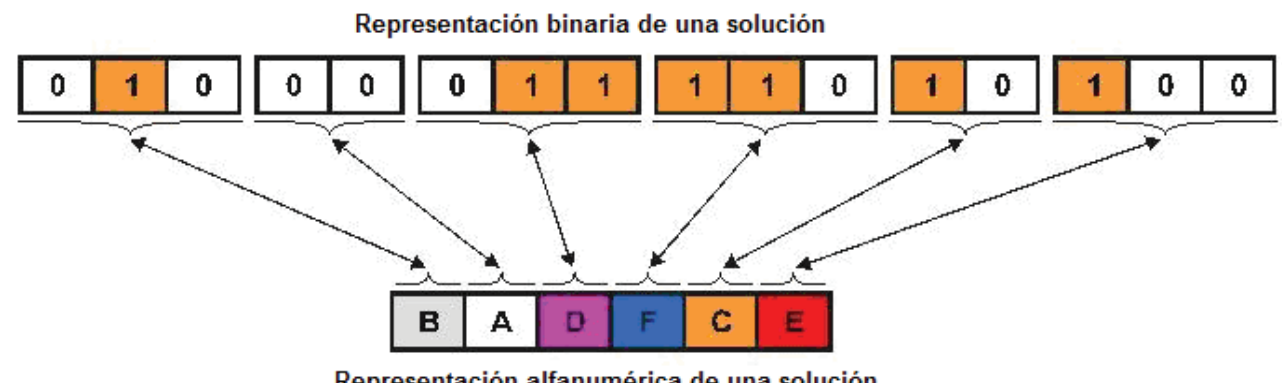

Representación alfanumérica de una solución

Figura 3.1. Conceptos de cromosoma y gen en un AG clásico y en el AG propuesto

En este trabajo, la totalidad de métodos heurísticos ensayados han sido formulados utilizando una representación alfanumérica de la solución, puesto que este tipo de codificación resulta muy útil en la representación de este tipo de variables, ya que nos permite identificar cada eslabón de la cadena con una variable de decisión.

Una cadena representa simbólicamente una solución del problema. Está constituida por una serie de variables alfanuméricas que definen de forma biunívoca una única solución del problema de optimización. Esta partícula recibe un nombre diferente en cada una de las metodologías de optimización empleada. De este modo, se habla de cromosoma en Algoritmos Genéticos, partícula en Particle Swarm Optimization, partitura en Harmony Search, meme en SFLA, etc. Para resolver el problema es necesario disponer de un conjunto discreto de posibles soluciones (cadenas). Este conjunto de cadenas es lo que forma la población de cualquiera de los métodos heurísticos aplicados. Una cadena $X$ genérica está constituida por un número de eslabones igual al de variables de decisión $\left(\mathrm{N}_{\mathrm{VD}}\right)$, de forma que la cadena genérica i de una población $\mathrm{P}$ se define como un vector de valores numéricos. 


$$
x^{i}=\left\{x_{1}^{i}, x_{2}^{i}, \ldots, x_{N_{v 0}}^{i}\right\}
$$

La aptitud de cierta cadena genérica $X^{i}$ se identifica a través del valor que adopta la función objetivo para la solución codificada. En el caso de los algoritmos propuestos para el diseño y ampliación de redes de abastecimiento la función objetivo se define como:

$$
F\left(X^{i}\right)=\sum_{j=1}^{N_{V D}} C_{j}\left(X_{j}^{i}\right) \cdot L_{j}+\lambda \cdot \sum_{s=1}^{N_{s}} \sum_{k=1}^{N_{R}} \delta_{k \cdot s} \cdot\left(H_{m i n, k}-H_{k, s}\right)
$$

donde $C_{j}$ es el coste unitario asociado al valor de la variable de decisión contenida en el eslabón j de la cadena i; y $L_{j}$ es la longitud de conducción de la tubería j. Asimismo existen $N_{R}$ restricciones impuestas que deben cumplir las posibles soluciones del problema. Estas restricciones se incluyen mediante una penalización en el coste total de la solución que afecta posteriormente a la aptitud de la cadena.

Las restricciones que deben cumplirse son las derivadas de satisfacer las restricciones de altura de presión mínima $\left(H_{\min , k}\right)$ en cada nudo $k$. Estas restricciones deben verificarse en todos los escenarios $\mathrm{N}_{\mathrm{s}}$ analizados, que usualmente son el funcionamiento normal del sistema y su funcionamiento bajo el escenario de fallo de alguna de las conducciones. La función penalización representa la diferencia entre la altura piezométrica del nudo $k$ en el escenario $s$ $\left(H_{k, s}\right)$ y la altura mínima requerida $\left(H_{\text {min, } k}\right)$. Para computar dicha penalización se definen dos variables. Una de ellas $\left(\delta_{k, s}\right)$ es una variable binaria que adopta el valor 1 si $H_{k, s}<H_{m i n, k} y$ adopta valor nulo en caso contrario. El parámetro $\lambda$ representa una función de peso que establece el valor de la penalización cuando no se cumplen las restricciones de presión en los nudos. El valor de $\lambda$ es lo suficientemente grande $\left(10^{7}\right)$ como para rechazar todas las soluciones que no cumplan la restricción de presión mínima.

Inicialmente, la formulación de este trabajo consideró como únicos componentes de la red a las conducciones. No obstante, la formulación empleada permite introducir otros elementos como bombas, depósitos, válvulas, etc sin invalidar los algoritmos.

El carácter aleatorio de estos métodos no asegura una exploración completa del espacio de soluciones, ni supone garantía alguna de alcanzar un mínimo de la función objetivo. No obstante, la mayoría de estos métodos ofrecen un conjunto de "buenas" soluciones que intentan mejorarse poco a poco.

Los siguientes puntos analizan en profundidad el modelo de optimización desarrollado para cada uno de los algoritmos evolutivos que utiliza este trabajo, como paso previo a la exposición de resultados. 


\subsection{Modelo de optimización Algoritmo PseudoGenético (APG)}

Un AG es una técnica de optimización numérica que se basa en las leyes de la evolución de Darwin. Su forma de trabajo trata de simular la evolución de una población de individuos, sometida a acciones aleatorias semejantes a las que actúan en la evolución biológica (reproducción, cruce y mutación), así como también a una selección de acuerdo con algún criterio, en función del cual se decide cuáles son los individuos más adaptados, que sobreviven, y cuáles son los menos aptos, que son descartados.

Los Algoritmos Genéticos presentan una serie de ventajas sobre otros métodos en lo que a optimización se refiere, que los hacen más robustos y preferibles para determinadas aplicaciones. De este modo, algunas características de interés de un AG son:

- Un AG es de carácter estocástico, lo que quiere decir que dos ejecuciones distintas pueden dar dos mejores soluciones distintas. Esta característica es útil por el hecho de que en un problema como el de diseño óptimo de una red de agua hay varias soluciones posibles, por lo que es interesante disponer de un método capaz de dar distintas soluciones en distintas ejecuciones.

- Son algoritmos de búsqueda múltiple, luego en una misma ejecución el algoritmo da varias soluciones. Así, pese a que la aptitud de los individuos de la población final es similar, los individuos suelen ser distintos entre sí. Esto amplia la posibilidad de elección de una solución final, según sea la naturaleza del problema.

- Es uno de los algoritmos que realiza una mayor búsqueda en el subespacio de posibles soluciones. De hecho, se considera que de todos los algoritmos de optimización estocásticos, los AG son uno de los que tiene mayor capacidad de exploración.

- Los AG presentan una convergencia excepcionalmente rápida al principio, bloqueada de forma inmediata. Esto se debe a que el AG es muy bueno descartando espacios de soluciones realmente malos. Cada cierto tiempo, la población vuelve a dar un salto evolutivo y se produce un incremento en la velocidad de convergencia excepcional. La razón de esto es que algunas veces aparece alguna mutación beneficiosa, o un individuo excepcional, que propaga un buen conjunto de cromosomas al resto de la población.

La búsqueda con AG es robusta, lo que quiere decir que para que un proceso de optimización no converja la elección de los parámetros debería ser realmente mala. Con una elección 
razonable de los parámetros, los AG convergen a una solución razonablemente buena si la representación es la adecuada.

Los AG son métodos sistemáticos para la resolución de problemas de búsqueda y optimización. Como ya se ha descrito en el anterior apartado, tradicionalmente han sido formulados en variables binarias. Sin embargo, en la aplicación diseñada en éste trabajo se han utilizado variables numéricas, por lo que en adelante nos referiremos al algoritmo utilizado como Algoritmo Pseudogenético (APG).

El funcionamiento del APG aplicado al diseño de redes de agua viene representado en forma de diagrama de flujo en la Figura 3.2. Se describe a continuación las distintas etapas que sigue el proceso de optimización.

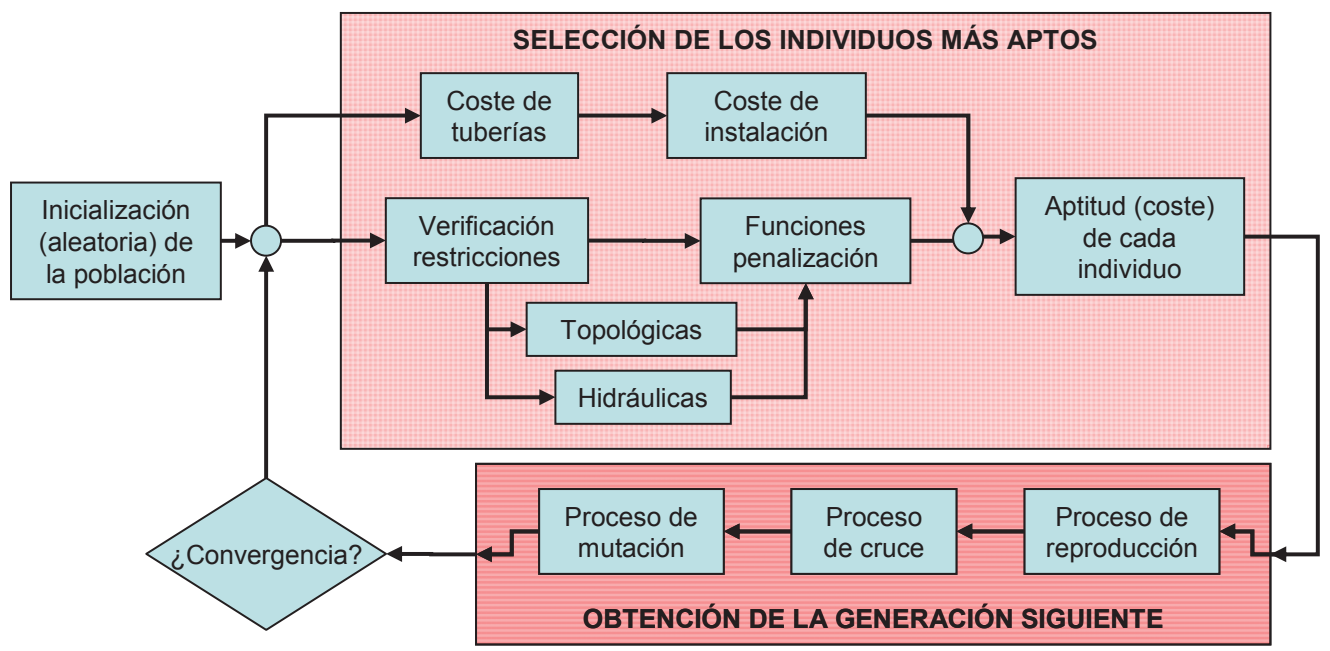

Figura 3.2. Algoritmo Genético aplicado al diseño óptimo de redes de agua

La idea básica es generar un conjunto de posibles soluciones, cada una de las cuales es llamada individuo. El conjunto de todas estas posibles soluciones es lo que se conoce como población del algoritmo. Cada uno de los pasos descritos a continuación consiste en la aplicación de un operador sobre la cadena alfanumérica. Estos operadores reciben el nombre de operadores genéticos y son fundamentalmente tres: Reproducción, cruce y mutación. Los tres son tratados con detalle en 3.2.1.

- Etapa 0. Definición de los parámetros del algoritmo

Esta etapa no forma parte del proceso de optimización en si, pero no se puede despreciar su importancia, puesto que es aquí donde la pericia del usuario ejerce cierta influencia en el buen hacer del algoritmo. 
Así, antes de iniciar el cálculo es fundamental la definición de los parámetros con los que va a trabajar el algoritmo. En el caso de un APG son cuatro: la probabilidad de cruce, la probabilidad de mutación, el tamaño de la población y el número de iteraciones que realizará el algoritmo sin cambio, que en este caso es la condición de convergencia que se impone al algoritmo.

- Etapa 1. Inicialización del algoritmo y selección de los individuos más aptos.

El cálculo comienza con la generación de una serie de cromosomas, cada uno de los cuales contiene una posible solución del problema de optimización. Esta primera generación es totalmente aleatoria.

Los cromosomas son ordenados en base a su aptitud. En el problema de diseño planteado, la aptitud de un determinado cromosoma viene dada por el coste asociado al diseño de la red de agua.

El software desarrollado permite el trabajo conjunto del APG diseñado junto con el software de simulación hidráulica de EPANET y sus librerías, EPANET Toolkit (Rossman, 2000). Cada uno de los cromosomas proporcionados por el APG es simulado en EPANET, con el objetivo de verificar que la solución dada cumple todas las restricciones impuestas por la función objetivo.

\section{- Etapa 2. Operadores genéticos}

Una vez los cromosomas se encuentran ordenados en base a su aptitud, éstos se reproducen atendiendo a una serie de criterios, que otorgan mayor probabilidad de reproducirse a los mejores individuos y menor probabilidad de reproducirse a los peores.

En la bibliografía es posible encontrar multitud de procesos de reproducción aplicados a AG, cuyo detalle puede seguirse en 3.2.1. En el APG diseñado el método de reproducción elegido es el llamado "método de reproducción constante", consistente en asignar a cada cadena de la población una probabilidad de reproducción, que dependerá directamente de la aptitud de cada cadena.

Los individuos de la nueva generación son emparejados, produciéndose un intercambio de material genético. Los operadores genéticos aplicados son dos: cruce y mutación.

El proceso de cruce escoge de modo aleatorio ciertas cadenas de la población intermedia creada y realiza un cambio de los distintos eslabones a partir de un cierto eslabón de cruce. Se genera entonces una nueva cadena que es combinación de otras dos.

El proceso de mutación se aplica a la población intermedia obtenida tras los procesos de reproducción y cruce. Se establece una frecuencia de mutación, se examina cada eslabón de la 
cadena, y si un número aleatorio generado por el APG está por debajo de esa probabilidad se produce un cambio en el valor del eslabón. Traducido al diseño de redes de agua, este cambio en el eslabón simboliza un cambio en el valor del diámetro de una determinada tubería.

- Etapa 3. Condición de convergencia

El ciclo se repite una y otra vez hasta que se cumpla la condición de convergencia. En la aplicación diseñada, el APG repite el ciclo hasta que se produzca un cierto número de repeticiones sin ninguna mejora en el mejor individuo de la población. Este número debe ser suficientemente alto como para evitar una convergencia temprana en un mínimo local, pero no tanto como para ralentizar excesivamente la convergencia del algoritmo.

\subsubsection{Operadores genéticos}

Tal como se ha visto en apartados anteriores, los operadores genéticos son funciones empleadas en AG que mantienen la diversidad genética de la población del algoritmo. Dicha variación genética es clave para el buen funcionamiento del APG, y viene dada de un modo análogo a los procesos que ocurren en el mundo natural: supervivencia de los más aptos, cruce entre especies y mutación biológica. La implementación de estos operadores genéticos es diferente en cada caso, puesto que existen multitud de tipos de reproducción, cruce o mutación. Las siguientes líneas describen algunos de ellos, tomando especial interés por la opción elegida para el APG diseñado en este trabajo.

\subsubsection{Proceso de reproducción}

Una parte fundamental para el buen funcionamiento de un AG es el proceso donde se seleccionan los candidatos a reproducirse. Así, la reproducción es el proceso por el cual se seleccionan de entre $\mathrm{N}_{\mathrm{C}}$ cadenas de una población cuáles serán aquellas que sobrevivirán a la siguiente generación. En los algoritmos genéticos el proceso de reproducción suele realizarse de modo probabilístico. No obstante, existen multitud de métodos de reproducción que pueden dividirse en tres grandes grupos:

- Selección proporcional

Son originalmente propuestos por Holland (1975) y se basan en un proceso de selección de individuos que tiene en cuenta la aptitud de cada individuo respecto al resto de la población. Las técnicas más importantes de selección proporcional son la ruleta, el sobrante estocástico, la universal estocástica y el muestreo determinístico. Además de estas técnicas, existen algunas otras menos utilizadas que también se engloban en este grupo, como son el escalamiento sigma, las jerarquías y la selección de Boltzmann.

La ruleta fue propuesta por DeJong (1975) y ha sido el método de reproducción más comúnmente utilizado en $\mathrm{AG}$, debido a su simplicidad. No obstante, este método es 
ineficiente, entre otras cosas porque permite la reproducción de los peores individuos con frecuencia. El sobrante estocástico fue propuesto por Booker (1982) y Brindle (1981) y se basa en la asignación determinística de las partes enteras de los valores esperados para cada individuo, utilizando luego otro esquema (proporcional) para la parte fraccionaria. Este método reduce los problemas de la ruleta, pero como contrapartida puede converger de modo prematuro, ya que introduce una mayor presión de selección.

La universal estocástica pretende minimizar la mala distribución de los individuos en la población en función de sus valores esperados. Baker (1987) es el creador de esta técnica de reproducción, pero no llega a resolver el mayor problema de la selección proporcional, que es la imprecisión entre valores esperados y número de copias de cada individuo que es seleccionado. El muestreo determinístico es una variante de la selección proporcional con la que experimentó Dejong, pero no resuelve los problemas de los anteriores métodos.

La selección por jerarquías busca evitar la convergencia prematura del resto de técnicas de selección proporcional. Esta técnica fue propuesta por Baker (1987) e intenta reducir la presión de selección. Los individuos se clasifican en función de su aptitud, pero se les selecciona en función de su rango. El uso de jerarquías permite no tener que escalar la aptitud, puesto que la diferencia entre las aptitudes absolutas se diluye. El uso de jerarquías previene la convergencia prematura, pero provoca que el proceso de convergencia sea más lento.

\section{- Selección mediante torneo}

Esta metodología de reproducción utiliza un proceso similar al de jerarquías, pero es computacionalmente más adecuada para la implementación en paralelo. El método compara de modo directo individuos, de modo que elige un número $\mathrm{x}$ de individuos, los compara $\mathrm{y}$ elige. Existen dos versiones de la selección mediante torneo: Determinística y probabilística.

La diferencia radica en la elección del ganador del torneo. En el caso de la versión determinística cuando se realiza la comparación entre individuos siempre se escoge el que tiene la aptitud más alta, mientras que en el caso probabilístico existe una función de probabilidad que elige al individuo, y que también deja la posibilidad de elegir al individuo con la aptitud más baja. En cualquier caso, el proceso debe repetirse $p$ veces con el objetivo de seleccionar $\mathrm{N}$ padres, donde $\mathrm{N}$ es el tamaño de la población.

Las principales ventajas de esta técnica son que es eficiente y fácil de implementar. En el caso de la versión determinista está garantizado que el mejor individuo será seleccionado $p$ veces, lo que introduce en el proceso una presión de selección alta. Es posible regular la presión de selección variando el tamaño de torneo, siendo esta selección más dura cuanto más grande es el torneo. 
- Selección uniforme

Es utilizada principalmente en AG no generacionales, y su principal característica es que tan sólo unos cuantos individuos (los menos aptos) son reemplazados en cada generación. Esta técnica fue propuesta por Whitley y se utiliza en sistemas basados en reglas en los que el aprendizaje es incremental. Éste es un mecanismo especializado de selección pero los AG no generacionales no son muy comunes en optimización.

En el APG utilizado en el presente trabajo se selecciona el método de reproducción constante. Las ventajas de esta metodología frente a otras en el diseño de redes de agua puede seguirse con detalle en Matías (2003).Este método puede clasificarse como de selección proporcional y en él se asigna a cada cadena de la población una probabilidad de selección para formar parte de la siguiente generación. Dicha probabilidad depende del orden según el coste de la cadena dentro de la población, y debe estar comprendida entre una probabilidad máxima $\mathrm{p}_{\max }$, asociada al individuo de coste menor, y una probabilidad mínima, asociada a la solución de coste mayor. Ambas probabilidades se definen como:

$$
p_{\max }=\frac{\beta}{N_{C}} \quad p_{\min }=\frac{2-\beta}{N_{C}}
$$

donde $\beta$ es una constante cuyo valor está comprendido entre 1,5 y 2 (Wang, 1991) y $N_{C}$ es el número de cromosomas. De acuerdo con este método, la probabilidad de selección para una cadena genérica i es:

$$
p_{i}=p_{\min }+\left(p_{\max }-p_{\min }\right) \frac{N_{C}-i}{N_{C}-1}
$$

La posibilidad que tiene cada cadena de reproducirse en la siguiente generación viene dada por el producto de la probabilidad $p_{i}$ por el número de cadenas $\mathrm{N}_{\mathrm{C}}$. Si el producto es mayor o igual a 1,5 la cadena se duplica; si está entre 0,5 y 1,5 la cadena se mantiene; y si es inferior a 0,5 la cadena se elimina de la siguiente generación.

La tabla 3.1 recoge el proceso de reproducción constante que se produce en una hipotética población de 16 cadenas. Los valores de la constante $\beta$ se muestran en las primeras filas, así como las probabilidades asociadas al individuo más caro y más barato. Las dos primeras columnas recogen la cadena y la aptitud que se asocia a cada una de ellas, y el resto de columnas muestra para cada valor de $\beta$ los valores de probabilidad de cada cadena $\mathrm{p}_{\mathrm{i}}$, el producto $\mathrm{p}_{\mathrm{i}} \cdot \mathrm{N}_{\mathrm{C}}$ y el número de copias de la cadena en cuestión que estarán en la siguiente generación. 


\begin{tabular}{|c|c|c|c|c|c|c|c|c|c|c|c|c|c|}
\hline \multicolumn{2}{|c|}{$\begin{array}{c}\text { Constante } \beta \\
\text { pmáx } \\
\text { pmin }\end{array}$} & \multicolumn{3}{|c|}{$\begin{array}{c}1,6 \\
0,1000 \\
0,0250 \\
\end{array}$} & \multicolumn{3}{|c|}{$\begin{array}{c}1,7 \\
0,1063 \\
0,0188 \\
\end{array}$} & \multicolumn{3}{|c|}{$\begin{array}{c}1,8 \\
0,1125 \\
0,0125 \\
\end{array}$} & \multicolumn{3}{|c|}{$\begin{array}{c}1,9 \\
0,1188 \\
0,0063 \\
\end{array}$} \\
\hline Cadena & Valor & pi & $\begin{array}{c}\text { pi*N }^{*} \\
\text { C }\end{array}$ & Indiv & pi & $\begin{array}{c}\mathrm{pi}^{*} \mathrm{~N} \\
\mathrm{C} \\
\end{array}$ & Indiv & pi & $\begin{array}{c}\mathrm{pi}^{*} \mathrm{~N} \\
\mathrm{C} \\
\end{array}$ & Indi & pi & $\begin{array}{c}\text { pi*N }^{*} \\
\text { C }\end{array}$ & Indiv \\
\hline 1 & 36 & 0,100 & 1,60 & 2 & 0,106 & 1,70 & 2 & 0,113 & 1,80 & 2 & 0,119 & 1,90 & 2 \\
\hline 2 & 327 & 0,095 & 1,52 & 2 & 0,100 & 1,61 & 2 & 0,106 & 1,69 & 2 & 0,111 & 1,78 & 2 \\
\hline 3 & 799 & 0,090 & 1,44 & 1 & 0,095 & 1,51 & 2 & 0,099 & 1,59 & 2 & 0,104 & 1,66 & 2 \\
\hline 4 & 1640 & 0,085 & 1,36 & 1 & 0,089 & 1,42 & 1 & 0,093 & 1,48 & 1 & 0,096 & 1,54 & 2 \\
\hline 5 & 3569 & 0,080 & 1,28 & 1 & 0,083 & 1,33 & 1 & 0,086 & 1,37 & 1 & 0,089 & 1,42 & 1 \\
\hline 6 & 4711 & 0,075 & 1,20 & 1 & 0,077 & 1,23 & 1 & 0,079 & 1,27 & 1 & 0,081 & 1,30 & 1 \\
\hline 7 & 5363 & 0,070 & 1,12 & 1 & 0,071 & 1,14 & 1 & 0,073 & 1,16 & 1 & 0,074 & 1,18 & 1 \\
\hline 8 & 7713 & 0,065 & 1,04 & 1 & 0,065 & 1,05 & 1 & 0,066 & 1,05 & 1 & 0,066 & 1,06 & 1 \\
\hline 9 & 10020 & 0,060 & 0,96 & 1 & 0,060 & 0,95 & 1 & 0,059 & 0,95 & 1 & 0,059 & 0,94 & 1 \\
\hline 10 & 13952 & 0,055 & 0,88 & 1 & 0,054 & 0,86 & 1 & 0,053 & 0,84 & 1 & 0,051 & 0,82 & 1 \\
\hline 11 & 14939 & 0,050 & 0,80 & 1 & 0,048 & 0,77 & 1 & 0,046 & 0,73 & 1 & 0,044 & 0,70 & 1 \\
\hline 12 & 15346 & 0,045 & 0,72 & 1 & 0,042 & 0,67 & 1 & 0,039 & 0,63 & 1 & 0,036 & 0,58 & 1 \\
\hline 13 & 15747 & 0,040 & 0,64 & 1 & 0,036 & 0,58 & 1 & 0,033 & 0,52 & 1 & 0,029 & 0,46 & 0 \\
\hline 14 & 16450 & 0,035 & 0,56 & 1 & 0,030 & 0,49 & 0 & 0,026 & 0,41 & 0 & 0,021 & 0,34 & 0 \\
\hline 15 & 18735 & 0,030 & 0,48 & 0 & 0,025 & 0,39 & 0 & 0,019 & 0,31 & 0 & 0,014 & 0,22 & 0 \\
\hline 16 & 19822 & 0,025 & 0,40 & 0 & 0,019 & 0,30 & 0 & 0,013 & 0,20 & 0 & 0,006 & 0,10 & 0 \\
\hline
\end{tabular}

\section{Tabla 3.1 Proceso de Reproducción constante}

El proceso de reproducción es de gran importancia en el funcionamiento de un AG, por lo que obviamente, tiene esa misma importancia en el desempeño de un APG. El resultado del ejemplo de reproducción constante realizado se muestra con mayor claridad en la Figura 3.3

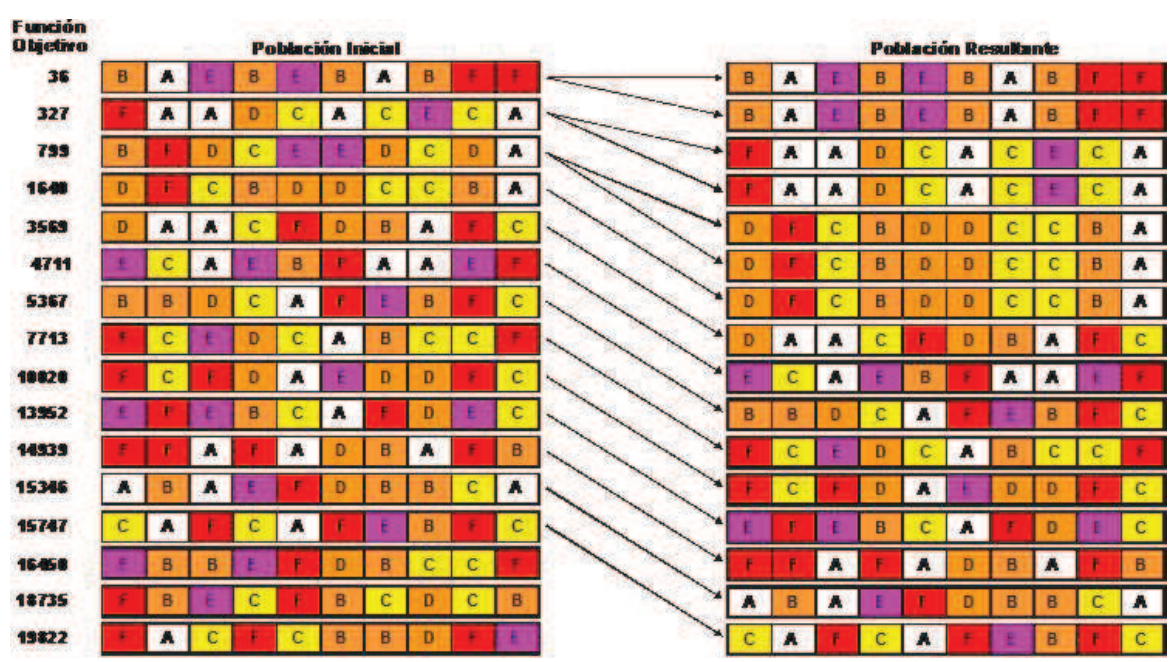

Figura 3.3 Esquema de selección. Proceso de reproducción constante 


\subsubsection{Proceso de cruce}

El proceso de cruce escoge de modo aleatorio ciertas cadenas de la población intermedia y realiza un cambio de los distintos eslabones a partir de un cierto eslabón de cruce. De esta forma uno de los parámetros característicos de un AG es el número de cadenas que se cruzan entre sí, que está definido por lo que se conoce como probabilidad de cruce $\mathrm{p}_{\mathrm{c}}$.

Pese a que originalmente las técnicas de cruce se han aplicado siempre a representaciones binarias, es posible su generalización a otros alfabetos de cardinalidad mayor, si bien en algunos casos requieren ciertas modificaciones. Existen tres técnicas básicas de cruce:

- Cruce de un punto

- Cruce de dos puntos

- Cruce uniforme

El cruce de un punto fue propuesto por Holland y fue el procedimiento más popular durante muchos años. Este tipo de cruce ha sido implementado en el APG estudiado, aunque con ciertas matizaciones. Así, cuando la codificación es binaria y se realiza el cruce la selección aleatoria del eslabón de cruce determina el punto donde se trocean las cadenas para cruzarlas entre sí. Esto puede originar la fracción del código binario que identifica una de las posibles variables de decisión. A este fenómeno se le denomina sesgo posicional y empeora la calidad de los resultados.

En el modelo de APG implementado (Figura 3.4) la selección de un eslabón de cruce no genera este efecto, puesto que cada eslabón de la cadena corresponde a una variable de decisión (diámetro). Por ello la utilización de los APG genera menos posibilidad de cambio en las soluciones finales que los AG clásicos.

Por otro lado, el proceso de cruce implementado en el APG permite que dos miembros de los mismos padres puedan ser emparejados, puesto que ello garantiza la perpetuidad de un individuo con buena puntuación. Pese a esto, no es conveniente que esta situación se repita en exceso, puesto que se corre el riesgo de que la población sea dominada por los descendientes de un gen en particular, lo que podría provocar la caída del cálculo en un mínimo local. 


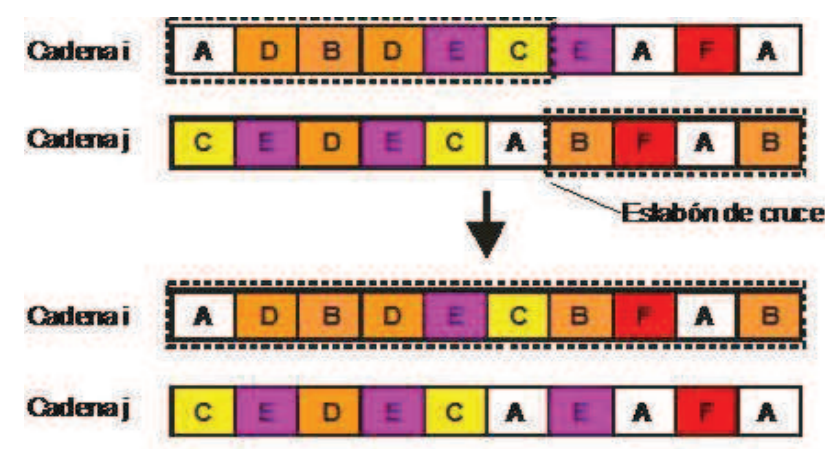

Figura 3.4 Proceso de cruce.

DeJong (1975) fue el primero en utilizar cruces de $\boldsymbol{n}$ puntos, como generalización del cruce de un punto. El valor $n=2$ es el que minimiza los efectos destructivos de la operación de cruce sobre código binario. Del mismo modo se han realizado intentos de cruce con $n>2$, pero no existe ningún estudio concluyente que confirme una mejora en los resultados ni consenso entre los distintos investigadores acerca del óptimo número de puntos de cruce.

El último tipo de cruce que abordaremos es el cruce uniforme. Este es un tipo de cruce de $n$ puntos, donde $n$ no queda fijado previamente. Esta tipología de cruce es más brusca que las anteriores y con el fin de mitigar este efecto se suele utilizar una probabilidad de cruce no superior a 0.5 , aunque algunos investigadores recomiendan utilizar valores más pequeños.

\subsubsection{Proceso de mutación}

El proceso de mutación se aplica a la población intermedia obtenida tras los procesos de reproducción y cruce. Una vez establecida la frecuencia de mutación, por ejemplo de un uno por mil, se examina cada eslabón de cada cadena cuando se crea un individuo a partir de sus padres. Si un número generado aleatoriamente está por debajo de esa probabilidad se cambiará el eslabón. Si no, se deja como está. La utilidad del proceso es la ampliación de las zonas de búsqueda dentro del espacio de soluciones factible.

En un $A G$ es un proceso que consiste en transponer el valor binario de eslabones aislados: si su valor es 0 pasa a ser 1 y viceversa. Hay que recordar que el APG utiliza una codificación alfanumérica basada en el código Gray, con el objetivo de evitar que el cambio de un único bit en la cadena genere un gran cambio en la variable de decisión. Esta codificación (tabla 3.2) tiene como principio que el cambio en un único bit genere tan solo un aumento o disminución de una unidad en la representación del diámetro (figura 3.5). 


\begin{tabular}{|c|c|c|c|}
\hline $\begin{array}{c}\text { ID } \\
\text { DIÁMETRO }\end{array}$ & $\begin{array}{c}\text { DIÁMETRO } \\
\text { INTERIOR }(\mathbf{m m})\end{array}$ & CóDIGO BINARIO & CóDIGO GRAY \\
\hline A & 100 & 000 & 000 \\
\hline B & 125 & 001 & 001 \\
\hline C & 150 & 010 & 011 \\
\hline D & 200 & 011 & 010 \\
\hline E & 250 & 100 & 110 \\
\hline F & 300 & 101 & 111 \\
\hline G & 350 & 110 & 101 \\
\hline H & 400 & 111 & 100 \\
\hline
\end{tabular}

Tabla 3.2. Código Gray

Tradicionalmente se ha considerado a la mutación como un operador secundario en los AG tradicionales, priorizando el uso del cruce como operador genético principal. En la práctica se suelen recomendar porcentajes de mutación de entre 0,001 y 0,01 para la representación binaria.

El APG diseñado presenta diferencias significativas a este respecto, ya que tal como se ha definido, genera una diversidad menor en el proceso de cruce. Para contrarrestar este efecto la mutación cobra mayor importancia, por lo que en nuestro caso se utilizarán porcentajes de mutación mayores. Así, el rango de probabilidad de mutación utilizado en los distintos procesos de optimización ha estado entre el 1 y el 10\% de probabilidad de mutación.

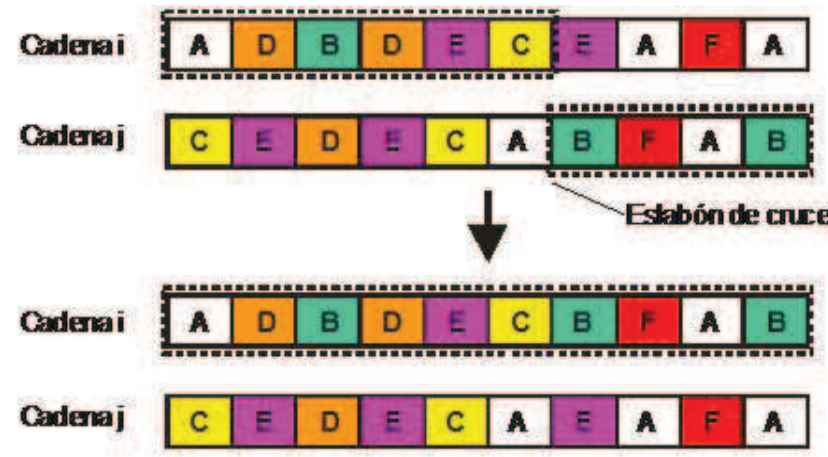

Figura 3.5. Proceso de mutación de un AG y un APG

La mutación es un parámetro del que no se debe abusar en exceso, ya que si bien genera diversidad en las posibles soluciones, el uso de probabilidades de mutación demasiado altas podría reducir el APG a una búsqueda aleatoria. Por ello, es recomendable utilizar otros mecanismos de generación de diversidad, tal como puede ser el incremento de la población del algoritmo o garantizar la generación aleatoria de la población inicial. 


\subsection{Modelo de Optimización Harmony Search (HS)}

La optimización Harmony Search es una técnica de búsqueda que trata de imitar la improvisación que sigue una banda de música cuando busca una melodía perfecta. Este tipo de optimización, propuesta por Geem (2001), ha sido utilizada con éxito en distintos problemas de optimización, y su aplicación al diseño de redes de distribución de agua es la que se trata en este trabajo.

Del mismo modo que en el resto de métodos basados en técnicas heurísticas, el carácter aleatorio del método no permite garantizar con absoluta certeza el mínimo absoluto del sistema, pero sí garantiza la obtención de un conjunto de buenas soluciones que mejoran poco a poco.

El método trata de encontrar cada vez una mejor melodía, que viene representada por una función objetivo que hay que minimizar. Las notas de cada instrumento musical determinan la calidad estética de la melodía y el valor de la función objetivo viene dado por la combinación de todas estas notas musicales, que conforman una partitura y que tratará de ser mejorada en cada iteración. Una nota musical representa una variable de decisión y una partitura completa representa una solución del problema. La figura 3.6 trata de representar la analogía entre improvisación musical y optimización ingenieril.
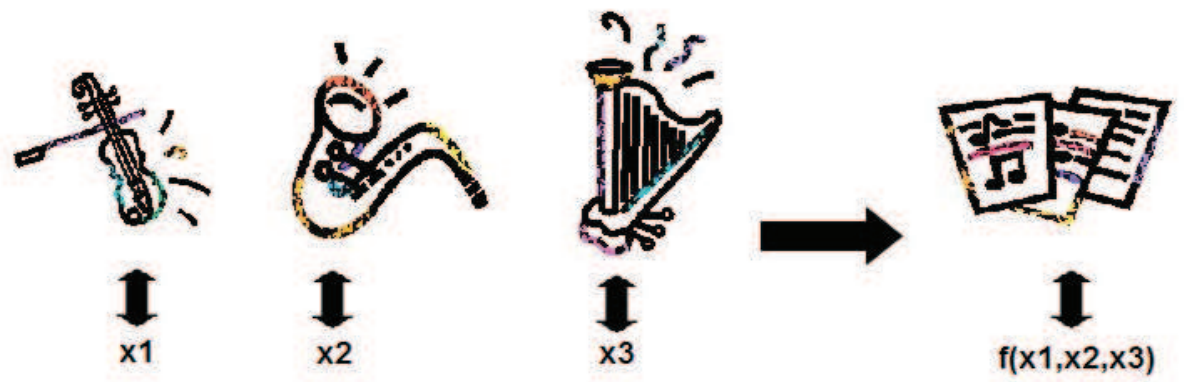

Figura 3.6 Analogía entre improvisación musical y optimización ingenieril.

Considerando un grupo de instrumentos musicales compuestos por un violín, un saxofón y un arpa. Cada uno de estos instrumentos podrá tocar una serie de notas. Esta serie de notas puede ser diferente para cada instrumento o puede ser la misma para todos ellos. En el caso de la aplicación al diseño de redes de agua todos los instrumentos tocarán las mismas notas, puesto que éstas representarán el diámetro elegido.

Las notas tocadas por cada instrumento se unen para formar una partitura, que tiene una determinada aptitud. Si la partitura creada es mejor que la peor partitura guardada en la memoria, ésta será incluida con las demás, mientras que la partitura peor es excluida. Este 
proceso se repite hasta que se cumplan las condiciones de finalización impuestas en el método.

HS es una técnica de optimización concebida para el cálculo con variables discretas. La técnica utilizada en el cálculo de optimización tiene la misma base que el resto de técnicas heurísticas, es decir:

$$
\text { Minimizar } \mathrm{F}(\mathrm{X}) \quad \text { donde } \mathrm{X}^{\mathrm{i}} \in x_{i}, i=1,2, \ldots N
$$

donde $\mathrm{F}(\mathrm{X})$ representa la función objetivo que el método trata de minimizar; $\mathrm{N}$ es el conjunto de todas las variables de decisión; $\mathrm{N}_{\mathrm{VD}}$ es el número de variables de decisión que tiene el problema, es decir, el número de instrumentos musicales que van a componer la partitura; $x_{i}$ representa el rango de posibles valores que puede tomar cada variable de decisión, es decir $x^{i}=\left(X_{1}^{i}, X_{2}^{i}, \ldots, X_{K}^{i}\right)$, donde todas estas variables son de tipo discreto; $\mathrm{K}$ es el número valores que tiene el rango, o lo que es lo mismo, el número de notas que puede tocar cada instrumento, que en este caso concreto equivale al número de diámetros posibles para la conducción. La aplicación realizada para el diseño de redes de agua viene representada en forma de diagrama de flujo en la figura 3.7.

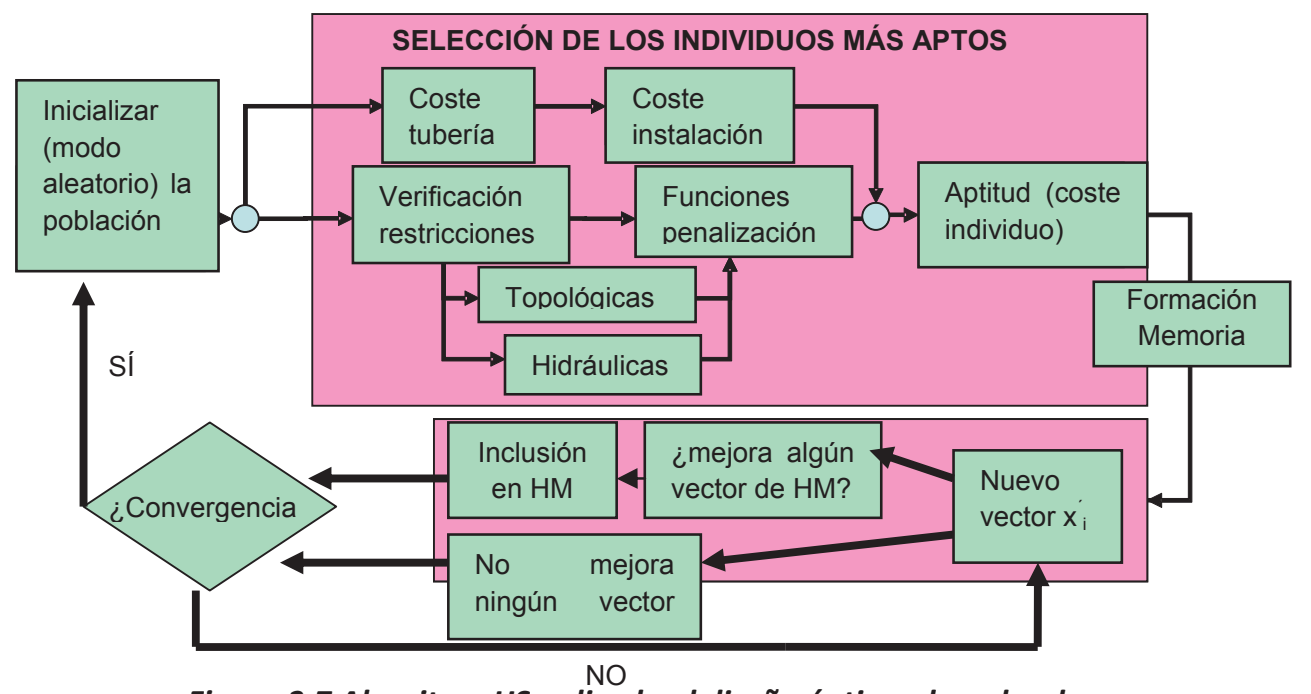

Figura 3.7 Algoritmo HS aplicado al diseño óptimo de redes de agua.

El proceso de optimización HS sigue una serie de etapas, que son enumeradas a continuación:

- Etapa 1. Definición de los parámetros del algoritmo

El primer paso a realizar antes de iniciar el cálculo es definir los parámetros con los que va a trabajar el algoritmo HS. Estos son el tamaño de la memoria (HMS), el ajuste del pitchrate 
(PAR), el ajuste de la memoria del algoritmo (HMCR) y el número de iteraciones que realizará el algoritmo (NI).

El significado del tamaño de memoria es similar al que siguen todos los algoritmos evolutivos cuando se habla de población del algoritmo. Así, el tamaño de la memoria representa el conjunto discreto de posibles soluciones con las que va a trabajar el algoritmo. La Memoria contiene tanto el conjunto de vectores solución del problema como el valor de la función objetivo. El resto de parámetros que requieren de un valor inicial al comenzar el proceso de optimización se abordan con mayor detalle en el 3.3.1.

- Etapa 2. Inicializar la memoria (HM).

Del mismo modo que en cualquier algoritmo evolutivo, el cálculo comienza con la generación de una población aleatoria. La representación de esta población es similar a la que tienen otros algoritmos evolutivos, tales como los genéticos:

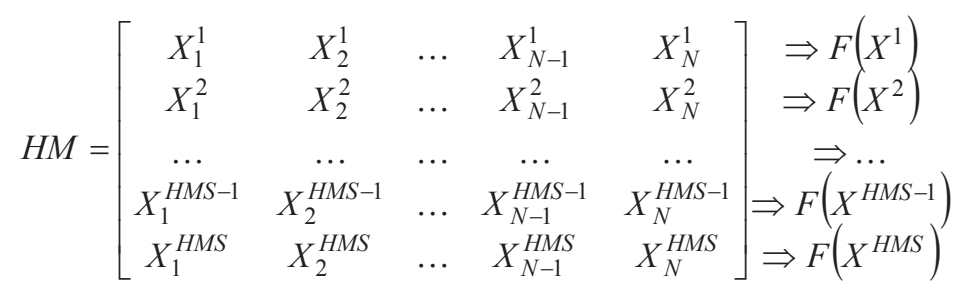

- Etapa 3. Improvisación de una nueva partitura.

Un nuevo vector solución (partitura) se genera a partir de una serie de reglas, como son las consideraciones de memoria, el ajuste del PAR y una selección aleatoria.

- Etapa 4. Definición de la nueva memoria

Si la aptitud (valor de la función objetivo) de la nueva partitura $X_{i}^{\prime}$ es mejor que la de la peor partitura almacenada en memoria, y no existe ningún vector idéntico almacenado, $X_{i}$ será incluida en $\mathrm{HM}$ mientras que la peor partitura existente hasta el momento es excluida.

- Etapa 5. Criterio de convergencia

Las etapas 3 y 4 son repetidas hasta que se cumple el criterio de convergencia que se haya introducido en el algoritmo. En este punto existen varias opciones: una de ellas es elegir un número fijo de iteraciones y ejecutar el algoritmo un determinado número de veces, con lo que una vez realizadas todas las simulaciones programadas el algoritmo dará la mejor solución obtenida. 
En la adaptación de HS realizada en este trabajo se ha optado por un criterio de convergencia distinto, basado en si el algoritmo tiene capacidad para seguir mejorando la mejor solución obtenida tras un determinado número de iteraciones o no. Así, el algoritmo finaliza su tarea cuando realiza número determinado de evaluaciones de la función objetivo sin mejorar la solución. Este número deberá ser lo suficientemente grande como para evitar una convergencia temprana del algoritmo, pero no tanto como para alargar en exceso el tiempo de cálculo del problema.

\subsubsection{Operadores HS}

HS es una técnica relativamente nueva (2001), y esto lleva asociado un menor conocimiento acerca del funcionamiento de sus operadores, puesto que la cantidad de información disponible es menor que en el caso de otras técnicas más afianzadas dentro de los algoritmos evolutivos. Fundamentalmente, HS trabaja con dos operadores propios de esta técnica de optimización. El primero de ellos realiza un ajuste de la memoria del algoritmo y es conocido como Harmony Memory Considering Rate (en adelante HMCR). El segundo de ellos se denomina Pitch Adjustment Rate (en adelante PAR). Además, el ajuste de los distintos parámetros debe incluir el número de individuos iniciales que debe tener la memoria del algoritmo, así como la condición de convergencia para el proceso de optimización.

- $\mathrm{HMCR}$

Cuando se forma una nueva partitura, la programación del algoritmo hace que el valor de cada variable de decisión sea elegido de entre los valores que esa misma variable de decisión ya tiene en otras partituras de la memoria. Matemáticamente esto quiere decir que el valor de cada $X_{1}^{\prime}$ es seleccionado de entre todos los valores que contiene el rango $\left(\mathrm{X}_{1}^{1}, \ldots, \mathrm{X}^{\mathrm{HMS}}{ }_{1}\right)$.

Este tipo de programación podría provocar caídas tempranas en óptimos locales, provocadas por una mala primera generación aleatoria. HMCR se puede definir como un parámetro que trata de controlar el balance entre la memoria del algoritmo y una exploración aleatoria que permita salir de esos mínimos locales.

HMCR puede variar entre 0 y 1 , y representa la probabilidad de elegir un valor para la variable de entre los almacenados en la memoria. Del mismo modo, la diferencia 1-HMCR representa la probabilidad de elegir un valor de modo aleatorio de entre todos los valores que puede tener la variable.

$$
X_{i}^{\prime} \leftarrow\left\{\begin{array}{c}
X_{i}^{\prime} \in\left\{X_{i}^{1}, X_{i}^{2}, \ldots, X_{i}^{H M S}\right\} \text { con probabilidad HMCR } \\
X_{i}^{\prime} \in x_{i} \text { con probabilidad }(1-H M C R)
\end{array}\right\}
$$

Por ejemplo, $\mathrm{HMCR}=0.9$ indica que el algoritmo escogerá el valor de la variable de decisión de entre los valores almacenados en la memoria con un $90 \%$ de probabilidad, mientras que en el 
restante $10 \%$ el algoritmo elegirá el valor de modo aleatorio de entre todas las posibilidades de la gama.

- PAR (Pitch Adjustment Rate)

Una vez obtenida la nueva partitura $X^{\prime}=\left(X_{1}^{\prime}, \ldots, X_{N}^{\prime}\right)$ se examina cada componente de este vector para determinar si debe ser sometido a un cierto ajuste o no. Esta operación tiene cierta semejanza con la mutación en AG y recibe el nombre de ajuste del PAR. La probabilidad de que un cierto componente del vector solución deba ser sometido a ajuste viene dado por:

$$
\text { Probabilidad de ajuste para } \mathrm{X}_{\mathrm{i}}^{\prime} \leftarrow\left\{\begin{array}{c}
\text { Sí con probabilidad PAR } \\
\text { No con probabilidad }(1-P A R)
\end{array}\right.
$$

Si una variable de decisión $X^{\prime}{ }_{i}$ debe ser ajustada, ésta es reemplazada por otra variable $X_{i}^{\prime}(k) \in x_{i}$, pero no de un modo aleatorio, sino por otra variable vecina $\mathrm{x}_{\mathrm{i}}^{\prime}$, de modo que:

$$
X_{i}^{\prime} \leftarrow X_{i}(k+b w)
$$

donde bw representa un ancho de banda, que delimita los valores entre los que se va a mover la variable. De este modo, un PAR de 0,15 indica que cada variable de decisión tendrá una probabilidad del $15 \%$ de ser cambiada por una variable que se encuentre dentro del ancho de banda disponible.

En la adaptación realizada para HS en este trabajo, las variables de decisión son los diámetros de los tubos, por lo que el ajuste del PAR se ha definido de tal forma que supone aumentar o disminuir el tubo según la gama disponible. Así, en el caso de que la variable de decisión deba ser ajustada, se realiza una tirada aleatoria que determina qué valor dentro del ancho de banda debe tomar la variable de decisión. En el algoritmo adaptado para diseño de redes de agua, $b w \in(-1,1)$, lo que quiere decir que el ajuste realizado en este caso será de una unidad hacia arriba o hacia abajo en la gama de diámetros disponible. El limitar el salto a un único diámetro permite potenciar la búsqueda local del algoritmo, puesto que saltos demasiado grandes provocan la convergencia del algoritmo hacia los extremos del espacio de soluciones.

\subsection{Modelo Particle Swarm Optimization modificado (PSO)}

La técnica heurística PSO fue inicialmente propuesta por J.Kennedy y R.Eberhart (1995). EI fundamento de este método se basa en el comportamiento social que tienen las bandadas (poblaciones) de pájaros (partículas) cuando migran a lugares desconocidos en busca de alimentos. Los "swarms" o bandadas son poblaciones de partículas que representan soluciones potenciales de un problema determinado. La búsqueda hacia nuevas soluciones es 
guiada por lo que podríamos denominar presión social, es decir, está basada en el conocimiento que tienen unos individuos en otros. Todos los pájaros pertenecientes a un "swarm" se comunican entre si para direccionar la búsqueda, emulando las técnicas de exploración que emplean los insectos o pájaros en la naturaleza.

Normalmente, una partícula o pájaro se representa como un vector, donde cada componente se corresponde con una variable de decisión del problema. Cada uno de estos pájaros lleva asociado un vector de fitness, que indica la aptitud del mismo, así como un vector fitness fbest, que hace referencia a la mejor posición en el espacio de soluciones en la que ha estado ese individuo en particular.

El proceso evolutivo en PSO no tiene un proceso de reproducción donde se creen descendientes a partir de unos padres tal como hacen los AG, sino que cada pájaro desarrolla un comportamiento social, adecuando su movimiento a la búsqueda de un objetivo. Cada pájaro vuela en una dirección específica, pero al estar comunicados entre sí son conocedores de que pájaro se encuentra en mejor posición. De este modo, el resto de pájaros vuelan hacia el que está en mejor posición, con una velocidad que dependerá de su posición actual. Cada uno de estos pájaros investiga el espacio de búsqueda desde su nueva posición local, y el proceso se repite hasta que la bandada converge hacia la mejor solución.

El proceso de optimización implica tanto un comportamiento social como un comportamiento inteligente, puesto que los pájaros aprenden tanto de su propia experiencia (búsqueda local) cómo de la experiencia del resto de la bandada (búsqueda global).

Inicialmente PSO fue propuesta para la optimización en espacios continuos, siendo escaso hasta el momento el trabajo aportado para su aplicación en espacios discretos. La adaptación realizada en este trabajo incluye el rediseño del método para que pueda manejar tanto variables continuas como variables discretas. Así, en el caso de variables continuas el método utiliza el algoritmo PSO tradicional, mientras que cuando se tratan variables discretas, el método utiliza el algoritmo propuesto por Jin et al (2007), que trabaja de modo similar al estándar de PSO, pero adaptado al estudio de espacios discretos.

En el caso del diseño óptimo de redes de agua, el objetivo es determinar los diámetros de las conducciones, por lo que es aconsejable utilizar la optimización en espacios discretos, puesto que es más práctico obtener una solución de diámetros comerciales directamente en lugar de tener que realizar una normalización posterior. El siguiente esquema muestra el proceso de optimización que sigue el algoritmo PSO en redes de agua: 


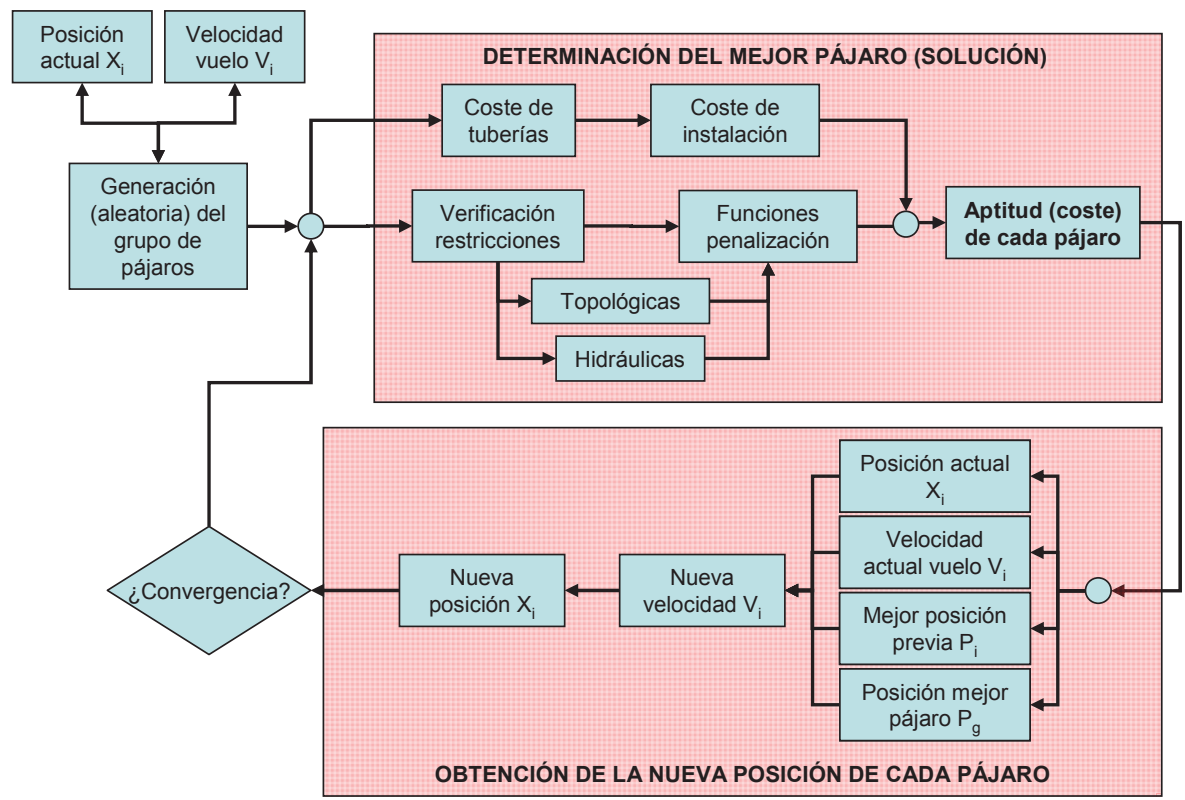

Figura 3.8. Optimización PSO aplicado al diseño de redes de agua

- Etapa 1. Definición de los parámetros del algoritmo

Como paso previo al inicio de la optimización PSO el usuario debe definir los parámetros de cálculo. La aplicación diseñada para el diseño óptimo de redes de agua permite elegir la velocidad máxima de vuelo a la que pueden volar los pájaros, las constantes $c_{1}$ y $c_{2}$ así como el valor del factor de inercia w. En este último caso, es posible elegir entre un w decreciente con el número de iteraciones o un valor fijo que se aplica a todo el proceso de optimización. Del mismo modo hay que determinar el número de partículas cuyo comportamiento va a desviarse del comportamiento social en cada iteración, valor dado por la probabilidad de despiste $\left(P_{\text {desp }}\right)$. El detalle de todos estos parámetros puede seguirse en 3.4.1.

- Etapa 2. Generación inicial

El proceso comienza con la generación aleatoria de un grupo de pájaros, cada uno de las cuales representa una solución del problema dado. El pájaro i-ésimo está representado por su posición en un espacio de $\mathrm{N}$-dimensiones, donde $\mathrm{N}$ es el número de variables. Durante todo el proceso de optimización cada pájaro tiene una serie de propiedades, que son:

Posición actual

Mejor posición previa

$$
X_{i}=\left(x_{i 1}, x_{i 2}, \ldots, x_{i N}\right)
$$


Velocidad de vuelo $\quad V_{i}=\left(v_{i 1}, v_{i 2}, \ldots, v_{i N}\right)$

La posición actual de un pájaro determina la aptitud (coste) de ese pájaro. El mejor de todos ellos actúa como una referencia para los demás, de modo que el resto desarrolla un comportamiento de aprendizaje.

- Etapa 3. Ciclos de aprendizaje

En cada ciclo del algoritmo todos los pájaros cambian su posición, intentando alcanzar la posición $\mathrm{P}_{\text {best }}$ del mejor pájaro en cada instante (best), al que llamaremos líder. La velocidad de vuelo de cada pájaro está relacionada con lo cerca o lejos que éste se encuentra del líder de acuerdo con la siguiente relación:

$$
\text { Nueva } V_{i}=w \cdot V_{i} \text { actual }+C_{1} \cdot \lambda_{1} \cdot\left(P_{i}-X_{i}\right)+C_{2} \cdot \lambda_{2} \cdot\left(P_{\text {best }}-X_{i}\right)
$$

$C_{1}$ y $C_{2}$ son dos constantes positivas que reciben el nombre de factor de aprendizaje, adquiriendo normalmente valores en torno a $2 ; \lambda_{1}$ y $\lambda_{2}$ son dos funciones aleatorias que se mueven entre 0 y 1 ;

En el primer término de la ecuación, $w$ (Shi y Eberhart, 1995) representa la inercia del pájaro y tiene en cuenta el impacto de la velocidad previa en la velocidad actual. Este operador sirve para equilibrar las búsquedas local y global y su programación decrece linealmente con el tiempo desde un valor cercano a 1 hasta 0,5. De este modo, el proceso comienza con un gran peso en la búsqueda global que se reduce con el tiempo, favoreciendo la búsqueda local del mínimo.

El segundo término de la ecuación de velocidad representa la cognición, que puede ser interpretado como el pensamiento particular que tiene un pájaro cuando compara su posición actual con la mejor que ha tenido.

Por último, el tercer término de la ecuación trata de representar la colaboración social entre los pájaros de la bandada, comparando la posición de un pájaro $\mathrm{X}_{\mathrm{i}}$ con la mejor posición $\left(\mathrm{P}_{\text {best }}\right)$ del mejor pájaro $\left(X_{\text {best }}\right)$.

Una vez se tiene la nueva velocidad del pájaro en un determinado ciclo, se calcula la nueva posición que va a ocupar el pájaro dentro del espacio de soluciones:

$$
\text { Nueva posición } X_{i}=\text { Posición actual } X_{i}+\text { Nueva } V_{i} ; V_{\max } \geq V_{i} \geq-V_{\max }
$$

donde $\mathrm{V}_{\max }$ es un límite superior de velocidad que sirve para limitar el cambio de velocidad de un pájaro y que es establecido por el usuario. Si alguna de las variables del vector posición obtiene un valor inferior a cero, el valor de dicha variable será igual a cero. Si por el contrario 
alguna variable tiene un valor superior al límite máximo, dicha variable será igual a ese máximo.

- Etapa 4. Condición de convergencia

El vuelo de los pájaros se prolonga en el tiempo hasta que se produce la condición de convergencia. La condición de convergencia fijada para PSO es la misma que la que se ha utilizado en el resto de algoritmos evolutivos estudiados, es decir, el algoritmo finaliza su tarea cuando se realiza un número determinado de iteraciones sin obtener mejor alguna en la solución.

En este punto hay que considerar que al final de cada iteración se determina un número de partículas cuyo comportamiento se va a alejar del aprendizaje social determinado por el líder del grupo. Este número vendrá determinado por el ajuste realizado para el parámetro $\mathrm{P}_{\text {desp }} \mathrm{Y}$ contribuye a aumentar la búsqueda global en el espacio de soluciones

\subsubsection{Operadores PSO}

De modo similar al resto de modelos, PSO tiene una serie de parámetros susceptibles de ajuste que tienen gran efecto de cara a la convergencia y el buen desempeño del algoritmo. Así, los principales parámetros utilizados en PSO son el tamaño de la población (no pájaros), las constantes de aceleración $C_{1}$ y $C_{2}$, la máxima variación de velocidad permitida y el factor de inercia w. La mayoría de estos parámetros aparecen en la ecuación 3.12, que determina la velocidad del pájaro en una determinada iteración. Las siguientes líneas profundizan sobre las principales características de estos parámetros.

\subsubsection{Población del algoritmo (№ partículas)}

Cada una de las partículas (pájaros) del algoritmo PSO contiene una posible solución del problema de optimización. Las ventajas e inconvenientes que implican elegir un número u otro de partículas en PSO no resultan diferentes del resto de métodos heurísticos. Así, tamaños de población demasiado pequeños implican una convergencia demasiado temprana hacia mínimos locales, mientras que tamaños excesivamente grandes ralentizan el tiempo de cálculo.

Así, se requiere tomar una decisión de compromiso entre calidad de la solución y rapidez del algoritmo. Un análisis de eficiencia como el realizado en el capítulo 6 facilita este tipo de decisiones, puesto que es capaz de cuantificar la mejora que proporciona el empleo de poblaciones más numerosas.

\subsubsection{Velocidad máxima $\left(\mathrm{V}_{\mathrm{lim}}\right)$}

La velocidad máxima $\left(\mathrm{V}_{\mathrm{lim}}\right)$ a la que pueden volar los pájaros es un parámetro de vital importancia en el algoritmo PSO, puesto que este parámetro determina la zona de búsqueda 
de soluciones en la que se centra el algoritmo. De este modo, si $V_{\lim }$ tiene un valor excesivamente alto es muy posible que los pájaros pasen de largo determinados espacios de soluciones. Al contrario, si $\mathrm{V}_{\text {lim }}$ es demasiado pequeña, los pájaros exploran suficientemente el espacio de soluciones más allá de la zona local en la que se mueven, es decir, que lo más probable es que queden atrapados en un mínimo local y se vean incapaces de salir.

Normalmente se consideran valores máximos de velocidad en torno al $10-20 \%$ del valor de la variable que se pretende optimizar. Si extrapolamos este dato al diseño de redes de agua, donde la variable de decisión es el diámetro de tubería, se tiene que según las recomendaciones, para una gama de 10 diámetros, la $\mathrm{V}_{\lim }$ a la que tendrían que volar los pájaros sería $\mathrm{V}_{\text {lim }}=(-2,2)$, que implicaría un máximo salto de 2 diámetros dentro de la gama entre iteración e iteración.

\subsubsection{Constantes de aceleración ( $\mathrm{C}_{1}$ y $\left.\mathrm{C}_{2}\right)$}

Las constantes de aceleración determinan la medida en que la partícula (pájaro) es influenciada en su desplazamiento. Así, $C_{1}$ está relacionada con el desplazamiento de la partícula dentro de su propia memoria y $C_{2}$ tiene que ver con el desplazamiento en relación al resto de partículas.

El valor de ambas constantes suele estipularse entre 1.5 y 2 según el autor. Así, Eberhart y Shi (2001) consideran que $C_{1}=C_{2}=2$ funcionan adecuadamente para la mayoría de problemas de optimización, mientras que otros autores como Clerc (2002) trabajan con $C_{1}=C_{2}=1.494$.

\subsubsection{Factor de inercia (w)}

Cuando se hablaba de velocidad máxima de vuelo se establecía una relación con la zona de búsqueda de soluciones del algoritmo PSO. De este modo, altas velocidades de vuelo favorecen la búsqueda global y bajas velocidades de vuelo favorecen la búsqueda local.

El factor de inercia no forma parte de la formulación original de PSO, sino que es un concepto que se desarrolló más tarde, con el fin de tener un mayor control sobre las zonas de exploración. La inclusión del factor de inercia en PSO la realizan por primera vez Shi \& Eberhart (1998). La formulación empleada en el desarrollo de la aplicación que se emplea en este trabajo incluye este término en la ecuación 3.12, de modo que se considera el factor de inercia como un parámetro más de estudio.

El factor de inercia es un valor que multiplica al primer término de la ecuación de velocidad, y que normalmente tiene valores algo inferiores a 1 para intentar limitar la velocidad de vuelo del pájaro, es decir, ralentiza el movimiento de los pájaros para que no pasen demasiado rápido por encima del espacio de soluciones sin llegar a detenerse. 
En un principio, la principal motivación de este parámetro era intentar eliminar la necesidad de limitar la máxima velocidad de vuelo de los pájaros $\left(\mathrm{V}_{\mathrm{lim}}\right)$, aunque la mayoría de estudios realizados concluyen que $\mathrm{V}_{\lim }$ no puede eliminarse del todo. En los ensayos realizados en la aplicación diseñada ambos parámetros se muestran esenciales para la convergencia del algoritmo, puesto que prescindir de cualquiera de ellos provoca que en determinadas redes los pájaros tiendan a desviarse hacia los extremos del rango de las variables de decisión.

En cuanto al valor óptimo del factor de inercia, existen distintas posibilidades en la bibliografía. Así, algunos investigadores han optado por considerar w como un valor fijo (Clerc, 1999), mientras que otros autores han considerado w como una función, que parte desde un valor cercano a 1 para ir bajando progresivamente con el número de iteraciones realizadas hasta valores próximos a 0,5. La principal ventaja de utilizar una función decreciente como la descrita es dar algo más de importancia a la búsqueda global en las primeras iteraciones para centrar la búsqueda en zonas locales al final del proceso de optimización.

La aplicación diseñada permite el uso de ambas opciones, siendo la función decreciente introducida:

$$
w=\frac{1}{2(\ln k+1)}
$$

donde $\mathrm{k}$ es el número de iteraciones realizadas.

\subsubsection{Probabilidad de despiste ( $\left.\mathrm{P}_{\text {desp }}\right)$}

La probabilidad de despiste no está incluida en la definición original del algoritmo PSO, sino que es una modificación introducida en el modelo de optimización desarrollado en este trabajo. Así, el ajuste dado a este parámetro determina un porcentaje de partículas cuyo comportamiento se va a alejar del aprendizaje social de la bandada.

Este parámetro se incluye en la formulación del modelo para evitar convergencias demasiado tempranas del algoritmo, ya que, las simulaciones realizadas con el algoritmo PSO original determinaban una exploración incompleta del espacio de soluciones, ya que debido al aprendizaje social, en pocas iteraciones casi todos los pájaros se emparejaban con el líder, reduciendo la búsqueda del algoritmo a un espacio demasiado local.

El valor dado a $P_{\text {desp }}$ implica el número de partículas que en una nueva iteración van a ser lanzadas a lugares aleatorios del espacio de soluciones, aumentando la diversidad de soluciones y mejorando en términos generales el desempeño del algoritmo. 


\subsection{Modelo de optimización Simulated Annealing (SA)}

El nombre adoptado por esta metodología de optimización viene del proceso de recocido de acero y cerámicas, una técnica consistente en calentar una determinada pieza para luego enfriarla lentamente, consiguiendo así la alteración de sus propiedades físicas. El calor es la causa de que un átomo aumente su energía y pueda así desplazarse desde una posición inicial (mínimo local) hacia otra que tenga una configuración con menor energía que la inicial (mínimo global). Así, el algoritmo requiere de una temperatura inicial, una temperatura final y una función de variación de temperatura. Dicha función es sumamente importante y de su correcta definición depende buena parte del éxito del algoritmo.

En este caso, las partículas que contienen una solución del problema de optimización las conocemos como piezas. En este caso, cada iteración del algoritmo SA lleva asociada una probabilidad que permite sustituir la solución actual por una nueva solución generada de modo aleatorio. De este modo, toda nueva solución que mejora las anteriores se acepta automáticamente, mientras que movimientos hacia soluciones peores se aceptan con una probabilidad dada. Conforme el proceso SA avanza es más complicado que soluciones peores sustituyan a las mejores.

Realizando una analogía con el proceso físico, esta probabilidad de cambio está relacionada con las leyes de la termodinámica, según las cuales a una temperatura T la probabilidad de un incremento energético de magnitud $\delta E$ se puede aproximar por:

$$
\operatorname{Prob}[\delta E]=e^{-\delta E / k \cdot T}
$$

donde $\mathrm{k}$ es una corriente física denominada de Boltzmann. Dicha constante no se considera, puesto que no tiene ningún sentido en un problema de optimización. De este modo se genera una perturbación aleatoria en el sistema y se calculan los cambios de energía resultantes: Si hay una caída energética, el cambio se acepta automáticamente; si por el contrario se produce un incremento energético, el cambio será aceptado con una probabilidad dada por (3.15). El proceso se repite durante un número predefinido de iteraciones en series decrecientes de temperaturas hasta que el sistema se enfría.

La idea de usar una función de temperatura es la de controlar la presión de selección. Así, al principio se utiliza un valor alto de temperatura, lo que provoca que la presión de selección sea baja. Conforme el proceso avanza, la temperatura disminuye, y esta disminución de T está asociada con un aumento del proceso de selección. De esta manera se incita a un comportamiento de exploración global en las primeras generaciones y se acota a un proceso de exploración local hacia el final del proceso evolutivo. 
La posibilidad de que soluciones peores entren en el sistema es la principal diferencia que presenta SA frente a otros algoritmos tradicionales de búsqueda, puesto que el resto de algoritmos tradicionales parten de una solución inicial que es mejorada paulatinamente al introducir pequeñas perturbaciones o cambios. Esto significa que el resto de algoritmos nunca vuelven sobre sus pasos, lo que en ocasiones puede provocar convergencias prematuras que hacen que el proceso de optimización finalice en un óptimo local, que no tiene necesariamente que ser el global.

El proceso de optimización SA fue diseñado para la optimización en espacios discretos, por lo que es fácilmente adaptable al diseño de redes de agua, donde se trata de determinar el diámetro de las conducciones. El algoritmo basado en SA sigue una serie de etapas, las cuales se muestran a continuación:

- Etapa 1. Definición de los parámetros del algoritmo

En primera instancia es necesario definir el valor de los parámetros con los que va a trabajar SA. El modelo permite elegir el valor de la temperatura inicial, el valor de la temperatura final, la función de reducción de temperatura y el número de iteraciones que va a realizar el algoritmo antes de cada bajada de temperatura.

- Etapa 2. Generar una solución inicial

El cálculo comienza con la generación de una solución aleatoria. En la mayoría de algoritmos evolutivos se generan tantas soluciones aleatorias como individuos tiene la población del algoritmo. En este sentido SA trabaja de un modo diferente, puesto que tan sólo crea una pieza (un individuo), de modo que todas las operaciones posteriores se aplican sobre una única pieza.

Esta primera solución se genera a la temperatura inicial elegida en la Etapa 1, a la que llamaremos $T_{0}$.

- Etapa 3. Generación nuevas soluciones en $T_{0}$

Un nuevo vector solución (pieza) se genera a partir de una serie de reglas en $T_{0}$, este nuevo vector solución sustituirá siempre al anterior si el coste que proporciona para la función objetivo es menor. En caso de que el valor de la función objetivo sea más alto sólo sustituirá al anterior según una probabilidad dada, de valor $\exp (-\delta / T)$, donde $\delta$ la diferencia de coste entre ambas soluciones y $T$ es la temperatura a la que nos encontramos en este momento.

Esta operación se repite en una determinada temperatura tantas veces como se haya indicado en Etapa 1, donde se definían los parámetros del algoritmo. 
- Etapa 4. Paso a una nueva temperatura

Una vez finalizados los cálculos a una determinada temperatura se produce un proceso de enfriamiento, donde la nueva temperatura será una u otra según la función de reducción de temperatura elegida en la Etapa 1. Una vez calculada la nueva temperatura se repite la Etapa 3.

En los primeros años de SA se utilizaron diversos programas de enfriamiento. El modelo empleado da la posibilidad de utilizar dos programas de enfriamiento distintos que se han considerado de particular interés, puesto que representan alternativas opuestas. El primero de ellos establece una velocidad de enfriamiento de tipo geométrico mientras que el segundo establece una velocidad de enfriamiento de tipo aritmético. El detalle de ambos puede seguirse en 3.5.1.

La diferencia entre trabajar a una temperatura u otra radica principalmente en la probabilidad que tiene cada temperatura de aceptar soluciones peores. Conforme la temperatura disminuye, esta probabilidad se hace más pequeña, por lo que teóricamente el algoritmo tiende a realizar su búsqueda de un modo cada vez más local conforme avanza el proceso de optimización.

- Etapa 5. Condición de parada

Las etapas 3 y 4 se repiten hasta que se cumple un determinado criterio de convergencia que da por finalizado el proceso de optimización. Existen distintas teorías acerca de cuál es el criterio de convergencia más adecuado en el algoritmo SA.

Así, una posibilidad es reducir la temperatura hasta cero, pero en la práctica la búsqueda converge por lo general a su óptimo local final mucho antes de ese valor nulo, por lo que una temperatura de parada excesivamente baja gastaría demasiado tiempo de búsqueda en las fases finales sin alcanzar una mejor solución. Por el contrario, si la temperatura final se fija en un valor muy alto, es posible que la búsqueda no consiga alcanzar ningún óptimo local, perdiendo la posibilidad de mejora que permite este tipo de algoritmo.

El modelo implementado en este trabajo no impone una temperatura de parada fija, sino que se ha optado por finalizar la simulación cuando no se producen mejoras en el coste durante un número determinado de simulaciones.

\subsubsection{Parámetros de optimización}

La implementación del modelo SA en cualquier problema de optimización requiere del ajuste de una serie de parámetros, que en mayor o menor medida determinan el éxito o el fracaso del método. De modo similar al resto de métodos heurísticos no existen reglas generales para 
todos los casos, sino que según la tipología del problema es necesario proceder de un modo u otro.

En el caso concreto del diseño de redes de agua es necesario tomar una serie de decisiones genéricas y específicas. Las decisiones específicas de aplicación al diseño de redes de agua comprenden la definición del espacio de soluciones y estructura de entornos, así como la función de coste (objetivo) y cómo se obtiene la solución inicial $\mathrm{X}_{0}$ del problema.

Por otro lado existen una serie de decisiones genéricas del método en sí, y que se refieren principalmente a la forma de control de la temperatura. Para ello es necesario definir el valor inicial de temperatura $\left(T_{0}\right)$, la función de decrecimiento de temperatura $(\alpha)$, el número de iteraciones realizadas antes de bajar de nuevo la temperatura (nrep) y la condición de convergencia final, donde se considera que el sistema ya está frío.

Pese a que no hay un conjunto concluyente de reglas que definan cómo tomar las mejores decisiones genéricas y específicas para un problema, sí que hay algunos consejos que ayudan en el proceso de elección de estos parámetros. Las siguientes secciones profundizan en el estudio de estos parámetros asociados a la optimización SA.

\subsubsection{Temperatura ( $\mathrm{T}$ )}

El parámetro $t$ es un parámetro de control al que se denomina temperatura por analogía con el proceso de enfriamiento físico. Una solución que suponga un incremento $\delta$ en la función de coste se aceptará con probabilidad $e^{-\delta / T}$. Por tanto, en el caso de que T alcance valores lo suficientemente pequeños no habrá movimientos hacia peores soluciones y la convergencia será a un óptimo local, que podrá coincidir o no con el óptimo global del sistema.

Algunos autores han elaborado estudios teóricos que demuestran que si t baja de un modo suficientemente lento, el proceso debe converger hacia un óptimo global con una probabilidad 1 , según $t$ tiende a 0 . Sin embargo, una función de reducción de temperatura $(\alpha)$ que garantice esa convergencia al óptimo global requeriría unos tiempos de cálculo excesivamente elevados.

Uno de los objetivos de cualquier procedimiento robusto de búsqueda es que la calidad de la solución final debe ser independiente de la solución inicial de partida. En concordancia con esta premisa, la temperatura inicial debe ser independiente de la solución inicial y lo suficientemente alta como para aceptar casi libremente las soluciones del entorno.

\subsubsection{Velocidad de enfriamiento}

La velocidad a la que se produce el enfriamiento es otro factor clave en el éxito de la estrategia. Esta velocidad viene determinada por un parte por el número de iteraciones 
realizadas en cada valor de temperatura (nrep), y por otra por la velocidad $\alpha$ a la que se realizará el enfriamiento. La teoría sugiere que se debería permitir que el sistema esté cerca del estado estacionario correspondiente a una determinada temperatura antes de reducir ésta, y que además la temperatura vaya gradualmente acercándose al valor 0.

Existe gran diversidad de funciones de enfriamiento que pueden ser utilizadas en el proceso de optimización. El modelo de optimización realizado ofrece dos alternativas distintas para realizar el enfriamiento: La primera de ellas equivale a enfriar la pieza utilizando una función aritmética, tal que $T \rightarrow T-\alpha$, con $\alpha>0$.

La segunda propone una alternativa de enfriamiento de tipo geométrico, tal que $T \rightarrow \alpha \cdot T$, con $\alpha<1$. En esta segunda opción, las evidencias empíricas dan a entender que valores elevados de $\alpha$ entre 0,8 y 0,99 (correspondientes a velocidades lentas de enfriamiento) son los que mejores resultados proporcionan). La distinta evolución de la temperatura en función del método de enfriamiento elegido se muestra de modo esquemático en la tabla 3.3.

\begin{tabular}{|c|c|c|}
\hline & $\begin{array}{c}\text { Enfriamiento } \\
\text { aritmético } \\
\boldsymbol{\alpha}=\mathbf{x}(\boldsymbol{\alpha}>\mathbf{1})\end{array}$ & $\begin{array}{c}\text { Enfriamiento } \\
\text { geométrico } \\
\boldsymbol{\alpha}=\mathbf{x}(\boldsymbol{\alpha}<1)\end{array}$ \\
\hline $\mathrm{T}_{0}$ & $\mathrm{~T}_{0}$ & $\mathrm{~T}_{0}$ \\
\hline $\mathrm{T}_{1}$ & $\mathrm{~T}_{0}-\mathrm{X}$ & $\mathrm{T}_{0^{*} \mathrm{X}}$ \\
\hline $\mathrm{T}_{2}$ & $\mathrm{~T}_{1}-\mathrm{x}$ & $\mathrm{T}_{1 * \mathrm{X}}$ \\
\hline$\ldots$ & $\ldots$ & $\ldots$ \\
\hline $\mathrm{T}_{\mathrm{n}}$ & $\mathrm{T}_{(\mathrm{n}-1)^{-\mathrm{X}}}$ & $\mathrm{T}_{(\mathrm{n}-1)^{*} \mathrm{X}}$ \\
\hline
\end{tabular}

Tabla 3.3. Funciones de enfriamiento de temperatura

Los resultados teóricos dan a entender que los detalles concretos del programa de enfriamiento no son tan importantes como la velocidad a la que se reduce la temperatura, de modo que cualquiera de las funciones utilizadas dará un resultado similar siempre que el enfriamiento se produzca por el mismo rango de temperaturas y para un número total de iteraciones similares.

Del mismo modo, la utilización de este tipo de funciones no garantiza una convergencia en programas de enfriamiento finitos. Van Laarhoven y Arts (1988) llegan a la conclusión de que para garantizar una solución próxima a la óptima son necesarios tiempos de computación de tipo exponencial.

La conclusión de todo esto es que la velocidad del programa de enfriamiento debe estar relacionada con las características del espacio de soluciones, definidas por la función de coste y la estructura de entornos elegida. Esto hace que sea fundamental una optimización de parámetros de cara a conseguir un buen funcionamiento del algoritmo de optimización. 


\subsection{Modelo de optimización Shuffled Frog Leaping Algorithm (SFLA)}

El algoritmo Shuffled Frog Leaping (SFLA) es otra de las técnicas metaheurísticas estudiadas. El funcionamiento es similar al resto de técnicas estudiadas, tratando de encontrar una solución global óptima a partir de la evolución de una población inicial totalmente aleatoria. Para ello realiza una búsqueda heurística basada en la evolución de memes, portados por una serie de individuos interactivos (ranas), que además realizan un intercambio global de la información entre la población.

El concepto de meme se asocia a una unidad teórica de información que se transmite de un individuo a otro (o de una generación a la siguiente). El término meme es un neologismo acuñado por Richard Dawkins en "El gen egoista" (1976), por la semejanza fonética con "gen" y para señalar la similitud radical con la memoria y la mimesis. De igual modo, el término memeplex representa un grupo de memes que forman un grupo organizado que comparte una misma creencia, tal como si fuera una religión.

Los algoritmos SFL combinan elementos de otros métodos de optimización puestos en práctica con anterioridad. Concretamente, la búsqueda local que realiza SFL está basada en los algoritmos PSO, cuyo detalle puede seguirse en el apartado 3.4, mientras que el intercambio global de información que se lleva a cabo una vez finalizada la búsqueda local tiene su origen en Shuffled Complex Evolution (SCE), técnica de optimización creada por Duan et al (1992). Tradicionalmente se considera a los algoritmos SFL como los herederos naturales de SCE, puesto que comparten con ellos la mayoría de características y métodos de búsqueda.

Algoritmos meméticos y genéticos comparten una serie de principios básicos, como puede ser la selección a través de la aptitud, la combinación de unas soluciones con otras o la mutación. Sin embargo, la evolución memética es algo más flexible que la genética, y esta diferencia es apreciable en los mecanismos que utilizan genes y memes para transmitir la información de unos miembros de la población a otros.

En el caso de un algoritmo genético, la información que contiene un cromosoma sólo se transmite de padres a hijos, por lo que la información sólo evoluciona de generación en generación. En el algoritmo SFL, la información que contiene un meme puede transmitirse entre dos individuos cualesquiera; es decir, se intercambia información entre individuos equivalentes y no sólo entre padres e hijos. Así si se produce una mejora durante la evolución memética, ésta queda incorporada en otros memes de forma inmediata, al contrario que en una evolución genética, donde es necesario esperar a la siguiente generación para incorporar dichas mejoras. 
Siguiendo con la comparación evolutiva entre genes y memes, la reproducción genética está limitada en cuanto al número de hijos que puede tener un único padre. En el caso de la reproducción de los memes, esta limitación no se produce, por lo que los mejores padres pueden reproducirse con mayor frecuencia. Esta es la principal diferencia de una evolución memética frente a una evolución genética, es decir, la posibilidad de que las ideas que mejoran el algoritmo se compartan entre todos los individuos de una determinada población y no sólo entre padres y descendientes.

Cada meme contiene un número determinado de memotipos. El memotipo es la unidad más pequeña de información, y en la aplicación realizada para diseño de redes de agua identifican los diámetros de los conductos de la red. El algoritmo SFL no cambia las características físicas de un individuo determinado, sino que aplica las ideas individuales de meme al conjunto, con el objetivo de tener una mejora progresiva de la población del algoritmo. El concepto de población es similar al que utiliza un algoritmo genético, con la salvedad de que en este caso hablamos de un espacio de soluciones que contiene memes.

Tradicionalmente, el algoritmo SFL se asocia a la búsqueda de comida por parte de una rana en un pantano. El pantano representaría el espacio de soluciones, mientras que cada una de las ranas representaría un meme. Si se considera un grupo de ranas que se encuentran en un pantano, existe un cierto número de piedras en posiciones discretas hacia las que las ranas pueden saltar. El objetivo de cada rana es encontrar la piedra que posee mayor cantidad de comida en el menor espacio de tiempo posible. Para ello, los memotipos pueden ser alterados de modo discreto, y el meme corresponde a la posición coordinada de las ranas, que pueden comunicarse entre si y mejorar sus memes particulares por "contagio" de unas a otras. La mejora de los memes implica cambios en las posiciones individuales de las ranas, que ajustan su capacidad de salto.

La población del algoritmo está constituida un número determinado de ranas, que a su vez son distribuidas en grupos, llamados memeplexes. Este tipo de división es similar al que se realiza en un SCE, con la salvedad de que un algoritmo SFL considera variables discretas, mientras que SCE sólo es aplicable a variables contínuas. Es posible definir a los memeplex como un conjunto de culturas distintas, pero paralelas, que tratan de alcanzar la misma meta por distintos caminos. Todos los memeplex trabajan de modo paralelo, intercambiando ideas e información de una manera independiente, explorando distintas zonas del espacio de soluciones. Así, dentro de cada memeplex, las ranas experimentan un contagio de ideas, evolucionando la población de un modo memético. Los saltos de las ranas (frog leaping) mejoran los memes y aproximan al grupo al objetivo. Estos saltos no dejan de ser una extensión de la técnica de búsqueda que utiliza PSO. No obstante, la formulación PSO original está orientada al tratamiento de variables continuas, mientras que SFL está orientada al trabajo con variables discretas. 
Después de un número definido de pasos de progresión memetica, los memeplexes intercambian información de un modo similar a como se realiza en SCE, en un proceso denominado "shuffling". El shuffling es algo así como mezclar de modo aleatorio a un conjunto de distintas culturas que han trabajado aisladas unas de otras, y que de repente se conocen y empiezan a intercambiar información y conocimiento entre ellas. Este proceso realza la calidad del meme, puesto que mezcla la mejor información que poseen las ranas de distintos memeplexes. El proceso de shuffling asegura que la evolución cultural queda encallada de un modo local, puesto que vuelve a mezclar a toda la población. Tras el shuffling, la búsqueda de soluciones óptimas en cada memeplex vuelve a comenzar y se reinicia el proceso. Tanto la búsqueda local como el shuffling posterior se repiten hasta que quedan cumplidos los criterios de convergencia definidos en el problema.

El modelo de optimización SFLA aplicado al diseño óptimo de redes de agua puede considerarse análogo al utilizado por los algoritmos genéticos, especialmente en lo que a codificación de las variables se refiere. Cuando se explicaba en detalle el modelo empleado en AG se hablaba de cromosomas que contenían genes, que era la unidad básica de información, y estos genes identificaban diámetros de una determinada red de distribución de agua.

En este caso, un meme representa una solución del problema de diseño. Un meme está formado por un número determinado de memotipos, cada uno de los cuales representa una variable de decisión del problema.

Cada memotipo tiene una representación numérica, que a su vez identifica el valor discreto de una variable, en este caso los diámetros de las tuberías de la red. Por ejemplo, si se dispone de una gama de 8 diámetros, los memotipos son codificados desde 0 hasta 7, donde el valor 0 corresponde al diámetro más pequeño de la gama y el valor 7 al más grande. De este modo, un meme está compuesto por tantos memotipos como incógnitas tenga el problema de diseño. Así, en el caso de diseño de una red de distribución, donde se conocen todos los datos salvo los diámetros de las tuberías, un meme estará compuesto por tantos memotipos como conductos tenga la red.

El proceso de optimización que sigue el algoritmo SFL para encontrar la mejor distribución de diámetros sigue un esquema parecido al que muestra la figura 3.9, que trata de reproducir con fidelidad las etapas seguidas por SFLA en el proceso de optimización. 


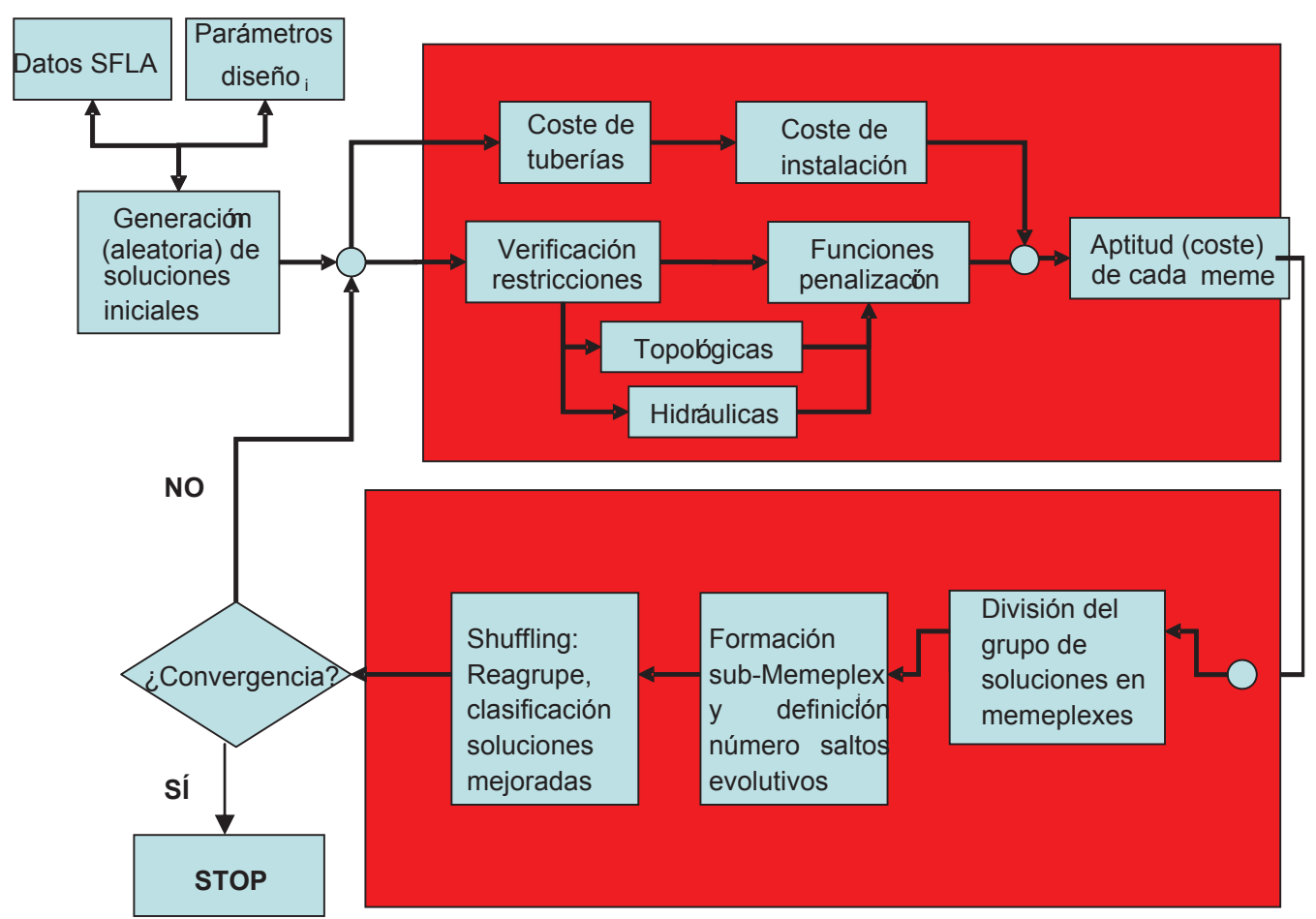

Figura 3.9. SFLA aplicado al diseño de redes de agua.

Inicialmente se crea una población aleatoria de ranas, cada una de las cuales representa una solución del problema. Cada una de estas ranas tiene una determinada posición dentro del espacio de soluciones, que viene definida por un vector $X^{i}$, que representa un meme con tantos memotipos (diámetros) como variables de decisión tenga el problema de diseño.

$$
X^{i}=\left\{X_{1}^{i}, X_{2}^{i}, \ldots, X_{N_{V D}}^{i}\right\}
$$

A continuación, las ranas son divididas en grupos denominados memeplexes dependiendo de su aptitud. En el diseño de redes de distribución de agua, la aptitud de una determinada solución viene definida por el coste asociado al diseño de la red, de modo que el menor coste implica la mejor aptitud. El número de memeplexes es un parámetro de optimización que elige el usuario y las ranas van a un memeplex u otro en función de su aptitud. De este modo, la rana con mejor aptitud iría al memeplex 1, la siguiente al memeplex 2 y así hasta completar toda la población.

Cada uno de estos memeplex evoluciona de un modo independiente, realizándose en cada uno de ellos una búsqueda local. Las ranas intercambian información, las mejores informan a las peores, que evolucionan en un proceso conocido como salto evolutivo. Por ejemplo, si suponemos dos ranas distintas de un memeplex, la rana con peor aptitud siempre 
evolucionará hacia la de mejor aptitud. En la optimización de diámetros que se realiza en este trabajo cada salto aproxima los diámetros proporcionados por la peor rana a los proporcionados por la mejor.

No obstante, el salto no garantiza en ningún momento que la aptitud de la nueva rana vaya a ser mejor que la de la peor rana. Es por ello que las ranas que no superan a sus predecesoras son descartadas. Las nuevas ranas sólo sustituyen a las anteriores si tienen mejor aptitud.

Del mismo modo, el salto nunca es perfecto, puesto que la nueva rana no puede ser copia de la rana con mejor aptitud. Esto resulta lógico, puesto que si todos los saltos fueran perfectos todas las ranas acabarían siendo idénticas, con lo que se caería rápidamente en mínimos locales y apenas se exploraría el espacio de soluciones. En este sentido, un salto parcial resulta más eficiente por dos motivos:

- Asegura que las ranas con mejor aptitud evolucionan o se mueven a áreas más prometedoras o con mayor probabilidad de encontrar mejores soluciones.

- Aumenta la variabilidad del proceso de búsqueda local al posibilitar el descubrimiento de zonas intermedias antes desconocidas.

Tras esta fase de búsqueda local, limitada por el número de saltos evolutivos determinados al principio del proceso de optimización, se disuelven los memeplexes y comienza la etapa que conocemos como shuffling, donde las ranas son mezcladas de nuevo, ordenadas otra vez en base a su actitud y recolocadas de nuevo en nuevos memeplexes. De este modo, al variar la población de los memeplexes se consigue que el siguiente grupo de saltos evolutivos vaya en otras direcciones de búsqueda. Ambas etapas de salto y mezcla se repiten hasta que se cumple la condición de convergencia impuesta y se da por concluido el problema de optimización.

\subsubsection{Operadores algoritmo SFL}

De idéntico modo a la mayoría de técnicas heurísticas, el modelo de optimización es sensible al valor dado a los parámetros utilizados. En el algoritmo SFL se consideran cinco parámetros característicos principales, que son el número de memeplexes $(\mathrm{m})$, el número de ranas por memeplex $(\mathrm{n})$, el número de saltos evolutivos $(\mathrm{N})$, el tamaño de sub-memeplex (q) y el coeficiente acelerador (C).

Eusuff y Lansey (2000) ya realizan un estudio completo acerca de la sensibilidad de parámetros, aplicado tan sólo a la red de los túneles de Nueva York. Eusuff y Lansey estudián sólo cuatro de los cinco parámetros principales, descartando el análisis de sensibilidad del número de ranas por memeplex. Las principales conclusiones a las que llegan Eusuff y Lansey es que el número de evoluciones entre shuffling y el número máximo de saltos evolutivos no 
influyen en términos absolutos para encontrar el mínimo coste de la red. Ambos concluyen que no tienen datos suficientes como para generalizar sus resultados a todas las redes posibles y abogan por realizar estudios distintos según las características de la red.

En esta tesis se lleva a cabo un estudio completo de sensibilidad de parámetros SFL, tal como se realiza en el resto de heurísticas estudiadas. El objetivo es extraer conclusiones generales y comparar los resultados, tanto con el resto de metodologías como con los datos que aportan Eusuff y Lansey. Tal como reseñan Eusuff y Lansey no existe una guía que permita suponer con anterioridad cuales son los rangos de trabajo óptimos en cada tipo de problema. La única opción es la propia experimentación en cada tipo de problema y extrapolar los datos siempre que las características y la experiencia previa lo permita.

Esta tesis estudia un total de cinco parámetros característicos de la optimización SFL. Se ha diferenciado entre los parámetros que son relativos tan sólo al número de ranas con las que se trabaja y entre los que son relativos a los propios saltos evolutivos, es decir, al proceso de optimización en si mismo.

\subsubsection{Parámetros relativos a la población del algoritmo (m y n)}

Los parámetros $\mathrm{m}$ y $\mathrm{n}$ definen la población total de ranas con la que va a trabajar el algoritmo. El parámetro $\mathbf{m}$ define el número de memeplexes en los que se va a dividir la población total, mientras que $\mathbf{n}$ define el número de ranas que habrá en cada uno de los memeplexes creados. El producto de ambos parámetros nos da el total de ranas con las que va a trabajar el proceso de optimización. Un memeplex es un conjunto de ranas, que evoluciona a lo largo del proceso de optimización como una cultura propia. El usuario tiene la posibilidad de elegir en cuántos memeplexes quiere distribuir a la población total de ranas, para lo que tiene que definir $\mathrm{m}$ y $\mathrm{n}$. Un punto de estudio a considerar es si un número determinado de ranas trabaja de modo distinto según sea la distribución de estas ranas en un mayor o menor número de memeplexes.

Hablando en términos más generales, de similar modo a como ocurre en otras técnicas heurísticas, trabajar con el mayor número posible de ranas facilita una búsqueda del óptimo más exhaustiva, pero también conlleva un mayor número de cálculos, por lo que retrasa en el tiempo la búsqueda del algoritmo. El estudio de población determinará cuáles son las poblaciones que obtienen mayor número de soluciones óptimas, mientras que el estudio de eficiencia determinará si la mejora obtenida al trabajar con poblaciones mayores compensa el mayor tiempo de cálculo empleado.

\subsubsection{Parámetros relativos a la naturaleza de los saltos evolutivos (N, Q y C)}

Los parámetros $\mathrm{N}, \mathrm{Q}$ y $\mathrm{C}$ inciden sobre la naturaleza de los saltos evolutivos que se generan entre las ranas. Así, $\mathrm{N}$ representa el número de saltos evolutivos que se produce en cada 
memeplex. Valores elevados de $\mathrm{N}$ pueden provocar una convergencia demasiado rápida del algoritmo, lo que suele ser sinónimo de soluciones de poca calidad, debido a la caída en mínimos locales.

De la misma manera, $Q$ representa el tamaño del submemeplex que se crea respecto al tamaño del propio memeplex. Es decir, viene a indicar cuál es la extensión sobre la que se van a producir los saltos evolutivos de la población. El significado que tiene el valor dado al parámetro $Q$, es que si por ejemplo $Q=0,5$, cada vez que se forme un submemeplex, el tamaño de éste será la mitad del memeplex del que proviene. Valores pequeños de $q$ suponen sub-memeplexes más pequeños, por lo que los saltos que se producen son entre ranas de aptitud más similar, y por tanto menores.

Por último, el coeficiente acelerador (C) incrementa la longitud de cada salto evolutivo, actuando como un factor multiplicativo. Si el valor de $\mathrm{C}$ es menor que 1 , el salto se ve reducido, mientras que si es mayor que 1 se ve incrementado. 


\section{CASOS DE ESTUDIO Y RESULTADOS}

\subsection{Introducción}

En el capitulo anterior se han desarrollado los distintos modelos de optimización para cada una de las técnicas de optimización que estudia este trabajo. La exposición de los resultados obtenidos por aplicación de los algoritmos evolutivos consta de distintas partes bien diferenciadas, si bien el objetivo final es certificar la aptitud de este tipo de metodología en el diseño óptimo de redes de agua. Para ello se aborda la resolución de una serie de problemas de diseño ampliamente conocidos en la bibliografía, cuyo estudio de diseño ya ha sido abordado previamente por otros investigadores. Este tipo de red de distribución, conocida como de benchmarking, permite la comparación entre los resultados proporcionados por otros autores y los propios de este trabajo.

Probablemente, la red de Hanoi y la red de los túneles de Nueva York sean las dos redes de benchmarking más populares en el diseño de redes de agua, siendo extraordinariamente numerosos los resultados existentes en la bibliografía acerca del mejor diseño para cada una de ellas. Este trabajo aplica los distintos modelos de optimización desarrollados al diseño óptimo de ambas redes, así como algunos de los métodos funcionales explicados en el apartado anterior. El objetivo al realizar el diseño con diferentes métodos es situar numéricamente la mejora producida con la utilización de métodos heurísticos respecto de las metodologías clásicas de optimización económica.

Además de las redes mencionadas, existen otras no tan conocidas en la bibliografía, pero de las que también se tiene cierto patrón de comparación con otros autores, como son la red de Go-Yang (Geem, 2001) o la red R-9 de Joao Pessoa, cuyo diseño óptimo es abordado por Gomes (2009). En ambos casos, el problema de diseño planteado se aborda por aplicación de los distintos modelos de optimización heurísticos desarrollados en este trabajo, de modo que es posible la comparación de resultados con los que proporcionan sus autores.

Cada uno de los procedimientos heurísticos permite el ajuste de una serie de parámetros de cálculo, cuyo rango de cálculo óptimo es, a priori, desconocido en cada caso. Es por ello que inicialmente, la rutina de cálculo empleada para abordar el diseño óptimo de una 
determinada red de distribución es la misma, independientemente de la metodología de optimización empleada. Así, la única forma de proceder cuando se desconoce el mejor ajuste en los parámetros es la realización de un alto número de simulaciones que abarque un barrido de posibilidades lo suficientemente grande para cada uno de los parámetros de ajuste.

Además de la propia metodología heurística, la definición completa de un modelo matemático requiere la introducción adecuada de todos los datos del sistema en cualquier software que tenga capacidad de análisis de redes de distribución. Actualmente existe un gran número de programas de análisis de redes que permiten el cálculo de redes malladas, pero en el caso que nos ocupa, los modelos de optimización desarrollados se integran con EPANET.

EPANET ha sido desarrollado íntegramente por la agencia para la protección del Medio Ambiente en EEUU, con el fin de disponer de una herramienta de cálculo acerca del comportamiento hidráulico en sistemas de distribución de agua. Actualmente representa uno de los mejores programas existentes en el campo de la simulación de sistemas hidráulicos, lo que unido a su libre distribución hace que sea uno de los más extendidos. La última versión del mismo incluso permite el desarrollo de plugins por parte del usuario, de modo que se pueden integrar pequeñas aplicaciones en el propio EPANET, lo que permite reorientar las características del programa a la resolución de otros problemas como puede ser el diseño de redes de agua.

\subsection{Red de Hanoi}

La red de Hanoi fue propuesta por Fujiwara y Khang (1990). El problema de diseño propuesto por esta red ha sido estudiado ampliamente por distintos investigadores, por lo que existe un amplio rango de soluciones en la bibliografía. La popularidad de esta red permite que sea posible la comparación de resultados obtenidos anteriormente con los resultados proporcionados por los distintos modelos de diseño que estudia este trabajo. El problema de diseño que plantea la red de Hanoi consta de un depósito, 31 nudos de demanda y 34 conducciones (figura 4.1). La red tiene tres mallas y dos terminaciones ramificadas. 


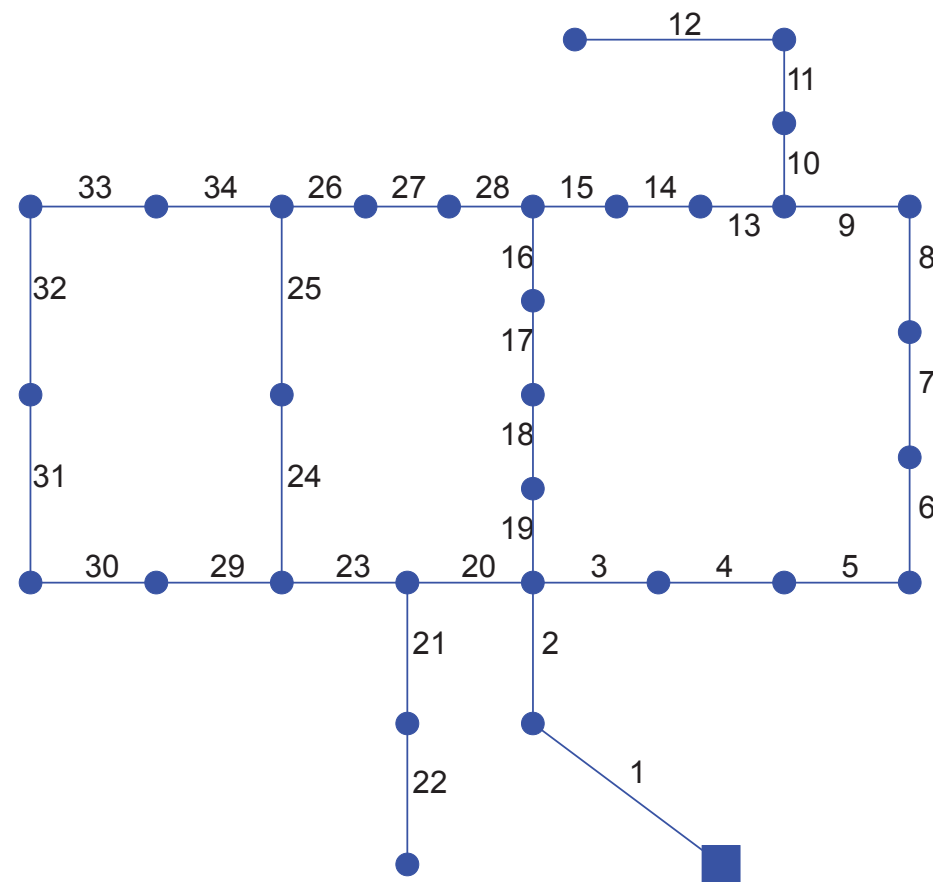

Figura 4.1. Red de Hanoi.

El objetivo del problema de diseño es el correcto dimensionamiento de las tuberías, teniendo en cuenta que se cumpla la principal restricción del problema, equivalente a mantener una presión mínima de servicio de 30 mca en todos los nudos. Las tablas que se muestran a continuación incluyen todos los datos necesarios para el diseño de la red propuesta:

\begin{tabular}{|c|c|c|c|c|c|}
\hline ID nudo & Cota $(\mathbf{m})$ & $\mathbf{Q}(\mathbf{I} / \mathbf{s})$ & ID nudo & Cota $(\mathbf{m})$ & $\mathbf{Q}(\mathbf{l} / \mathbf{s})$ \\
\hline 1 & 100 & $-5538,9$ & 12 & 0 & 155.56 \\
\hline 2 & 0 & 247,22 & 13 & 0 & 261,11 \\
\hline 3 & 0 & 236,11 & 14 & 0 & 170,83 \\
\hline 4 & 0 & 36,11 & 15 & 0 & 77,78 \\
\hline 5 & 0 & 201,39 & 16 & 0 & 86,11 \\
\hline 6 & 0 & 279,17 & 17 & 0 & 240,28 \\
\hline 7 & 0 & 375,00 & 18 & 0 & 373,61 \\
\hline 8 & 0 & 152,78 & 19 & 0 & 16,67 \\
\hline 9 & 0 & 145,83 & 20 & 0 & 354,17 \\
\hline 10 & 0 & 145,83 & 21 & 0 & 258,33 \\
\hline 11 & 0 & 138,89 & \multicolumn{3}{|l}{} \\
\hline
\end{tabular}

Tabla 4.1. Red de Hanoi. Cota y demanda de los nudos. 


\begin{tabular}{|c|c|c|c|c|c|c|c|}
\hline ID Línea & $\begin{array}{l}\text { Nudo } \\
\text { Inicial }\end{array}$ & $\begin{array}{l}\text { Nudo } \\
\text { Final }\end{array}$ & Longitud (m) & ID Línea & $\begin{array}{l}\text { Nudo } \\
\text { Inicial }\end{array}$ & $\begin{array}{l}\text { Nudo } \\
\text { Final }\end{array}$ & Longitud (m) \\
\hline 1 & 1 & 2 & 100 & 18 & 18 & 19 & 800 \\
\hline 2 & 2 & 3 & 1350 & 19 & 3 & 19 & 400 \\
\hline 3 & 3 & 4 & 900 & 20 & 3 & 20 & 2200 \\
\hline 4 & 4 & 5 & 1150 & 21 & 20 & 21 & 1500 \\
\hline 5 & 5 & 6 & 1450 & 22 & 21 & 22 & 500 \\
\hline 6 & 6 & 7 & 450 & 23 & 20 & 23 & 2650 \\
\hline 7 & 7 & 8 & 850 & 24 & 23 & 24 & 1230 \\
\hline 8 & 8 & 9 & 850 & 25 & 24 & 25 & 1300 \\
\hline 9 & 9 & 10 & 800 & 26 & 25 & 26 & 850 \\
\hline 10 & 10 & 11 & 950 & 27 & 26 & 27 & 300 \\
\hline 11 & 11 & 12 & 1200 & 28 & 16 & 27 & 750 \\
\hline 12 & 12 & 13 & 3500 & 29 & 23 & 28 & 1500 \\
\hline 13 & 13 & 14 & 800 & 30 & 28 & 29 & 2000 \\
\hline 14 & 14 & 15 & 500 & 31 & 29 & 30 & 1600 \\
\hline 15 & 15 & 16 & 550 & 32 & 30 & 31 & 150 \\
\hline 16 & 16 & 17 & 2730 & 33 & 31 & 32 & 860 \\
\hline 17 & 17 & 18 & 1750 & 34 & 25 & 32 & 950 \\
\hline
\end{tabular}

Tabla 4.2. Red de Hanoi. Longitud de las líneas

Uno de los aspectos que contribuye a definir la solución óptima de la red es la gama de diámetros candidatos utilizada. El diseño realizado en este trabajo incluye la gama original propuesta en la bibliografía (Savic, 1997)

\begin{tabular}{|c|c|c|}
\hline № Diámetro & $\begin{array}{c}\text { Diámetro } \\
\text { (mm) }\end{array}$ & $\begin{array}{c}\text { Coste } \\
\text { (um/m) }\end{array}$ \\
\hline A & 304,8 & 45,73 \\
\hline B & 406,4 & 70,40 \\
\hline C & 508,0 & 98,39 \\
\hline D & 609,6 & 129,33 \\
\hline E & 762,0 & 180,75 \\
\hline F & 1016,0 & 278,28 \\
\hline
\end{tabular}

Tabla 4.3. Gama de diámetros utilizada en el diseño de la red de Hanoi.

Previamente a la utilización de algoritmos heurísticos se ha realizado el diseño de la red aplicando métodos de diseño funcional. El objetivo es comprobar si existe mejora respecto a estos métodos cuando se utilizan metodologías heurísticas, así como poder cuantificar esta mejora, si es que la hay. Así, la tabla 4.4 muestra el coste de diseño obtenido para la red por algunos métodos funcionales, como son los métodos de diámetro mínimo, diámetro máximo, pendiente económica aplicada a todos los nudos y pendiente económica aplicada a los defectos. Asimismo, se muestra la solución alcanzada por LEHNSNET, metodología de diseño basada en programación dinámica. 


\begin{tabular}{|l|}
\hline DISEÑO SIN FIABILIDAD \\
\hline Método 1: Diámetros Mínimos: Corrección por Pendiente \\
problema resuelto en 145 iteraciones \\
6801585.0 um \\
\hline Método 2: Diámetros Máximos \\
problema resuelto en 177 iteraciones \\
6779195.0 um \\
\hline Método 3: Pendiente Económica aplicada a todos los nudos \\
problema resuelto en 291 iteraciones \\
6909356.0 um \\
\hline Método 4: Pendiente Económica aplicada a los defectos \\
problema resuelto en 397 iteraciones \\
6434 107.0 um \\
\hline Método 5: Lehnsnet \\
6420000.0 um \\
\hline
\end{tabular}

Tabla 4.4. Coste de diseño obtenido para la red de Hanoi utilizando metodologías no heurísticas sin considerar criterios de fiabilidad.

Dentro de los métodos funcionales, el mejor resultado de diseño para la red de Hanoi lo obtiene el programa LEHNSNET, que obtiene un coste mínimo de diseño para la red de Hanoi de 6,42 millones de um.

Los resultados obtenidos a través de las distintas técnicas funcionales de diseño permiten hacerse una idea acerca del coste de diseño de la red de Hanoi. La idea es mejorar el coste proporcionado por estas técnicas al aplicar distintas metodologías heurísticas. Así, la tabla 4.5 recoge los resultados obtenidos por distintos investigadores que han trabajado este problema de diseño, así como los resultados obtenidos por medio de los algoritmos estudiados en este trabajo, basados todos ellos en técnicas heurísticas de diseño. En dicha tabla se destacan en sombreado los diámetros que son diferentes respecto de la solución propuesta por Savic y Waters que verifica las restricciones de presión en los nudos.

El coste mínimo obtenido para la red de Hanoi fue de 6,081 (en millones um) en cuatro de los cinco métodos de optimización estudiados. Dicho resultado representa el mejor coste de diseño obtenido hasta la fecha para esta red, siempre que se cumplan todos los requisitos de presión mínima en el sistema. La solución 2 de Savic mejora el coste global de la instalación, pero no cumple las especificaciones de presión en todos los nudos, que en este caso es de un mínimo de 30 mca en cada nudo del sistema. 


\begin{tabular}{|c|c|c|c|c|c|c|c|}
\hline \multirow[b]{2}{*}{ Línea } & \multicolumn{4}{|c|}{ Soluciones bibliografía } & \multicolumn{3}{|c|}{ Soluciones obtenidas } \\
\hline & Matías $^{(1)}$ & Savic1 $^{(2)}$ & Savic $2^{(3)}$ & Gomes $^{(4)}$ & $\begin{array}{c}\text { APG/HS/SFLA/PS } \\
0^{(5)}\end{array}$ & $S A^{(6)}$ & APG $2^{(7)}$ \\
\hline 1 & 1016 & 1016 & 1016 & 1016 & 1016 & 1016 & 1270 \\
\hline 2 & 1016 & 1016 & 1016 & 1016 & 1016 & 1016 & 1270 \\
\hline 3 & 1016 & 1016 & 1016 & 1016 & 1016 & 1016 & 1016 \\
\hline 4 & 1016 & 1016 & 1016 & 1016 & 1016 & 1016 & 1016 \\
\hline 5 & 1016 & 1016 & 1016 & 1016 & 1016 & 1016 & 1016 \\
\hline 6 & 1016 & 1016 & 1016 & 1016 & 1016 & 1016 & 762 \\
\hline 7 & 1016 & 1016 & 1016 & 1016 & 1016 & 1016 & 762 \\
\hline 8 & 1016 & 1016 & 1016 & 1016 & 1016 & 1016 & 762 \\
\hline 9 & 1016 & 762 & 1016 & 1016 & 1016 & 762 & 762 \\
\hline 10 & 762 & 762 & 762 & 1016 & 762 & 762 & 609,6 \\
\hline 11 & 609,6 & 762 & 609,6 & 1016 & 609,6 & 762 & 609,6 \\
\hline 12 & 609,6 & 609,6 & 609,6 & 609,6 & 609,6 & 609,6 & 508 \\
\hline 13 & 508 & 406,4 & 508 & 609,6 & 508 & 406,4 & 1016 \\
\hline 14 & 406,4 & 406,4 & 406,4 & 609,6 & 406,4 & 406,4 & 762 \\
\hline 15 & 304,8 & 304,8 & 304,8 & 609,6 & 304,8 & 304,8 & 1016 \\
\hline 16 & 304,8 & 406,4 & 304,8 & 304,8 & 304,8 & 304,8 & 1016 \\
\hline 17 & 406,4 & 508 & 406,4 & 406,4 & 406,4 & 406,4 & 1016 \\
\hline 18 & 609,6 & 609,6 & 508 & 508 & 609,6 & 609,6 & 1016 \\
\hline 19 & 609,6 & 609,6 & 508 & 508 & 508 & 508 & 1016 \\
\hline 20 & 1016 & 1016 & 1016 & 1016 & 1016 & 1016 & 1016 \\
\hline 21 & 508 & 508 & 508 & 508 & 508 & 508 & 609,6 \\
\hline 22 & 304.8 & 304.8 & 304.8 & 304.8 & 304.8 & 304.8 & 406.4 \\
\hline 23 & 1016 & 1016 & 1016 & 1016 & 1016 & 1016 & 1016 \\
\hline 24 & 762 & 762 & 762 & 762 & 762 & 762 & 762 \\
\hline 25 & 762 & 762 & 762 & 609.6 & 762 & 762 & 1016 \\
\hline 26 & 508 & 508 & 508 & 406.4 & 508 & 609.6 & 1016 \\
\hline 27 & 304.8 & 304.8 & 304,8 & 508 & 304,8 & 406,4 & 1016 \\
\hline 28 & 304,8 & 304,8 & 304,8 & 609,6 & 304,8 & 304,8 & 1016 \\
\hline 29 & 406,4 & 406,4 & 406,4 & 406,4 & 406,4 & 406,4 & 508 \\
\hline 30 & 304,8 & 406,4 & 406,4 & 304,8 & 304,8 & 406,4 & 508 \\
\hline 31 & 304,8 & 304,8 & 304,8 & 304,8 & 304,8 & 304,8 & 508 \\
\hline 32 & 406,4 & 304,8 & 304,8 & 406,4 & 406,4 & 406,4 & 304,8 \\
\hline 33 & 406,4 & 406,4 & 406,4 & 406,4 & 406,4 & 406,4 & 406,4 \\
\hline 34 & 609,6 & 508 & 508 & 609,6 & 609,6 & 609,6 & 406,4 \\
\hline $\begin{array}{c}\text { Coste } \\
\text { (millones um) }\end{array}$ & 6,093 & 6,187 & 6,073 & 6,42 & 6,081 & 6,125 & 8,068 \\
\hline
\end{tabular}

(1) Solución obtenida de los trabajos de Matías (2003).

(2) Solución obtenida por Savic y Walters (1997).

(3) Solución obtenida por Savic y Walters (1997), sin cumplir restricciones de presión.

(4) Solución obtenida por Pimentel, en aplicación de la Metodología Lehnsnet.

(5) Solución obtenida en este trabajo con los algoritmos APG, HS, SFLA y PSO.

(6) Solución obtenida en éste trabajo con el algoritmo de Simulated Annealing (SA).

(7) Solución obtenida considerando con APG considerando la fiabilidad del sistema.

\section{Tabla 4.5. Coste de diseño obtenido para la red de Hanoi utilizando metodologías} heurísticas. 
Si se compara de manera general los resultados obtenidos con métodos funcionales y los dados por las distintas técnicas heurísticas se observa una mejora evidente, tanto en el caso de los cálculos realizados sin fiabilidad como en los cálculos realizados con fiabilidad. Así, en el diseño sin fiabilidad la solución obtenida por Lehnsnet $(6,42$ millones de um) es superior en un $5,57 \%$ a la solución obtenida por aplicación de metodologías heurísticas basadas en algoritmos evolutivos (6,081 millones de um).

Si se considera el diseño con fiabilidad la diferencia es aún mayor, puesto que la solución obtenida por las técnicas funcionales (9,825 miles de um) es un $21,77 \%$ más costosa que la obtenida por el APG. El análisis de la solución con fiabilidad que proporciona el APG permite notar que los diámetros mayores estaban ya presentes en la solución no fiable. Por el contrario aquellos diámetros que eran de tamaño menor en la solución no fiable deben ser mayores en la solución fiable, para asumir una mayor capacidad de transporte en caso de rotura o fallo.

\subsection{Red de Nueva York}

Al igual que ocurre en el caso de la red de Hanoi, el problema de diseño que plantea la red de los túneles de Nueva York ha sido ampliamente abordado por distintos investigadores que centran su estudio en el desarrollo de metodologías de diseño. En este caso, más que un problema de diseño es un problema de ampliación de la red, puesto que en las condiciones iniciales no es capaz de cumplir los criterios de abastecimiento que se le demandan. En este caso, la red consta de 20 nudos, 21 tuberías y un depósito de cota 300 pies, que alimenta por gravedad al resto de la red, cuyo esquema puede verse en la Figura 4.2.

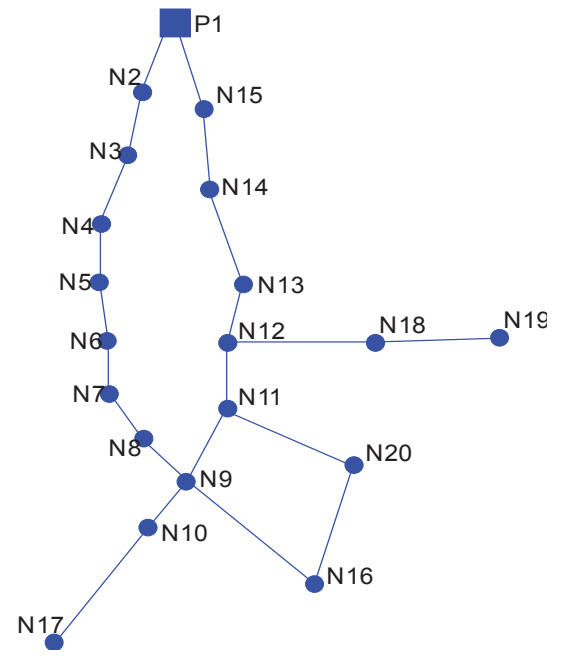

Figura 4.2. Red de los túneles de Nueva York 
El problema no es de diseño puro, ya que el objetivo es añadir nuevos conductos en paralelo a los ya existentes, puesto que la red actual no satisface en todos los nudos los requerimientos mínimos de presión (nudos 16-20), por lo que el problema se convierte en un problema de diseño-ampliación de la red. Los datos completos de la red son:

\begin{tabular}{|c|c|c|c|c|c|}
\hline ID Nudo & Cota $(\mathrm{m})$ & $Q(1 / s)$ & ID Nudo & Cota $(\mathrm{m})$ & $\mathrm{Q}(\mathrm{l} / \mathrm{s})$ \\
\hline 1 & 91,437 & , & 12 & 47,724 & 3315,903 \\
\hline 2 & 47,724 & 2616,476 & 13 & 47,724 & 3315,903 \\
\hline 3 & 47,724 & 2616,476 & 14 & 47,724 & 2616,476 \\
\hline 4 & 47.724 & 2497.546 & 15 & 47.724 & 2616.476 \\
\hline 5 & 47.724 & 2497.546 & 16 & 47.724 & 4813.863 \\
\hline 6 & 47.724 & 2497.546 & 17 & 53.149 & 1628.19 \\
\hline 7 & 47.724 & 2497.546 & 18 & 47.724 & 3315.903 \\
\hline 8 & 47.724 & 2497.546 & 19 & 47.724 & 3315.903 \\
\hline 9 & 47.724 & 4813.863 & 20 & 47.724 & 4813.863 \\
\hline 10 & 47.724 & 28.31684 & & & \\
\hline 11 & 47.724 & 4813.863 & & & \\
\hline
\end{tabular}

Tabla 4.6. Red de los túneles de Nueva York, Cota y demanda de los nudos,

\begin{tabular}{|c|c|c|c|c|c|}
\hline ID Línea & $\begin{array}{c}\text { Diámetro } \\
\text { original }(\mathrm{mm})\end{array}$ & Longitud (m) & ID Línea & $\begin{array}{c}\text { Diámetro } \\
\text { original }(\mathrm{mm})\end{array}$ & Longitud (m) \\
\hline 1 & 4572 & 3535,564 & 12 & 5181,6 & 3718,438 \\
\hline 2 & 4572 & 6034,842 & 13 & 5181,6 & 7345,439 \\
\hline 3 & 4572 & 2224,967 & 14 & 5181,6 & 6431,069 \\
\hline 4 & 4572 & 2529,757 & 15 & 5181,6 & 4724,245 \\
\hline 5 & 4572 & 2621,194 & 16 & 1828,8 & 8046,456 \\
\hline 6 & 4572 & 5821,489 & 17 & 1828,8 & 9509,447 \\
\hline 7 & 3352,8 & 2925,984 & 18 & 1524 & 7314,96 \\
\hline 8 & 3352,8 & 3809,875 & 19 & 1524 & 4388,976 \\
\hline 9 & 4572 & 2925,984 & 20 & 1524 & 11703,94 \\
\hline 10 & 5181,6 & 3413,648 & 21 & 1828,8 & 8046,456 \\
\hline 11 & 5181,6 & 3413,648 & & & \\
\hline
\end{tabular}

Tabla 4.7. Red de los túneles de Nueva York. Longitud y Diámetro original de las líneas.

Ya se ha visto con anterioridad que el cálculo de diseño aplicando cualquier metodología heurística requiere de la definición de una gama de diámetros que permita la exploración del espacio de soluciones. Para la red de los túneles de Nueva York, los diámetros utilizados son de la gama original (Schaake, 1969) y viene dada en la tabla 4.8.

\begin{tabular}{|c|c|c|c|c|c|}
\hline ID Diámetro & Diámetro ("') & Coste (um/m) & $\begin{array}{c}\text { ID } \\
\text { Diámetro }\end{array}$ & Diámetro (") & Coste (um/m) \\
\hline$A$ & 36 & 307,04 & 1 & 132 & 1537,76 \\
\hline$B$ & 48 & 438,65 & $\mathrm{~J}$ & 144 & 1712,96 \\
\hline $\mathrm{C}$ & 60 & 578,48 & $\mathrm{~K}$ & 156 & 1891,7 \\
\hline $\mathrm{D}$ & 72 & 725,22 & $L$ & 168 & 2073,77 \\
\hline$E$ & 84 & 877,98 & $\mathrm{LL}$ & 180 & 2259,0 \\
\hline $\mathrm{F}$ & 96 & 1036,08 & $\mathrm{M}$ & 192 & 2447,21 \\
\hline $\mathrm{G}$ & 108 & 1199,01 & $\mathrm{~N}$ & 204 & 2638,27 \\
\hline $\mathrm{H}$ & 120 & 1366,35 & & & \\
\hline
\end{tabular}

Tabla 4.8. Gama de diámetros utilizada en el diseño de la red de los túneles de Nueva York. 
Antes de someter la red de Nueva York a metodologías de diseño heurísticas se realiza un diseño previo con métodos funcionales. El cálculo de la red basado en este tipo de metodología nos permite adquirir una idea del coste total que puede tener el diseño de la red, y al mismo tiempo, nos permite comparar distintos métodos, de modo que podemos certificar si existe una mejora tras aplicar metodologías de diseño heurístico, así como cuantificar de cuánto es esta mejora. Los métodos funcionales que se contemplan en este caso son los de diámetro mínimo, diámetro máximo, pendiente económica aplicada a todos los nudos y pendiente económica aplicada a los defectos. El estudio se completa con la solución aportada por LEHNSNET, metodología basada en programación dinámica.

\begin{tabular}{|l|}
\hline DISEÑO SIN FIABILIDAD \\
\hline Método 2: Diámetros Máximos \\
problema resuelto en 106 iteraciones \\
144.868.200 um \\
\hline Método 3: Pendiente Económica aplicada a todos los nudos \\
problema resuelto en 262 iteraciones \\
113.860.300 um \\
\hline Método 4: Pendiente Económica aplicada a los defectos \\
problema resuelto en 424 iteraciones \\
122.420.400 um \\
\hline Método 5: Lehnsnet \\
41,24 millones um \\
\hline
\end{tabular}

Tabla 4.9. Coste de diseño obtenido para la red de Nueva York utilizando metodologías no heurísticas sin considerar criterios de fiabilidad.

La mejor solución de diseño para la red de Nueva York entre los métodos funcionales la aporta LEHNSNET, con un coste de 41,24 millones de um. La diferencia entre LEHNSNET y el resto de métodos funcionales es muy grande, del orden de prácticamente la mitad de la solución obtenida por diámetros mínimos, que el método funcional más cercano de entre los empleados.

La utilización de algoritmos evolutivos en el problema de diseño-ampliación de la red de los túneles de Nueva York permite mejorar el coste de instalación obtenido cuando se aplicaban métodos funcionales. La tabla 4.10 muestra distintas soluciones obtenidas por aplicación de heurísticas de diseño, considerando tanto los resultados propios como los obtenidos por otros investigadores, a fin de poder establecer criterios de comparación.

\begin{tabular}{|c|c|c|c|c|c|c|}
\hline & Murphy & Savic $^{2}$ & $\begin{array}{c}\text { Morgan y } \\
\text { Goulter }^{3}\end{array}$ & $\begin{array}{c}\text { Sol } \\
\text { AG/HS/SFLA/PSO }\end{array}$ & Sol SA $^{5}$ & $\begin{array}{c}\text { Sol }^{\text {AG/HS/SFLA/PSO }^{4}} \\
\text { fiab }^{6}\end{array}$ \\
\hline 1 & 0 & 0 & 0 & 0 & 0 & 0 \\
\hline 2 & 0 & 0 & 0 & 0 & 0 & 60 \\
\hline 3 & 0 & 0 & 0 & 0 & 0 & 0 \\
\hline 4 & 0 & 0 & 0 & 0 & 0 & 0 \\
\hline 5 & 0 & 0 & 0 & 0 & 0 & 0 \\
\hline 6 & 0 & 0 & 0 & 0 & 0 & 0 \\
\hline 7 & 0 & 108 & 144 & 144 & 0 & 0 \\
\hline 8 & 0 & 0 & 0 & 0 & 0 & 0 \\
\hline
\end{tabular}




\begin{tabular}{|c|c|c|c|c|c|c|}
\hline 9 & 0 & 0 & 0 & 0 & 0 & 0 \\
\hline 10 & 0 & 0 & 0 & 0 & 0 & 0 \\
\hline 11 & 0 & 0 & 0 & 0 & 0 & 0 \\
\hline 12 & 0 & 0 & 0 & 0 & 0 & 0 \\
\hline 13 & 0 & 0 & 0 & 0 & 0 & 192 \\
\hline 14 & 0 & 0 & 0 & 0 & 0 & 204 \\
\hline 15 & 120 & 0 & 0 & 0 & 120 & 60 \\
\hline 16 & 84 & 96 & 96 & 96 & 84 & 96 \\
\hline 17 & 96 & 96 & 96 & 96 & 96 & 84 \\
\hline 18 & 84 & 84 & 84 & 84 & 84 & 96 \\
\hline 19 & 72 & 72 & 60 & 72 & 72 & 0 \\
\hline 20 & 0 & 0 & 0 & 0 & 0 & 96 \\
\hline 21 & 72 & 72 & 84 & 72 & 72 & 0 \\
\hline $\begin{array}{c}\text { Coste } \\
\text { (millones } \\
\text { um) }\end{array}$ & 38,812 & 37,130 & 39,200 & 38,642 & 38,812 & 68,786 \\
\hline \multicolumn{7}{|c|}{$\begin{array}{l}\text { (1) Solución obtenida por Murphy (1993)6. } \\
\text { (2) Solución obtenida por Savic (1997). No cumple las especificaciones de presión mínima en Epanet2. } \\
\text { (3) Solución obtenida por Morgan y Goulter } \\
\text { (4) Solución obtenida en este trabajo con los algoritmos Pseudogenético, Harmony Search, Frog Shuffled } \\
\text { Leaping Algorithm, Particle Swarm Optimization } \\
\text { (5) Solución obtenida en éste trabajo con Simulated Annealing. } \\
\text { (6) Solución obtenida considerando criterios de fiabilidad trabajo con los algoritmos Pseudogenético. Harmony } \\
\text { Search, Frog Shuffled Leaping }\end{array}$} \\
\hline
\end{tabular}

Tabla 4.10. Coste de diseño obtenido para la red de Nueva York utilizando metodologías heurísticas.

De similar modo a lo que ocurría en el caso de la red de Hanoi, cuatro de los cinco métodos estudiados coinciden en la mejor solución de diseño para la red de los túneles de Nueva York, que en este caso es 38,642 millones de um. De nuevo, el algoritmo SA es el único que no es capaz de encontrar este mínimo, obteniendo como mejor solución 38,812 millones de um.

La solución de diseño obtenida es la de menor coste entre las que se encuentran en la bibliografía, aunque son varios los autores que han llegado a la misma solución con diferentes metodologías. Así, trabajos como los de Eusuff y Lansey (2003), Matías (2003) o Zecchin et al (2006) llegan a la misma solución de diseño para este caso.

Si se comparan los resultados obtenidos por métodos evolutivos con los que proporcionan las técnicas funcionales de diseño, de nuevo parece que se impone claramente el uso de técnicas evolutivas en lo que a mejor solución económica se refiere, puesto que el resultado de diseño obtenido mediante técnicas funcionales es un $6 \%$ mayor.

Savic (1997) propone una solución alternativa de menor coste (37,130 millones de um), pero esta solución no cumple las condiciones de presión mínima si trata de resolverse mediante EPANET, pese a que en los resultados que proporciona Savic en su trabajo sí parece cumplir dichas restricciones. 
Conviene recordar en este punto la influencia que tienen los parámetros de la fórmula de Hazen-Williams en los resultados obtenidos. Así, el programa EPANET, utilizado para el análisis de las RDA permite la utilización de esta fórmula, cuya forma original es:

$$
v=C R_{h}^{0,63} J^{0,54}
$$

con:

$$
\begin{aligned}
& \mathrm{Rh}=\text { radio hidráulico, en } \mathrm{ft} \text { (pies) } \\
& \mathrm{J}=\text { gradiente hidráulico } \\
& \mathrm{V}=\text { velocidad, en } \mathrm{ft} / \mathrm{s} \text { (pies/s) } \\
& \mathrm{C}=\text { coeficiente de } \mathrm{HW}, \text { cuyo valor cambia según el sistema de unidades }
\end{aligned}
$$

Para mantener el valor de $C$, se introduce la constante de conversión $\alpha$, y teniendo en cuenta que el radio hidráulico para una sección circular de radio $R$ y diámetro $D$ es $R h=D / 4$ la fórmula queda:

$$
v=\alpha C D^{0,63} J^{0,54}
$$

donde $D$ es el diámetro interior de la tubería y a toma un valor de 0,55 en unidades imperiales y de 0,355 para unidades $\mathrm{SI}$. Si se relaciona la pérdida de carga hf y el caudal $Q$, para una tubería de longitud $L$ se tiene que:

$$
h_{f}=w \cdot \frac{L}{C^{a} D^{b}} Q^{a}
$$

donde $\mathrm{w}$ representa una constante numérica de conversión que depende de las unidades utilizadas, $a=1 / 0,54$ y $b=2,63 / 0,54$. Distintos investigadores han utilizado para $w$, $a$ y $b$ distintos valores numéricos, dependiendo de la aproximación o redondeo aplicado. La adopción de diferentes valores para estos coeficientes supone variaciones en los resultados obtenidos del análisis de la red. Dichas modificaciones afectan a la pérdida de carga, velocidad y caudal circulante por las tuberías, a la presión y altura piezométrica de los nudos.

Cuanto más grande es la constante w más grandes son las pérdidas de carga, por lo que mayores son los diámetros requeridos para cumplir las condiciones de presión mínima en un determinado problema. Así, en el caso de diseño económico, puede cambiar la solución óptima. Como ejemplo de la importancia de lo mencionado basta es suficiente con valorar los resultados obtenidos por Savic, que utiliza como programa de análisis Ganet (2001) y los que se presentan en este trabajo, basados en EPANET. 
Savic utiliza en sus cálculos un coeficiente w de valor 10,5088 mientras que EPANET utiliza un w de valor 10,5879. De este modo, si introducimos la solución óptima proporcionada por Savic en EPANET, la restricción de presión, determinada en un mínimo de 30 mca no se verifica en los nudos 16, 17 y 19. Esto implica que dicha solución no es válida para EPANET y la red obtenida en el diseño óptimo tendría un mayor coste económico.

Por tanto, es importante especificar qué parámetros se han utilizado en la fórmula de HW que calcula la pérdida de carga continua en una tubería, puesto que puede inducir variaciones importantes en el resultado.

\subsection{Red R-9 de Joao Pessoa}

La red R-9 es una red de trazado real ubicada en la ciudad de Joao Pessoa (Brasil). Su construcción data de 1982 y consta de 61 nudos de consumo, conectados entre sí a través de 72 conductos, considerando como alimentación del sistema un depósito de cabecera de altura fija. El esquema de la red (figura 4.3), así como todos los datos necesarios para el dimensionamiento se toman del trabajo de Formiga (2005).

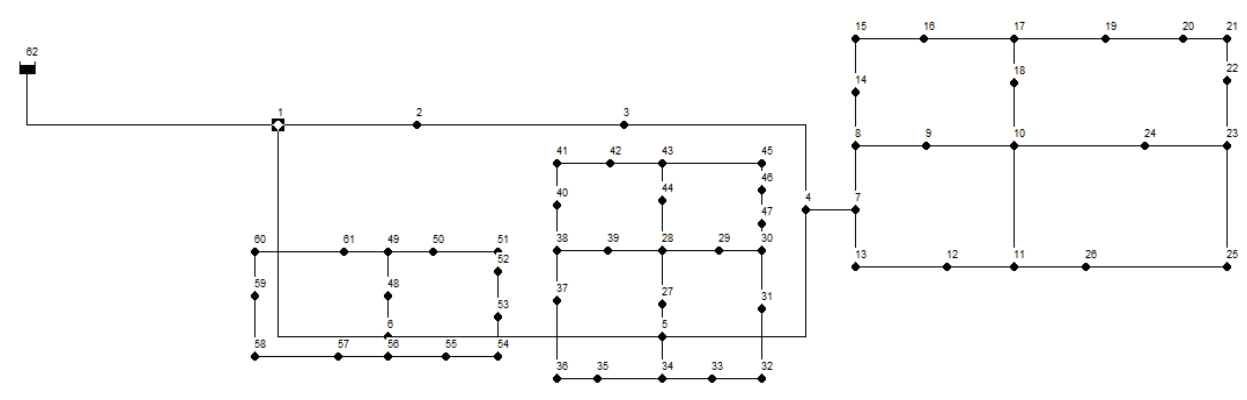

Figura 4.3. Red R-9 de Joao Pessoa (Brasil)

El objetivo del problema de diseño es dimensionar los conductos de la red de modo que se cumpla una serie de condiciones para el abastecimiento. En este caso, la restricción principal es el cumplimiento de una presión mínima para todos los nudos, cuya consigna queda establecida en 15 mca. Para ello se dispone de todos los datos de entrada de la red, mostrados en las tablas 4.11 y 4.12 . 
4. Casos de estudio y resultados

\begin{tabular}{|c|c|c|c|c|c|}
\hline ID Nudo & Cota $(\mathrm{m})$ & $\mathrm{Q}(\mathrm{l} / \mathrm{s})$ & ID Nudo & Cota (m) & $\mathrm{Q}(\mathrm{I} / \mathrm{s})$ \\
\hline 1 & 5 & 2,51 & 32 & 4,5 & 4,09 \\
\hline 2 & 5 & 44,07 & 33 & 5 & 3,68 \\
\hline 3 & 4 & 41,24 & 34 & 5 & 4,04 \\
\hline 4 & 4,5 & 1,04 & 35 & 6 & 3,22 \\
\hline 5 & 4,5 & 0,86 & 36 & 4,5 & 2,53 \\
\hline 6 & 4,5 & 1,32 & 37 & 4,5 & 2,31 \\
\hline 7 & 4,5 & 1,35 & 38 & 4 & 2,50 \\
\hline 8 & 5 & 8,59 & 39 & 4 & 2,89 \\
\hline 9 & 4,5 & 6,40 & 40 & 4 & 2,48 \\
\hline 10 & 5 & 6,07 & 41 & 4 & 4,61 \\
\hline 11 & 3,5 & 4,95 & 42 & 4 & 3,47 \\
\hline 12 & 3,5 & 8,38 & 43 & 4 & 3,61 \\
\hline 13 & 3,5 & 11,70 & 44 & 4 & 5,17 \\
\hline 14 & 5 & 5,63 & 45 & 4 & 6,48 \\
\hline 15 & 6 & 5,57 & 46 & 4,5 & 4,91 \\
\hline 16 & 6 & 6,30 & 47 & 4 & 6,50 \\
\hline 17 & 6 & 3,26 & 48 & 4,5 & 4,97 \\
\hline 18 & 6 & 3,60 & 49 & 3 & 2,97 \\
\hline 19 & 6 & 4,83 & 50 & 5 & 1,80 \\
\hline 20 & 6 & 4,50 & 51 & 4 & 2,96 \\
\hline 21 & 5 & 2,80 & 52 & 3 & 4,66 \\
\hline 22 & 3 & 5,46 & 53 & 4,5 & 4,54 \\
\hline 23 & 3,5 & 62,45 & 54 & 4,5 & 8,80 \\
\hline 24 & 6 & 8,19 & 55 & 4,5 & 4,26 \\
\hline 25 & 3,5 & 58,87 & 56 & 5 & 2,98 \\
\hline 26 & 3,5 & 3,26 & 57 & 5 & 3,91 \\
\hline 27 & 4,3 & 4,36 & 58 & 4,7 & 3,70 \\
\hline 28 & 4 & 4,25 & 59 & 5 & 1,86 \\
\hline 29 & 2,5 & 4,56 & 60 & 5 & 3,12 \\
\hline 30 & 2,5 & 8,32 & 61 & 4,5 & 3,52 \\
\hline 31 & 3,5 & 4,94 & & & \\
\hline
\end{tabular}

Tabla 4.11. Red de Joao Pessoa. Cota y demanda de los nudos.

\begin{tabular}{|c|c|c|c|c|c|c|c|}
\hline ID Línea & $\begin{array}{l}\text { Nudo } \\
\text { Inicial }\end{array}$ & $\begin{array}{c}\text { Nudo } \\
\text { Final }\end{array}$ & Longitud (m) & ID Línea & $\begin{array}{l}\text { Nudo } \\
\text { Inicial }\end{array}$ & $\begin{array}{c}\text { Nudo } \\
\text { Final }\end{array}$ & Longitud (m) \\
\hline 1 & Dep. & 1 & 2540 & 37 & 32 & 31 & 285 \\
\hline 2 & 1 & 2 & 350 & 38 & 33 & 32 & 210 \\
\hline 3 & 2 & 3 & 1140 & 39 & 34 & 33 & 240 \\
\hline 4 & 3 & 4 & 1430 & 40 & 5 & 34 & 250 \\
\hline 5 & 4 & 5 & 1020 & 41 & 34 & 35 & 340 \\
\hline 6 & 6 & 5 & 1430 & 42 & 35 & 36 & 270 \\
\hline 7 & 1 & 6 & 1710 & 43 & 36 & 37 & 240 \\
\hline 8 & 4 & 7 & 220 & 44 & 37 & 38 & 160 \\
\hline 9 & 7 & 8 & 190 & 45 & 39 & 38 & 260 \\
\hline 10 & 8 & 9 & 295 & 46 & 28 & 39 & 250 \\
\hline 11 & 9 & 10 & 390 & 47 & 38 & 40 & 330 \\
\hline 12 & 11 & 10 & 370 & 48 & 40 & 41 & 230 \\
\hline 13 & 12 & 11 & 190 & 49 & 42 & 41 & 385 \\
\hline 14 & 13 & 12 & 310 & 50 & 43 & 42 & 160 \\
\hline 15 & 7 & 13 & 205 & 51 & 44 & 43 & 330 \\
\hline 16 & 8 & 14 & 305 & 52 & 28 & 44 & 210 \\
\hline 17 & 14 & 15 & 295 & 53 & 43 & 45 & 150 \\
\hline 18 & 15 & 16 & 300 & 54 & 45 & 46 & 255 \\
\hline 19 & 16 & 17 & 290 & 55 & 47 & 46 & 260 \\
\hline 20 & 18 & 17 & 180 & 56 & 30 & 47 & 230 \\
\hline 21 & 10 & 18 & 315 & 57 & 6 & 48 & 115 \\
\hline
\end{tabular}




\begin{tabular}{|c|c|c|c|c|c|c|c|}
\hline 22 & 17 & 19 & 300 & 58 & 48 & 49 & 180 \\
\hline 23 & 20 & 19 & 295 & 59 & 49 & 50 & 140 \\
\hline 24 & 21 & 20 & 215 & 60 & 50 & 51 & 215 \\
\hline 25 & 22 & 21 & 140 & 61 & 51 & 52 & 175 \\
\hline 26 & 23 & 22 & 220 & 62 & 52 & 53 & 180 \\
\hline 27 & 23 & 24 & 220 & 63 & 53 & 54 & 260 \\
\hline 28 & 10 & 24 & 285 & 64 & 54 & 55 & 205 \\
\hline 29 & 25 & 23 & 300 & 65 & 55 & 56 & 255 \\
\hline 30 & 26 & 25 & 315 & 66 & 56 & 6 & 260 \\
\hline 31 & 11 & 26 & 170 & 67 & 57 & 56 & 275 \\
\hline 32 & 5 & 27 & 110 & 68 & 58 & 57 & 315 \\
\hline 33 & 27 & 28 & 280 & 69 & 59 & 58 & 200 \\
\hline 34 & 28 & 29 & 225 & 70 & 59 & 60 & 175 \\
\hline 35 & 29 & 30 & 200 & 71 & 60 & 61 & 300 \\
\hline 36 & 30 & 31 & 190 & 72 & 61 & 49 & 250 \\
\hline
\end{tabular}

Tabla 4.12. Red de Joao Pessoa. Longitud de las líneas.

El dimensionado de la red utilizando cualquier metodología de diseño requiere de una gama de diámetros, que en este caso es coincidente con la proporcionada por Gomes (2009) y cuyo detalle se recoge en la tabla 4.13 .

\begin{tabular}{|c|c|c||c|c|c|}
\hline ID Diámetro & Diámetro $(\mathbf{m m})$ & Coste $(\mathbf{u m} / \mathbf{m})$ & ID Diámetro & Diámetro (mm) & Coste \\
\hline A & 100 & 1629 & $\mathrm{~F}$ & 350 & 11012 \\
\hline B & 150 & 4054 \\
\hline C & 200 & 5769 & $\mathrm{G}$ & 400 & 12397 \\
\hline $\mathrm{D}$ & 250 & 7718 & $\mathrm{H}$ & 450 & 15501 \\
\hline $\mathrm{E}$ & 300 & 9237 & $\mathrm{I}$ & 500 & 17686 \\
\hline & & $\mathrm{J}$ & 600 & 23132 \\
\hline
\end{tabular}

Tabla 4.13. Gama original de diámetros.

La tabla 4.14 muestra el coste de diseño obtenido para la red R-9 de Joao Pessoa aplicando métodos funcionales, de modo que las restricciones impuestas sean las mismas que posteriormente se aplicarán al diseño con métodos heurísticos. Estos resultados no sólo dan una idea del coste total de la red, sino que además permiten comparar metodologías más clásicas con los algoritmos heurísticos que se van a utilizar.

\begin{tabular}{|c|}
\hline DISEÑO SIN FIABILIDAD \\
\hline $\begin{array}{l}\text { Método 1: Diámetros Mínimos: Corrección por Pendiente } \\
\text { problema resuelto en } 210 \text { iteraciones } \\
214200600 \text { um }\end{array}$ \\
\hline $\begin{array}{l}\text { Método 2: Diámetros Máximos } \\
\text { problema resuelto en } 247 \text { iteraciones } \\
226425000 \text { um }\end{array}$ \\
\hline $\begin{array}{l}\text { Método 3: Pendiente Económica aplicada a todos los nudos } \\
\text { problema resuelto en } 364 \text { iteraciones } \\
221321600 \text { um }\end{array}$ \\
\hline $\begin{array}{l}\text { Método 4: Pendiente Económica aplicada a los defectos } \\
\text { problema resuelto en } 467 \text { iteraciones } \\
208647700 \text { um }\end{array}$ \\
\hline
\end{tabular}

Tabla 4.14. Coste de diseño obtenido por distintos métodos funcionales para la red de Joao Pessoa. 
Cada una de las metodologías ensayadas da un resultado distinto para el diseño de la red de Joao Pessoa. Entre las metodologías funcionales, el mejor resultado económico lo obtiene el método de la pendiente económica aplicada a los defectos, con un coste de diseño de 208,647 millones de um. Este resultado de diseño permite hacerse una idea acerca del coste global que tiene la instalación de los conductos de la red.

La red de Joao Pessoa no es tan conocida en la bibliografía como otras redes de benchmarking, no obstante, además del resultado de diseño obtenido por distintos métodos funcionales se cuenta con otro patrón de comparación. Así, el dimensionamiento de la red de Joao Pessoa ha sido simulado por el Laboratorio de Eficiencia Energetica e Saneamiento de la Universidad Federal de Paraiba, utilizando la herramienta de diseño Lehnsnet. El mejor resultado de diseño obtenido por dicha herramienta es de 199,39 millones de um. La siguiente tabla muestra la solución de diseño que proporciona LEHNSNET, así como las proporcionadas por los algoritmos evolutivos que estudia este trabajo:

\begin{tabular}{|c|c|c|c|c|c|}
\hline Línea & Lehnsnet $^{(1)}$ & $\begin{array}{c}\text { Sol }^{(2)} \\
\text { APG/HS/SFLA/P } \\
\text { SO }\end{array}$ & Línea & Lehnsnet $^{(1)}$ & $\begin{array}{c}\text { Sol }^{(2)} \\
\text { AG/HS/SFLA/P } \\
\text { SO }\end{array}$ \\
\hline 1 & 600 & 600 & 37 & 100 & 100 \\
\hline 2 & 600 & 500 & 38 & 100 & 100 \\
\hline 3 & 600 & 450 & 39 & 100 & 100 \\
\hline 4 & 500 & 450 & 40 & 150 & 100 \\
\hline 5 & 350 & 100 & 41 & 100 & 100 \\
\hline 6 & 100 & 300 & 42 & 100 & 100 \\
\hline 7 & 250 & 400 & 43 & 100 & 100 \\
\hline 8 & 400 & 400 & 44 & 100 & 100 \\
\hline 9 & 200 & 400 & 45 & 100 & 100 \\
\hline 10 & 100 & 400 & 46 & 100 & 100 \\
\hline 11 & 100 & 400 & 47 & 100 & 100 \\
\hline 12 & 100 & 100 & 48 & 100 & 100 \\
\hline 13 & 400 & 100 & 49 & 100 & 100 \\
\hline 14 & 400 & 100 & 50 & 100 & 100 \\
\hline 15 & 400 & 100 & 51 & 150 & 150 \\
\hline 16 & 150 & 100 & 52 & 150 & 150 \\
\hline 17 & 150 & 100 & 53 & 100 & 100 \\
\hline 18 & 100 & 100 & 54 & 100 & 100 \\
\hline 19 & 100 & 100 & 55 & 100 & 100 \\
\hline 20 & 100 & 150 & 56 & 150 & 100 \\
\hline 21 & 100 & 200 & 57 & 150 & 150 \\
\hline 22 & 100 & 100 & 58 & 150 & 100 \\
\hline 23 & 100 & 100 & 59 & 100 & 100 \\
\hline 24 & 150 & 100 & 60 & 100 & 100 \\
\hline 25 & 150 & 100 & 61 & 100 & 100 \\
\hline 26 & 150 & 150 & 62 & 100 & 100 \\
\hline 27 & 100 & 350 & 63 & 100 & 100 \\
\hline 28 & 100 & 350 & 64 & 100 & 100 \\
\hline 29 & 300 & 200 & 65 & 150 & 100 \\
\hline 30 & 350 & 100 & 66 & 150 & 150 \\
\hline 31 & 350 & 100 & 67 & 100 & 100 \\
\hline 32 & 250 & 250 & 68 & 100 & 100 \\
\hline
\end{tabular}




\begin{tabular}{|c|c|c|c|c|c|}
\hline 33 & 250 & 250 & 69 & 100 & 100 \\
\hline 34 & 150 & 150 & 70 & 100 & 100 \\
\hline 35 & 150 & 150 & 71 & 100 & 100 \\
\hline 36 & 100 & 100 & 72 & 100 & 100 \\
\hline $\begin{array}{c}\text { Coste (millones } \\
\text { um) }\end{array}$ & 199,39 & 192,366 & & & \\
\hline \multicolumn{6}{|c|}{$\begin{array}{l}\text { (1) Solución obtenida por Lehnsnet } \\
\text { (2) Solución obtenida en este trabajo con los algoritmos Pseudogenético, Harmony Search, Frog Shuffled } \\
\text { Leaping Algorithm, Particle Swarm Optimization }\end{array}$} \\
\hline
\end{tabular}

Los cuatro métodos heurísticos basados en desarrollos evolutivos coinciden en la mínima solución encontrada para la red de Joao Pessoa, con un coste de 192.366 miles de um. Esta solución mejora todas las obtenidas hasta el momento con métodos funcionales, así como la obtenida por el programa Lehnsnet, que utiliza un algoritmo basado en programación dinámica.

Comparativamente, la solución proporcionada por los algoritmos evolutivos ensayados es un $3,65 \%$ más barata que la proporcionada por Lehnsnet. Aparentemente no supone una gran mejora, pero en una red de tamaño tan considerable como la de Joao Pessoa supone un ahorro de prácticamente 7 millones de um. El resto de metodologías funcionales que muestra la tabla 4.14 ofrecen resultados muy alejados de las técnicas evolutivas, puesto que todas resuelven el problema de diseño con costes por encima del $8 \%$ respecto a la solución ofrecida por las distintas heurísticas. 


\subsection{Red de Go-Yang}

La red de GoYang fue presentada por primera vez por Kim et al (1994) y su trazado está compuesto por 22 nudos y 30 tuberías, formando un total de 9 mallas distintas. La alimentación del sistema se realiza por una bomba $(4,52 \mathrm{~kW})$ desde un depósito de cota fija $71 \mathrm{~m}$. El problema queda reducido a realizar el dimensionamiento óptimo de la red (figura 4.5) de modo que cumpla las restricciones de presión impuestas para un correcto abastecimiento.

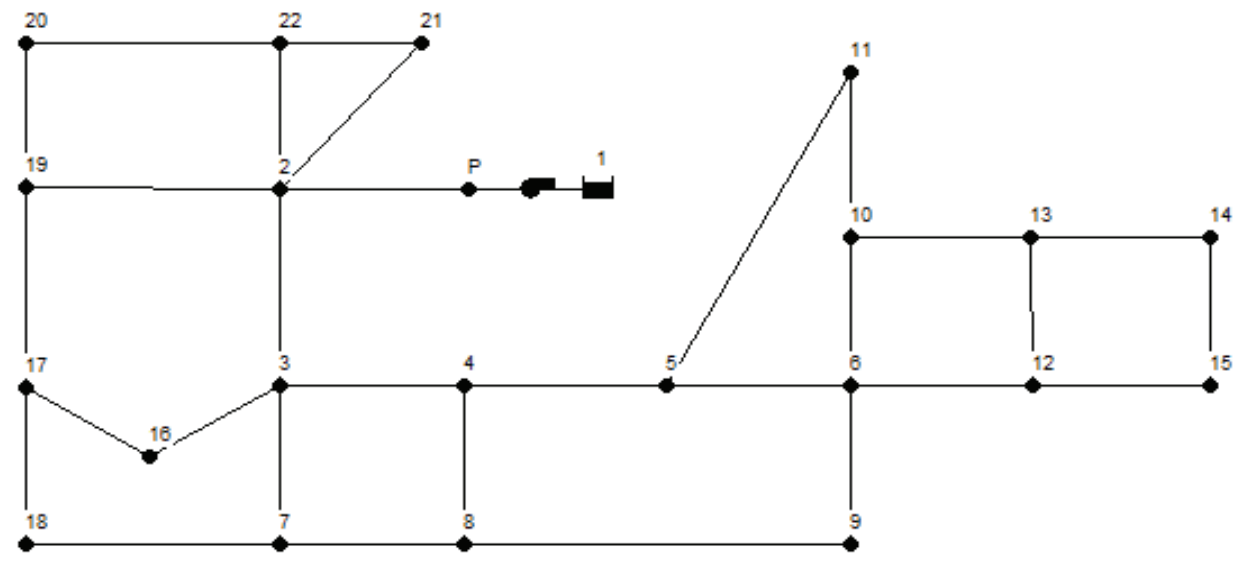

Figura 4.5. Red de Go-Yang

El coeficiente de Hazen-Williams utilizado para el cálculo de las pérdidas de carga es 100, mientras que la mínima presión de funcionamiento demandada es de 15 mca. Los datos completos para la definición de la red son:

\begin{tabular}{|c|c|c|c|c|c|}
\hline ID Nudo & Cota $(\mathrm{m})$ & $Q(1 / s)$ & ID nudo & Cota $(\mathrm{m})$ & $\mathrm{Q}(\mathrm{I} / \mathrm{s})$ \\
\hline 1 & 71 & & 12 & 58,6 & 0,434 \\
\hline 2 & 56,4 & 1,771 & 13 & 59,3 & 0,434 \\
\hline 3 & 53,8 & 0,816 & 14 & 59,8 & 0,729 \\
\hline 4 & 54,9 & 0,677 & 15 & 59,2 & 5,156 \\
\hline 5 & 56 & 0,868 & 16 & 53,6 & 1,250 \\
\hline 6 & 57 & 0,781 & 17 & 54,8 & 0,920 \\
\hline 7 & 53,9 & 0,729 & 18 & 55,1 & 0,642 \\
\hline 8 & 54,5 & 0,556 & 19 & 54,2 & 1,372 \\
\hline 9 & 57,9 & 0,486 & 20 & 54,5 & 1,441 \\
\hline 10 & 62,1 & 0,347 & 21 & 62,9 & 0,365 \\
\hline 11 & 62,8 & 0,486 & 22 & 61,8 & 9,253 \\
\hline
\end{tabular}

Tabla 4.16. Red de Go-Yang. Cota y demanda de los nudos. 


\begin{tabular}{|c|c|c|c|}
\hline ID Línea & Longitud (m) & ID Línea & Longitud (m) \\
\hline 1 & 165 & 16 & 261 \\
\hline 2 & 124 & 17 & 72 \\
\hline 3 & 118 & 18 & 373 \\
\hline 4 & 81 & 19 & 98 \\
\hline 5 & 134 & 20 & 110 \\
\hline 6 & 135 & 21 & 98 \\
\hline 7 & 202 & 22 & 246 \\
\hline 8 & 135 & 23 & 174 \\
\hline 9 & 170 & 24 & 102 \\
\hline 10 & 113 & 25 & 92 \\
\hline 11 & 335 & 26 & 100 \\
\hline 12 & 115 & 27 & 130 \\
\hline 13 & 345 & 28 & 90 \\
\hline 14 & 114 & 29 & 185 \\
\hline 15 & 103 & 30 & 90 \\
\hline
\end{tabular}

Tabla 4.17. Red de Go-Yang. Longitud de las líneas

El dimensionado de la red requiere la utilización de una gama de diámetros en la que apoyar los cálculos. Para la red de Go-Yang, la gama utilizada se corresponde con la proporcionada por Geem (2001):

\begin{tabular}{|c|c|c||c|c|c|}
\hline No diámetro & Diámetro $(\mathbf{m m})$ & Coste $(\mathbf{u m} / \mathbf{m})$ \\
\hline 0 & 80 & 37.890 & No diámetro & Diámetro (mm) & Coste \\
\hline 1 & 100 & 38.933 \\
\cline { 3 - 5 } & 125 & 40.563 & 4 & 200 & 47.624 \\
\hline 3 & 150 & 42.554 & 5 & 250 & 54.125 \\
\hline 3 & 6 & 7 & 300 & 62.109 \\
\hline
\end{tabular}

Tabla 4.18. Red de Go-Yang. Gama de diámetros

El cálculo de la red se realiza inicialmente aplicando métodos funcionales, tal como se realiza con el resto de redes. Se aplican en total 4 metodologías, con los siguientes resultados de diseño:

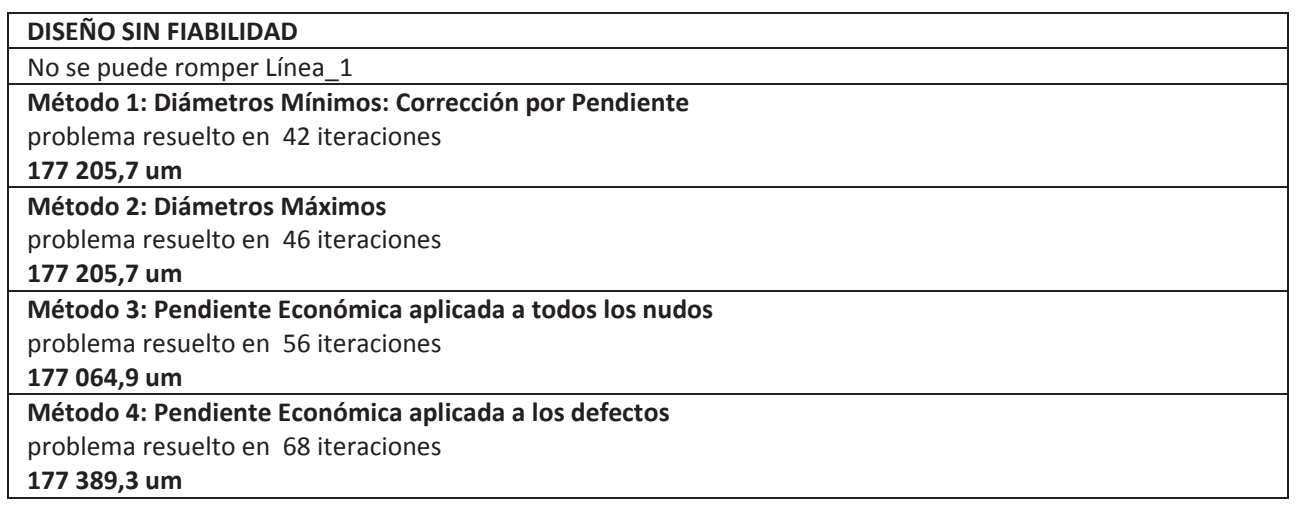

Tabla 4.19. Coste de diseño obtenido por distintos métodos funcionales para Go-Yang.

El diseño de la red a través de métodos funcionales da como mejor solución un coste global de instalación de 177064,9 um, garantizando el cumplimiento de las restricciones de presión 
impuestas para la red. Esta mínima solución la obtiene la metodología funcional basada en aplicar el criterio de pendiente económica aplicada a todos los nudos. Retomando el diseño de redes mediante metodologías heurísticas, la tabla 4.20 recoge los resultados obtenidos por Geem utilizando distintas técnicas de optimización, así como los resultados obtenidos por los algoritmos evolutivos en este trabajo:

\begin{tabular}{|c|c|c|c|c|}
\hline \multirow[b]{2}{*}{ Línea } & \multicolumn{3}{|c|}{ Soluciones bibliografía } & \multirow{2}{*}{$\begin{array}{l}\text { Soluciones obtenidas } \\
\text { Sol APG/HS/SFLA/PSO }\end{array}$} \\
\hline & $\begin{array}{l}\text { Diámetros } \\
\text { originales1 }\end{array}$ & NLP2 & Geem (HS)3 & \\
\hline 1 & 200 & 200 & 150 & 150 \\
\hline 2 & 200 & 200 & 150 & 150 \\
\hline 3 & 150 & 125 & 125 & 125 \\
\hline 4 & 150 & 125 & 150 & 125 \\
\hline 5 & 150 & 100 & 100 & 100 \\
\hline 6 & 100 & 100 & 100 & 80 \\
\hline 7 & 80 & 80 & 80 & 80 \\
\hline 8 & 100 & 80 & 80 & 80 \\
\hline 9 & 80 & 80 & 80 & 80 \\
\hline 10 & 80 & 80 & 80 & 80 \\
\hline 11 & 80 & 80 & 80 & 80 \\
\hline 12 & 80 & 80 & 80 & 80 \\
\hline 13 & 80 & 80 & 80 & 80 \\
\hline 14 & 80 & 80 & 80 & 80 \\
\hline 15 & 100 & 80 & 80 & 80 \\
\hline 16 & 80 & 80 & 80 & 80 \\
\hline 17 & 80 & 80 & 80 & 80 \\
\hline 18 & 80 & 100 & 100 & 80 \\
\hline 19 & 80 & 125 & 125 & 80 \\
\hline 20 & 80 & 80 & 80 & 80 \\
\hline 21 & 80 & 80 & 80 & 80 \\
\hline 22 & 80 & 80 & 80 & 80 \\
\hline 23 & 80 & 80 & 80 & 100 \\
\hline 24 & 80 & 80 & 80 & 80 \\
\hline 25 & 80 & 80 & 80 & 80 \\
\hline 26 & 80 & 80 & 80 & 80 \\
\hline 27 & 80 & 80 & 80 & 100 \\
\hline 28 & 80 & 80 & 80 & 80 \\
\hline 29 & 80 & 100 & 100 & 80 \\
\hline 30 & 80 & 80 & 80 & 80 \\
\hline $\begin{array}{l}\text { Coste } \\
\text { (um) }\end{array}$ & $179.428,600$ & $179.142,700$ & $177.135,800$ & $177.009,555$ \\
\hline \multicolumn{5}{|c|}{$\begin{array}{l}\text { (1) Solución diámetros originales red. } \\
\text { (2) Solución NLP proporcionada por Geem (2001). } \\
\text { (3 Solución obtenida Geem con algoritmo basado en HS. } \\
\text { (4) Solución obtenida en este trabajo con los algoritmos Pseudogenético, Harmony Search, Frog Shuffled } \\
\text { Leaping Algorithm, Particle Swarm Optimization }\end{array}$} \\
\hline
\end{tabular}

Tabla 4.20. Coste de diseño obtenido para la red de Go-Yang utilizando metodologías heurísticas. 
Todas las metodologías heurísticas empleadas coinciden en el mismo resultado de diseño, con un coste de instalación de 177009,555 um. Esta solución mejora ligeramente la proporcionada por Geem, así como todas las obtenidas por medio de métodos funcionales.

Las diferencias entre los distintos métodos de diseño empleados son menores para la red de Go-Yang. Este hecho tiene su explicación en la mayor sencillez de la red, puesto que tanto por tamaño como por la restricción de presión considerada no plantea grandes dificultades de diseño. Este hecho se observa con facilidad en las distintas soluciones de diseño que se muestran, puesto que a la gran mayoría de conducciones les basta con tomar el tamaño más pequeño de la gama considerada para cumplir con las condiciones de diseño.

Esto equivale a decir que probablemente el coste de la red podría ser reducido aún más ampliando la gama de diámetros, de modo que se consideren tamaños menores de instalación para las distintas líneas, que permitan ajustar aún más los costes de diseño. 


\section{ANÁLISIS ESTADÍSTICO DE SOLUCIONES}

\subsection{Introducción}

El capitulo anterior presenta las distintas redes analizadas, presentando en cada caso la mejor solución obtenida considerando en cada caso una serie de restricciones de diseño. Obviamente, la solución óptima de diseño no se obtiene en cada simulación realizada, sino que es un proceso de búsqueda que se puede considerar tedioso y que depende, en gran medida, de la correcta configuración de parámetros de cada algoritmo de cálculo.

Así, una vez se realiza un número de simulaciones suficientemente alto es posible la realización de análisis estadísticos que filtran los resultados en base a cualquier criterio, ordenándolos según el coste final obtenido, según la probabilidad de encontrar una solución mejor a una dada, según el valor que adquiera un determinado parámetro, etc. Este tipo de análisis permiten la toma de decisiones en cuanto a cuál es la técnica más adecuada para el problema de optimización.

El objetivo en cada caso será la determinación del ajuste óptimo para cada uno de los parámetros que envuelve el proceso de diseño, de forma que la probabilidad de encontrar la mínima solución para el problema de diseño sea lo más elevada posible. Asimismo, comparando el ajuste obtenido para cada modelo de optimización en las distintas redes, se trata de encontrar reglas generales que permitan extrapolar los resultados a otros casos de diseño que puedan plantearse. Este tipo de análisis estadístico, que prioriza únicamente la obtención de la mejor solución posible, recibe el nombre de análisis de parámetros y se desarrolla ampliamente en 5.2.

Cada metodología de diseño tiene sus propios parámetros de ajuste, que determinan en cada caso un modelo de comportamiento en la búsqueda del óptimo del sistema. No es una tarea sencilla el encontrar parámetros de ajuste que sean comunes a distintos algoritmos heurísticos. Probablemente, el único parámetro de ajuste que tiene presencia en cualquiera de los modelos de optimización desarrollados es el tamaño de la población inicial con la que trabaja un algoritmo. Pese a tener el mismo significado, en cada técnica evolutiva recibe un nombre distinto, a saber: tamaño de la población en APG, número de pájaros en PSO, tamaño 
de la memoria en HS, etc. No obstante, la función que realiza dentro del proceso de optimización es la misma, por lo que es el único parámetro que permite una relación directa entre distintos algoritmos de optimización. Es por ello que su análisis estadístico se realiza de modo independiente al resto de parámetros, abordándose su estudio detallado en el apartado 5.3 .

Tanto el análisis de parámetros general como el específico para el número de individuos que intervienen en el proceso de optimización consideran únicamente la mejora del proceso de diseño desde un punto de vista cuantitativo, es decir, obtener la mejor solución de diseño posible. No obstante, existen otras consideraciones a realizar, como por ejemplo la velocidad con la que un determinado algoritmo de cálculo alcanza la solución final de diseño. En este sentido, hay que tener en cuenta que la definición de velocidad que realiza este trabajo no está referida a un espacio temporal, sino al número de evaluaciones de la función objetivo que realiza una determinada metodología antes de llegar a la solución definitiva de diseño. El objetivo de este tipo de definición es alejar la definición de velocidad de la potencia del hardware utilizado, ciñendo este criterio únicamente a la cantidad de evaluaciones que será necesario realizar hasta encontrar la solución final del problema de diseño. La influencia de los distintos parámetros de ajuste en la velocidad de cálculo de cada metodología puede seguirse con detalle en el apartado 5.4 .

\subsection{Análiaia de parámetroa}

Cada una de las técnicas de optimización empleadas tiene una serie de parámetros susceptibles de ajuste, de los que depende el buen funcionamiento del algoritmo en mayor o menor medida. Una correcta configuración de estos parámetros contribuye a disminuir el factor de aleatoriedad que tienen los algoritmos evolutivos en la búsqueda del óptimo, aumentando considerablemente su probabilidad de éxito. La siguiente tabla enumera los algoritmos de optimización utilizados en este trabajo, así como los parámetros de ajuste estudiados en cada caso, exceptuando el tamaño de la población con la que trabaja el algoritmo, que se trata en capítulo aparte.

\begin{tabular}{|l|c|c|c|c|}
\hline \multicolumn{1}{|c|}{ APG } & PSO & SFLA & HS & SA \\
\hline & w & C & & Temperatura inicial \\
Prob. Cruce & $\mathrm{C}_{1}$ & $\mathrm{Q}$ & HMCR & $\alpha$ \\
Prob. Mutación & $\mathrm{C}_{2}$ & $\mathrm{~N}$ & PAR & Calc $\times \mathrm{T}$ \\
& $\mathrm{V}_{\text {lim }}$ & $\mathrm{m}$ & & \\
& $\mathrm{P}_{\text {desp }}$ & $\mathrm{n}$ & & \\
& & & & \\
\hline
\end{tabular}

Tabla 5.1. Parámetros de estudio en cada técnica de optimización 
Lógicamente, cuanto mayor es el número de parámetros susceptibles de optimización más complicado es el ajuste del algoritmo. El esfuerzo adicional que supone optimizar una mayor cantidad de parámetros puede merecer o no la pena en función de los resultados obtenidos. Del mismo modo, tal como muestran los resultados, alguno de estos parámetros puede tener una influencia nula en el buen hacer del algoritmo.

El número de simulaciones mínimas realizadas para cada red con cada uno de estos métodos supera las 30000 , de cara a tener una muestra suficientemente representativa para cada uno de los métodos. Los siguientes subapartados analizan los resultados obtenidos para diferentes redes con cada uno de estos métodos. El objetivo es la obtención de una serie de reglas de aplicación general para el ajuste de los distintos parámetros de cálculo en cada metodología de diseño.

Destacar por último que para la metodología de optimización basada en el algoritmo SA no se ha realizado ningún tipo de análisis estadístico de soluciones, puesto que los resultados obtenidos en el capítulo 4 muestran como esta técnica resulta muy inferior al resto en cuanto a la optimización del problema de diseño de redes de agua, por lo que se opta por descartarla y centrar los esfuerzos en el resto de algoritmos desarrollados en esta tesis.

\subsubsection{Ajuste de parámetros Algoritmo Pseudogenético (APG)}

Los operadores genéticos susceptibles de optimización son las probabilidades de cruce y mutación. En ambos casos, el análisis se centra en realizar simulaciones con distintas probabilidades de que actúe el operador, a fin de analizar la influencia que ejerce cada uno de ellos en la solución final que proporciona el algoritmo. En el caso del algoritmo APG para el diseño de redes de distribución se mantiene como parámetro de cálculo invariable el tamaño de población, que se mantiene constante en 100 individuos.

No obstante, el número de individuos de los que consta el APG también puede considerarse como un parámetro susceptible de optimización, que se analiza como caso particular en el apartado 5.4, debido a la importancia que tiene en la buena ejecución del algoritmo. Además, el número de individuos que interviene en la población inicial de cada uno de los métodos estudiados es el único parámetro de cálculo que puede considerarse común a todos los métodos heurísticos que plantea este trabajo.

La siguiente tabla ilustra el rango en el que se va a mover cada uno de los parámetros que pueden ser ajustados en la optimización genética. Cabe recordar que el algoritmo utilizado en este trabajo no es un algoritmo genético puro, sino que presenta ciertas modificaciones, lo que hace que el rango de valores utilizado para cada parámetro resulte algo diferente al que puede encontrarse en la bibliografía. 


\begin{tabular}{|c|c|c|}
\hline \multicolumn{2}{|c|}{ PARÁMETROS } & RANGO DE VALORES \\
\hline Probabilidad de cruce & Pc & $10-20-30-40-50-60-70-80-90(\%)$ \\
\hline Probabilidad de mutación & Pm & $10-20-30-40-50-60-70-80-90(\%)$ \\
\hline Población (constante) & N & 100 (individuos) \\
\hline
\end{tabular}

Tabla 5.2. Rango de estudio de parámetros para APG.

Los siguientes subapartados analizan estadísticamente los resultados obtenidos para cada una de las redes de distribución simuladas. El análisis estadístico realizado con APG se presenta de forma independiente para cada una de las redes, para posteriormente realizar un análisis más general aplicable a cada uno de los métodos estudiados.

\subsubsection{Red de Hanoi}

Ya se ha mencionado previamente que la red de Hanoi es un problema de diseño ampliamente conocido y estudiado en la bibliografía. La interpretación inicial de los resultados se realiza mediante la representación del histograma y el gráfico de probabilidad acumulada de las soluciones obtenidas (figura 5.1). El histograma contiene la totalidad de las simulaciones realizadas, por lo que incluye todas las posibles combinaciones realizadas entre las probabilidades de cruce y mutación.

El representar la totalidad de simulaciones realizadas permite detectar las soluciones más frecuentes, así como determinar la probabilidad de obtener una solución mejor a una dada.

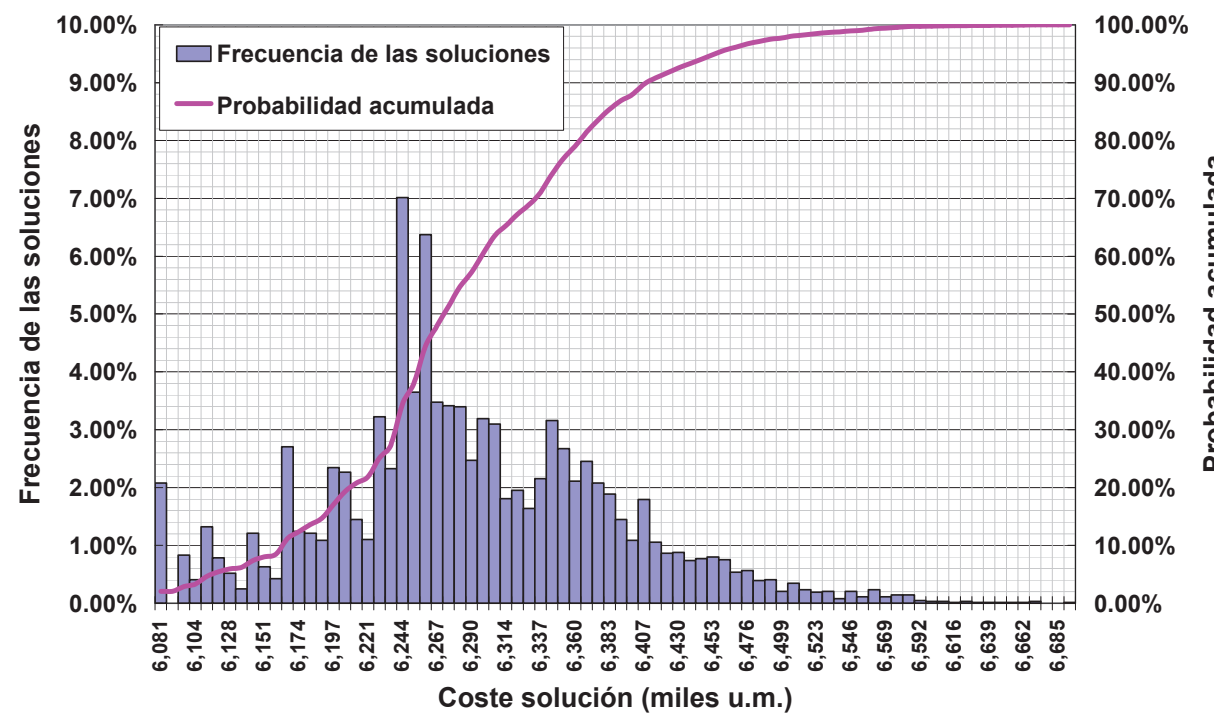

Figura 5.1. Histograma de soluciones obtenidas mediante APG para la red de Hanoi. 
Los algoritmos genéticos son uno de los métodos heurísticos más robustos, de modo que el $100 \%$ de las simulaciones realizadas dan resultados factibles para la red de agua diseñada. Esto quiere decir que un algoritmo genético funciona de un modo correcto prácticamente con cualquier configuración que tenga de inicio, independientemente de que existan determinados ajustes para los distintos parámetros en las que funcione mejor.

Así, para determinar la influencia que tienen los distintos parámetros de cálculo se adopta como valor óptimo de diseño la solución que corresponde a un coste de 6,081 miles de unidades monetarias. Considerado este valor como óptimo de diseño en la red, se analiza para cada posible combinación de mutación y cruce la probabilidad de que el APG obtenga la solución considerada como óptima de diseño. La representación de esta tasa de éxito en la obtención del valor óptimo se muestra en la figura 5.2

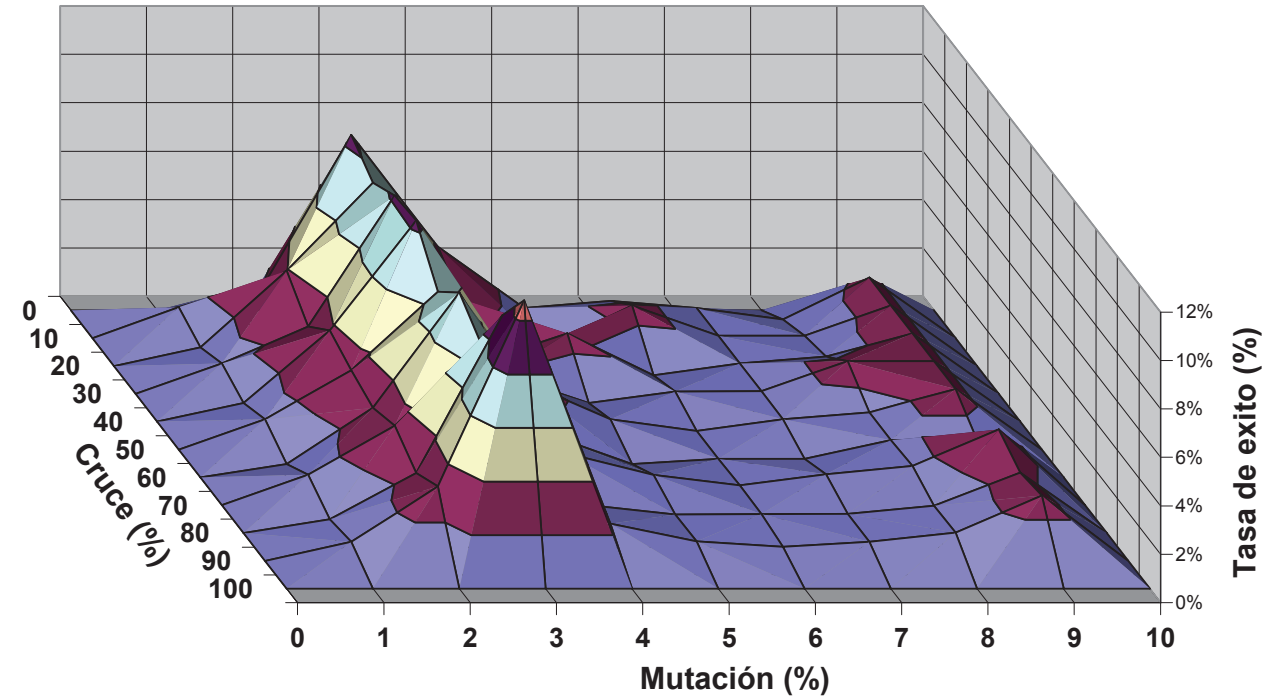

Figura 5.2. Probabilidad de obtención del mínimo según cruce y mutación

La figura pone de manifiesto cómo existen valores en las probabilidades de mutación y cruce que provocan que el APG no genere la solución óptima para la red. Así, en la figura se aprecia que la mejor combinación de parámetros para la red de Hanoi corresponde a una probabilidad de mutación del 3-4\%, no ejerciendo la probabilidad de cruce una influencia tan pronunciada como la probabilidad de mutación. No obstante, se observa un pequeño pico en torno al $90 \%$ de probabilidad de cruce.

En ocasiones no es preciso encontrar la solución óptima del problema, sino que el disponer de un conjunto de soluciones algo superiores en coste, pero obtenidas de una forma rápida y fácil es suficiente. Así, una de las principales características que poseen los algoritmos genéticos es que la mayoría de configuraciones permiten la obtención de lo que denominamos "buenas soluciones", independientemente de que no se consiga el óptimo de 
diseño. En este trabajo se define el concepto de buena solución como toda solución de diseño para una determinada red cuyo coste no sobrepase el coste de la solución óptima en más de un $3 \%$.

La figura 5.3 muestra la probabilidad de obtener una buena solución para cada combinación de probabilidades de mutación y cruce. El tipo de representación es similar al que muestra la figura 5.2, con la diferencia de que ahora el coste de referencia no es la solución de menor coste, sino 6,263 millones de um, valor que corresponde al coste de la solución óptima para la red de distribución más un $3 \%$ adicional.

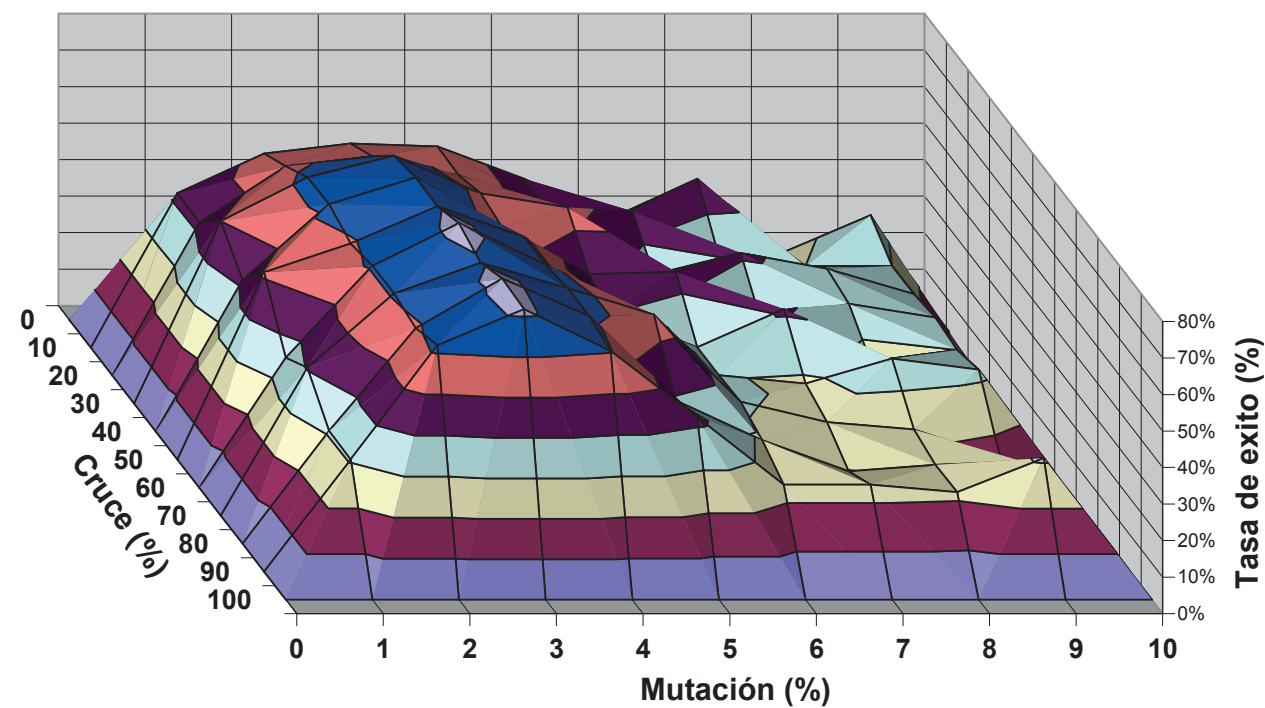

Figura 5.3. Probabilidad de obtener una "buena solución" respecto al cruce y la mutación

Al considerar el concepto de buena solución, la figura 5.3 muestra una tasa de éxito notablemente superior a la obtenida cuando se consideraban únicamente soluciones óptimas. Este dato demuestra la robustez del método de optimización, puesto que no sólo es capaz de obtener soluciones óptimas para la red, sino que también permite obtener con frecuencia un conjunto de buenas soluciones cercanas a este óptimo del sistema.

Así, considerando la mejor combinación de parámetros (mutaciones en torno al 3-4\%) alrededor de un $60-70 \%$ de las soluciones entran en los límites definidos como buena solución del problema de diseño. Del mismo modo, apenas hay combinaciones de parámetros que tengan una tasa de éxito inferior al $30 \%$, lo que da una idea de la robustez del APG en problemas de optimización. 


\subsubsection{Red de Nueva York}

La red de Nueva York es un problema de diseño-ampliación aparentemente mucho más sencillo de resolver, puesto que el número de posibles combinaciones de diseño es menor que en la red de Hanoi. Teóricamente, la búsqueda de buenas soluciones de diseño debe ser más sencilla para cualquiera de los algoritmos de optimización que presenta este trabajo, puesto que el número de posibilidades es menor.

El proceso de optimización aplicado en la red de NY es análogo al realizado para la red de Hanoi, por lo que los rangos estudiados para los distintos parámetros son los mismos (ver tabla 5.2).

De cara a la correcta interpretación de los resultados es importante recordar el significado exacto de los parámetros que se analizan. Así, una probabilidad de cruce de valor 0,1 implica que cada cadena (posible solución) del APG tiene una probabilidad del 10\% de verse sometida al operador de cruce. En el caso de la mutación el significado es análogo, de modo que un valor 0,01 hace que cada uno de los genes que forma una determinada cadena tenga una probabilidad de mutar del $1 \%$.

Para la red de Nueva York el número de simulaciones es de más de 8000, de modo que cada posible combinación de parámetros se repite 100 veces. El histograma representa el total de simulaciones realizadas:

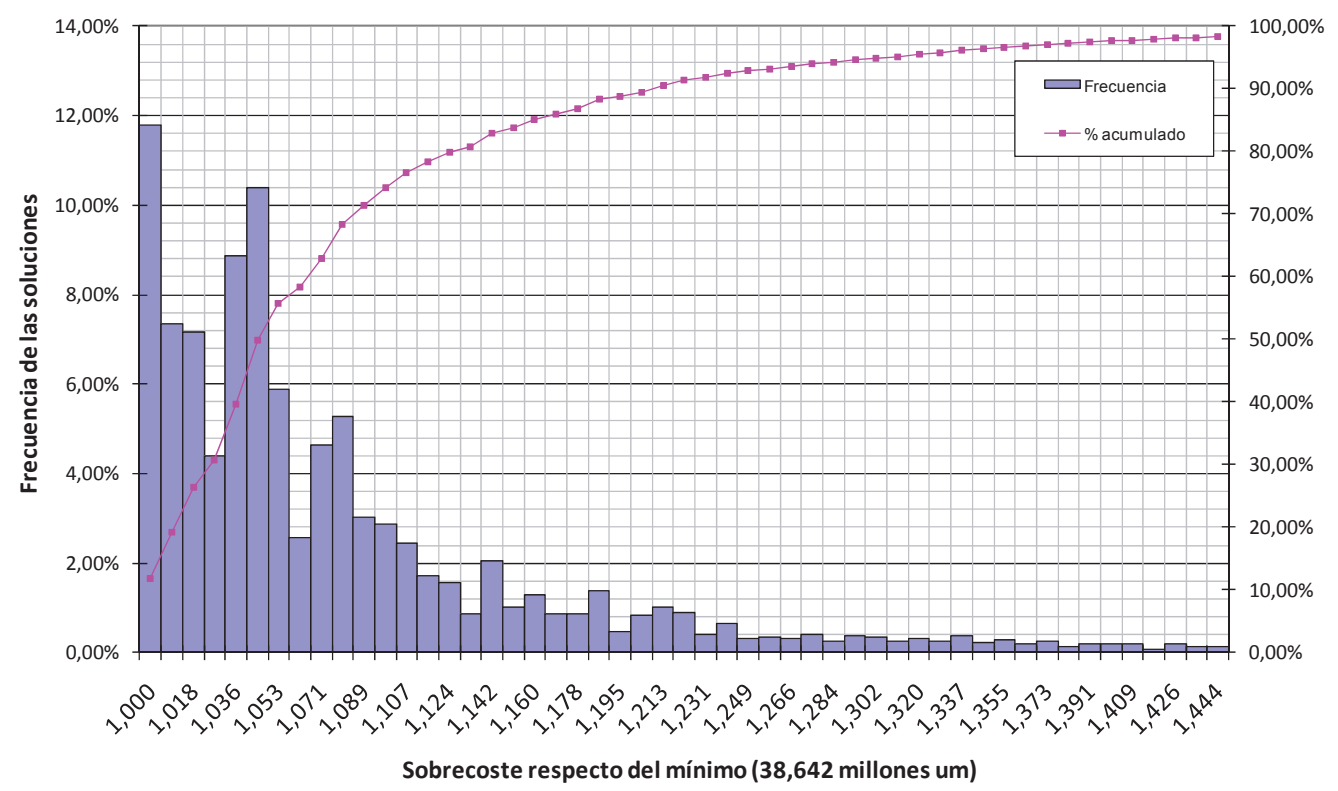

Figura 5.4. Histograma de soluciones obtenidas mediante APG para la red de los túneles de Nueva York. 
Los resultados que proporciona el histograma son sensiblemente mejores a los obtenidos para la red de Hanoi, ya que prácticamente un $12 \%$ de las simulaciones consiguen obtener la solución de mínimo coste, que en este caso corresponde a 38,642 millones de um. Este resultado entra dentro de la lógica, puesto que en este caso el número de soluciones posible es de $16^{21}$, mientras que en el caso de la red de Hanoi es de $6^{34}$. El número de posibles soluciones viene de la relación entre el número de tuberías que tiene la gama con la que se calcula y el número de tuberías que tiene la red de distribución. Un número mayor de combinaciones posibles puede provocar la caída del algoritmo de búsqueda en un mayor número de mínimos locales, lo que generalmente dificulta la obtención de una mejor solución final.

El valor óptimo de diseño que se adopta para la red de los túneles de Nueva York es 38,642 millones de um. Esta solución es la que presenta el menor coste cumpliendo todas las restricciones de diseño. Se analiza la probabilidad de obtener este valor óptimo para cada combinación de cruce y mutación (Figura 5.5)

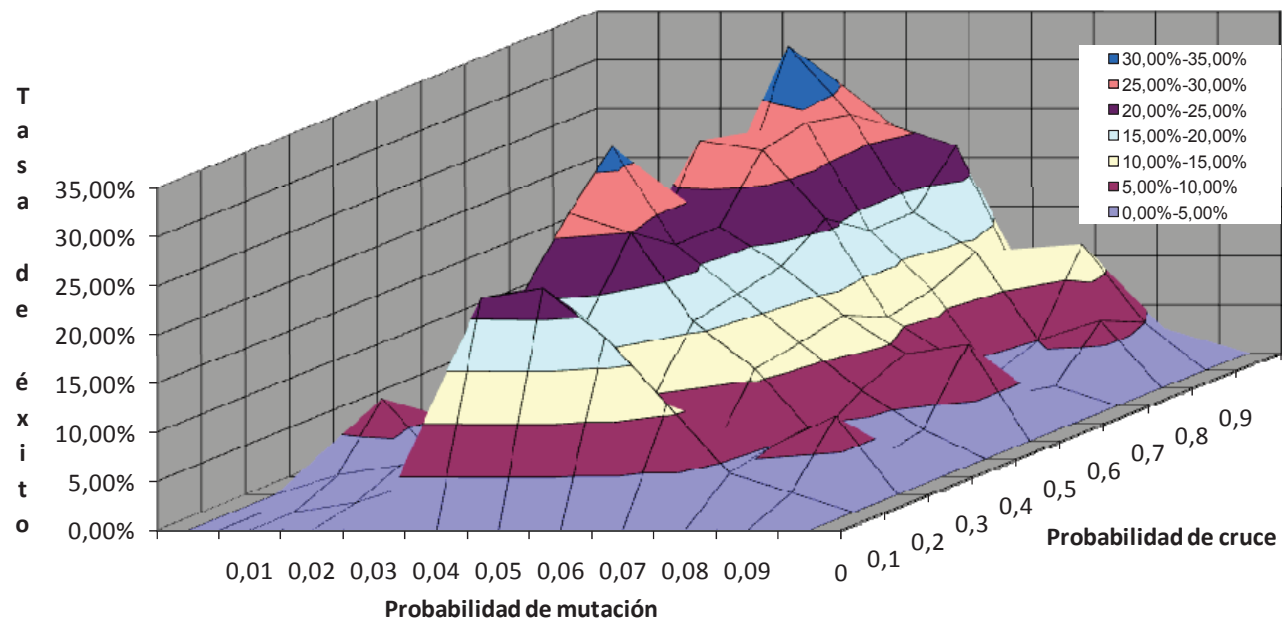

Figura 5.5. Probabilidad de obtener mínima solución de diseño respecto a las probabilidades cruce y mutación

El gráfico permite extraer ciertas conclusiones, y es que la hipótesis planteada en el estudio de la red de Hanoi acerca de la mayor influencia que ejerce la probabilidad de mutación en el resultado final parece confirmarse. En este caso, la probabilidad óptima de mutación está alrededor del $4-5 \%$, si bien los resultados del resto de valores también mejoran respecto del estudio de Hanoi.

Por otro lado, y desde un punto de vista cuantitativo, parece que probabilidades de cruce mayores obtienen una ligera mejoría en el desempeño del algoritmo, puesto que la figura 
permite apreciar un pico cercano al $30 \%$ de soluciones óptimas con probabilidades de cruce de más de un $60 \%$ y probabilidades de mutación en torno al 4-5\%.

La figura 5.6 se obtiene al ampliar los resultados a la probabilidad de obtener una buena solución. En el caso de la red de los túneles de Nueva York, el límite monetario que marca una buena solución queda fijado en 39,801 millones de um, valor que corresponde al coste de la mínima solución más un $3 \%$ adicional.

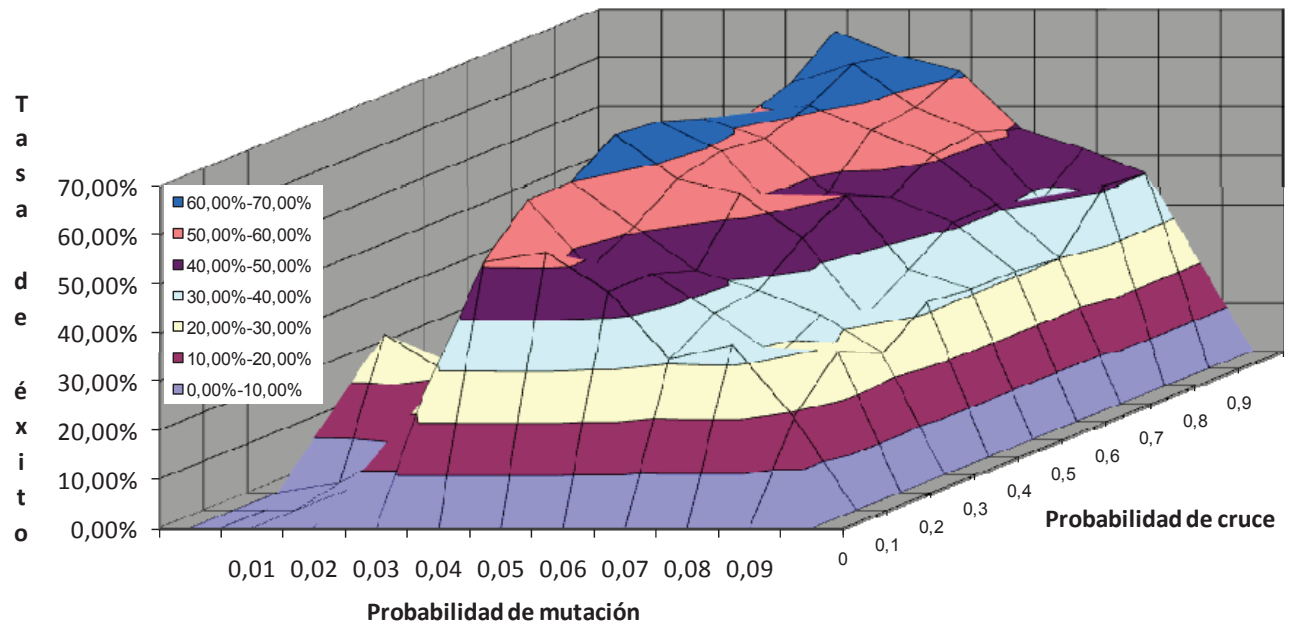
Figura 5.6. Probabilidad de obtener una buena solución de diseño respecto a las
probabilidades cruce y mutación

La consideración del concepto de "buena solución" permite apreciar lo robusta que es la metodología de optimización con APG, puesto que todas las combinaciones de parámetros simuladas permiten la obtención de un alto porcentaje de buenas soluciones. Más concretamente, sobre un total de 8100 simulaciones realizadas sin análisis previo de parámetros se obtuvo alrededor de un $40 \%$ de buenas soluciones.

Si se considera tan sólo la combinación óptima de parámetros que resulta de realizar el análisis estadístico $\left(P_{m}=0,04 \div 0,05, P_{c}=0,9\right)$ el porcentaje de "buenas soluciones" crece hasta un $65 \%$ de las simulaciones realizadas.

\subsubsection{Red R-9 de Joao Pessoa}

La red R-9 de Joao Pessoa tiene una serie de características de particular interés que la diferencian del resto de problemas de optimización analizados en este trabajo. Así, la red R-9 es la que tiene un mayor tamaño de todas las redes ensayadas, por lo que el número de posibles combinaciones a la hora de escoger una solución es mucho mayor. Esta situación 
provoca que el número de mínimos locales en el espacio de soluciones sea más grande, por lo que obtener repetibilidad en la solución de coste mínimo resulta muy complicado.

Para el problema de diseño planteado, la gama de diámetros utilizada consta de 10 diámetros distintos, que abarca desde los 100 hasta los 600 mm. La red R-9 de Joao Pessoa tiene un total de 72 tuberías, por lo que el número de combinaciones distintas es de $10^{72}$. Esta situación provoca que el planteamiento del análisis de resultados en esta red sea algo diferente, puesto que en lugar de analizar la probabilidad de obtener una solución óptima, se va a analizar tan sólo la probabilidad de obtener buenas soluciones.

El histograma muestra las 16200 simulaciones realizadas con una población para el algoritmo de 100 individuos, donde el objetivo es el estudio acerca de la influencia de las probabilidades de cruce y mutación.

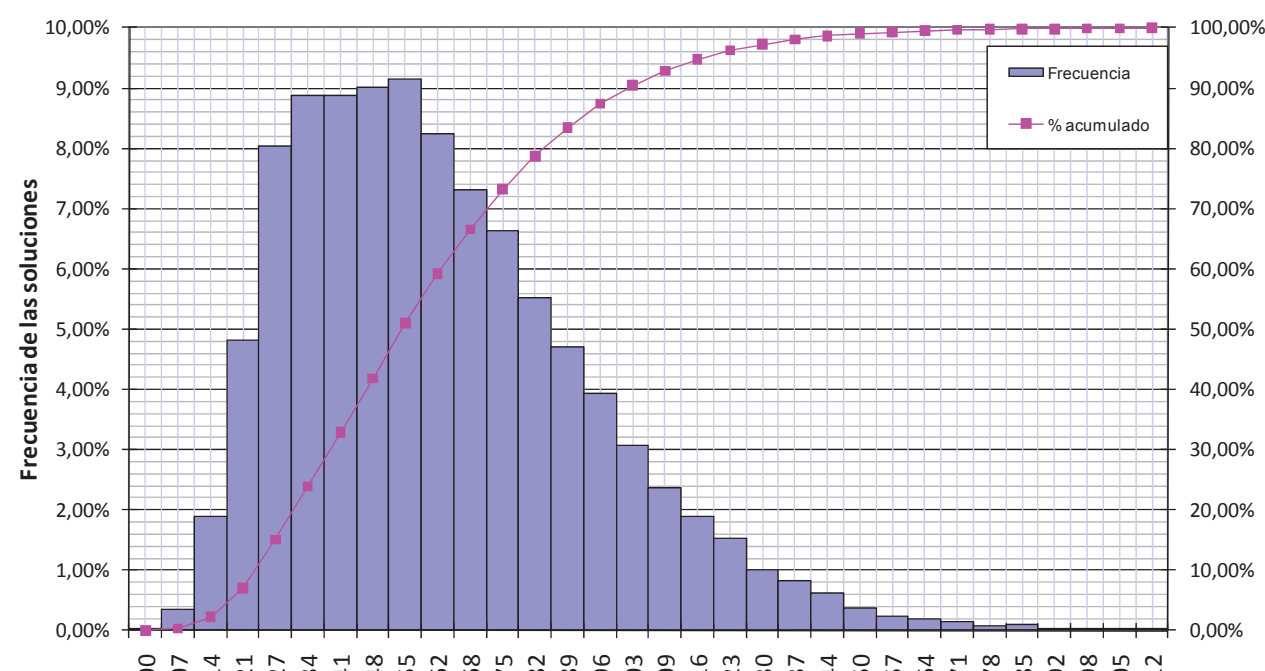

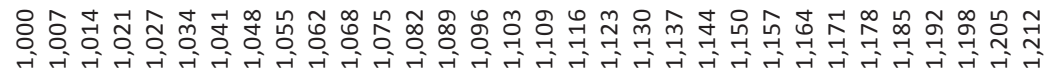

Sobrecoste respecto del mínimo (192,366 millones um)

Figura 5.7. Histograma de soluciones obtenidas mediante APG para la red $R-9$ de Joao Pessoa.

El análisis del histograma confirma las premisas que se tenían establecidas antes de realizar el análisis estadístico. Así, el valor mínimo de diseño para la red es de 192,366 millones de um, pero dicho valor no tiene repetibilidad; es decir, de un total de 16200 simulaciones, este valor tan sólo se ha obtenido una vez. Sin embargo, esto no quiere decir que el APG funcione mal en redes más grandes, sino que la propia complejidad de la red dificulta encontrar el óptimo de la red para cualquier metodología. En este sentido, los resultados obtenidos por otras metodologías basadas en programación dinámica dan un coste aproximado de 205 millones 
de um, mientras que APG consigue reducir ese valor en un $60 \%$ de las ocasiones sin realizar ningún tipo de optimización previa.

En el caso concreto de la red R-9 se realizan dos análisis de "buena solución". Por un lado, y con el objetivo de aproximar el análisis estadístico a lo que sería un análisis de soluciones mínimas se realiza un análisis para buenas soluciones que no superen en más de un $1 \%$ el óptimo de la red. Tras este primer análisis se realiza un segundo basado en el concepto de buena solución que ha considerado este trabajo en el resto de apartados, es decir, soluciones que superan el mínimo coste de la red en un 3\% como máximo.

Así, adoptando como valor óptimo de diseño 192,366 millones de um, la siguiente figura muestra la probabilidad de obtener una buena solución no superior en más de un $1 \%$ al óptimo de la red para cada probabilidad de cruce y mutación. De este modo, el coste límite de instalación para entrar en la definición de buena solución (1\%) es de 194,289 millones de um.

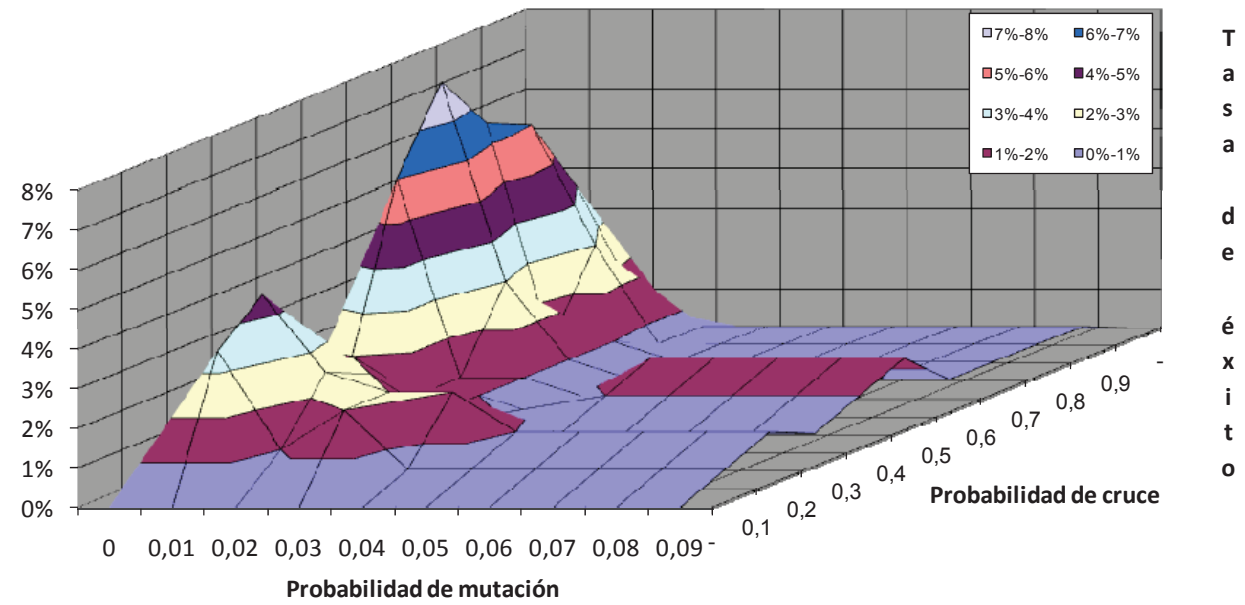

Figura 5.8. Probabilidad de obtener una buena solución (1\%) de diseño respecto a las probabilidades de cruce y mutación

La figura tiene una forma similar a la obtenida en el estudio de mínimos para la red de Hanoi, aunque en este caso la probabilidad de mutación más adecuada está en torno al $1 \%$. De acuerdo con los resultados que se obtienen en el resto de redes, parece claro que probabilidades bajas de mutación permiten obtener soluciones de menor coste.

Respecto a la probabilidad de cruce, el gráfico muestra un pico evidente en torno al $50-60 \%$, en contraste con los resultados vistos en el resto de redes, donde la diferencia con respecto a la probabilidad de cruce no tiene picos tan marcados. Si ampliamos el concepto de buena solución hasta un $3 \%$ de coste adicional respecto al mínimo obtenido y se representa de 
nuevo la probabilidad de obtener buenas soluciones en función de los parámetros de cruce y mutación se obtiene la siguiente figura:

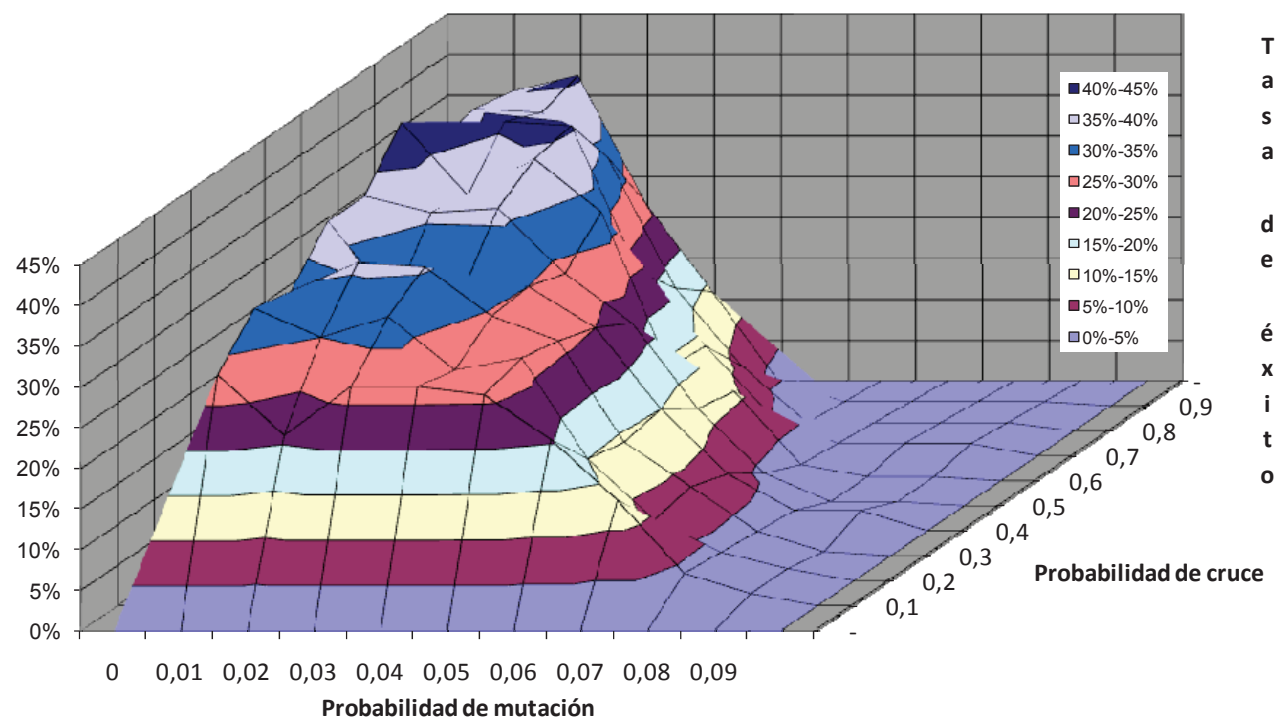

Figura 5.9. Probabilidad de obtener una buena solución (3\%) respecto a las probabilidades de cruce y mutación.

Cuando se amplía el concepto de buena solución hasta un 3\%, la diferencia de resultados obtenidos entre las distintas probabilidades de cruce se minimiza, cumpliéndose de nuevo el patrón que sigue APG en el resto de redes, donde la probabilidad de cruce en el rango estudiado no es determinante para encontrar buenas soluciones.

El nuevo límite establecido para entrar dentro de la definición de buena solución (3\%) es de 198,137 millones de um. Al considerar este límite, la probabilidad de éxito se multiplica por 5 en las mejores zonas, lo que confirma la capacidad del algoritmo para no sólo encontrar mínimos absolutos, sino para encontrar muchas otras soluciones alrededor de ese mínimo absoluto.

Concretamente, el ampliar el concepto de buena solución permite aumentar el porcentaje de éxito hasta cifras cercanas al $35 \%$ en la zona de mutación más baja. Del mismo modo, cuanto mayor es el límite de la buena solución menos restrictivo es el rango de los parámetros de cálculo para el buen funcionamiento del APG. Así, se puede observar en la figura 5.9 como probabilidades de mutación de hasta un $5 \%$ son capaces de proporcionar buenas soluciones en un $20 \%$ de sus ejecuciones.

Para finalizar, cabe destacar el hecho de que en zonas de mutación superiores al 7\%, el APG se ve prácticamente incapaz de alcanzar buenas soluciones de diseño. Este resultado va en 
concordancia con lo visto en el análisis de otras redes, pero mucho más evidente en este caso, probablemente debido a la propia complejidad de la red.

\subsubsection{Red de Go-Yang}

El problema de diseño en Go-Yang trata de encontrar el dimensionamiento más económico para la red teniendo en cuenta que todos los nudos deben estar por encima de los $30 \mathrm{mca}$ de presión, garantizando así el correcto funcionamiento de la red.

El estudio de los parámetros genéticos para la red de Go-Yang se realiza de idéntico modo al resto de las redes (ver tabla 5.1), variando las probabilidades de cruce y mutación y manteniendo constante la población del algoritmo (100 individuos). El objetivo es confirmar las directrices obtenidas en el resto de las redes, de cara a sacar conclusiones para el problema general de diseño de redes de agua. Se representa en primer lugar el histograma completo de soluciones, así como el gráfico de probabilidad acumulada (figura 5.10).

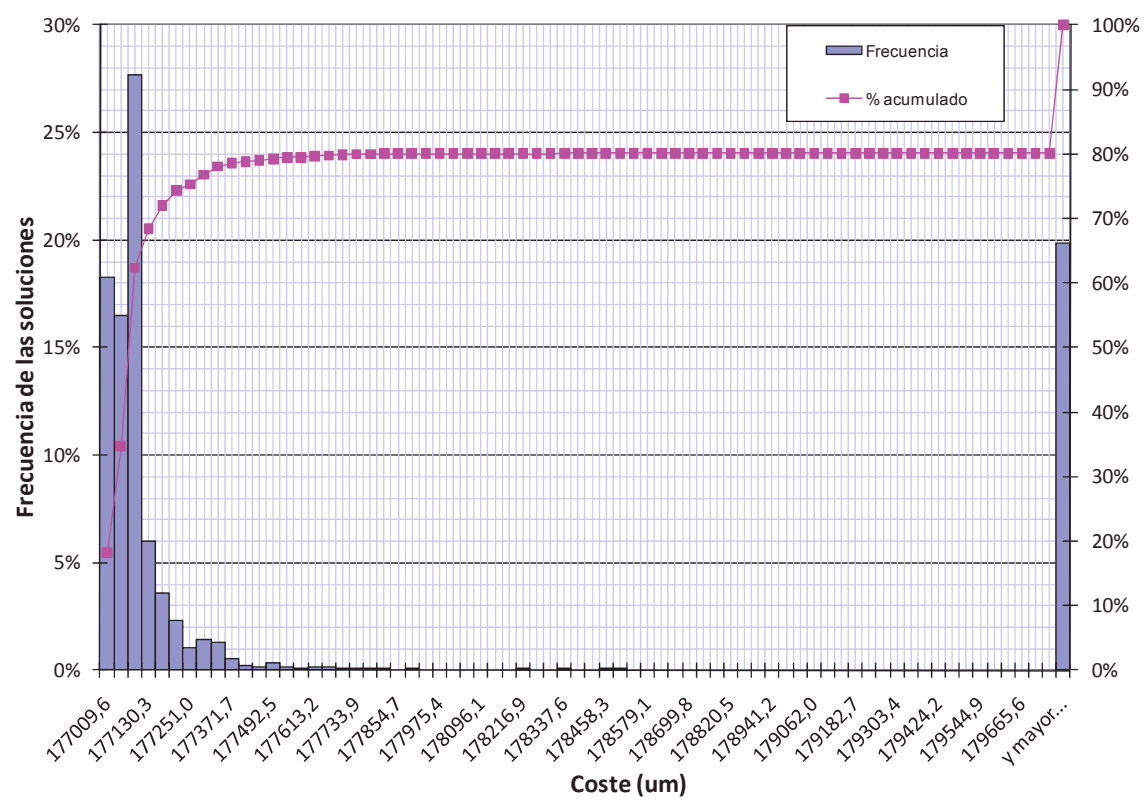

Figura 5.10. Histograma de soluciones obtenidas mediante APG para la red de Go-Yang.

La principal conclusión que se puede sacar del histograma es que la solución de mínimo coste se obtiene con relativa facilidad, puesto que un $18 \%$ de las simulaciones realizadas consigue la solución de diseño de 177.009,6 um, correspondiente al valor mínimo absoluto conseguido en esta red. Se da el caso además que prácticamente un $60 \%$ más de las simulaciones restantes se encuentra en los alrededores de ese óptimo, con menos de un $1 \%$ de diferencia respecto al óptimo de diseño. 
La explicación a esto radica en el hecho de que la red de Go-Yang, pese a tener un tamaño similar a otros problemas de mayor complejidad como podría ser la red de Hanoi, no plantea grandes dificultades de diseño para el APG.

El estudio de los parámetros de cálculo de APG permite encontrar las mejores combinaciones para las probabilidades de cruce y mutación. La figura 5.11 muestra la probabilidad de obtener la solución de mínimo coste según las probabilidades de cruce y mutación para una población constante de 100 individuos.

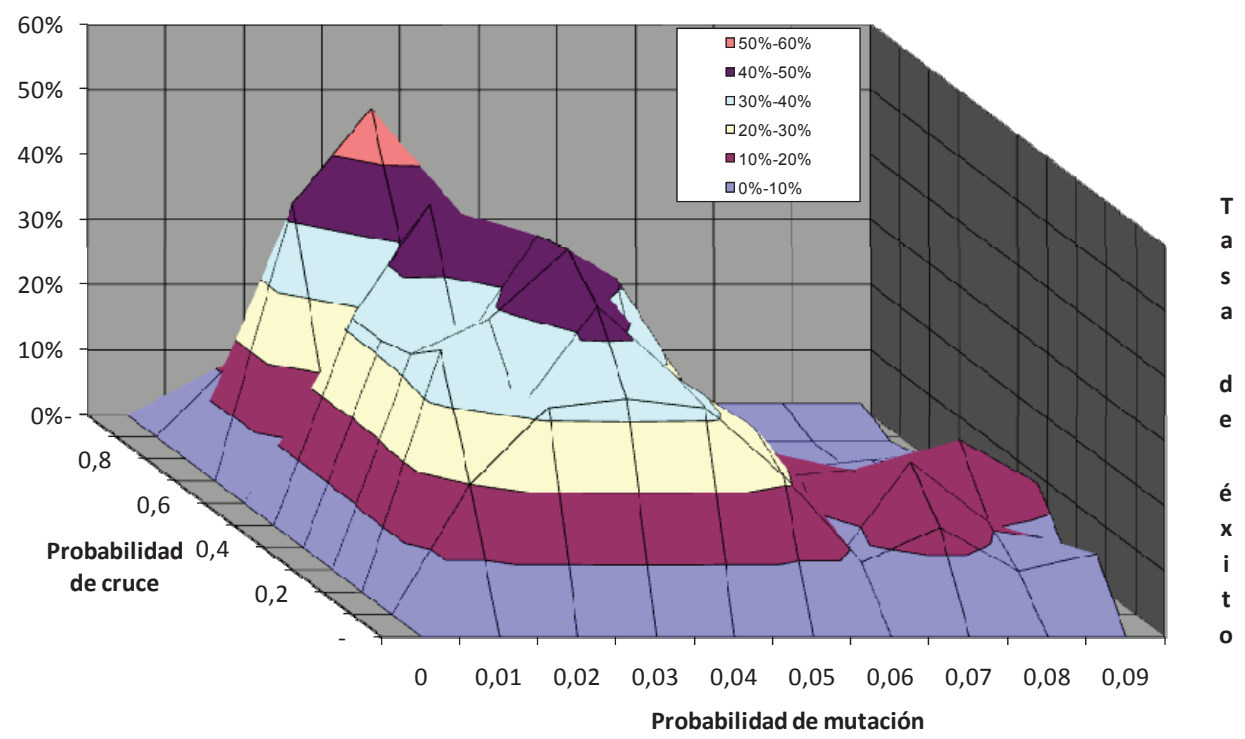

\section{Figura 5.11. Probabilidad de obtener solución mínima solución de diseño según probabilidades de cruce y mutación}

La figura muestra como el funcionamiento del APG sigue el mismo patrón obtenido en el resto de redes, es decir, las probabilidades de mutación más bajas son las que mejores resultados proporcionan. En este caso, la probabilidad de mutación se encuentra entre el 2 y el $3 \%$, donde estos valores, combinados con probabilidades de cruce menores del $70 \%$ tienen prácticamente un $50 \%$ de posibilidades de encontrar la solución de mínimo coste para la red de Go-Yang. Es importante destacar este punto, puesto que implica que una de cada dos simulaciones del problema va a ser capaz de proporcionar el óptimo de la red.

Respecto a la probabilidad de cruce, en las redes de Hanoi, Nueva York y Joao Pessoa destaca el hecho de que desde un punto de vista cuantitativo la probabilidad de cruce ejerce una menor influencia en el funcionamiento del algoritmo que la probabilidad de mutación. En el caso de la red de Go-Yang se repite esta misma situación, y al menos desde un punto de vista 
cuantitativo, la probabilidad de cruce no parece representar una decisión crítica de cara a obtener mejores resultados en la simulación.

Es posible ampliar el análisis a la obtención de buenas soluciones, considerando como buena solución las que no superan en más de un 3\% la solución de mínimo coste. En la red de GoYang el límite de buenas soluciones quedaría establecido en 182.319 um. En este caso, el $100 \%$ de las simulaciones realizadas entran dentro del límite de buenas soluciones.

\subsubsection{Ajuste de parámetros Algoritmo PSO modificado}

El algoritmo PSO aplicado al diseño de redes de agua presenta diferencias respecto del algoritmo PSO original. La más significativa de todas ellas es la utilización de un nuevo parámetro de cálculo, al que se denomina "probabilidad de despiste", y cuyo objetivo es aumentar la diversidad de las soluciones, evitando la caída en mínimos locales con demasiada premura.

Esta probabilidad de despiste $\left(\mathrm{P}_{\text {desp }}\right)$ será uno de los parámetros clave a optimizar, junto al resto de parámetros clásicos que entran dentro de la definición original de PSO, cómo son el límite de velocidad de vuelo para una determinada partícula y el valor de las constantes $C_{1}$ y $\mathrm{C}_{2}$.

El valor del factor de inercia se considera como una función decreciente, que parte desde un valor cercano a 1 para ir bajando progresivamente con el número de iteraciones realizadas hasta valores próximos a 0,5. El objetivo de este tipo de función es otorgar mayor importancia a la búsqueda global en las primeras iteraciones para centrar la búsqueda en zonas más locales al final del proceso de optimización.

De similar modo al resto de técnicas heurísticas, el número de individuos que componen la población del algoritmo es otro parámetro de particular interés en cuanto al buen desempeño del algoritmo. El proceso de optimización correspondiente se trata como caso aparte en el apartado 5.3, junto con el análisis de población del resto de métodos heurísticos. Así, en el diseño de todas las redes de agua que se muestran a continuación se considera el tamaño de población constante e igual a 100 individuos.

Con el resto de parámetros que componen el algoritmo PSO se realizan multitud de simulaciones alternando los valores de cada uno de ellos, de modo que al final se obtiene una muestra de simulaciones suficientemente grande que permite evaluar cuales son las combinaciones más óptimas desde el punto de vista de obtención de la mejor solución.

En el caso de las constantes $C_{1}$ y $C_{2}$, la mayoría de los investigadores aconsejan valores en torno a 1,8 y 2 . No obstante, en las simulaciones realizadas en este trabajo se ha ampliado este campo de aplicación, con el objetivo de confirmar o desmentir estos valores como óptimos de cálculo. 
Por último, la probabilidad de despiste $\left(\mathrm{P}_{\text {desp }}\right)$, que indica el porcentaje de pájaros que se aleja del aprendizaje social de la bandada, varía entre un 10 y un $40 \%$ del total de la población. Este parámetro representa la principal diferencia entre la formulación original de PSO y el algoritmo que presenta este trabajo. La siguiente tabla resume el intervalo de aplicación de cada uno de los parámetros nombrados anteriormente

\begin{tabular}{|c|c|c|}
\hline \multicolumn{2}{|c|}{ PARÁMETROS } & RANGO DE VALORES \\
\hline Límite de velocidad & $\mathrm{V}_{\text {lim }}$ & $10-20-30-40(\%)$ \\
\hline Probabilidad de despiste & $\mathrm{P}_{\text {desp }}$ & $10-20-30-40(\%)$ \\
\hline Constante & $\mathrm{C}_{1}$ & $1,4-1,6-1,8-2$ \\
\hline Constante & $\mathrm{C}_{2}$ & $1,4-1,6-1,8-2$ \\
\hline
\end{tabular}

Tabla 5.3. Rango de estudio de parámetros para PSO modificado.

\subsubsection{Red de Hanoi}

Para el diseño de la red de Hanoi con el algoritmo PSO modificado se han realizado 25600 simulaciones, de modo que cada posible combinación de parámetros se repite 400 veces, a fin de tener una muestra suficientemente representativa que permita tomar conclusiones.

El histograma de soluciones muestra la totalidad de soluciones obtenidas. En este caso se muestran dos histogramas. El primero de ellos corresponde a una serie de simulaciones realizadas con el algoritmo PSO original aplicado al estudio de variables discretas. Esta experiencia previa con el algoritmo PSO original consta de 10000 simulaciones, donde no se aplica el parámetro de la probabilidad de despiste, por ser éste de formulación propia.

La figura 5.12 muestra el histograma de soluciones obtenido con el algoritmo PSO original, que presenta una forma similar a una campana de Gauss. En las simulaciones realizadas no se ha obtenido en ningún caso el valor de coste mínimo de 6,081 millones de um, siendo la mejor solución obtenida para el problema de diseño de la red de Hanoi de 6,153 millones de um. El histograma se ha representado en base al sobrecoste que tienen las soluciones obtenidas respecto a la mejor solución obtenida en todos los métodos. 


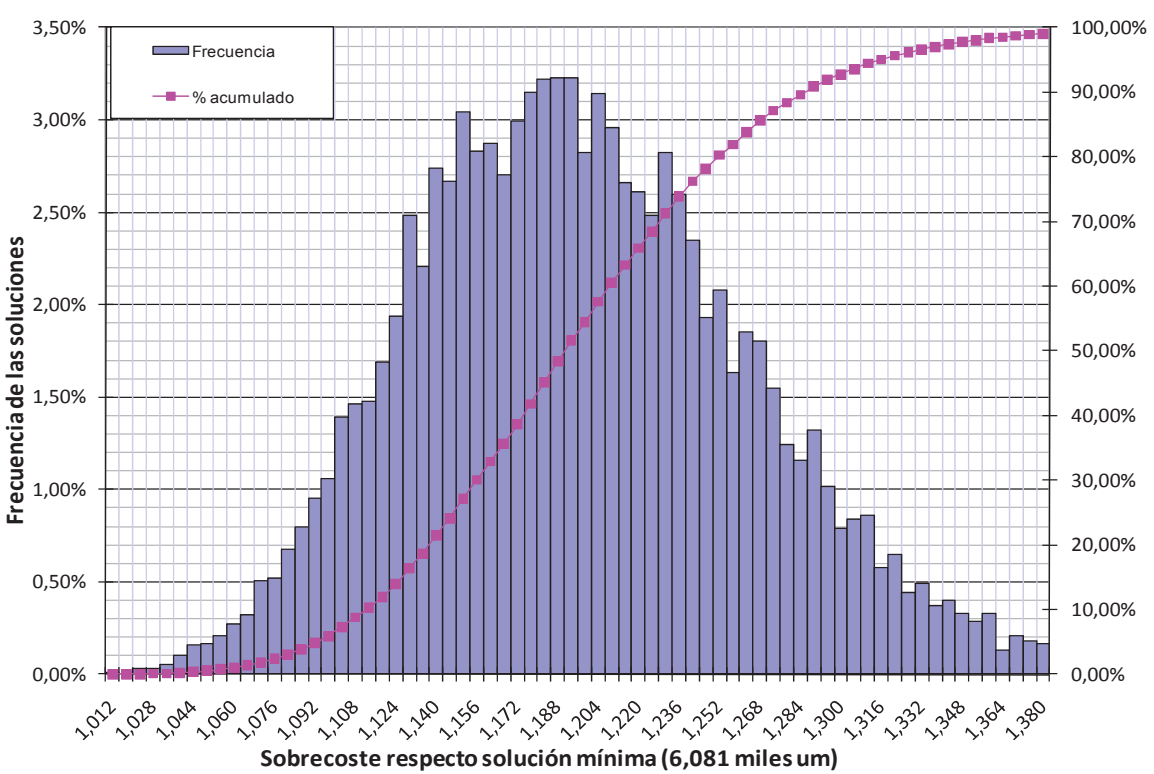

Figura 5.12. Histograma de soluciones para la red de Hanoi aplicando algoritmo PSO original.

Por otro lado, el histograma de la figura 5.13 corresponde al estudio realizado con el algoritmo PSO modificado, de modo que las simulaciones mostradas contemplan el parámetro de la probabilidad de despiste.

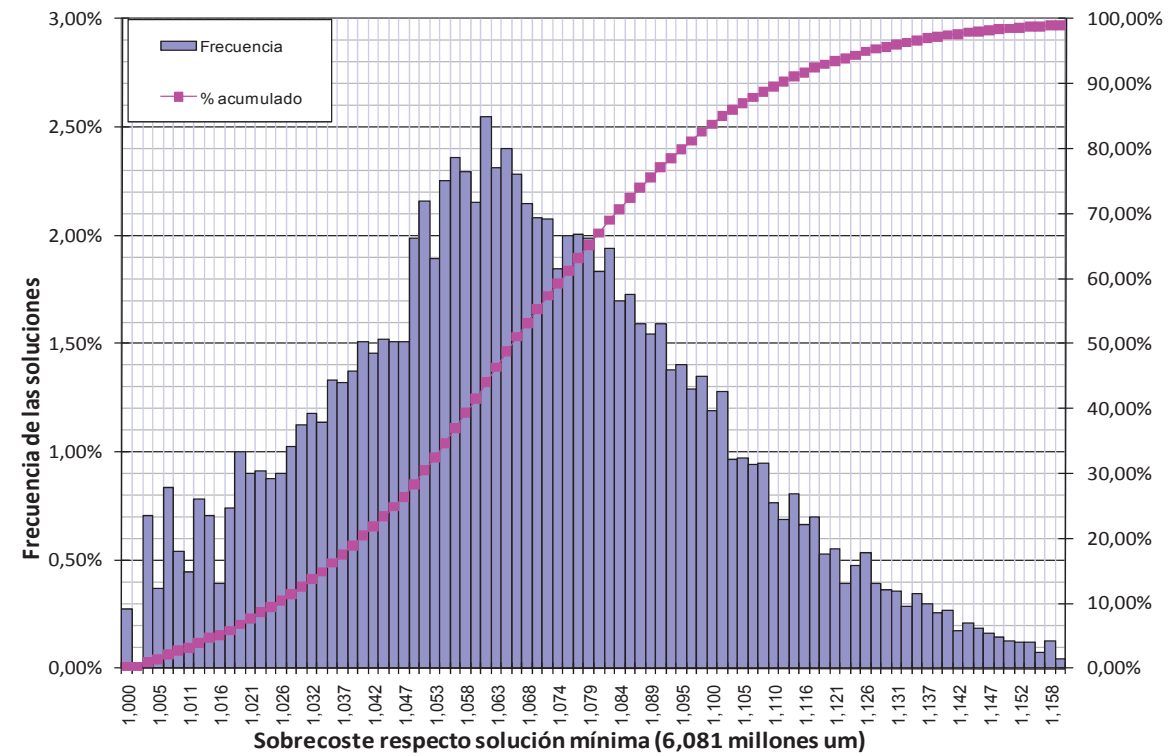

Figura 5.13. Histograma de soluciones para la red de Hanoi aplicando algoritmo PSO modificado. 
En este caso, la mejor solución de diseño obtenida para el conjunto de simulaciones realizadas coincide con la mínima solución obtenida en todos los métodos, es decir, 6,081 miles de um. Así, el nuevo parámetro introducido (probabilidad de despiste) mejora el desempeño general del algoritmo, puesto que no tan sólo consigue mejorar la solución mínima obtenida, sino que el coste medio obtenido por el resto de simulaciones es sensiblemente inferior respecto a la formulación original de PSO.

Así, en las soluciones obtenidas con el algoritmo PSO original, tan sólo un $0,12 \%$ del total de simulaciones realizadas entrarían dentro de lo que se ha considerado una buena solución de diseño ( $3 \%$ sobre el mínimo coste), mientras que el algoritmo PSO modificado eleva la cifra de buenas soluciones hasta un 14,88\%, que si bien sigue estando lejos de otras técnicas heurísticas sí que mejora considerablemente los resultados obtenidos por la formulación original. Si se alarga el margen hasta un sobrecoste del $10 \%$ respecto de la solución de mínimo coste (6,689 millones de um) el algoritmo PSO original apenas presenta un $5 \%$ de simulaciones dentro de este margen, mientras que el algoritmo PSO modificado con el parámetro de despiste obtiene un $80 \%$ de las simulaciones dentro de este rango.

La diferencia de resultados entre ambos algoritmos PSO es evidente y se produce, principalmente, porque la introducción del parámetro de despiste evita convergencias demasiado tempranas del algoritmo. El introducir este nuevo parámetro permite prolongar la búsqueda por otras zonas del espacio de soluciones, puesto que en cada iteración un porcentaje del total de pájaros "olvidan" su aprendizaje social y propio para irse a otras zonas del espacio de soluciones de un modo aleatorio.

El análisis estadístico de soluciones se realiza tan sólo para el algoritmo PSO modificado. La solución que se adopta como valor óptimo de diseño es la que corresponde a un coste para la red de 6,081 millones de um. Para determinar la influencia que tienen los distintos parámetros de cálculo se procede de igual manera que en el resto de métodos, aunque en este caso particular se obvia el análisis estadístico de mínimos, puesto que el algoritmo PSO no se muestra especialmente efectivo obteniendo el valor óptimo de diseño en la red de Hanoi. Así, dicho valor óptimo se obtiene tan sólo en un $1 \%$ del total de simulaciones realizadas, por lo que es conveniente centrar el esfuerzo en el análisis estadístico de buenas soluciones.

De igual manera que en anteriores análisis, el concepto de buena solución para la red de Hanoi viene dado por todo valor de diseño inferior a 6,263 millones de um, que corresponde a una solución de diseño un 3\% más cara que la mínima absoluta. Considerando este valor, las siguientes figuras tratan de analizar la probabilidad de obtener una buena solución para cada posible combinación de los distintos parámetros de cálculo del algoritmo PSO modificado. 
El primer parámetro de interés en la heurística PSO es la máxima velocidad a la que puede moverse un pájaro en cada iteración del algoritmo. La limitación de este parámetro es necesaria, puesto que evita que los pájaros se muevan demasiado deprisa hacia los extremos del espacio de soluciones, provocando así una convergencia demasiado temprana del algoritmo. En terminología PSO aplicada al diseño de redes de agua, la velocidad máxima tiene relación con el máximo salto que puede dar un individuo dentro de la gama de diámetros entre dos iteraciones. Las figuras 5.14 y 5.15 representan la probabilidad de obtener una buena solución en función de la velocidad máxima y las constantes $C_{1}$ y $C_{2}$. La bibliografía recomienda para dichas constantes valores cercanos a 2 . En el estudio de parámetros se han incluido las constantes $C_{1}$ y $C_{2}$ para cerciorar que efectivamente estas recomendaciones son adecuadas.

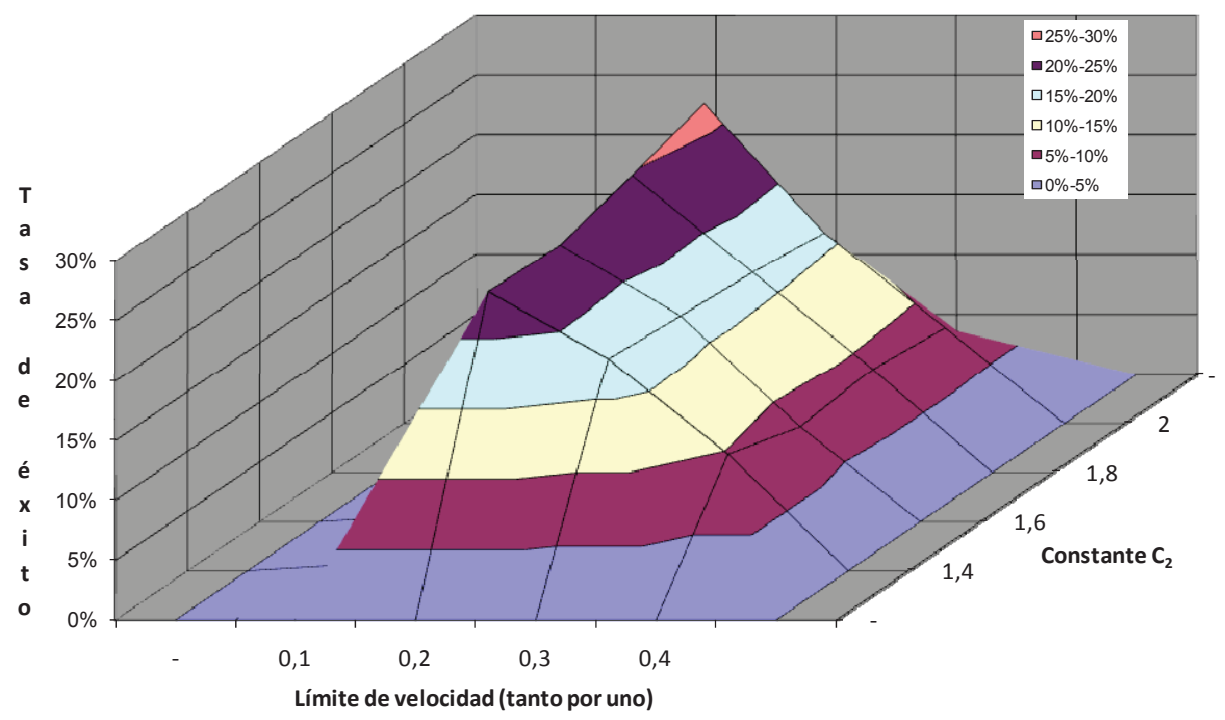

Figura 5.14. Probabilidad de obtener una buena solución según límite de velocidad y constante $C_{2}$ para la red de Hanoi 


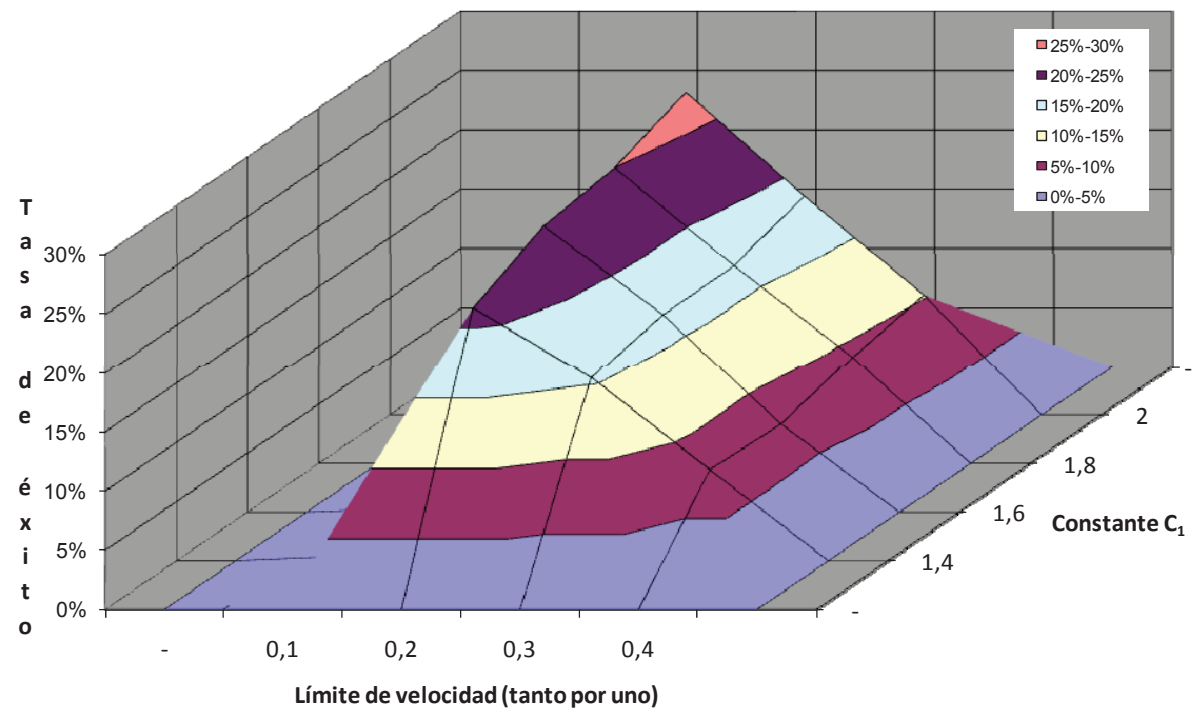

Figura 5.15. Probabilidad de obtener una buena solución según límite de velocidad y constante $C_{1}$ para la red de Hanoi

La constante $\mathrm{C}_{1}$ está relacionada con el desplazamiento de la partícula dentro de su propia memoria, mientras que $C_{2}$ tiene que ver con el desplazamiento en relación al resto de partículas; es decir, $C_{1}$ tiene relación con la búsqueda local que ejerce el algoritmo mientras que $C_{2}$ es participe de la búsqueda global de la partícula en el espacio de soluciones. Ambas figuras son prácticamente idénticas, por lo que en este caso no se puede decir que ninguna de ellas ejerza una influencia mayor que la otra en el desempeño del algoritmo. Además, dentro del rango estudiado, ambas constantes confirman los valores recomendados en la bibliografía, puesto que el pico en ambos casos se obtiene para un valor de la constante igual a 2 .

En el caso de la velocidad máxima de la partícula, ambas figuras muestran claramente como limitar la velocidad de la partícula a un $20 \%$ del rango de la variable es lo más adecuado. Esta limitación implica que entre iteración e iteración, un determinado conducto no podrá cambiar el valor de su diámetro en más de un $20 \%$ del total de variables (diámetros) disponibles.

Con estas condiciones, el algoritmo PSO consigue alrededor de un $25 \%$ de buenas soluciones. Si la velocidad máxima se limita por debajo del $20 \%$ el algoritmo se prácticamente incapaz de encontrar buenas soluciones, mientras que si se utiliza una limitación de velocidad por encima de este $20 \%$ el algoritmo pierde efectividad de manera progresiva.

La principal diferencia entre la formulación original del algoritmo PSO y la utilizada en esta tesis es el parámetro de cálculo bautizado como "probabilidad de despiste". La siguiente 
figura relaciona la probabilidad de obtener una buena solución con el límite de velocidad y la probabilidad de despiste.

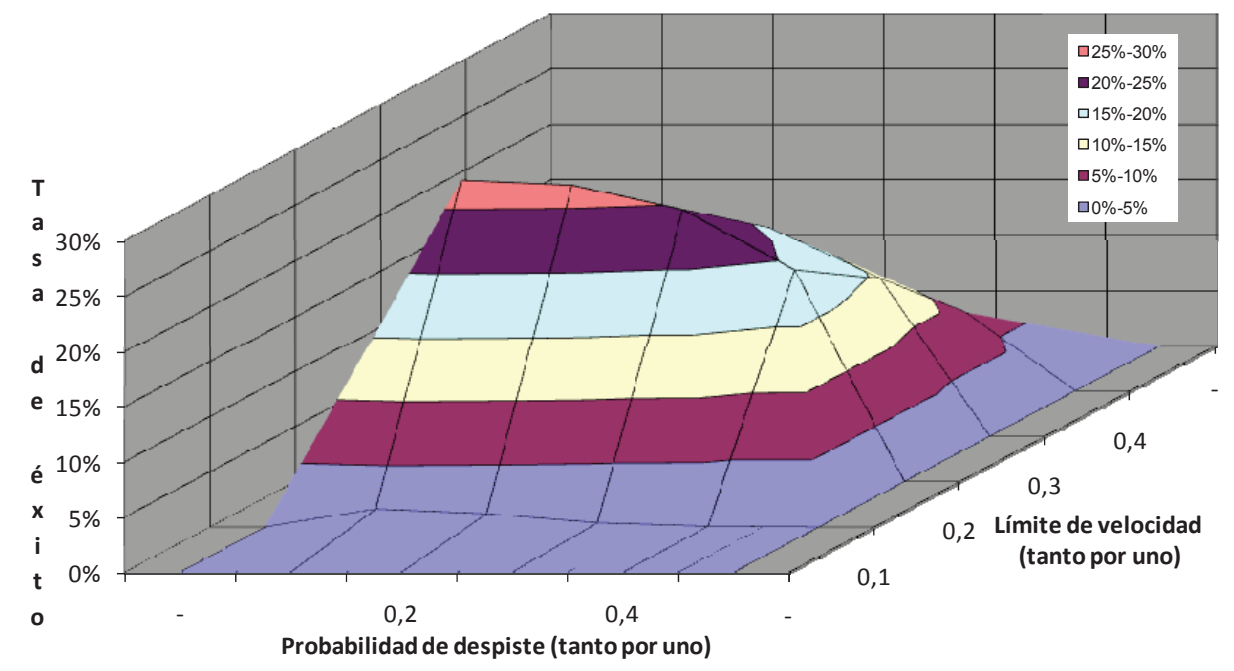

Figura 5.16. Probabilidad de obtener una buena solución según Límite de velocidad y Probabilidad de despiste para la red de Hanoi

La optimización del límite de velocidad es muy clara y sigue la misma tendencia que en el resto de gráficos, siendo una limitación del $20 \%$ la óptima en este parámetro. Por otro lado, si se tienen en cuenta los valores de la probabilidad de despiste, parece claro que $P_{\text {desp }}$ entre el 10 y el $20 \%$ son las que mejor funcionan. Valores superiores no mejoran los resultados, sino que empeoran paulatinamente. Esto es lógico, puesto que $\mathrm{P}_{\text {desp }}$ introduce un factor aleatorio necesario para crear diversidad, pero conforme dicho factor aumenta también lo hace la parte aleatoria del algoritmo. Por ejemplo, una $\mathrm{P}_{\text {desp }}$ del $90 \%$ implica que sólo un $10 \%$ de la bandada perseguiría al líder, mientras que los restantes individuos irían a posiciones aleatorias del espacio de soluciones. Obviamente, esta situación no es aconsejable, siendo $P_{\text {desp }}$ entre el 10 y el $20 \%$ las más adecuadas para el diseño de la red de Hanoi, tal como se puede apreciar en la figura 5.16.

También es interesante estudiar la influencia en los resultados cuando se relaciona $\mathrm{P}_{\text {desp }}$ con las constantes $C_{1}$ y $C_{2}$. Las figuras 5.17 y 5.18 muestran la probabilidad de encontrar una buena solución en función de estos parámetros. Cabe destacar que estas figuras contienen todo el barrido de simulaciones realizadas con el algoritmo PSO modificado, aunque sólo se representen los parámetros de interés en cada caso. 


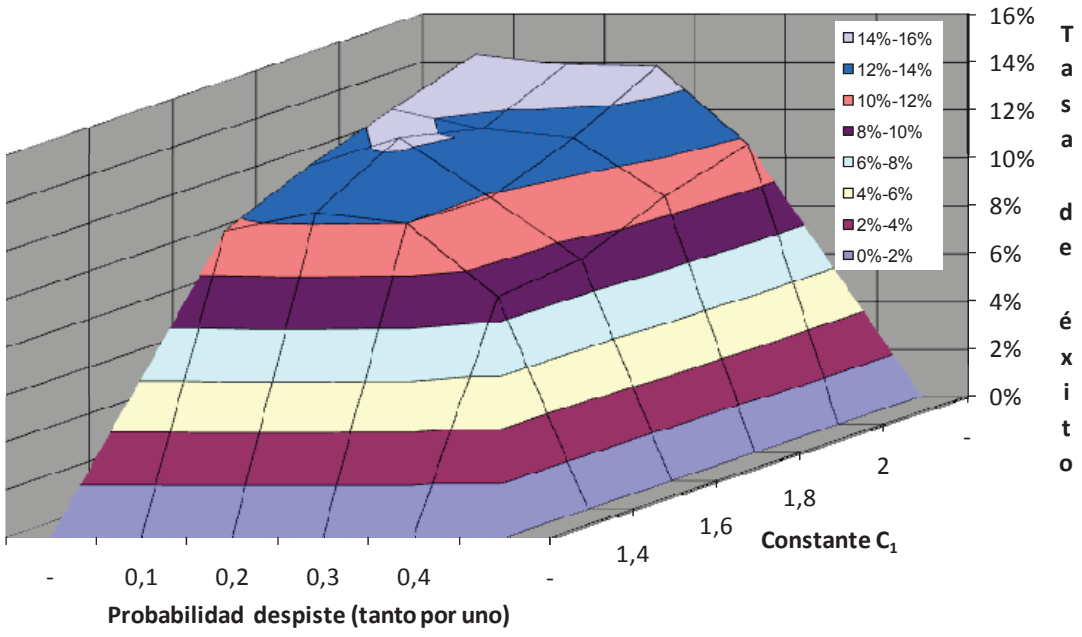

Figura 5.17. Probabilidad de obtener una buena solución según la probabilidad de despiste y $C_{1}$.

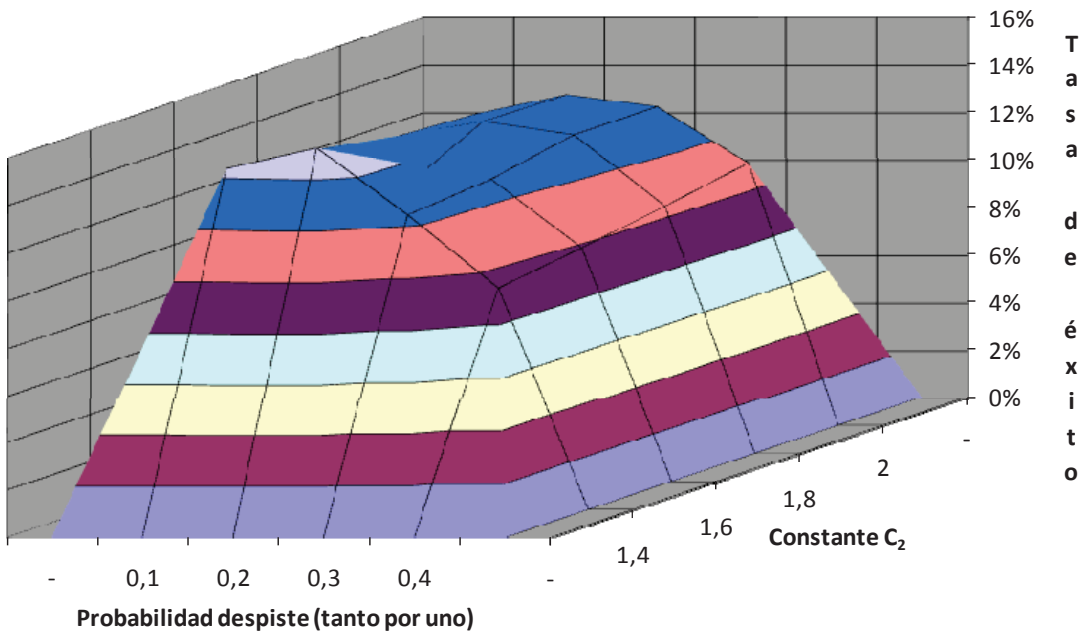

Figura 5.18. Probabilidad de obtener una buena solución según la probabilidad de despiste

$$
\text { y } C_{2} \text {. }
$$

La representación de los datos no muestra en esta red diferencias tan grandes como en figuras anteriores, puesto que la influencia que ejercen $P_{\text {desp }}$ y las constantes no es tan crítica como la que ejerce la velocidad de vuelo de las partículas. No obstante, ambos gráficos confirman que probabilidades de despiste entre un 10 y un $20 \%$ consiguen mejores resultados, disminuyendo la efectividad del algoritmo conforme crece $P_{\text {desp. }}$.

Por su parte, la constante $\mathrm{C}_{2}$ obtiene mejores resultados cuando su valor es cercano a dos, pero la diferencia entre la mejor combinación $\left(C_{2}=2, P_{\text {desp }}=0,1\right)$ y la peor $\left(C_{2}=1,4, P_{\text {desp }}=0,4\right)$ es 
tan sólo de un 5,56\%. Algo similar ocurre con la representación de la constante $C_{2}$, donde la mejor combinación es $\left(C_{1}=1,4, P_{\text {desp }}=0,2\right)$, con un $15,25 \%$ de buenas soluciones obtenidas y la peor es $\left(C_{1}=1,4, P_{\text {desp }}=0,4\right)$ con un $9,38 \%$. La diferencia es de un $6 \%$. Estas diferencias resultan significativas, pero no tanto como se veía en el caso de la velocidad de vuelo, parámetro que resulta más crítico en este caso.

Se representa por último la probabilidad de obtener una buena solución en función de las constantes $\mathrm{C}_{1}$ y $\mathrm{C}_{2}$.

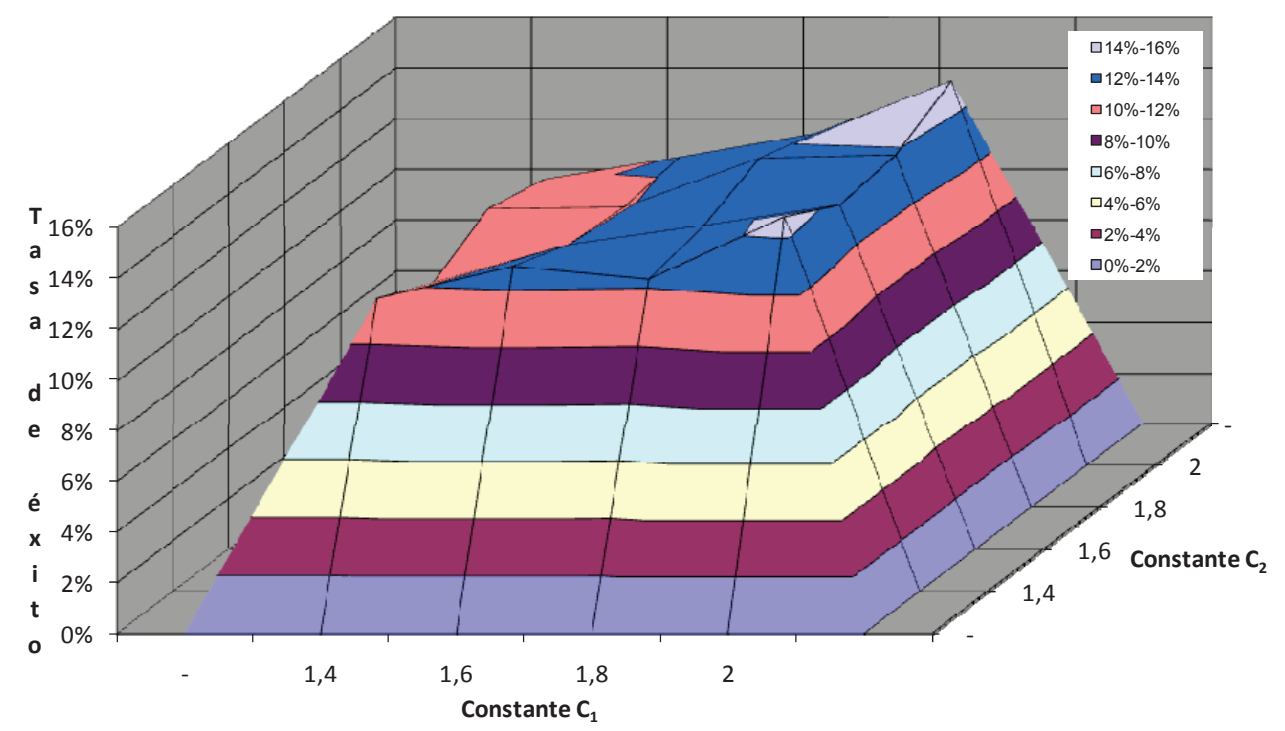

Figura 5.19. Probabilidad de obtener una buena solución según las constantes $C_{1}$ y $C_{2}$.

La figura muestra como la tendencia general de ambas constantes es de mejora valores cercanos a 2, si bien el algoritmo también es capaz de encontrar un número aceptable de buenas soluciones con valores inferiores.

A la vista de los resultados obtenidos se pueden tomar algunas conclusiones interesantes respecto del papel que juega la optimización de parámetros en este método. Así, el límite de velocidad con el que se mueven los pájaros en el espacio de soluciones representa, sin lugar a dudas, el parámetro más crítico de todos los que entran en juego en la configuración del algoritmo PSO, puesto que es el que mayor influencia tiene en la probabilidad de obtener o no una buena solución. Es tal la importancia de éste parámetro que una mala elección del mismo puede provocar la no obtención de buenas soluciones en el proceso, disminuyendo a prácticamente 0 la eficacia del algoritmo.

Del mismo modo, no hay que despreciar la función que ejerce la probabilidad de despiste en el buen desempeño del algoritmo. Así, los histogramas de las figuras 5.17 y 5.18 demuestran 
que la metodología PSO mejora ostensiblemente sus resultados cuando se utiliza este parámetro. En las figuras representadas se aprecia con claridad que $\mathrm{P}_{\text {desp }}$ óptima está entre un 10 y un $20 \%$, ya que valores superiores provocan un aumento excesivo en la aleatoriedad del cálculo, disminuyendo el número de buenas soluciones obtenidas.

Por último, como parámetros menos críticos en la configuración óptima de los parámetros se sitúan las constantes $C_{1}$ y $C_{2}$, puesto que si bien existen unas recomendaciones generales dadas por distintos autores acerca de la conveniencia de utilizar valores cercanos a 2 , los resultados obtenidos en la red de Hanoi no muestran a estos parámetros tan determinantes en la obtención de buenas soluciones.

\subsubsection{Red de Nueva York}

Las primeras conclusiones tomadas en la red de Hanoi acerca de los distintos parámetros deben confirmarse en el resto de redes, por lo que se realiza idéntico estudio en la red de los túneles de Nueva York. El rango de estudio para cada uno de los parámetros de la optimización PSO es el mismo que se muestra en la tabla 5.3.

El tamaño de población, que en este caso corresponde al número de individuos que entra en juego en cada optimización del algoritmo se considera constante e igual a 100. Del mismo modo, el factor de inercia $w$ en cada iteración se calcula con la misma función decreciente utilizada anteriormente.

El número de simulaciones realizadas en este caso fue de 25600, realizándose un total de 1600 repeticiones para cada una de las combinaciones realizadas. El histograma de soluciones obtenido es el siguiente:

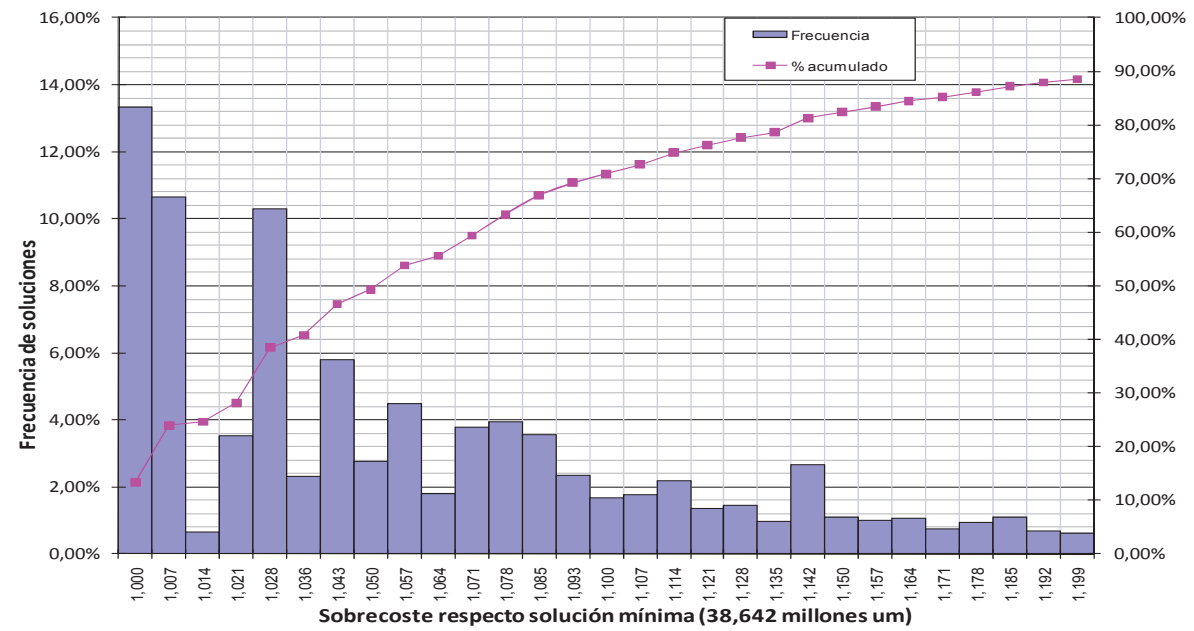

Figura 5.20. Histograma de soluciones obtenido para PSO modificado en la red de los túneles de Nueva York. 
La mejor solución de diseño obtenida tiene un coste de 38,642 millones de um, valor coincidente con la mejor solución obtenida con cualquiera de los restantes métodos. La mayor simplicidad de este problema de diseño frente a otros más complejos como Hanoi o R9 de Joao Pessoafacilita la obtención del mínimo absoluto de diseño en la red de Nueva York. El histograma de soluciones muestra como la solución de coste mínimo es la más repetida de todas, alcanzándose en un $13,35 \%$ de las simulaciones realizadas. Si se considera el concepto de buena solución hasta un 3\% adicional (39,801 millones de um) el porcentaje de éxito crece hasta prácticamente un $40 \%$ del total de simulaciones realizadas.

El análisis estadístico completa el estudio de diseño mediante PSO, proporcionando el mejor rango de cálculo para cada uno de los parámetros de optimización de la metodología. Así, de modo similar a como se procede en el resto de casos, las siguientes líneas analizan la probabilidad de encontrar la mínima/buena solución de diseño en función de los distintos parámetros de ajuste que tiene la metodología.

En la red de Hanoi, el parámetro más crítico de cuantos componen la optimización PSO resultó ser el límite de velocidad de vuelo entre iteraciones. Las figuras que se muestran a continuación muestran la probabilidad de obtener la mínima solución de diseño en función de $\mathrm{V}_{\lim } \mathrm{Y}$ las constantes $\mathrm{C}_{1}$ y $\mathrm{C}_{2}$ :

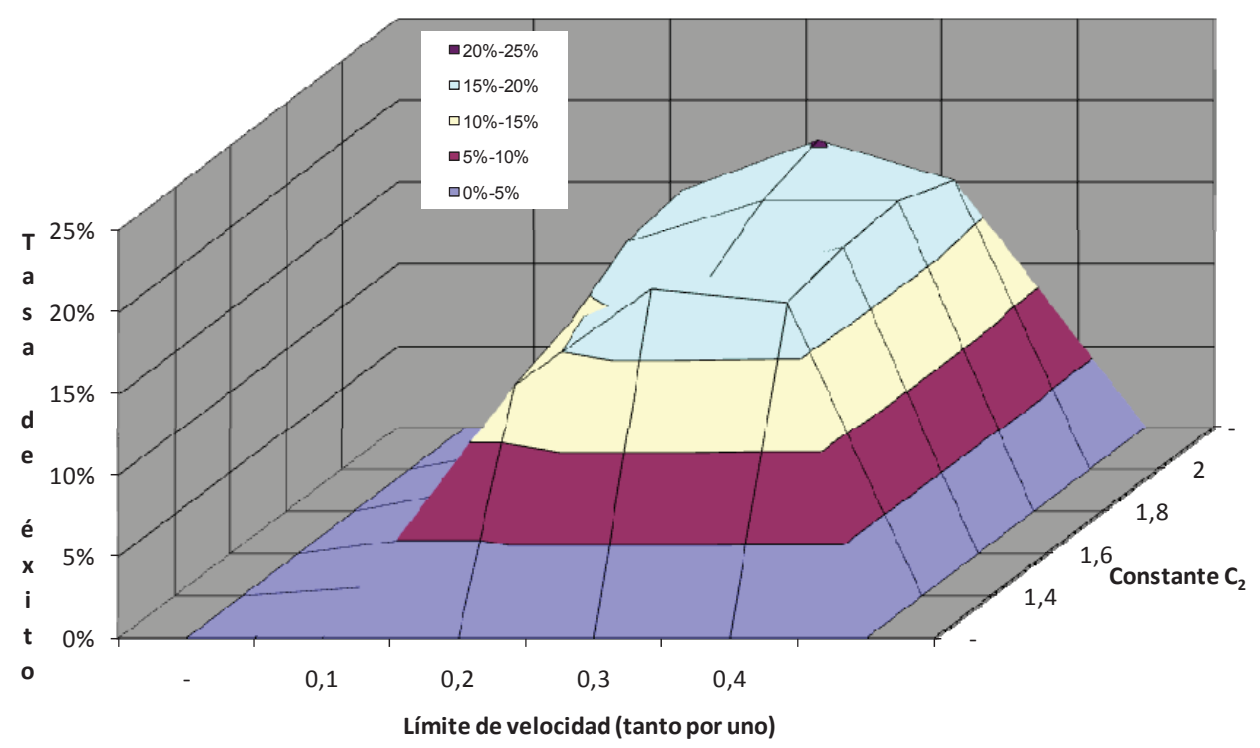

Figura 5.21. Probabilidad de obtener mínima solución según el límite de velocidad de vuelo y $C_{2}$. 


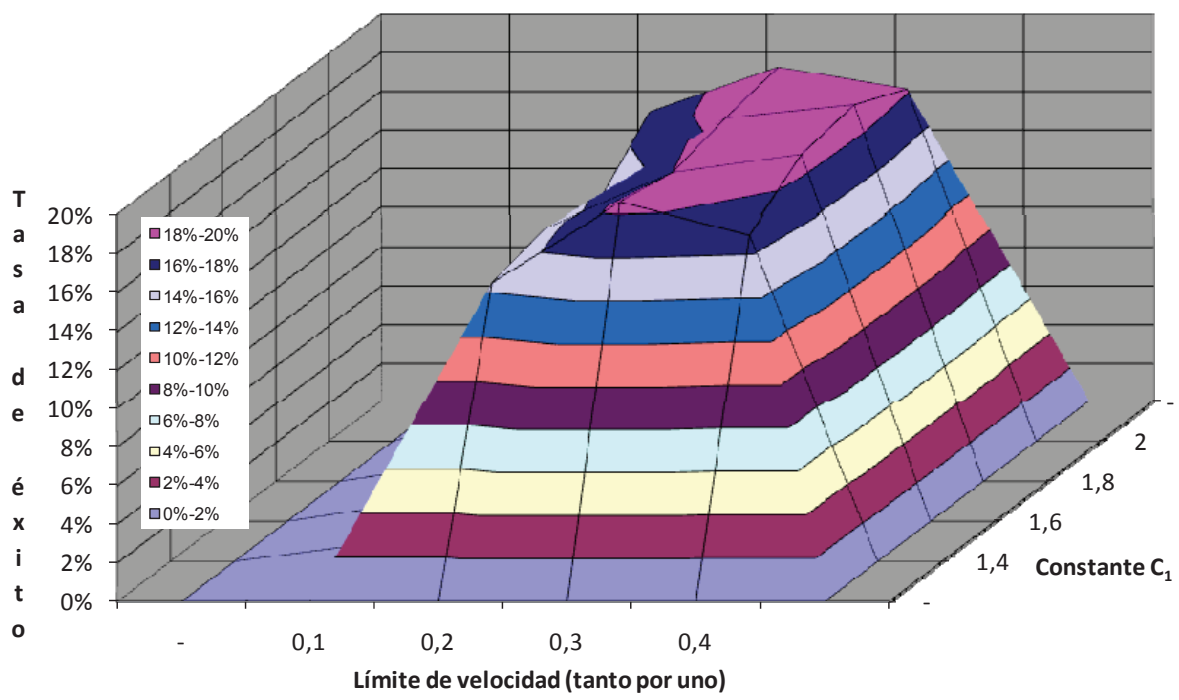

Figura 5.22. Probabilidad de obtener mínima solución según el límite de velocidad de vuelo y $C_{1}$.

La principal conclusión que se toma de ambas figuras es que el rango de trabajo óptimo que muestra la limitación de velocidad es distinto al obtenido en el resto de redes. Así, en el diseño óptimo de la red de Nueva York no parece tan crucial el evitar que los pájaros se muevan demasiado rápido, puesto que cuanta más libertad de movimiento se le da a un determinado individuo mejores son los resultados obtenidos.

En la red de los túneles de Nueva York, limitaciones de velocidad en torno al 30-40\% del rango de la variable es lo más adecuado. Así, para esta red, donde la gama de diámetros utilizada consta de 15 diámetros diferentes, esta limitación equivale a no saltar más de 6 diámetros de la gama entre dos iteraciones consecutivas del algoritmo. El tamaño de la gama utilizada para esta red es probablemente el factor diferencial respecto del resto de redes estudiadas, puesto que al ser mucho mayor no tiene tanta importancia que los saltos entre iteraciones sean tan grandes, ya que en este caso no provoca una convergencia temprana del algoritmo.

La figura que se muestra a continuación también representa la probabilidad de obtener una solución mínima en función del límite de velocidad, pero en este caso la representación es en función de la probabilidad de despiste. 


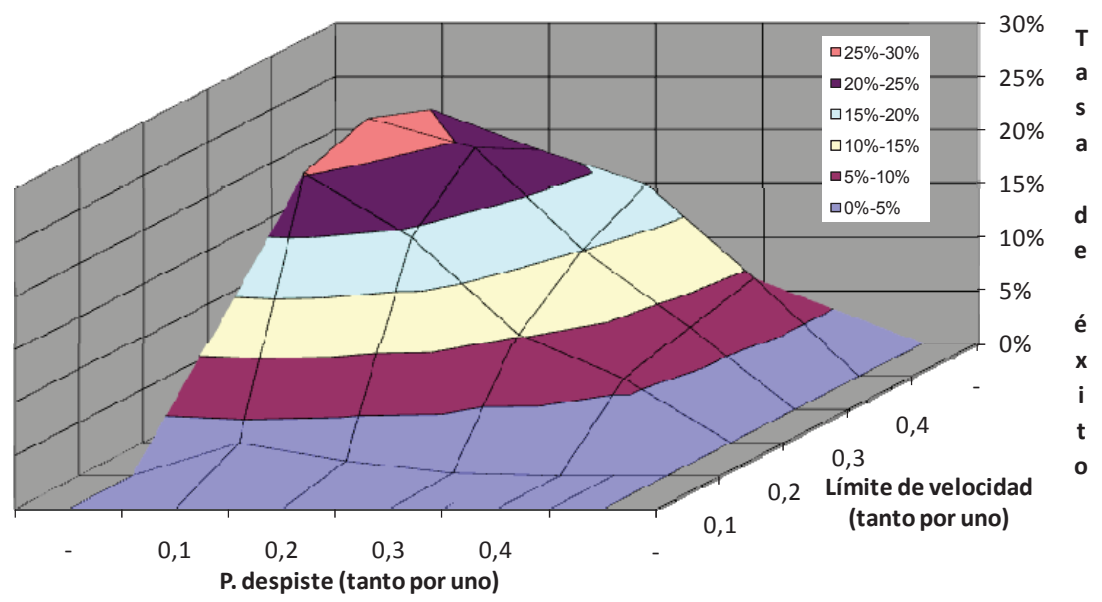

Figura 5.23. Probabilidad de obtener mínima solución según el límite de velocidad de vuelo y la probabilidad de despiste.

En este caso los resultados obtenidos sí son similares a los obtenidos en el caso de Hanoi, de modo que conforme $P_{\text {desp }}$ aumenta el algoritmo de cálculo se hace menos efectivo, disminuyendo progresivamente el número de mínimos obtenidos. Se puede concluir en el caso de la red de Nueva York que $P_{\text {desp }}$ óptima está en torno al $10 \%$. Así, con $P_{\text {desp }}=0,1$ y $V_{\text {lim }}=0,1-0,3$ el porcentaje de éxito en la obtención de la mínima solución para la red está en torno al $25 \%$.

De similar modo, es posible relacionar la $P_{\text {desp }}$ con las constantes $C_{1}$ y $C_{2}$ :

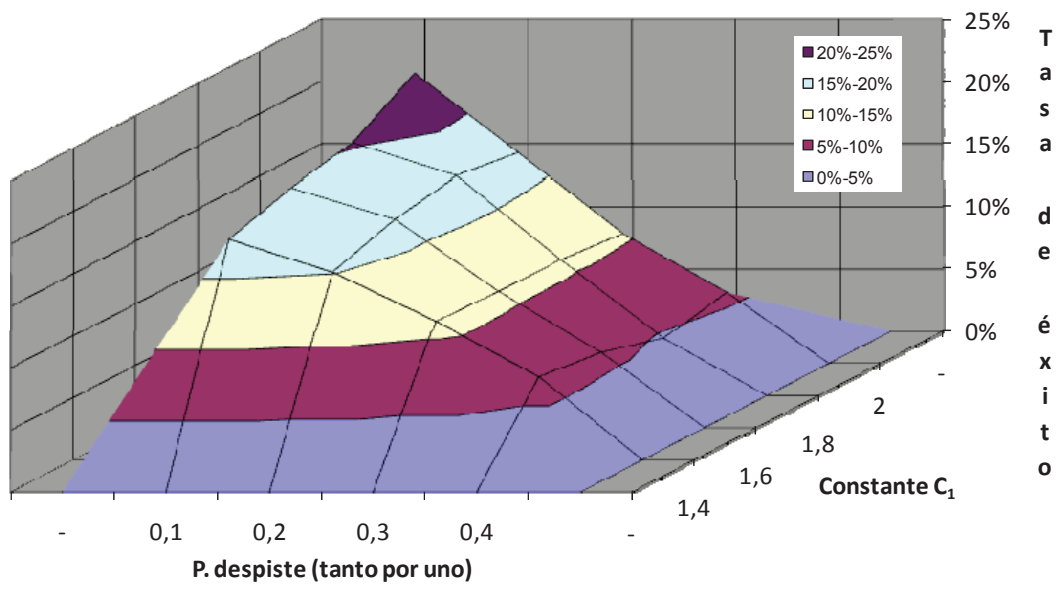

Figura 5.24. Probabilidad de obtener mínima solución según la probabilidad de despiste y $C_{1}$. 


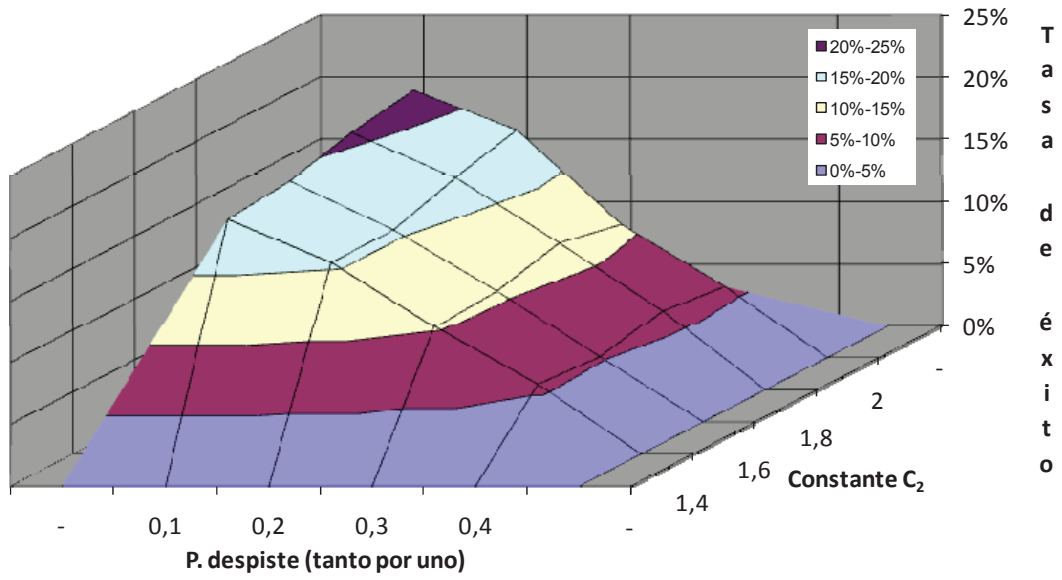

Figura 5.25. Probabilidad de obtener mínima solución según $P_{\text {desp }}$ y $C_{2}$.

Ambas figuras confirman la mayor influencia de la $P_{\text {desp }}$ frente al valor de las constantes $C_{1} y$ $\mathrm{C}_{2}$ en el rango considerado. Así, si bien valores cercanos a 2 en ambas constantes consiguen un porcentaje de éxito algo mayor, la diferencia entre los distintos valores no es superior a un $5 \%$. Sin embargo, la diferencia entre una probabilidad de despiste de un $40 \%$ y una del $10 \%$ se traduce en una diferencia en la tasa de éxito cercana al $20 \%$, lo que denota la importancia de acertar en el valor de este parámetro.

Cabe destacar la similitud de ambos gráficos, tanto en la forma como en las cifras de éxito en el diseño óptimo. La siguiente figura relaciona ambas constantes entre sí.

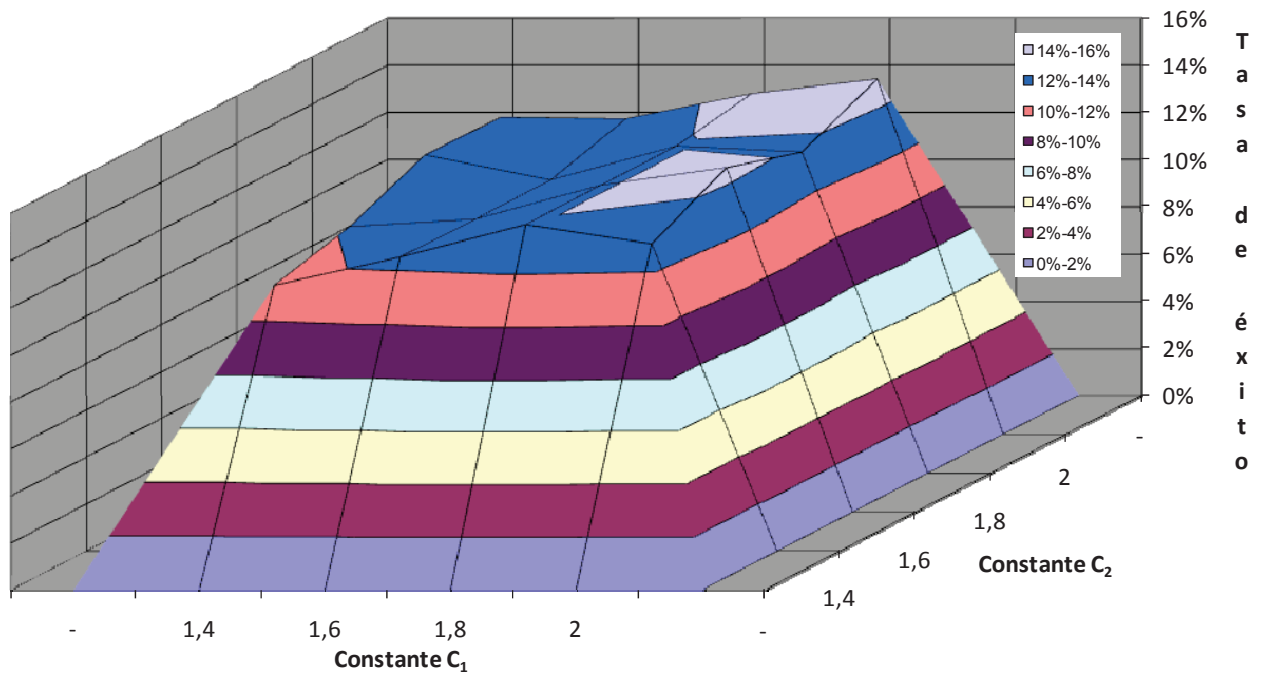

Figura 5.26. Probabilidad de obtener mínima solución según $C_{1}$ y $C_{2}$. 
Los resultados para ambas constantes siguen el mismo patrón que en el resto de redes, de modo que desde un punto de vista cuantitativo está claro que valores cercanos a 2 funcionan algo mejor en ambas constantes. No obstante, la diferencia en el rango estudiado no hace pensar que estas constantes resulten críticas en el buen funcionamiento del algoritmo desde un punto de vista de obtención de la mejor solución posible.

Al igual que en el resto de casos, es posible ampliar el análisis estadístico a la obtención de buenas soluciones. En la red de Nueva York se considera una buena solución a toda aquella que tenga un coste de diseño inferior a 39,801 millones de um, equivalente a un $3 \%$ de sobrecoste respecto a la solución mínima. En este caso, los resultados respecto a la optimización de parámetros son similares a los ya vistos en la obtención de mínimas soluciones, con representaciones gráficas prácticamente idénticas, por lo que no se considera de interés mostrarlas. Obviamente, el número de "buenas soluciones" que obtiene la metodología aumenta considerablemente respecto al número de "mínimas" soluciones de diseño, situándose normalmente por encima del 50\% salvo en combinaciones paramétricas muy desfavorables.

La siguiente tabla muestra para cada pareja de parámetros cuál es la mejor combinación desde un punto de vista cuantitativo del problema. Es decir, tan sólo teniendo en cuenta la capacidad de obtener el mínimo absoluto de diseño o bien una buena solución.

\begin{tabular}{|c|c|c|c|c|}
\hline & & $\mathbf{P}_{\text {desp }}(\%)$ & $\mathrm{C}_{1}$ & $\mathrm{C}_{2}$ \\
\hline \% Mínimos & $\mathrm{V}_{\lim }(\%)$ & $\left(\mathrm{V}_{\lim }=30, \mathrm{P}_{\text {desp }}=10\right)$ & $\left(\mathrm{V}_{\lim }=40, \mathrm{C}_{1}=1,8\right)$ & $\left(\mathrm{V}_{\text {lim }}=40, \mathrm{C}_{2}=1,8\right)$ \\
& & $27,25 \%$ & $19,44 \%$ & $19 \%$ \\
\hline \% B.S & $\mathrm{V}_{\lim }(\%)$ & $\left(\mathrm{V}_{\text {lim }}=30, \mathrm{P}_{\text {desp }}=10\right)$ & $\left(\mathrm{V}_{\lim }=30, \mathrm{C}_{1}=2\right)$ & $\left(\mathrm{V}_{\lim }=30, \mathrm{C}_{1}=2\right)$ \\
& & $62,19 \%$ & $54,38 \%$ & $53,31 \%$ \\
\hline
\end{tabular}

\begin{tabular}{|c|c|c|c|}
\hline & & $\mathrm{C}_{1}$ & $\mathrm{C}_{2}$ \\
\hline \% Mínimos & $\mathbf{P}_{\text {desp }}(\%)$ & $\left(\mathrm{P}_{\text {desp }}=10, \mathrm{C}_{1}=2\right)$ & $\left(\mathrm{P}_{\text {desp }}=10, \mathrm{C}_{2}=2\right)$ \\
& & $23,25 \%$ & $21,50 \%$ \\
\hline \% B.S & $\mathbf{P}_{\text {desp }}$ (\%) & $\left(\mathrm{P}_{\text {desp }}=10, \mathrm{C}_{1}=2\right)$ & $\left(\mathrm{P}_{\text {desp }}=10, \mathrm{C}_{1}=1,8\right)$ \\
& & $54,38 \%$ & $49,88 \%$ \\
\hline
\end{tabular}

Tabla 5.4. Resultados obtenidos para la red de los túneles de Nueva York.

Los resultados mostrados concluyen que el concepto de buena solución aumenta en más del doble el éxito de las simulaciones, alcanzando con relativa facilidad cifras cercanas al $50 \%$.

En el caso de las constantes $C_{1}$ y $C_{2}$, la mejor combinación con el resto de parámetros siempre es $1,8 \circ 2$, certificando los valores obtenidos en las restantes redes y confirmando la recomendación de otros autores al respecto para estos parámetros, al menos desde un punto de vista de obtener la mejor solución posible. 
El límite de velocidad óptimo para un determinado individuo entre dos iteraciones cualesquiera se encuentra alrededor del $30 \%$ para la red de Nueva York, valor superior al del resto de redes cuyo diseño óptimo estudia este trabajo. Tal como ya se ha mencionado, el límite de velocidad para un determinado pájaro obedece a la necesidad de acotar el salto entre dos determinados valores para una variable, a fin de evitar una convergencia temprana del algoritmo. En la red de Nueva York, la gama de diámetros es más extensa que en el resto de redes, puesto que consta de un total de 15 posibles valores, lo que permite que la $V_{\lim }$ no sea tan restrictiva como en el resto de redes.

Por último, la probabilidad de despiste $\left(\mathrm{P}_{\text {desp }}\right)$ alcanza su valor óptimo en torno al $10 \%$. Esta configuración, combinada con un valor óptimo para el límite de velocidad de vuelo del pájaro $\left(V_{\text {lim }}=0,3\right)$ arroja un porcentaje de éxito en la obtención del mínimo de más de un $25 \%$ y de más de un $60 \%$ en la obtención de una buena solución de diseño.

\subsubsection{Red R-9 de Joao Pessoa}

El rango de estudio para cada uno de los parámetros que entran en juego en la optimización PSO para la red R-9 de Joao Pessoa sigue el mismo criterio que en anteriores redes. Así, el tamaño de población se considera constante e igual a 100 individuos, mientras que el valor del factor de inercia $w$ para cada iteración se calcula con la misma función decreciente que se utiliza en el resto de redes.

El número de simulaciones realizadas en este escenario fue de 25600, realizándose un total de 1600 repeticiones para cada una de las combinaciones de parámetros. El histograma de soluciones obtenido es el siguiente:

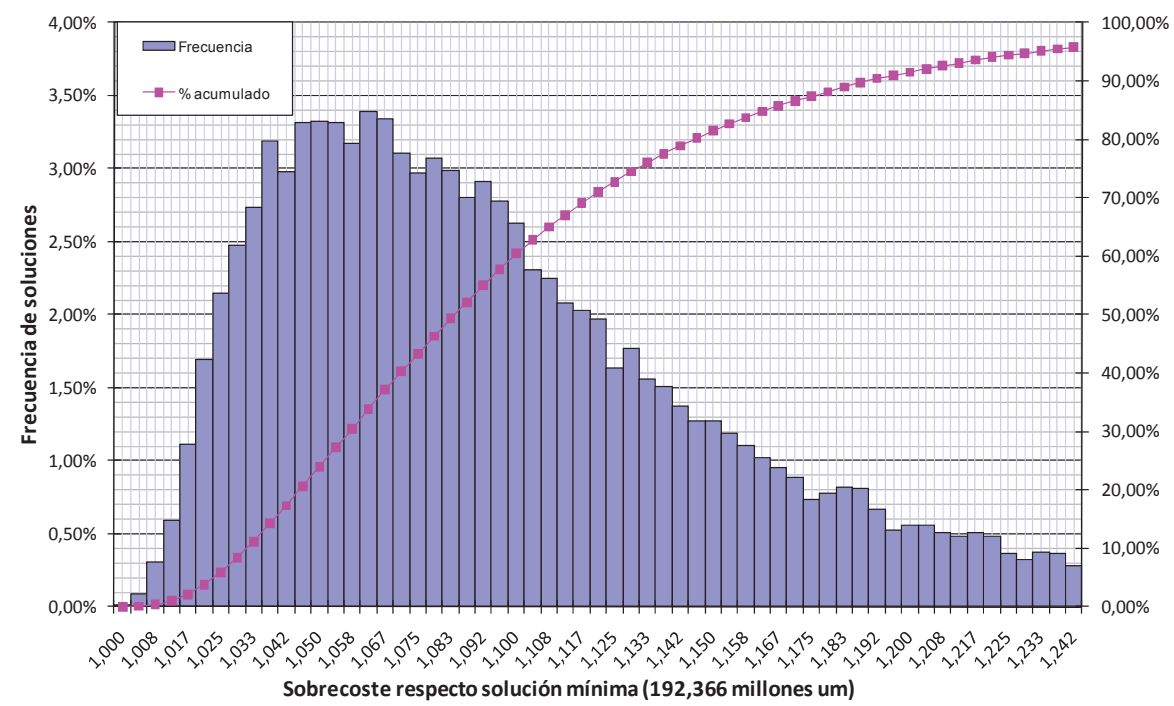

Figura 5.27. Histograma de soluciones obtenido para PSO modificado en la red $R-9$ de Joao Pessoa 
La mejor solución de diseño obtenida por el conjunto de todos los métodos heurísticos para la red de Joao Pessoa tiene un coste de 192,366 millones de um, valor que también es obtenido por la metodología PSO, aunque con escasa repetibilidad.

El gráfico representa el total de simulaciones realizadas ordenadas en función del coste adicional porcentual respecto de la mínima solución de diseño. Así, la solución mínima de diseño se consigue tan sólo una vez entre el total de simulaciones realizadas, mientras que lo que se entendería como una buena solución de diseño se obtiene en algo más de un $11 \%$ del total de simulaciones. De estos resultados es lógico concluir que no merece la pena realizar ningún tipo de análisis estadístico basado en la obtención de la mínima solución de diseño, por lo que se concentra el esfuerzo en analizar los distintos parámetros para la obtención de buenas soluciones del problema de diseño.

Así, siguiendo la línea establecida en el resto de redes, las figuras que siguen muestran la probabilidad de obtener buenas soluciones para el problema en función de los distintos valores que puede tomar cada uno de los parámetros de cálculo. El límite establecido en términos monetarios para la red de Joao Pessoa queda establecido en 198,137 millones de um, valor monetario que corresponde al mínimo coste de diseño más un $3 \%$ adicional.

Inicialmente se muestra la influencia del límite de velocidad de vuelo de un determinado pájaro en cada iteración. Este parámetro se ha mostrado hasta ahora como uno de los más influyentes para el buen desempeño del algoritmo. Las siguientes figuras analizan el número de buenas soluciones obtenidas comparando este límite de velocidad con el valor de las constantes $C_{1}$ y $C_{2}$, que se relacionan a su vez con el peso otorgado por a la búsqueda local y global de un pájaro determinado.

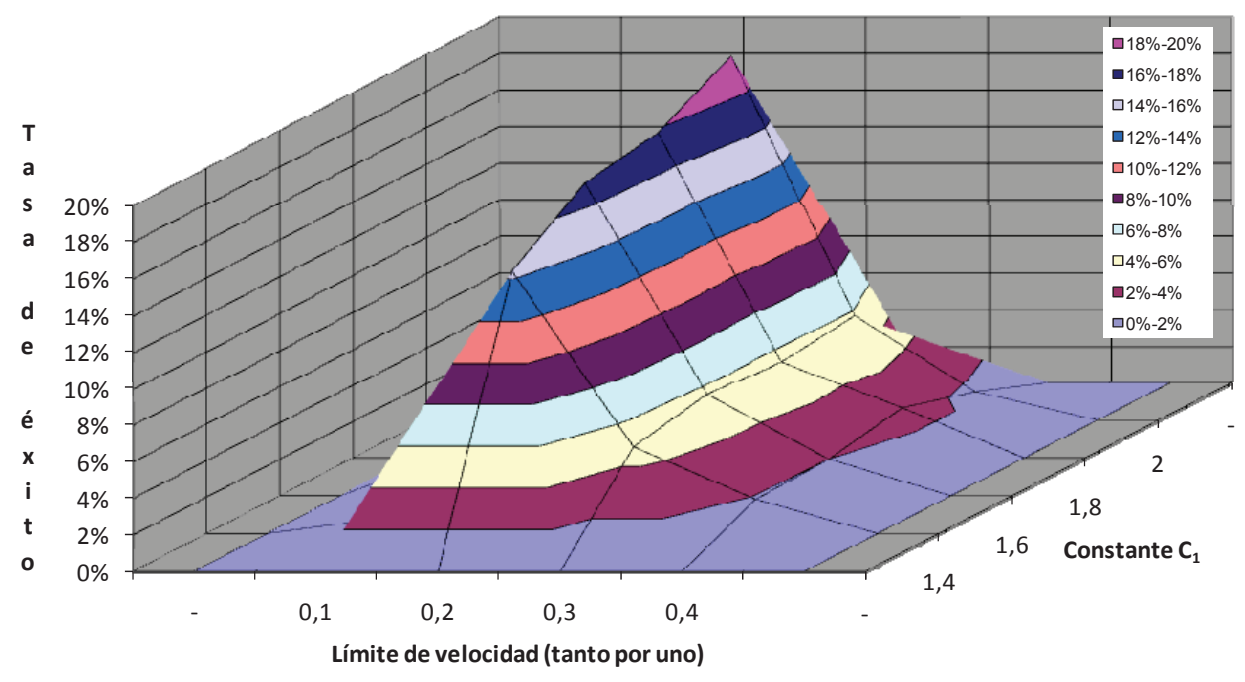

Figura 5.28. Probabilidad de obtener una buena solución según límite de velocidad de vuelo y $C_{1}$. 


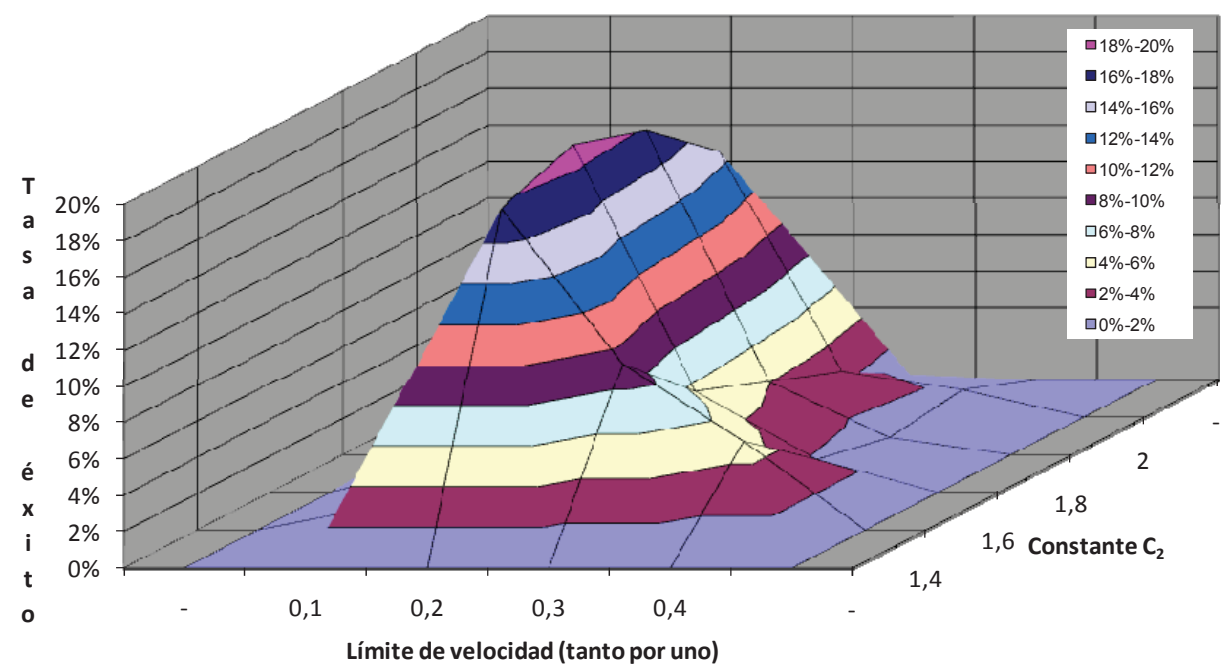

Figura 5.29. Probabilidad de obtener una buena solución según límite de velocidad de vuelo $y C_{2}$.

En la red de Joao Pessoa, la gama de diámetros empleada para la resolución del problema consta de 10 diámetros diferentes, siendo el más pequeño de diámetro $100 \mathrm{~mm}$ y el más grande de $600 \mathrm{~mm}$. A la vista de ambas figuras, el límite de velocidad de vuelo óptimo está en torno al $20 \%$ del rango de la variable, lo que implica que entre iteración e iteración un determinado pájaro no cambia el diámetro de un conducto más de 2 posiciones dentro de la gama.

Tal como se ha visto en el resto de redes, la influencia de las constantes no es tan determinante en el desempeño del algoritmo siempre que su valor esté dentro de un rango razonable. La red de Joao Pessoa no constituye una excepción en este aspecto. Así, para la constante $\mathrm{C}_{1}$, el valor óptimo a la vista de la figura 5.28 está en torno a 2, de modo que para la combinación $\left(C_{1}=2, V_{\text {lim }}=0,1\right)$ se tiene una probabilidad cercana al $20 \%$ de encontrar una buena solución. Esta probabilidad de éxito disminuye progresivamente conforme lo hace el valor $C_{1}$, de modo que cuando $C_{1}=1,4$ la probabilidad de encontrar una buena solución cae hasta un $14 \%$.

Para el parámetro $C_{2}$ los mejores resultados se consiguen con $C_{2}=1,6$, de modo que se obtiene casi un $20 \%$ de probabilidad de buena solución cuando el límite de velocidad es del $20 \%$. Este dato supone una novedad respecto al estudio de constantes realizado hasta ahora, puesto que normalmente siempre se ha obtenido el mejor resultado en torno al valor de 2. En este caso concreto la tendencia general se invierte y los peores resultados son los obtenidos con valores altos de $\mathrm{C}_{2}$, si bien la diferencia no es muy notable. La siguiente figura muestra la 
probabilidad de obtener una buena solución en función de la constante $C_{2}$ y de la probabilidad de despiste:

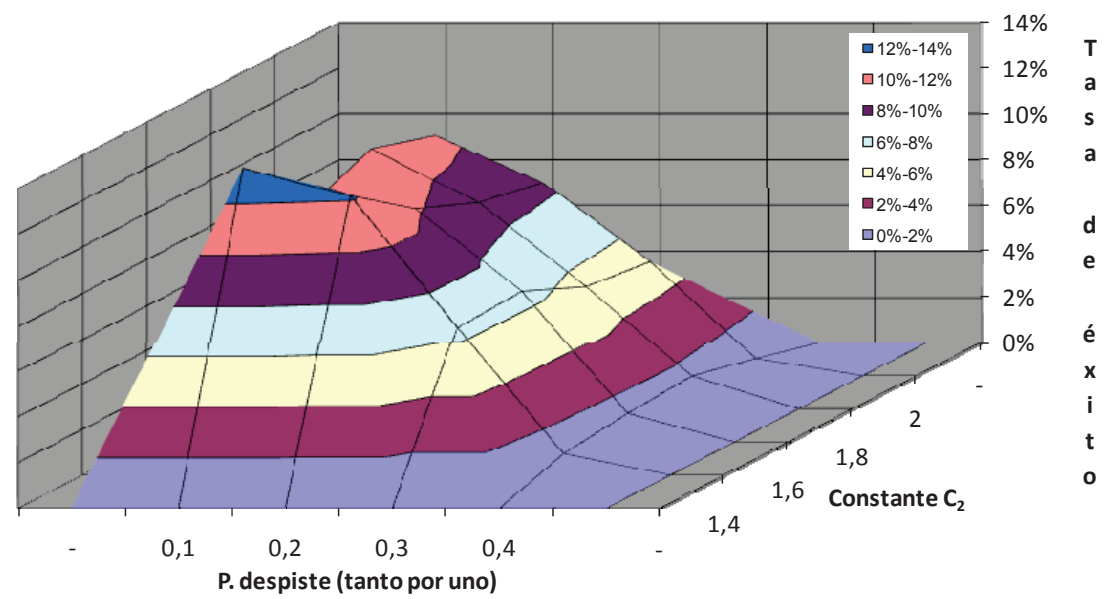

\section{Figura 5.30. Probabilidad de encontrar una "buena solución" para la red de Joao Pessoa en} función de la probabilidad de despiste y $C_{2}$.

La figura confirma la tendencia que muestra $C_{2}$ en esta red, donde la probabilidad de encontrar una buena solución aumenta para valores de $C_{2}$ inferiores. Cabe destacar que el valor $C_{2}$ tiene relación con el desplazamiento de una partícula en relación al resto, por lo que este resultado minimiza la importancia de la búsqueda global para esta red en concreto, otorgando cierta prioridad a la búsqueda local que lleva a cabo cada partícula $\left(C_{1}\right)$. El estudio de ambas constantes se completa con la figura 5.31, donde se aprecia un pico de éxito claro cuando $C_{1}=2$ y $C_{2}=1,4$, mostrándose como la mejor combinación de diseño para esta red. 


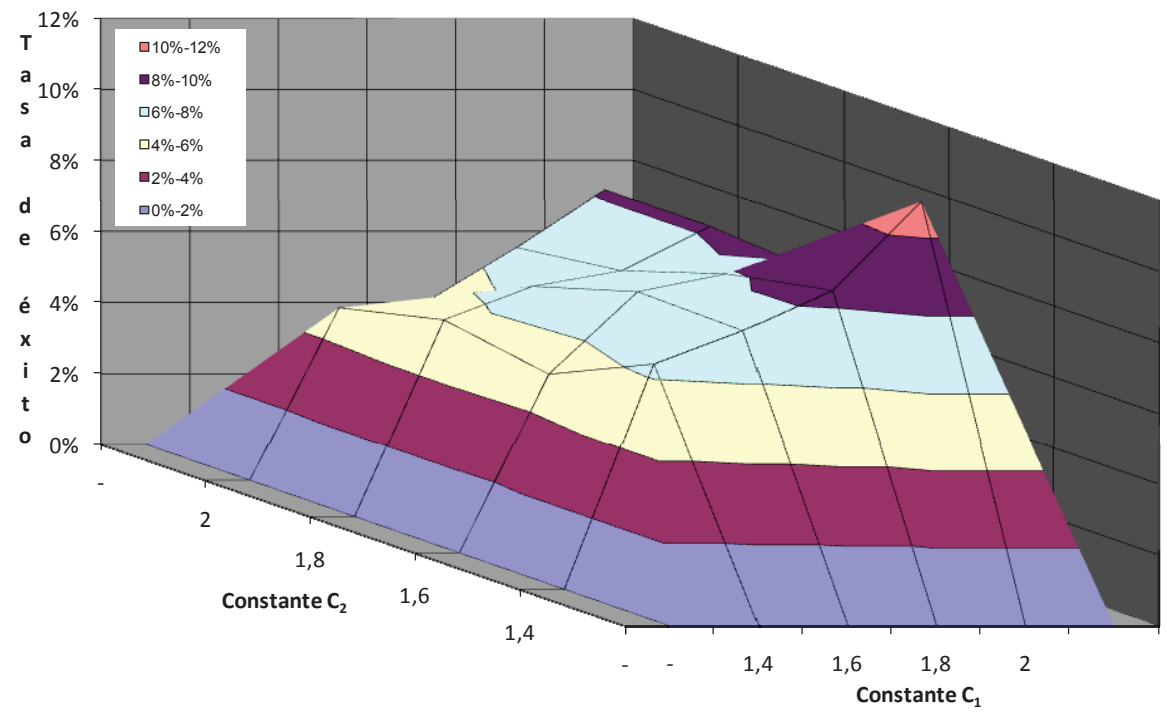

Figura 5.31. Probabilidad de encontrar una "buena solución" para la red de Joao Pessoa en función de las constantes $C_{1}$ y $C_{2}$

Por otro lado, tal como muesta la figura 5.30, la probabilidad de despiste sigue la tendencia general del resto de redes, de modo que $\mathrm{P}_{\text {desp }}$ entre un 10 y un $20 \%$ parece la óptima para la búsqueda de buenas soluciones, disminuyendo la eficacia del algoritmo conforme se aumenta este valor. Así, para una $P_{\text {desp }}$ en torno al $10 \%$ y un valor $C_{2}=1,4$ el porcentaje de buenas soluciones obtenidas para la red $\mathrm{R}-9$ es de un $13,44 \%$. Si se analiza la $\mathrm{P}_{\text {desp }}$ en función de la otra constante.

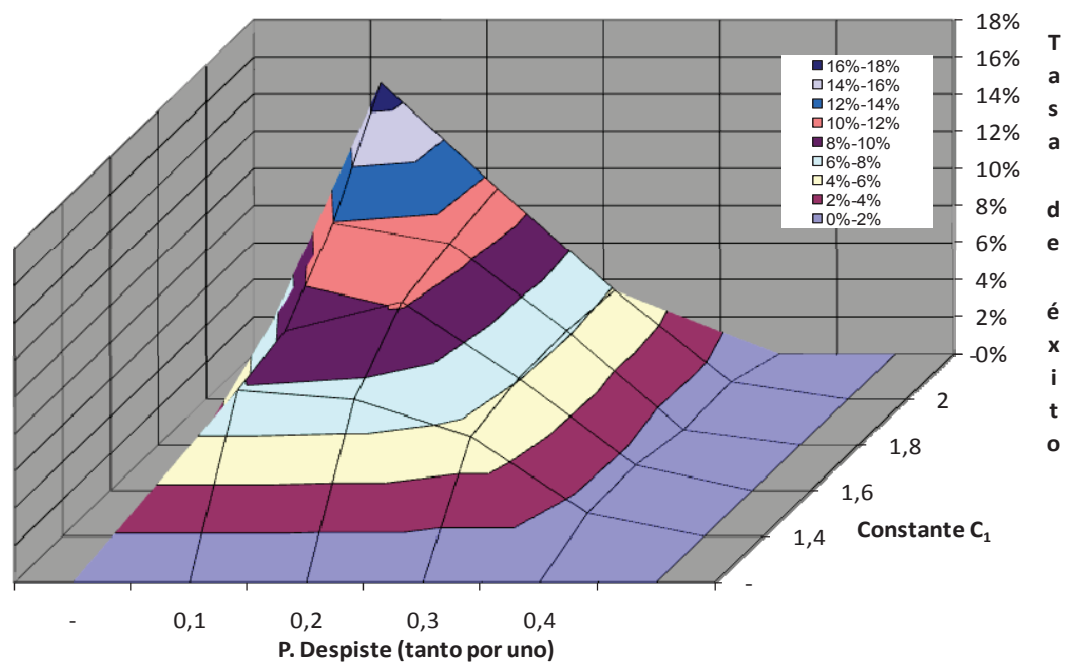

Figura 5.32. Prob. de encontrar una "buena solución" para la red $R-9$ en función de $P_{\text {desp }}$ y $C_{1}$ 
La figura permite apreciar con claridad las conclusiones sacadas del resto de figuras, de modo que para $C_{1}=2$ y $P_{\text {desp }}=10 \%$ el porcentaje de "buenas soluciones" obtenidas llega hasta un $17 \%$, destacando sobremanera del resto de combinaciones de ambos parámetros. Para finalizar el estudio acerca del ajuste de parámetros de la red de Joao Pessoa tan sólo resta comparar los dos parámetros que hasta el momento se han mostrado como los más críticos, es decir, $\mathrm{V}_{\lim } \mathrm{Y}$ $P_{\text {desp. }}$

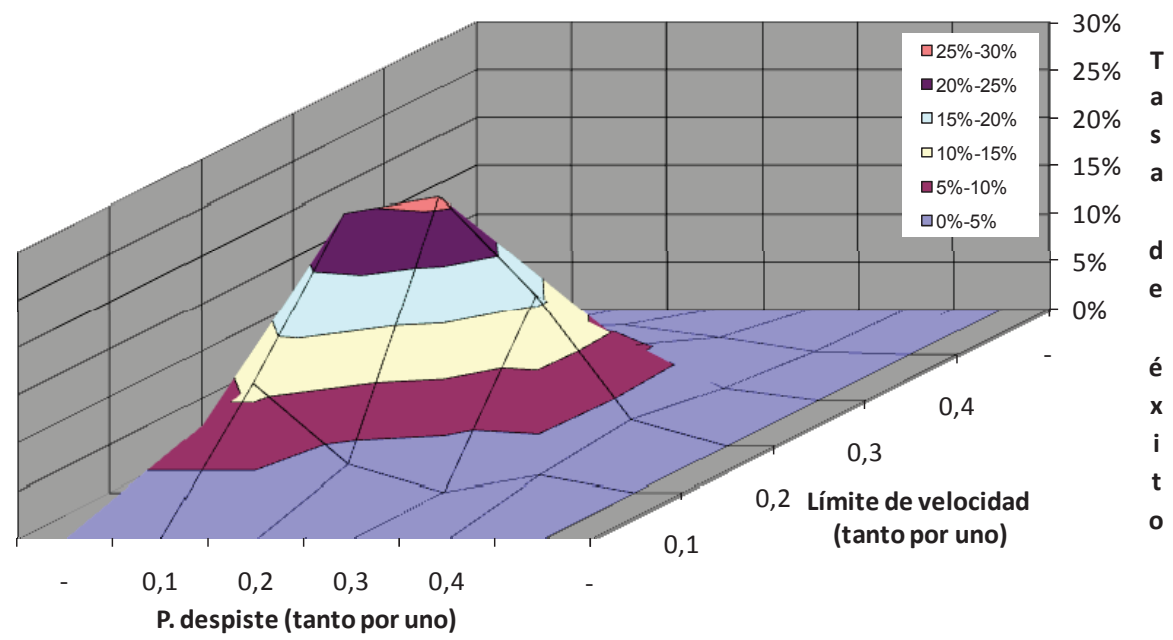

Figura 5.33. Probabilidad de encontrar una "buena solución" para la red R-9 en función de

$$
P_{\text {desp }} y V_{\text {lim }}
$$

La figura no hace más que confirmar todas las conclusiones sacadas hasta ahora de los valores óptimos para ambos parámetros. Así, para un límite de velocidad de un $20 \%$ y una probabilidad de despiste entre el 10 y el $20 \%$ se obtiene una media del $25 \%$ de simulaciones que dan como resultado una buena solución de diseño, sea cuales sean los valores del resto de parámetros.

Este porcentaje de "buenas soluciones" obtenidas confirma a ambos parámetros como los más críticos en la optimización PSO, puesto que ojeando el resto de optimizaciones realizadas en este apartado se observa como en ningún caso la combinación óptima de cualquier pareja de parámetros consigue llegar a una probabilidad de obtener una buena solución tan alta como en este caso. Como resumen de todo lo expuesto para esta red se muestra para cada pareja de parámetros cual es la mejor combinación desde un punto de vista cuantitativo del problema: 


\begin{tabular}{|c|c|c|c|c|}
\hline & & $\mathbf{P}_{\text {desp }}(\%)$ & $\mathbf{C}_{1}$ & $\mathbf{C}_{2}$ \\
\hline \% B.S & $\mathbf{V}_{\text {lim }}$ (\%) & $\left(\mathrm{V}_{\lim }=20, \mathrm{P}_{\text {desp }}=20\right)$ & $\left(\mathrm{V}_{\lim }=20, \mathrm{C}_{1}=2\right)$ & $\left(\mathrm{V}_{\lim }=20, \mathrm{C}_{2}=1,6\right)$ \\
& & $26,13 \%$ & $19,94 \%$ & $19,13 \%$ \\
\hline
\end{tabular}

\begin{tabular}{|c|c|c|c|}
\hline & & $\mathbf{C}_{1}$ & $\mathbf{C}_{2}$ \\
\hline \% B.S & $\mathbf{P}_{\text {desp }}(\%)$ & $\left(\mathrm{P}_{\text {desp }}=10, \mathrm{C}_{1}=2\right)$ & $\left(\mathrm{P}_{\text {desp }}=10, \mathrm{C}_{1}=1,4\right)$ \\
& & $17,06 \%$ & $13,44 \%$ \\
\hline
\end{tabular}

Tabla 5.5. Resultados obtenidos para la red de los túneles de Nueva York.

\subsubsection{Red de Go-Yang}

Para finalizar el estudio acerca del ajuste de parámetros en la metodología PSO, se realiza un estudio acerca del diseño óptimo de la red de Go-Yang. En este caso, la gama de diámetros utilizada tiene 8 diámetros distintos, siendo de $80 \mathrm{~mm}$ el más pequeño y de $350 \mathrm{~mm}$ el más grande, lo que da un total de $8^{30}$ posibles soluciones para la red.

El estudio de diseño óptimo se realiza de idéntico modo al resto de las redes, variando el límite de velocidad de vuelo, la probabilidad de despiste y el valor de las constantes $C_{1}$ y $C_{2}$. Del mismo modo, se mantiene constante la población del algoritmo (100 individuos), así como la función decreciente para el factor de inercia (w). El objetivo es confirmar la tendencia observada en el resto de redes acerca de los valores adecuados para cada parámetro. Se representa en primer lugar el histograma completo de soluciones, así como el gráfico de probabilidad acumulada. 


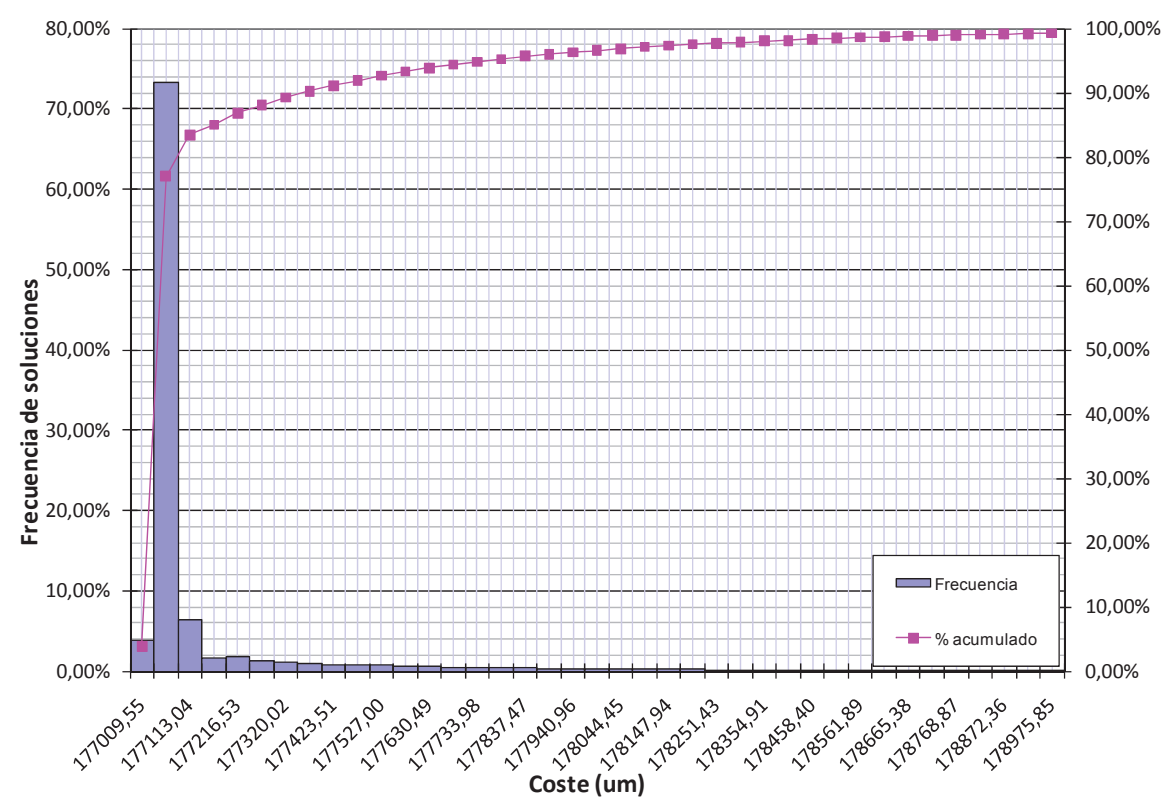

Figura 5.34. Histograma de soluciones obtenido para PSO modificado en la red de Go-Yang

Ya se ha visto en apartados previos que la red de Go-Yang reviste menor complejidad de diseño que el resto de redes diseñadas en este trabajo, por lo que normalmente la probabilidad de obtener soluciones cercanas al óptimo es mayor. En el caso de diseño óptimo mediante la metodología PSO tan sólo un 3,78\% consigue la solución de mínimo coste, de valor 177009,6 um. En contraste con este dato, hasta un $73 \%$ del total de simulaciones se sitúa en la siguiente solución de diseño para la red, de coste 177061,3 um, valor apenas un $0,3 \%$ superior a la solución considerada como óptima de diseño.

El estudio de los parámetros de cálculo permite encontrar las mejores combinaciones para los distintos parámetros de cálculo de la optimización PSO. El rango de estudio utilizado para cada uno de ellos es el mismo que en el resto de redes. Las figuras 5.35 y 5.36 muestran la probabilidad de obtener la solución de mínimo coste en función de la velocidad máxima a la que puede volar un determinado pájaro. Ambas representaciones re realizan en base a las constantes $\mathrm{C}_{1}$ y $\mathrm{C}_{2}$. 


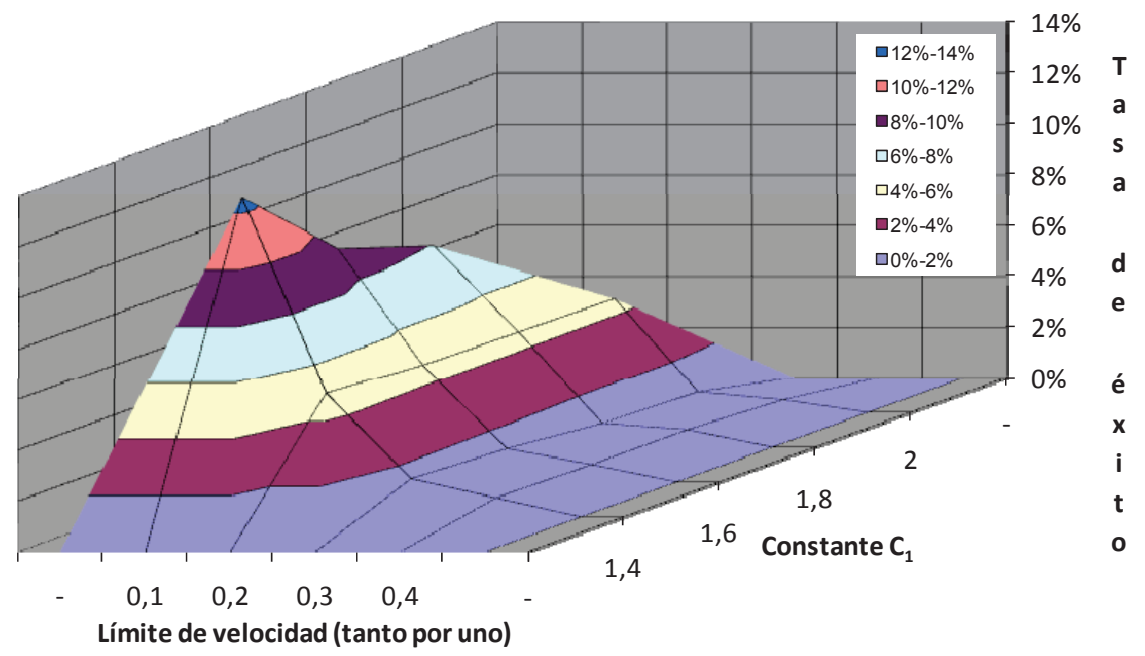

Figura 5.35. Probabilidad de encontrar solución mínima para la red de Go-Yang en función del límite de velocidad y la constantes $C_{1}$.

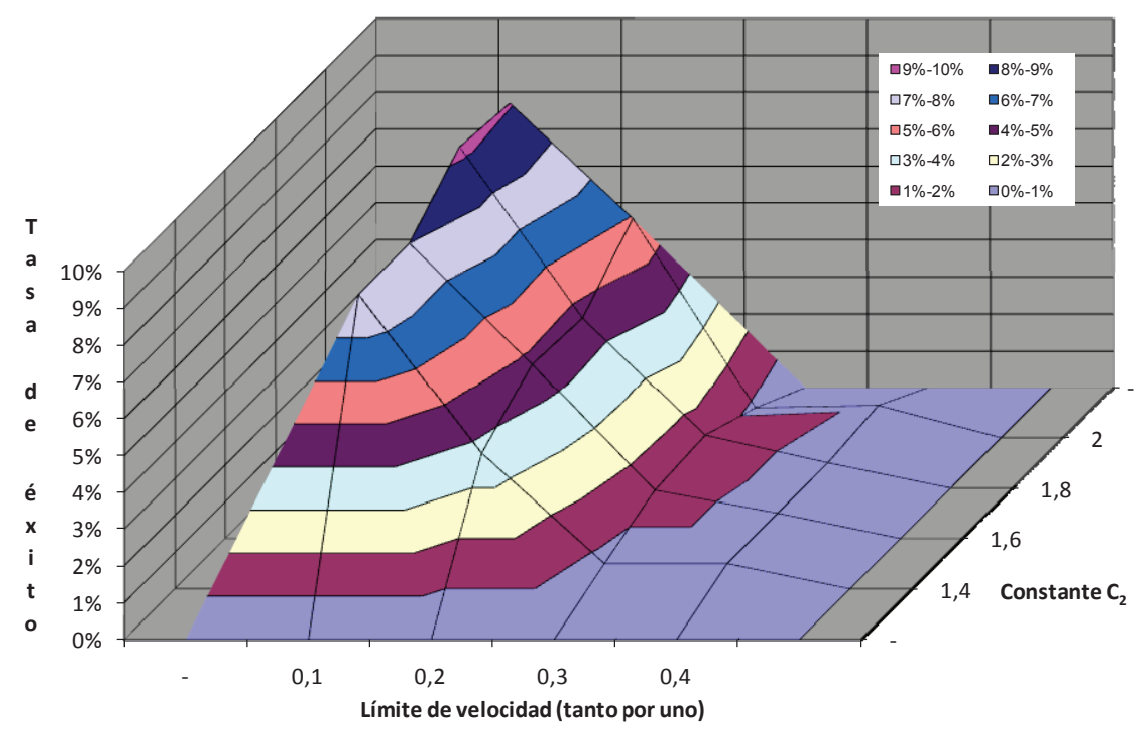

Figura 5.36. Probabilidad de encontrar solución mínima para la red de Go-Yang en función del límite de velocidad y la constantes $C_{2}$.

Ya se ha visto en otras redes como la influencia que ejerce el limitar la velocidad de vuelo de un determinado individuo parece tener cierta relación con la amplitud de la gama de diámetros utilizada en el diseño. En la red de Go-Yang, la gama utilizada consta de 8 diámetros diferentes, que abarcan desde los $80 \mathrm{~mm}$ hasta los $350 \mathrm{~mm}$. En estas condiciones, ambas figuras muestran claramente como el límite de velocidad de vuelo óptimo está en 
torno a un $10 \%$ del rango de la variable. El significado de este límite en la red de Go-Yang es que un determinado pájaro no debe cambiar el tamaño de diámetro de un determinado conducto en más de una posición entre dos iteraciones consecutivas.

Respecto a las constantes, la figura 5.36 muestra como valores de $C_{2}$ alrededor de 1,8 y 2 son los que mayor probabilidad tienen de obtener la solución de mínimo coste. Así, cuando el límite de velocidad de vuelo es de un $10 \%$ y el valor de la constante $C_{2}$ es 1,8 se obtiene la solución óptima de diseño el $9,25 \%$ de las simulaciones. En cuanto a la constante $C_{1}$, los mejores resultados se obtienen para valores bajos de $C_{1}$, de modo que para $C_{1}=1,4$ y $V_{\text {lim }}=0,1$ el número de soluciones óptimas obtenidas es de un $12,56 \%$.

En el mismo sentido, las figuras inferiores muestran la probabilidad de encontrar la solución óptima de diseño en función de la probabilidad de despiste y de estas mismas constantes $C_{1}$ y $\mathrm{C}_{2}$.

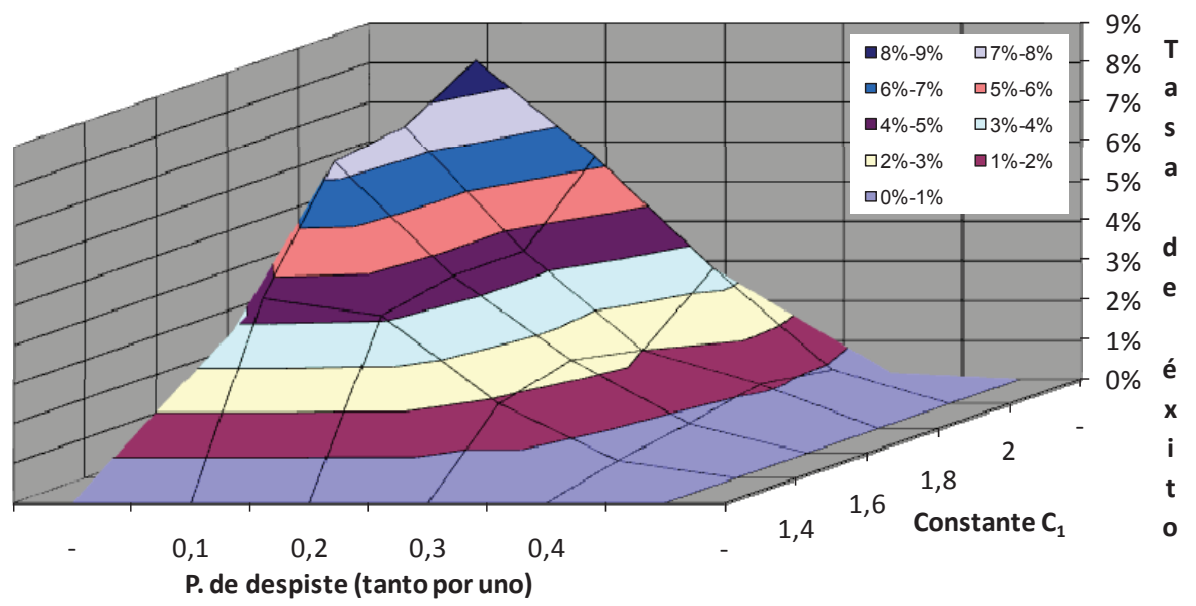

Figura 5.37. Probabilidad de encontrar solución mínima para la red de Go-Yang en función de la probabilidad de despiste y la constantes $C_{1}$ 


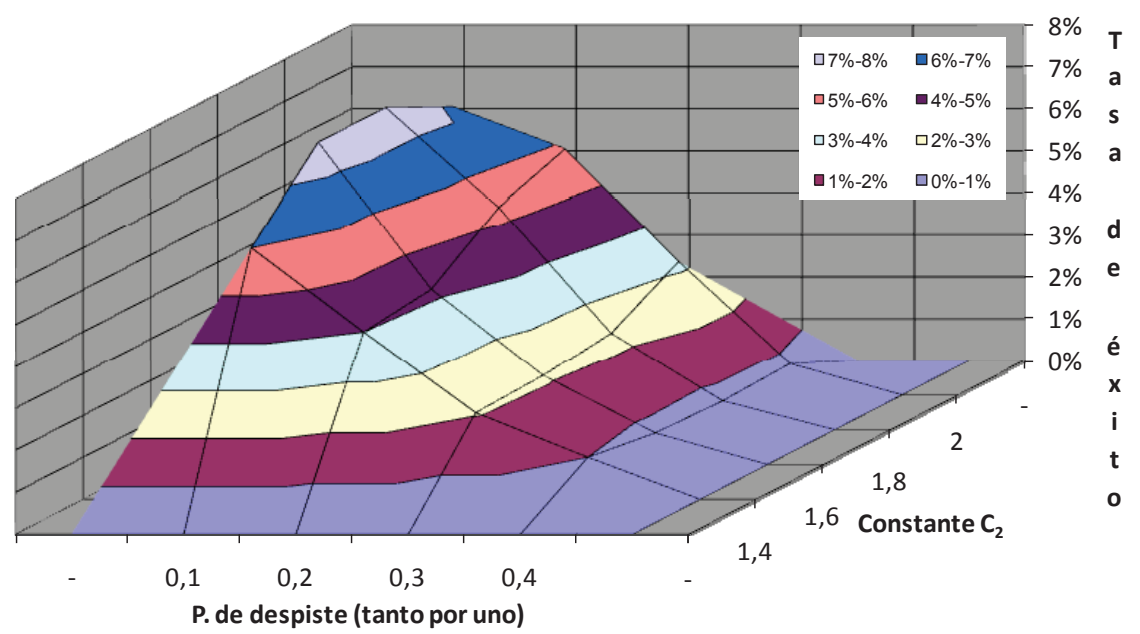

Figura 5.38. Probabilidad de encontrar solución mínima para la red de Go-Yang en función de la probabilidad de despiste y la constantes $C_{2}$

Ambas figuras muestran resultados conformes a los ya vistos en el resto de redes, de modo que probabilidades de despiste en torno al $10 \%$ proporcionan mayor cantidad de soluciones óptimas de diseño, disminuyendo la efectividad del algoritmo conforme aumenta esta probabilidad de despiste. Así, cuando $P_{\text {desp }}=0,1$ y $C_{1}>1,6$ la probabilidad de encontrar la mínima solución de diseño está en torno a un $8 \%$, probabilidad que desciende paulatinamente conforme lo hace $P_{\text {desp }}$ hasta llegar a prácticamente 0 .

Del mismo modo, la figura 5.38 muestra como para probabilidades de despiste del $10 \%$ el porcentaje de mínimos se encuentra entre un 6 y un $8 \%$ para todo el rango de $C_{2}$ simulado, descendiendo hasta prácticamente cero coincidiendo con el aumento de la probabilidad de despiste.

Dados los resultados, las constantes $C_{1}$ y $C_{2}$ se muestran de nuevo como variables importantes pero no críticas en la optimización de parámetros desde un punto de vista cuantitativo. La siguiente figura contiene la totalidad de simulaciones realizadas y muestra la probabilidad de obtener una solución mínima en función del valor de ambas constantes, sea cual sea el valor del resto de parámetros. 


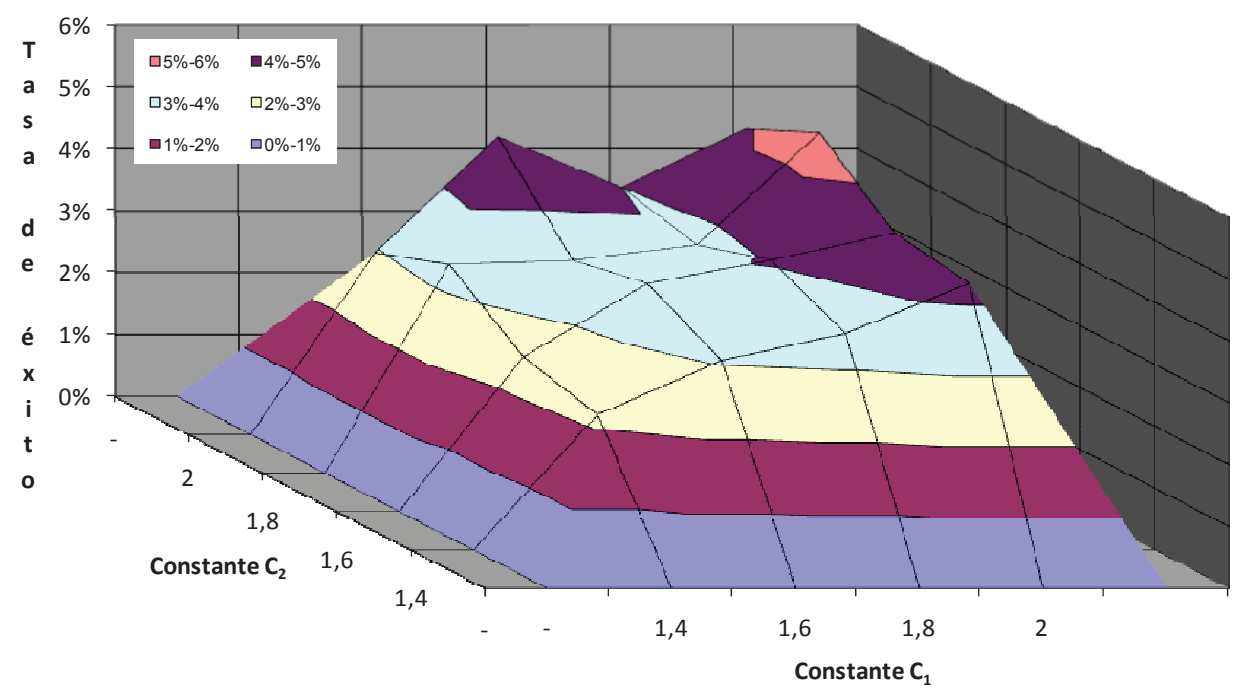

Figura 5.39. Probabilidad de encontrar solución mínima para la red de Go-Yang en función de las constantes $C_{1}$ y $C_{2}$.

La figura pone de manifiesto que si tan sólo se optimiza el valor de las constantes la probabilidad de encontrar una solución óptima de diseño es escasa, puesto que la mejor combinación para ambas constantes $\left(C_{1}=1,8-C_{2}=2\right)$ apenas consigue un 5,50\% de éxito en la obtención de mínimos. Si se realiza esta misma representación, pero analizando los otros dos parámetros, es decir, $\mathrm{V}_{\lim } \mathrm{y} \mathrm{P}_{\text {desp }}$, se obtiene el gráfico de la figura 5.40.

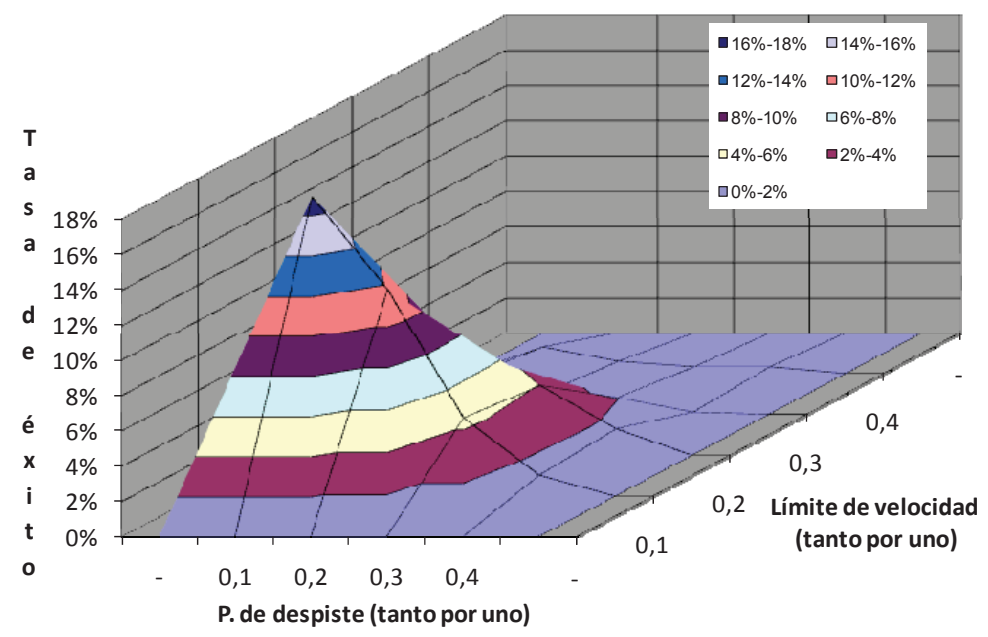

Figura 5.40. Probabilidad de encontrar solución mínima para la red de Go-Yang en función del límite de velocidad y la probabilidad de despiste. 
Para una velocidad máxima de vuelo del $10 \%$ y una probabilidad de despiste del $10 \%$ la probabilidad de encontrar la solución mínima de diseño es de un 16,94\%. Este porcentaje es el más alto de todas las posibles combinaciones realizadas para esta red. La figura pone de manifiesto la importancia de estos dos parámetros en el diseño óptimo mediante la metodología PSO, puesto que el resto de combinaciones obtienen valores muy alejados del óptimo.

Tal como se ha visto en el resto de redes, todos los parámetros no tienen la misma importancia desde el punto de vista cuantitativo, siendo $V_{\text {lim }}$ y $P_{\text {desp }}$ variables de mayor importancia que las constantes $C_{1}$ y $C_{2}$. Como resumen de resultados la siguiente tabla muestra para cada pareja de parámetros cual es la mejor combinación para obtener la solución óptima del problema de diseño de la red de Go-Yang:

\begin{tabular}{|c|c|c|c|c|}
\hline & & $\mathbf{P}_{\text {desp }}(\%)$ & $\mathbf{C}_{1}$ & $\mathbf{C}_{2}$ \\
\hline$\%$ & $\mathbf{V}_{\text {lim }}(\%)$ & $\left(\mathrm{V}_{\lim }=10, \mathrm{P}_{\text {desp }}=0,1\right)$ & $\left(\mathrm{V}_{\lim }=10, \mathrm{C}_{1}=1,4\right)$ & $\left(\mathrm{V}_{\lim }=10, \mathrm{C}_{2}=1,8\right)$ \\
mínimos & & $16,94 \%$ & $12,56 \%$ & $9,25 \%$ \\
\hline
\end{tabular}

\begin{tabular}{|c|c|c|c|}
\hline & & $\mathbf{C}_{1}$ & $\mathbf{C}_{2}$ \\
\hline \% mínimos & $\mathbf{P}_{\text {desp }}(\%)$ & $\left(\mathrm{P}_{\text {desp }}=10, \mathrm{C}_{1}=2\right)$ & $\left(\mathrm{P}_{\text {desp }}=10, \mathrm{C}_{1}=1,6-1,8\right)$ \\
& & $8,69 \%$ & $7,69 \%$ \\
\hline
\end{tabular}

Tabla 5.6. Resultados obtenidos para la red de los túneles de Nueva York

\subsubsection{Ajuste de parámetros Harmony Search (HS)}

Los parámetros susceptibles de optimización en la correcta configuración del algoritmo HS son el ajuste del PAR y la probabilidad HMCR. HMCR representa la probabilidad de que la variable adquiera un valor de entre los que se encuentran almacenados en la memoria, mientras que el ajuste del PAR es la probabilidad de que una variable del vector de solución se vea sometida a un determinado ajuste.

La condición de convergencia requiere en el caso de HS un tratamiento distinto del resto de métodos vistos hasta ahora. Así, en todos los métodos que estudia este trabajo se ha considerado como criterio de convergencia que se produjera un determinado número de simulaciones sin cambio en la mejor solución obtenida. En métodos heurísticos como APG, PSO o SFLA el valor elegido se considera lo suficientemente alto como para que el algoritmo tenga un tiempo suficiente de búsqueda, y lo suficientemente bajo como para no prolongar innecesariamente el cálculo del algoritmo.

HS trabaja de modo distinto al resto de métodos nombrados, por lo que el criterio de convergencia de APG, PSO y SFLA no resulta adecuado. Así, tanto APG como PSO y SFLA realizan en cada iteración del algoritmo casi tantos cálculos en EPANET como individuos 
tienen en su población, puesto que cada individuo de la población inicial tiene posibilidad de evolucionar.

La evolución de la población en HS se produce de un modo alternativo. En este caso se crea una población inicial de partículas (partituras), cada una de las cuales representa una posible solución del problema de optimización. Cada generación del algoritmo crea un nuevo vector solución, que se incorpora al resto si mejora al peor de los ya almacenados. La función objetivo de las partituras que ya estaban no es evaluada de nuevo, por lo que cada iteración del algoritmo realiza una única nueva evaluación de la función objetivo. HS es el método que menos evaluaciones de la función objetivo realiza por generación, por lo que la condición de convergencia que utilizan el resto de metodologías resulta insuficiente.

En adelante, todos los procesos de optimización realizados con el algoritmo HS aplican una condición de parada basada en un número de iteraciones sin cambio entre 5000 y 10000 . El estudio detallado acerca de la elección de estos límites puede seguirse en el apartado 5.4.

\subsubsection{Red de Hanoi}

A partir de las recomendaciones dadas por Geem (2001), la siguiente tabla muestra el rango utilizado para cada uno de los parámetros involucrados en la metodología HS en el diseño óptimo de la red de Hanoi:

\begin{tabular}{|c|c|c|}
\hline \multicolumn{2}{|c|}{ PARÁMETROS } & RANGO DE VALORES \\
\hline Tamaño de la memoria & N & 30 \\
\hline Probabilidad HMCR & HMCR & $0,85-0,99$ (de 0,1 en 0,1 ) \\
\hline Ajuste PAR & PAR & $0,05-1$ (10 valores) \\
\hline
\end{tabular}

Tabla 5.7. Rango de parámetros utilizado en el diseño óptimo de la red de Hanoi aplicando HS.

El tamaño de la memoria es un valor constante y se estima en 30, dejándose el análisis acerca del número de individuos con el que debe trabajar el algoritmo como caso aparte (ver apartado 5.3). En este caso, el número de simulaciones fue de más de 20000, realizando 200 cálculos en cada posible combinación de parámetros, con el objetivo de tener una muestra suficientemente representativa. El histograma representa la totalidad de soluciones que convergen a una solución factible de diseño: 


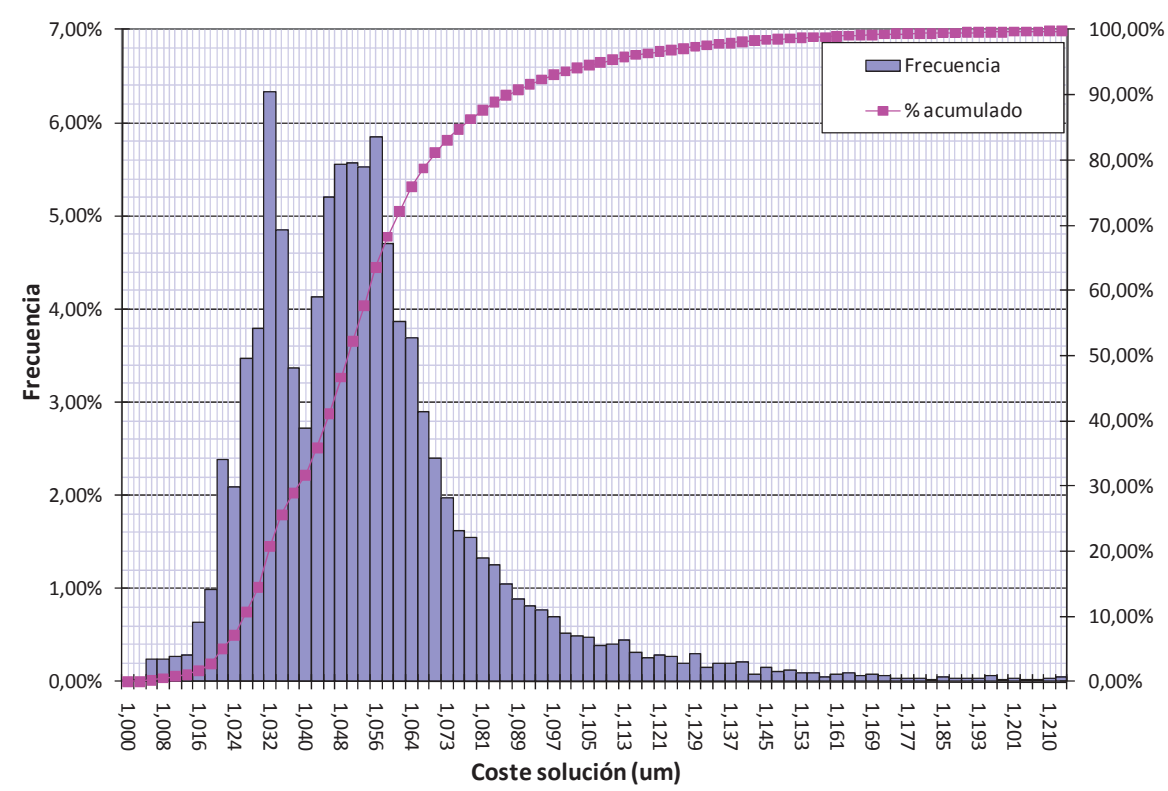

Figura 5.41. Histograma de soluciones de diseño para la red de Hanoi utilizando Harmony Search.

HS no se muestra como un método especialmente robusto, puesto que de una correcta selección de parámetros va a depender no sólo el encontrar mejores soluciones, sino también el encontrar soluciones factibles para el problema de optimización, por lo que requiere ciertos conocimientos previos del usuario para un correcto funcionamiento. Así, prácticamente un $25 \%$ de las simulaciones realizadas no convergen a una solución factible, por lo que no se consideran para realizar el histograma de soluciones.

El óptimo del sistema (6,081 millones de um) se obtiene tan sólo un par de veces, lo que imposibilita un análisis estadístico, carente de sentido en esta ocasión. Entre todas las simulaciones realizadas tan sólo se obtiene el óptimo de diseño en una ocasión, lo que implica bien una mala selección de parámetros o bien que esta metodología no es la más adecuada para obtener el óptimo para este caso concreto.

Pese a no mostrarse efectivo en la búsqueda del óptimo, HS sí que encuentra buenas soluciones para el problema, por lo que en este caso el análisis estadístico se centra en esa capacidad. De este modo, la figura 5.42 muestra la tasa de éxito de esta metodología en la búsqueda de buenas soluciones de diseño: 


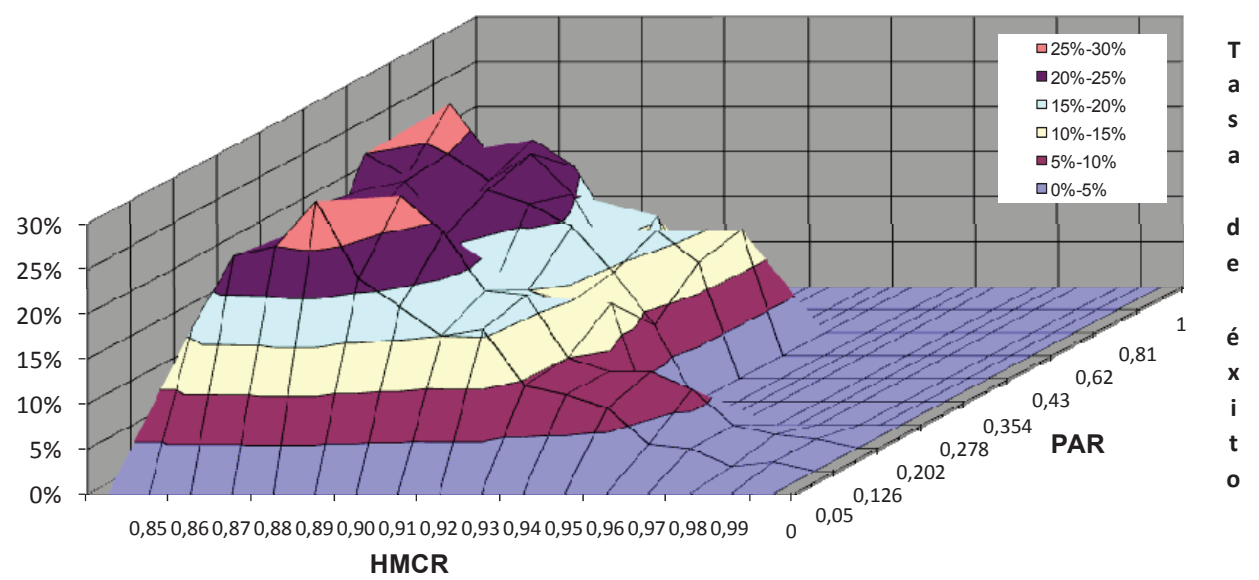

\section{Figura 5.42. Probabilidad de obtener una buena solución respecto HMCR y PAR en la red de Hanoi}

La figura permite sacar ciertas conclusiones respecto a la metodología utilizada. Así, por un lado parece claro que probabilidades HMCR por encima de 0,93 no funcionan adecuadamente, ya que no sólo no proporcionan buenas soluciones sino que ni siquiera convergen a una solución factible de diseño, por lo que en futuros análisis resulta conveniente la eliminación de estos valores. Del mismo modo, ajuste de PAR por encima de 0,62 no convergen a soluciones factibles. En vista de estos resultados, parece lógico plantear como hipótesis el descartar ajustes del PAR por encima de 0,5 en análisis futuros. En este sentido, el estudio de la red de Nueva York se planteaba de idéntico modo al de la red de Hanoi, con el objetivo de confirmar la hipótesis planteada.

Considerando un ajuste del PAR que dé lugar a convergencia, la figura muestra como el valor del HMCR resulta más crítico cuando se considera la probabilidad de obtener mejores soluciones, puesto que salvo algún pequeño pico, la posibilidad de obtener una buena solución se mantiene constante en las isolíneas de PAR. Así, en esta primera aproximación, HS proporciona alrededor de un $25 \div 30 \%$ de buenas soluciones en su mejor zona de trabajo, por lo que en este aspecto proporciona unos resultados sensiblemente inferiores a otros métodos como por ejemplo APG, capaz de obtener hasta un $60 \%$ de buenas soluciones.

Una vez determinadas aquellas zonas de HMCR y PAR donde el algoritmo HS no converge hacia soluciones factibles se tomó la determinación de realizar otra ronda de simulaciones, de cara a realizar un análisis estadístico más realista acerca de las posibilidades que ofrece esta técnica de optimización. Así, de cara a homogeneizar los cálculos con el resto de metodologías se amplió el tamaño de la memoria a 100 individuos, mientras que en los restantes parámetros se eliminaron aquellas zonas de cálculo donde el algoritmo no tenía 
convergencia hacia soluciones factibles. El valor de los distintos parámetros realizados se muestra en la tabla inferior:

\begin{tabular}{|c|c|c|}
\hline \multicolumn{2}{|c|}{ PARÁMETROS } & RANGO DE VALORES \\
\hline Tamaño de la memoria & $\mathrm{N}$ & 100 \\
\hline Probabilidad HMCR & HMCR & $0,87-0,93$ (7 valores) \\
\hline Ajuste PAR & PAR & $0,1-0,5$ (5 valores) \\
\hline
\end{tabular}

Tabla 5.8. Rango de parámetros utilizado en el diseño óptimo de la red de Hanoi aplicando HS

Esta nueva tanda de cálculos consta de un total de 7000 simulaciones, distribuidas de modo que cada posible combinación de parámetros se repite 200 veces. El grado de convergencia hacia soluciones factibles alcanza en este caso el $100 \%$ de las simulaciones realizadas. La figura inferior muestra la probabilidad de obtener una buena solución de diseño en función de la probabilidad HMCR y el ajuste del PAR:

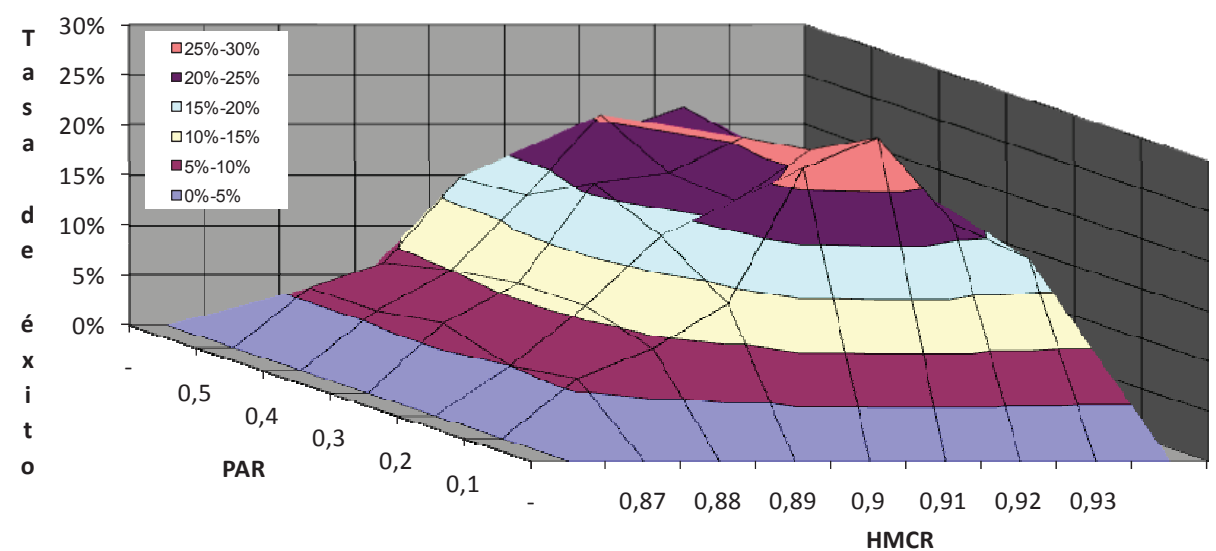

Figura 5.43. Probabilidad de obtener una buena solución respecto HMCR y PAR en la red de Hanoi

Observando la figura parece claro que probabilidades HMCR entre 0,9 y 0,92 proporcionan la mejor zona de trabajo en la red de Hanoi, superando el $20 \%$ de "buenas soluciones", independientemente del ajuste de PAR considerado. En este último caso, la diferencia entre utilizar un ajuste del PAR u otro no resulta tan importante siempre que se garantice la convergencia hacia soluciones factibles de diseño.

\subsubsection{Red de los túneles de Nueva York}

El estudio en la red de Hanoi permite sacar ciertas conclusiones de interés, que deben verse refrendadas en el análisis estadístico de soluciones obtenidas para la red de los túneles de 
Nueva York. Se considera el mismo rango de parámetros del caso anterior (tabla 5.7). El tamaño de la memoria, que representa la población del algoritmo, se considera constante y de valor 100. El número de simulaciones realizadas fue 27000 , realizándose 200 cálculos para cada una de las posibles combinaciones. El histograma de soluciones obtenido es el siguiente:

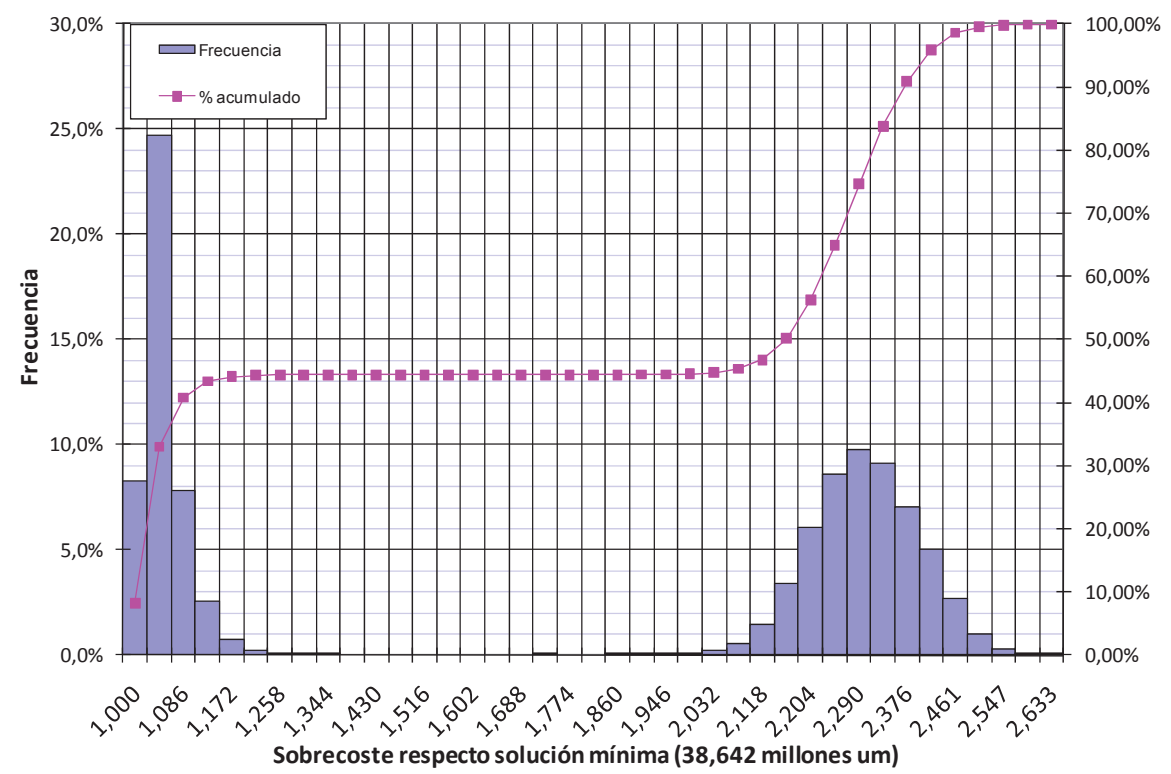

Figura 5.43. Histograma de soluciones de diseño para la red de los túneles de Nueva York utilizando Harmony Search.

El histograma muestra dos zonas claramente diferenciadas. La zona de la izquierda representa las soluciones que convergen hacia soluciones factibles. El mínimo coste obtenido para la red de los túneles de Nueva York es 38,642 millones de um, que iguala el mínimo coste obtenido con el resto de métodos. Tal como se vio en la red de Hanoi, el algoritmo HS no es una técnica tan robusta como otras, por lo que una buena elección de valores para los parámetros del algoritmo es crucial. De este modo, la zona de la derecha del histograma representa soluciones que no convergen hacia soluciones factibles, y vienen dadas por una elección incorrecta de los parámetros.

En este caso, el óptimo de diseño se obtiene en más de un $8 \%$ del total de simulaciones. Los siguientes gráficos analizan la posibilidad de obtener tanto el valor de mínimo coste como una buena solución (3\%) en función de los parámetros de optimización. 


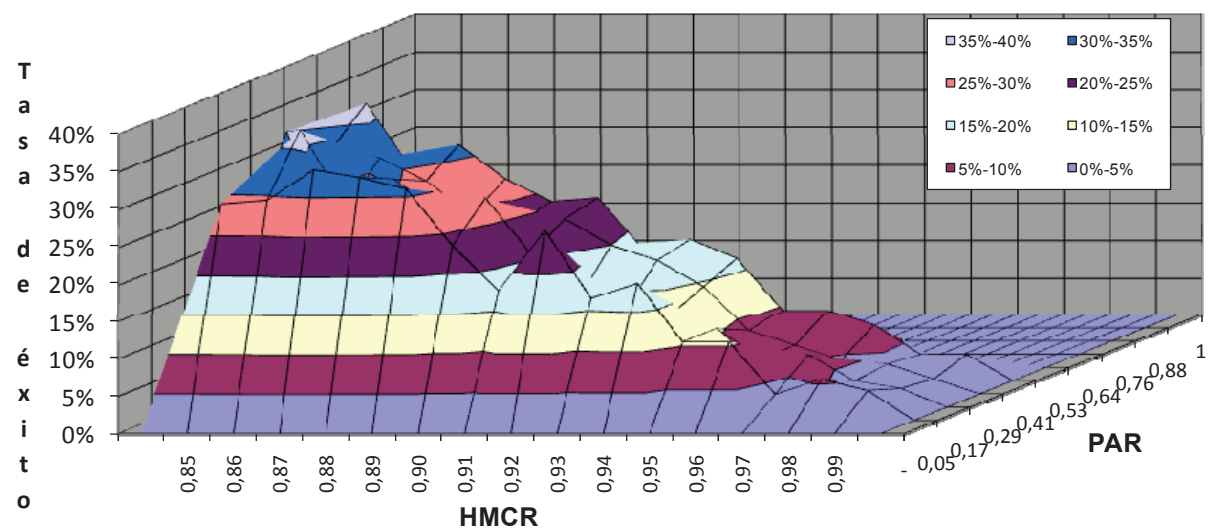

Figura 5.44. Probabilidad de obtener solución óptima respecto a probabilidad HMCR y ajuste del PAR en la red de NY

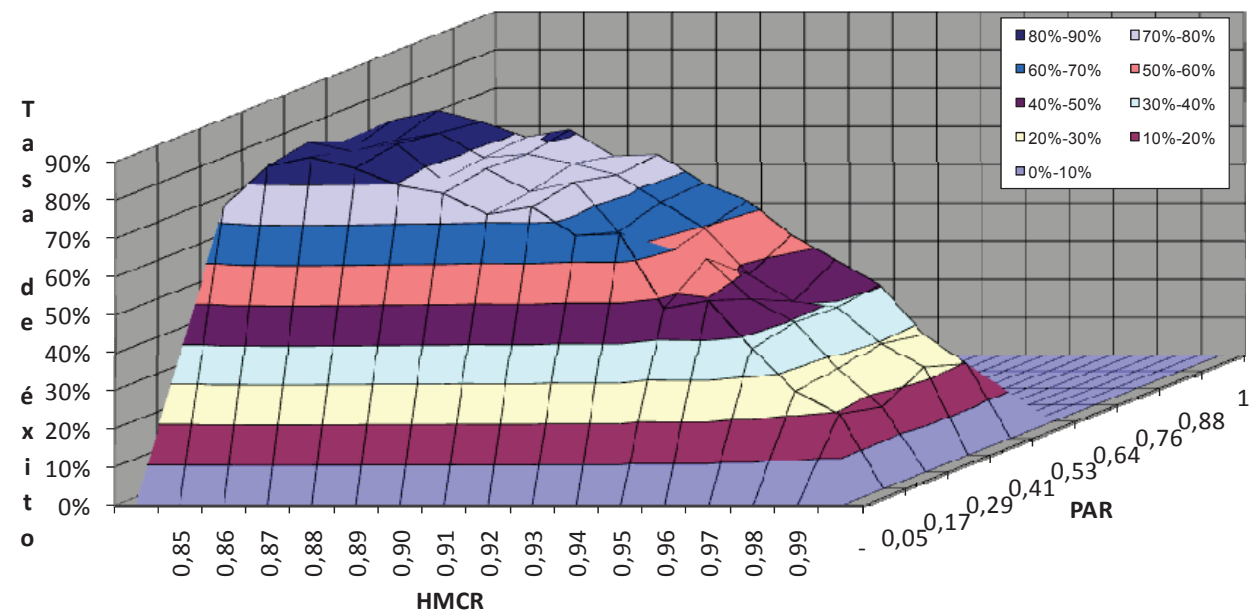

Figura 5.45. Probabilidad de obtener una buena solución respecto probabilidad HMCR y ajuste del PAR en la red de NY

La figura 5.44 muestra que cuando el ajuste del PAR se encuentra por encima de 0.5 el algoritmo no es capaz de encontrar ni una sola solución de mínimo coste. Por el contrario, siempre que dicho ajuste se encuentra por debajo de 0.5 , el algoritmo HS muestra una capacidad similar en todos los valores para encontrar soluciones mínimas, por lo que en este rango, el porcentaje de éxito depende de la probabilidad HMCR.

La mayor simplicidad de la red de Nueva York ( $16^{21}$ posibles casos) respecto a otras redes consideradas en este trabajo permite tener la posibilidad de obtener el óptimo de diseño con todo el rango de probabilidades estudiado para HMCR. Sin embargo, dentro del intervalo de 
valores simulado, las probabilidades más bajas de HMCR son las que obtienen un \% mayor de éxito. Así, probabilidades para HMCR entre 0,85 y 0,88 dan un porcentaje superior al $30 \%$ en la obtención de soluciones con el mínimo coste de diseño.

La figura 5.45, que muestra la probabilidad de obtener una buena solución, es prácticamente idéntica a la figura 5.44, pero con mayores porcentajes de éxito. Al ampliar el rango de soluciones que se consideran aptas, la probabilidad de éxito sube a más de un $80 \%$ en el rango óptimo de diseño para los parámetros estudiados. Del mismo modo, las simulaciones realizadas con ajustes para el PAR por encima de 0,5 no proporcionan buenas soluciones. La siguiente tabla muestra el coste medio que se obtiene para cada probabilidad de PAR estudiada:

\begin{tabular}{|c|c||c|c|}
\hline PAR & COSTE MEDIO & PAR & COSTE MEDIO \\
\hline 0,05 & 39912791,7 & 0,64 & 88776990,6 \\
\hline 0,17 & 39903500,6 & 0,7625 & 88070723,3 \\
\hline 0,29 & 39887649 & 0,88125 & 87989309,9 \\
\hline 0,41 & 39871379,2 & 1 & 89178473,5 \\
\hline 0,53 & 88105710,8 & & \\
\hline
\end{tabular}

Tabla 5.8. Coste medio de la red de Go-Yang en función de la probabilidad PAR

Tal como se aprecia en la tabla, cuando el valor de ajuste para el PAR es superior a 0,5, el algoritmo no sólo no encuentra soluciones de calidad, sino que ni siquiera es capaz de converger hacia soluciones que podamos considerar factibles. Los resultados que se obtenían en la red de Hanoi eran similares, por lo que en adelante no se consideran ajustes del PAR por encima de 0,5 , puesto que el algoritmo no converge.

Si tan sólo se tiene en cuenta las probabilidades de PAR que sí convergen hacia soluciones factibles, las figuras 5.44 y 5.45 apenas sugieren diferencias entre unos valores de PAR y otros teniendo en cuenta sólo la obtención de óptimos/buenas soluciones. Es por ello que a la hora de elegir qué rango de PAR es mejor entre 0,05 y 0,62 es necesario acudir a otros criterios de comparación, como puede ser la influencia del valor de PAR sobre el número de evaluaciones de la función objetivo realizadas.

\subsubsection{Red R-9 de Joao Pessoa}

En el diseño de la red R-9 de Joao Pessoa con el algoritmo HS se procede de modo similar al resto de redes, aplicando el conocimiento que proporciona la experiencia previa, con el objetivo de realizar un menor número de simulaciones. Así, los apartados 5.2.3.1 y 5.2.3.2 demuestran que para el ajuste del PAR, valores superiores a 0,5 no convergen hacia soluciones factibles, por lo que se ha optado por eliminar del estudio de las restantes redes estos valores.

EI PAR es por tanto un parámetro que se puede considerar de convergencia y no de optimización, puesto que una vez se produce la convergencia hacia una solución factible no 
hay ajustes mejores que otros desde un punto de vista cuantitativo. Por ello, en el estudio de esta red se considera un ajuste del PAR entre 0,05 y 0,15. En realidad, teniendo en cuenta las conclusiones derivadas de las redes de Hanoi y Nueva York, no parece que tenga gran influencia en el cálculo dejar un PAR constante. No obstante, se ha preferido emplear tres valores distintos para confirmar la hipótesis planteada.

En el caso del parámetro HMCR, el rango de valores empleado en el diseño de la red R-9 se encuentra entre 0,87 y 0,96 . El número de repeticiones realizadas para cada posible combinación de PAR y HMCR fue de 400, resultando 18000 simulaciones en total. En el diseño de la red de Joao Pessoa, el criterio de convergencia utilizado es finalizar la simulación si se produce un determinado número de iteraciones sin cambio en la mejor solución obtenida. Así, se realizaron 9000 simulaciones con un criterio de convergencia de 5000 y otras 9000 simulaciones con un criterio de convergencia de 10000. Se descarta utilizar una condición de convergencia mayor por la gran lentitud del cálculo, puesto que la red es la de mayor tamaño de todas las que se ensayan. La figura 5.46 representa el histograma de todas las soluciones obtenidas:

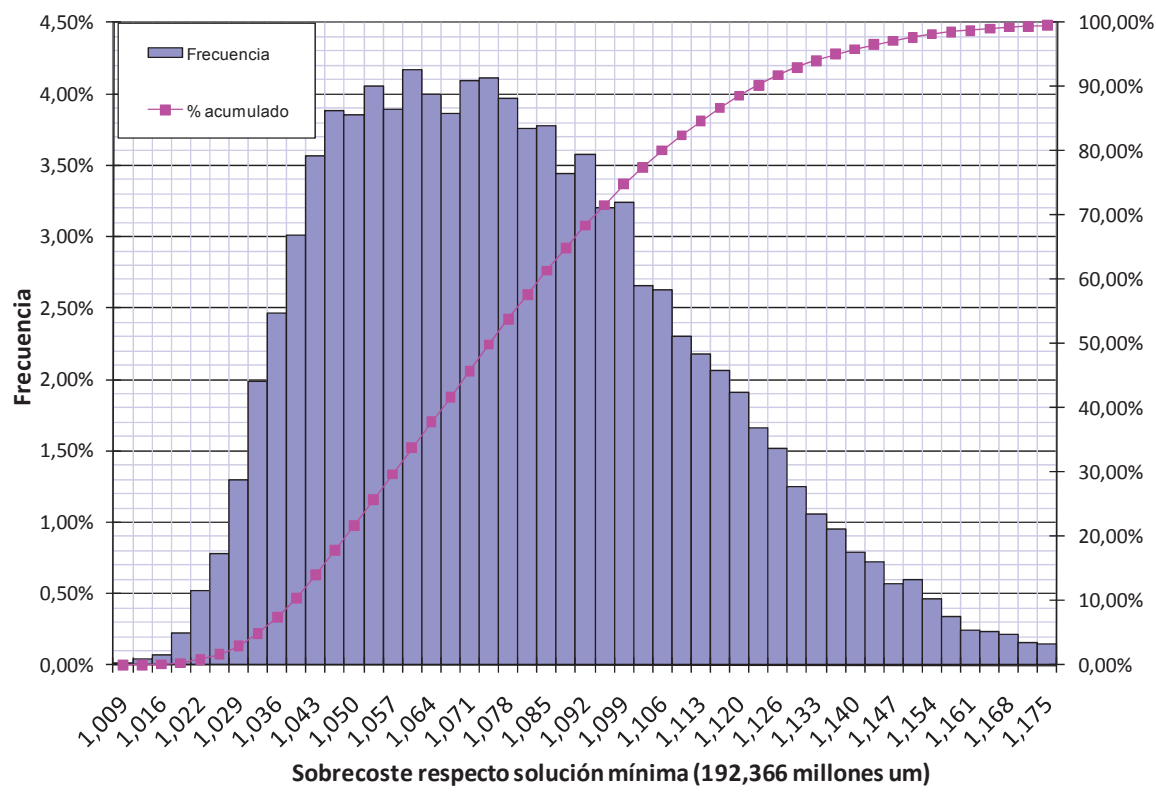

Figura 5.46. Histograma de soluciones para la red $\mathbf{R}-9$ diseñada con algoritmo HS

El mínimo coste de diseño obtenido por medio del algoritmo HS es 194,849 millones de um. Este coste de diseño es superior en algo más de un $1 \%$ al mínimo encontrado con otros métodos, como APG o SFLA. En base a esto, la representación del histograma en el eje x está realizada en base al mínimo coste absoluto de diseño que se ha encontrado (192,366 millones um). 
De este modo, el análisis estadístico de soluciones se realiza en torno al concepto de buena solución, que implica un aumento en el coste de la red de un máximo del 3\% respecto a la mínima solución de diseño obtenida por todos los métodos. Esta condición implica que el máximo coste de diseño para que un vector solución entre dentro de lo que se considera una buena solución de diseño es de 198,137 millones um.

La siguiente figura muestra la probabilidad de encontrar una buena solución para la red de Joao Pessoa en función del valor dado a los parámetros del algoritmo HS.

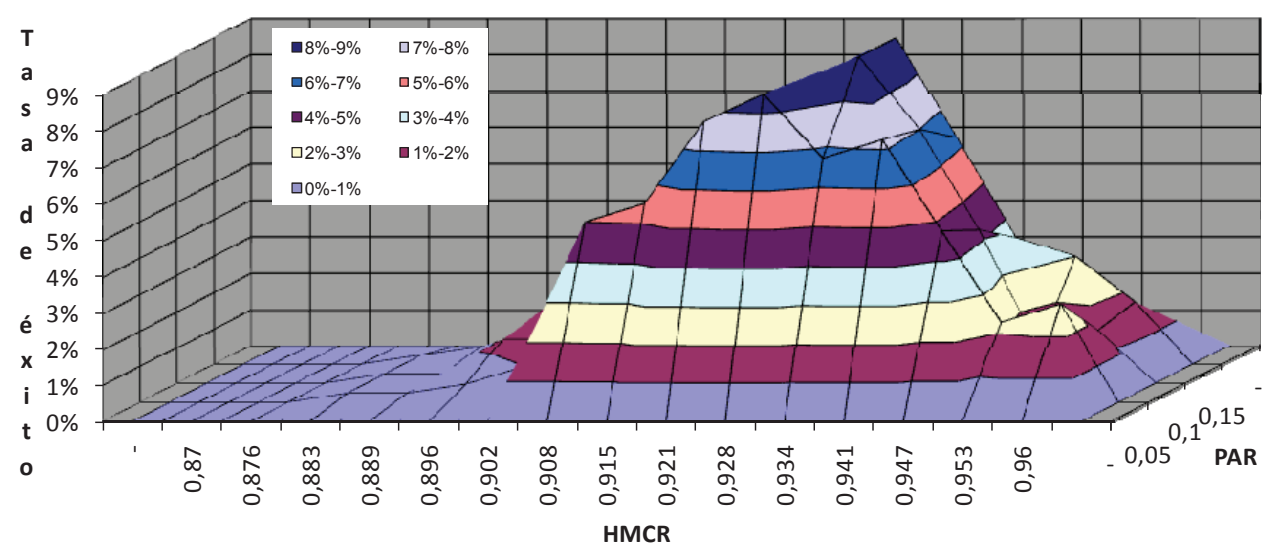

Figura 5.47. Probabilidad de encontrar una buena solución según HMCR y PAR en la red R-9 de Joao Pessoa

Observando la figura parece claro que probabilidades de HMCR entre 0,92 y 0,94 son las que mejor funcionan desde el punto de vista de la obtención de buenas soluciones. En este rango de HMCR existe un 7-9\% de probabilidad de obtener una buena solución.

Por otro lado, en el rango de ajuste estudiado para el PAR, éste no ejerce ninguna influencia en la probabilidad de obtener una buena solución. El diseño de la red de Joao Pessoa confirma la hipótesis planteada en el resto de redes, es decir, el PAR es un parámetro de convergencia, de modo que si se asegura que éste tenga un valor adecuado que permita al algoritmo encontrar soluciones factibles no se requiere ningún otro tipo de optimización.

Desde un punto de vista cuantitativo, el porcentaje de buenas soluciones es bajo si se compara con otros métodos como APG o SFLA, donde se obtiene un porcentaje de buenas soluciones superior al $35 \%$ en las mejores combinaciones. No obstante, hay que tener en cuenta que el número de evaluaciones de la función objetivo que realiza HS es sustancialmente menor.

En relación a esto, cuanto mayor es la condición de convergencia mayor es la cantidad de evaluaciones de la función objetivo que se permite realizar al algoritmo. En este caso, se han 
realizado 9000 simulaciones con un criterio de convergencia de 5000 simulaciones sin cambio y otras 9000 con un criterio de convergencia de 10000 simulaciones sin cambio. Las figuras que se muestran a continuación representan la probabilidad de obtener una buena solución en función de su condición de finalización y de las probabilidades de HMCR y ajuste del PAR:

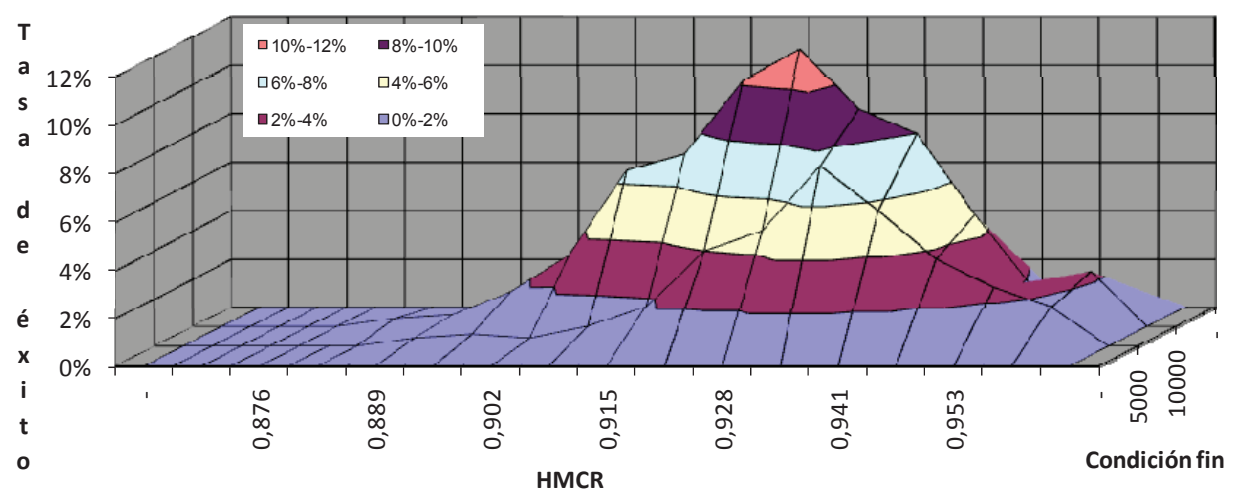

Figura 5.47. Probabilidad de obtener una buena solución en función de condición fin y HMCR

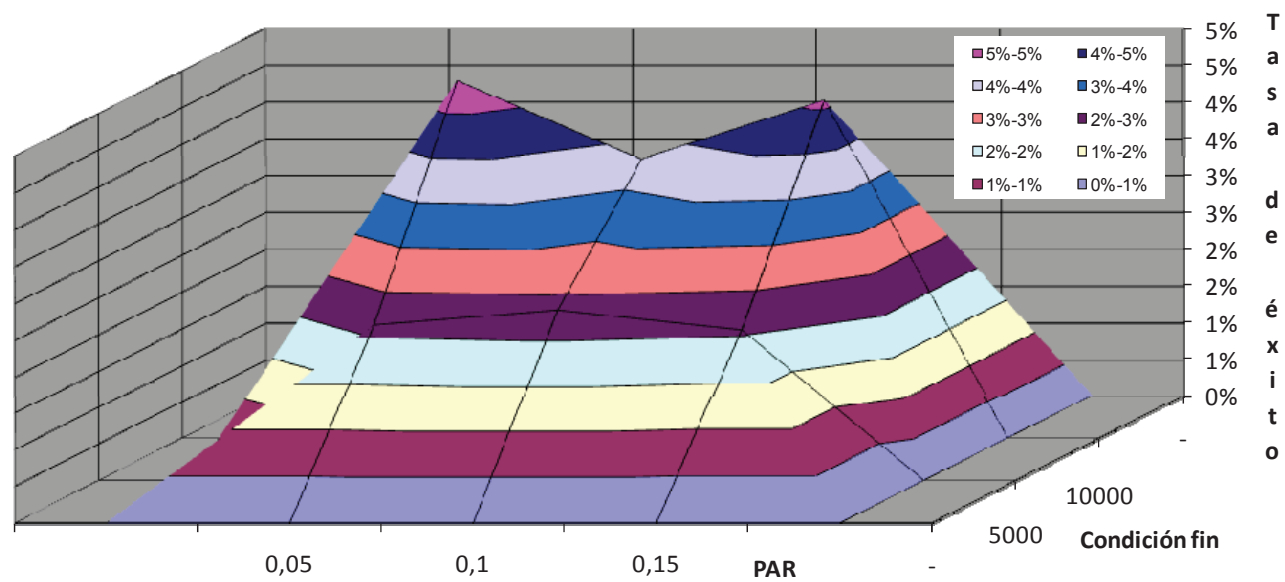

Figura 5.48. Probabilidad de obtener una buena solución en función de condición fin y PAR

Ambas figuras permiten apreciar como el número de buenas soluciones es mayor cuando también lo es la condición de convergencia para el algoritmo. Esto es lógico, puesto que a mayor número de evaluaciones de la función objetivo, mayor es la probabilidad de encontrar mejores soluciones.

El criterio de convergencia adquiere especial importancia cuando el espacio de soluciones es elevado, puesto que el número de posibles soluciones es mayor y requiere de una mayor exploración por parte del algoritmo. La red R-9 de Joao Pessoa tiene $10^{72}$ posibles soluciones, 
puesto que el trazado tiene 72 tuberías y cada una de ellas puede tener 10 posibles diámetros.

\subsubsection{Red de Go-Yang}

El proceso de optimización realizado para el diseño óptimo de la red de Go-Yang sigue las mismas directrices que las de la red de Joao Pesoa. De este modo, la población del algoritmo se considera constante y de valor igual a 30 individuos. Para los restantes parámetros del algoritmo HS, en el caso del ajuste de PAR no se consideran valores por encima de 0,5 , puesto que dan problemas de convergencia hacia buenas soluciones. Es por ello que los valores considerados para este parámetro se encuentran entre 0,05 y 0,15.

Otro parámetro de interés para la optimización es la probabilidad HMCR, que en este caso se estudia en un rango comprendido entre 0,87 y 0,96 . Estos valores indican la probabilidad de elegir un valor para la variable de decisión entre los almacenados en la memoria y viene dada en tanto por uno.

Respecto a la condición de convergencia del algoritmo HS se han realizado la mitad de los cálculos con una condición de convergencia del algoritmo 5000 iteraciones sin cambio y la otra mitad de los cálculos con una condición de convergencia de 10000 iteraciones sin cambio. Variar la condición de final del proceso de optimización permite extraer conclusiones acerca de la importancia de ésta en cuanto a la obtención de óptimos y buenas soluciones se refiere.

Así, se han realizado un total de 12000 simulaciones con estos parámetros, cuyos resultados vienen dados en el siguiente histograma de soluciones:

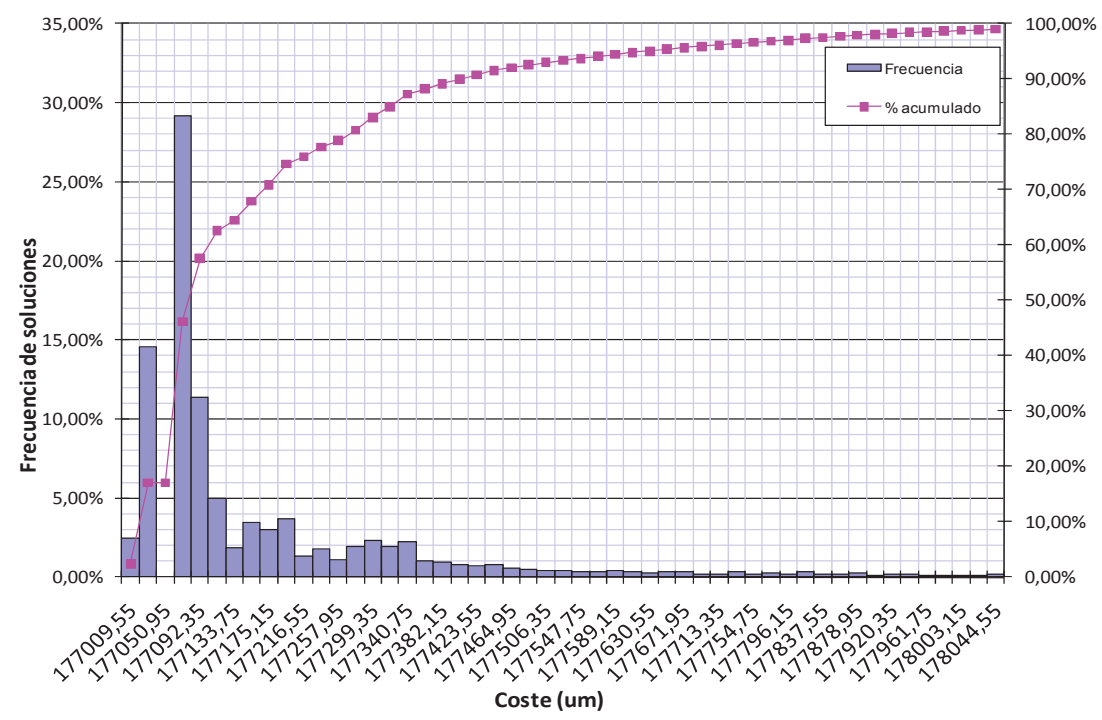

Figura 5.49. Histograma de soluciones para la red de Go-Yang aplicando metodología HS. 
La menor complejidad de la red de Go-Yang en cuanto a diseño permite que el número de soluciones que proporciona el algoritmo cerca del mínimo coste de diseño sea elevado. En el histograma se observa como apenas un $2,5 \%$ de las simulaciones realizadas obtienen el coste mínimo de diseño en esta red, de valor 177.009 um. Este valor es coincidente con el coste mínimo que obtiene el resto de métodos, por lo que podemos considerarlo a efectos prácticos como el óptimo del sistema.

Cabe destacar que pese a que el número de óptimos no es muy elevado, sí que se dan soluciones próximas a este óptimo con relativa facilidad, de modo que el $100 \%$ de las simulaciones tienen como resultado un coste de diseño que supera el óptimo en menos de un 1\%. Es por ello que en este caso no tiene sentido el realizar un análisis de buenas soluciones, puesto que el $100 \%$ de las simulaciones realizadas entrarían dentro de este concepto.

Los siguientes gráficos muestran la probabilidad de obtener el óptimo en función de los distintos parámetros estudiados, de cara a obtener la mejor combinación posible para los parámetros de ajuste en HS.

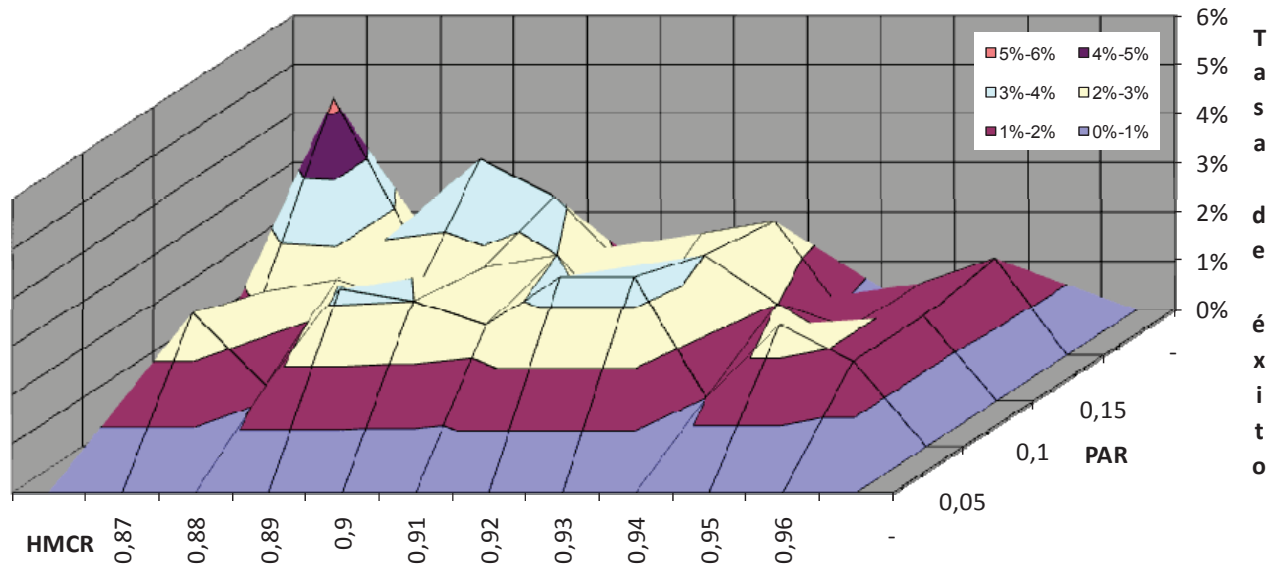

Figura 5.50. Probabilidad de obtener solución óptima en función de HMCR y PAR

Al contrario que en otras redes de diseño, la figura 5.50 no proporciona excesiva información respecto a cuál es la combinación más óptima desde un punto de vista cuantitativo de obtención del óptimo. El gráfico no permite apreciar ajustes para los distintos parámetros que destaquen de una forma clara, siendo la probabilidad de obtener una solución óptima inferior al $6 \%$ en todas ellas.

Los resultados obtenidos por el algoritmo HS en la red de Go-Yang están en la línea de los obtenidos en el resto de redes, puesto que $\mathrm{HS}$ no se ha mostrado como una técnica especialmente eficiente en la búsqueda de óptimos. No obstante, en el resto de redes diseñadas, determinadas combinaciones en el rango de parámetros estudiado se mostraban 
más efectivas que otras, de modo que era posible elegir una combinación óptima. En este caso, el estudio de los parámetros HMCR y PAR no permite elegir una combinación óptima en el rango estudiado.

Por otro lado, en consonancia con el diseño realizado con HS para la red R-9 de Joao Pessoa, se utilizaron dos condiciones de convergencia distintas en las simulaciones realizadas para la red de Go-Yang. Las siguientes figuras muestran la probabilidad de obtener el óptimo en función de los parámetros de HS y la condición de fin de cálculo elegida.

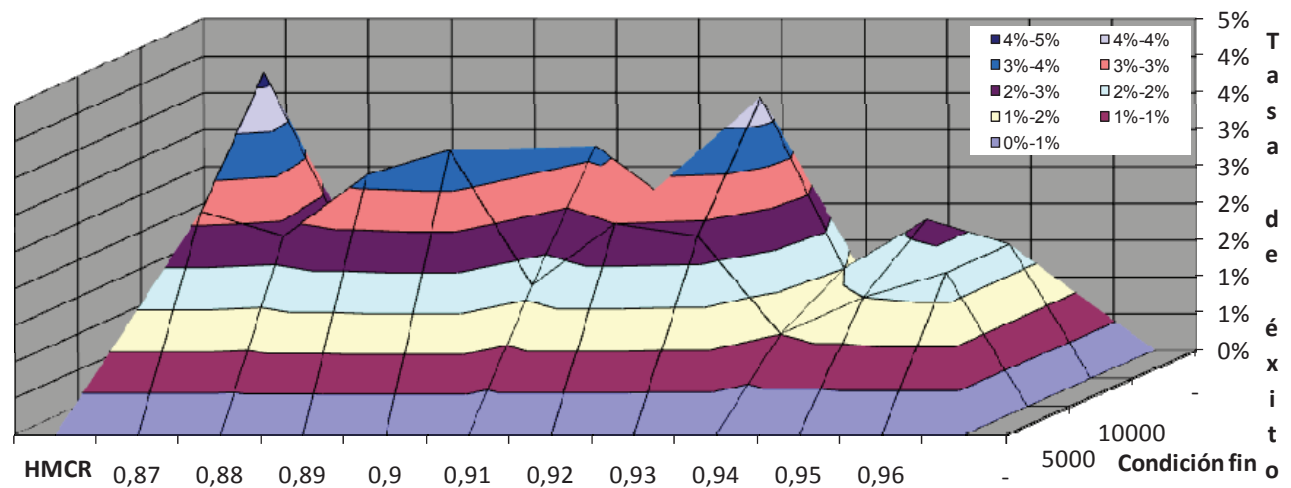

Figura 5.51. Probabilidad de obtener solución óptima en función de HMCR y condición fin.

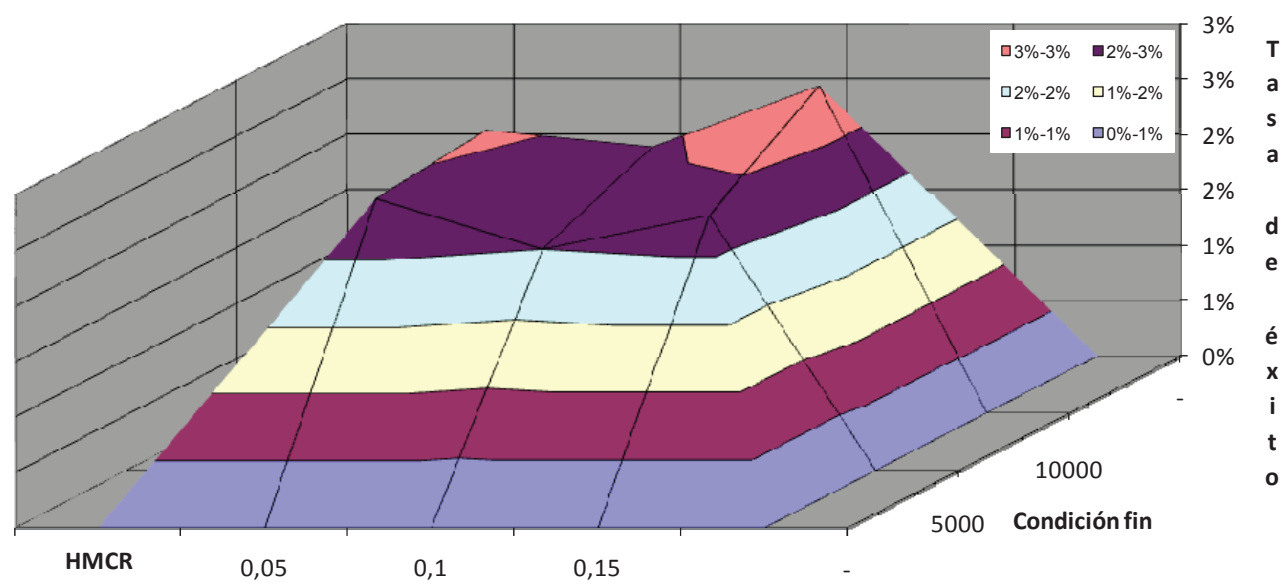

Figura 5.52. Probabilidad de obtener solución óptima en función de PAR y condición fin.

Ambas figuras permiten apreciar como la diferencia entre usar 5000 o 10000 iteraciones sin cambio como condición de parada del algoritmo en esta red es mínima, puesto que el porcentaje de soluciones óptimas obtenidas con una condición de parada u otra apenas difiere. Cabe destacar que en el caso de la red R-9 de Joao Pessoa ocurría la situación 
contraria, tal que los resultados obtenidos con una condición de parada más grande resultaban ser significativamente mejores.

La diferencia en estos resultados entre ambas redes probablemente haya que buscarla en el tamaño y complejidad de una y otra. En el caso de la red de Go-Yang, el número de escenarios solución posible es $10^{30}$, puesto que el número de tuberías de la red es 30 , pudiendo tener cada una de ellas 10 posibles valores correspondientes a la gama de tuberías utilizada para el cálculo. Por su lado, la red R-9 de Joao Pessoa consta de 72 tuberías y cada una de ellas puede tomar 10 posibles diámetros, de modo que el total de escenarios posibles es $10^{72}$. En base a esto, la red de Joao Pessoa tiene $10^{42}$ veces más escenarios posibles que la red de Go-Yang, motivo por el que cuanto más se alargue el cálculo más probabilidades tendrá el algoritmo de encontrar una mejor solución. En el caso de la red de Go-Yang, al ser el número de escenarios menor, el alargar el cálculo no proporciona una mejora considerable, puesto que 5000 iteraciones sin cambio se antojan como suficientes a la vista de los resultados obtenidos.

\subsubsection{Ajuste de parámetros Algoritmo SFL}

El análisis de los parámetros óptimos para SFLA es probablemente el más complejo de todos los realizados, puesto que el número de parámetros que requiere su configuración es de cinco, con la dificultad adicional que ello implica. Los distintos parámetros, así como el rango de valores estudiados se muestran en la siguiente tabla:

\begin{tabular}{|c|c|c|}
\hline \multicolumn{2}{|c|}{ PARÁMETROS } & RANGO DE VALORES \\
\hline Memeplexes & $m$ & 10 \\
\hline Ranas por Memeplex & $n$ & 10 \\
\hline Ranas por Submemeplex & $Q$ & $0.25,0.43,0.62,0.81,1$ \\
\hline Pasos evolutivos & $N$ & $5,11.25,17.5,23,75,30$ \\
\hline Parámetro aceleración & $C$ & $1,1.375,1.75,2.125,2.5$ \\
\hline
\end{tabular}

Tabla 5.9. Rango de valores utilizados para los distintos parámetros SFLA

Pese al mayor número de parámetros susceptibles de ajuste, la forma de trabajar en el algoritmo SFL es similar a la empleada en el resto de metodologías. Así, inicialmente se dejaron como parámetros de cálculo fijos el número de memeplexes y el número de ranas por memeplex. Ambos parámetros definen el tamaño de población del algoritmo. De este modo, para el análisis de $\mathrm{Q}, \mathrm{N}$ y $\mathrm{C}$ consideramos un tamaño fijo de población de 100 individuos, por lo que tanto el número de memeplexes como el de ranas por memeplex es 10.

Los tres parámetros restantes $\mathrm{Q}, \mathrm{N}$ y $\mathrm{C}$ se someten a análisis estadístico. Para cada uno de ellos se consideran cinco valores diferentes, por lo que en total hay un total de 125 combinaciones distintas entre estos parámetros. 


\subsubsection{Red de Hanoi}

En el caso de la red de Hanoi se realizan 200 simulaciones con cada una de las posibles combinaciones. Inicialmente se muestra el histograma, que representa la totalidad de las simulaciones realizadas, para posteriormente realizar el análisis estadístico y encontrar la combinación más adecuada.

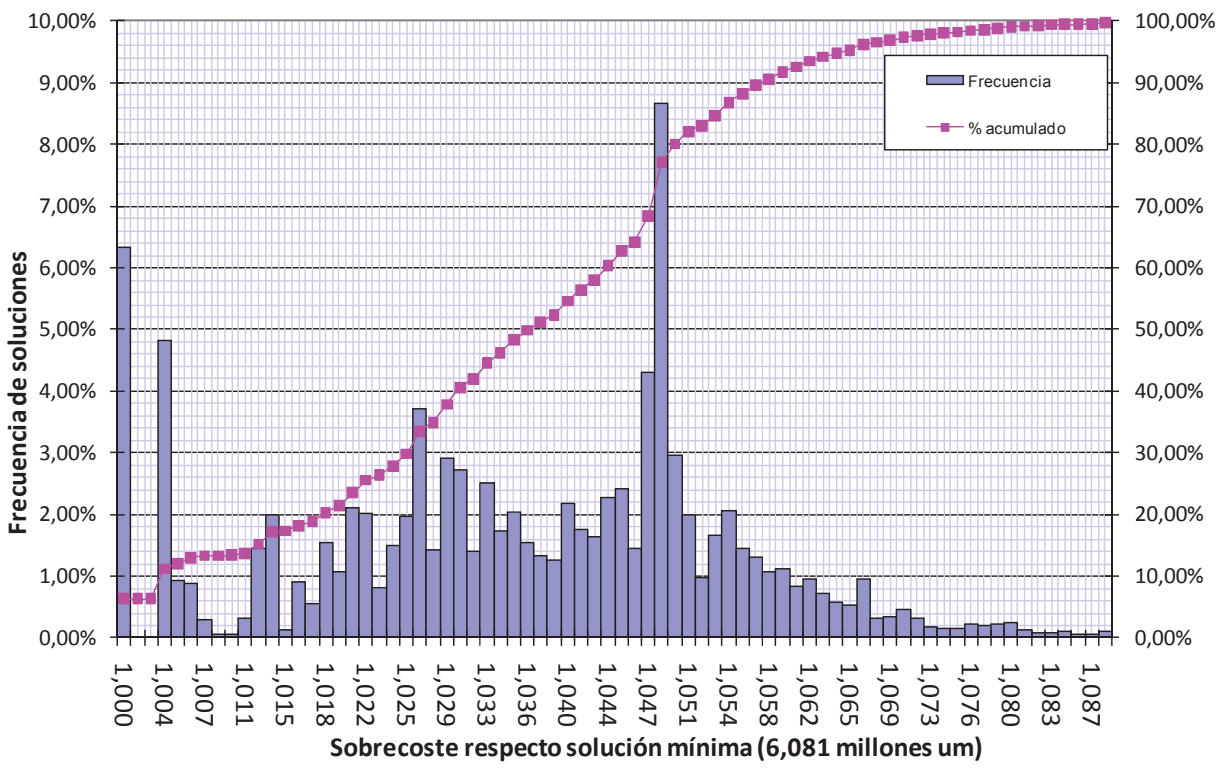

\section{Figura 5.53. Histograma de soluciones para la red de Hanoi utilizando algoritmo SFLA.}

Cabe destacar en esta ocasión la diferencia existente entre el histograma de soluciones que obtiene SFLA y el de otros métodos como pueda ser HS o SA, donde la forma del histograma recuerda a una campana de Gauss. En SFLA el número de óptimos obtenidos para la red de Hanoi es mayor que en el resto de métodos. Además, llama la atención el hecho de que no hay valores entre 6,081 y 6,103 millones de um, lo que parece indicar que el algoritmo no registra una tendencia a caer en mínimos locales cuando ya se encuentra cerca de la solución óptima.

Los siguientes gráficos analizan la influencia de cada uno de estos parámetros en la obtención del óptimo de la red de Hanoi. El objetivo es hallar la configuración óptima de estos tres parámetros, para posteriormente realizar el estudio de población en el apartado 5.2. Así, para las simulaciones que obtuvieron el valor óptimo de diseño, los gráfico 5.53, 5.54 y 5.55 estudian la influencia de $Q, N$ y $C$ en los cálculos realizados: 


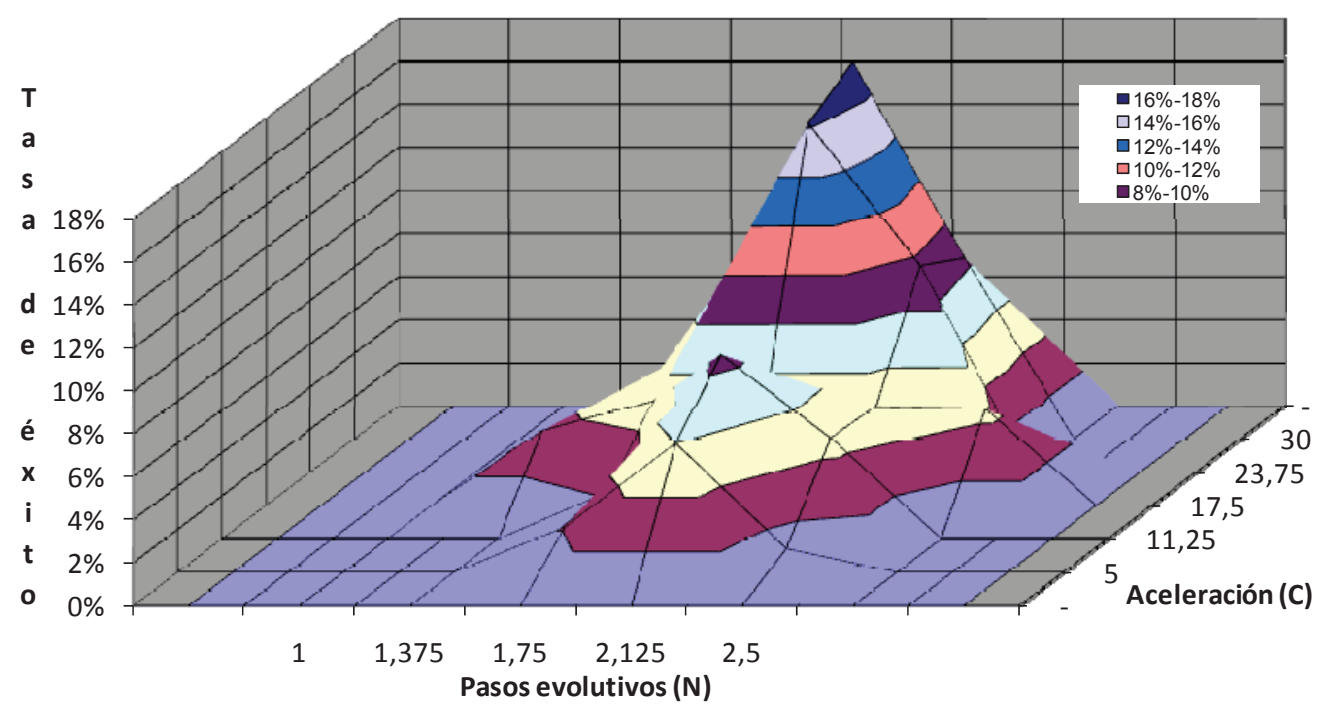

Figura 5.53. Probabilidad de obtener el mínimo respecto a $\mathrm{N}$ y $\mathrm{C}$ en la red de Hanoi.

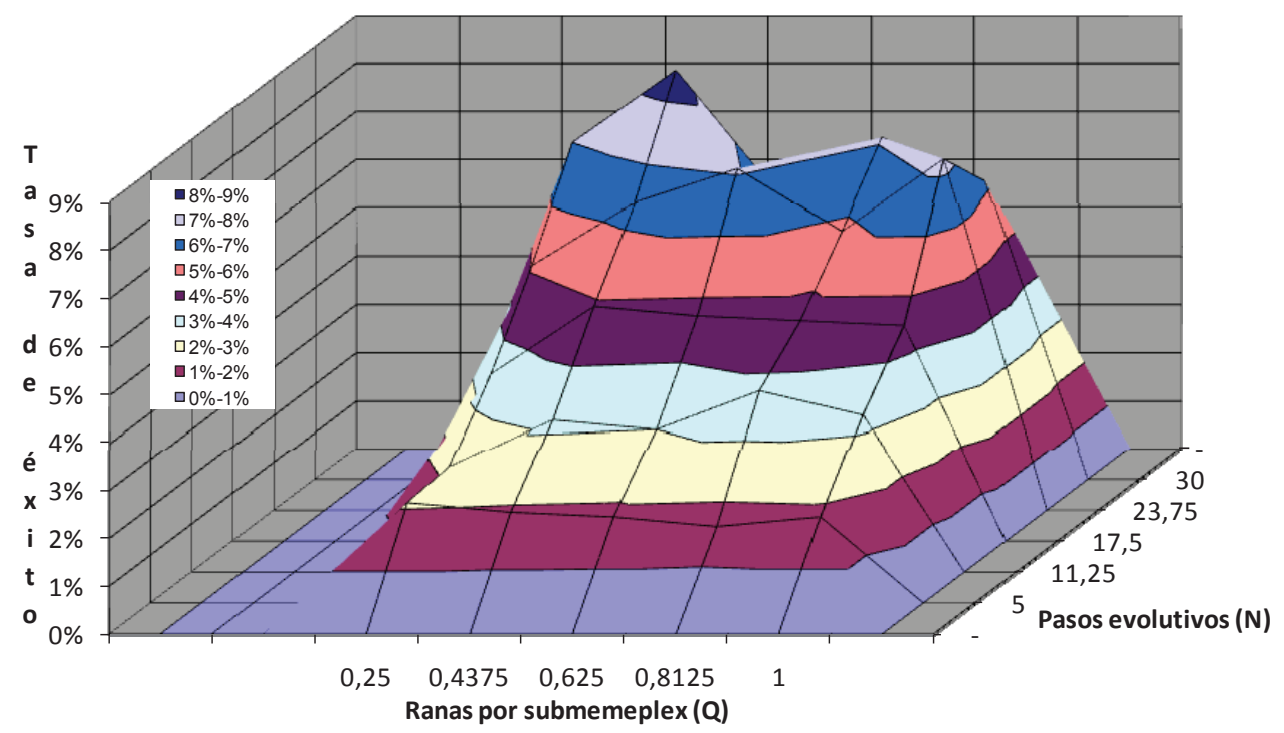

Figura 5.54. Probabilidad de obtener el mínimo respecto a $Q$ y $N$ en la red de Hanoi. 


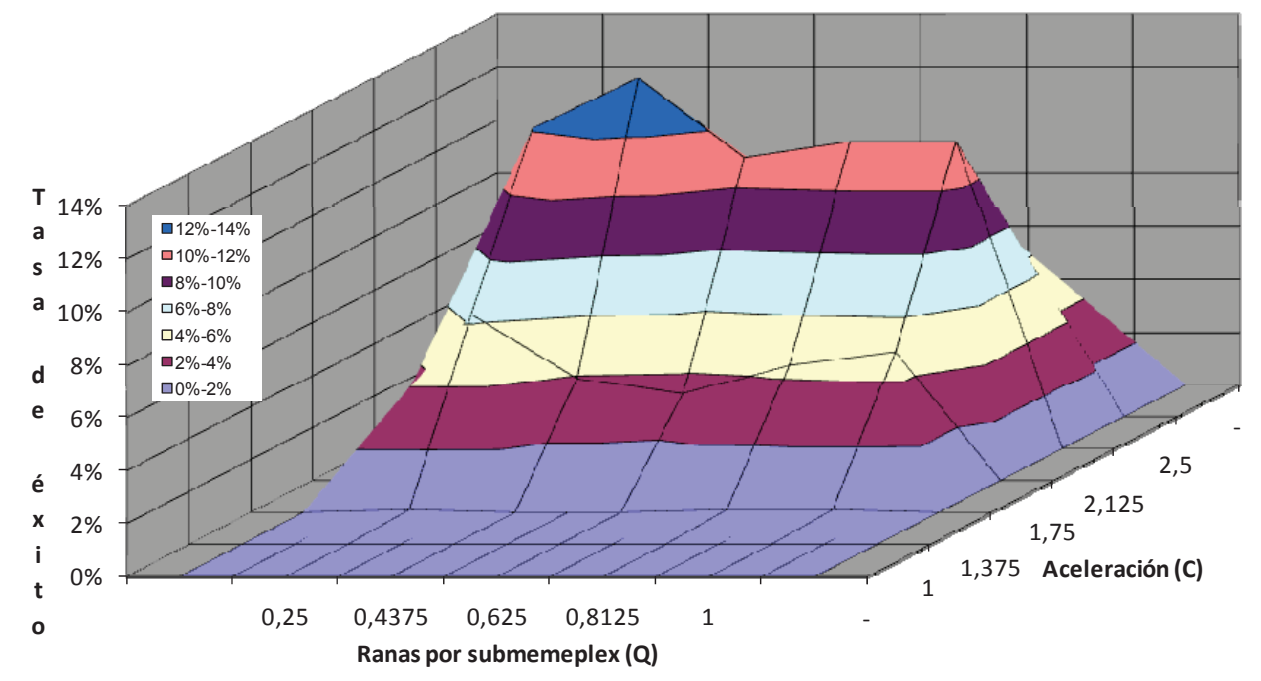

Figura 5.55. Probabilidad de obtener el mínimo respecto a $C$ y $Q$ en la red de Hanoi.

En una primera estimación, los resultados son algo superiores en las mejores zonas a los obtenidos con el APG, puesto que el mínimo se obtiene entre el 10 y el $15 \%$ de las ocasiones. Del mismo modo, SFLA se muestra en la red de Hanoi muy superior a HS y PSO en lo que a número de óptimos se refiere.

De las tres figuras anteriores se pueden extraer las siguientes conclusiones:

- Las figuras muestran que el número de óptimos aumenta conforme el número de pasos evolutivos $(\mathrm{N})$ es mayor. En las simulaciones realizadas el mayor número de pasos evolutivos utilizados es 30 .

- Para el parámetro de aceleración C, el valor óptimo parece rondar el 2,25. Éste es el parámetro que menos dudas crea acerca de su óptimo en esta red, puesto que tanto valores inferiores como superiores dan porcentajes menores de éxito.

- Por último, el número de ranas por submemeplex Q parece ser el parámetro menos influyente en lo que a obtención del mínimo se refiere, puesto que apenas se aprecian diferencias residuales entre unos valores y otros.

Todas estas conclusiones son tenidas en cuenta desde la perspectiva única de obtención del mínimo coste. Así, desde un punto de vista únicamente cuantitativo la combinación óptima de parámetros sería la correspondiente a $\mathrm{C}=2,25, \mathrm{~N}=30$ y como valor $\mathrm{Q}$, pese a no tener una influencia tan marcada, se ha escogido como valor 0,8125. Se realizaron 1800 simulaciones más con los parámetros óptimos, obteniéndose el mínimo coste para la red de Hanoi en un $31 \%$ de las ocasiones, muy por encima de todos los resultados mostrados hasta ahora. La 
representación de los cálculos realizados con los parámetros óptimos, junto con el resto de cálculos realizados se muestra en la figura 5.56.

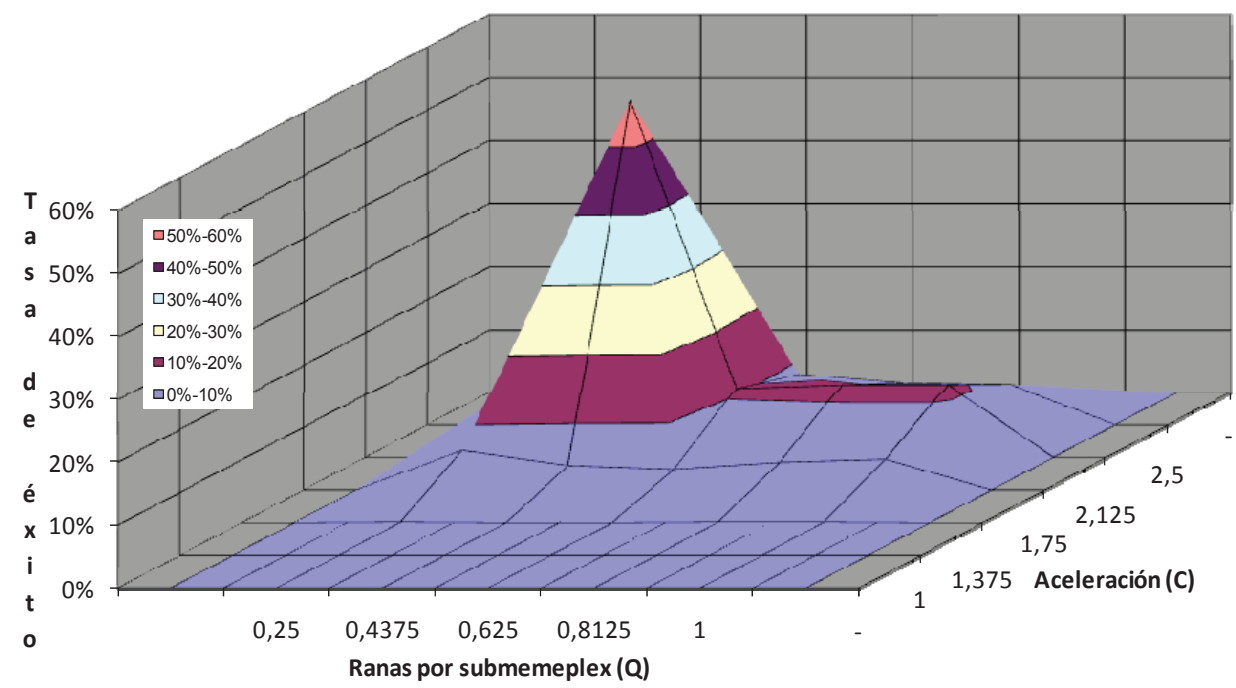

Figura 5.56. Simulación con parámetros óptimos SFLA para la red de Hanoi

La figura 5.56 pone de manifiesto la importancia del análisis estadístico de parámetros, puesto que en la red de Hanoi, la probabilidad de encontrar un mínimo es más del doble si la simulación se realiza con una correcta selección de parámetros.

No obstante, es necesario remarcar que este apartado tan sólo tiene en cuenta el análisis cuantitativo, centrado en la obtención del mínimo coste. En el proceso de optimización también se hace necesario tener cuenta otro tipo de consideraciones, como puede ser el gasto computacional que se pueda derivar de utilizar unos valores $u$ otros en los parámetros de cálculo. Este tipo de estudio se realiza en el análisis estadístico de eficiencia que se lleva a cabo en el capítulo 6.

Asimismo, resulta interesante el estudio de las soluciones obtenidas por SFLA considerando el concepto de buena solución. 


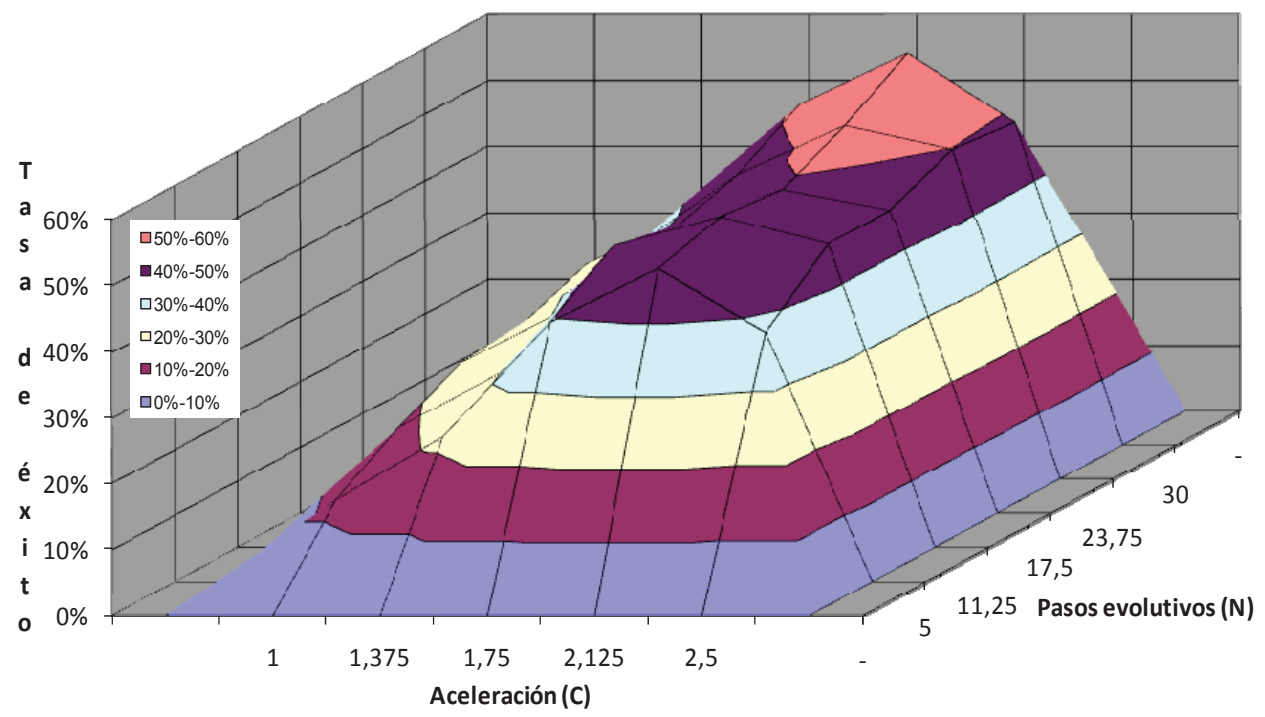

Figura 5.57. Probabilidad de obtener una buena solución respecto a $C$ y $N$ en la red de Hanoi.

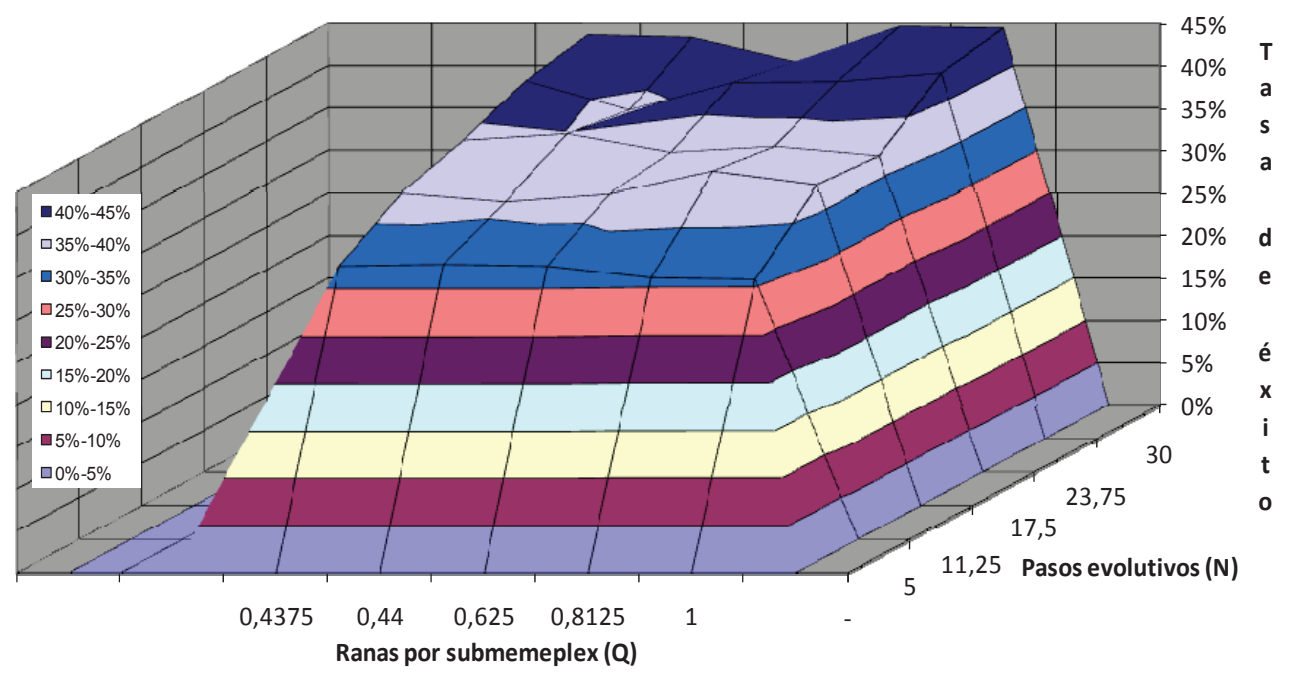

Figura 5.58. Probabilidad de obtener una buena solución respecto a $Q$ y $N$ en la red de Hanoi 


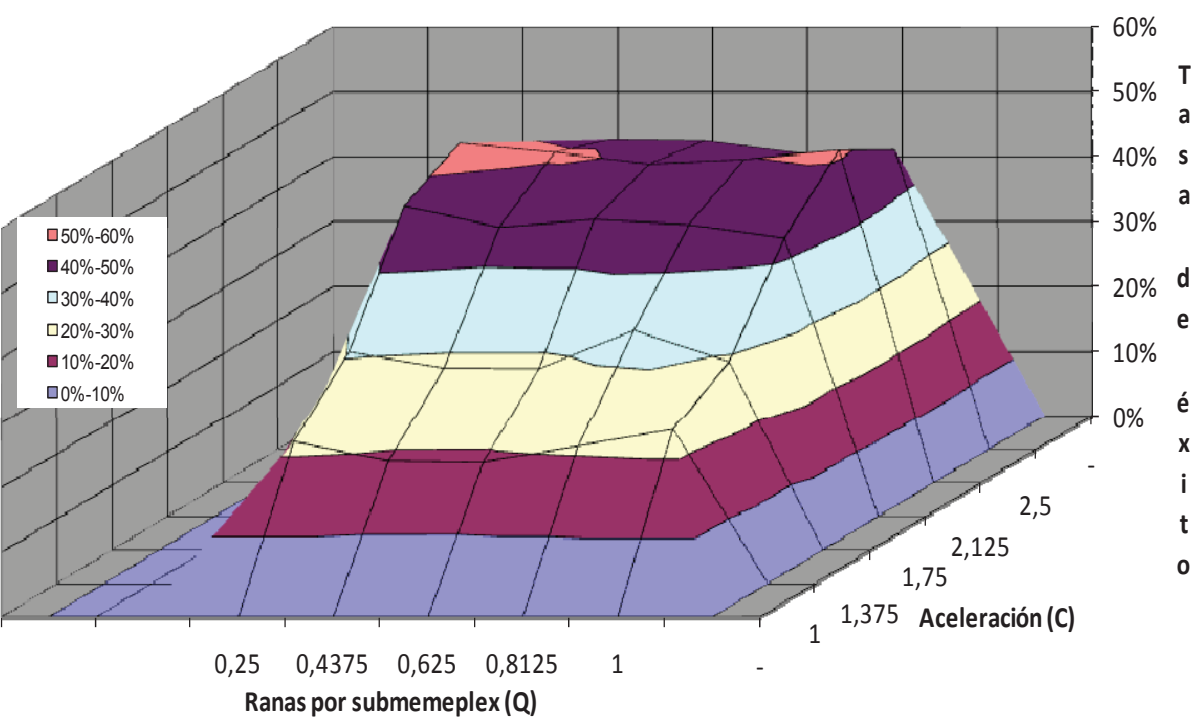

Figura 5.59. Probabilidad de obtener una buena solución respecto a $Q$ y $C$ en la red de Hanoi

Tal como ocurre en todos los métodos evolutivos estudiados, la mejora que se produce al considerar el concepto de buena solución es evidente. Los tres gráficos confirman la configuración óptima de parámetros que ya se había obtenido. Así, la configuración óptima elegida consiguió alcanzar una buena solución en el $62,1 \%$ de las simulaciones realizadas, lo que la sitúa a la altura de APG y muy por encima de HS y PSO.

\subsubsection{Red de Nueva York}

El rango de parámetros utilizado para el estudio de la red de Nueva York con el algoritmo SFL es idéntico al utilizado en Hanoi. El objetivo es confirmar los resultados obtenidos con una tipología de red distinta. En este caso, la red de Nueva York plantea, en principio, menos dificultades de diseño, puesto que tanto el número de tuberías como la gama utilizada son de menor tamaño.

El histograma permite la representación de las 26000 simulaciones realizadas en la red de los túneles de Nueva York (Figura 5.60). 


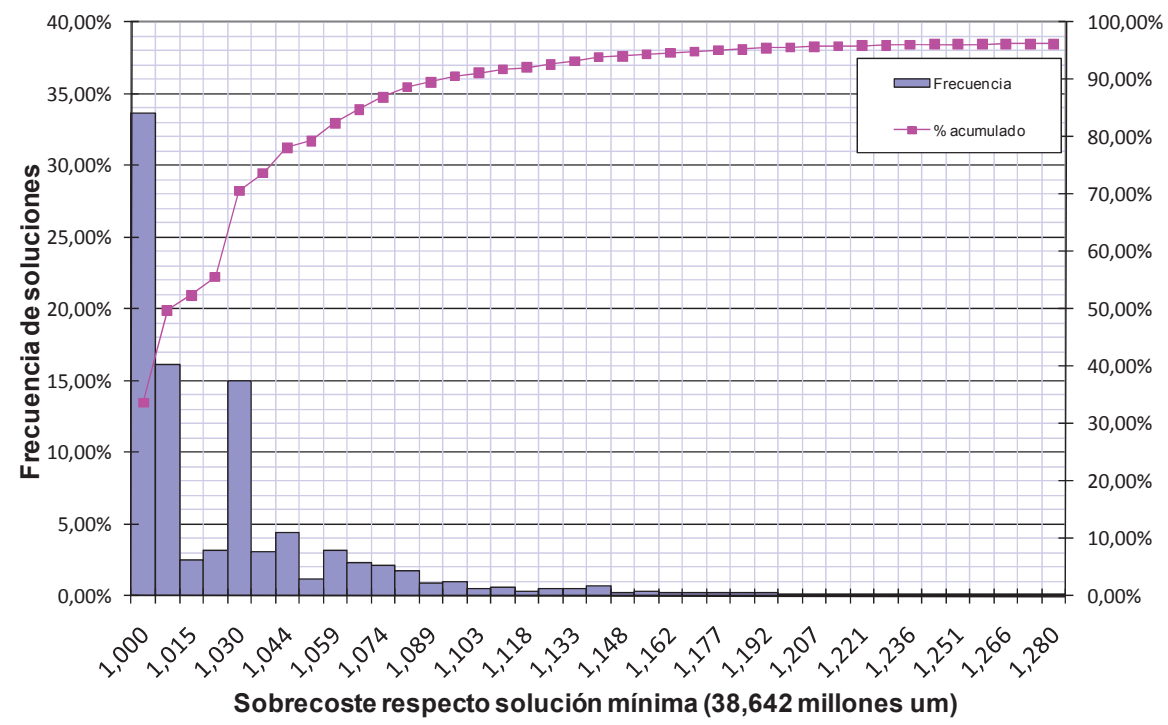

Figura 5.60. Histograma de soluciones para la red de los túneles de Nueva York utilizando el algoritmo SFL.

El mínimo coste obtenido en el diseño fue de 38,642 millones de um. Cabe destacar la alta repetibilidad que consigue SFLA en la obtención de la solución de mínimo coste del problema de diseño, puesto que más de un $30 \%$ de las simulaciones totales consiguen alcanzar este óptimo de diseño. En primera instancia, los resultados son muy buenos, puesto que ninguno de los métodos restantes consigue ni siquiera acercarse a estos porcentajes.

Es posible afinar aún más el método, realizando un análisis estadístico que determinará cuales son los mejores parámetros. Además de estimar la mejor combinación en este caso, es de interés confirmar si esta combinación óptima es similar a la que se obtenía para la red de Hanoi. Así, las siguientes figuras relacionan el valor de los parámetros $\mathrm{Q}, \mathrm{N}$ y $\mathrm{C}$ con la obtención del óptimo de la red. 


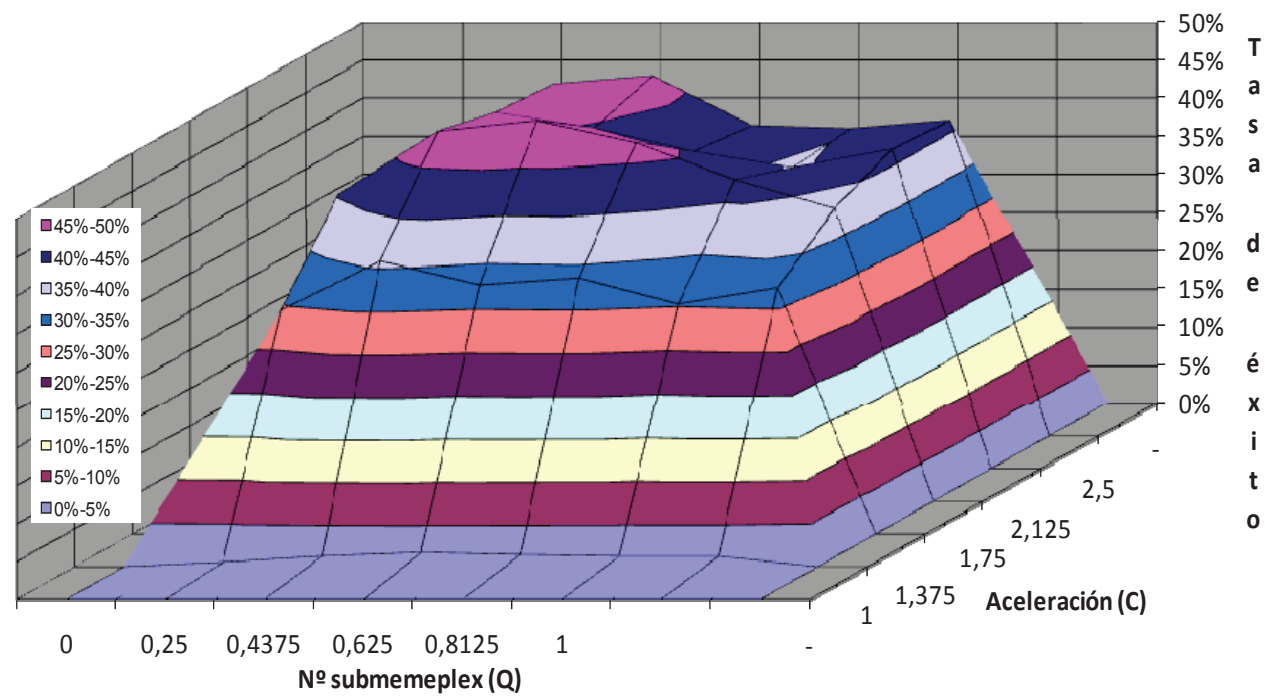

Figura 5.61. Probabilidad de obtener el valor mínimo respecto a $Q$ y $C$ en la red de los túneles de Nueva York

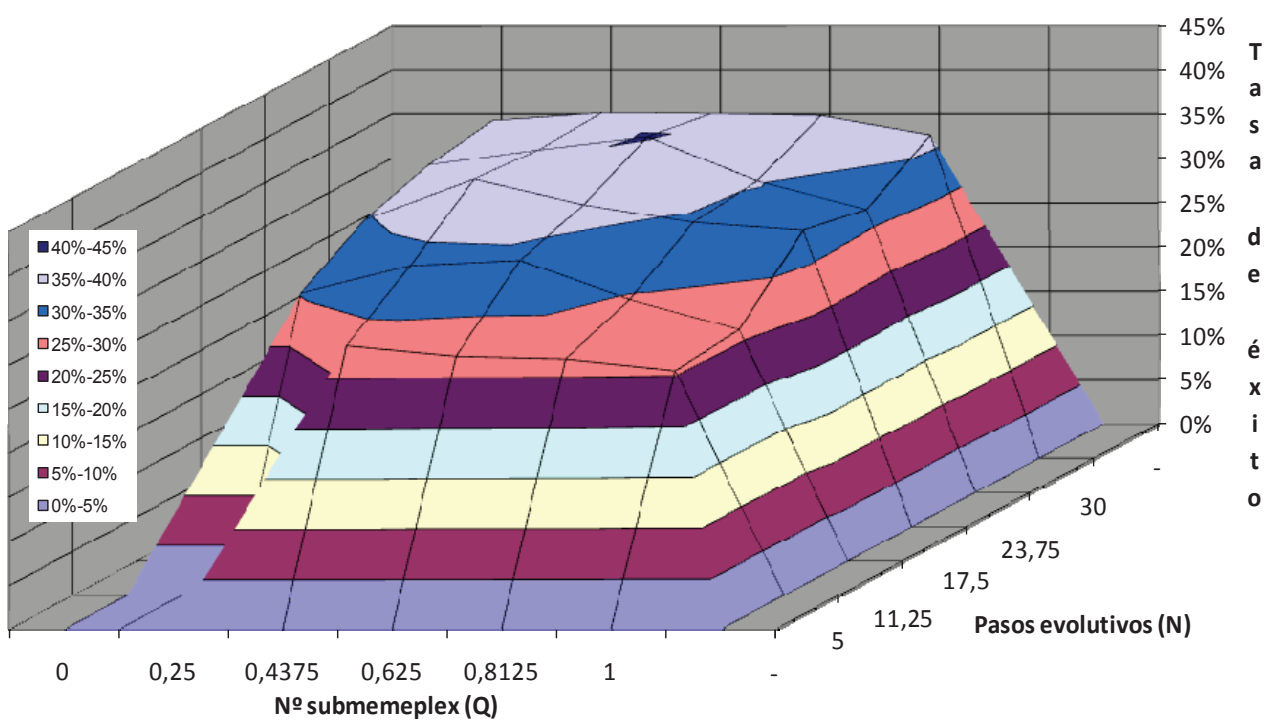

Figura 5.62. Probabilidad de obtener el valor mínimo respecto a $Q$ y $N$ en la red de los túneles de Nueva York 


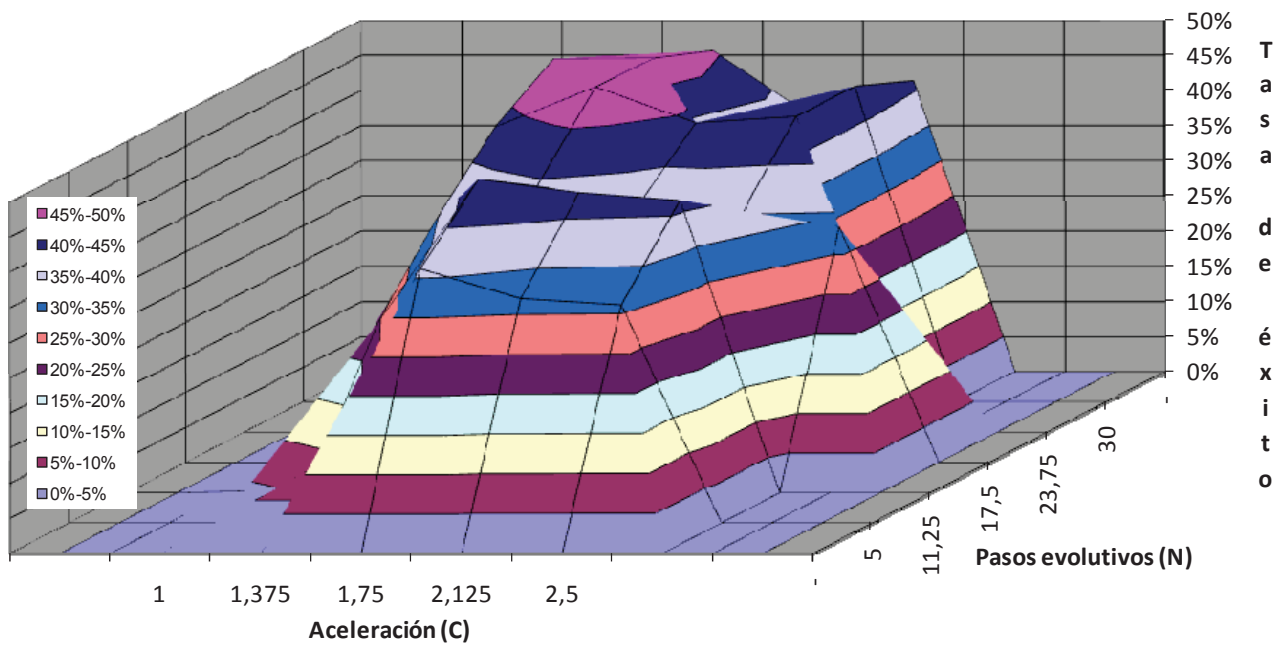

Figura 5.63. Probabilidad de obtener el valor mínimo respecto a $\mathrm{N}$ y $\mathrm{C}$ en la red de los túneles de Nueva York

Los resultados obtenidos siguen la misma pauta ya vista en la red de Hanoi. Así, en el caso de $\mathrm{N}$, el algoritmo tiene más probabilidad de encontrar mínimos cuanto mayor es su valor. La diferencia no es especialmente grande con el resto del rango estudiado. Así pues, desde un punto de vista cuantitativo en cuanto a la obtención del mínimo coste, $\mathrm{N}=30$ sería el valor óptimo. No obstante, será necesario tener en cuenta otros factores, como pueda ser el coste computacional, puesto que la diferencia con valores de $\mathbf{N}$ no mucho menores a 30 no es muy grande. De modo general en todas las figuras mostradas, las zonas de color fucsia indican una probabilidad por encima del $45 \%$ de encontrar el coste mínimo del sistema.

El parámetro de aceleración C proporciona resultados aceptables en la mayoría de rangos estudiados. Así, para un valor de C=1 SFLA apenas es capaz de proporcionar mínimos en el sistema, pero en el siguiente valor del rango estudiado $(C=1,375)$ se obtiene una proporción de mínimos superior al $30 \%$ sea cual sea la combinación con el resto de parámetros. Del mismo modo, cuanto mayor es el valor de C mejor proporción de mínimos se obtiene en las simulaciones realizadas, si bien, del mismo modo que en el caso de $\mathrm{N}$ será necesario el análisis de otros factores para determinar cual es el valor de C óptimo.

Por último, respecto al número de submemeplexes (Q), parece que valores más bajos de este parámetro mejoran el desempeño del algoritmo en la búsqueda del óptimo global, si bien todas las configuraciones experimentadas proporcionan buenos resultados.

La figura 5.64 muestra los resultados obtenidos cuando se elige una combinación óptima de parámetros de cálculo atendiendo tan sólo a criterios cuantitativos de obtención del mínimo, que en este caso corresponde a los valores $Q=0,44, N=23,75$ y $C=1,75$. 


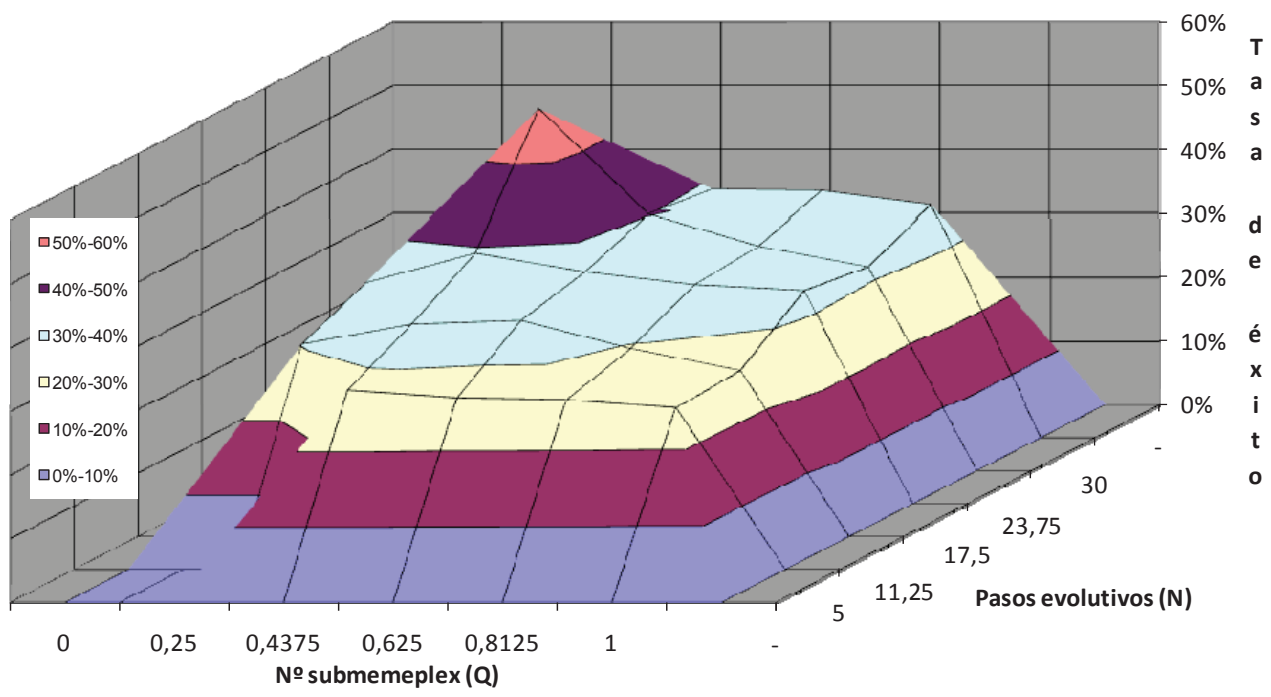

Figura 5.64. Combinación óptima de parámetros para la red de los túneles de Nueva York

Los valores elegidos como óptimos para N, Q y C eleva el número de mínimos obtenidos para la red de Nueva York hasta el $70 \%$ de éxito en las simulaciones realizadas. En la figura se aprecia el contraste con el resto de combinaciones con las que se ha trabajado, que de nuevo pone de manifiesto la importancia del análisis estadístico para encontrar la mejor combinación de parámetros.

\subsubsection{Red R-9 de Joao Pessoa}

En un principio, la metodología de trabajo realizada con SFLA para la red de Joao Pessoa no presenta diferencias significativas respecto a lo ya realizado en otras redes. Así, el rango de valores estudiado es coincidente con el realizado en Hanoi y NY.

Así, se han realizado en este punto un total de 10000 simulaciones, donde los parámetros $\mathrm{m}$ y $\mathrm{n}$ tienen un valor constante, mientras que $\mathrm{Q}, \mathrm{C}$ y $\mathrm{N}$ cambian su valor en cada configuración. Estos últimos tres parámetros se someten a análisis estadístico. Cada una de las configuraciones obtenidas se ha repetido 100 veces, a fin de tener una muestra lo bastante representativa en el análisis estadístico. El histograma de soluciones muestra la totalidad de simulaciones obtenidas con una población del algoritmo de 100 individuos (10×10). 


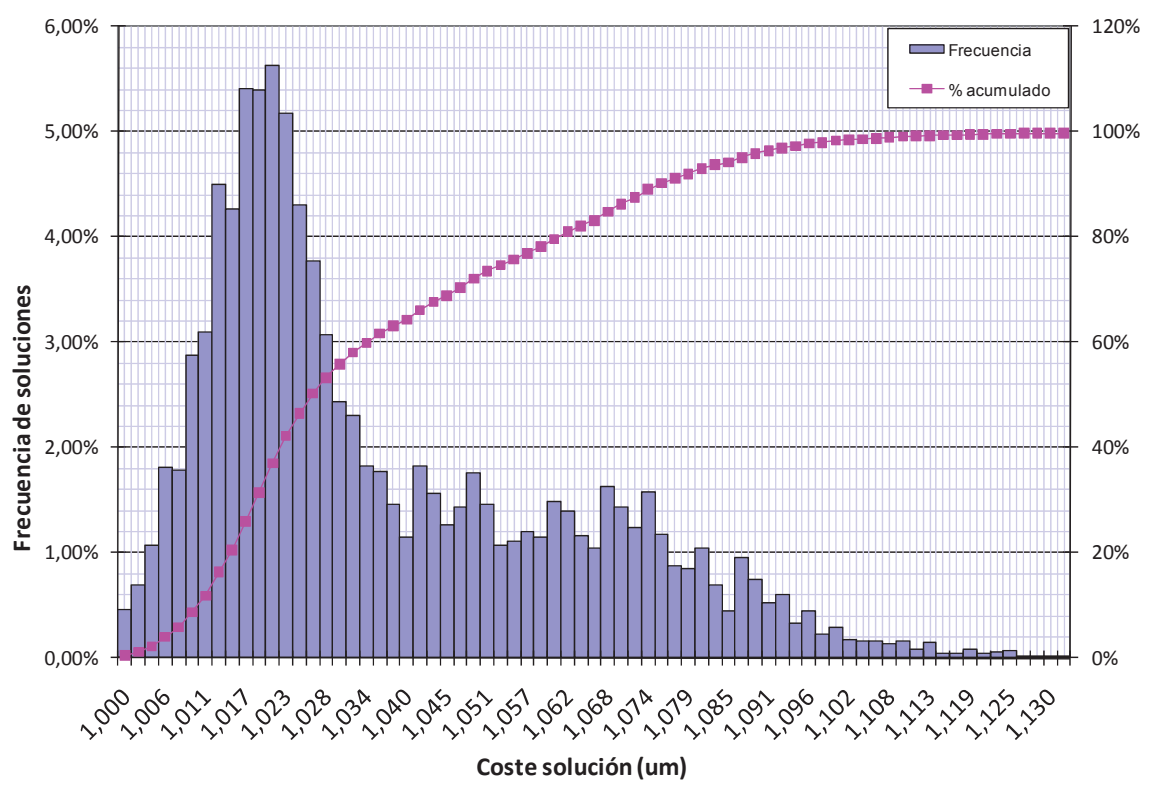

Figura 5.65. Histograma de soluciones para la red R-9 de Joao Pessoa utilizando el algoritmo SFL.

El mínimo coste de diseño que obtiene el algoritmo SFL para la red de Joao Pessoa es de 192,366 millones de um. El histograma de la red muestra diferencias muy significativas respecto a los histogramas de Hanoi y NY. En este caso, el número de óptimos obtenidos porcentualmente hablando es muy inferior, puesto que apenas un 0,46\% del total de simulaciones obtenidas consigue la solución de mínimo coste. El contraste respecto al resto de redes estudiadas es muy grande y la explicación hay que buscarla en la complejidad de la red, que también es mayor.

Por esta razón, el análisis de parámetros óptimos se realiza en esta ocasión en base a la obtención de una buena solución, que en este caso se va a considerar como toda solución de diseño que tiene un coste máximo adicional de un 3\% por encima de la solución mínima obtenida. Así, el coste límite que según esta definición entra dentro del concepto de buena solución es de 198,137 millones de um.

Considerando dicho concepto, el algoritmo SFL proporciona una buena solución un 55\% de las ocasiones. Este dato, considerando que hasta el momento no se ha realizado ninguna optimización de parámetros, sino que el histograma representa el total de las simulaciones realizadas puede considerarse como muy bueno en una red de estas dimensiones.

El análisis estadístico permite analizar las distintas configuraciones de parámetros y extraer conclusiones generales de acuerdo a los resultados obtenidos en las otras redes. Así, las 
siguientes figuras relacionan el valor de los parámetros $\mathrm{Q}, \mathrm{N}$ y $\mathrm{C}$ con la obtención de una buena solución para la red de Joao Pessoa.

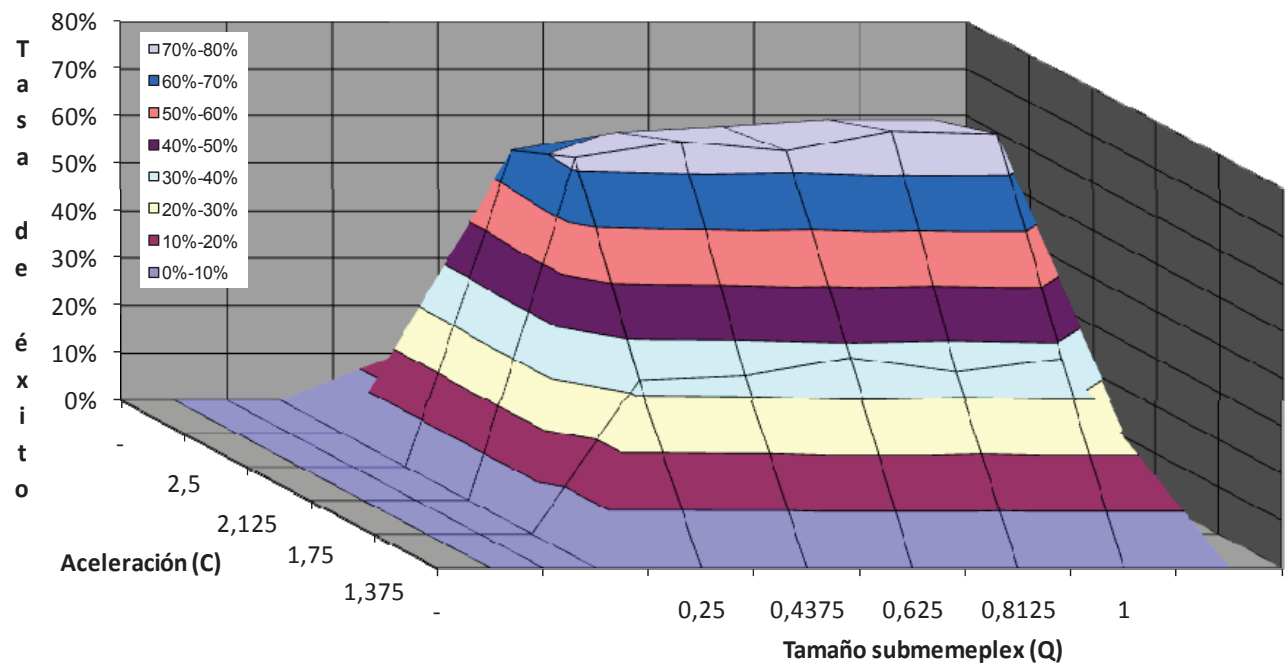

Figura 5.66. Probabilidad de obtener una buena solución para la red R-9 de Joao Pessoa según Cy $Q$.

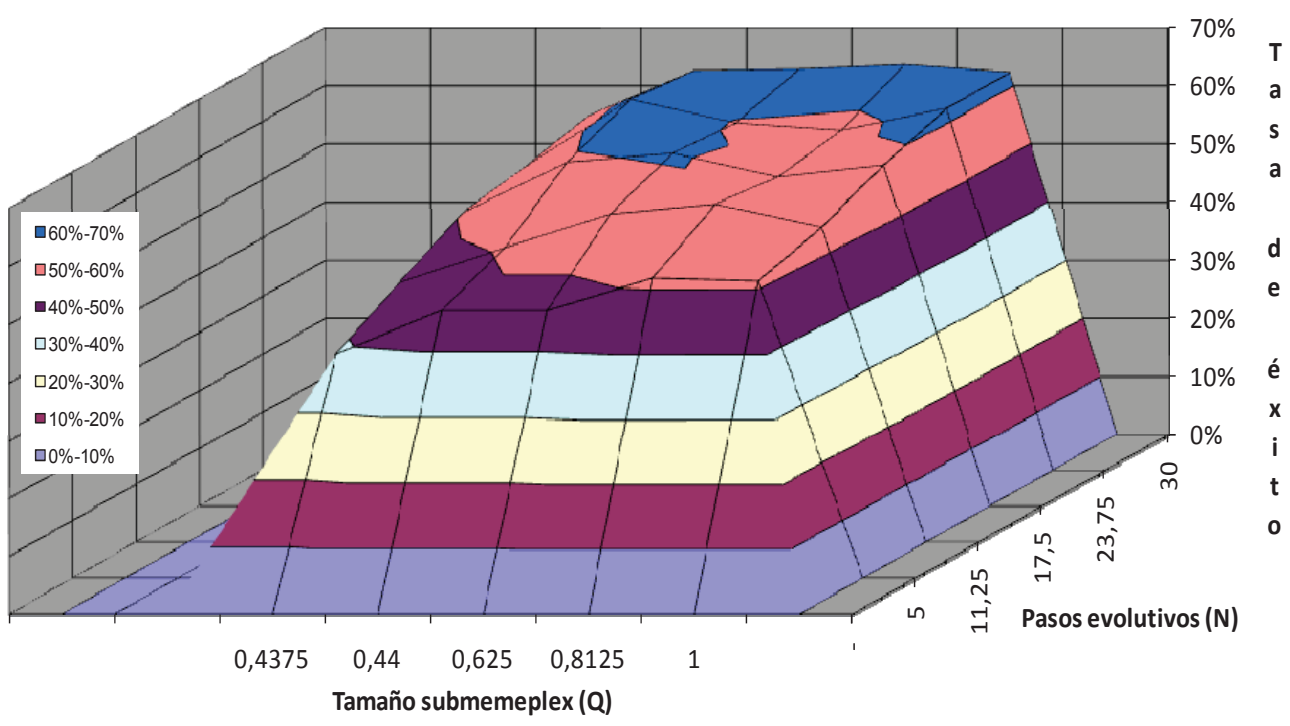

Figura 5.67. Probabilidad de obtener una buena solución para la red R-9 de Joao Pessoa según $N$ y $Q$. 


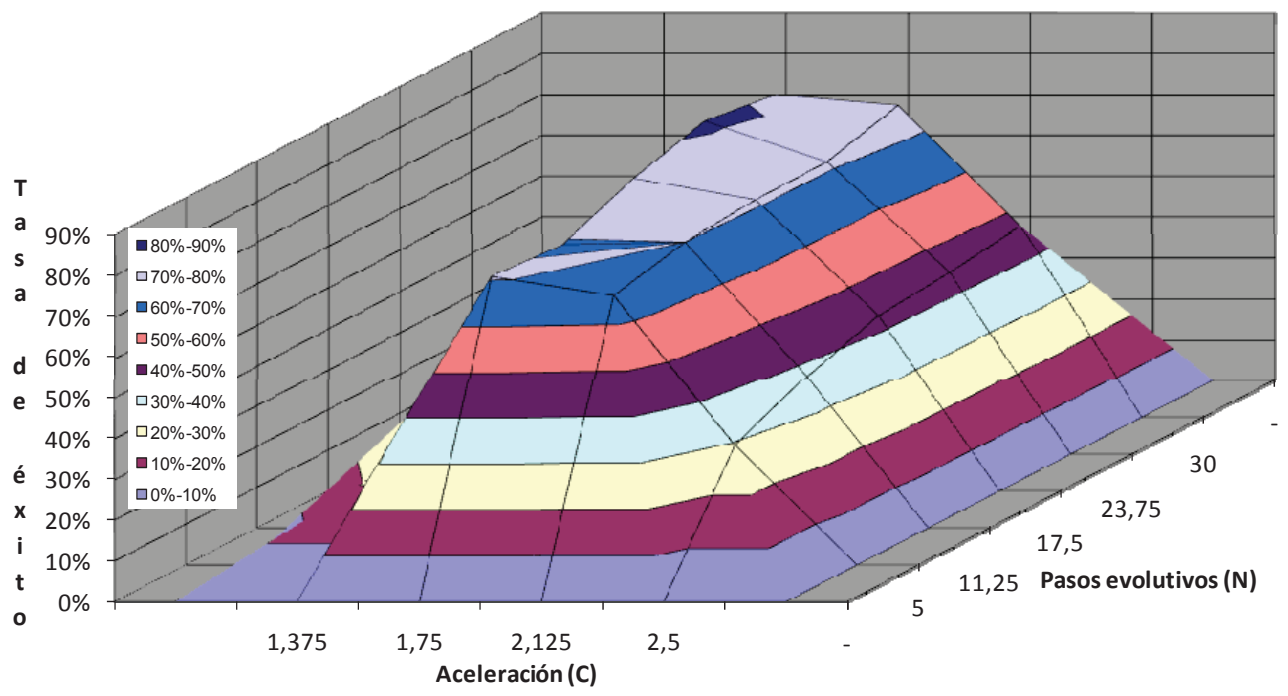

Figura 5.68. Probabilidad de obtener una buena solución para la red R-9 de Joao Pessoa según Cy $N$.

Las figuras anteriores relacionan los distintos parámetros con la probabilidad de obtener una buena solución. Las conclusiones que se pueden sacar respecto a cada uno de los parámetros son:

- Los resultados obtenidos para la red de Joao Pessoa confirman la mayoría de hipótesis planteadas en Hanoi y Nueva York. Así, El algoritmo SFL se muestra mucho más efectivo desde un punto de vista cuantitativo (obtención de mejores soluciones) cuanto mayor es el número de pasos evolutivos. La diferencia porcentual en la obtención de buenas soluciones cuando se considera el valor más pequeño $(\mathrm{N}=5)$ o el más grande $(\mathrm{N}=30)$ es de aproximadamente un $10-15 \%$. Lo significativa o no que resulta esta diferencia hay que buscarla en el análisis de eficiencia, que relaciona el análisis cuantitativo que se plantea este apartado con la velocidad de cálculo del algoritmo.

- El tamaño de submemeplex se confirma como el parámetro menos sensible desde un punto de vista de obtención de la mínima solución posible. Si se presta atención a las figuras 5.66 y 5.67 , ambas muestran con claridad como independientemente del valor de $\mathrm{Q}$ los resultados son similares en cuanto a buenas soluciones obtenidas. A la vista de los resultados obtenidos en las redes de Hanoi, NY y R-9 es posible afirmar que el rango de $Q$ estudiado no genera diferencias desde un punto de vista 
cuantitativo. El análisis de eficiencia permitirá determinar si existe diferencia en cuanto a la velocidad de utilizar un valor de $Q$ u otro.

- Para el parámetro de aceleración (C) se puede afirmar con rotundidad que el valor óptimo está comprendido entre 1,75 y 2,25 , puesto que todas las simulaciones realizadas fuera de este rango dan porcentajes de éxito menores.

\subsubsection{Red de Go-Yang}

El proceso de optimización de parámetros para el algoritmo SFLA en la red de Go-Yang sigue las mismas directrices que en el resto de redes de agua, a fin de confirmar el rango de trabajo óptimo que parece establecerse en esta metodología heurística.

Así, partiendo de una población del algoritmo constante de 100 individuos (10x10) se procede al estudio de la constante de aceleración $\mathrm{C}$, el número de saltos evolutivos $\mathrm{N}$ y el tamaño de submemeplex $\mathrm{Q}$. El número de repeticiones para cada posible combinación de estos tres parámetros ha sido de 100, realizándose un total de 10000 cálculos en este proceso de optimización. El histograma de soluciones representa la totalidad de simulaciones realizadas:

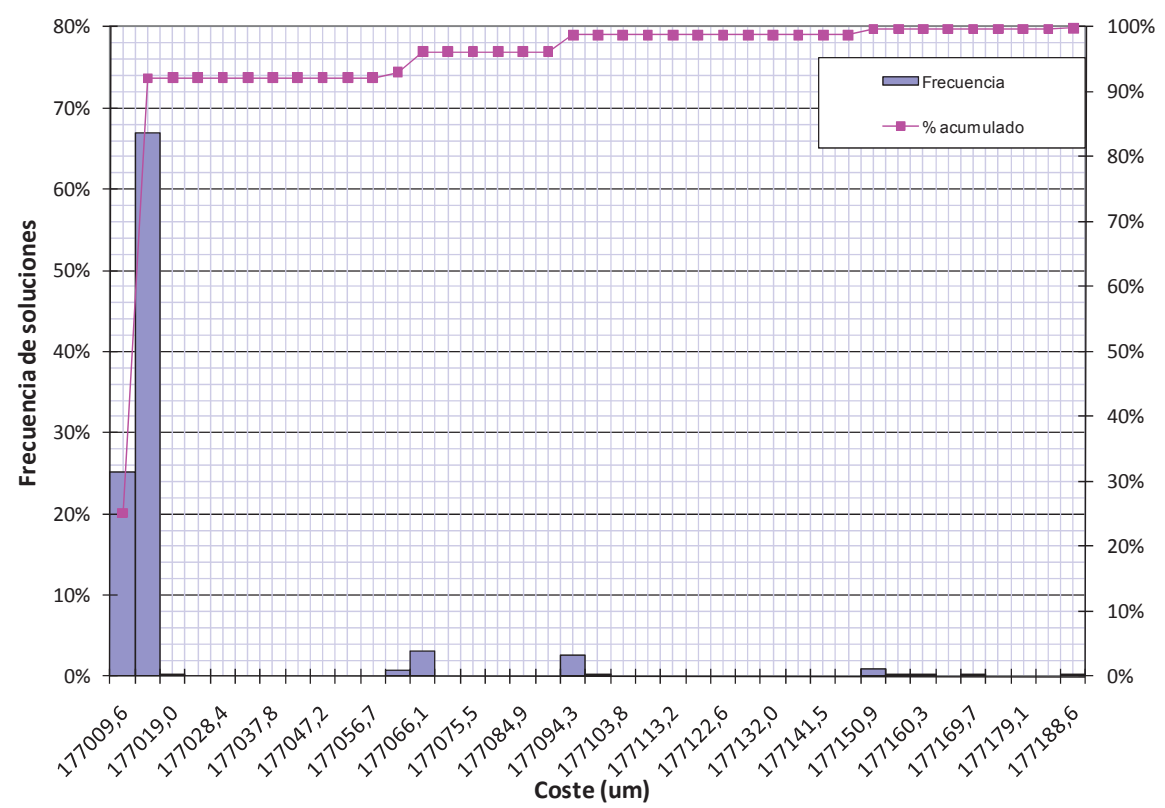

Figura 5.69. Histograma de soluciones para la red R-9 de Joao Pessoa utilizando el algoritmo SFL.

El coste mínimo de diseño obtenido para la red de Go-Yang es de 177.009,6 um. El resultado obtenido coincide con el que proporciona el resto de métodos heurísticos estudiados. En el caso de SFLA cabe destacar la frecuencia de obtención de esta solución de mínimo coste, puesto que un $25 \%$ del total de simulaciones realizadas consigue llegar a este óptimo. Del 
mismo modo, la segunda mejor solución está asociada a un coste de 177.014,3 um, solución a la que llega otro $62 \%$ de las simulaciones realizadas. En resumen, el $92 \%$ de las simulaciones realizadas se encuentran entre estos dos valores.

Si se desglosan estos resultados en función del valor de cada uno de los parámetros de cálculo estudiados se obtienen las siguientes figuras:

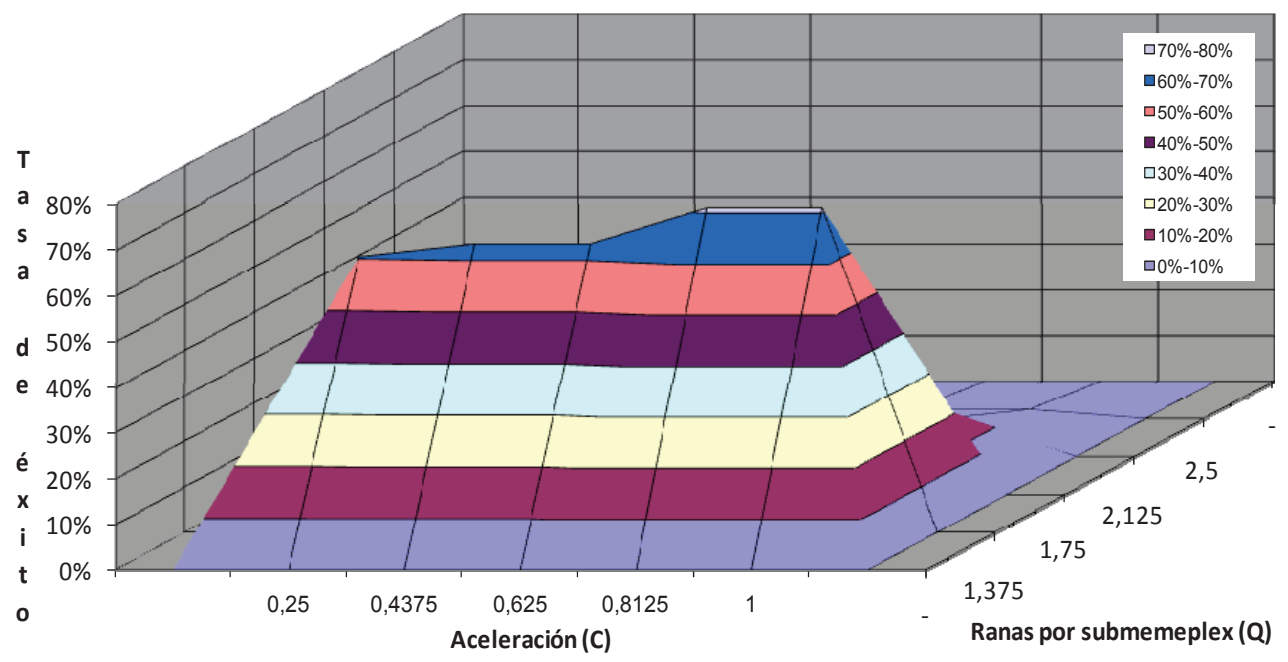

Figura 5.70. Probabilidad de obtener el mínimo coste en la red de Go-Yang según C y Q.

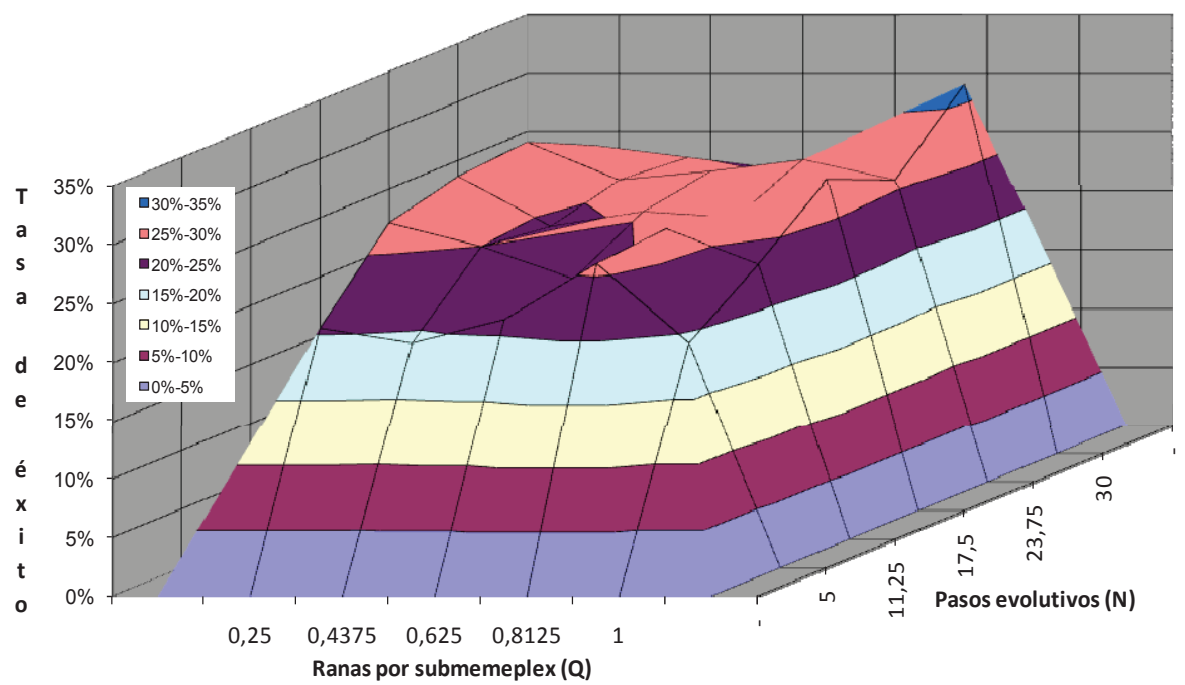

Figura 5.71. Probabilidad de obtener el mínimo coste en la red de Go-Yang según $N$ y Q. 


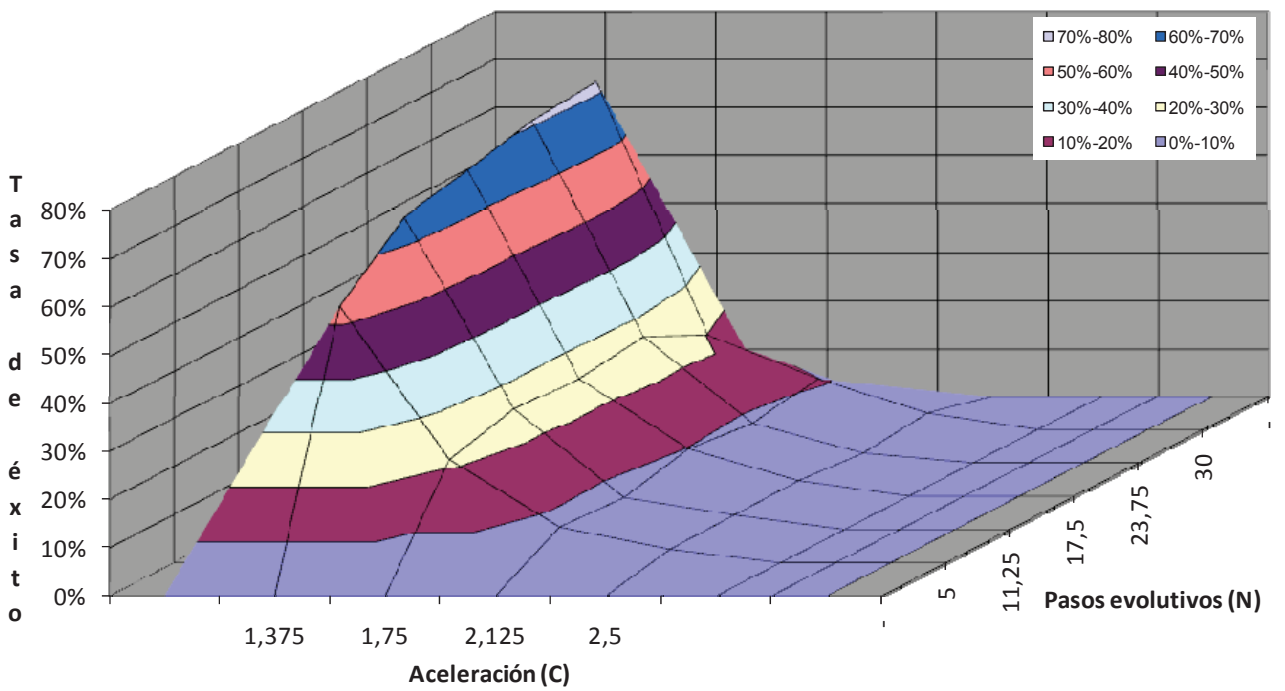

Figura 5.72. Probabilidad de obtener el mínimo coste en la red de Go-Yang según C y $N$.

Las figuras muestran la probabilidad de obtener una mínima solución en función del valor de los distintos parámetros estudiados. En la línea de lo visto en el resto de redes, el número de mínimos obtenidos por el algoritmo es mayor cuanto más alto es el número de pasos evolutivos, si bien la diferencia no es excesivamente grande. En este sentido, si se analiza la figura 5.72, la diferencia es bastante significativa en la mejor combinación posible de parámetros, que correspondería a la isolínea $\mathrm{C}=1,375$. Con estos valores, la diferencia entre el menor número de pasos evolutivos $\mathrm{N}=5$ y el mayor $\mathrm{N}=30$ es de prácticamente un $20 \%$ cuando se trata de obtener la solución de mínimo coste.

El parámetro de aceleración (C) resulta de nuevo el más sensible si se observa la obtención de mínimos desde un punto de vista cuantitativo, puesto que la diferencia entre los distintos valores de $\mathrm{C}$ estudiados son muy significativas. En la red de Go-Yang el valor óptimo para este parámetro se encuentra en 1,375, que en este caso corresponde con el mínimo valor estudiado para C. La efectividad del algoritmo en la búsqueda del óptimo desciende bruscamente conforme aumenta el valor de C, tal como se aprecia en las figuras superiores.

Por último, el análisis del número óptimo de ranas por submemeplex no proporciona nuevos datos respecto a las conclusiones que se llegaban en el resto de redes estudiadas. De este modo, las figuras 5.71 y 5.72 muestran la independencia del algoritmo respecto a este parámetro de cálculo, puesto que independientemente del valor de $\mathrm{Q}$, los resultados son similares en el número de mínimos obtenidos. Las mínimas diferencias que se producen entre unos valores y otros no pueden ser atribuidas a una determinada tendencia, sino a la propia aleatoriedad que posee este tipo de métodos. 
De este modo, para la red de Go-Yang, la combinación óptima de parámetros para el algoritmo SFL desde un punto de vista cuantitativo sería $\mathrm{C}=1,375$ y N=30. En cuanto al valor de $Q$, tal como se ha visto en líneas superiores no parece tener mayor influencia. La siguiente figura muestra el \% de mínimos obtenidos con los parámetros óptimos, en función de Q.

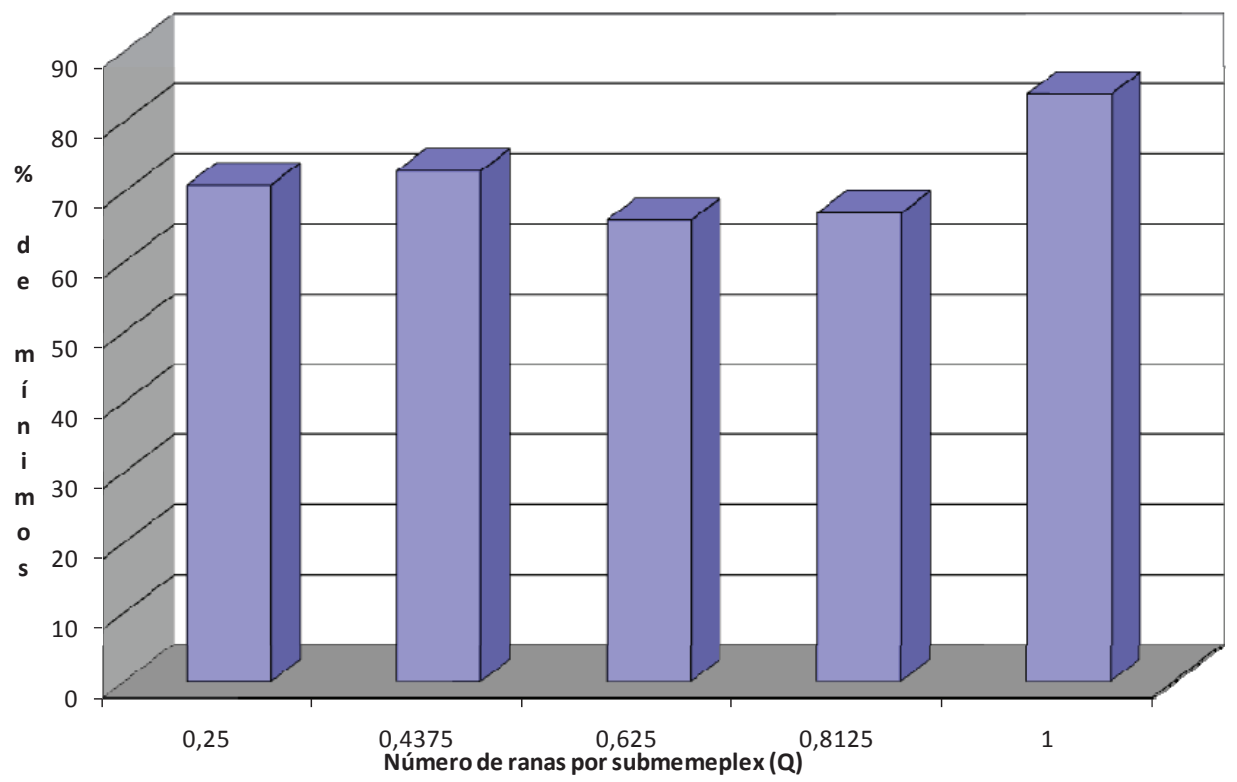

Figura 5.73. Porcentaje de soluciones mínimas obtenidas con ajuste óptimo de parámetros $(C=1,375, N=30)$

El ajuste óptimo de parámetros permite obtener un porcentaje de obtención de la mínima solución superior al $65 \%$ en todas las combinaciones de Q. A la vista de los resultados el valor 1 podría ser considerado como óptimo para $Q$, puesto que el $84 \%$ de las simulaciones realizadas alcanzan la solución mínima. No obstante, los resultados no indican una tendencia que sugiera mejores resultados con $\mathrm{Q}$ mayores, puesto que los valores de $\mathrm{Q}$ menores funcionan mejor que los intermedios, por lo que parece más una cuestión de estadística similar al resultado que se obtendría si se tirara 100 veces un dado.

Es posible ampliar el análisis a la obtención de buenas soluciones, pero en este caso concreto no tiene sentido, puesto que el $100 \%$ de las simulaciones realizadas cumplen con el criterio de buena solución que se ha establecido en este trabajo; es decir, soluciones cuyo coste no supere en más de un $3 \%$ el mínimo coste de la red. Este resultado es sensacional, puesto que permite asegurar como mínimo la obtención de una buena solución sea cual sea la combinación de parámetros elegida. 


\subsection{Análiaia de población del algoritmo}

El tamaño de población del algoritmo es el único parámetro de cálculo que se encuentra presente en todas las metodologías de cálculo heurístico analizadas en este trabajo. Por ello es oportuno realizar un estudio independiente del resto de parámetros de ajuste de los distintos algoritmos. El objetivo de este apartado es establecer la influencia del número de individuos en los resultados obtenidos para un determinado proceso de optimización. En este caso, el problema que nos ocupa es el diseño óptimo de redes de agua a presión.

Estudios previos demuestran que el tamaño de población debe ser lo suficientemente grande como para garantizar diversidad en las soluciones. El principal problema que se genera al utilizar poblaciones elevadas radica en que el tiempo de convergencia del algoritmo es mucho mayor, por lo que se antoja necesario llegar a una solución de compromiso dependiendo del enfoque que se haga del problema.

Este apartado tan sólo evalúa la influencia que tiene el número de individuos involucrados desde un punto de vista cuantitativo. Es decir, solo se plantea como influye el tamaño de población en el número de mínimos/buenas soluciones de diseño para una determinada red de agua sin importarnos el aumento del tiempo de cálculo. Así, es evidente que cuanto mayor es el número de individuos involucrados en el proceso de optimización mayor es el tiempo de convergencia, pero será el análisis de eficiencia que se realiza en el siguiente apartado el que determine si la mejora conseguida al aumentar la población inicial de un algoritmo compensa el aumento de recursos utilizados.

El análisis de población realizado plantea el mismo modo de trabajo en todos los algoritmos de optimización. Así, se realizan nuevas tandas de simulaciones, donde el tamaño de población de cada algoritmo varía, mientras que los parámetros de ajuste de cada metodología se mantienen constantes en sus mejores valores, aprovechando los datos obtenidos en el estudio de parámetros del apartado 5.2. El objetivo es doble; por un lado se comprueba la mejora de los resultados una vez realizado el ajuste de parámetros, mientras que por otro se estudian los resultados obtenidos en función del tamaño de población utilizado en cada metodología de optimización.

\subsubsection{Ajuste de población Algoritmo PseudoGenético (APG)}

El análisis estadístico realizado en 5.2.1 analiza el rango de operación óptimo para cada operador genético cuando se trata de obtener soluciones óptimas. Para ello se realiza un elevado número de simulaciones que cubre un determinado rango de probabilidades para los operadores genéticos de mutación y cruce. En el análisis estadístico posterior se determinó cual era el mejor ajuste en ambos parámetros, manteniendo constante la población genética, con un valor de 100 individuos. 
El estudio de población que se muestra a continuación aprovecha la optimización de parámetros realizada para cada red y utiliza el mejor ajuste determinado para estudiar la influencia del número de individuos en los resultados de diseño obtenidos.

\subsubsection{Red de Hanoi}

Tal como se ha expuesto anteriormente, el objetivo de este apartado es determinar la influencia del tamaño de población en el diseño óptimo de las distintas redes, al tiempo que se comprueba la mejora de resultados tras el ajuste de parámetros realizado. La siguiente tabla muestra los mejores valores determinados para los operadores de cruce y mutación en la red de Hanoi. El proceso de optimización de estos operadores puede seguirse en el apartado 5.2.1.

\begin{tabular}{|c|c|c|}
\hline \multicolumn{2}{|c|}{ PARÁMETROS } & RANGO DE VALORES \\
\hline Probabilidad de mutación & $P_{m}$ & 0,03 \\
\hline Probabilidad de cruce & $P_{c}$ & $0,1-0,9$ \\
\hline
\end{tabular}

Tabla 5.10. Rango óptimo de cálculo para los operadores genéticos en la red de Hanoi.

Los resultados obtenidos para la red de Hanoi indican que el número de soluciones de mínimo coste aumenta si la probabilidad de mutación está en torno al 3\% (algo más de un gen por cromosoma). En ese caso, la probabilidad de encontrar el mínimo estaba en torno al 10-12\%. El mismo análisis ponía de manifiesto que la probabilidad de cruce no ejerce una influencia tan grande en la obtención de mínimos cuando el tamaño de población es fijo y de 100 individuos.

Se estudia a continuación la influencia que tiene el tamaño de población en el desempeño del algoritmo APG, para lo que se considera como ajuste óptimo del operador de mutación el valor obtenido en el apartado 5.2.1.1. A partir de este resultado se realiza una nueva tanda de simulaciones, de modo que se realizan 25000 cálculos con tamaños de población que se mueven entre 25 y 225 individuos.

Del mismo modo, la probabilidad de cruce entre cadenas se varía entre el 10 y el $90 \%$, con el objetivo de comprobar si realmente ejerce una influencia en el cálculo menor que la mutación o esta conclusión sólo es posible sacarla cuando el tamaño de la población se mantiene constante. El histograma muestra todas las simulaciones realizadas con poblaciones entre 25 y 225 individuos. 


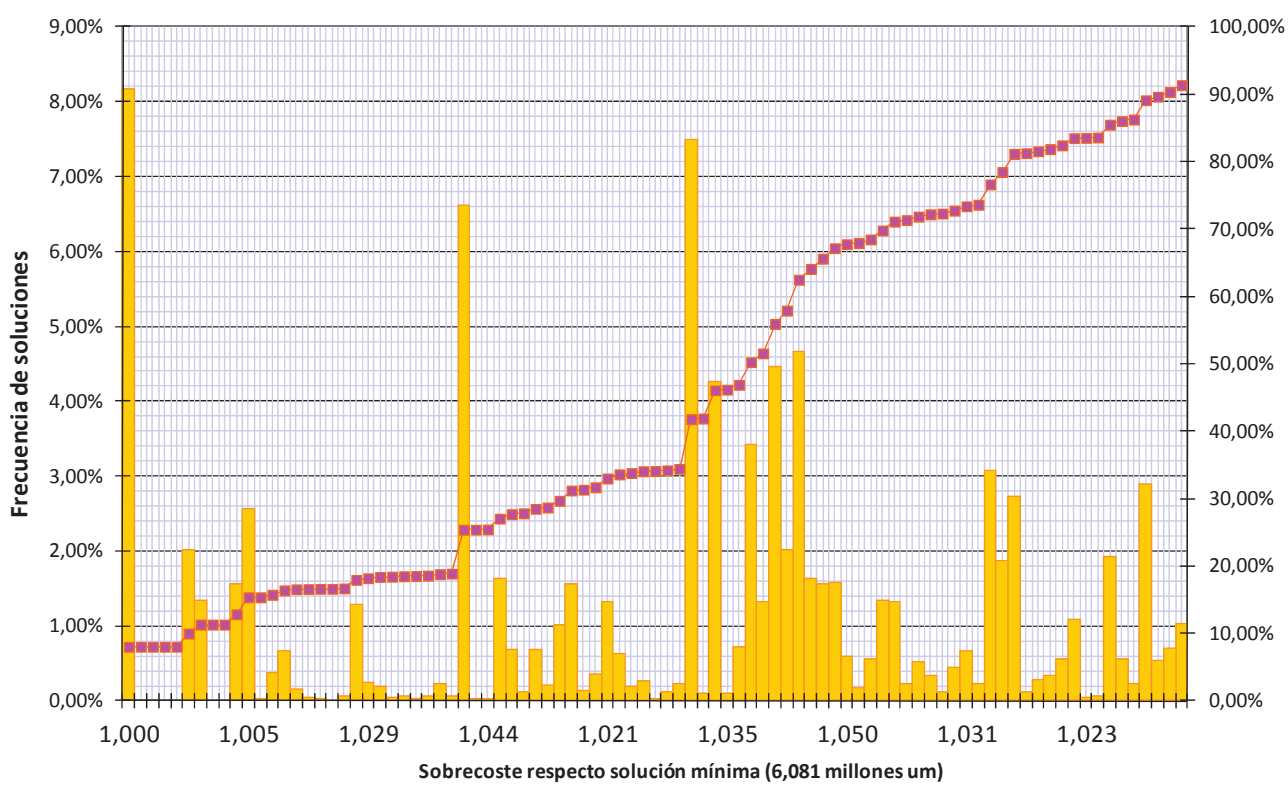

Figura 5.74. Histograma de soluciones para la red de Hanoi con operadores de mutación y cruce óptimos

En el histograma, el valor 1,00 del eje de abcisas corresponde con la mejor solución posible de diseño para esta red (6,081 millones de um), de modo que el resto de valores están ordenados en función de cuánto se alejan en tanto por cien de esta solución óptima.

Analizando los datos proporcionados por el histograma, cabe destacar que la probabilidad de obtener la solución óptima de diseño en esta tanda de simulaciones está en torno al 8\%, dato que mejora significativamente los resultados del histograma de la figura 5.2.1, donde apenas un $2 \%$ del total de simulaciones realizadas obtenían la mejor solución de diseño. Esta mejora es lógica, puesto que en este caso, el proceso no parte de cero, ya que dos de los tres parámetros de cálculo (probabilidades de cruce y mutación) ya tienen el ajuste óptimo para los operadores genéticos, lo que repercute de modo positivo en los cálculos realizados en esta nueva batería de simulaciones.

Tomando como valor óptimo de diseño para la red de Hanoi la solución que corresponde a un coste de 6,081 millones de um, la figura 5.75 analiza la probabilidad de obtener este óptimo según los valores de población y cruce. Esto nos permite determinar el tamaño/s de población donde el algoritmo funciona mejor o peor, así como confirmar o desmentir la escasa influencia que ejercía la probabilidad de cruce en la obtención de óptimos para la red. 


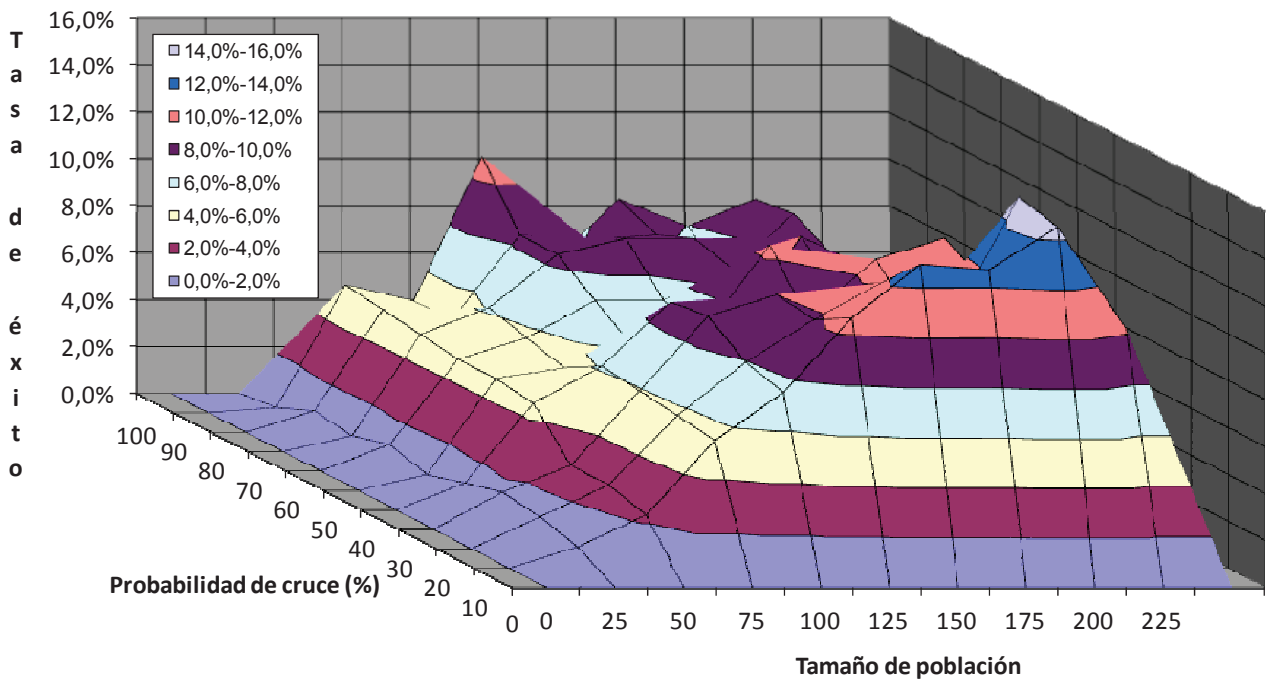

\section{Figura 5.75. Probabilidad de obtención solución mínima (6,081 millones um) respecto al tamaño de la población inicial y la probabilidad de cruce.}

La figura 5.75 pone de manifiesto que conforme aumenta el tamaño de la población también lo hace la probabilidad de obtener el valor mínimo, si bien llega un momento en el que dicha mejora queda estable. En primera instancia, la mejor combinación de valores está en poblaciones de 200 con probabilidades de cruce alrededor del 10\%, pero será necesario evaluar si compensa esta ligera mejora con la disminución de la velocidad de cálculo que provoca el trabajar con poblaciones mayores.

Del mismo modo cabe destacar que al variar el tamaño de población la influencia que ejerce la probabilidad de cruce en el cálculo deja de ser despreciable. La figura muestra que para el diseño de la red de Hanoi probabilidades de cruce menores aumentan la posibilidad de encontrar el óptimo de la red. Esto parece indicar que la probabilidad de cruce no tiene una gran influencia en el desempeño del algoritmo cuando se trabaja siempre con la misma población, pero sí tiene cierta influencia en el cálculo cuando se cambia el tamaño inicial de la población. El estudio de población en el resto de redes debe permitir generalizar esta conclusión.

\subsubsection{Red de Nueva York}

Para la red de Nueva York, el análisis de parámetros determina que probabilidades de mutación en torno al 4-5\% son las más adecuadas para el funcionamiento del APG. Del mismo modo, probabilidades de cruce por encima de 0,6 mejoran ligeramente los resultados, aunque la influencia de este parámetro no es tan marcada como la del operador de mutación. 
El número de individuos utilizado en cada simulación era constante y de valor 100. En estas condiciones, la combinación óptima de los operadores de cruce y mutación proporciona una probabilidad de encontrar el valor óptimo de diseño cercana al 30\%. Dicho valor óptimo para la red de Nueva York queda estipulado en 38,642 millones de um.

Utilizando la experiencia previa se plantea ahora una nueva tanda de simulaciones, donde los valores utilizados para los distintos operadores de cálculo vienen recogidos en la tabla inferior:

\begin{tabular}{|c|c|c|}
\hline \multicolumn{2}{|c|}{ PARÁMETROS } & RANGO DE VALORES \\
\hline Probabilidad de mutación & $P_{m}$ & $0,04-0,05$ \\
\hline Probabilidad de cruce & $P_{c}$ & $0,6-0,9$ \\
\hline
\end{tabular}

Tabla 5.11. Rango óptimo de cálculo para los operadores genéticos en la red de Nueva York.

Para determinar el tamaño de población más adecuado se realizan un total de 14400 simulaciones, tomando configuraciones óptimas en ambos operadores genéticos y variando el tamaño de población entre 25 y 225 individuos. La siguiente figura muestra el histograma de soluciones para el conjunto de simulaciones realizadas:

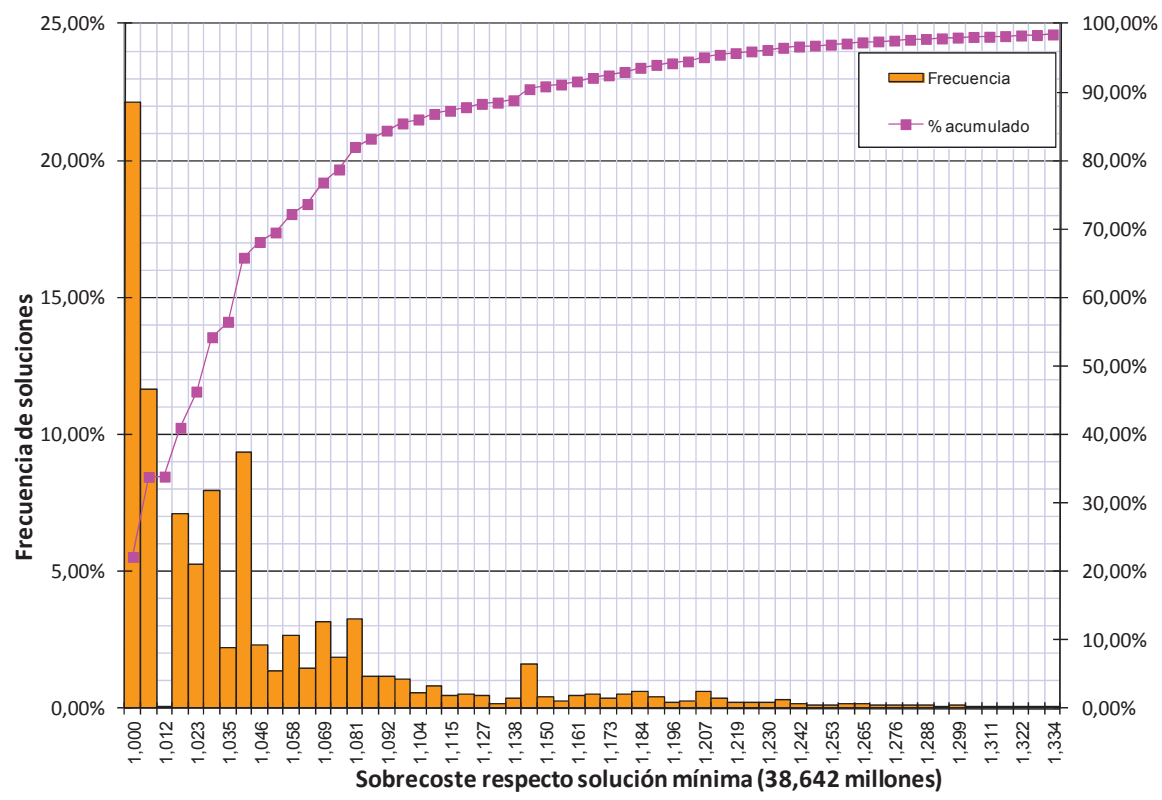

Figura 5.76. Histograma de soluciones para la red los túneles de Nueva York con operadores de mutación y cruce óptimos.

El histograma de soluciones contempla la totalidad de simulaciones realizadas con todas las poblaciones, de modo que un $22 \%$ de las simulaciones realizadas alcanzan la solución de 
mínimo coste. Esta cifra mejora significativamente el $12 \%$ de éxito que se apreciaba en el histograma mostrado en la figura 5.76 y pone de manifiesto una vez más la importancia de la optimización de parámetros, puesto que estas simulaciones contemplan ya valores óptimos para 2 de los 3 parámetros a considerar en el APG.

El eje de abscisas muestra el sobrecoste de diseño de la red respecto de la solución de mínimo coste obtenida en todos los métodos. Así, el valor 1 corresponde al mínimo coste de diseño para la red de Nueva York (38,642 millones de um), mientras que el resto de índices indica cuanto se alejan las soluciones de la óptima en tanto por cien. Así, una buena solución para la red vendrá representada por toda aquella que tenga un índice igual o menor a 1,03. El $56 \%$ de las simulaciones realizadas entran dentro de esta definición.

Las siguientes figuras muestran la probabilidad de obtener una solución óptima de diseño o una buena solución en función del tamaño de población. Para ello se realizan dos representaciones, una que relaciona el tamaño de población con la probabilidad de cruce (figura 5.77) y una segunda representación que relaciona el tamaño de población con la probabilidad de mutación (figura 5.78).

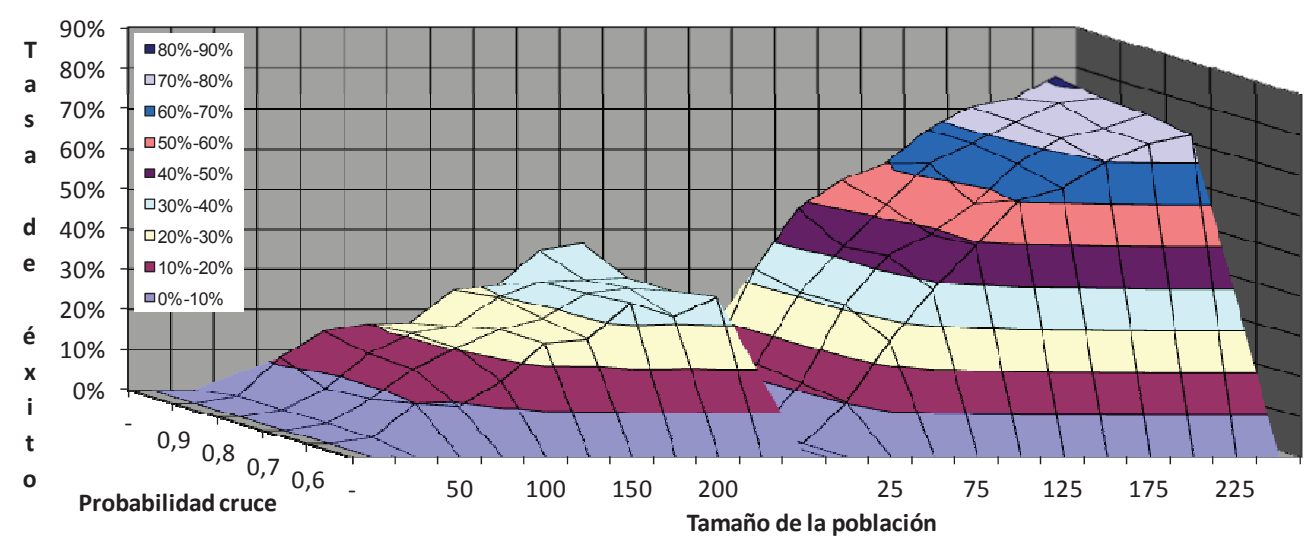

\section{Figura 5.77. Probabilidad de obtención mínimo/buena solución en función tamaño de población y probabilidad de cruce.}

La figura 5.77 muestra de un modo claro como la probabilidad de encontrar mejores soluciones aumenta con tamaños de población más grandes. En el rango estudiado no parece existir un punto de inflexión a partir del cual la probabilidad de éxito quede estable, sino que los resultados mejoran progresivamente sin alcanzar un máximo.

Analizando los resultados según la probabilidad de cruce, los resultados no muestran ninguna diferencia significativa en el rango estudiado, de modo que desde el punto de vista de la obtención de mínimas/buenas soluciones no tiene ningún efecto el utilizar una probabilidad de cruce u otra en el rango que ya se determinó como óptimo. 
Así, para un tamaño de población de 225 individuos, la probabilidad de obtener la solución de mínimo coste para la red de los túneles de Nueva York está en torno al 35-40\%, mientras que la probabilidad de obtener una buena solución sube hasta un $75-80 \%$.

En todos los análisis realizados hasta el momento el operador genético de mutación se ha mostrado mucho más determinante en la probabilidad de encontrar mejores soluciones que el operador de cruce. El problema de diseño de la red de los túneles de Nueva York no es una excepción y las diferencias existentes entre realizar los cálculos con una probabilidad de mutación u otra son significativas. La figura 5.78 muestra la probabilidad de encontrar una mínima/buena solución en función del tamaño de población y la probabilidad de mutación:

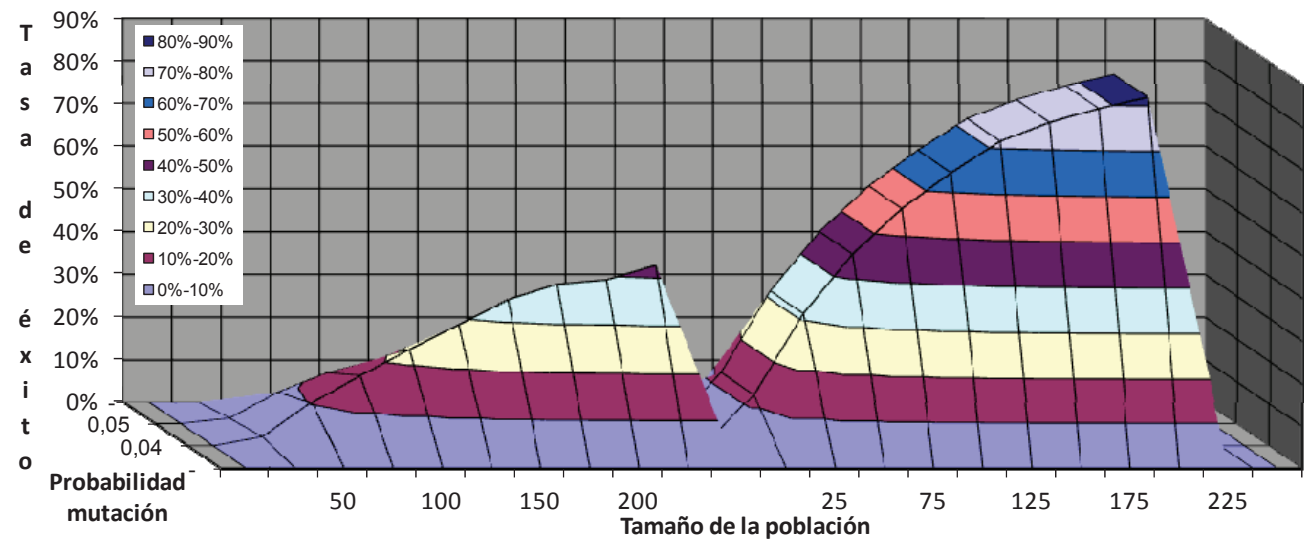

\section{Figura 5.78. Probabilidad de obtención mínimo/buena solución en función tamaño de población y probabilidad de mutación.}

La figura 5.78 muestra como dentro del rango óptimo de probabilidad de mutación existen diferencias cuando se trata de encontrar la solución óptima de diseño, que se ven acentuadas con el tamaño de población. Así, si se atiende únicamente a la probabilidad de encontrar la solución óptima de diseño, se muestra más efectivo el utilizar una probabilidad de mutación de un 4\%, de modo que para una población de 225 individuos se consigue que un $42 \%$ de las simulaciones realizadas alcancen este valor óptimo.

La diferencia entre ambas probabilidades de mutación desaparece cuando se trata de analizar la capacidad del APG de obtener buenas soluciones. En este caso, la figura permite apreciar que la diferencia entre utilizar un valor de mutación u otro es no es significativa en el rango utilizado.

Del análisis realizado, la principal conclusión que se puede sacar del proceso de optimización del diseño de la red de Nueva York es que cuanto mayor es el tamaño de población mayor es la probabilidad de encontrar mejores soluciones, no existiendo en esta red en particular un 
tamaño máximo de individuos a partir del cual se deje de mejorar el porcentaje de éxito en el rango estudiado.

\subsubsection{Red R-9 de Joao Pessoa}

En el caso de la red de Joao Pessoa, el proceso de optimización previo determina que la probabilidad de mutación óptima para el diseño de esta red se encuentra en torno al $1 \%$ mientras que la probabilidad de cruce óptima está entre el 5 y el $6 \%$. Con estas condiciones y un tamaño de población constante e igual a 100 la probabilidad de encontrar una buena solución era algo superior al $40 \%$.

En la red de Joao Pessoa no tiene sentido realizar un análisis estadístico de soluciones óptimas, puesto que la repetibilidad de la mínima solución obtenida es inexistente, debido a la mayor complejidad de la red y a la gran cantidad de mínimos locales existentes en el campo de soluciones. En este caso resulta mucho más práctica la definición de un concepto de buena solución, tomando como referencia la solución de diseño más económica de entre todos los métodos heurísticos planteados.

La solución de diseño que proporciona un coste menor es coincidente en APG y SFLA y tiene un coste de 192,366 millones de um. A partir de este valor se considera buena solución del problema de diseño a toda aquella que no supere un coste de diseño para la red de 198,137 millones de um, valor que corresponde a la solución mínima de diseño más un $3 \%$ adicional.

Así, a partir de la experiencia previa de optimización se realiza una nueva tanda de simulaciones, donde se mantienen constantes los operadores genéticos de cruce y mutación, variando a partir de ahora tan sólo el número de individuos que intervendrán en el proceso de optimización. El valor numérico que toman ambos operadores es coincidente con el rango óptimo determinado en 5.2.1.3 y viene dado en la tabla inferior.

\begin{tabular}{|c|c|c|}
\hline \multicolumn{2}{|c|}{ PARÁMETROS } & RANGO DE VALORES \\
\hline Probabilidad de mutación & $P_{m}$ & 0,01 \\
\hline Probabilidad de cruce & $P_{c}$ & $0,5-0,6$ \\
\hline
\end{tabular}

Tabla 5.12. Rango óptimo de cálculo para los operadores genéticos en la red de Hanoi.

El estudio de población se realiza sobre un total de 3600 simulaciones, donde el rango de individuos que componen la población genética varía entre 25 y 225 individuos. La figura 5.79 muestra la probabilidad de obtener una buena solución de diseño en función del número de individuos que componen la población genética. La probabilidad de mutación considerada es de un $1 \%$, mientras que la probabilidad de cruce se encuentra entre el 50 y el $60 \%$. 


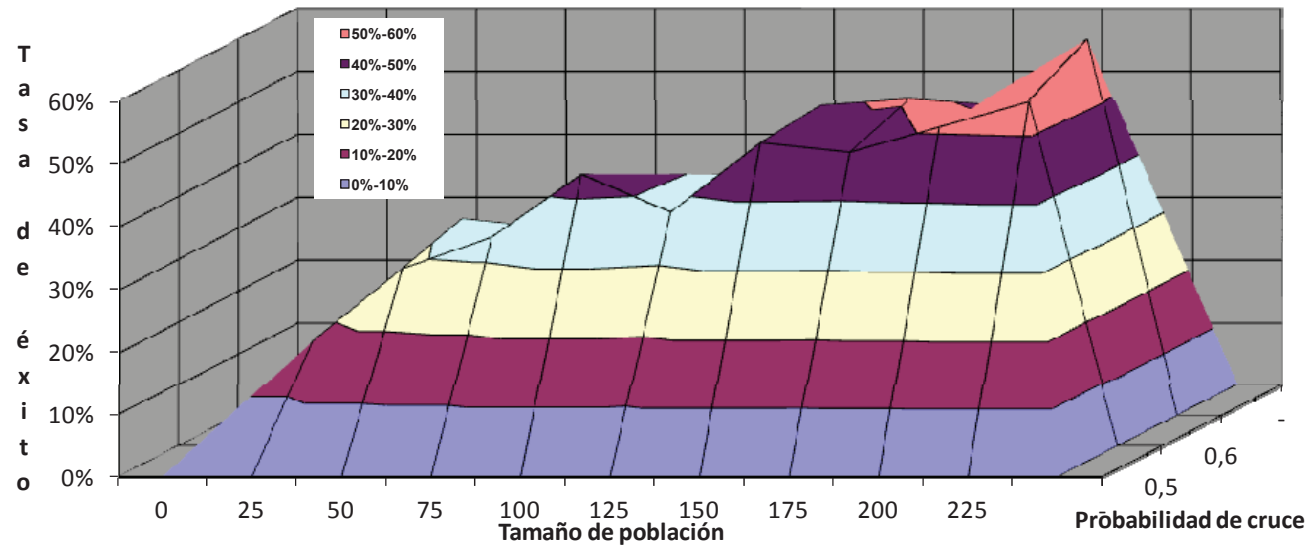

Figura 5.79. Probabilidad de obtención buena solución en función tamaño de población y probabilidad de cruce para la red de Joao Pessoa.

Los resultados siguen la misma línea que en el resto de redes. De este modo, la tendencia general del algoritmo APG es encontrar un mayor número de buenas soluciones cuando el número de individuos es más numeroso. No obstante, la probabilidad de encontrar una buena solución no sigue una relación lineal con el tamaño de la población. Así, la probabilidad de encontrar una buena solución crece de un modo más o menos proporcional hasta llegar a un tamaño de población de 150 individuos. A partir de este punto, no existen diferencias significativas desde un punto de vista cuantitativo entre utilizar 150 individuos o 200, puesto que los resultados obtenidos son prácticamente idénticos. La población más numerosa de todas las estudiadas (225 individuos) es también la que mejores resultados proporciona, puesto que en este valor se produce un nuevo salto en la probabilidad de obtener una buena solución, alcanzándose una probabilidad de éxito del $60 \%$.

\subsubsection{Red de Go-Yang}

Para los operadores genéticos, el análisis previo realizado determina los valores de la tabla inferior como los más adecuados en el proceso de diseño óptimo de la red de Go-Yang:

\begin{tabular}{|c|c|c|}
\hline \multicolumn{2}{|c|}{ PARÁMETROS } & RANGO DE VALORES \\
\hline Probabilidad de mutación & $P_{m}$ & $0,02-0,03$ \\
\hline Probabilidad de cruce & $P_{c}$ & $0,6-0,8$ \\
\hline
\end{tabular}

Tabla 5.13. Rango óptimo de cálculo para los operadores genéticos en la red de Go-Yang.

La tanda de simulaciones con la que se obtiene este rango de trabajo se realiza con un tamaño de población constante e igual a 100 individuos. En estas condiciones, la configuración óptima para las probabilidades de cruce y mutación obtenía probabilidades cercanas al $50 \%$ en la obtención de soluciones mínimas de diseño en la red de Go-Yang. Dicha 
solución mínima de diseño es la correspondiente a 177.009,6 miles de um y es coincidente en todas las técnicas de diseño estudiadas en este trabajo.

Este apartado realiza un estudio acerca del tamaño de población más adecuado para el diseño de la red, de modo que utilizando la configuración óptima que muestra la tabla 5.13 se realizan 10800 nuevas simulaciones, donde el tamaño de población inicial del algoritmo varía entre 25 y 225 individuos. El gráfico inferior muestra la probabilidad de obtener la mejor solución de diseño en función del número de individuos que componen la población genética. La probabilidad de mutación considerada oscila entre el 2 y el $3 \%$ mientras que la probabilidad de cruce se encuentra entre el 60 y el $80 \%$.

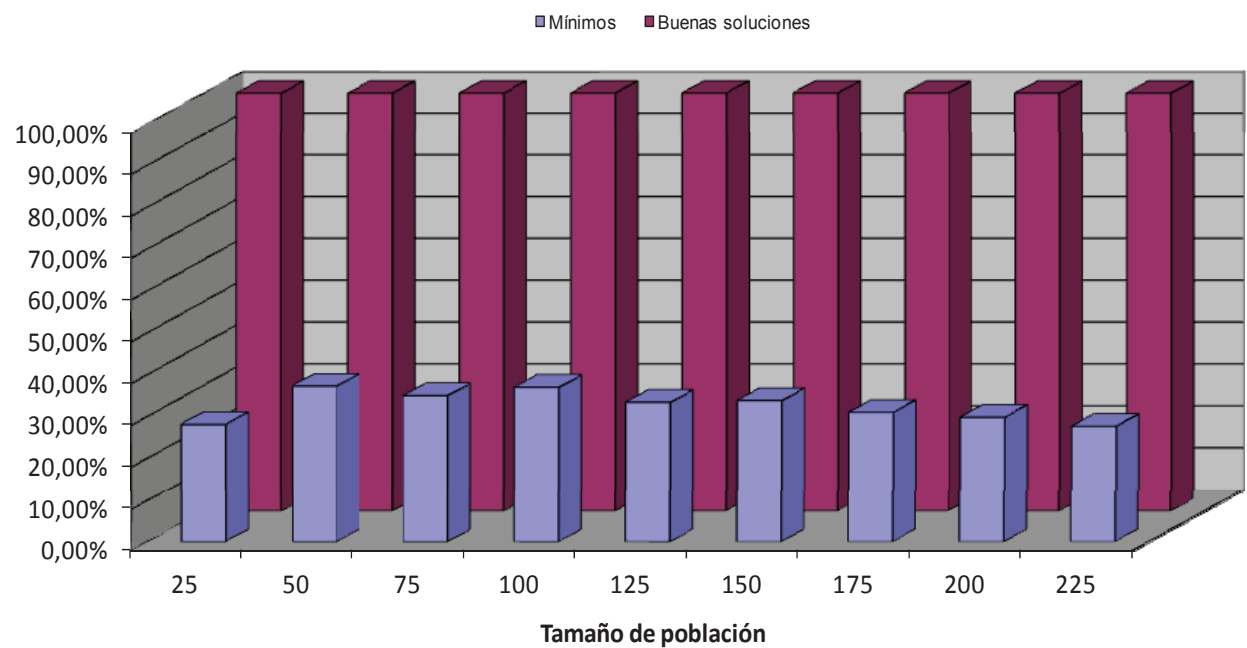

\section{Figura 5.80. Probabilidad de obtención buena solución en función tamaño de población} para la red de Go-Yang.

Numéricamente, el gráfico muestra como las peores poblaciones desde un punto de vista cuantitativo en cuanto a obtención de mínimos son las que ocupan los extremos. En el caso de utilizar pocos individuos (25) esta característica sigue la tendencia del resto de casos estudiados y responde a un patrón lógico, puesto que al ser menor el tamaño de la población existe una menor posibilidad de exploración, lo que lleva a convergencias tempranas.

En el caso de los mayores tamaños de población la situación que se produce no es habitual. En el resto de redes estudiadas normalmente se llega a un tamaño de población lo suficientemente grande como para que a partir de dicho tamaño la mejora quede estabilizada. Sin embargo, para el problema de diseño de la red de Go-Yang existe un determinado tamaño de población a partir del cual la probabilidad de encontrar la mínima solución de diseño no sólo no mejora, sino que empeora. En principio, esta situación no tiene una explicación lógica, puesto que teóricamente, un mayor número de cadenas genéticas debe permitir una mayor capacidad de exploración, por lo que es de esperar que a mayor 
tamaño de población se obtengan siempre mejores resultados desde el punto de vista cuantitativo, aún a costa de sacrificar un mayor tiempo de cálculo.

Las siguientes figuras muestran la probabilidad de obtener una solución de coste mínimo en función del tamaño de población, considerando también en este caso el valor de los operadores genéticos empleados.

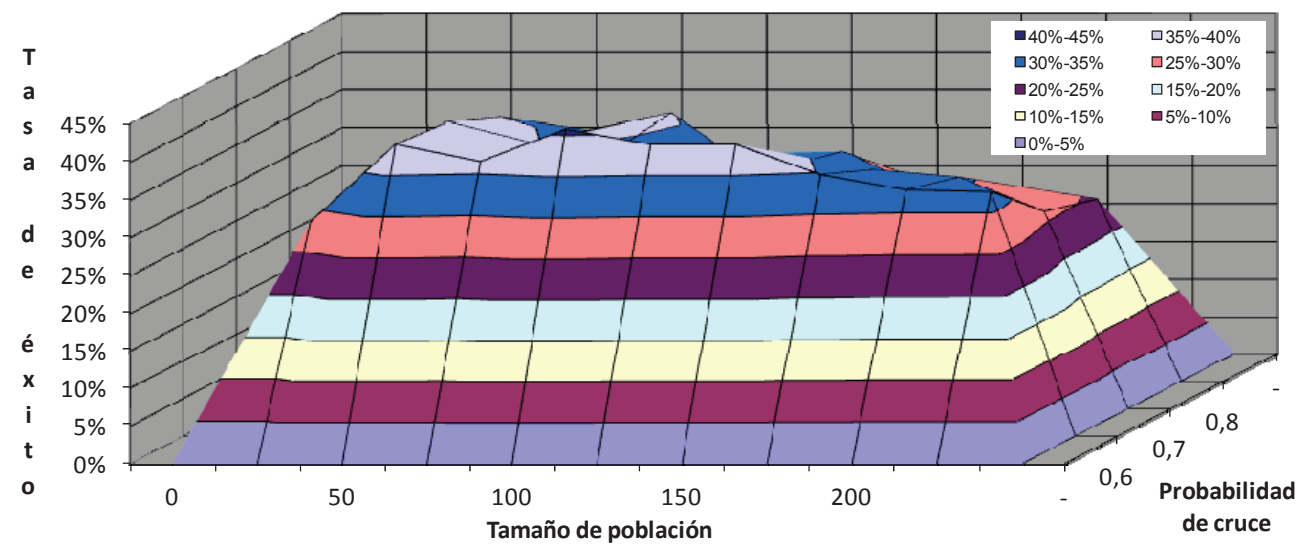

Figura 5.81. Probabilidad de obtención mínima solución en función tamaño de población y probabilidad de cruce.

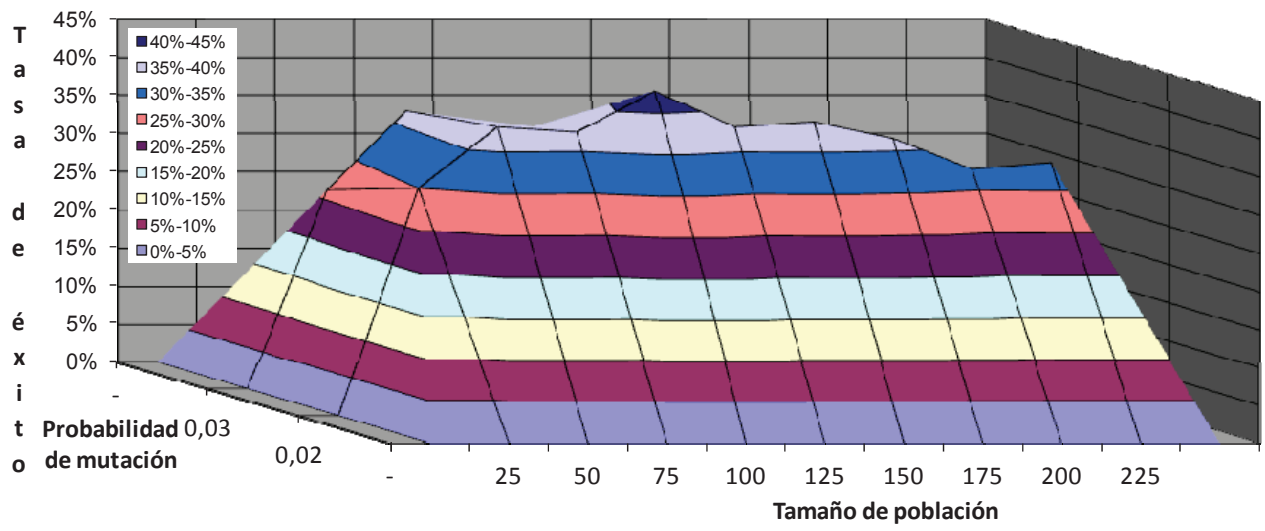

Figura 5.82. Probabilidad de obtención mínima solución en función tamaño de población y probabilidad de mutación.

La figura 5.81 representa la probabilidad de obtener una mínima solución en función del número de individuos con los que trabaja el APG y la probabilidad de que entre en acción el operador genético de cruce. La representación muestra como dentro del rango óptimo elegido para el operador de cruce, probabilidades de cruce de un $60 \%$ obtienen resultados ligeramente mejores. Esta probabilidad de cruce, combinada con un tamaño de población de 
100 individuos proporciona un porcentaje de éxito de un 40\% en la obtención de mínimas soluciones.

En el caso del operador genético de mutación, la figura 5.82 muestra como probabilidades de mutación en torno al $2 \%$ obtienen mayor número de soluciones de coste mínimo, obteniéndose el pico de probabilidad en una población de tamaño 100 individuos. A pesar de ello, la diferencia que se da entre tamaños de población comprendidos entre 50 y 175 individuos es escasa desde la perspectiva de obtener un mayor número de soluciones de coste mínimo, por lo que se puede considerar todo este rango como adecuado atendiendo tan sólo a criterios cuantitativos de obtención de una mínima solución.

El tamaño de la red de Go-Yang, unido a una menor complejidad de diseño respecto de otras redes, provocaba que en el estudio de parámetros óptimos se consiga una probabilidad de éxito del $100 \%$ en la obtención de buenas soluciones. De igual manera, cuando se extiende el estudio al número de individuos más adecuado en APG para el diseño óptimo de la red de GoYang, el número de buenas soluciones obtenidas sigue siendo de un $100 \%$ con todos los tamaños de población simulados, por lo que carece de sentido realizar un análisis estadístico.

\subsubsection{Ajuste de población Algoritmo PSO modificado}

Ya se ha nombrado en este trabajo que el algoritmo PSO utilizado no corresponde de manera exacta a la formulación original de esta técnica de optimización, siendo la diferencia más significativa la introducción de un nuevo parámetro, denominado probabilidad de despiste, y cuya función es evitar la caída en mínimos locales que provoquen convergencias tempranas del algoritmo.

El ajuste de parámetros analizaba los distintos operadores libres de configuración por parte del usuario, de modo que una adecuada selección de valores conduzca a la mejora de los resultados de diseño. Así, dicho apartado concluye, desde un punto de vista cuantitativo (obtener la mejor solución posible de diseño) cuáles son los valores más adecuados tanto para esta probabilidad de despiste como para el resto de parámetros clásicos que utiliza PSO, como son el límite de velocidad de vuelo que puede alcanzar una determinada partícula y el valor de las constantes $\mathrm{C}_{1}$ y $\mathrm{C}_{2}$.

Las conclusiones obtenidas en dicho estudio son utilizadas a continuación para determinar cuál es la influencia del tamaño de la población en el procedimiento de diseño que sigue el algoritmo. Así, la forma de proceder de este apartado será la realización de una nueva batería de simulaciones para cada una de las redes de benchmarking utilizadas, teniendo en cuenta que para cada una de ellas se utilizará el valor óptimo de cada parámetro tal como se obtuvo en el apartado 5.2.2, variando en este caso únicamente el tamaño de la población inicial del algoritmo PSO. 


\subsubsection{Red de Hanoi}

Una de las principales conclusiones obtenidas del estudio acerca de los distintos parámetros de cálculo era que el efecto que ejerce cada parámetro en el buen hacer del algoritmo PSO es distinto. Así, tanto el valor de la probabilidad de despiste $\left(P_{\text {desp }}\right)$ como el límite de la velocidad de vuelo $\left(\mathrm{V}_{\text {lim }}\right)$ se mostraban como una decisión crítica respecto del valor de las constantes $C_{1}$ y $C_{2}$ en la obtención de la mejor solución posible de diseño.

No obstante, aún configurando el mejor valor de diseño para cada parámetro, la capacidad que demuestra el algoritmo PSO para encontrar la solución mínima de diseño en la red de Hanoi es prácticamente nula, por lo que se centró el análisis estadístico en la obtención de buenas soluciones de diseño, definición donde entra toda aquella que no supere en más de un 3\% la solución mínima de diseño. Así, el ajuste de parámetros realizado para la red de Hanoi determina los siguientes valores óptimos para los distintos parámetros PSO:

\begin{tabular}{|c|c|c|}
\hline \multicolumn{2}{|c|}{ PARÁMETRO } & RANGO DE VALORES \\
\hline Probabilidad de despiste & $\mathrm{P}_{\text {desp }}$ & 0,1 \\
\hline Velocidad límite de vuelo & $\mathrm{V}_{\text {lim }}$ & 0,2 \\
\hline Constante 1 & $\mathrm{C}_{1}$ & 2 \\
\hline Constante 2 & $\mathrm{C}_{2}$ & 2 \\
\hline
\end{tabular}

Tabla 5.14. Rango óptimo de cálculo para los operadores PSO en la red de Hanoi.

Adaptando estos valores para cada parámetro a una población fija de 100 individuos se conseguía que alrededor de un $25 \%$ de las simulaciones realizadas obtuvieran una buena solución de diseño para la red de Hanoi.

El estudio de población realiza el diseño de la red de forma inversa, de modo que se mantiene fijo el valor de todos los parámetros en sus mejores valores, alternando en esta ocasión distintos tamaños de población. Así, el número de individuos que intervienen en el proceso de optimización se ha variado entre 25 y 225 individuos. La totalidad de soluciones obtenidas se muestran en el siguiente histograma. 


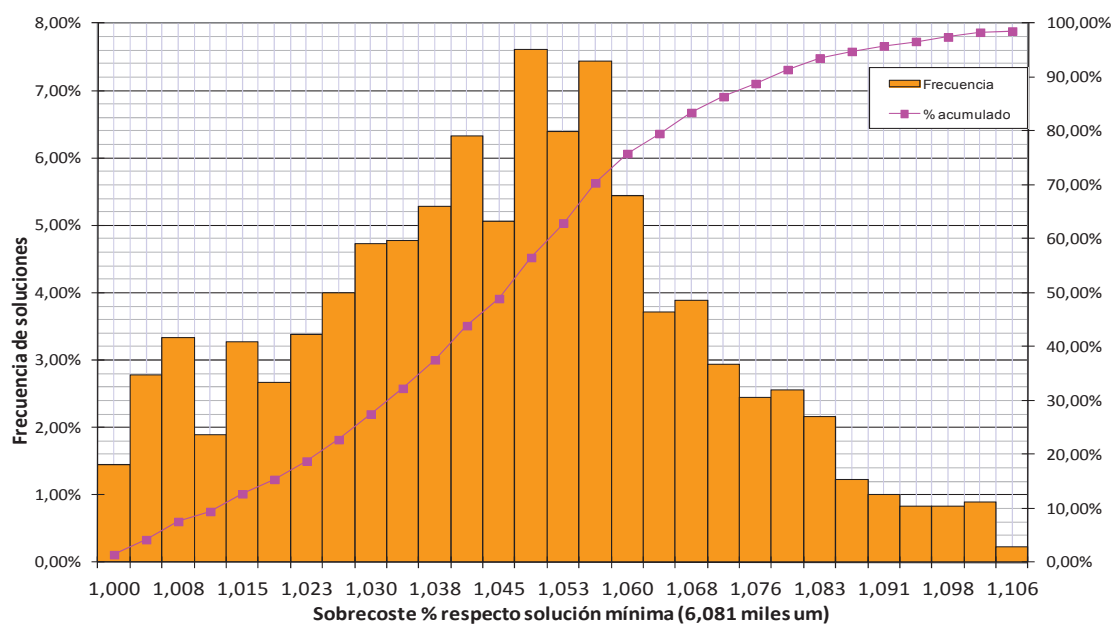

Figura 5.83. Histograma de soluciones para el estudio de población en la red de Hanoi.

El histograma muestra la totalidad de simulaciones realizadas, de modo que el valor 1,00 corresponde a la solución de mínimo coste (6,081 mil,lones de um), mientras que el resto de soluciones quedan cuantificadas como el incremento porcentual respecto de esta solución. Tal como ya se ha nombrado, el algoritmo PSO no tiene facilidad para encontrar la mínima solución en la red de Hanoi, de modo que dicha solución de diseño se obtiene tan sólo 26 veces en las 1800 simulaciones realizadas, apenas algo más de un $1 \%$. No obstante, la figura muestra como más del $30 \%$ de las simulaciones realizadas entran dentro del concepto de buena solución, alcanzándose soluciones inferiores al límite del 3\% en 555 ocasiones de las 1800 simulaciones realizadas.

Si se comparan estos datos con los obtenidos en el apartado 5.2.2.1 se comprueba que la mejoría es evidente, puesto que la optimización realizada para los parámetros $\mathrm{P}_{\text {desp }}, \mathrm{V}_{\text {lim }} \mathrm{Y}$ las constantes de cálculo provocan una mejora en el número de buenas soluciones, doblando prácticamente la probabilidad de obtener una buena solución, puesto que se pasa de probabilidades de éxito cercanas al $15 \%$ a probabilidades cercanas al $30 \%$.

El análisis de población para el algoritmo PSO tiene como objetivo aumentar todavía más el filtrado ya realizado de parámetros, de modo que sea posible cuantificar de cuanto es la mejora cuando se utilizan poblaciones más numerosas y cuanto empeoran los resultados si utilizamos poblaciones más pequeñas. Este apartado tan sólo trata los datos desde un punto de vista cuantitativo, sin entrar en debate acerca de cuál es la opción computacionalmente más costosa, punto que se trata ampliamente en el capítulo 6. Así, la figura 5.84 muestra el porcentaje obtenido de mínimos y buenas soluciones en función únicamente del tamaño de población del algoritmo, teniendo en cuenta que el resto de parámetros utilizados corresponden a la configuración óptima en cada caso. 


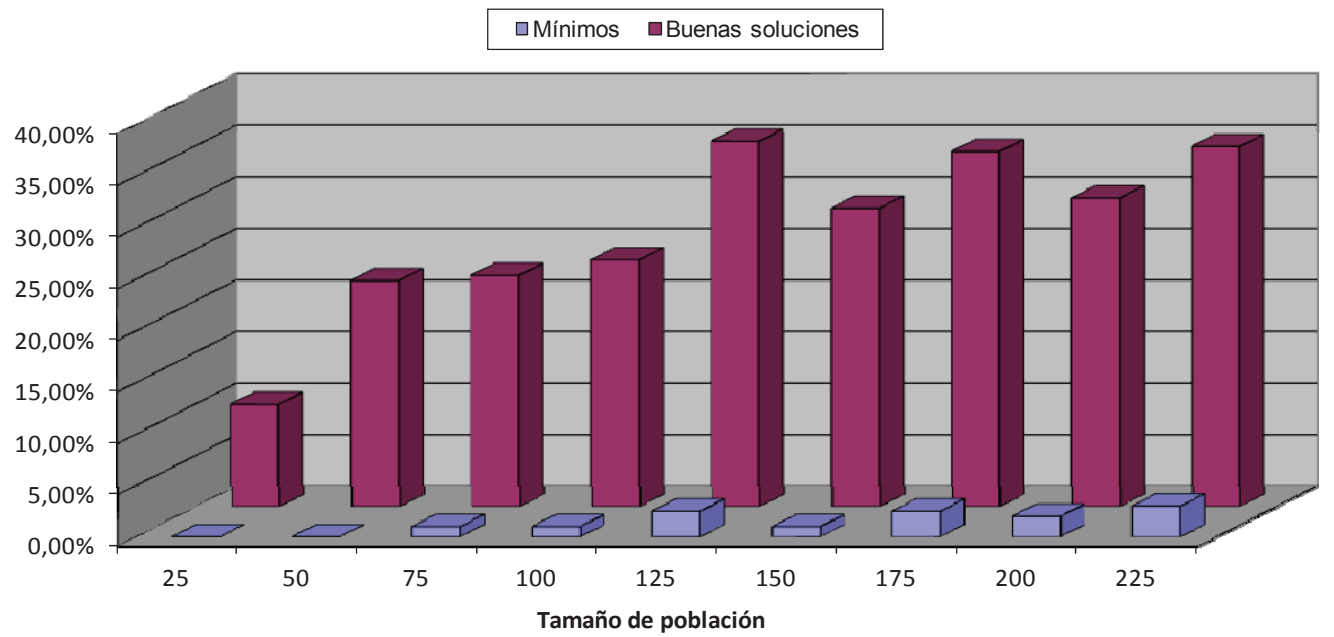

Figura 5.84. Probabilidad de obtención mínimos/buena solución en función tamaño de población para la red de Hanoi utilizando PSO.

Respecto al número de soluciones óptimas de diseño no existe ningún número determinado de partículas a partir del cual mejore significativamente la probabilidad de encontrar la solución mínima de diseño, puesto no existe ningún tamaño de población que supere siquiera el $5 \%$ de probabilidad de éxito.

No obstante, si se centra el estudio en la obtención de buenas soluciones de diseño, los resultados muestran como conforme aumenta el número de individuos que intervienen en el proceso de optimización también lo hace la probabilidad de encontrar una solución por debajo de 6,263 millones de um (coste límite definido para una buena solución de diseño). Sin embargo, esta mejora no es lineal y para poblaciones superiores a los 125 individuos los resultados dejan de mejorar de forma regular, produciéndose cierta irregularidad en los resultados. Lo que sí que parece claro a tenor de los resultados obtenidos es que tamaños de población por debajo de 50 individuos son insuficientes, puesto que la probabilidad de encontrar una buena solución se encuentra por debajo del $10 \%$.

Del mismo modo, si se tuviera que elegir un tamaño de población óptimo en base a la probabilidad de obtener una buena solución parece claro pensar que cualquier población por encima de los 125 individuos es adecuada en esta red, puesto que todas obtienen porcentajes de éxito por encima del 30\%, mientras que poblaciones menores de 50 individuos no son aconsejables, puesto que son insuficientes desde un punto de vista cuantitativo a la hora de obtener buenas soluciones de diseño para la red de Hanoi. 


\subsubsection{Red de Nueva York}

Para la red de Nueva York se procede de idéntico modo cuando se trata de definir el tamaño de población más adecuado. Así, a partir del estudio de parámetros realizado en 5.2.2.2 se definen los valores óptimos de diseño para los parámetros $V_{\text {limm }}, P_{\text {desp }}, C_{1}$ y $C_{2}$. Estos valores se mantendrán constantes en las simulaciones realizadas a partir de ahora, de modo que tan sólo variará el número de individuos que intervienen en el proceso de optimización, determinando de esta forma la influencia que ejerce el tamaño de la población inicial del algoritmo en la obtención de mínimas soluciones de diseño.

Una de las principales conclusiones a las que se llega en el análisis estadístico previo revelaba que la mayor simplicidad del problema de diseño de la red de Nueva York frente a otros facilitaba la obtención de soluciones óptimas de diseño. Así, en las simulaciones realizadas se daba la circunstancia de que la solución de coste mínimo era la más repetida de todas, alcanzándose en un $13,35 \%$ de las simulaciones realizadas. Del mismo modo, cuando se consideraba el concepto de buena solución la probabilidad de éxito aumentaba hasta casi un $40 \%$ del total de simulaciones realizadas.

El análisis estadístico filtra todavía más estos datos, de modo que la combinación óptima de diseño aumenta la probabilidad de obtener una solución mínima de diseño hasta cifras cercanas al $25 \%$, mientras que la probabilidad de obtener una buena solución quedaba por encima del $60 \%$. Esta combinación óptima de diseño en lo que al valor de cada parámetro se refiere queda definida en la tabla inferior.

\begin{tabular}{|c|c|c|}
\hline \multicolumn{2}{|c|}{ Parámetros } & Rango de valores \\
\hline Probabilidad de despiste & $\mathrm{P}_{\text {desp }}$ & 0,1 \\
\hline Velocidad límite de vuelo & $\mathrm{V}_{\text {lim }}$ & 0,3 \\
\hline Constante 1 & $\mathrm{C}_{1}$ & 2 \\
\hline Constante 2 & $\mathrm{C}_{2}$ & 2 \\
\hline
\end{tabular}

Tabla 5.15. Rango óptimo de cálculo para los operadores PSO en la red de los túneles de Nueva York.

Utilizando los valores de la tabla para cada parámetro y variando la población del algoritmo entre 25 y 225 individuos se realiza una nueva batería de simulaciones, donde el objetivo es aumentar la probabilidad de encontrar la solución de mínimo coste del algoritmo. De este modo, se realiza un total de 1800 simulaciones, cuyo resumen de resultados viene dado por el histograma que muestra la figura 5.85 . 


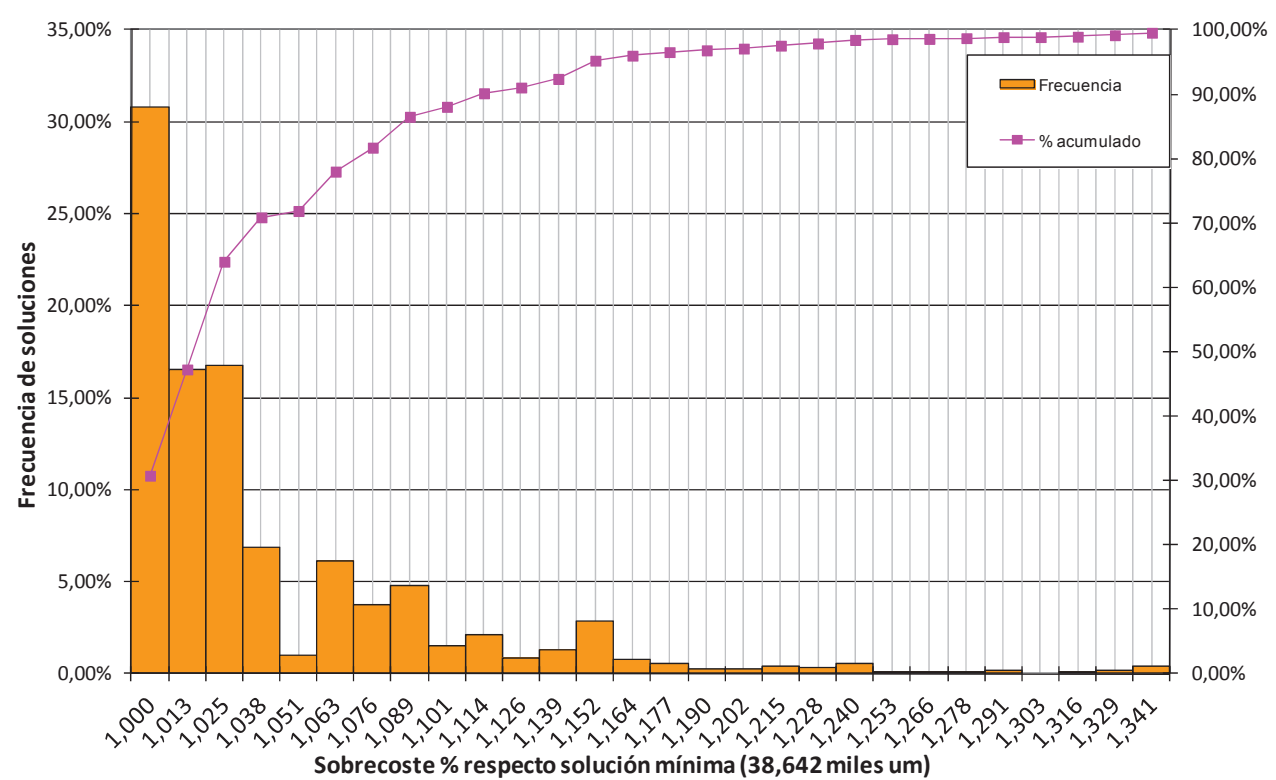

Figura 5.85. Histograma de soluciones para el estudio de población en la red de Nueva York con PSO.

El valor 1 en el eje de abscisas corresponde con la mejor solución posible de diseño, de modo que el resto de valores representa en \% cuánto se alejan de esta solución óptima el resto de soluciones obtenidas por el algoritmo. Así, el 30\% de las simulaciones realizadas con la configuración óptima de parámetros obtiene la solución de mínimo coste para la red de Nueva York, mientras que si se considera el concepto de buena solución la probabilidad de éxito aumenta hasta el $64 \%$.

El histograma de soluciones muestra como la mayoría de simulaciones aparecen claramente desplazadas hacia el lado izquierdo, lo que identifica las mejores soluciones de diseño. Esta situación viene favorecida por la optimización de parámetros realizada previamente

La figura 5.86 muestra un filtrado de las simulaciones realizadas en este apartado, de modo que analiza los resultados obtenidos únicamente en función del tamaño de población utilizado, a fin de cuantificar la influencia del número de individuos en el proceso de optimización de la red de Nueva York: 


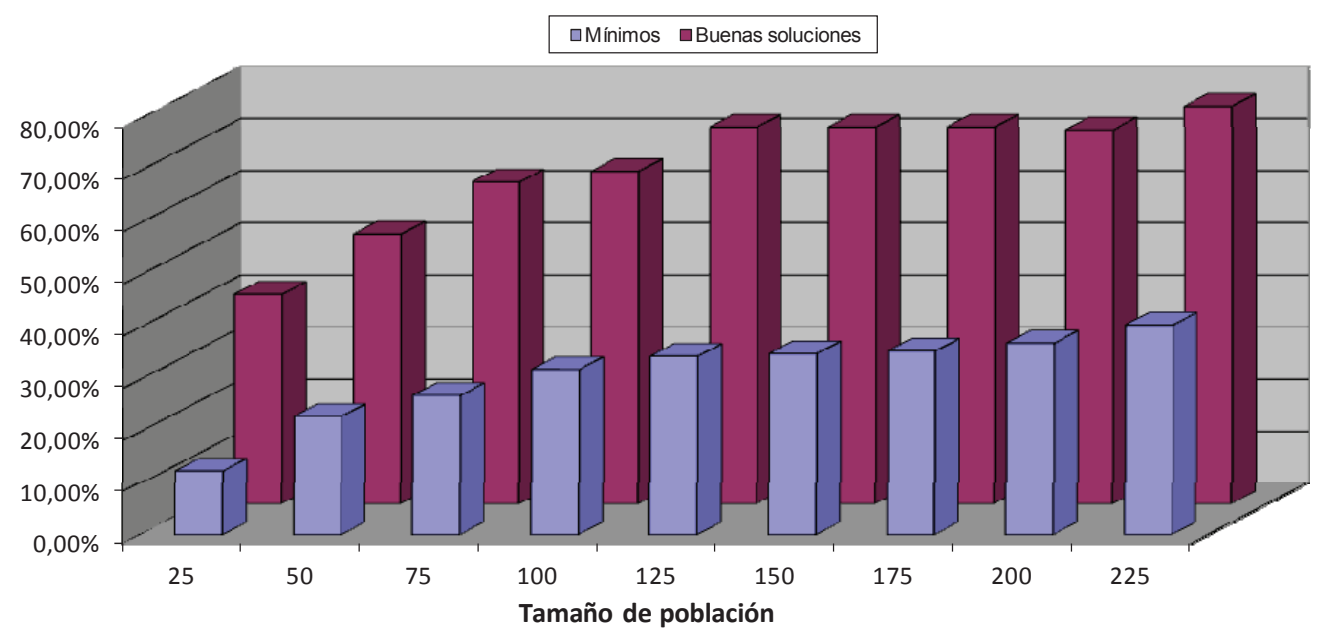

Figura 5.86. Probabilidad de obtención mínimos/buena solución en función tamaño de población para la red de NY utilizando PSO.

La probabilidad de encontrar una mejor solución crece con el número de individuos que intervienen en el proceso de optimización. De este modo, el menor tamaño de población (25 individuos) es el que obtiene la probabilidad más pequeña de encontrar una mínima o una buena solución, mientras que el tamaño de población más grande ( 225 individuos) es el que registra las probabilidades más altas cuando se trata de encontrar mejores soluciones.

La mejora producida con el aumento del tamaño de población no es lineal, es decir, llega un determinado tamaño de población a partir del cual la mejora producida deja de ser tan perceptible. Para el caso de la red de Nueva York este punto de inflexión parece que queda establecido en 125 individuos, tamaño de población a partir del cual el porcentaje de éxito se mantiene más o menos sin variaciones.

De acuerdo a esto, la elección de un tamaño de población óptimo en base a la probabilidad de obtener soluciones mínimas o buenas soluciones para la red de Nueva York viene supeditada a la elección de poblaciones que superen los 125 individuos, cifra a partir de la cual se obtiene una probabilidad de éxito superior al $35 \%$ en la obtención de mínimas soluciones de diseño.

\subsubsection{Red R-9 de Joao Pessoa}

Inicialmente, el estudio se plantea del mismo modo que en anteriores casos; es decir, una vez definidos los valores óptimos para los parámetros $V_{\text {lim }}, P_{\text {desp }}, C_{1}$ y $C_{2}$ se realiza una batería de simulaciones donde estos parámetros quedan definidos como constantes, mientras que el número de individuos que interviene en el proceso de optimización varía entre 25 y 225 individuos. 
El análisis estadístico previo se centra en la obtención de buenas soluciones, puesto que en tan sólo una ocasión se conseguía la solución mínima de diseño. El objetivo de este análisis era realizar un filtrado de valores para cada parámetro de cálculo, teniendo en cuenta que el único parámetro que permanecía invariable era el tamaño de la población, que se mantenía constante en 100 individuos. Así, considerando como buena solución costes de diseño que no excedan en más de un $3 \%$ la solución mínima absoluta, se obtuvo una probabilidad de éxito de alrededor del $25 \%$ con el mejor ajuste posible para los distintos parámetros. Dichos valores vienen representados en la siguiente tabla:

\begin{tabular}{|c|c|c|}
\hline \multicolumn{2}{|c|}{ PARÁMETROS } & RANGO DE VALORES \\
\hline Probabilidad de despiste & $P_{\text {desp }}$ & 0,15 \\
\hline Velocidad límite de vuelo & $\mathrm{V}_{\text {lim }}$ & 0,2 \\
\hline Constante 1 & $\mathrm{C}_{1}$ & 2 \\
\hline Constante 2 & $\mathrm{C}_{2}$ & 2 \\
\hline
\end{tabular}

Tabla 5.16. Rango óptimo de cálculo para los operadores PSO en la red R-9 de Joao Pessoa.

Utilizando los valores referidos en la tabla para cada parámetro y alternando tamaños de población entre 25 y 225 individuos se realizan 1800 nuevas simulaciones, cuyos resultados de diseño muestra de modo general el histograma siguiente:

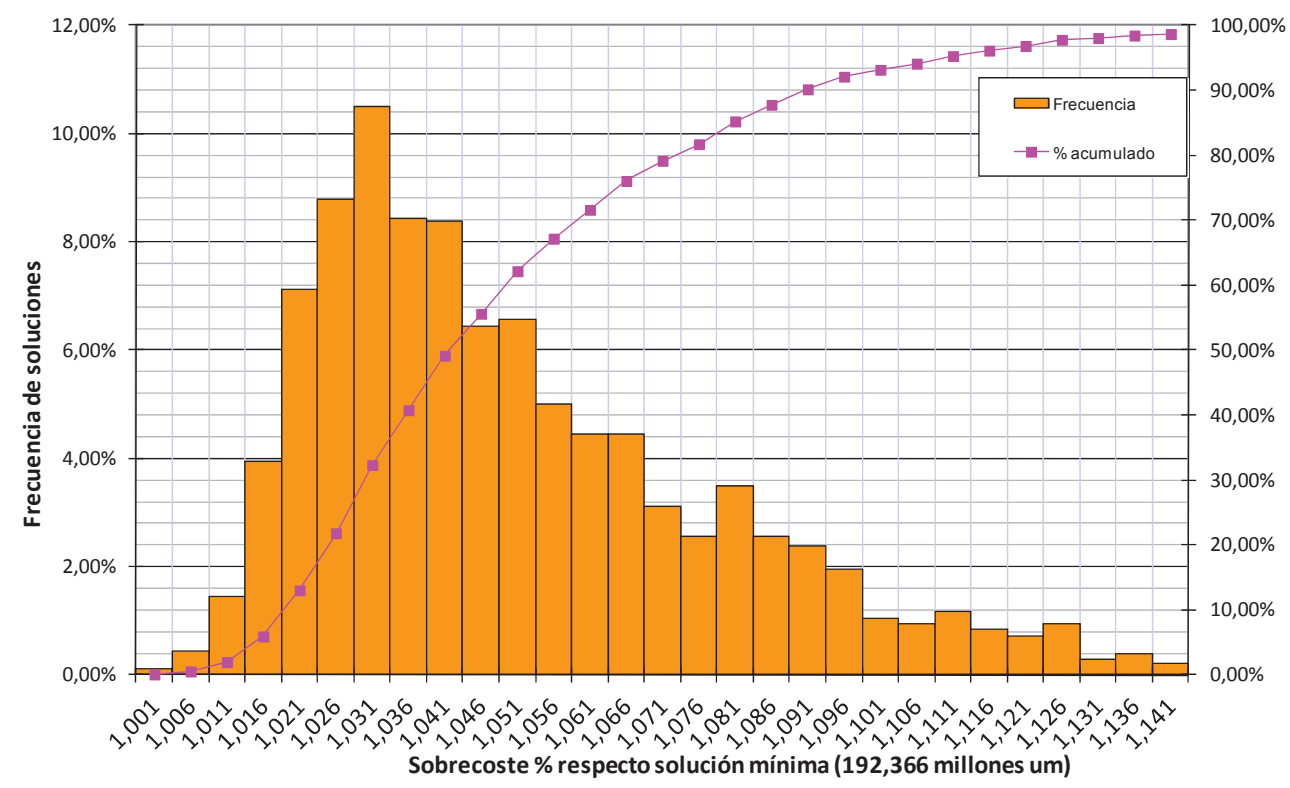

Figura 5.87. Histograma de soluciones para el estudio de población en la red $R-9$ de Joao Pessoa.

La solución de diseño obtenida en la tanda de simulaciones que presenta menor coste es de 192,533 millones de um. Esta solución no es coincidente con la mejor solución de diseño 
obtenida de modo absoluto, con un coste de 192,366 millones de um, pero se aproxima en menos de un $1 \%$.

Si se comparan los resultados obtenidos en esta ronda de simulaciones con el histograma de soluciones de la figura 5.27 se aprecia como el resultado de diseño medio tiene un coste mucho más bajo en esta ocasión. Así, hasta un $33 \%$ de las simulaciones realizadas entran dentro de la definición de buena solución de diseño, frente al $11 \%$ que se obtiene en la anterior tanda de simulaciones. Esta gran diferencia viene marcada por el ajuste de parámetros realizado, puesto los cálculos realizados ahora cuentan con cuatro de los cinco parámetros de ajuste optimizados.

A priori, la complejidad de la red de Joao Pessoa debe favorecer la obtención de mejores resultados con mayores tamaños de población, puesto que al haber un mayor número de individuos buscando en el espacio de soluciones, la probabilidad de encontrar un mínimo local del que ya no se pueda salir tiene que ser más pequeña. La siguiente figura representa la influencia del tamaño de población en el diseño óptimo de la red de Joao Pessoa con el algoritmo PSO modificado.

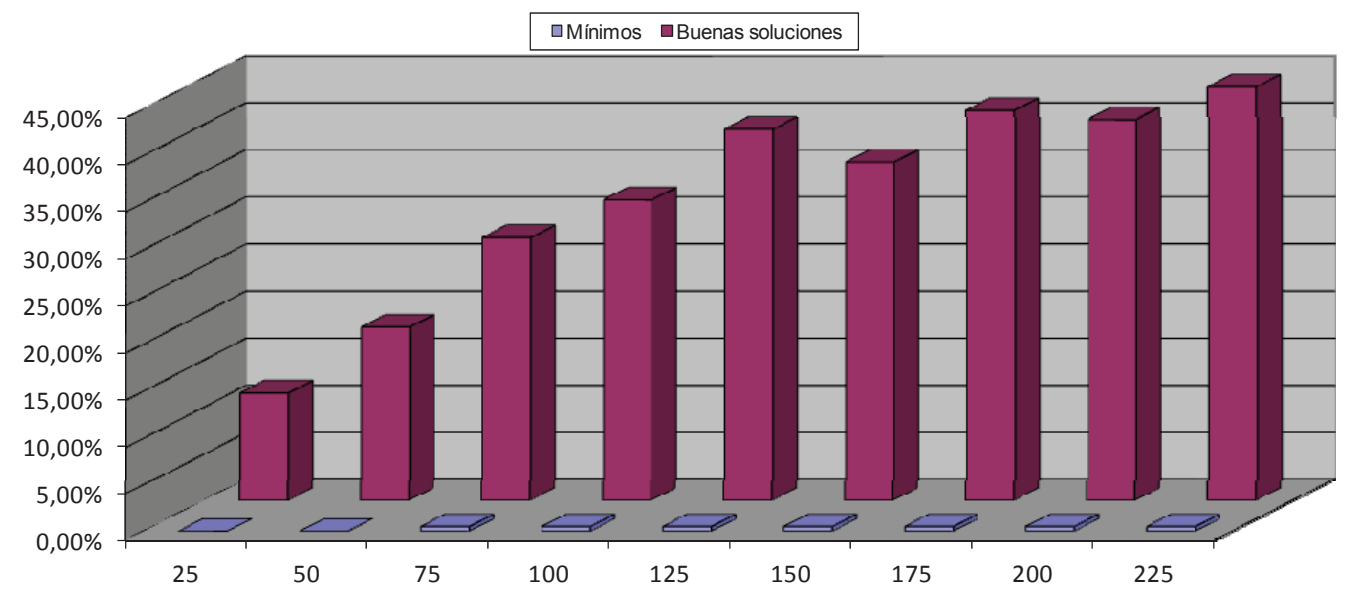

Figura 5.88. Probabilidad de obtención mínimos/buena solución en función tamaño de población para la red de Joao Pessoa utilizando PSO.

Tal como muestra la figura, el comportamiento respecto al número de individuos que intervienen en el proceso de optimización sigue las mismas directrices que en el resto de redes.

El menor tamaño de población empleado es de 25 individuos, que a la vista de los resultados se antoja insuficiente para manejar una red como la de Joao Pessoa, puesto que apenas el 10 $\%$ de las simulaciones consigue una buena solución de diseño. Conforme aumentamos el tamaño de la población también lo hace la probabilidad de obtener mejores soluciones. Tal 
como ocurre en los casos anteriores, la mejora es continua hasta llegar a un determinado tamaño de población (125 individuos) donde dicha mejora queda algo más estabilizada.

Así, entre una población de 25 individuos y una población de 125 individuos la diferencia de probabilidades para encontrar una buena solución es de un 30\%, mientras que la diferencia entre una población de 125 y una de 225 es de apenas un $14 \%$.

\subsubsection{Red de Go-Yang}

La red de Go-Yang es la que ofrece menos posibilidades distintas de diseño, debido a su tamaño y al tamaño de la gama utilizada para los conductos, por lo que es la que reviste una menor complejidad. En contraste con esta afirmación, la metodología de diseño basada en el algoritmo PSO tan sólo obtiene un 3,78\% de soluciones de mínimo coste en la primera batería de simulaciones realizada en el apartado 5.2.2.4. No obstante, hasta un $73 \%$ del total de simulaciones se situaba en la siguiente solución de diseño, catalogada dentro del concepto de buena solución.

Así, para la red de Go-Yang la mejor solución de diseño encontrada a nivel global tiene un coste de 177.009,6 um, por lo que el límite para que un determinado diseño sea considerado como buena solución del problema queda establecido en 182.319,8 um, correspondiente a la solución óptima más un 3\% de margen adicional.

El ajuste de parámetros realizado define una serie de valores óptimos para los distintos parámetros de la metodología PSO, como son $\mathrm{V}_{\text {lim }}, \mathrm{P}_{\text {desp }}, \mathrm{C}_{1}$ y $\mathrm{C}_{2}$. Partiendo del ajuste óptimo para cada uno de estos valores se realiza una nueva batería de simulaciones, donde el único parámetro de cálculo que toma distintos valores es la población del algoritmo, que toma valores entre 25 y 225 individuos.

\begin{tabular}{|c|c|c|}
\hline \multicolumn{2}{|c|}{ PARÁMETROS } & RANGO DE VALORES \\
\hline Probabilidad de despiste & $\mathrm{P}_{\text {desp }}$ & 0,1 \\
\hline Velocidad límite de vuelo & $\mathrm{V}_{\text {lim }}$ & 0,1 \\
\hline Constante 1 & $\mathrm{C}_{1}$ & 1,8 \\
\hline Constante 2 & $\mathrm{C}_{2}$ & 2 \\
\hline
\end{tabular}

Tabla 5.17. Rango óptimo de cálculo para los operadores PSO en la red de Go-Yang.

Utilizando el ajuste óptimo para $V_{\text {lim }}, P_{\text {desp }}, C_{1}$ y $C_{2}$ y variando el tamaño de la población en saltos de 25 individuos se realizan un total de 1800 simulaciones, a fin de tener una muestra lo suficientemente representativa. El histograma de soluciones inferior muestra los resultados obtenidos en esta ronda de simulaciones: 


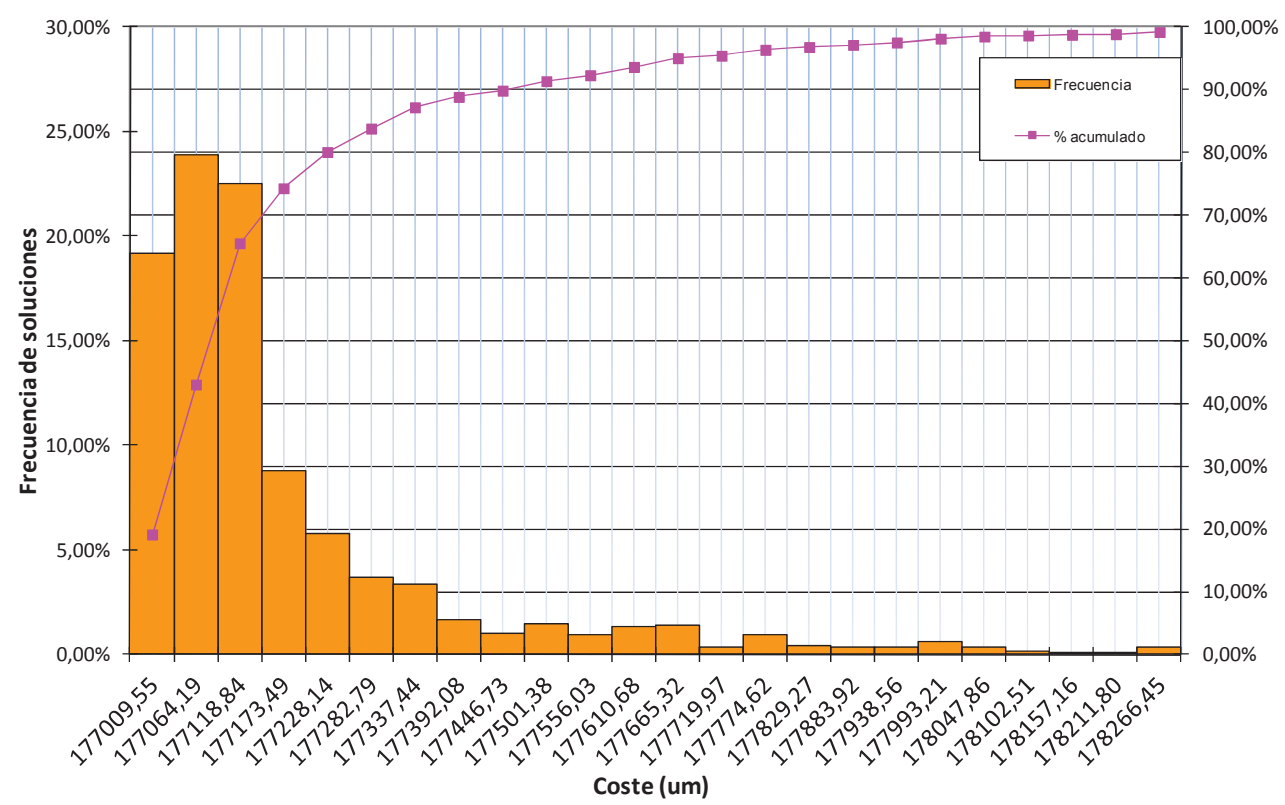

Figura 5.89. Histograma de soluciones para el estudio de población en la red de Go-Yang utilizando metodología PSO.

La mejor solución de diseño obtenida cuesta 177.009,55 um, valor que coincide con la mejor solución absoluta. En esta tanda de simulaciones, prácticamente el $20 \%$ de los cálculos realizados obtienen el óptimo de diseño, mejorando ampliamente los resultados del apartado 5.2.2.4, donde los resultados previos a la optimización apenas ofrecían un $4 \%$ de soluciones óptimas (ver figura 5.34).

En cuanto al número de buenas soluciones, el menor número de posibilidades de diseño que ofrece esta red favorece que prácticamente todas las simulaciones se acerquen al óptimo, de modo que el $100 \%$ de las soluciones obtenidas entran dentro de la definición de buena solución de diseño que da este trabajo, puesto que ninguna supera en más de un $3 \%$ la solución óptima. La figura 5.90 muestra un filtrado de resultados en función del número de individuos que intervienen en la simulación: 


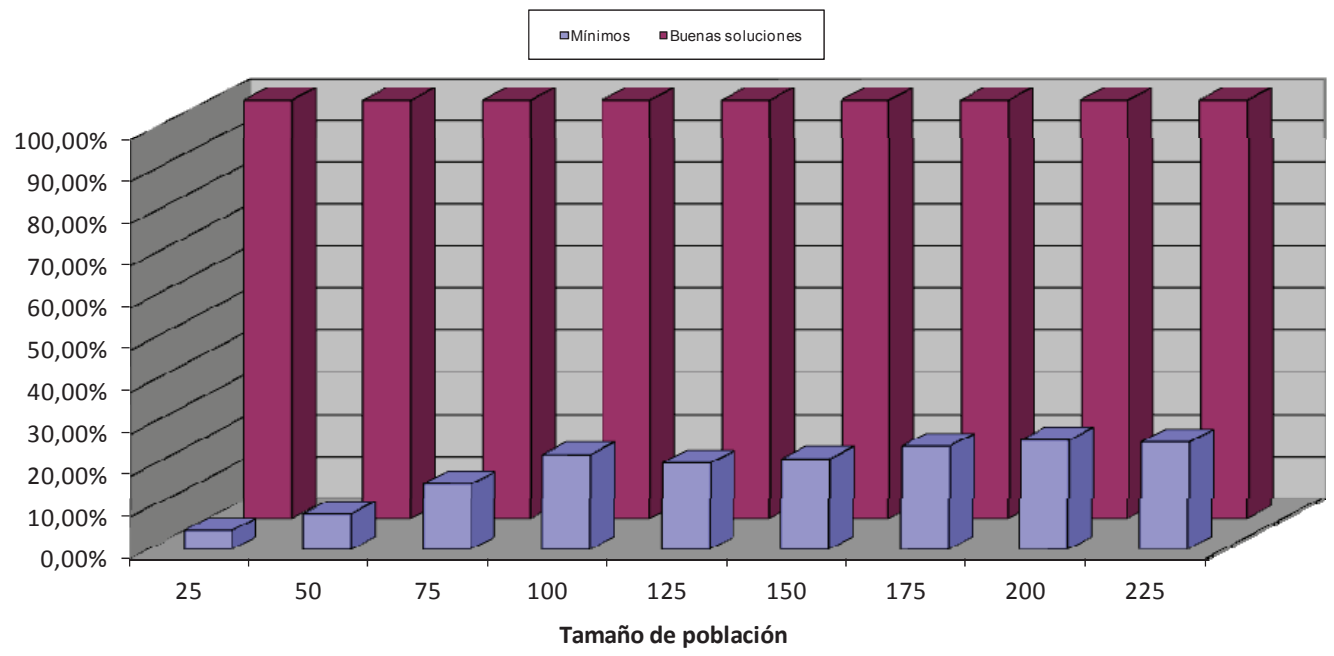

Figura 5.90. Probabilidad de obtención mínimos/buena solución en función tamaño de población para la red de Go-Yang utilizando PSO.

La influencia del tamaño de población en los resultados sigue la misma tendencia que en el resto de redes, si bien la menor dificultad de diseño de la red de Go-Yang facilita que todos los tamaños de población ensayados consigan obtener la solución de mínimo coste con mayor o menor facilidad. Obviamente, cuando se ensaya con tan sólo 25 individuos se obtienen los peores resultados, puesto que apenas un $5 \%$ de las simulaciones consiguen la solución óptima, pero aún así éste es el único caso donde poblaciones tan pequeñas consiguen el óptimo de diseño.

El patrón de comportamiento del resto de poblaciones es idéntico, de modo que conforme aumentamos el número de individuos que intervienen en el proceso de optimización los resultados van mejorando, hasta llegar a determinado tamaño de población donde la mejora queda estabilizada.

Para la red de Go-Yang éste punto de inflexión parece quedar establecido en torno a los 100 individuos, donde se obtiene un $23 \%$ de probabilidad de obtener el óptimo. A partir de aquí, el aumento de la población de individuos no se acompaña de una mejora en los resultados, quedando estos bastante estabilizados, siempre con una probabilidad entre el 23 y el $26 \%$ de obtener el óptimo.

\subsubsection{Ajuste de población del algoritmo Harmony Search}

El análisis estadístico realizado en el aparatado 5.2.2 analiza el rango de operación óptimo tanto para la probabilidad HMCR como para el ajuste del PAR, manteniendo constante el tamaño de población con el que trabaja el algoritmo. Los resultados derivados del análisis estadístico permiten descartar ciertos valores para ambos parámetros que entorpecían la 
búsqueda del óptimo, de modo que la experiencia previa adquirida se ha aplicado para las simulaciones que se muestran a continuación.

\subsubsection{Red de Hanoi}

Una de las principales conclusiones derivadas del análisis estadístico realizado para la probabilidad HMCR fue que cuando ésta era superior a 0,93 (tanto por uno) no sólo no obtenía valores óptimos de diseño si no que ni siquiera proporcionaba soluciones factibles de diseño. Esto quiere decir que limitar la búsqueda de diámetros a los que ya se encuentran de modo aleatorio dentro de las primeras generaciones del algoritmo es, en general, perjudicial para el algoritmo de búsqueda.

Del mismo modo, para el grado de ajuste (PAR) que tiene un determinado diámetro dentro del vector de soluciones ocurre lo mismo cuando la probabilidad de que se produzca dicho ajuste sea superior a 0,62 (tanto por uno). En este caso, el algoritmo no es capaz de proporcionar soluciones factibles para la red de Hanoi.

En el estudio de población todos estos valores no aptos han sido descartados, de modo que la probabilidad HMCR queda acotada entre 0,88 y 0,92, mientras que el PAR se ha ajustado entre 0,05 y 0,15 . Ambos rangos de trabajo pueden ser considerados como el ajuste de parámetros óptimo en HS para la red de Hanoi.

El tamaño de población estudiado para el algoritmo se ha variado desde los 15 individuos hasta los 135, modificando dicho tamaño de 15 en 15.

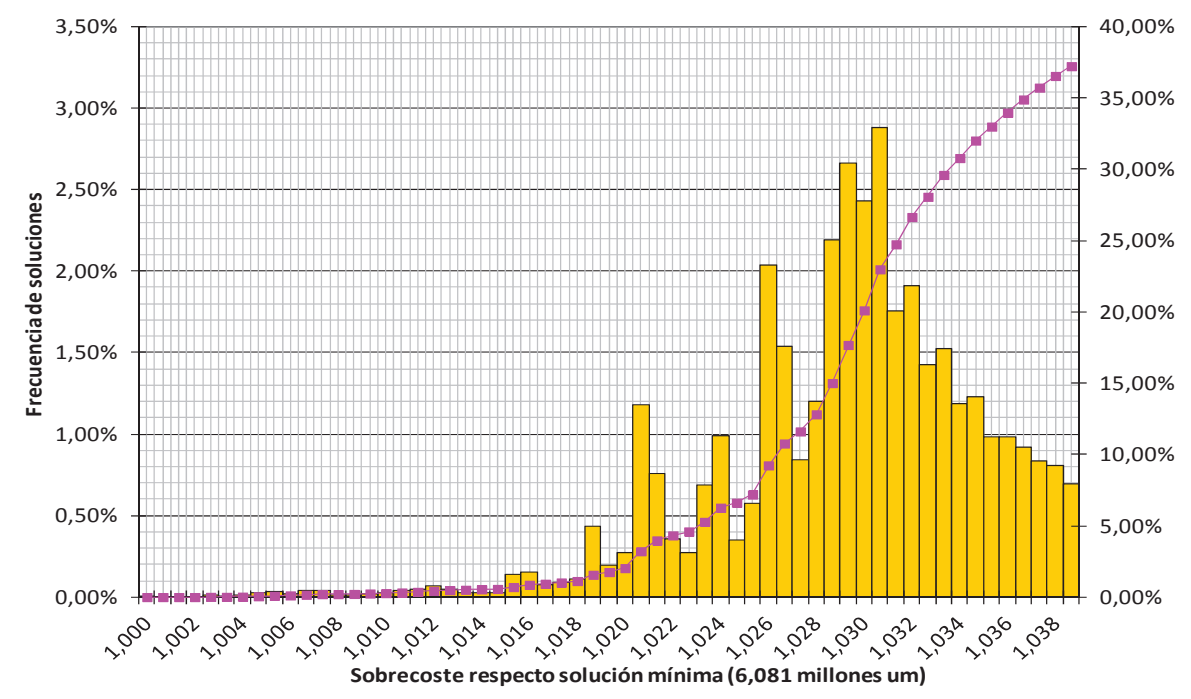

Figura 5.91. Histograma de soluciones para el estudio de población en la red de Hanoi utilizando metodología HS. 
La figura 5.91 representa la totalidad de simulaciones realizadas con esta configuración. Los resultados confirman, tal como se vio en el apartado 5.3.3.1, que la técnica heurística HS no encuentra el mínimo coste de diseño de la red de Hanoi con facilidad. Por otro lado, prácticamente un $50 \%$ de las simulaciones realizadas sí que entran dentro de la definición de buena solución.

De modo similar a como se procede en el resto de análisis, la figura 5.92 muestra la probabilidad de obtener una buena solución del problema de diseño en función del tamaño de población y el parámetro PAR. En la figura se observa como el tamaño de población ejerce una influencia bastante considerable en el porcentaje de éxito cuando se trata de encontrar buenas soluciones. Así, simulaciones donde la población del algoritmo se encuentra por encima de 30 y por debajo de 105 individuos tienen una probabilidad superior al 20\% de encontrar una buena solución para el problema de diseño. El pico de éxito en el caso de la red de Hanoi se encuentra en poblaciones de 60-75 individuos, dato que debe confirmarse en la simulación de otras redes antes de generalizar este intervalo de población como el más adecuado para el proceso de diseño.

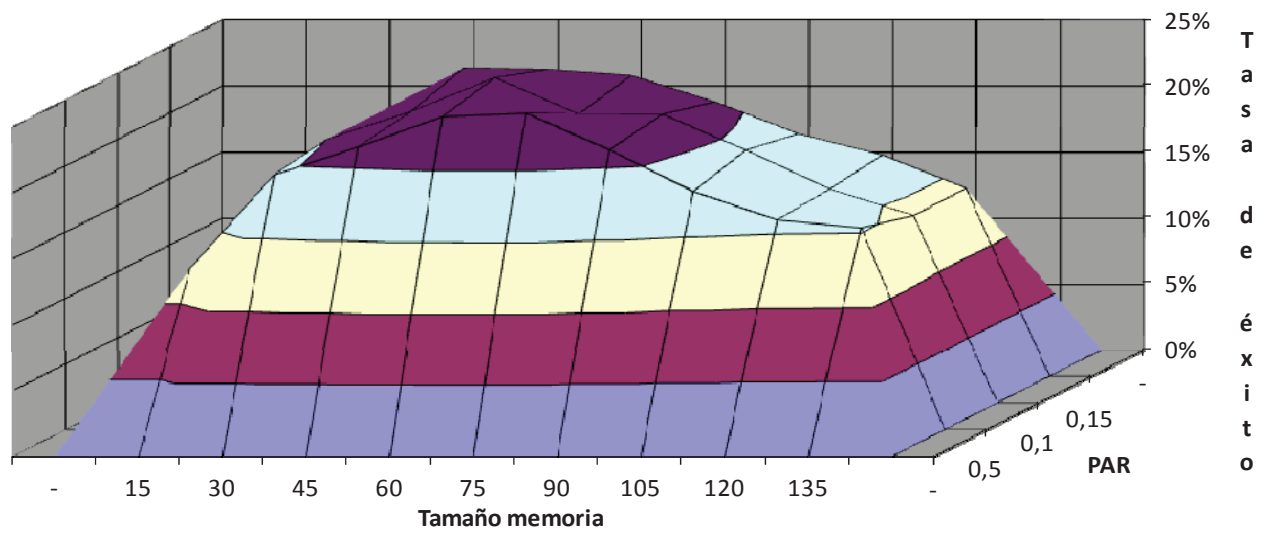

Figura 5.92. Probabilidad de obtener mínimo respecto a PAR y tamaño de memoria

De la misma manera, la figura inferior muestra la probabilidad de obtener una buena solución en función del parámetro HMCR y el tamaño de población. Tal como ocurría en la anterior figura, tamaños de población entre 60-75 individuos son los que mejor funcionan, mientras que valores de HMCR por debajo de 0,90 obtienen porcentajes de buenas soluciones por encima de un $25 \%$ siempre que se combinen con tamaños de población adecuados. Es importante destacar que los valores óptimos de $\operatorname{HMCR}(0,89-0,90)$ no funcionan con tamaños de población del algoritmo por encima de 75 , de modo que a partir de este número de individuos el algoritmo no trabaja adecuadamente. 


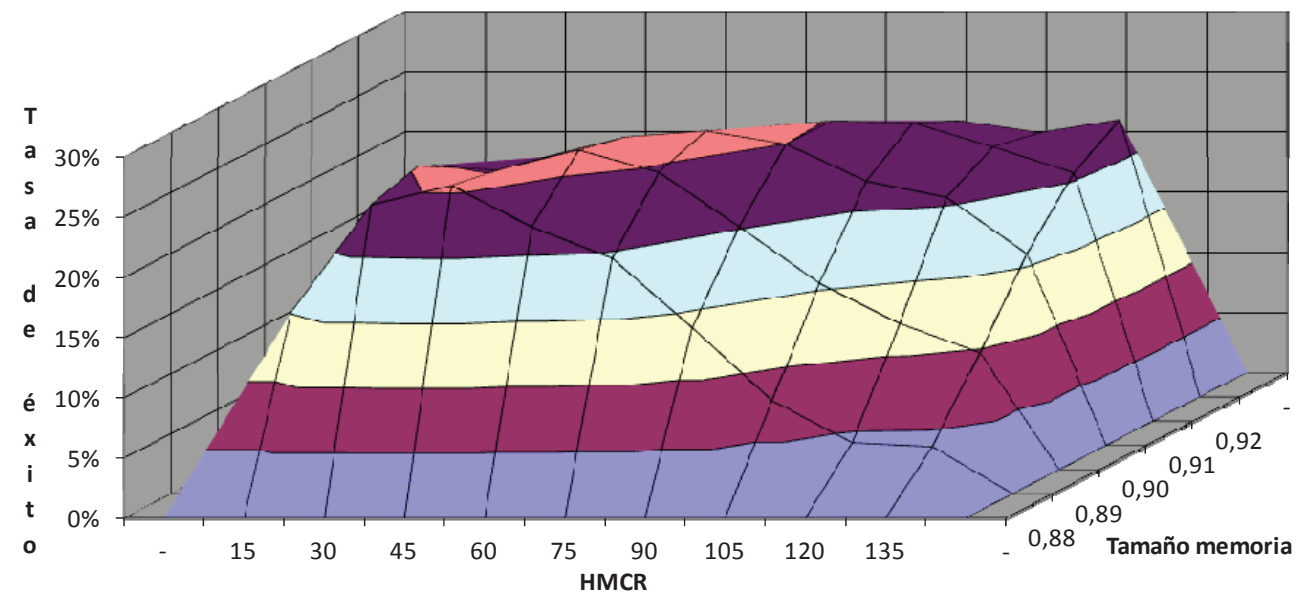

Figura 5.93. Probabilidad de obtener una buena solución respecto a HMCR y tamaño de memoria

\subsubsection{Red de Nueva York}

El método desarrollado para analizar la influencia de la población en el diseño de la red de Nueva York sigue las mismas directrices que en el apartado anterior. De este modo, el rango de población estudiado va desde los 25 individuos hasta las 225. Los restantes parámetros se han ajustado a valores cercanos a los que el estudio de parámetros realizado en 5.1 consideró como óptimo. De este modo, se consideran probabilidades HMCR inferiores a 0,9 y una ajuste PAR de 0,15 .

El histograma de soluciones muestra la totalidad de simulaciones realizadas en estas condiciones, siendo de especial interés la comparación entre este histograma, donde las simulaciones realizadas tienen valor adecuado 2 de los 3 parámetros susceptibles de ajuste (HMCR y PAR) y el que se mostraba en la figura 5.43, que comprende un rango de parámetros mucho más extenso, así como un único tamaño de población. 


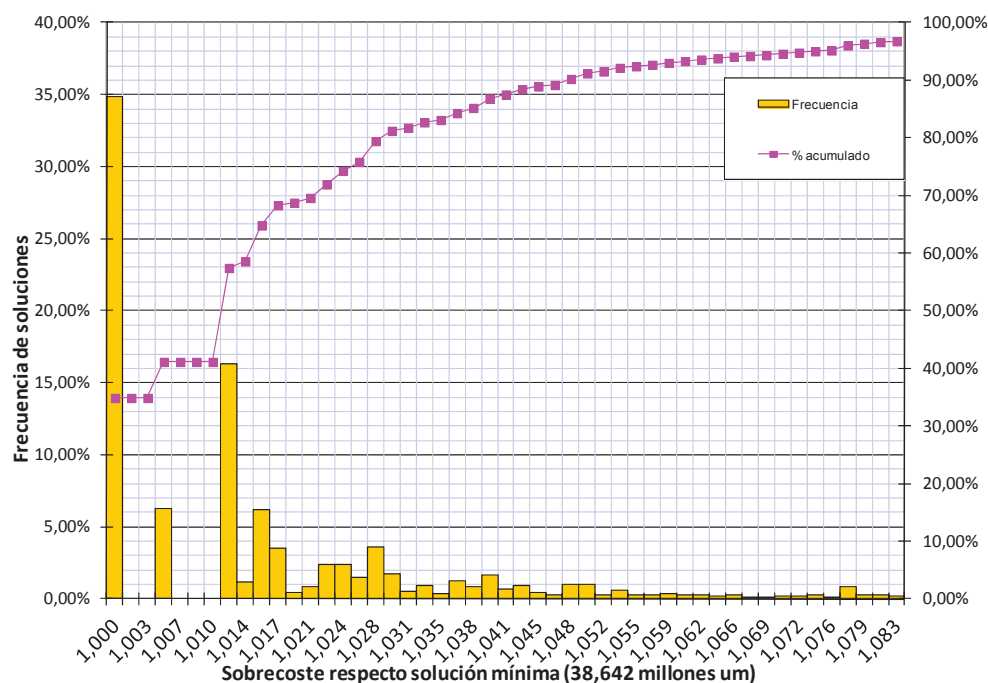

Figura 5.94. Histograma de soluciones para el estudio de población en la red de Nueva York utilizando Harmony Search.

La figura representa el histograma de soluciones de todas las simulaciones realizadas. En el eje de abscisas, el valor 1 representa el coste mínimo de diseño obtenido, que en este caso es 38,642 millones de um, coincidente con el mínimo coste de diseño encontrado para esta red cuando se cumplen todos los requisitos de presión mínima establecidos.

La primera conclusión importante que se puede extraer del histograma de soluciones es que el porcentaje de soluciones de mínimo coste obtenidas aumenta considerablemente tras realizar el proceso de optimización de parámetros, puesto que hasta un $35 \%$ de las simulaciones realizadas consigue la solución óptima para la red de los túneles de Nueva York. Estos resultados mejoran sobremanera los obtenidos en el apartado 5.2.3.2, donde apenas un $8 \%$ del total de simulaciones realizadas conseguían alcanzar el coste de diseño mínimo en la red.

El objetivo de este apartado es estudiar la probabilidad de obtener soluciones de mínimo coste para la red de los túneles de Nueva York tomando como parámetro principal el tamaño de población del algoritmo. Así, la siguiente figura muestra dicha probabilidad relacionando el tamaño de población con combinaciones cercanas a la que se considera óptima en los restantes parámetros. 


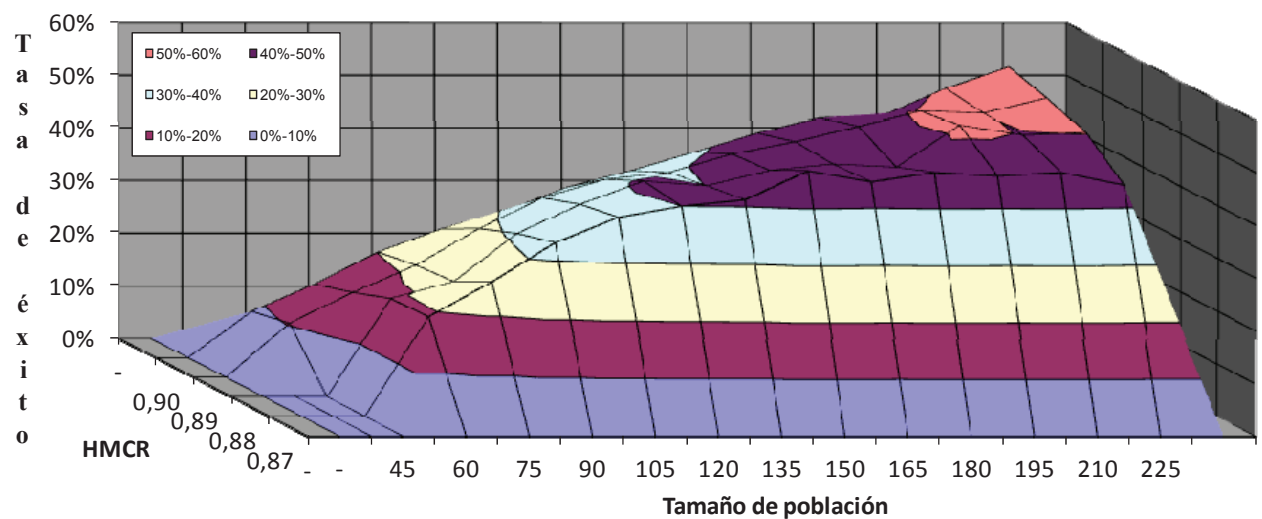

Figura 5.95. Probabilidad de obtener mínima solución respecto a HMCR y tamaño de memoria.

La figura permite apreciar como tamaños de memoria mayores favorecen de un modo considerable la probabilidad de obtener la mínima solución de diseño. Los resultados que se obtienen en la red de Nueva York por el algoritmo HS son parecidos a los vistos en la red de Hanoi, aunque en este caso la probabilidad de obtener el óptimo sube considerablemente.

De este modo, un tamaño de memoria de 225 individuos, correspondiente al mayor tamaño estudiado en esta simulación proporciona una probabilidad de obtención del óptimo en torno al 50\%. Conforme el tamaño de población es más pequeño el número de mínimas soluciones obtenidas decrece, hasta llegar al 10\% que se obtiene en el mínimo tamaño de población incluido en las simulaciones (45 individuos).

En este caso, la probabilidad de obtener la solución de mínimo coste aumenta con el tamaño de población de un modo prácticamente lineal, de modo que no se llega a alcanzar una población límite a partir de la cual no se obtengan mejoras considerables en el índice de soluciones óptimas obtenidas.

Obviamente, el utilizar tamaños de memoria más grandes conlleva un gasto computacional mayor, puesto que el número de evaluaciones de la función objetivo también aumenta. En este tipo de casos es una decisión de compromiso elegir una configuración del algoritmo que dilata el cálculo en el tiempo a cambio de tener mejores resultados u optar por otro tipo de configuración que no otorga la misma garantía de obtención del óptimo, pero que a cambio realiza el cálculo en menos tiempo. El estudio de eficiencia que se presenta en el capítulo 6 trata de acabar con esta disyuntiva, realizando una evaluación del algoritmo en función de ambos factores.

De la misma manera, la siguiente figura muestra la probabilidad de obtener una buena solución en función del tamaño de la memoria y de la probabilidad HMCR, considerando 
como buena solución un sobrecoste máximo respecto del óptimo global obtenido en esta red de un $3 \%$. Así, esta figura incluye todas aquellas simulaciones iguales o inferiores a 39,801 miles de um.

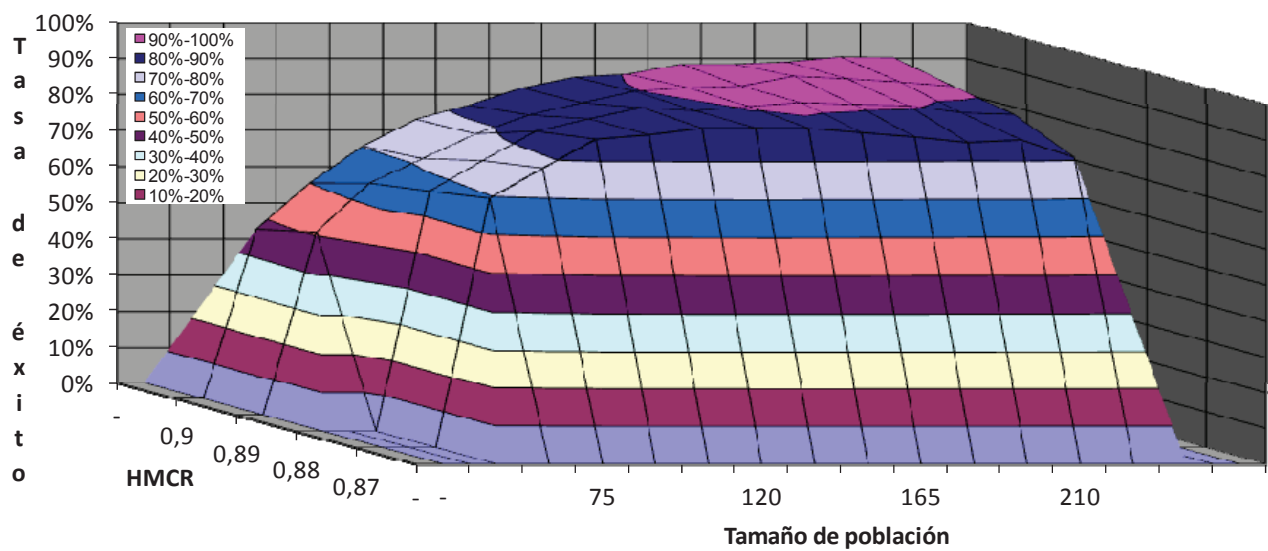

Figura 5.96. Probabilidad de obtener buena solución respecto a probabilidad HMCR y tamaño de memoria.

El número de buenas soluciones que consigue el algoritmo HS en la red de los túneles de Nueva York es elevado. Así, las mejores zonas, que corresponden a aquellas con mayor tamaño de memoria, llegan a obtener una buena solución en alrededor del $90 \%$ de las simulaciones. Cabe destacar que la pendiente del gráfico es mucho menos abrupta que en el gráfico de probabilidad de obtención de mínimas soluciones, con lo que si el objetivo no es encontrar la mínima solución, sino un conjunto de buenas soluciones para la red, resulta mucho más interesante trabajar con tamaños de memoria menores, puesto que el gasto computacional es menor.

En este sentido, los resultados obtenidos en tamaños de memoria de entre 120 y 210 individuos apenas tienen variaciones, siendo en este caso mucho más interesante trabajar con una población lo más pequeña posible.

\subsubsection{Red R-9 de Joao Pessoa}

Ya se mencionado anteriormente que la red R-9 de Joao Pessoa tiene mayor dificultad de diseño, puesto que al tener un tamaño considerablemente mayor, el número de posibilidades de diseño crece de forma exponencial. Esto provoca que el planteamiento en este caso sea siempre algo diferente, puesto que tanto el análisis de parámetros como ahora el de población se centra en la obtención de lo que se considera una buena solución. Esta decisión se toma en base a la escasa repetibilidad que se obtiene de la mínima solución de diseño, así como por la gran variedad de soluciones obtenidas en una red de este tamaño. 
Esta variabilidad de soluciones se aprecia en el histograma de soluciones que muestra la figura 5.97. En este caso se han realizado un total de 43200 simulaciones, con un tamaño de memoria comprendido entre 15 y 135 individuos. El valor de los parámetros HMCR y PAR se toma en base a valores cercanos a los que se consideraron como óptimos para esta red en 5.2.3.3. Así, para la probabilidad de HMCR se toman valores en torno a 0,92 , mientras que en el caso del PAR se toman valores lo suficientemente bajos como para asegurar la convergencia del algoritmo, en este caso se toman valores entre 0,01 y 0,05 .

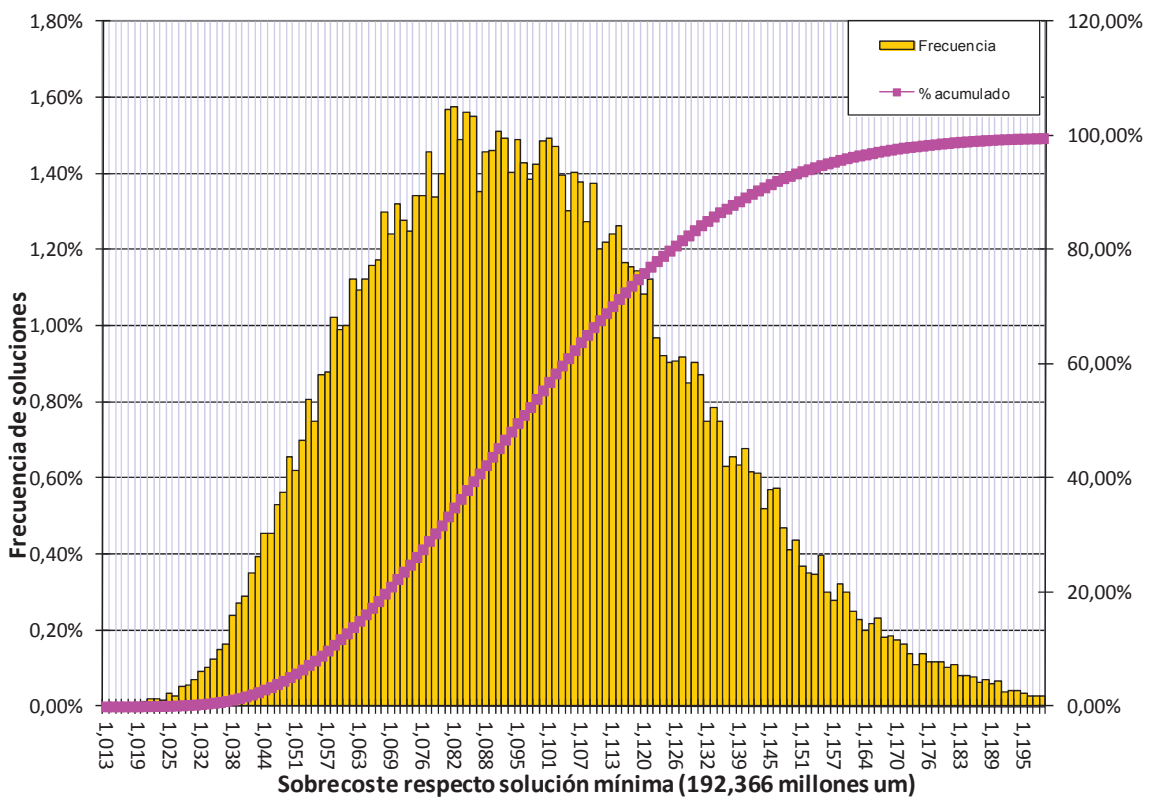

Figura 5.97. Histograma de soluciones para el estudio de población en la red de Joao Pessoa utilizando Harmony Search.

El histograma representa la totalidad de simulaciones realizadas. El coste mínimo utilizado como referencia corresponde a la solución de diseño de menor coste obtenida entre todas las simulaciones realizadas con todos los métodos. Esta solución corresponde a un valor de 192,366 millones de um. La forma del histograma en esta red es muy diferente a la que se obtiene en el resto de redes diseñadas mediante HS. En este caso, la forma recuerda bastante a una campana de Gauss, lo que indica la gran variedad de posibles soluciones que hay en esta red y la relativa dificultad que tiene el algoritmo para salir de los mínimos locales existentes.

En las simulaciones realizadas con el algoritmo HS, éste no ha sido capaz de alcanzar dicha solución mínima, por lo que el estudio estadístico se plantea en base a la obtención de una buena solución, que queda definida como aquella que supera a la mínima en no más de un 
3\%. En este caso, el coste límite para considerar a una solución del problema de diseño como buena viene dado por el valor 198,137 millones de um.

La figura 5.98 representa la probabilidad de encontrar una buena solución en función del tamaño de memoria (población) y la probabilidad HMCR. Cabe destacar que la probabilidad HMCR óptima para el diseño de esta red se encuentra en torno al valor 0,92.

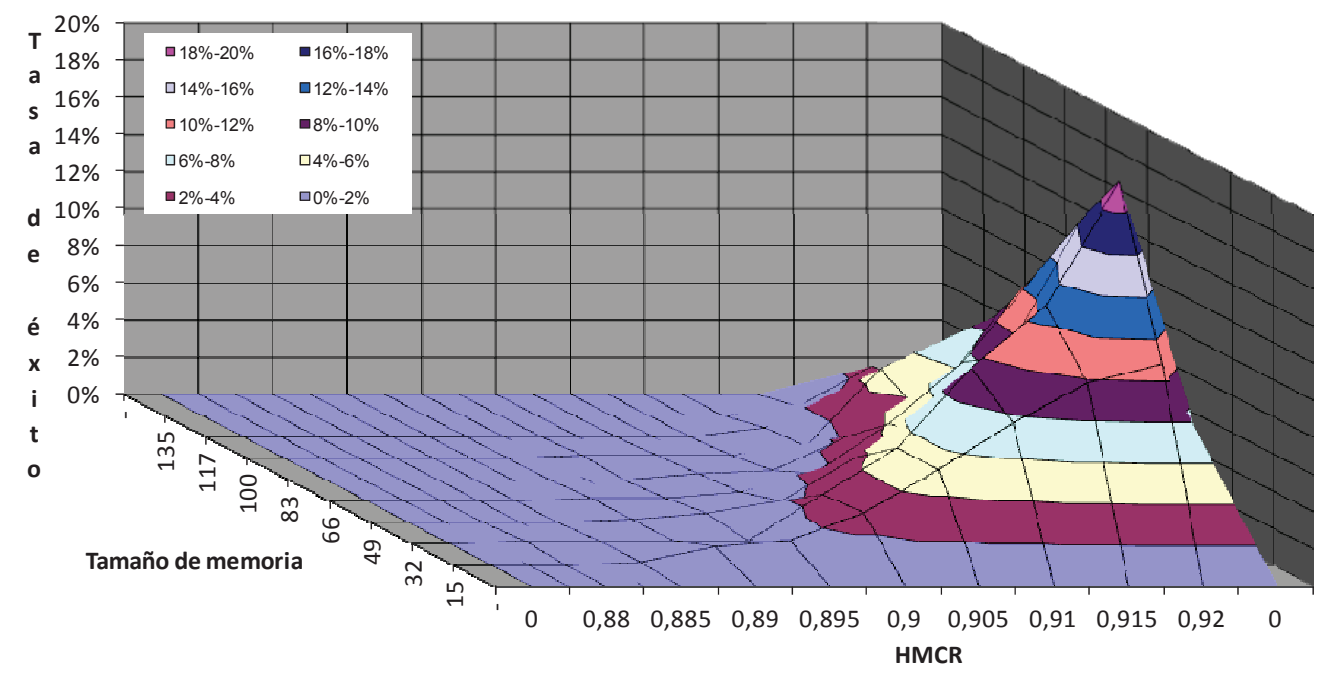

Figura 5.98. Probabilidad de obtener una buena solución en función probabilidad HMCR y tamaño de memoria para la red de Joao Pessoa.

En la figura se aprecia como tamaños de memoria más pequeños son los que obtienen la mayor cantidad de buenas soluciones. Esta circunstancia no es habitual, puesto que lo lógico es que mayores poblaciones de individuos sean las que proporcionen una mayor probabilidad de éxito, aún a cuenta de un mayor costo computacional. En este caso particular, esta circunstancia no se produce, puesto que claramente la probabilidad de obtener una buena solución disminuye drásticamente conforme el tamaño de la memoria es más grande.

Del mismo modo, las posibilidades de éxito crecen considerablemente cuando la probabilidad HMCR se encuentra en valores cercanos a 0,92, valor que ya se determinó como óptimo cuando se realizaba el análisis de las probabilidades PAR y HMCR. Cabe destacar que para este valor óptimo se obtienen buenas soluciones en todos los tamaños de población estudiados, aunque la probabilidad de obtenerlas disminuye de forma clara conforme aumenta el tamaño de la memoria.

La importancia del análisis de parámetros queda reflejado en la forma de la gráfica que se obtiene, puesto que hay zonas en el campo de parámetros estudiado donde el algoritmo HS no es capaz de encontrar ninguna buena solución, mientras que en la zona óptima, que 
corresponde al menor tamaño de memoria combinado con la probabilidad óptima HMCR $(0,92)$ se encuentran buena soluciones un $20 \%$ de las simulaciones.

La figura 5.99 también representa la probabilidad de obtener una buena solución según el tamaño de memoria empleado, pero en esta ocasión se representa en función de la probabilidad de ajuste PAR.

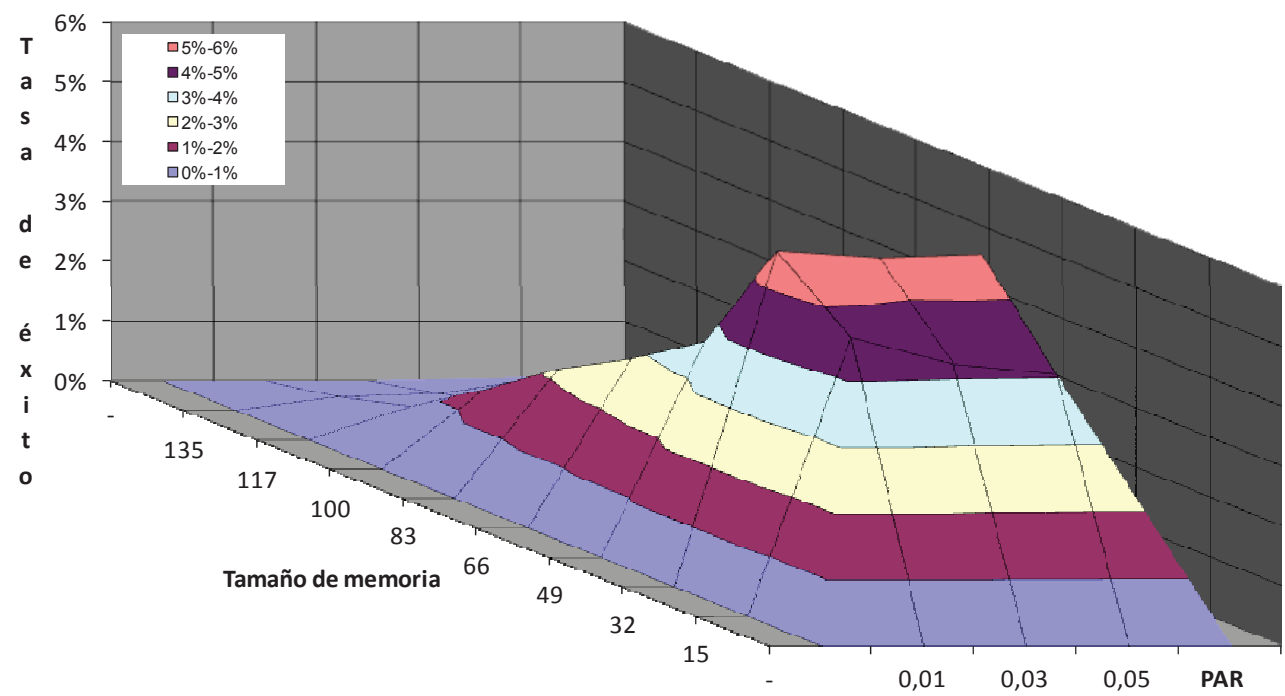

Figura 5.99. Probabilidad de obtener una buena solución en función probabilidad PAR y tamaño de memoria para la red de Joao Pessoa

La figura 5.99 confirma el mejor funcionamiento de tamaños de memoria más pequeños frente a memorias con un mayor número de individuos. En este caso, la probabilidad PAR, frente a la que se representa el tamaño de memoria, no ejerce ninguna influencia en la probabilidad de obtener una buena solución, puesto que las tres curvas obtenidas son prácticamente paralelas. Este resultado está en consonancia con todos los análisis realizados para el algoritmo HS, puesto que una de las principales conclusiones para esta técnica gira alrededor del futuro tratamiento de este parámetro como de convergencia y no de optimización.

La importancia del análisis individual de todos los parámetros se pone de manifiesto en este gráfico, donde la optimización de sólo dos parámetros (tamaño de memoria y PAR) proporciona una probabilidad máxima de obtención de una buena solución de alrededor de un $6 \%$. El considerar también la optimización del parámetro HMCR implica elevar esta cifra hasta el $20 \%$ que se aprecia en la figura 5.98 . 


\subsubsection{Red de Go-Yang}

La principal conclusión que se obtuvo del análisis de parámetros para este caso particular es que no existían valores mejores que otros en el rango de parámetros estudiado. Así, para la probabilidad PAR, los resultados obtenidos en todas las redes muestran a éste parámetro como un parámetro exclusivamente de convergencia. El límite para la convergencia del algoritmo está aproximadamente en 0,62, de modo que valores inferiores a éste aseguran la convergencia del algoritmo hacia soluciones de diseño factibles.

El otro parámetro susceptible de cálculo en HS, la probabilidad HMCR, se ha mostrado susceptible de optimización en todas las redes salvo en la red de Go-Yang, que supone una excepción, puesto que tal como se ve en 5.2.3.4 no existen probabilidades HMCR que destaquen por encima de otras. Esta situación convierte el diseño de la red de Go-Yang mediante el algoritmo HS en el único caso entre los estudiados donde la optimización de parámetros no permite la mejora de resultados de diseño.

Dada esta situación, en el estudio de población se ha optado por realizar los cálculos con un rango amplio para ambos parámetros, de modo que HMCR está comprendido entre 0,87 y 0,93 , mientras que la probabilidad PAR se ha ajustado entre 0,05 y 0,15. Este rango de trabajo se aproxima al ajuste de parámetros óptimo del resto de redes.

Del mismo modo, el tamaño de población estudiado para el algoritmo se ha variado desde los 15 individuos hasta los 135, modificando dicho tamaño de 15 en 15. Este rango para el número de individuos que entran en juego en el proceso está en consonancia con los ya vistos en el resto de redes para la metodología HS. La figura 5.100 representa la totalidad de simulaciones realizadas en el análisis de población para la red de Go-Yang.

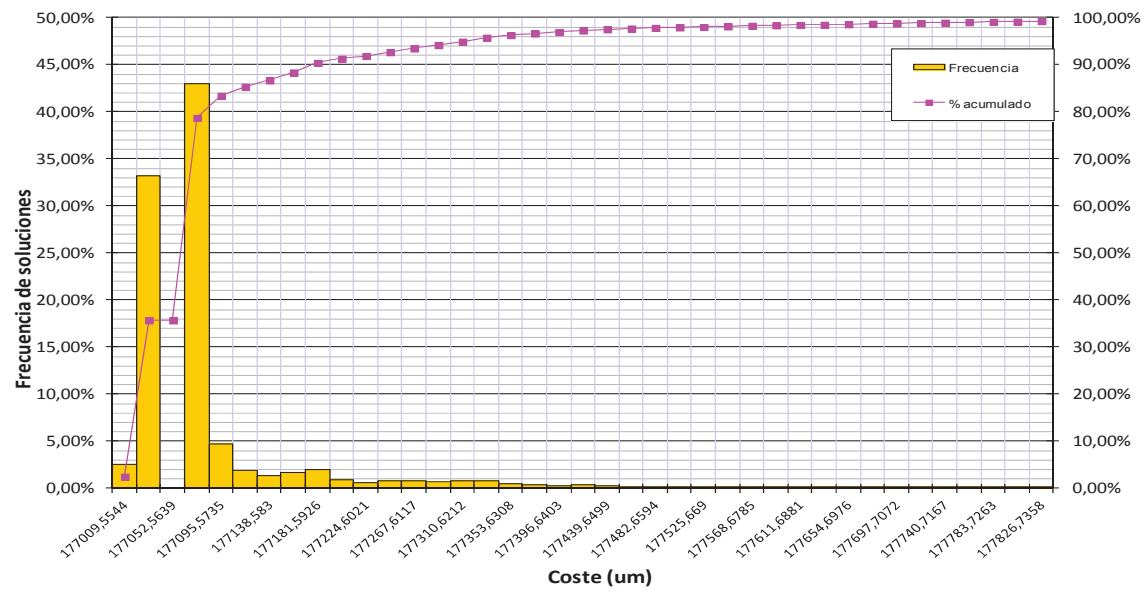

Figura 5.100. Histograma de soluciones para el estudio de población en la red de Go-Yang utilizando Harmony Search. 
El histograma es prácticamente idéntico al que se obtenía en la figura 5.49, circunstancia que resulta lógica, puesto que en este caso no existe una optimización de parámetros que permita la mejora de resultados. Así, HS consigue el coste óptimo de diseño para esta red, de valor 177.000 um, pero dicho valor apenas tiene una repetibilidad del 3\%. A pesar de esta efectividad tan baja encontrando la solución óptima el $100 \%$ de las simulaciones realizadas entran dentro del concepto de buena solución y un 99,98\% de ellas ofrecen una solución de diseño que no difiere más de un $1 \%$ de la solución óptima.

Las figuras mostradas a continuación muestran la probabilidad de encontrar la mínima solución de diseño en función del tamaño de memoria y el resto de parámetros que componen la optimización HS.

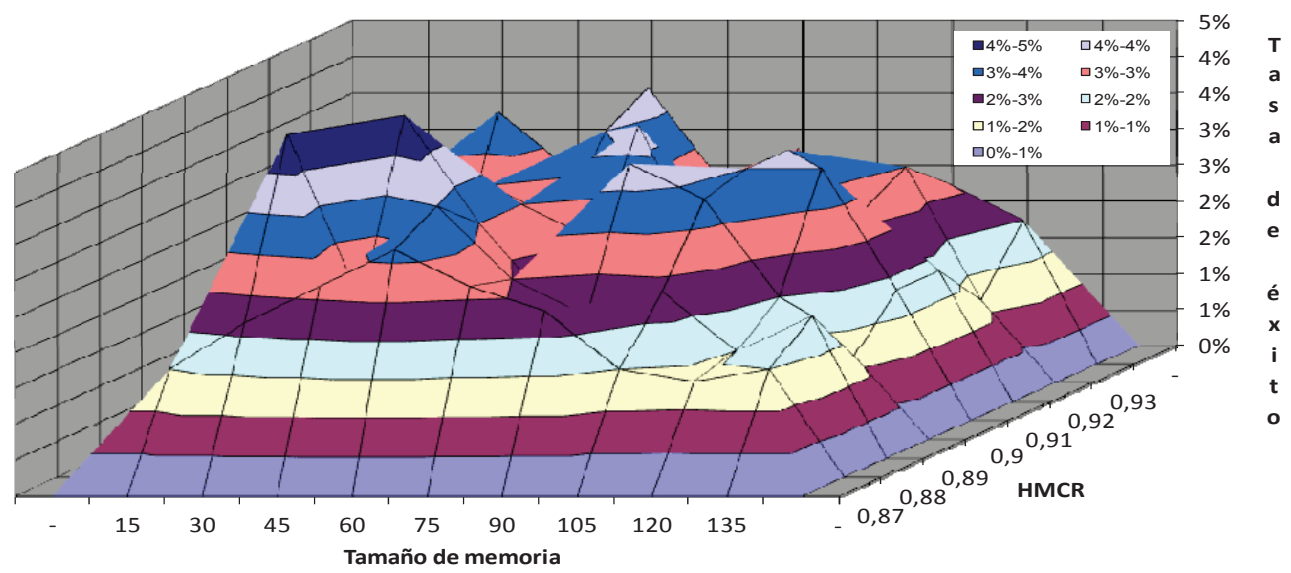

Figura 5.101. Probabilidad de obtener mínima solución en función probabilidad HMCR y tamaño de memoria para la red de Go-Yang.

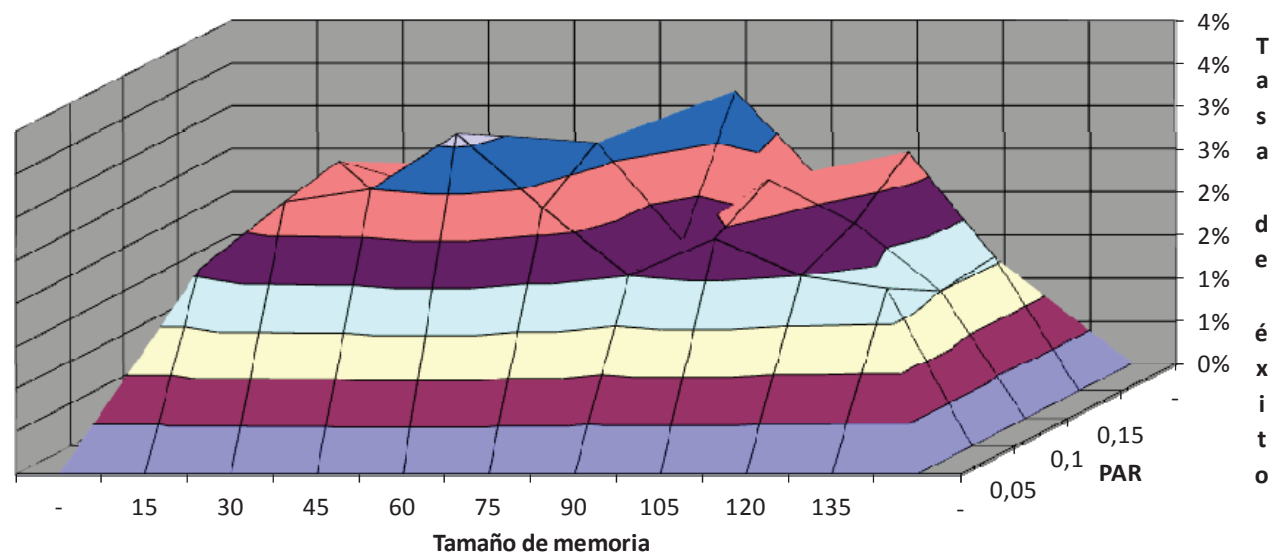

Figura 5.102. Probabilidad de obtener mínima solución en función probabilidad PAR y tamaño de memoria para la red de Go-Yang. 
Para la red de Go-Yang, los resultados no muestran grandes diferencias entre ejecutar la simulación con más individuos o menos. Así, la figura 5.101, que analiza la probabilidad de encontrar una mínima solución en función del tamaño de memoria y de la probabilidad HMCR muestra una forma irregular, con un pequeño pico en torno a 30 individuos. No obstante, dicho pico apenas representa una probabilidad del 4,5\% de encontrar la solución óptima, y dado que este dato no se reproduce con todos los valores HMCR en este tamaño de población no se puede considerar este tamaño de memoria como un valor claramente mejor a los demás.

Del mismo modo, la figura 5.102 no aporta mayor información respecto a la influencia del tamaño de la memoria en el diseño óptimo de la red de Go-Yang. A la vista de los resultados no parece que exista, en este caso particular, una relación directa entre el coste de la solución obtenida y el tamaño de memoria utilizado.

De todos los casos estudiados en este trabajo, el diseño óptimo de la red de Go-Yang mediante algoritmo HS es el único donde la optimización de parámetros no mejora sustancialmente los resultados obtenidos. Este hecho en no es necesariamente negativo, más aún es un punto a favor del método para redes con un menor número de mínimos locales. No obstante, para establecer en este caso particular si existe alguna combinación mejor que otra será necesario basar el criterio únicamente en el análisis de eficiencia, que relaciona el coste de una determinada solución con el número de evaluaciones de la función objetivo y que se muestra en detalle en el capítulo 6 de esta tesis.

\subsubsection{Ajuste de población para el algoritmo Shuffled Frog Leaping (SFL)}

Ya se ha mencionado con anterioridad que la metodología de diseño SFLA es la técnica heurística que posee un mayor número de parámetros de ajuste, por lo que es la que genera mayores dificultades en la optimización de parámetros hasta encontrar la configuración óptima. El apartado 5.2.4 analiza la mejor combinación posible para los parámetros de aceleración (C), número de pasos evolutivos (N) y tamaño del submemeplex (Q), con una población constante de 100 individuos, al igual que en el resto de métodos estudiados.

Los resultados derivados del análisis estadístico previo permiten obtener un rango de trabajo adecuado para estos tres parámetros, que permite la mejora global de resultados aprovechando la experiencia previa adquirida. Así, utilizando el mejor intervalo de cálculo para C, Q y N los subapartados siguientes se centran en la influencia que tiene el número de individuos involucrados en el proceso de optimización.

En la metodología SFLA, el tamaño total de la población del algoritmo viene dado por el producto del número de memeplexes $(\mathrm{m})$ por el número de ranas que hay en cada memeplex (n). Por ejemplo, si el algoritmo trabaja con 10 memeplexes, y cada uno de estos memeplexes contiene 10 ranas, la población total de individuos del algoritmo es 10x10=100. Los siguientes 
subapartados analizan la influencia de estos dos parámetros en el coste obtenido de para las distintas redes de benchmarking analizadas.

\subsubsection{Red de Hanoi}

Tras el estudio de optimización, el mejor ajuste dado para los distintos parámetros de cálculo que no dependen de la población del algoritmo, es decir, tamaño de submemeplex (Q), número de pasos evolutivos (N) y coeficiente de aceleración (C) viene dado en la tabla 5.16. Este rango de valores está considerado como óptimo para la red de Hanoi, pese a que en el caso del tamaño de submemeplex, el ajuste obtenido no variaba significativamente la efectividad del algoritmo en la búsqueda de la mejor solución, por lo que se optó por coger un valor medio.

Así, con N, C y Q como valores constantes se realizan nuevas simulaciones donde se estudia la influencia del tamaño de la población en el diseño económico de la red, para lo que se consideran como variables a los parámetros $m$ y $n$, que identifican el número de memeplexes y el número de ranas por memeplex. En el proceso de optimización realizado se ha considerado un número variable de memeplexes entre 10 y 30, mientras que el número de ranas contenidas en cada memeplex se ha variado entre 10 y 30 . Así, el índice de población estudiado está entre 100 y 900 ranas. De esta manera, el valor de los distintos parámetros de cálculo queda:

\begin{tabular}{|c|c|c|}
\hline \multicolumn{2}{|c|}{ PARÁMETROS } & RANGO DE VALORES \\
\hline Memeplexes & $\mathrm{m}$ & $10,20,30$ \\
\hline Ranas por Memeplex & $\mathrm{n}$ & $10,20,30$ \\
\hline Tamaño Submemeplex & $\mathrm{Q}$ & 0.81 \\
\hline Pasos evolutivos & $\mathrm{N}$ & 30 \\
\hline Parámetro aceleración & $\mathrm{C}$ & 2.25 \\
\hline
\end{tabular}

Tabla 5.18. Rango óptimo de cálculo para los operadores SFLA en la red de Hanoi.

Con la configuración de parámetros que muestra la tabla se realizan nuevas simulaciones, de modo que cada combinación posible para $\mathrm{m}$ y $\mathrm{n}$ se repite 200 veces. La siguiente figura muestra el histograma de soluciones obtenido para esta tanda de simulaciones, realizada aprovechando el rango óptimo de los parámetros $\mathrm{Q}, \mathrm{N}$ y $\mathrm{C}$. 


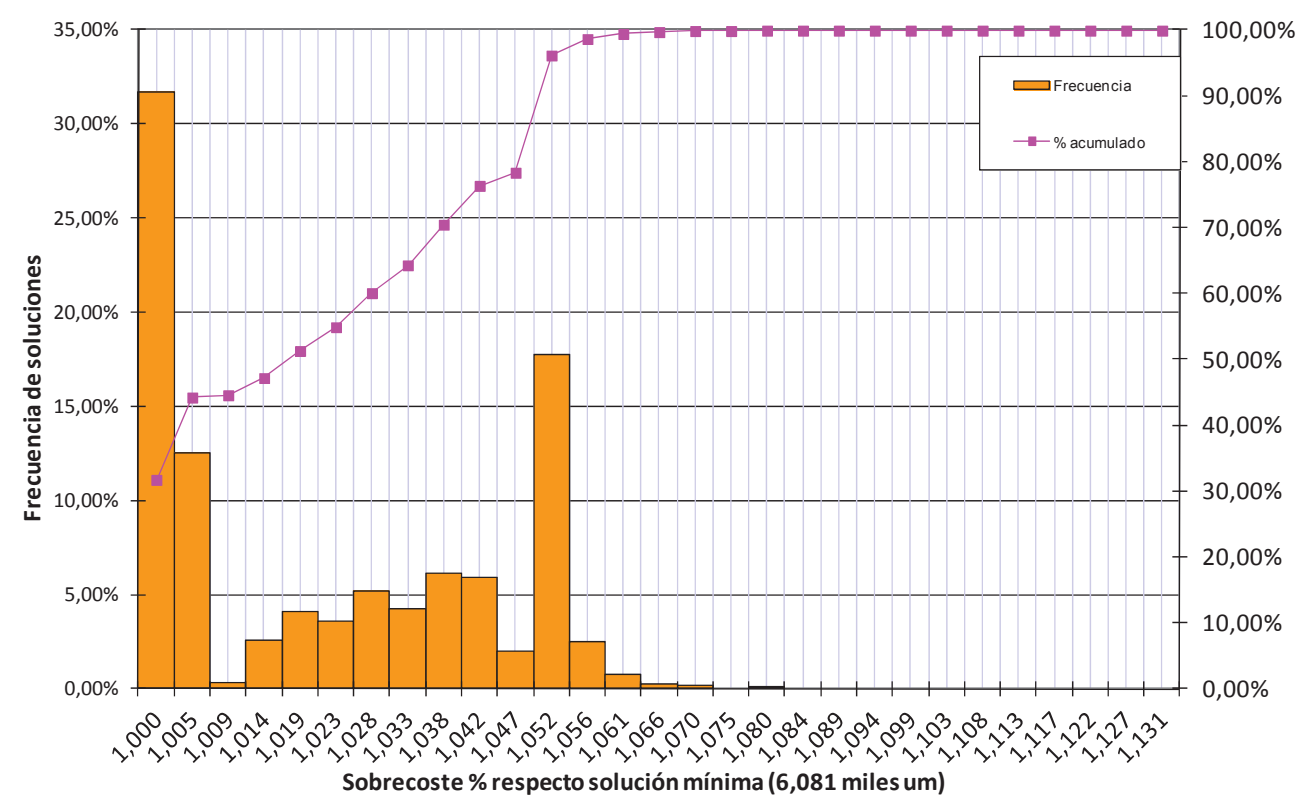

Figura 5.103. Histograma de soluciones para la red de Hanoi con $m$ y $n$ variables.

Comparando el histograma de la figura 5.103 con el que se obtenía antes de la optimización de parámetros (figura 5.53) destaca el incremento notable en el número de soluciones óptimas conseguidas, que pasa de un porcentaje cercano al $6 \%$ a una probabilidad de más de un $30 \%$ de obtención de la solución mínima del problema de diseño en la red de Hanoi. Esta solución mínima corresponde a un coste de 6,081 millones de um.

Del mismo modo, basando el análisis en el concepto de buena solución, que corresponde a todas las simulaciones cuyo coste de diseño se encuentra por debajo de 6,263 millones de um se tiene que más de un $60 \%$ de las simulaciones realizadas entran dentro de esta definición.

El análisis que se realiza a continuación pretende mejorar estos resultados. Para ello se realiza un análisis estadístico de soluciones para $\mathrm{m}$ y $\mathrm{n}$, parámetros que definen el número de individuos con los que trabaja el algoritmo SFL. Así, la siguiente figura muestra la probabilidad de encontrar una mínima/buena solución del problema de diseño variando el tamaño de población y manteniendo constantes el resto de parámetros. El número de individuos totales con los que trabaja el algoritmo en cada simulación viene dado por el producto de $\mathrm{m}$ y $\mathrm{n}$. 


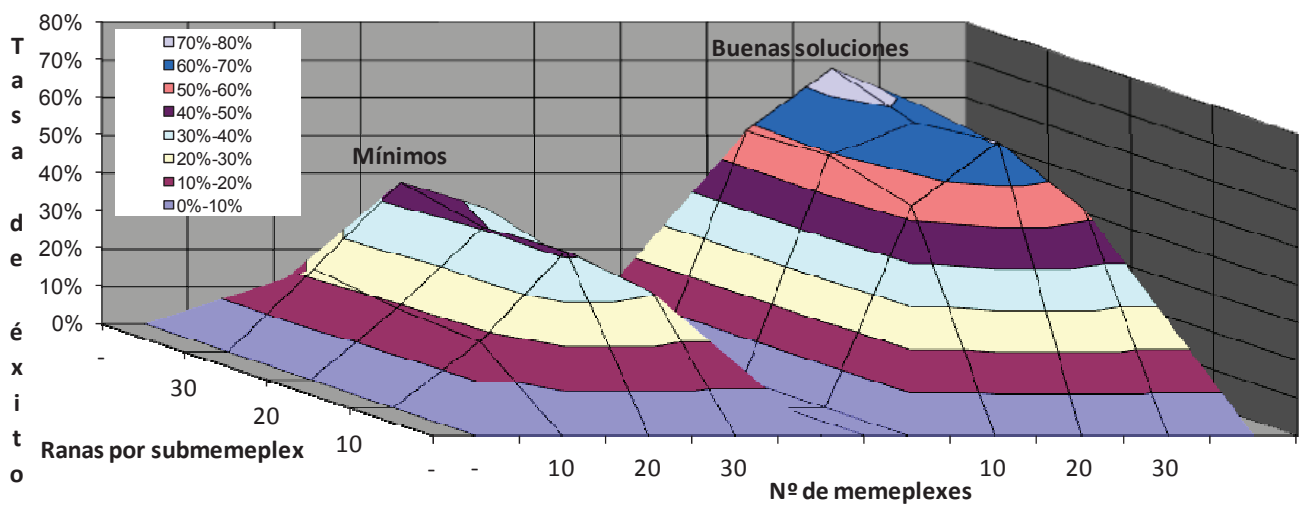

Figura 5.104. Probabilidad de obtención mínima/buena solución respecto al número de memeplexes y al número de ranas por submemeplex en la red de Hanoi.

La primera conclusión de cierto interés que puede tomarse de la figura es que la distribución de la población de ranas es importante. Esto quiere decir que el mismo número de ranas no se comporta igual si se distribuyen en un número distinto de memeplexes. Así, en el gráfico que muestra la probabilidad de obtener una solución de mínimo coste se aprecia claramente como el número de memeplexes óptimo es 20 , alcanzándose la solución de mínimo coste (6.081 millones de um) en más de un 40 \% de las simulaciones realizadas. Esta configuración resulta ser la mejor entre todos los métodos evaluados en este trabajo.

Del mismo modo, los resultados también mejoran cuanto mayor es el número de ranas en un determinado submemeplex, pero la influencia de este parámetro es significativamente menor. En este caso, para afirmar con rotundidad cuál es el número óptimo de ranas por submemeplex será necesario recurrir a un estudio de eficiencia, que muestre si la ligera mejoría obtenida utilizando un mayor número de ranas por submemeplex compensa el aumento en el tiempo de cálculo que supone utilizar poblaciones superiores. A la vista de los resultados obtenidos, lo que sí parece claro es que independientemente del número de ranas totales que se vayan a utilizar para el cálculo es conveniente distribuirlas en un número de memeplexes cercano a 20.

Si se tiene en cuenta el concepto de buena solución los resultados de diseño proporcionados por SFLA mejoran todavía más, puesto que se obtienen probabilidades de éxito por encima del $70 \%$ cuando el número de submemeplexes es 20 (óptimo del sistema) y cercanos al $50 \%$ en los casos restantes.

A la vista de los resultados, se puede concluir que para la red de Hanoi, la técnica de optimización basada en SFLA es la que mejores resultados generales obtiene, considerando únicamente la probabilidad de obtener una mínima/buena solución para el problema de diseño. 


\subsubsection{Red de Nueva York}

Para la red de Nueva York se procede de igual modo para definir el tamaño de población más adecuado cuando se trabaja con el algoritmo de optimización SFL. Así, del estudio de parámetros se define un grado de ajuste óptimo para los parámetros $\mathrm{N}, \mathrm{Q}$ y $\mathrm{C}$. El ajuste definido se mantiene constante en todas las simulaciones realizadas a partir de ahora, de modo que los únicos parámetros que tomarán distintos valores en las nuevas simulaciones son los relacionados con el tamaño de la población del algoritmo. El ajuste óptimo determinado para $\mathrm{N}, \mathrm{Q}$ y $\mathrm{C}$, así como el rango de trabajo elegido para los parámetros que determinan la población del algoritmo SFLA viene dado en la tabla inferior.

\begin{tabular}{|c|c|c|}
\hline \multicolumn{2}{|c|}{ PARÁMETROS } & RANGO DE VALORES \\
\hline Memeplexes & $\mathrm{m}$ & $10,20,30$ \\
\hline Ranas por Memeplex & $\mathrm{n}$ & $10,20,30$ \\
\hline Tamaño Submemeplex & $\mathrm{Q}$ & 0.62 \\
\hline Pasos evolutivos & $\mathrm{N}$ & 24 \\
\hline Parámetro aceleración & $\mathrm{C}$ & 1.75 \\
\hline
\end{tabular}

Tabla 5.19. Rango óptimo de cálculo para los operadores SFLA en la red de Nueva York.

Con los parámetros N, C y Q constantes se estudia la influencia del tamaño de la población en el diseño económico de la red. Así, se considera un número variable de memeplexes entre 10 y 30. Del mismo modo, el número de ranas que contiene cada memeplex está entre 10 y 30. Dado que el tamaño total de población viene dado por el producto de $\mathrm{m}$ y $\mathrm{n}$, el rango simulado para el tamaño de población está entre 100 y 900 ranas.

Así, manteniendo constantes $\mathrm{N}, \mathrm{Q}$ y $\mathrm{C}$ y variando el ajuste de $\mathrm{m}$ y $\mathrm{n}$ se realizan un total de 1800 nuevas simulaciones, que a priori deben mejorar los resultados obtenidos en el apartado 5.2.4.2, puesto que 3 de los 5 parámetros susceptibles de ajuste se encuentran ya optimizados. El histograma de soluciones muestra la totalidad de simulaciones realizadas en estas condiciones. 


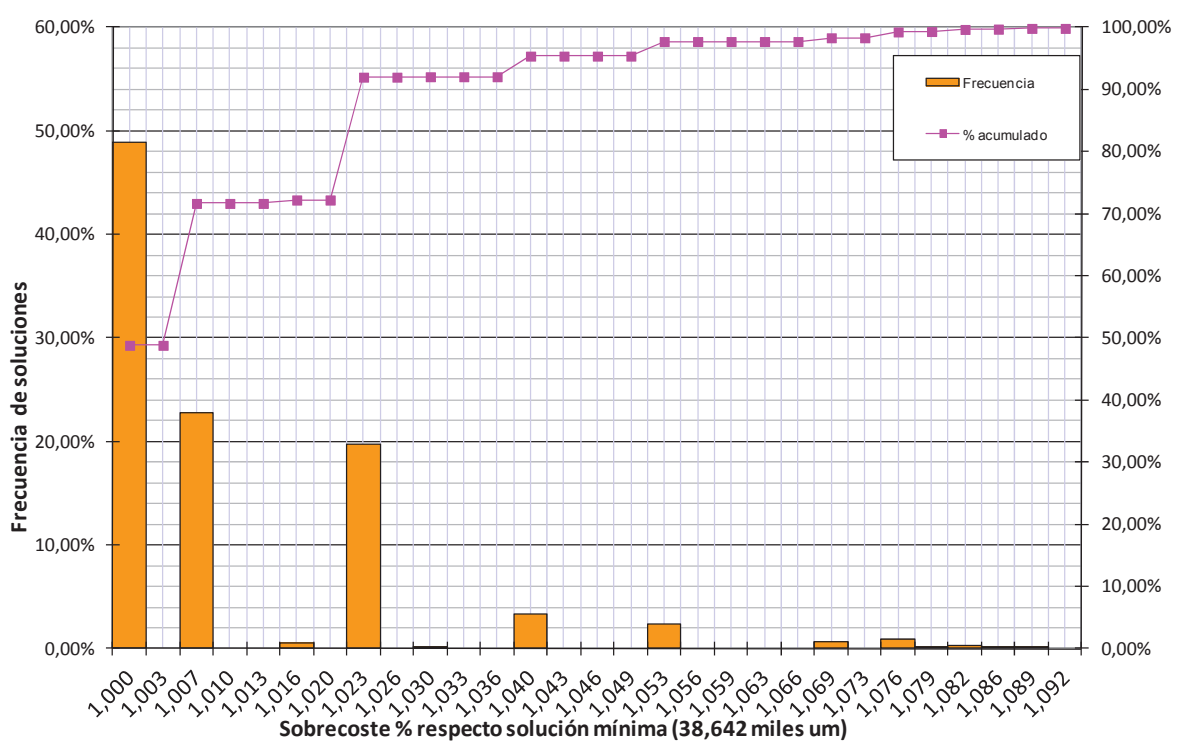

Figura 5.105. Histograma de soluciones para la red de Nueva York con $m$ y $n$ variables.

Tal como se aprecia en la figura, prácticamente el $50 \%$ de los cálculos obtienen como resultado final la solución de mínimo coste para la red de Nueva York. Resulta de especial interés el comparar los resultados obtenidos en esta ronda de simulaciones con los realizados previamente, que carecían de ajuste para los distintos parámetros. Así, si se compara este histograma con el de la figura 5.60, que representa las simulaciones realizadas sin ningún tipo de ajuste para $\mathrm{N}, \mathrm{Q}$ y $\mathrm{C}$ se comprueba como el ajuste de parámetros permite aumentar la probabilidad de obtener el óptimo de diseño (38,642 millones de um) en más de un 15\%. Del mismo modo, si se evalúa la probabilidad de obtener una buena solución (coste de diseño por debajo de 39,801 millones de um) el algoritmo SFLA obtiene una probabilidad de éxito de más de un $90 \%$, lo que supone un incremento del $20 \%$ respecto al número de buenas soluciones que se obtenían sin realizar ningún tipo de optimización paramétrica.

La figura 5.106 muestra la probabilidad de encontrar la solución mínima de diseño en función del número de memeplexes $(\mathrm{m})$ y del número de ranas que contiene cada uno de los memeplexes (n). La finalidad de este gráfico es comprobar si la calidad de la solución desde un punto de vista cuantitativo se ve influenciada por el número de individuos que entran en juego en el proceso de optimización: 


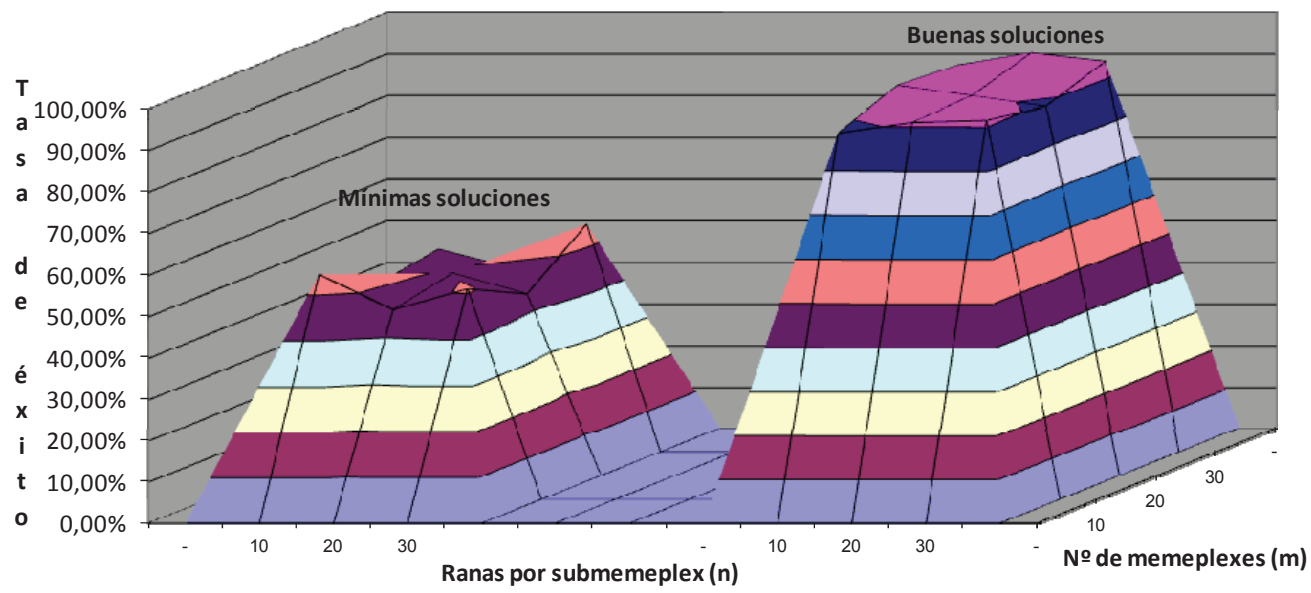

Figura 5.106. Probabilidad de obtención de mínimo/buena solución respecto al número de memeplexes y al número de ranas por submemeplex.

Para la red de Nueva York se da la particularidad de que la mayor probabilidad de obtención del óptimo se obtiene con las dos combinaciones extremas, de modo que cuando ( $\mathrm{m}=10$, $\mathrm{n}=10$ ) el $54,5 \%$ de las simulaciones obtiene el valor mínimo de 38,642 millones de um. Del mismo modo, cuando $(m=30, n=30)$ la probabilidad de obtener la solución mínima es de un $55 \%$. Esto quiere decir que desde un punto de vista cuantitativo de obtención de mínimas soluciones no parece que haya una gran diferencia en el rango estudiado de $\mathrm{m}$ y $\mathrm{n}$. Si se extrapola esta conclusión al número de individuos absoluto que entra en juego en el proceso de optimización la conclusión es que se están obteniendo los mismos resultados con 100 individuos que con 900 .

Así, en el gráfico que representa el análisis de mínimas soluciones no es posible apreciar grandes picos del estilo de los que mostraba la figura que analizaba el diseño de la red de Hanoi con el algoritmo SFL. Esta situación demuestra que para este caso particular de diseño el algoritmo no obtiene mejores soluciones al aumentar el número de individuos, por lo que para determinar si es más adecuado un número de individuos u otro será necesario acudir a otro tipo de comparaciones, como pueda ser el análisis de velocidad del algoritmo o el análisis de eficiencia.

La situación se repite si se observa el gráfico que muestra la probabilidad de obtener una buena solución, si bien aparece un pequeño pico cuando el número de ranas por memeplex (n) es de 30 . No obstante, en todas las configuraciones testeadas el \% de buenas soluciones obtenidas para esta red está en torno a un $90 \%$. 


\subsubsection{Red R-9 de Joao Pessoa}

Una de las principales conclusiones a las que se llega en el análisis estadístico previo de la red de Joao Pessoa es que el tamaño de ésta, así como la amplitud de la gama de diámetros empleada, dificultaba la repetibilidad en la obtención de la mínima solución, que en este caso corresponde a un coste de diseño de 192,366 millones de um. Así, la ronda de simulaciones realizada en el apartado 5.2.4.3 previa al ajuste de parámetros revelaba que la probabilidad de obtener el óptimo de diseño ni siquiera llegaba al 1\%.

Debido a la escasa repetibilidad, el análisis estadístico de soluciones se centró en la probabilidad de encontrar lo que se considera una buena solución, de modo que sin realizar ningún tipo de ajuste de parámetros el algoritmo era capaz de proporcionar una buena solución de diseño el $55 \%$ de las ocasiones. Una vez realizado el análisis estadístico de soluciones, que determina el mejor ajuste posible para el número de pasos evolutivos (N), el coeficiente de aceleración (C) y el tamaño de submemeplex (Q), la probabilidad de encontrar una buena solución de diseño para la red de Joao Pessoa crecía hasta casi el $80 \%$.

Partiendo de este ajuste óptimo para $\mathrm{N}, \mathrm{Q}$ y $\mathrm{C}$ se realiza a continuación una nueva serie de simulaciones, donde estos tres parámetros quedan definidos como constantes con el ajuste óptimo obtenido, mientras que el número de memeplexes $(\mathrm{m})$ y el número de ranas por submemeplex (n) toman distintos valores entre 10 y 30 . Así, el número de simulaciones realizadas para el estudio de población del algoritmo SFLA para la red de Joao Pessoa es de 1800, realizándose 200 cálculos con cada una de las posibles configuraciones resultantes. La tabla inferior resume los distintos valores empleados para cada parámetro de cálculo.

\begin{tabular}{|c|c|c|}
\hline \multicolumn{2}{|c|}{ PARÁMETROS } & RANGO DE VALORES \\
\hline Memeplexes & $\mathrm{m}$ & $10,20,30$ \\
\hline Ranas por Memeplex & $\mathrm{n}$ & $10,20,30$ \\
\hline Tamaño Submemeplex & $\mathrm{Q}$ & 0.62 \\
\hline Pasos evolutivos & $\mathrm{N}$ & 30 \\
\hline Parámetro aceleración & $\mathrm{C}$ & 2 \\
\hline
\end{tabular}

Tabla 5.20. Rango óptimo de cálculo para los operadores SFLA en la red de Joao Pessoa.

Mantener los parámetros $\mathrm{N}, \mathrm{C}$ y Q constantes permite el estudio de la influencia que ejerce el tamaño de la población del algoritmo en el diseño económico de la red. El índice de población estudiado está entre 100 (10×10) y 900 (30×30) ranas en cada simulación. El histograma de soluciones representa la totalidad de simulaciones realizadas en estas condiciones. 


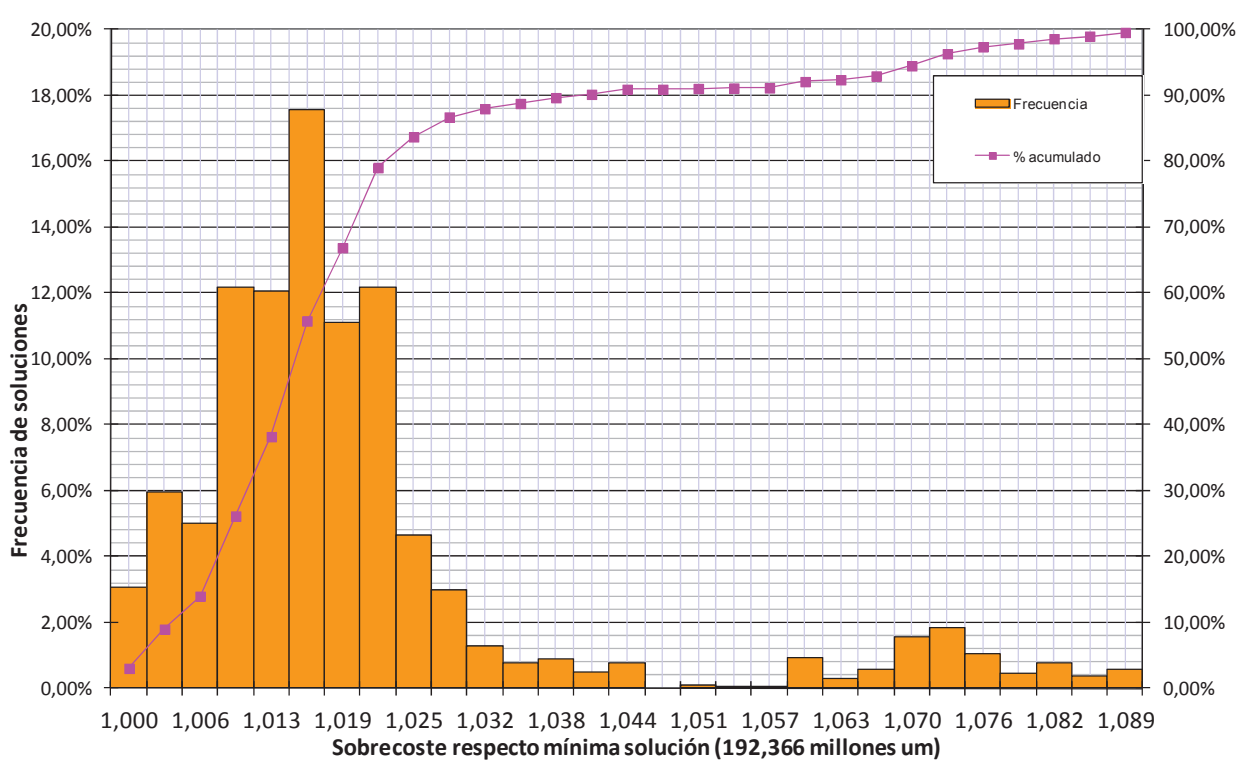

Figura 5.107. Histograma de soluciones para la red de Joao Pessoa con $m$ y $n$ variables.

La mejor solución obtenida por todos los métodos en el diseño óptimo de la red de Joao Pessoa tiene un coste de 192,366 millones de um. Ya se ha visto con anterioridad que el mayor tamaño de la red de Joao Pessoa junto a la amplitud de la gama de diámetros provoca que la repetibilidad de esta mínima solución sea escasa, puesto que el número de posibles soluciones de diseño es el más elevado entre todas las redes estudiadas, lo que dificulta el desempeño del algoritmo.

No obstante, el histograma muestra como alrededor de un 3\% de las simulaciones realizadas alcanzan este óptimo de diseño, lo que multiplica por seis la posibilidad de obtenerlo respecto a los resultados que se obtenían en el apartado 5.2.3.4. Esta mejora viene dada por la utilización en esta tanda de simulaciones de los valores óptimos para el tamaño de submemeplex (Q), el número de pasos evolutivos (N) y la aceleración (C).

Pese a esta mejora, el número de mínimas soluciones es escaso, por lo que el análisis de población se realiza en base a la obtención de una buena solución de diseño, o lo que es lo mismo, toda solución de diseño con un máximo coste adicional de un $3 \%$ por encima de la solución mínima. Así, el coste límite según esta definición es de 198,137 millones de um.

Considerando dicho concepto, la tanda de cálculos que representa la figura 5.42 calcula una buena solución el $87,22 \%$ de las ocasiones, probabilidad de éxito que supera ampliamente el $55 \%$ que proporcionaba el algoritmo antes de realizar ningún tipo de ajuste de parámetros. 
El análisis estadístico que sigue a continuación permite analizar los resultados obtenidos en función del tamaño de la población del algoritmo, que en este caso particular viene dado por el número de memeplexes (m) y el número de ranas por submemeplex (n). Así, las siguientes figuras relacionan el valor de los parámetros $m$ y $n$ con la obtención de una buena solución en la red R-9 de Joao Pessoa.

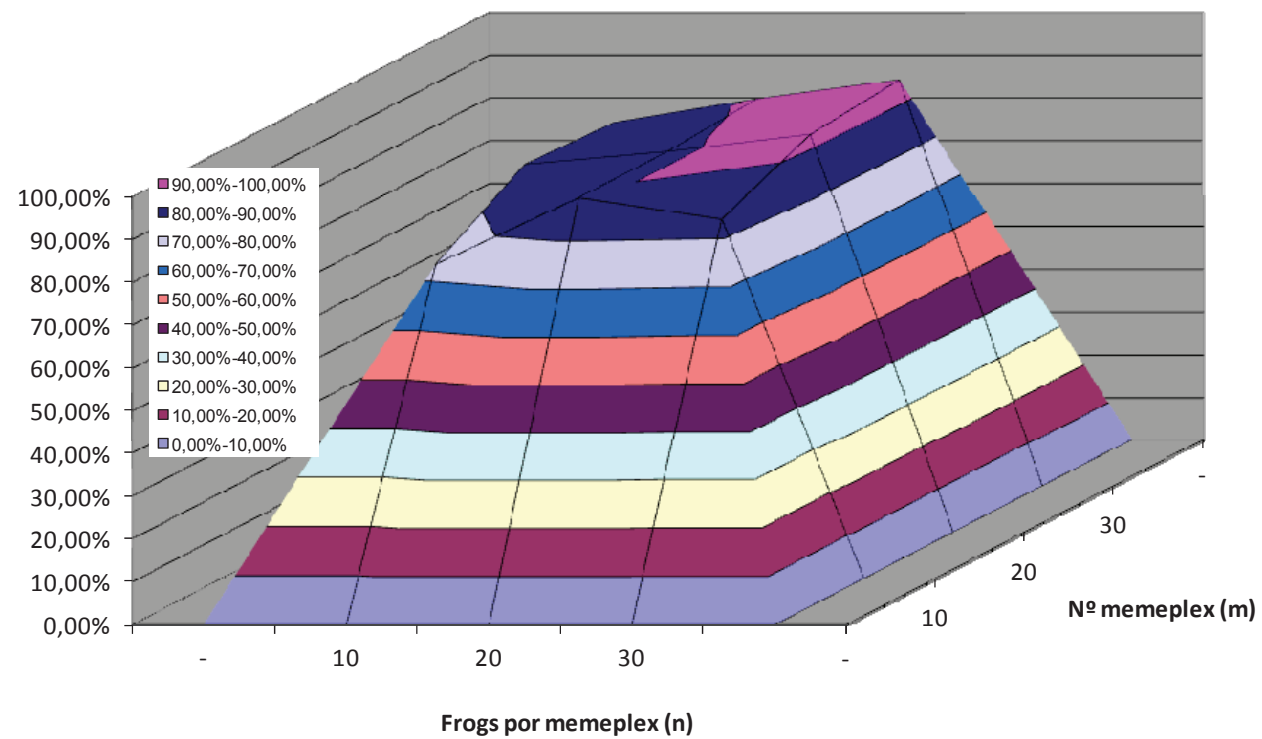

\section{Figura 5.108. Probabilidad de encontrar una buena solución respecto al número de memeplexes y al número de ranas por submemeplex en la red de Joao Pessoa.}

La representación muestra como la probabilidad de encontrar una buena solución aumenta conforme crece la población inicial del algoritmo. En este caso, la mayor complejidad de la red provoca que la diferencia entre utilizar 100 individuos (10×10) o 900 (30x30) sea considerable, puesto que el porcentaje de éxito varía en más de un $20 \%$ entre ambas configuraciones. Pese a ello no se puede afirmar que los resultados obtenidos con poblaciones más pequeñas sean malos, puesto que todas las configuraciones testeadas superan el $73 \%$ de buenas soluciones obtenidas.

En el análisis de la red de Hanoi, el porcentaje de éxito de algoritmo mostraba como la distribución de la población ejercía una influencia clave en el buen desempeño del algoritmo, de modo que el número de memeplexes $(\mathrm{m})$ representaba el parámetro de población crítico. Para la red de Joao Pessoa, la figura 5.108 no muestra este tipo de distribución óptima para m y n. En este caso, las diferencias establecidas se deben únicamente al tamaño de población total con el que trabaja el algoritmo, de modo que es absolutamente indiferente el valor de $\mathrm{m}$ ó n siempre que el número de individuos final sea el más elevado posible. 
Así, la principal conclusión que puede sacarse para la red de Joao Pessoa es que, desde un punto de vista cuantitativo, la probabilidad de encontrar buenas soluciones crece con el número de ranas que emplea el algoritmo, lo que no quiere decir que sea la configuración más eficiente, puesto que el empleo de recursos también es mayor.

\subsubsection{Red de Go-Yang}

El análisis de población realizado para el diseño óptimo para la red de Go-Yang sigue el mismo modelo que en el resto de redes. Así, utilizando los valores óptimos de N, Q y C determinados en 5.2.4.4 se realizan suficientes simulaciones con distintos tamaños de población, a fin de determinar la influencia que ejercen el número de memeplexes $(\mathrm{m})$ y el número de ranas por memeplex (n). La tabla inferior muestra el ajuste determinado para cada parámetro, de modo que con cada posible combinación se realizan 200 simulaciones distintas, a fin de tener una muestra lo suficientemente representativa para realizar un análisis estadístico.

\begin{tabular}{|c|c|c|}
\hline \multicolumn{2}{|c|}{ PARÁMETROS } & RANGO DE VALORES \\
\hline Memeplexes & $\mathrm{m}$ & $10,20,30$ \\
\hline Ranas por Memeplex & $\mathrm{n}$ & $10,20,30$ \\
\hline Tamaño Submemeplex & $\mathrm{Q}$ & 0.62 \\
\hline Pasos evolutivos & $\mathrm{N}$ & 30 \\
\hline Parámetro aceleración & $\mathrm{C}$ & 2 \\
\hline
\end{tabular}

Tabla 5.21. Rango óptimo de cálculo para los operadores SFLA en la red de Go-Yang.

La figura inferior representa el histograma de soluciones de todas las simulaciones realizadas, con un tamaño de población para el algoritmo que varía entre 100 (10x10) y 900 (30×30).

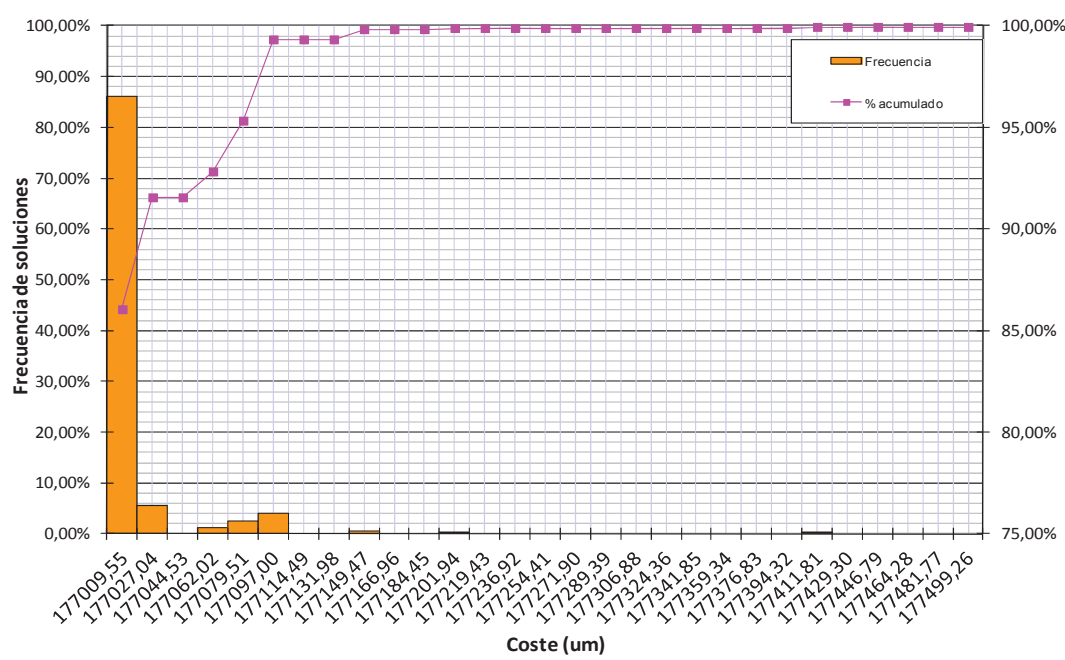

Figura 5.109. Histograma de soluciones para la red de Go-Yang con $m$ y $n$ variables. 
Ya se ha visto anteriormente que la mejor solución de diseño obtenida para la red de Go-Yang tiene un coste de 177.009,6 um. El histograma de soluciones muestra como el algoritmo SFL obtiene esta solución en más de un $80 \%$ de las simulaciones realizadas. Este porcentaje de éxito tan elevado se debe a la optimización de parámetros realizada en el apartado anterior, donde con ayuda de herramientas estadísticas se determina el valor óptimo para tres de los cinco parámetros de ajuste que tiene el algoritmo $(\mathrm{Q}, \mathrm{N}$ y C). El ajuste óptimo para estos parámetros triplica la probabilidad de obtener una mínima solución, puesto que sin el ajuste de $\mathrm{Q}, \mathrm{N}$ y $\mathrm{C}$ el algoritmo sólo proporciona un $25 \%$ de mínimas soluciones, tal como permite apreciar la figura 5.68 .

Por otro lado, si se considera el concepto de buena solución, que en este caso corresponde a soluciones de diseño que se encuentren por debajo de 182.319 um, el algoritmo SFL obtiene en esta ronda de simulaciones un $100 \%$ de éxito.

Pese al excelente rendimiento que ofrece el algoritmo SFL con un buen ajuste paramétrico, este apartado tiene como objetivo el estudio de la influencia del tamaño de población en los resultados, por lo que el análisis estadístico que sigue a continuación trata de mejorar aún más estos resultados.

Así, de modo análogo al resto de redes, se estudia la influencia del número de memeplexes y del número de ranas por memeplex, cuya combinación define el número de individuos con los que trabaja el algoritmo SFL. De esta manera, la figura inferior muestra la probabilidad de encontrar una mínima solución para el problema de diseño cuando varía el número de individuos manteniendo constantes el resto de parámetros. Cabe destacar que en este caso no tiene sentido introducir la probabilidad de obtener una buena solución en las figuras, puesto que dicha probabilidad es del $100 \%$ dentro del rango de población estudiado.

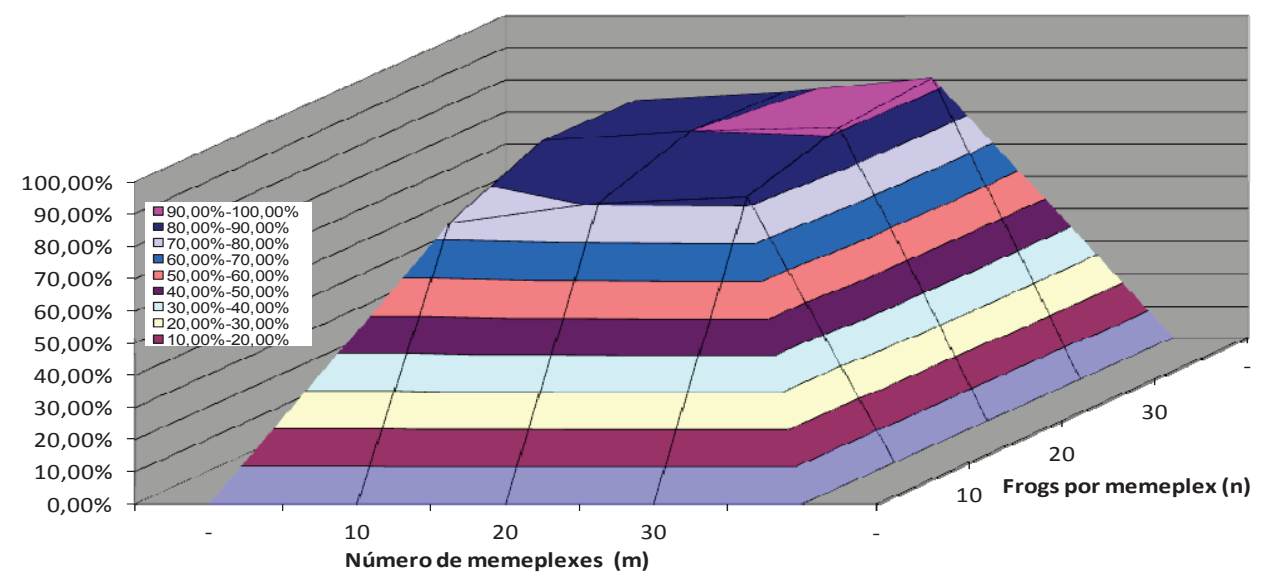

Figura 5.110. Probabilidad de encontrar mínima solución respecto al número de memeplexes y al número de ranas por submemeplex en la red de Go-Yang. 
El menor tamaño de la red, así como una gama de diámetros no demasiado extensa hace que la red de Go-Yang tenga menos posibilidades de diseño que el resto de redes simuladas, lo que repercute favorablemente en la dificultad que encuentra el algoritmo en el proceso de diseño. Es por ello que la probabilidad de obtener la solución óptima es la más elevada entre todas las redes.

Tal como se puede observar en la figura, el comportamiento del algoritmo SFL en la red de Go-Yang es muy similar al que se observa para la red de Joao Pessoa en el apartado anterior. Así, cuanto mayor es el número de individuos mayor es también la probabilidad de encontrar la solución óptima de diseño. No obstante, cualquier tamaño de población entre los simulados tiene una probabilidad de éxito por encima del $70 \%$ cuando se trata de encontrar la solución de mínimo coste. Así, el peor porcentaje de éxito corresponde a una población de 100 individuos (10x10), que obtiene un $74,5 \%$ de mínimas soluciones, mientras que una población de 900 individuos (30×30) eleva este porcentaje hasta el 93,5\%.

Como conclusión, cabe destacar que la distribución de resultados obtenida para la red de GoYang es prácticamente idéntica a la que se obtiene en la red de Joao Pessoa, tanto en la forma del gráfico como en los resultados numéricos obtenidos. Esto significa que la influencia de la población del algoritmo se debe únicamente al tamaño total de la población, no apreciándose ningún tipo de influencia que se deba tan sólo al número de memeplexes $(\mathrm{m})$, tal como ocurría en la red de Hanoi.

\subsection{Análisis de la velocidad de cálculo en los modelos de optimización desarrollados}

La gran cantidad de factores que intervienen en el desempeño de un determinado método heurístico de diseño hace que hablar de "velocidad" de un algoritmo quizá no sea el término más adecuado si se intenta relacionar el término con una base temporal.

En el ámbito de aplicación en el que se mueve un método heurístico, el término "velocidad" se refiere al número de evaluaciones de la función objetivo que realiza el algoritmo de cálculo antes de encontrar la solución final del problema, puesto que es la forma más sencilla para tener una idea acerca de la rapidez con la que trabaja un algoritmo independientemente del hardware que se esté utilizando.

Todos los algoritmos utilizados requieren de una condición de parada para finalizar el cálculo del problema de diseño. Esta condición de parada implica la realización de un número determinado de evaluaciones de la función objetivo sin que se registre ninguna mejora en ella.

El valor de la condición de convergencia es de libre configuración, teniendo en cuenta que el número de evaluaciones sin cambio debe ser un número lo suficientemente grande como 
para que el algoritmo sea capaz de de un mínimo local si se encuentra atrapado, pero no tanto como para provocar una excesiva ralentización del cálculo.

Para métodos heurísticos como APG, PSO y SFLA se ha estimado, atendiendo a pruebas realizadas, que entre 800-1000 generaciones sin cambio es un número razonable para que el proceso de optimización no quede atrapado demasiado pronto. El número de evaluaciones de la función objetivo que se produce en cada generación de un determinado algoritmo depende de cada método. Por ejemplo, tanto APG como SFLA realizan en cada iteración tantas evaluaciones de la función objetivo como cadenas de la población inicial sufren un cambio tras la aplicación de los distintos operadores.

La programación de todos los algoritmos es similar en este aspecto, puesto que la función objetivo se evalúa solamente si se produce un cambio entre iteración e iteración. Sin embargo, no todos los algoritmos trabajan del mismo modo. Así, PSO evalúa la función objetivo de cada miembro de la población en todas las iteraciones, puesto que todos los pájaros experimentan un cambio de posición en cada iteración. Esto quiere decir que si tenemos una población inicial de 100 individuos y aplicamos una condición de parada de 800 generaciones sin cambio, PSO realizará 80000 evaluaciones de la función objetivo sin que se produzca ninguna mejora antes de dar por finalizado el proceso de optimización.

En el caso del algoritmo HS el total de evaluaciones de la función objetivo que realiza el método antes de parar es independiente de la población del algoritmo, puesto que cada iteración crea únicamente un nuevo vector solución, que en función de su valía sustituye o no a uno de los vectores solución de la población original. Esto implica que la condición de convergencia en HS no puede ser la misma que en el resto de métodos, puesto que 800 generaciones sin cambio se antojan insuficientes teniendo en cuenta que en cada una de estas generaciones HS realiza aproximadamente 1/100 parte de los cálculos que pueden realizar el resto de metodologías cuando la población es de 100 individuos.

Para ser consecuentes con el criterio de convergencia aplicado en el resto de metodologías, lo más natural es insertar para HS una condición de convergencia lo suficientemente alta como para que el número de evaluaciones de la función objetivo realizadas sin cambio antes de finalizar el cálculo sea similar al resto de métodos.

Evidentemente, una formulación de este tipo no es trivial, puesto que implica la realización de un estudio detallado del número de vectores solución cuyo cálculo no se repite en dos iteraciones consecutivas del algoritmo, teniendo en cuenta que este número no es constante y depende de los parámetros del algoritmo y la evolución de la población en cada caso y método.

En lugar de esto, se ha optado por realizar un estudio acerca de la condición de convergencia en HS, con el objetivo de establecer un punto de parada adecuado para el algoritmo. Dicho 
estudio se ha realizado sobre la red de Hanoi, realizándose un total de 33600 simulaciones, con los siguientes parámetros de cálculo:

\begin{tabular}{|c|c|}
\hline PARÁMETRO & RANGO DE VALORES \\
\hline Tamaño de población & $30-45-60$ \\
\hline HMCR & $0,89-0,9$ \\
\hline PAR & 0,15 \\
\hline
\end{tabular}

Tabla 5.22. Ajuste de parámetros empleado para el estudio de la condición de convergencia en HS.

Cada configuración posible con estos parámetros se ha repetido 800 veces con distintos valores en el número de iteraciones sin cambio que se requieren para parar el cálculo, a fin de establecer una relación entre el número de buenas soluciones obtenidas y la condición de parada del algoritmo. El criterio de buena solución que se utiliza es el mismo que en el resto de análisis de optimización realizados hasta ahora; es decir, un $3 \%$ de coste adicional respecto a la mínima solución obtenida. En el caso de la red de Hanoi este valor límite es 6,263 millones de um. La figura 5.111 muestra el porcentaje de buenas soluciones obtenidas aplicando distintas condiciones de parada del algoritmo.

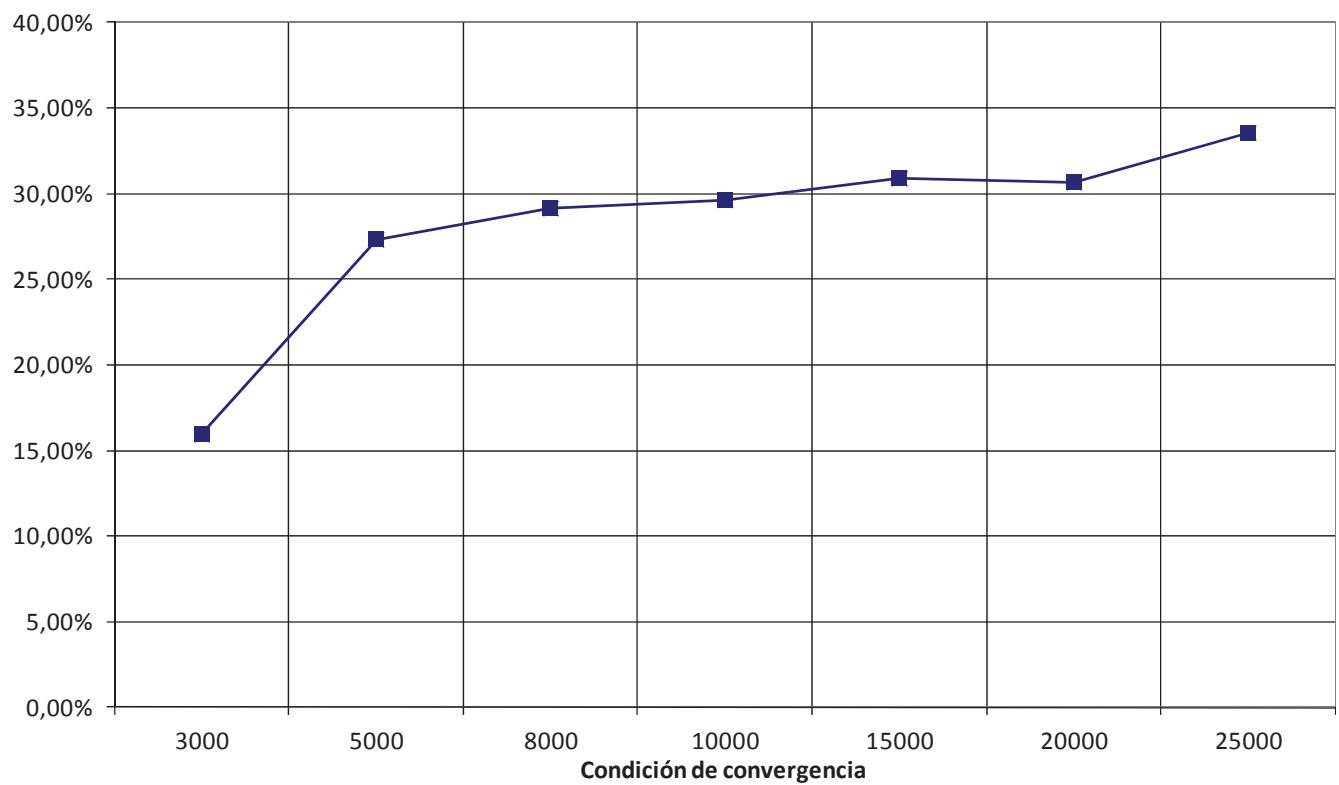

Figura 5.111. Probabilidad de obtener una buena solución con HS para la red de Hanoi en función de condición parada.

La principal conclusión que se puede sacar de la figura es que el porcentaje de buenas soluciones no depende linealmente del número de simulaciones sin cambio que se establece 
como criterio de convergencia. Así, cuando la condición de parada pasa de 3.000 a 5.000 simulaciones sin cambio se aprecia un salto cuantitativo importante en la probabilidad de obtener una buena solución. Sin embargo, entre 5.000 y 25.000 el salto que se produce es mucho menor. Si se concretan las cifras, lo cierto es que la diferencia entre utilizar como criterio de convergencia 3000 o 5000 es de un $12 \%$, pero entre 5.000 y 25.000 la mejora producida es tan sólo de un $6 \%$.

El utilizar un mayor número de simulaciones sin mejora como criterio de convergencia del algoritmo implica alargar el cálculo, de modo que hay que tomar una decisión de compromiso que permita obtener las mejores soluciones con el mínimo coste computacional. Para la metodología basada en HS, el ensayo realizado en la red de Hanoi aconseja no tomar menos de 5.000 simulaciones sin cambio como criterio de parada. Del mismo modo, la figura 5.111 deja claro que la mejora obtenida entre tomar 5.000 y 25.000 simulaciones sin cambio no justifica en primera instancia el aumento de tiempo de cálculo que debe emplear el algoritmo. La solución de compromiso que se adopta a tenor de los resultados obtenidos es realizar para todos los cálculos basados en HS un criterio de convergencia entre 5.000 y 10.000 iteraciones sin cambio.

Las siguientes líneas analizan la velocidad con la que trabaja cada uno de los algoritmos de optimización en función de los distintos valores empleados para cada parámetro de cálculo. Así, en este tipo de análisis el resultado final obtenido queda en un segundo plano. Para ello se tiene en cuenta tan sólo el número de evaluaciones de la función objetivo realizadas, de modo que cuanto mayor sea éste mayor será también el tiempo de cálculo empleado en el proceso de optimización.

\subsubsection{Influencia de los parámetros en la velocidad de cálculo del APG}

Inicialmente, la figura 5.112 muestra el número medio de evaluaciones de la función objetivo realizadas hasta alcanzar el mínimo en el proceso de diseño de la red de Hanoi en función de las probabilidades de cruce y mutación. 


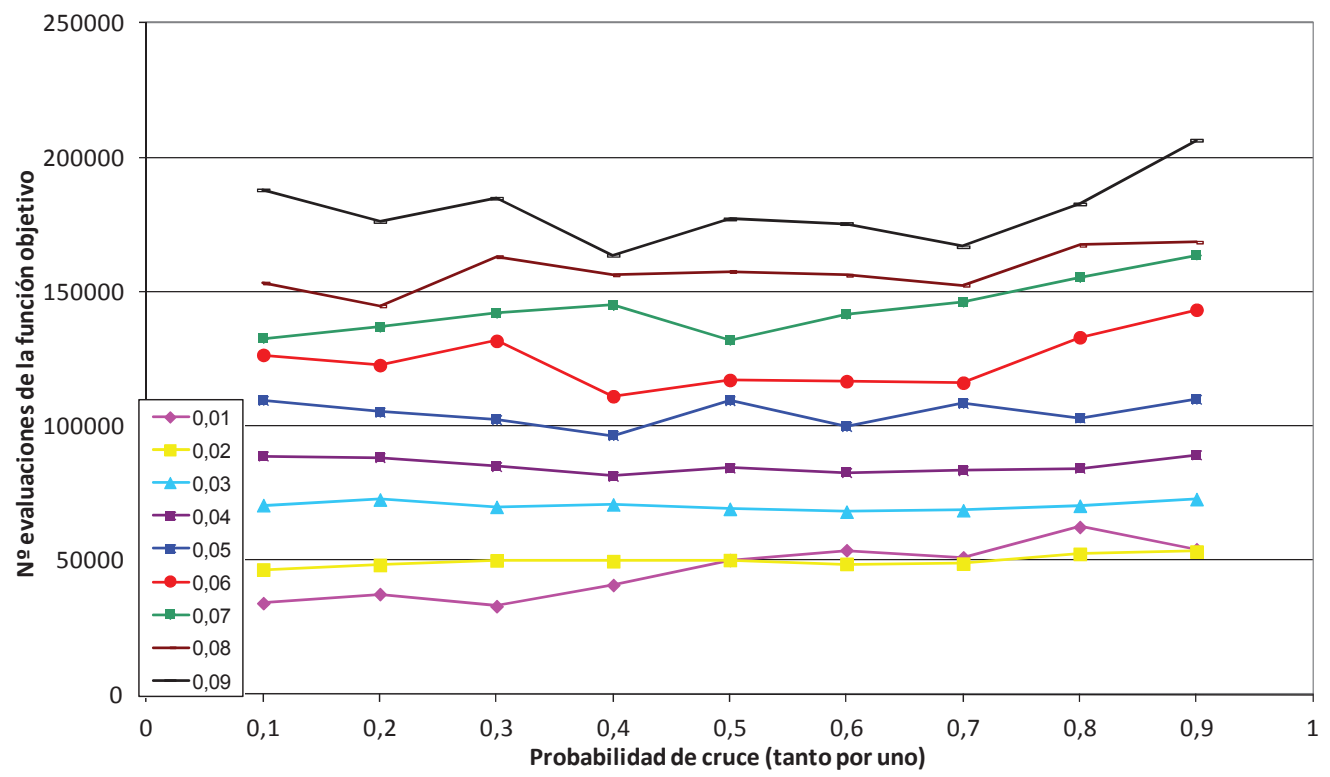

Figura 5.112. Número medio de evaluaciones de la F.O realizadas por APG en el diseño de la red de Hanoi según probabilidades de cruce y mutación.

La figura 5.112 relaciona el número de evaluaciones realizadas con el valor de los parámetros de cruce y mutación. La principal conclusión que da el gráfico es que conforme la probabilidad de mutación es mayor también lo es el número de evaluaciones que realiza el algoritmo hasta encontrar la solución final.

En el caso de la probabilidad de cruce, el comportamiento es sumamente irregular según sea el valor de la probabilidad de mutación, por lo que se antoja bastante complicado sacar algún tipo de conclusión. Así, en un rango de probabilidad entre un 2-4 \% de mutación, el número de evaluaciones de la F.O es prácticamente constante, no apreciándose apenas variación entre unos valores de cruce y otros. Sin embargo, el resto de líneas de isomutación no tienen una tendencia clara, aunque sí que se aprecia un ligero aumento del número de evaluaciones conforme crece la probabilidad de cruce. Aún así, no parece que con un tamaño de población constante de 100 unidades sea posible relacionar el número de evaluaciones de la F.O realizadas con la probabilidad de cruce.

La conclusión más lógica que se puede tomar de la figura anterior es que conforme la probabilidad de mutación es mayor el número de evaluaciones medias de la F.O crece en gran medida, lo que provoca mayor lentitud en el cálculo. Las figuras inferiores muestran el mismo análisis para la red R-9 de Joao Pessoa y la red de Go-Yang. 


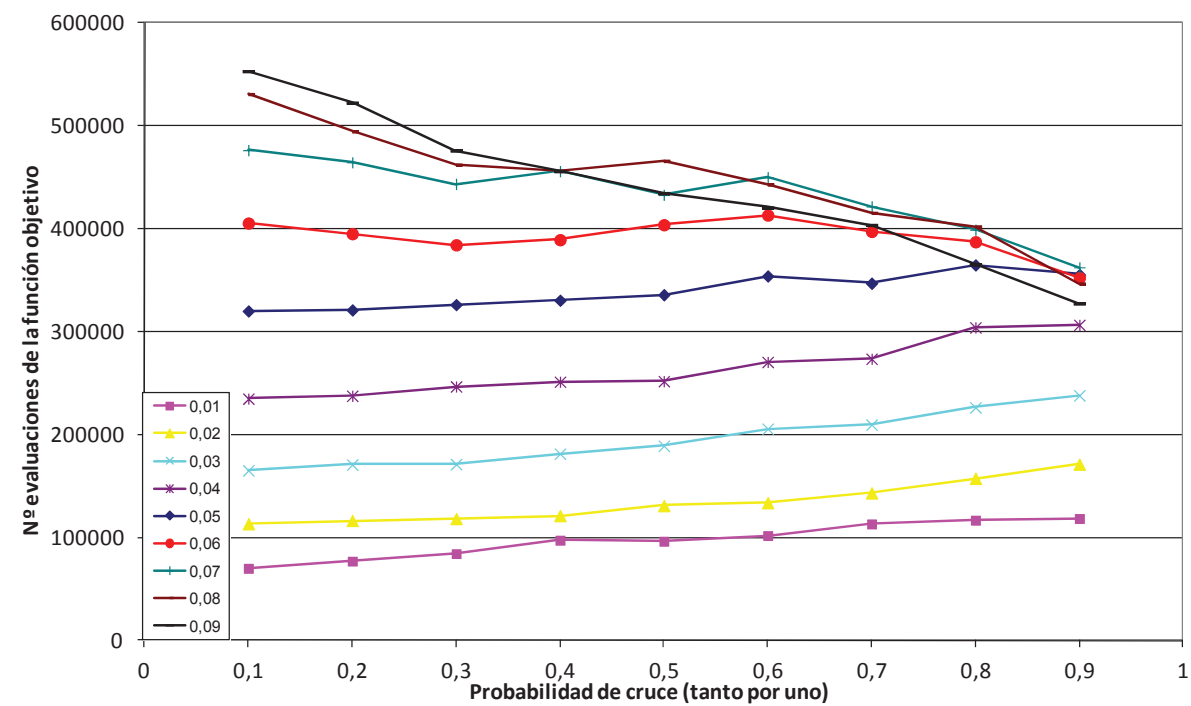

Figura 5.113. Número medio de evaluaciones realizadas por APG en el diseño de la red $\mathbf{R}-9$ según probabilidades de cruce y mutación.

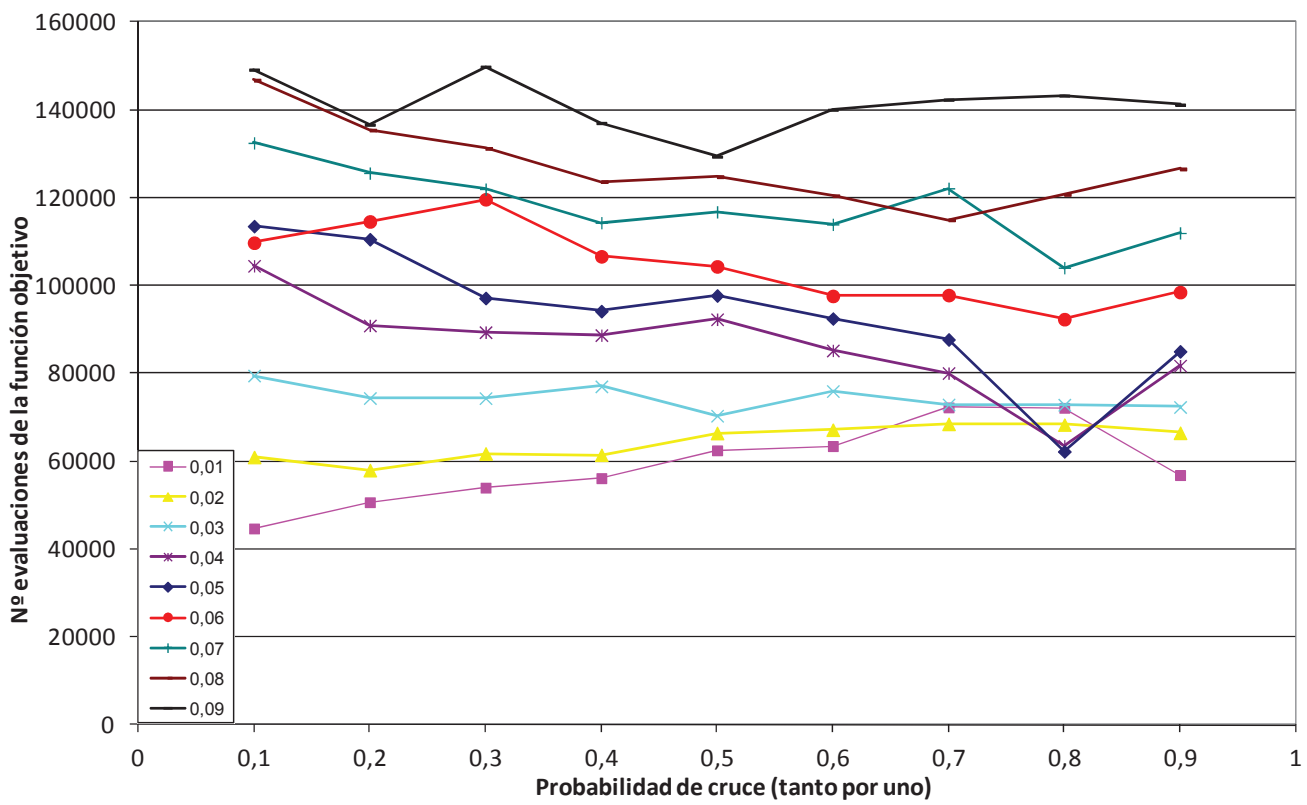

Figura 5.114. Número medio de evaluaciones realizadas por APG en el diseño de la red de Go-Yang según probabilidades de cruce y mutación.

El análisis de evaluaciones de la F.O en ambas redes permite realizar un análisis similar a lo que ya se observaba en el diseño de la red de Hanoi. Es decir, conforme la probabilidad de 
mutación es mayor el número de evaluaciones medias que realiza el algoritmo hasta encontrar la solución final también lo es. Por otro lado, la irregularidad del número de evaluaciones realizadas respecto a la probabilidad de cruce impide sacar ningún tipo de tendencia acerca de este parámetro, por lo que la conclusión más plausible es que la probabilidad de cruce no tiene una influencia directa en el número de evaluaciones realizadas $y$, por tanto, en la velocidad con la que calcula el APG.

En el caso de la red R-9 esta tendencia se aprecia con claridad, ya que las líneas de probabilidad de mutación más bajas realizan claramente muchas menos iteraciones que las líneas de probabilidad de mutación más altas. Si se acude a los extremos resulta esclarecedor comprobar cómo probabilidades de mutación de 0,01-0,02 realizan menos de 50000 evaluaciones hasta alcanzar la solución final, mientras que probabilidades de mutación por encima de 0,08 están por encima de las 200000 evaluaciones de media, lo que supone un esfuerzo cuatro veces mayor.

La red R-9 es la que presenta estos datos de un modo más extremo, y probablemente tiene su explicación en que ésta es de todas las estudiadas la red de mayor tamaño, lo que dificulta el cálculo, puesto que es la que tiene el mayor número posibles soluciones de diseño. Esto dificulta el desempeño de las peores combinaciones de parámetros, lo que provoca que la mejora progresiva de las soluciones obtenidas sea más lenta.

La red de Go-Yang sigue la misma tendencia respecto al menor número de iteraciones realizadas cuando la probabilidad de mutación es baja, confirmando las conclusiones realizadas anteriormente. Confirmando la hipótesis planteada en las otras redes, la probabilidad de cruce no parece tener una influencia tan marcada en el número de iteraciones realizadas.

La excepción a las conclusiones sacadas hasta ahora se encuentra en los datos que proporciona la red de Nueva York. Así, la figura 5.115 muestra el número medio de evaluaciones de la función objetivo para el diseño de la red de los túneles de Nueva York. 


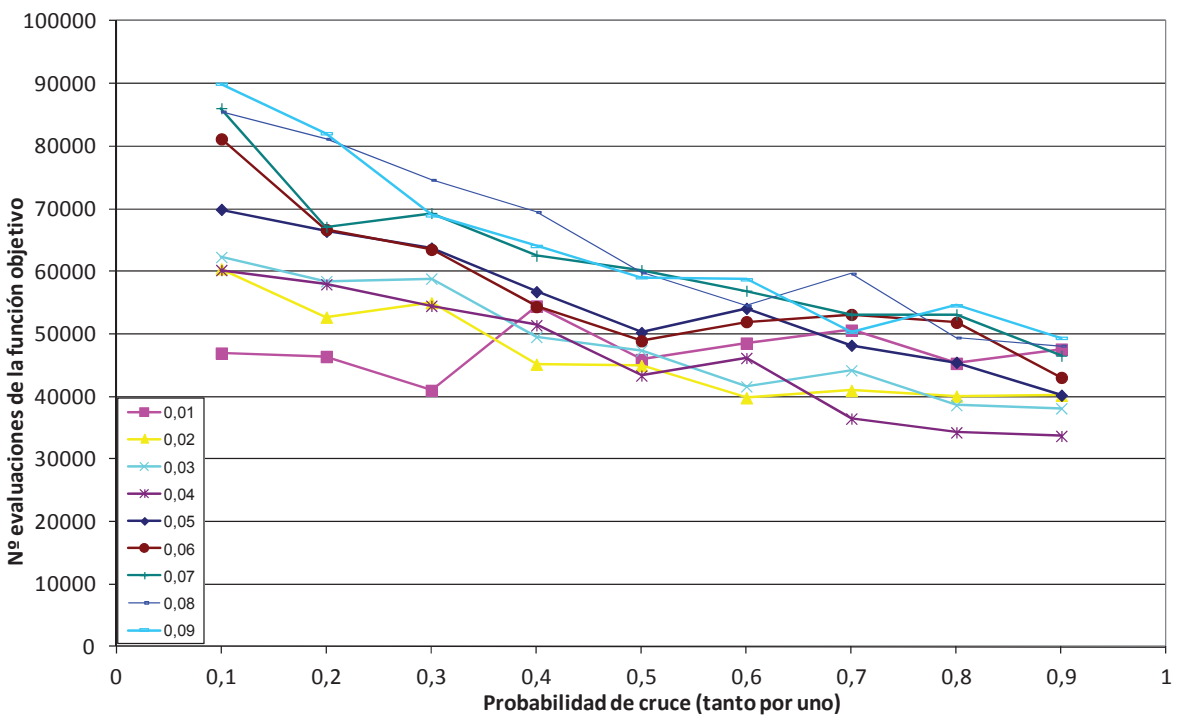

Figura 5.115. Número de evaluaciones medias según probabilidades de cruce y mutación para la red de Nueva York.

La figura muestra para esta red un comportamiento algo distinto al de las otras redes de benchmarking estudiadas. Por un lado, la tendencia general respecto al mayor número de evaluaciones realizadas conforme aumenta la probabilidad de mutación sigue cumpliéndose, si bien las diferencias entre unos valores y otros son menores. No obstante, la diferencia fundamental se encuentra en el número de evaluaciones realizadas según la probabilidad de cruce. En el resto de redes ya se ha comentado la ausencia de una relación directa entre $\mathrm{P}_{\mathrm{c}} \mathrm{Y}$ velocidad del algoritmo; sin embargo, en la red de Nueva York sí que parece que probabilidades de cruce mayores dan como resultado un número menor de evaluaciones de la función objetivo, y por tanto, una mayor velocidad de cálculo del algoritmo.

Del mismo modo, cabe destacar que la diferencia entre el número de evaluaciones al utilizar unos parámetros de cálculo u otros son menores en la red de Nueva York que en el resto de redes mostradas. La explicación a esta situación es necesario buscarla en las características particulares de dicha red, puesto que éste no es un problema de diseño puro, sino un problema de rehabilitación de una red que ya tiene un diseño previo. Esto, unido a que el tamaño de la red no es excesivamente grande hace que la dificultad del problema de diseño sea menor. Esta menor complejidad provoca que la búsqueda del óptimo en el espacio de soluciones sea más sencilla, puesto que el número de posibles soluciones y de mínimos locales es menor, lo que simplifica el proceso de búsqueda. La mayor simplicidad del problema provoca que la diferencia entre utilizar unas probabilidades de cruce/mutación u otras no afecte tanto a la velocidad del algoritmo, puesto que todas las combinaciones posibles son capaces de resolver rápidamente el problema. 
Para comprobar dicha hipótesis se realizó un estudio rápido de diseño sobre una de las redes de benchmarking más sencillas y conocidas en la bibliografía, como es la red de Asperovits y Shamir (1977). Esta red está compuesta por un depósito, ocho tuberías y seis nudos de demanda sometidos a una condición de carga. Éste es un problema de diseño mucho más sencillo que los planteados anteriormente, puesto que el número de tuberías a diseñar es menor, lo que disminuye el número posible de soluciones. El coste óptimo del sistema es 419.000 um, valor conseguido por la mayoría de investigadores que han estudiado esta red. La figura 5.116 muestra el número de iteraciones realizadas por el APG según la probabilidad de cruce y mutación.

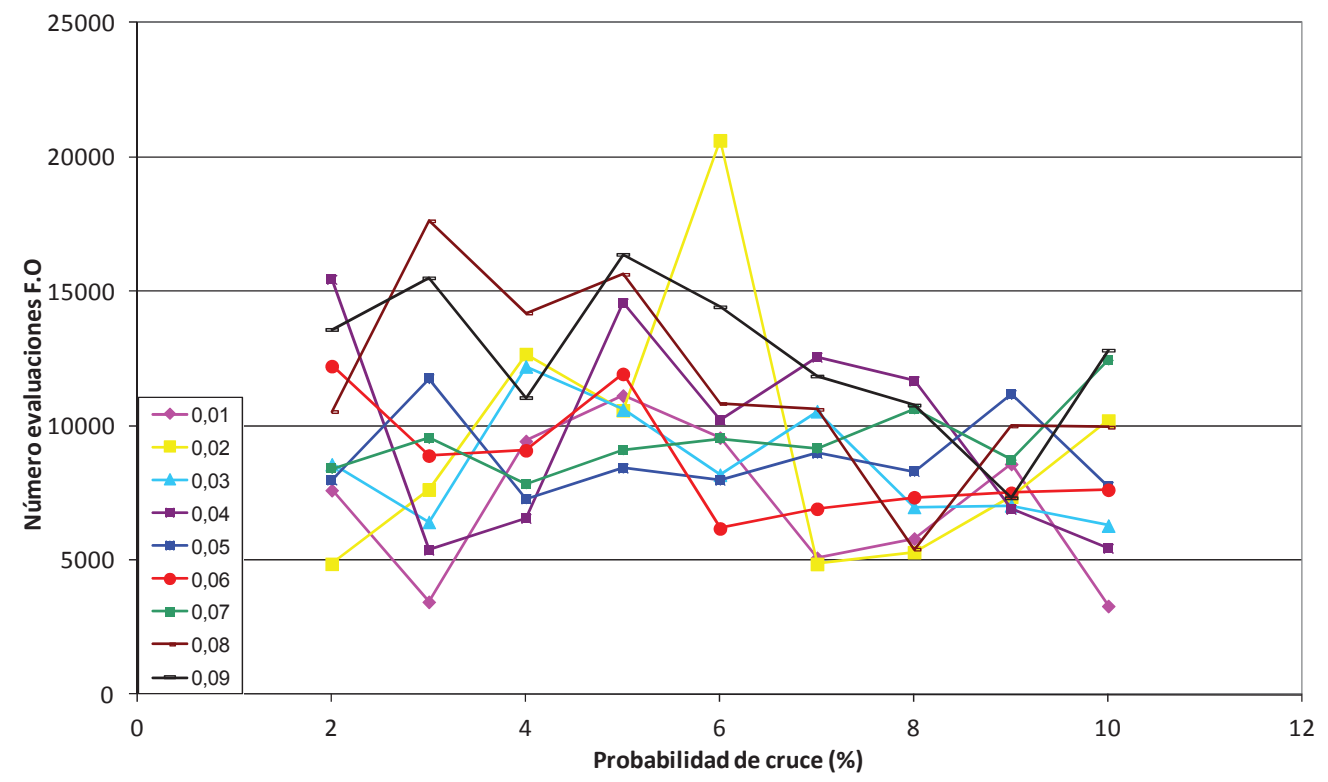

Figura 5.116. Número de evaluaciones medias hasta encontrar la solución final según probabilidad de cruce y mutación para la red de Asperovits y Shamir.

En la figura se aprecia la ausencia de relación entre el número de evaluaciones de la función objetivo y la probabilidad de cruce o mutación que tenga el algoritmo. Del mismo modo, cabe destacar las pocas iteraciones que necesita el algoritmo para encontrar la solución final, puesto que partiendo de una solución totalmente aleatoria apenas necesita entre $100 \div 200$ iteraciones para encontrar una solución de mínimo coste o próxima a ella, lo que supone en tiempo apenas $10 \div 15$ segundos.

\subsubsection{Influencia de los parámetros en la velocidad de cálculo del algoritmo PSO modificado}

El análisis estadístico que realiza esta tesis acerca de la técnica de optimización basada en PSO considera 4 parámetros susceptibles de ajuste: la velocidad límite a la que se mueve un 
determinado pájaro entre iteración e iteración $\left(\mathrm{V}_{\text {lim }}\right)$, la probabilidad de que un pájaro se desvíe de la bandada en busca de nuevas soluciones $\left(P_{\text {desp }}\right)$ y las constantes $C_{1}$ y $C_{2}$, que determinan el peso de las búsquedas local y global en el algoritmo.

Las figuras $5.117,5.118,5.119$ y 5.120 analizan la influencia que ejerce cada uno de estos parámetros en el número de evaluaciones que realiza el algoritmo hasta que encuentra la solución final de diseño en una determinada simulación. Inicialmente se analiza el número de evaluaciones medias realizadas en función de $\mathrm{V}_{\lim } \mathrm{Y} \mathrm{P}_{\text {desp }}$ en el proceso de diseño de la red de Hanoi. Ambos parámetros se mostraron como los más críticos en la calidad de las soluciones desde un punto de vista cuantitativo (ver 5.2.2). Con el objetivo de tener una visión global se realiza este estudio para cada una de las redes de diseño.

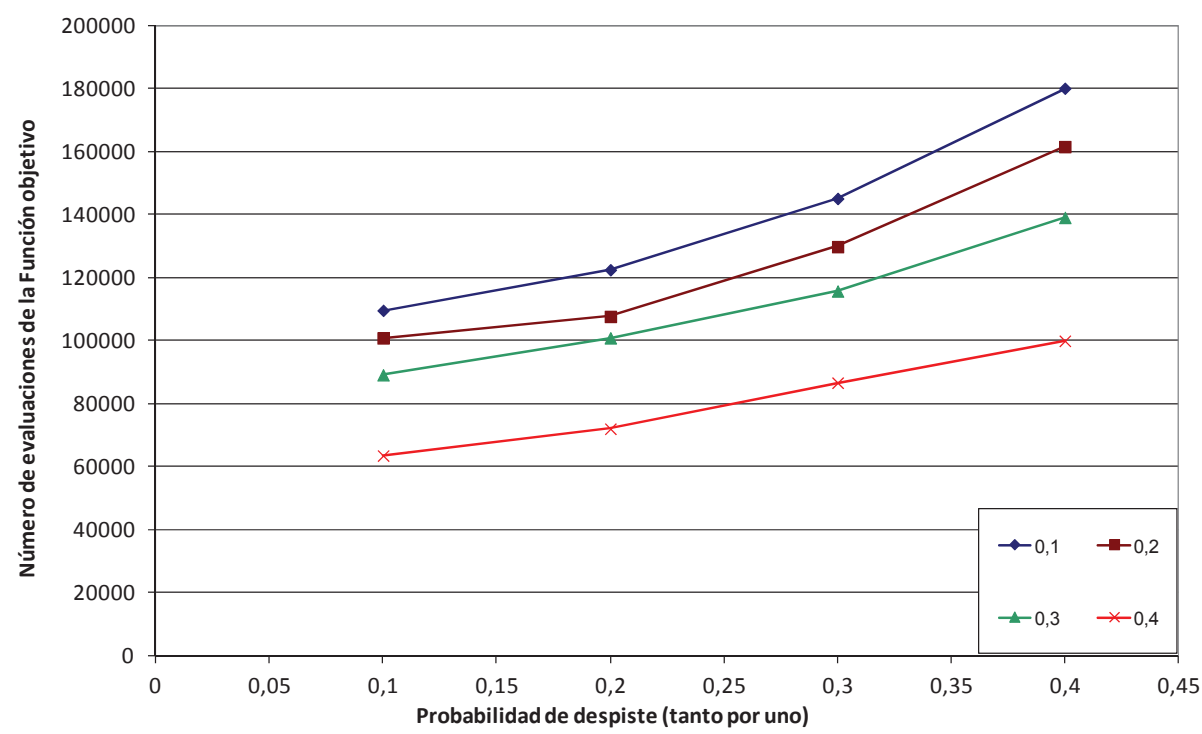

Figura 5.117. Evaluaciones medias de la F.O hasta encontrar la solución final en función de $\boldsymbol{P}_{\text {desp }} \boldsymbol{y} \boldsymbol{V}_{\text {lim }}$ para la red de Hanoi.

La figura 5.117 permite apreciar como conforme aumenta la probabilidad de despiste también lo hace el número de evaluaciones realizadas por el algoritmo PSO, independientemente de cuál sea el valor de la velocidad límite de vuelo.

Del mismo modo, considerando ahora el límite de velocidad de vuelo de un pájaro entre iteración e iteración se observa como conforme dicho límite es mayor el número de evaluaciones de la función objetivo disminuye. Ambas evoluciones se producen en mayor o menor medida en todas las redes diseñadas con el algoritmo PSO modificado, por lo que se puede considerar como inherente al método de diseño. Las figuras inferiores muestran el mismo estudio para las redes de Nueva York, R-9 y Go-Yang. 


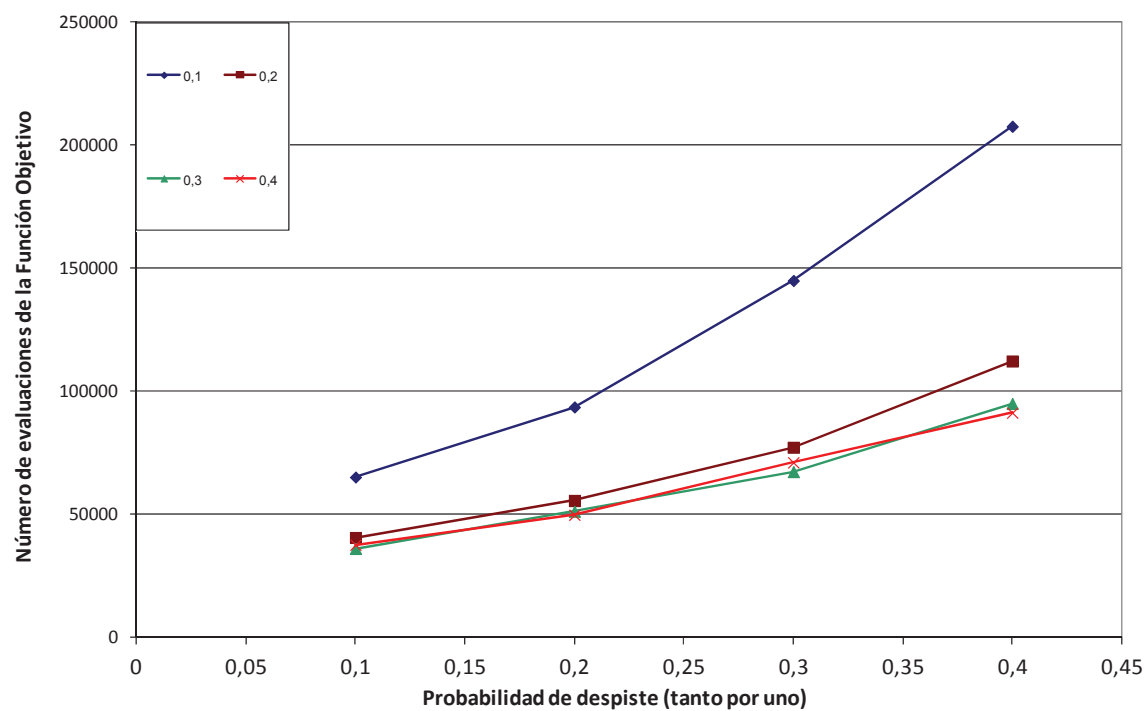

Figura 5.118. Evaluaciones medias de la F.O hasta encontrar la solución final en función de $P_{\text {desp }}$ y $V_{\text {lim }}$ para la red de Nueva York.

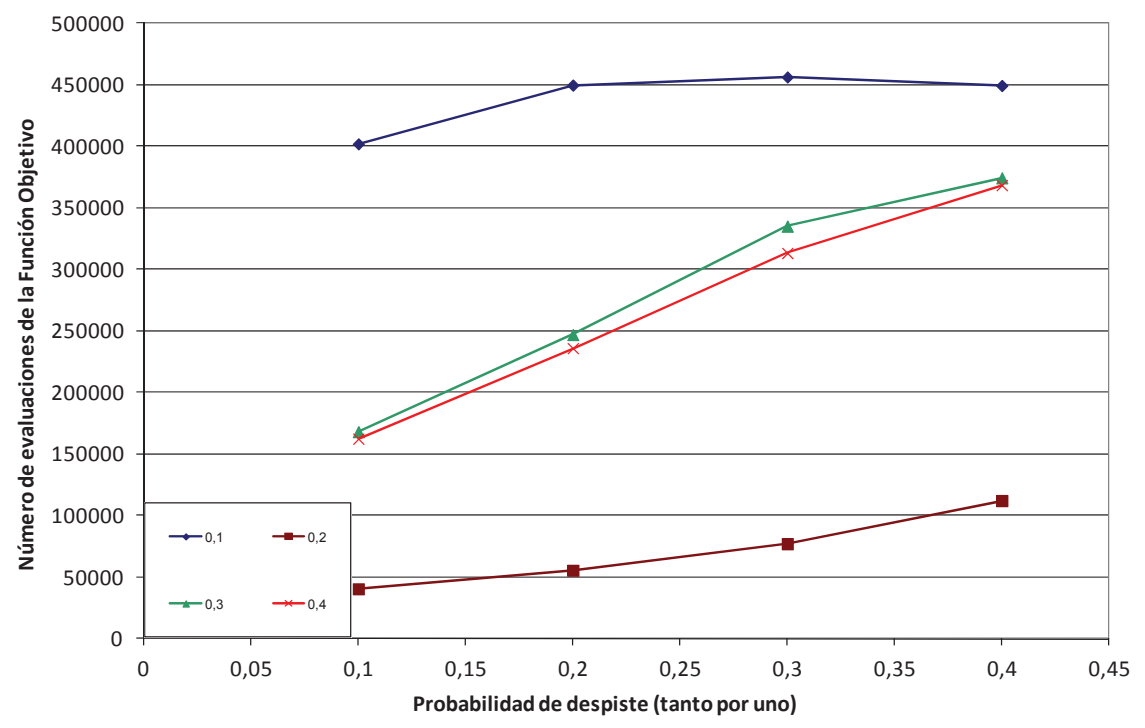

Figura 5.119. Evaluaciones medias de la F.O hasta encontrar la solución final en función de $P_{\text {desp }}$ y $V_{\text {lim }}$ para la red $R-9$ de Joao Pessoa. 


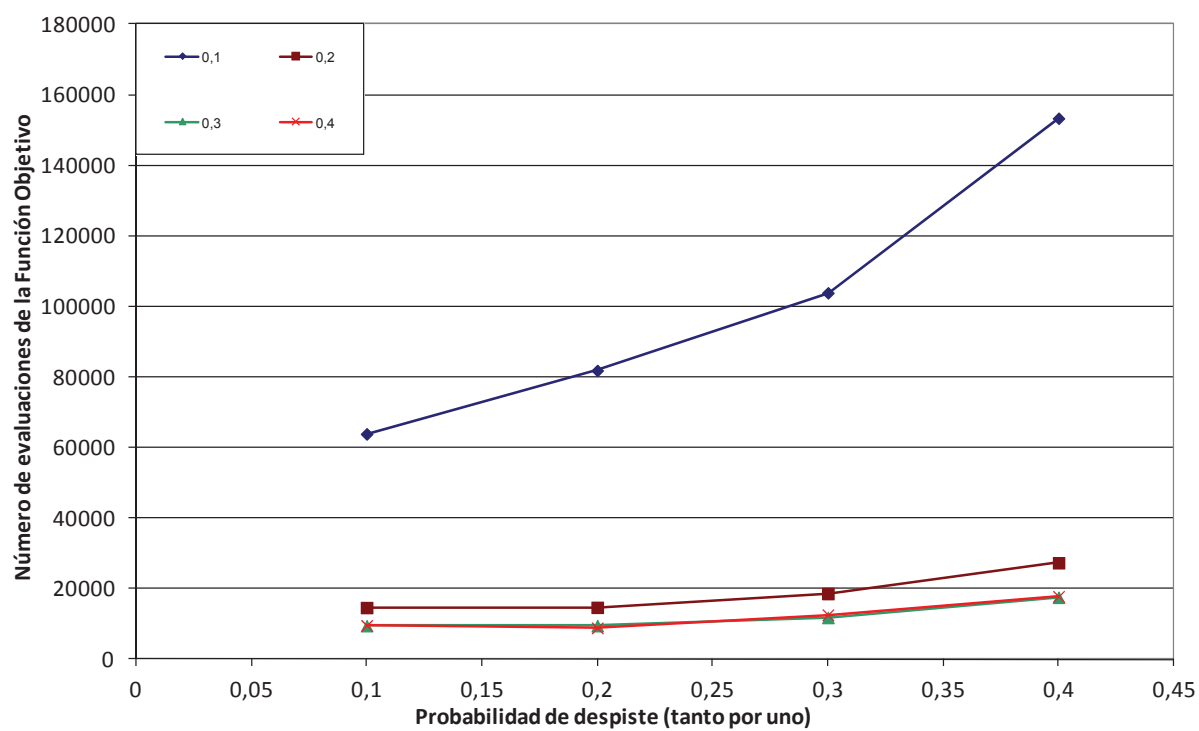

Figura 5.120. Evaluaciones medias de la F.O hasta encontrar la solución final en función de $P_{\text {desp }} y V_{\text {lim }}$ para la red de Go-Yang.

A simple vista se aprecia como el comportamiento del algoritmo PSO es distinto en cada una de las redes, si bien todas comparten una serie de características que permiten tomar una serie de conclusiones generales que las relaciona a todas ellas. Por ejemplo, en todas las redes el número de evaluaciones de la función objetivo es mayor conforme aumenta la probabilidad de despiste del algoritmo. Esta situación implica que el proceso de búsqueda es más largo cuanto mayor es el número de pájaros que tienen un comportamiento anárquico respecto de la posición del líder en cada iteración, prolongando la búsqueda en otros puntos del espacio de soluciones. La probabilidad de despiste solventa uno de los principales problemas que tiene la formulación original del algoritmo PSO, que es la convergencia demasiado temprana del algoritmo al seguir todos los individuos a su líder.

La siguiente tabla muestra la diferencia porcentual de evaluaciones realizadas para cada una de las redes entre la probabilidad de despiste que menos evaluaciones realiza $\left(P_{\text {desp }}=0,1\right)$ y la que más $\left(P_{\text {desp }}=0,4\right)$.

\begin{tabular}{|c|c|c|c|c|}
\hline $\mathbf{V}_{\lim }$ & Hanoi & NY & R-9 & Go-Yang \\
\hline $\mathbf{0 , 1}$ & $60,87 \%$ & $31,38 \%$ & $89,46 \%$ & $41,66 \%$ \\
\hline $\mathbf{0 , 2}$ & $62,41 \%$ & $36,15 \%$ & $46,44 \%$ & $53,38 \%$ \\
\hline $\mathbf{0 , 3}$ & $64,10 \%$ & $38,06 \%$ & $44,93 \%$ & $54,18 \%$ \\
\hline $\mathbf{0 , 4}$ & $63,57 \%$ & $41,28 \%$ & $44,11 \%$ & $53,77 \%$ \\
\hline
\end{tabular}

Tabla 5.23. Diferencia \% acerca del número de evaluaciones entre extremos considerados para $\boldsymbol{P}_{\text {desp. }}$. 
Los datos de la tabla muestran una disminución considerable en el número de evaluaciones para probabilidades de despiste menores. Es importante considerar que la probabilidad de despiste se introduce precisamente para aumentar el número de evaluaciones y evitar convergencias tempranas, pero el aumentar en exceso este número de iteraciones podría disminuir la eficacia del algoritmo, por lo que se hace necesario buscar soluciones de compromiso que fijen el punto óptimo de este parámetro. El estudio de eficiencia ayuda a tomar este tipo de decisiones.

No obstante, el objetivo del análisis de velocidad es únicamente analizar que configuraciones prolongan el cálculo, y en este sentido es evidente que conforme se aumenta la probabilidad de que un determinado pájaro no siga a su líder aumenta el tiempo de cálculo del algoritmo. El ahorro iterativo que se produce es distinto para cada una de las redes, siendo la red de los túneles de Nueva York la que muestra las mayores diferencias. En este caso, el número de evaluaciones de la función objetivo para una probabilidad de despiste del $10 \%$ de los individuos oscila entre el $30 \div 40 \%$ de las que se realizarían en el caso de trabajar con probabilidad de despiste del $40 \%$.

El ahorro de tiempo que se produce con este tipo de configuración es considerable, pero si el proceso de optimización no alcanza los objetivos deseados en cuanto a la calidad de la solución obtenida esta disminución del tiempo de cálculo no sirve de mucho. En este sentido, el análisis de eficiencia que se lleva a cabo en el capítulo 6 de esta tesis relaciona los conceptos de calidad de la solución de diseño y velocidad con la que trabaja el algoritmo.

Para las constantes $C_{1}$ y $C_{2}$ el apartado 5.2 de esta tesis muestra como la influencia que ejercen ambas constantes en la obtención de mínimos/buenas soluciones de diseño es mucho menor que la ejercida por $\mathrm{V}_{\text {lim }} \mathrm{Y} \mathrm{P}_{\text {desp }}$. El análisis realizado a continuación trata de establecer si el valor de dichas constantes influye o no en la velocidad con la que el algoritmo determina la solución final de diseño en cada caso. Así, la siguiente figura muestra el número de evaluaciones de la función objetivo en función de $C_{1}$ y $C_{2}$ para las redes de Hanoi, Nueva York, R-9 y Go-Yang. 
5. Análisis estadístico de soluciones

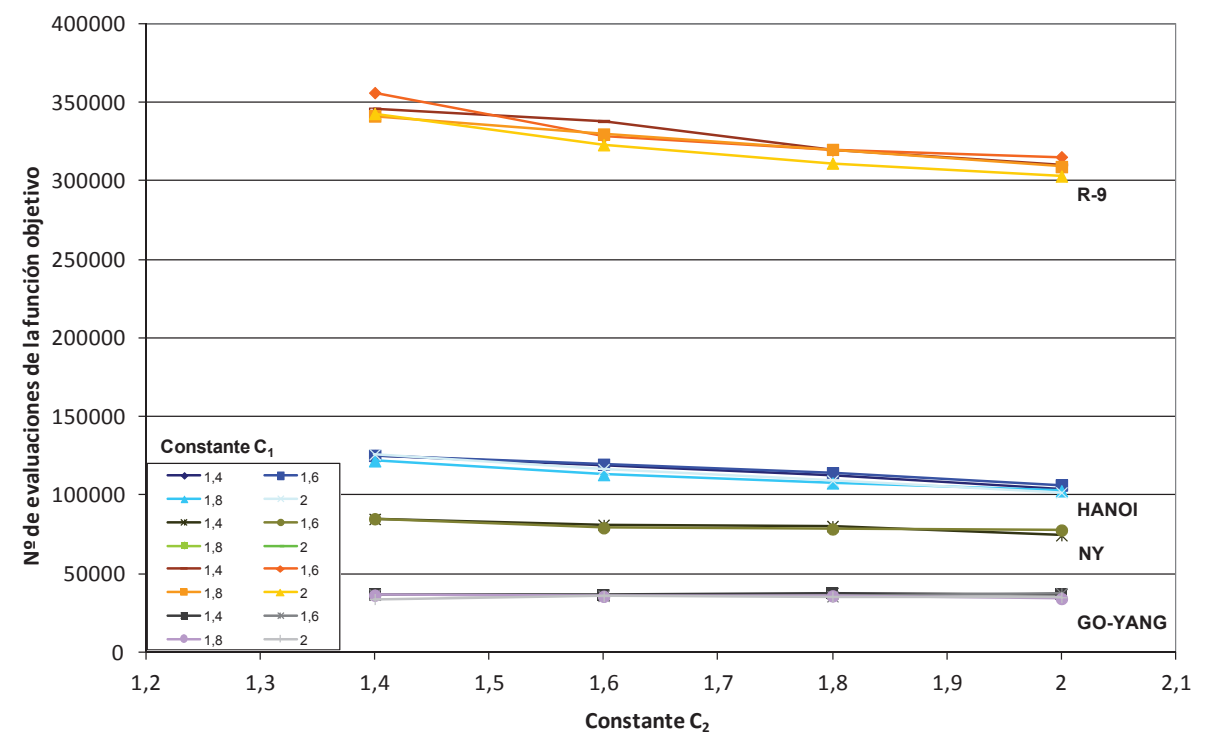

Figura 5.121. Número de evaluaciones de la función objetivo en función $C_{1}$ y $C_{2}$.

En la figura, la escala de color anaranjado corresponde a la red R-9 de Joao Pessoa, la escala de azules representan la red de Hanoi, la de tonos verdosos corresponde a la red de los túneles de Nueva York y la escala de grises representa el comportamiento en la red de GoYang. De la figura se extraen una serie de conclusiones acerca tanto de la velocidad con la que trabaja el algoritmo para cada red como de la posible influencia que ejercen ambas constantes en el cálculo.

En primer lugar, la figura permite distinguir con claridad como el algoritmo PSO realiza mayor número de evaluaciones cuando el tamaño y complejidad de la red de distribución es mayor. Esta circunstancia es perfectamente lógica, puesto que al trabajar sobre un mayor número de posibles escenarios también es más costoso encontrar al mejor de todos ellos.

La red de Joao Pessoa está muy por encima del resto en cuanto a número total de evaluaciones realizadas, lo que implica una mayor lentitud en el cálculo respecto a las restantes redes. A la inversa, la red de Go-Yang, que resulta ser la de mayor simplicidad, es la que menos evaluaciones de la función objetivo precisa hasta obtener el resultado deseado. Así, el número de evaluaciones medias para el diseño de la red de Joao Pessoa está en torno a $300 \div 350$ mil evaluaciones, mientras que en el caso de la red de Go-Yang el problema queda resuelto en alrededor de 35.000 evaluaciones.

Respecto a la constante $C_{1}$, la figura no permite distinguir con claridad si existe una influencia real de dicha constante en la velocidad del algoritmo, puesto que en la mayoría de combinaciones de $C_{1}$ da la sensación de que se superponen unos valores con otros. Esta 
superposición de valores es mayor cuanto menos compleja es la red. Así, en el caso de la red de Go-Yang prácticamente es imposible distinguir entre las distintas isolíneas $C_{1}$, mientras que en la red de Joao Pessoa las isolíneas $C_{1}$ están separadas entre si, de modo que es posible la distinción entre ellas.

Para mayor detalle, la tabla 5.22 muestra la diferencia porcentual en el número de iteraciones realizadas entre valores de $C_{1}$. En la tabla, el primer valor representa, para cada valor de $C_{2}$, la diferencia porcentual en el número de evaluaciones entre el valor de $C_{1}$ que mayor número de evaluaciones medias realiza y el que menos, mientras que el segundo valor representa la diferencia porcentual entre el número de evaluaciones realizadas por el menor valor de $C_{1}$, que corresponde a 1,4 y el mayor, que corresponde a 2.

\begin{tabular}{|c|c|c|c|c|}
\hline$C_{2}$ & $\begin{array}{c}\text { Hanoi } \\
\text { Dif \% ( } C_{1} \text { Max-Min) } \\
/ / \\
\text { Dif \% }\left(C_{1}=1,4-C_{1}=2\right)\end{array}$ & $\begin{array}{c}N Y \\
\text { Dif \% (C } C_{1} \text { Max-Min) } \\
/ \\
\text { Dif \% }\left(C_{1}=1,4-C_{1}=2\right)\end{array}$ & $\begin{array}{c}\text { R-9 } \\
\text { Dif \% (C } C_{1} \text { Max-Min) } \\
/ \\
\text { Dif \% }\left(C_{1}=1,4-C_{1}=2\right)\end{array}$ & $\begin{array}{c}\text { Go-Yang } \\
\text { Dif \% (C } C_{1} \text { Max-Min) } \\
/ \\
\text { Dif \% }\left(C_{1}=1,4-C_{1}=2\right)\end{array}$ \\
\hline 1,4 & $3,28 /-0,68$ & $2,26 / 1$ & $4,19 / 0,88$ & $7,71 / 7,70$ \\
\hline 1,6 & $5,57 / 1,88$ & $4,80 /-2,63$ & $4,47 / 4,47$ & $2,86 / 2,55$ \\
\hline 1,8 & $5,72 / 2,89$ & $4,21 /-2,05$ & $2,70 / 2,54$ & $5,80 / 5,80$ \\
\hline 2 & $4,47 / 2,05$ & $8,16 /-8,88$ & $3,88 / 2,40$ & $8,89 / 5,23$ \\
\hline Media (Abs) & $4,76 / 1,87$ & $4,86 / 3,64$ & $3,81 / 2,66$ & $6,32 / 5,66$ \\
\hline
\end{tabular}

Tabla 5.22. Diferencia \% acerca del número de evaluaciones según valores $C_{1}$ para cada valor $C_{2}$.

El objetivo de este tipo de representación es evaluar si existe algún tipo de relación entre el valor de $C_{1}$ y el número de evaluaciones realizadas. Así, si los índices Dif \% ( $C_{1}$ Max-Min) y Dif $\%\left(C_{1}=\mathbf{1}, 4-C_{1}=2\right)$ fueran coincidentes en la mayoría de situaciones implicaría una dependencia entre el número de evaluaciones realizadas y el valor de $C_{1}$. Esta situación no se produce más que en un par de los casos analizados, que puede atribuirse simplemente a una cuestión estadística, por lo que no se puede establecer ningún tipo de relación entre el número de evaluaciones de la función objetivo y el valor de la constante $C_{1}$.

En cualquier caso, la diferencia máxima que se produce entre el mejor y el peor valor de $\mathrm{C}_{1}$ rara vez supera el $5 \%$, tal como atestigua el valor medio de desviación mostrado en cada una de las redes. Con estos datos la conclusión más lógica es no tener en cuenta criterios de velocidad para la elección del mejor valor de $\mathrm{C}_{1}$.

En el caso de $\mathrm{C}_{2}$, la figura 5.121 permite apreciar como la tendencia general del algoritmo PSO es realizar un menor número de evaluaciones de la función objetivo cuando el valor numérico de $C_{2}$ es mayor. La tabla 5.25 da valores numéricos a la impresión general que tomamos de la figura, de modo que: 
5. Análisis estadístico de soluciones

\begin{tabular}{|c|c|c|c|c|}
\hline $\mathrm{C}_{1}$ & $\begin{array}{c}\text { Hanoi } \\
\text { Dif \% (C2 Max-Min) } \\
/ \\
\text { Dif \% }\left(C_{2}=1,4-C_{2}=2\right)\end{array}$ & $\begin{array}{c}\mathrm{NY} \\
\text { Dif \% (C2 Max-Min) } \\
/ \\
\text { Dif \% }\left(C_{2}=1,4-C_{2}=2\right)\end{array}$ & $\begin{array}{c}\text { R-9 } \\
\text { Dif \% (C2 Max-Min) } \\
/ \\
\text { Dif \% }\left(C_{2}=1,4-C_{2}=2\right)\end{array}$ & $\begin{array}{c}\text { Go-Yang } \\
\text { Dif \% ( } C_{2} \text { Max-Min) } \\
/ \\
\text { Dif \% }\left(C_{2}=1,4-C_{2}=2\right)\end{array}$ \\
\hline 1,4 & $17,04 / 17,04$ & $12,08 / 12,08$ & $10,23 / 10,23$ & $2,68 /-0,72$ \\
\hline 1,6 & $15,05 / 15,05$ & $8,40 / 8,40$ & $11,48 / 11,48$ & $5,00 /-2,21$ \\
\hline 1,8 & $15,70 / 15,70$ & $7,09 / 7,09$ & $9,43 / 9,43$ & $5,90 / 5,90$ \\
\hline 2 & $19,30 / 19,30$ & $3,30 / 3,30$ & $11,61 / 11,61$ & $5,14 /-3,42$ \\
\hline Media (Abs) & $16,77 / 16,77$ & $7,72 / 7,72$ & $10,69 / 10,69$ & $4,68 / 3,06$ \\
\hline
\end{tabular}

Tabla 5.25. Diferencia \% acerca del número de evaluaciones según valores $C_{2}$ para cada valor $C_{1}$

El análisis de $C_{2}$ muestra unos resultados muy diferentes a los obtenidos en el análisis de $C_{1}$. Para $\mathrm{C}_{2}$, en las redes de Hanoi, NY y R-9 el $100 \%$ de las configuraciones testeadas muestran el valor más alto de $\mathrm{C}_{2}$ como el que menos evaluaciones de la función objetivo realiza hasta encontrar la solución final de diseño.

Del mismo modo, en términos generales las diferencias registradas en el número de evaluaciones en cuanto a utilizar un valor de $C_{2} u$ otro son mayores que las que se registraban en el análisis de $C_{1}$. Las redes que tienen mayor complejidad, es decir, un mayor número de escenarios posibles, son las que registran un mayor ahorro iterativo. Así, en el caso de la red de Hanoi, el utilizar un valor de $C_{2}=2$ supone un ahorro de entre un 15 y un $20 \%$ de evaluaciones de la función respecto a utilizar $C_{2}=1,4$, mientras que en la red R-9 de Joao Pessoa el ahorro es de algo más de un $10 \%$ como término medio.

El caso de la red de Go-Yang supone la excepción a la regla general en el análisis de $C_{2}$. Así, en esta red, los valores $C_{2}=1,4$ y $C_{2}=2$ no corresponden necesariamente con la configuración que más/menos iteraciones realiza, teniendo la red un comportamiento anárquico en este sentido. Del mismo modo, la media de ahorro computacional entre las distintas configuraciones de $C_{2}$ es el más bajo de todas las redes, alcanzando apenas un 4,68\%. Este resultado, alejado de la tendencia general que muestra el algoritmo en las otras redes de diseño se atribuye a la mayor sencillez de diseño de la red de Go-Yang, que proporciona buenos resultados con prácticamente cualquier configuración.

De acuerdo a los resultados obtenidos, la conclusión general es que tres de los cuatro parámetros de cálculo cuya configuración realiza el usuario afectan al número de evaluaciones de la función objetivo que realiza el algoritmo PSO. Así, en el rango utilizado en este estudio, los valores en torno a 2 para $C_{2}$ favorecen el ahorro en el número de evaluaciones que realizará el algoritmo respecto a los valores inferiores, mientras que conforme aumenta el límite de velocidad de vuelo o la probabilidad de despiste de un determinado pájaro también lo hace el número de evaluaciones de la función objetivo. 


\subsubsection{Influencia de los parámetros en la velocidad de cálculo del algoritmo HS}

El estudio de velocidad realizado para la técnica heurística de diseño basada en Harmony Search sigue los mismos criterios que los aplicados anteriormente en APG y PSO, teniendo en cuenta que tanto el modo de funcionamiento como los parámetros de cálculo son distintos.

La principal diferencia a la hora de comparar la velocidad a la que calcula HS con el resto de técnicas es el distinto tratamiento que realiza esta técnica a la población del algoritmo. Así, la población del algoritmo es conocida en HS como "tamaño de la memoria inicial". Este parámetro tiene su equivalente en el resto de métodos, ya sea población inicial del algoritmo en $A P G$, número de ranas en SFLA, etc.

Así, HS parte de un tamaño de memoria inicial que consta de un número determinado de vectores, cada uno de los cuales representa una posible solución del problema de diseño. Cada generación de HS crea un nuevo vector solución, que es evaluado y que pasa a formar parte de la memoria inicial si es mejor que el peor de los vectores solución que ya componían la memoria del algoritmo. Como en cada generación del algoritmo se crea un único vector, se realiza una única evaluación de la función objetivo, por lo que sólo se realiza una evaluación de la función objetivo.

Tal como se ha visto a lo largo de la tesis, el resto de algoritmos heurísticos trabajan de modo distinto, puesto que cada generación realiza tantas consultas de la función objetivo como vectores solución cambian su valor. Por ejemplo, en el caso de APG, se evalúa la función objetivo de todos los vectores solución que cruzan o mutan en cada generación; en el caso de PSO se evalúa la función objetivo de cada uno de los pájaros que cambia su posición en cada generación (todos), etc. Esta situación provoca que el proceso de cálculo en HS suela ser más rápido, si bien los resultados en cuanto a obtención de mínimos son peores, como ya se vio en los apartados dedicados al ajuste óptimo de parámetros.

La figura 5.122 representa el número de evaluaciones de la función objetivo que realiza HS en función de los dos principales parámetros de cálculo que quedan a elección del usuario, HMCR y PAR. La figura representa el comportamiento en el proceso de diseño óptimo de la red de Hanoi. 


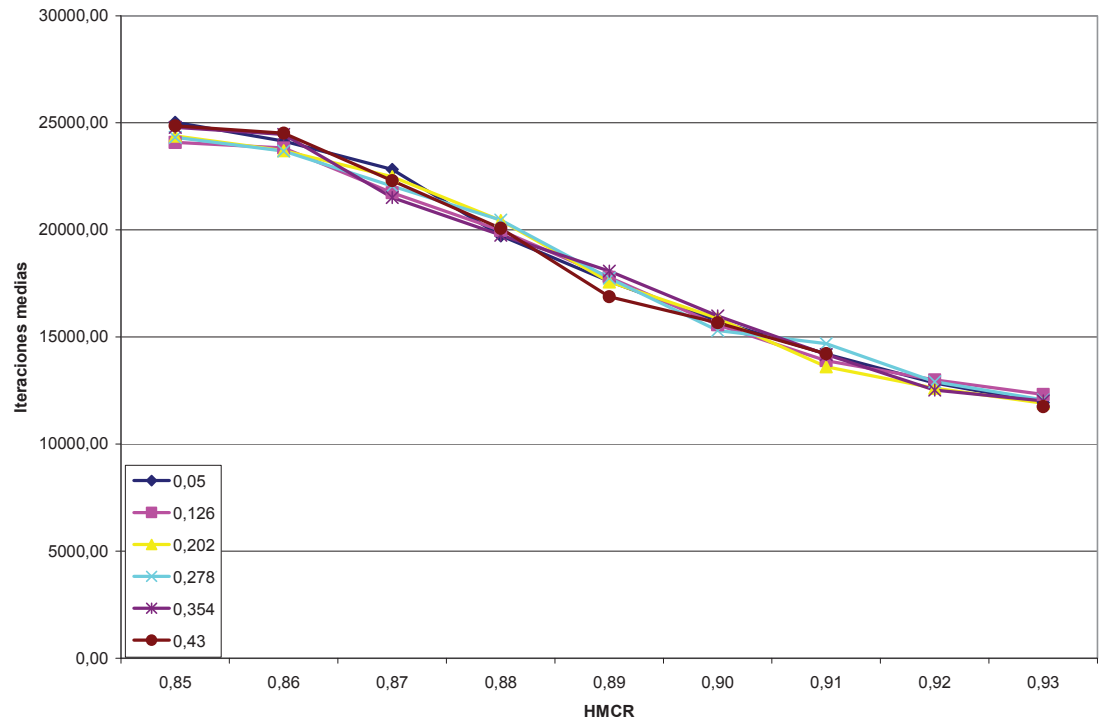

Figura 5.122. Número de evaluaciones en función de HMCR y Pitchrate para la red de Hanoi

A primera vista, el primer dato que llama la atención del gráfico es el menor número de evaluaciones de la función objetivo que en términos generales realiza HS en comparación con el resto de métodos heurísticos analizados. Así, mientras APG, PSO o SFLA no realizan menos de 50.000 evaluaciones de la función objetivo en cada proceso de optimización de la red de Hanoi, el algoritmo HS realiza un máximo de 25.000 evaluaciones en la configuración más lenta de todas las testeadas. La principal explicación, tal como se esboza en líneas superiores, es el distinto tratamiento de la población inicial del algoritmo, puesto que HS realiza un único cálculo de la función objetivo en cada iteración.

La figura 5.122 permite apreciar como el número de simulaciones que realiza HS disminuye de modo casi lineal conforme aumenta el valor de la probabilidad HMCR, de modo que el algoritmo trabaja más rápido cuanto mayor es el valor de éste parámetro. Respecto al ajuste del PAR, la figura no muestra ningún tipo de influencia de este parámetro en el número de evaluaciones realizadas por el algoritmo, puesto que las isolíneas de las distintas probabilidades PAR testeadas quedan prácticamente superpuestas.

En el estudio de parámetros realizado en 5.2.3 para HS se llega a la conclusión de que el ajuste del PAR no influía en la calidad de la solución final, sino que únicamente se debía tener en cuenta que tuviera un valor lo suficientemente bajo como para permitir la convergencia hacia una solución factible. Del análisis de velocidad realizado para la red de Hanoi, es posible concluir que el PAR tampoco tiene influencia en la velocidad del algoritmo. 
Para confirmar la hipótesis que plantea el parámetro de ajuste como únicamente de convergencia, la figura 5.123 muestra la influencia del tamaño de población inicial y del ajuste del PAR en el número de evaluaciones medias obtenidas para el diseño de la red de Hanoi.

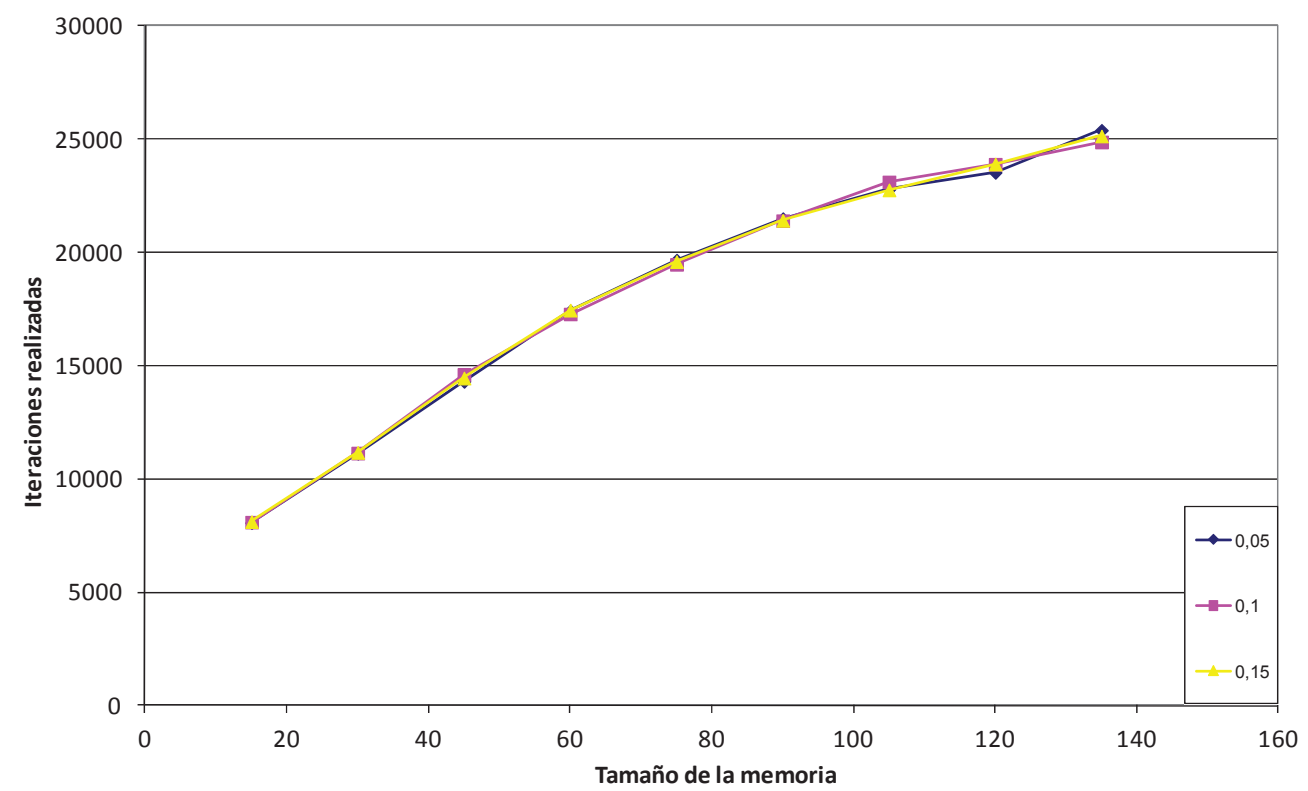

Figura 5.123. Número de evaluaciones en función de tamaño de población y probabilidad de pitchrate para la red de Hanoi

Las tres curvas están prácticamente superpuestas. Esta situación implica que la probabilidad de que se dé un ajuste del PAR no influye en el número de evaluaciones que realiza el algoritmo. Si se realiza la misma representación en función del tamaño inicial de memoria y el parámetro HMCR: 


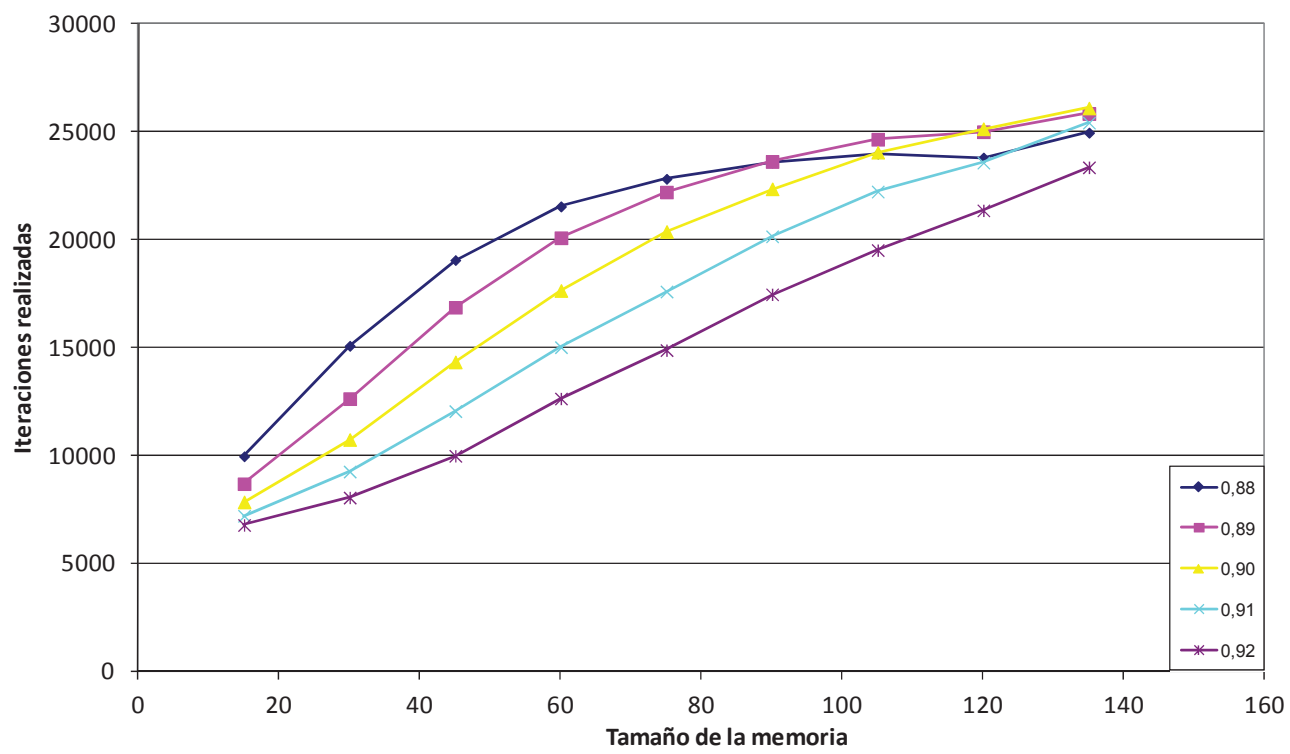

Figura 5.124. Número de evaluaciones en función de tamaño de población y probabilidad HMCR para la red de Hanoi.

De modo similar a la figura 5.123, la figura 5.124 muestra como el número de evaluaciones de la función objetivo es menor conforme la probabilidad HMCR es mayor. Del mismo modo, el número de evaluaciones aumenta con el incremento del tamaño inicial de la memoria, circunstancia lógica que se da en todos los métodos heurísticos estudiados.

Las distintas representaciones confirman la hipótesis que plantea la probabilidad de pitchrate como un parámetro únicamente de convergencia. Así, cualquier valor de ajuste que tome este parámetro capaz de converger hacia soluciones factibles se puede considerar como óptimo. En todas las redes testeadas el algoritmo HS tiene una convergencia del $100 \%$ con valores pequeños de PAR, por lo que en adelante se realizan todas las simulaciones con un ajuste para el PAR en torno a $0,05 \div 0,15$.

Las conclusiones que tomamos de la red de Hanoi son fácilmente verificables en el resto de redes de diseño. Así, las siguientes figuras muestran la representación de datos en las redes de los túneles de Nueva York, Joao Pessoa y Go-Yang. Esto permite generalizar las conclusiones obtenidas. 


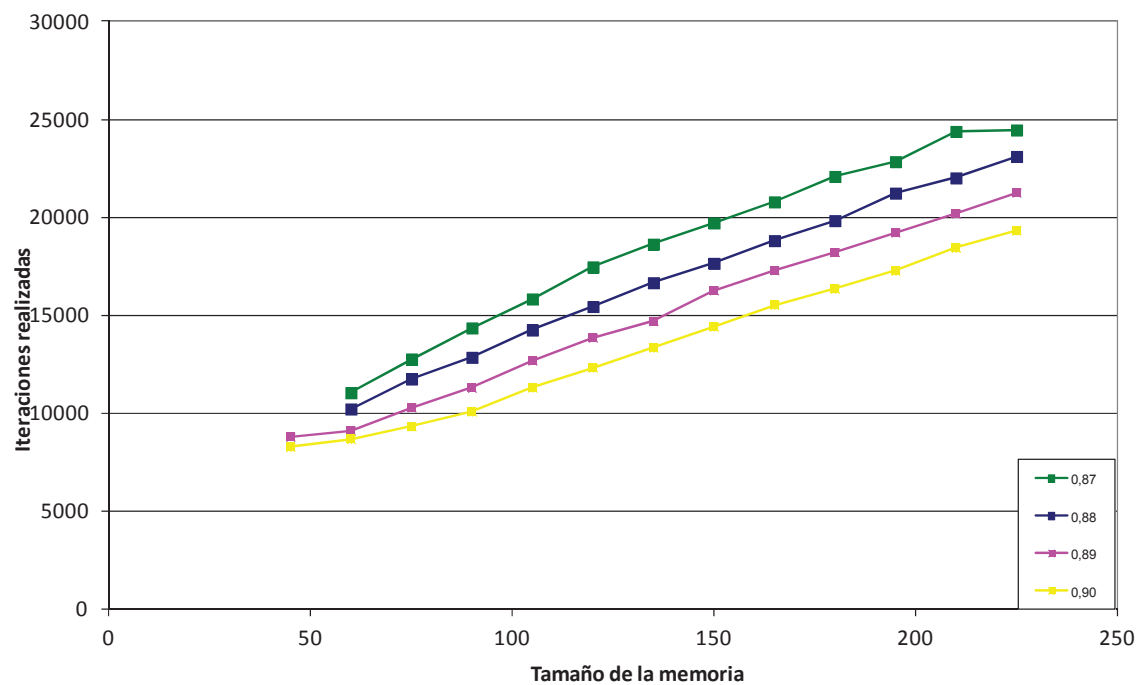

Figura 5.125. Número de evaluaciones medias en función del tamaño de memoria y HMCR en el diseño de la red de Nueva York

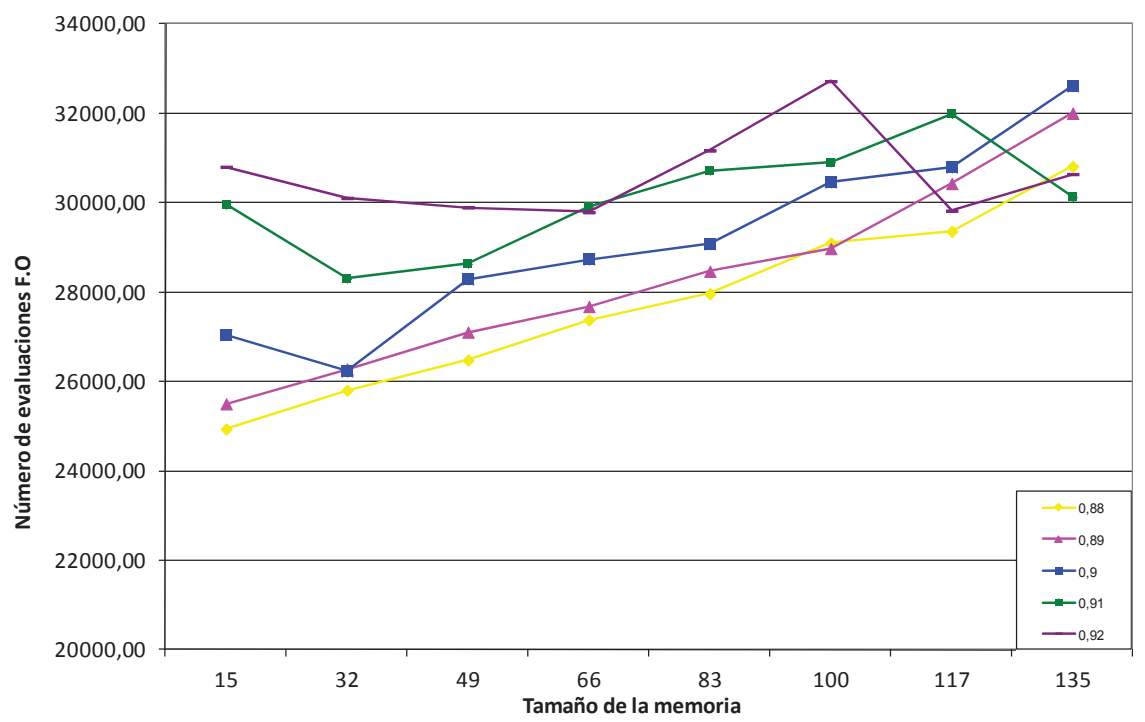

Figura 5.126. Número de evaluaciones medias en función del tamaño de memoria y HMCR en el diseño de la red $R-9$ de Joao Pessoa 


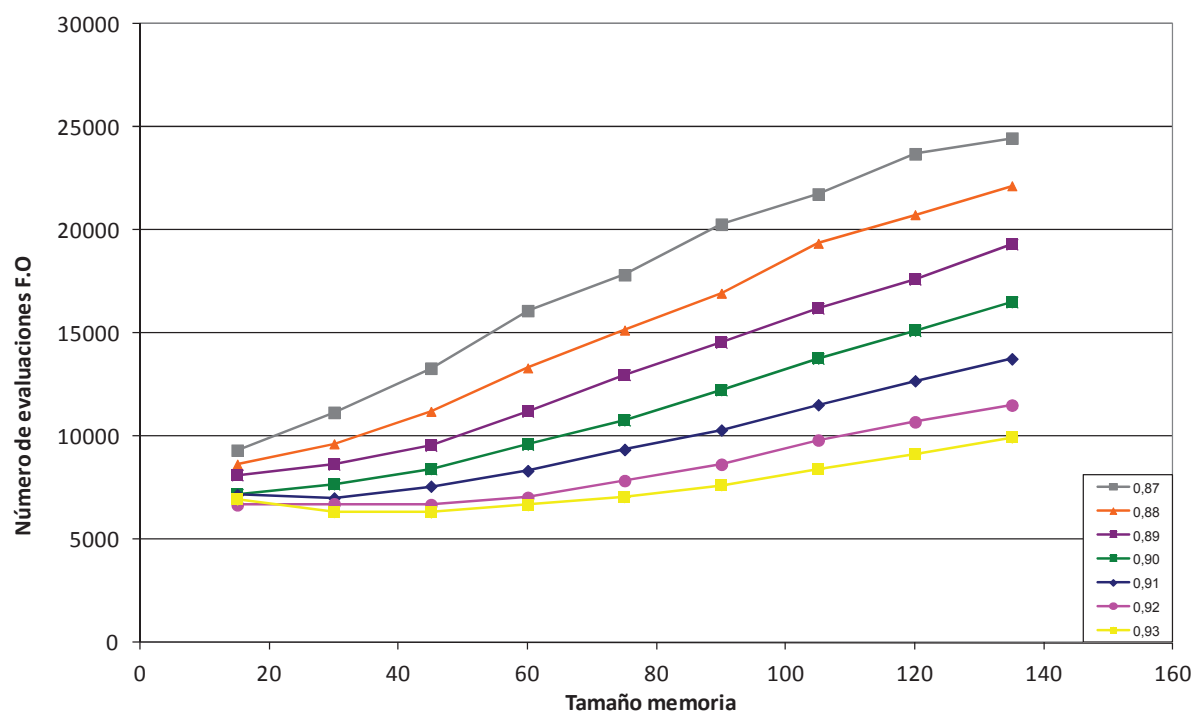

Figura 5.127. Número de evaluaciones medias en función del tamaño de memoria y HMCR en el diseño de la red de Go-Yang

El comportamiento del parámetro de ajuste HMCR y del tamaño de memoria es similar en todas las redes, mostrando alguna irregularidad tan sólo en la red R-9 de Joao Pessoa, si bien la hipótesis que plantea la disminución del número de evaluaciones conforme disminuye la probabilidad HMCR y el tamaño de memoria sí que se cumple.

Del mismo modo, para todas las redes crece el número de evaluaciones de la función objetivo cuando el tamaño inicial de la memoria es más grande. Este comportamiento es lógico, puesto que al ser la memoria inicial mayor, la probabilidad de que en cada generación se cree una nueva partitura que supere a alguna de las ya existentes también es superior, al haber un mayor número de soluciones iniciales aleatorias susceptibles de ser mejoradas. Este hecho alarga el cálculo del algoritmo, lo que puede mejorar las mejores soluciones del algoritmo. El estudio de eficiencia permitirá cuantificar si se produce alguna mejora ostensible y si compensa o no prolongar el tiempo de cálculo.

En el mismo sentido, es posible analizar otras vías que permiten prolongar el número de iteraciones que realiza el algoritmo. Así, es posible modificar la condición de convergencia del algoritmo, de modo que el número de iteraciones sin cambio que realice el algoritmo antes de dar por finalizado el cálculo sea más grande o más pequeño.

Así, de modo similar a cómo se procedía en el resto de metodologías, las siguientes tablas cuantifican de modo numérico cuál es el ahorro porcentual que se produce entre distintas 
configuraciones de los parámetros de ajuste. En este caso, la tabla 5.24 muestra el ahorro porcentual según el parámetro de ajuste HMCR para cada red.

\begin{tabular}{|c|c|c|c|c|}
\hline $\begin{array}{c}\text { Tamaño } \\
\text { memoria }\end{array}$ & $\begin{array}{c}\text { Hanoi } \\
\text { Dif \% (HMCR Max- } \\
\text { Min) / } \\
\text { Dif \% (HMCR) }\end{array}$ & $\begin{array}{c}\text { NY } \\
\text { Dif (HMCR Max- } \\
\text { Min) / } \\
\text { Dif \% (HMCR) }\end{array}$ & $\begin{array}{c}\text { Go-Yang } \\
\text { Dif \% (HMCR Max- } \\
\text { Min) / } \\
\text { Dif \% (HMCR) }\end{array}$ & $\begin{array}{c}\text { Go-Yang } \\
\text { Dif \% (HMCR Max- } \\
\text { Min) / } \\
\text { Dif \% (HMCR) }\end{array}$ \\
\hline $\mathbf{4 5}$ & $47,61 / 47,61$ & $5,85 / 5,85$ & $52,46 / 52,46$ & $11,43 /-12,43$ \\
\hline $\mathbf{7 5}$ & $34,79 / 34,79$ & $26,83 / 26,83$ & $60,37 / 60,37$ & $10,29 /-11,46$ \\
\hline $\mathbf{1 0 5}$ & $20,83 / 18,64$ & $28,41 / 28,41$ & $61,20 / 61,20$ & $11,45 /-12,45$ \\
\hline $\mathbf{1 3 5}$ & $10,52 / 6,22$ & $28,19 / 28,19$ & $59,26 / 59,26$ & $7,62 / 0,56$ \\
\hline $\mathbf{1 6 5}$ & - & $25,13 / 25,13$ & - & - \\
\hline
\end{tabular}

Tabla 5.24. Diferencia \% acerca del número de evaluaciones según probabilidad HMCR.

La tabla muestra numéricamente el ahorro iterativo para cada tamaño de población según la probabilidad HMCR considerada. Así, el primer número de cada casilla muestra porcentualmente cuál es la diferencia en número de evaluaciones entre el mejor y el peor valor de HMCR para una determinada población. Del mismo modo, el segundo valor muestra esta misma diferencia porcentual en el caso de ser calculada entre el valor más alto HMCR y el menor. Obviamente, si ambos valores coinciden en la mayoría de configuraciones es posible deducir una dependencia entre el número de evaluaciones de la función objetivo y el valor de la probabilidad HMCR.

Analizando los datos que proporciona la tabla se observa como los resultados obtenidos para las redes de Hanoi, Nueva York y Go-Yang son similares. Todas estas redes basan su comportamiento en un mayor ahorro iterativo conforme mayor es el valor del parámetro HMCR para todos los tamaños de memoria considerados. No obstante, numéricamente existen pequeñas diferencias entre ellas.

Así, en la red de Hanoi, el mayor ahorro iterativo se produce para las menores poblaciones, de modo que conforme aumenta el tamaño de la memoria el ahorro producido en el número de iteraciones disminuye progresivamente. Por el contrario, en las redes de Nueva York y GoYang, el ahorro iterativo es mucho más constante en todas las poblaciones.

En el caso de la red de Nueva York, la disminución del número de evaluaciones es más o menos constante a partir de un tamaño de memoria de 75 individuos, de modo que la diferencia entre trabajar con una menor o mayor probabilidad HMCR está cuantificada en alrededor de un $25 \div 30 \%$ más de iteraciones. Para la red de Go-Yang el comportamiento es casi idéntico, con la diferencia de que el ahorro iterativo es mayor, puesto que entre trabajar con el valor máximo HMCR considerado en este caso 0,93 y el mínimo 0,87 existe una diferencia de un $60 \%$ en el número de evaluaciones realizadas de la función objetivo. En una red tan compleja como la R-9 esta diferencia se antoja muy considerable desde un punto de visto computacional. 
Por último, el patrón de comportamiento que sigue la red R-9 de Joao Pessoa respecto al número de evaluaciones de la F.O realizadas supone la excepción con el resto de redes de diseño. En este caso, los valores más grandes de HMCR no se relacionan con un ahorro iterativo, sino que más bien la tendencia general es la de realizar un mayor número de evaluaciones conforme aumenta el valor HMCR. Esto quiere decir que la tendencia se invierte respecto del resto de redes, si bien las diferencias numéricas entre unas configuraciones y otras son las más pequeñas porcentualmente. Así, entre la peor y la mejor configuración de HMCR apenas hay un $10 \%$ de diferencia en término medio, lo que supone el menor ahorro iterativo producido de entre todas las redes.

De los datos de la tabla, parece claro concluir que el ahorro iterativo es mayor cuanto menor es la complejidad de la red, entendiendo por complejidad el número de posibles soluciones de diseño que puede tener una determinada red. Así, el mayor ahorro iterativo en función de la configuración del parámetro HMCR se produce en la red de Go-Yang, que es la más simple de todas las estudiadas, mientras que la red que se ve menos afectada porcentualmente en el número de evaluaciones es la red R-9 de Joao Pessoa, que resulta ser la red de diseño más compleja de todas las testeadas. No obstante, el número de evaluaciones necesarias para resolver completamente la red de Go-Yang está entre 6000 y 9000 , mientras que el número de evaluaciones que se requieren para resolver la red R-9 está entre 24000 y 30000, por lo que en términos absolutos ese $10 \%$ de diferencia no es despreciable.

\subsubsection{Influencia de los parámetros en la velocidad de cálculo del algoritmo SFL}

El algoritmo de optimización SFL tiene 5 parámetros susceptibles de ajuste, dos de los cuales tienen relación directa con lo que conocemos como población del algoritmo. Estos dos parámetros son el número de memeplexes $(\mathrm{m})$ y el número de ranas por memeplex $(\mathrm{n})$ y su influencia en la velocidad del algoritmo no se aborda aquí, puesto que el comportamiento general de todas las metodologías heurísticas nos indica que cuanto mayor es el tamaño inicial de la población mayor es también el número de evaluaciones que realiza un algoritmo heurístico.

El análisis de velocidad para este algoritmo se centra en la influencia que ejercen los parámetros relacionados con la naturaleza de los saltos evolutivos, que son el número de saltos evolutivos (N), el tamaño de submemeplex (Q) y el coeficiente acelerador (C). Las siguientes figuras muestran la relación que hay entre el número de evaluaciones realizadas para la función objetivo y el valor que toman estos parámetros en las simulaciones realizadas.

Inicialmente se muestra el número de evaluaciones realizadas por el algoritmo SFL para cada una de las redes de distribución en función del tamaño de submememeplex (q) y el coeficiente acelerador (C). 
RED DEHANOI

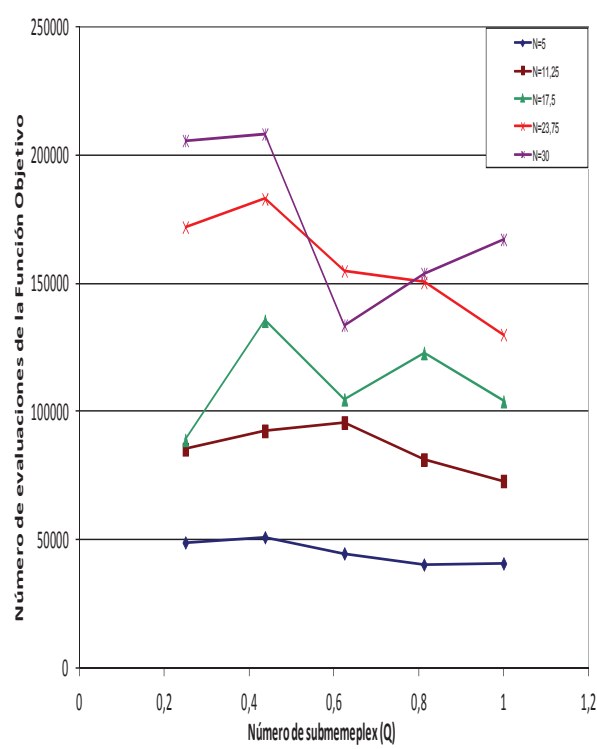

REDR-GDEIOAOPESSOA

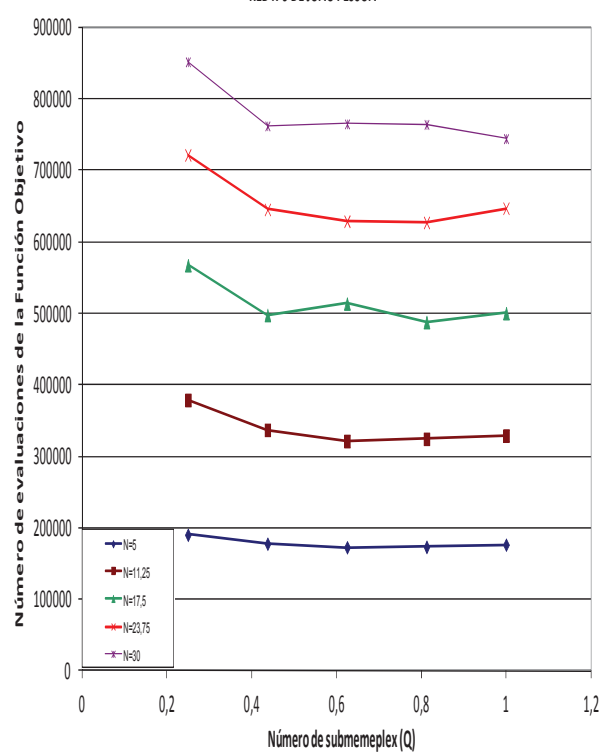

REDDENUEA YORK

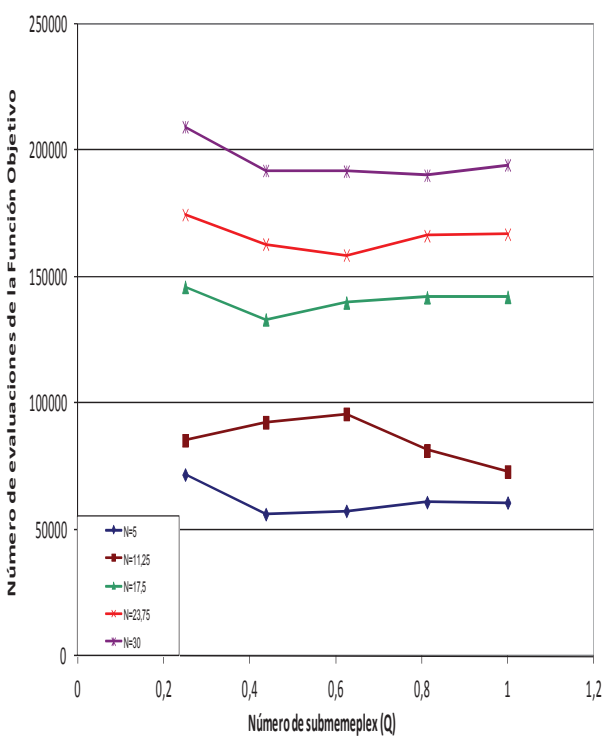

REDDEGO-YANG

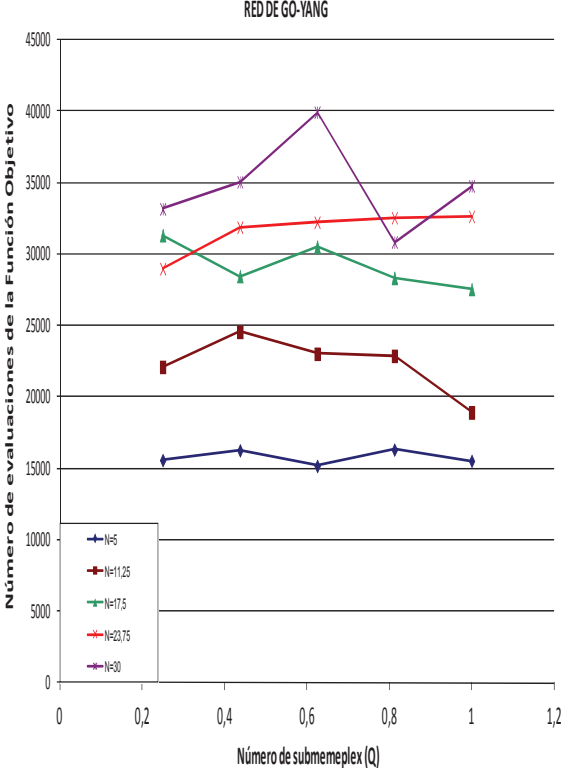

Figura 5.128. Representaciones del número de evaluaciones medias en función del tamaño de submemeplex (Q) y el coeficiente acelerador (C) para las distintas redes.

A tenor de los resultados obtenidos parece clara la existencia de una relación entre el número de evaluaciones de la función objetivo y el valor del coeficiente de aceleración. Así, los 
resultados obtenidos en todas las redes muestran como el algoritmo realiza un mayor número de evaluaciones conforme aumenta el número de saltos evolutivos $\mathrm{N}$.

Para el tamaño de submemeplex (Q) los análisis realizados no muestran ninguna relación directa entre el número de evaluaciones realizadas por el algoritmo y este parámetro. De esta manera, para las redes de Nueva York y Joao Pessoa apenas varía el número de evaluaciones para un determinado valor fijo de $\mathrm{N}$ cuando se varía tan sólo el valor de $\mathrm{Q}$. En las redes de Hanoi y Go-Yang sí que se producen ciertos saltos en las isolíneas de $\mathrm{N}$ al variar q, pero dichos saltos son aleatorios y no siguen ningún tipo de orden, por lo que no se puede establecer ninguna relación digna de destacar.

Prosiguiendo con el análisis, las siguientes figuras muestran ahora el número de evaluaciones realizadas por el algoritmo SFL para cada una de las redes de distribución en función del coeficiente acelerador (C) y el número de saltos evolutivos que se producen en cada memeplex $(\mathrm{N})$.
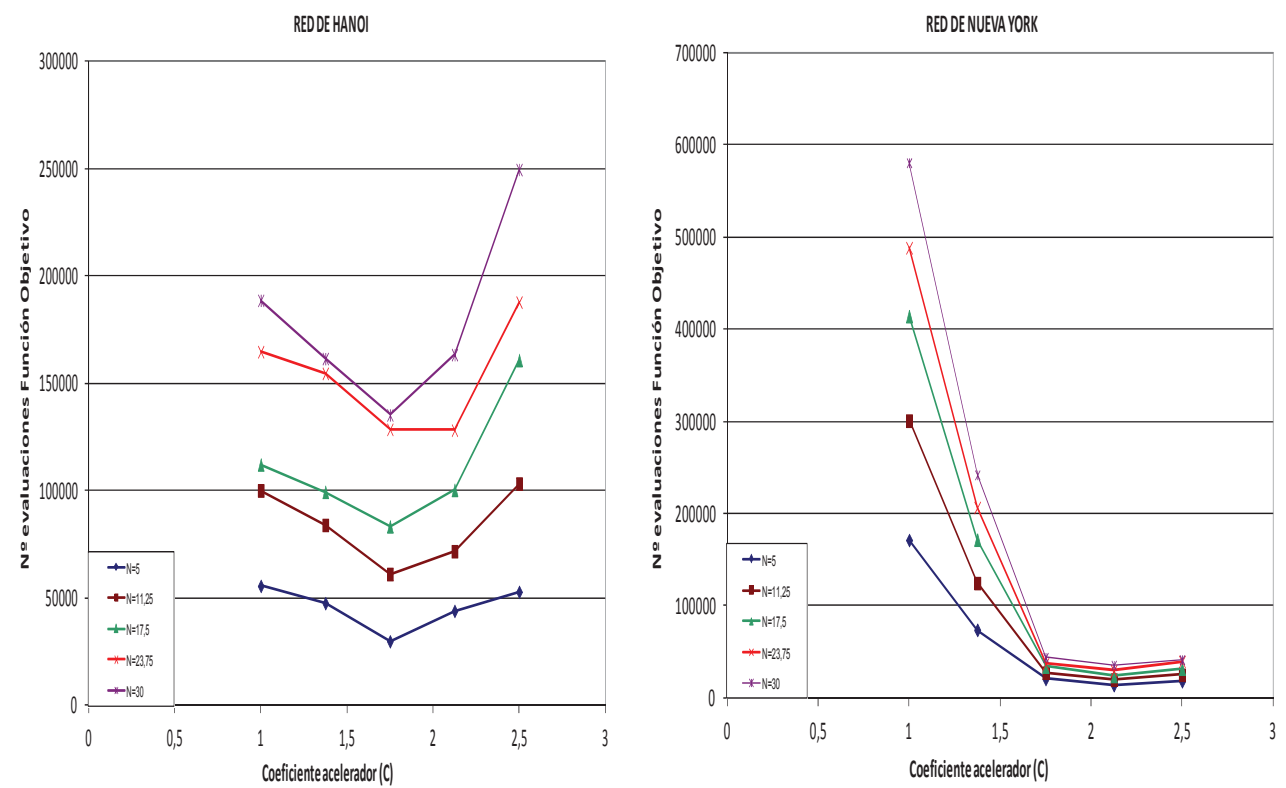
RED R-9DE JOAO PESSOA

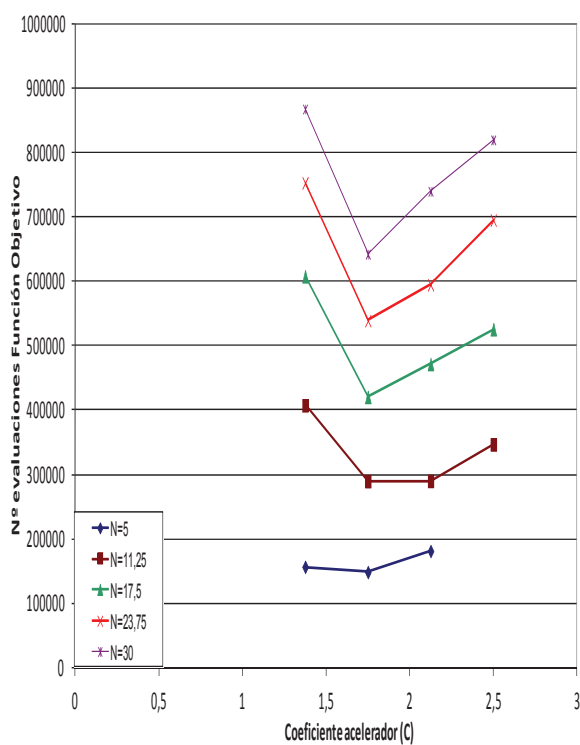

REDDEGO-YANG

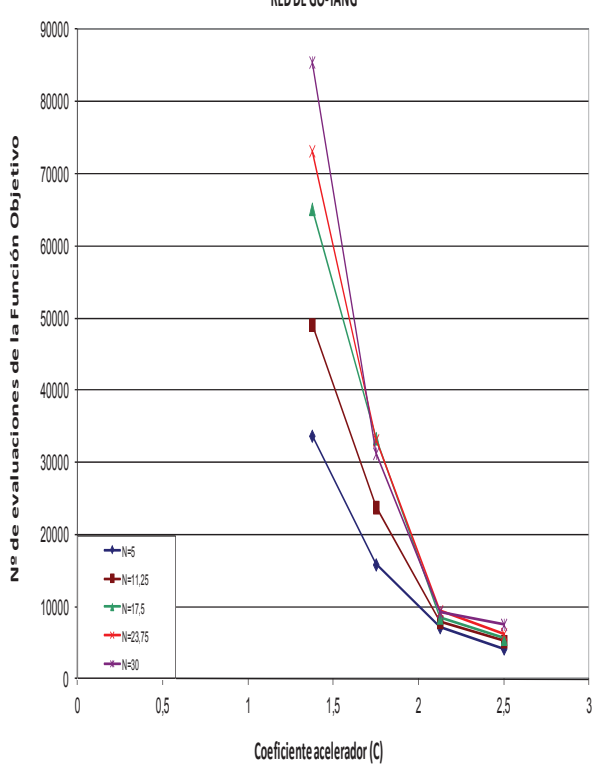

Figura 5.129. Representaciones del número de evaluaciones medias en función del coeficiente acelerador y del número de saltos evolutivos.

El primer dato que llama la atención en la representación realizada es el parecido que muestran entre si las figuras en parejas de dos. Así, el comportamiento que tiene el algoritmo en el diseño de las redes de Nueva York y Go-Yang es prácticamente idéntico y parecida circunstancia se da entre las redes de Hanoi y Joao Pessoa.

Para las redes de Go-Yang y Nueva York, el valor óptimo para el coeficiente acelerador desde un punto de vista que contemple tan sólo la velocidad de cálculo está a partir de dos. Esto quiere decir que el algoritmo requiere realizar un menor número de iteraciones cuando incrementamos la longitud del salto que realiza cada rana en una determinada iteración. A grosso modo, esta operación prioriza algo más la búsqueda global del algoritmo en detrimento de la búsqueda local. Así, la figura 5.129 permite apreciar como el número de evaluaciones que realiza la función objetivo disminuye en gran medida conforme aumenta el valor de C hasta llegar a los alrededores de 2, momento en el que esta disminución queda estabilizada y el aumento de $\mathrm{C}$ no garantiza una búsqueda más rápida de la solución por parte del algoritmo.

Por otro lado, el comportamiento del algoritmo para las redes de Hanoi y Joao Pessoa es ligeramente distinto. En primera instancia el comportamiento es similar, puesto que cuanto mayor es el valor del coeficiente acelerador menor es el número de evaluaciones que realiza el algoritmo hasta encontrar el valor óptimo de diseño. Sin embargo, una vez se llega a 
valores de $\mathrm{C}$ en los que ya no se produce una mejora, el número de evaluaciones no queda estabilizado, sino que vuelve a crecer.

La razón más lógica que explica esta diferencia de comportamiento estriba en la propia tipología de las redes analizadas. De este modo, ya se ha resaltado en varias ocasiones la diferente complejidad de diseño de las redes analizadas, entendiendo por complejidad el número de posibles soluciones que ofrece cada una de ellas en función del número de conductos de la propia red y de la gama de diámetros utilizada para resolverla. En este sentido, la red de Go-Yang es la más sencilla de resolver, mientras que la red de Joao Pessoa es la que reviste una mayor complejidad. Esta diferencia entre las distintas redes se aprecia en el número de iteraciones que utiliza cualquiera de los métodos para resolver unas redes y otras.

Así, para las redes menos complejas, el algoritmo SFL encuentra la solución con relativa facilidad, tal como muestra el apartado 5.2. Esta menor complejidad provoca que a partir de un determinado valor para el coeficiente acelerador el proceso de optimización se produzca a gran velocidad, de modo que en unas 10.000 evaluaciones de la función objetivo se termine la búsqueda con posiciones de óptimo o muy cercanas al óptimo, donde la posibilidad de mejora es o muy pequeña o imposible, por lo que el algoritmo termina su búsqueda.

Esta situación no se produce en las redes de Hanoi y Joao Pessoa. El mayor número de posibles soluciones que tienen ambas redes provocan que la búsqueda sea más compleja. Esta situación se aprecia tanto en el número de mínimas soluciones obtenidas, que es menor, como en el número de evaluaciones de la función que se realizan en cada simulación, que puede resultar hasta casi 10 veces mayor. Así, la figura 5.129, que muestra el número de evaluaciones para las redes de Hanoi y Joao Pessoa, tiene en principio un mismo comportamiento para el coeficiente acelerador hasta valores en torno a 1,75. Sin embargo, si se sigue aumentando el valor de C, el número de evaluaciones no se mantiene constante, sino que vuelve a crecer. Esta circunstancia puede ser provocada porque el aumentar el peso de la búsqueda global permite saltos más grandes hacia mejores zonas, puesto que en el caso de estas redes más complejas la posibilidad de mejora es mayor, al haber un mayor número de posibles soluciones.

Así, desde un punto de vista que analice solamente el gasto computacional queda claro que valores en torno a $1,75 \div 2$ son los que menos evaluaciones de la función objetivo realizan en términos generales. Para el caso particular de redes más complejas, como Hanoi o Joao Pessoa, dar valores más altos a $\mathrm{C}$ aumenta el gasto computacional. Si prolongar el gasto computacional compensa o no la mejora obtenida es otro tema totalmente distinto que queda tratado en el análisis de eficiencia del apartado 6 de este trabajo. 
Por otro lado, respecto al número de saltos evolutivos, no se obtiene con representaciones del número de evaluaciones una mayor información que la que ya se conocía, es decir, el coste computacional aumenta conforme lo hace también el número de saltos evolutivos programados, circunstancia que es perfectamente lógica, puesto que estamos aumentando el número de cálculos que se realizan en cada iteración. La siguiente tabla cuantifica el ahorro iterativo que se produce cuando utilizamos el menor valor considerado en el número de saltos evolutivos $(\mathrm{N}=5)$ y el mayor valor $(\mathrm{N}=30)$.

\begin{tabular}{|c|c|c|c|c|}
\hline $\begin{array}{c}\text { Coeficiente } \\
\text { acelerador } \\
\text { (C) }\end{array}$ & $\begin{array}{c}\text { Hanoi } \\
\text { Dif \% (N=5, } \mathbf{N = 3 0 )}\end{array}$ & $\begin{array}{c}\mathbf{N Y} \\
\text { Dif \% (N=5, } \mathbf{N = 3 0 )}\end{array}$ & $\begin{array}{c}\mathbf{R}-\mathbf{9} \\
\text { Dif \% (N=5, } \mathbf{N = 3 0 )}\end{array}$ & $\begin{array}{c}\text { Go-Yang } \\
\text { Dif \% (N=5, } \mathbf{N = 3 0 )}\end{array}$ \\
\hline $\mathbf{1}$ & 29,45 & 29,50 & - & - \\
\hline $\mathbf{1 , 3 7 5}$ & 29,45 & 30,49 & 25,04 & 39,43 \\
\hline $\mathbf{1 , 7 5}$ & 22,03 & 46,64 & 24,40 & 50,75 \\
\hline $\mathbf{2 , 1 2 5}$ & 26,89 & 39,42 & 20,07 & 77,05 \\
\hline $\mathbf{2 , 5}$ & 21,17 & 43,63 & 22,11 & 55,96 \\
\hline Media (Abs) & 32,25 & 47,42 & 22,91 & 55,8 \\
\hline
\end{tabular}

Tabla 5.27. Diferencia \% acerca del número de evaluaciones según número de saltos evolutivos

El ahorro iterativo que se produce para valores pequeños de $\mathrm{N}$ es bastante considerable, y dicho ahorro es mayor cuanto más compleja es la red. Así, en la red R-9 de Joao Pessoa, que posee un mayor número de posibles soluciones, el proceso de optimización se ve muy reducido cuando el número de saltos es 5 , realizando en todos los valores de $\mathrm{C}$ alrededor de un $20 \div 25 \%$ de las evaluaciones que realiza el algoritmo cuando $\mathrm{N}=30$, es decir, prácticamente 5 veces menos. Conforme disminuye la complejidad de la red, también lo hace el ahorro iterativo que se obtiene de utilizar un menor número de saltos evolutivos, de modo que para la red de Go-Yang, que representa la red de mayor simplicidad el ahorro iterativo se encuentra tan sólo cercano a la mitad.

\subsection{Resumen de resultados}

A lo largo de este capítulo se ha determinado el mejor ajuste de parámetros posible para cada una de las técnicas de diseño planteadas en base a distintos criterios. En este sentido, se ha tenido en cuenta no sólo la posibilidad de obtener la mejor solución económica de diseño, sino que también se ha analizado la cantidad de recursos computacionales necesarios para obtener dicha solución, en lo que se conoce como análisis de velocidad.

Cada una de las técnicas evolutivas analizadas tiene sus propios parámetros de ajuste, que determinan el comportamiento de la metodología de optimización durante el proceso. Este subapartado muestra en forma de tabla resumen los principales resultados obtenidos para cada uno de los casos simulados. 


\subsubsection{Análisis de parámetros}

Inicialmente se consideró en todos los modelos de optimización un tamaño de población constante de 100 individuos, realizando el ajuste del resto de parámetros en cada caso. El primer análisis realizado se considera en base a la probabilidad de obtener la solución mínima de diseño en cada caso. Las tablas 5.29, 5.30, 5.31 y 5.32 muestran la probabilidad de obtener mínimas/buenas soluciones en todos los métodos y todas las redes considerando el mejor ajuste posible en los parámetros más representativos de cada metodología.

\begin{tabular}{|c|c|c|c|c|}
\hline & $\begin{array}{c}\text { Prob. de } \\
\text { cruce (\%) }\end{array}$ & $\begin{array}{c}\text { Prob. de } \\
\text { mutación (\%) }\end{array}$ & $\begin{array}{c}\text { Mínimas } \\
\text { soluciones (\%) }\end{array}$ & $\begin{array}{c}\text { Buenas } \\
\text { soluciones (\%) }\end{array}$ \\
\hline Red de Hanoi & - & $3 \div 4$ & 8 & $60 \div 70$ \\
\hline $\begin{array}{c}\text { Red de Nueva } \\
\text { York }\end{array}$ & $>60$ & $4 \div 5$ & 30 & 65 \\
\hline $\begin{array}{c}\text { Red R-9 de } \\
\text { Joao Pessoa }\end{array}$ & - & $1 \div 2$ & 1 & 35 \\
\hline $\begin{array}{c}\text { Red de Go- } \\
\text { Yang }\end{array}$ & - & $2 \div 3$ & $45 \div 50$ & 100 \\
\hline
\end{tabular}

Tabla 5.28. Ajuste de parámetros para el APG considerando la probabilidad de obtener mínima/buena solución.

\begin{tabular}{|c|c|c|c|c|}
\hline & $\begin{array}{c}\text { Límite de } \\
\text { velocidad (\%) }\end{array}$ & $\begin{array}{c}\text { Prob. de } \\
\text { despiste (\%) }\end{array}$ & $\begin{array}{c}\text { Mínimas } \\
\text { soluciones (\%) }\end{array}$ & $\begin{array}{c}\text { Buenas } \\
\text { soluciones (\%) }\end{array}$ \\
\hline Red de Hanoi & 20 & $10 \div 20$ & 1 & 25 \\
\hline $\begin{array}{c}\text { Red de Nueva } \\
\text { York }\end{array}$ & $30 \div 40$ & 10 & 27 & 62 \\
\hline $\begin{array}{c}\text { Red R-9 de } \\
\text { Joao Pessoa }\end{array}$ & 20 & 20 & 1 & 26 \\
\hline $\begin{array}{c}\text { Red de Go- } \\
\text { Yang }\end{array}$ & 10 & 10 & 17 & 100 \\
\hline
\end{tabular}

Tabla 5.29. Ajuste de parámetros para algoritmo PSO modificado considerando la probabilidad de obtener mínima/buena solución.

\begin{tabular}{|c|c|c|c|c|}
\hline & HMCR (\%) & PAR (\%) & $\begin{array}{c}\text { Mínimas } \\
\text { soluciones (\%) }\end{array}$ & $\begin{array}{c}\text { Buenas } \\
\text { soluciones (\%) }\end{array}$ \\
\hline Red de Hanoi & $90-92$ & $<50$ & 1 & 20 \\
\hline $\begin{array}{c}\text { Red de Nueva } \\
\text { York }\end{array}$ & $85-88$ & $<50$ & 0 & 80 \\
\hline $\begin{array}{c}\text { Red R-9 de } \\
\text { Joao Pessoa }\end{array}$ & $92-94$ & $<50$ & $3 \div 5$ & 100 \\
\hline $\begin{array}{c}\text { Red de Go- } \\
\text { Yang }\end{array}$ & $87-94$ & $<50$ & & $7 \div 9$ \\
\hline
\end{tabular}

Tabla 5.30. Ajuste de parámetros para algoritmo HS considerando la probabilidad de obtener mínima/buena solución. 


\begin{tabular}{|c|c|c|c|c|c|}
\hline & Q & C & N & $\begin{array}{c}\text { Mínimas } \\
\text { soluciones } \\
\text { (\%) }\end{array}$ & $\begin{array}{c}\text { Buenas } \\
\text { soluciones } \\
\text { (\%) }\end{array}$ \\
\hline $\begin{array}{c}\text { Red de } \\
\text { Hanoi }\end{array}$ & 0,81 & 2,25 & 30 & 31 & 62 \\
\hline $\begin{array}{c}\text { Red de } \\
\text { Nueva York }\end{array}$ & 0,44 & 1,75 & 30 & 70 & 100 \\
\hline $\begin{array}{c}\text { Red R-9 de } \\
\text { Joao Pessoa }\end{array}$ & $0,25 \div 1$ & $1,75 \div 2,25$ & 30 & $1 \div 2$ & 100 \\
\hline $\begin{array}{c}\text { Red de Go- } \\
\text { Yang }\end{array}$ & $0,25 \div 1$ & 1,375 & 30 & 70 & 70 \\
\hline
\end{tabular}

Tabla 5.31. Ajuste de parámetros para algoritmo SFL considerando la probabilidad de obtener mínima/buena solución.

En términos generales, el algoritmo de optimización SFL tiene mayor facilidad para encontrar la mínima solución de diseño en cualquiera de las redes de diseño planteadas, mientras que los algoritmos PSO y HS tienen mayores dificultades para encontrar estas soluciones mínimas. Considerando el concepto de buena solución de diseño, que engloba a toda solución que no supere en más de un $3 \%$ la solución mínima, los resultados mejoran susceptiblemente en cualquiera de las técnicas de optimización planteadas, si bien APG y SFL siguen estando por delante con amplia diferencia.

Analizando los resultados en función de cada una de las redes propuestas hay que tener en cuenta que la repetibilidad de soluciones depende en gran medida de la propia red. Así, la red R-9 de Joao Pessoa es la de diseño más complejo, debido tanto al tamaño como al número de mínimos locales, por lo que la repetibilidad a la hora de encontrar la mínima solución es pequeña en cualquiera de los métodos planteados. A la inversa, la red de Go-Yang, con un menor número de conducciones y menores dificultades de diseño permite convergencias sencillas hacia una solución óptima, puesto que cualquiera de las metodologías planteadas.

\subsubsection{Análisis del tamaño de población}

Una vez determinado el mejor ajuste para cada una de las técnicas de optimización, el apartado 5.3 mantiene constante esta configuración variando únicamente el tamaño de población en cada una de las técnicas, a fin de determinar el efecto de aumentar/disminuir el tamaño de población en la obtención de la mejor solución posible.

Así, en el caso del APG, la obtención de mejores soluciones es mayor en todas las redes cuanto mayor es el tamaño de población con el que trabaja el algoritmo excepto en la red de Go-Yang. En esta red, los resultados no permiten apreciar ningún tipo de mejora cuando se utilizan poblaciones más grandes, aunque esta circunstancia es lógica, puesto que es la red más sencilla y no hace falta un mayor número de individuos para encontrar la mínima solución de diseño. 
En el caso del algoritmo PSO, los resultados en todas las redes de diseño muestran como si bien el aumento del tamaño de población favorece la obtención de mejores soluciones llega un límite a partir del cual dicha mejora queda estabilizada. Así, para el algoritmo PSO los análisis realizados muestran en todas las redes como para poblaciones superiores a los 125 individuos la probabilidad de obtener una mejor solución queda estable.

Quizá el caso menos claro entre todas las metodologías venga dado por el algoritmo HS, donde el comportamiento respecto al tamaño de población es tan distinto entre unas redes y otras que no es posible sacar ningún patrón de comportamiento. Así, para la red de Hanoi, la probabilidad de obtener mejores soluciones es mayor en poblaciones intermedias; para la red de Nueva York, las mejores soluciones se ven favorecidas con poblaciones más grandes; para la red de Joao Pessoa el número de buenas soluciones es mayor con poblaciones pequeñas y por último, para la red de Go-Yang no se aprecia ninguna relación entre el tamaño de población y las soluciones obtenidas.

Por último, el análisis de población para el algoritmo SFL determina resultados muy parecidos a los obtenidos en el APG, de modo que cuanto mayor es el número de individuos involucrados en el proceso de optimización mayor es el número mínimos y buenas soluciones obtenidas.

\subsubsection{Análisis de velocidad del algoritmo}

El apartado 5.3 analiza la influencia de los distintos parámetros de cada metodología en la velocidad con la que alcanzan la solución definitiva en cada simulación, entendiendo como velocidad del algoritmo el número de evaluaciones de la función objetivo realizadas durante el cálculo.

- Para la metodología de optimización basada en el APG el número de evaluaciones es mayor conforme aumenta la probabilidad de mutación del algoritmo, lo que disminuye la velocidad con la que resuelve el algoritmo. Respecto al parámetro de cruce es prácticamente imposible establecer una relación entre el número de evaluaciones realizadas y el valor del operador genético, por lo que la conclusión más plausible es que no hay relación entre velocidad del algoritmo y probabilidad de cruce. Esto no quiere decir que no se pueda producir alguna excepción debido a las especiales características de algún proceso de diseño, como pueda ser el caso de la red de Nueva York, donde el algoritmo realiza menor número de evaluaciones de la función objetivo conforme aumenta el valor de la probabilidad de cruce.

- En el caso del algoritmo PSO son cuatro los parámetros de ajuste que tratan de relacionarse con el esfuerzo computacional hasta alcanzar la solución definitiva de diseño. Así, considerando el límite de velocidad de una partícula entre dos iteraciones se observa como conforme disminuye este operador aumenta el número 
de evaluaciones de la función objetivo, ralentizando el cálculo. Del mismo modo, el número de evaluaciones de la F.O también es más grande cuanto mayor es la probabilidad de despiste dada a una determinada partícula. Esta circunstancia es lógica y es un indicativo de buen funcionamiento del parámetro, puesto que es introducido en la formulación para crear diversidad y evitar convergencias demasiado tempranas.

Por último, respecto a las constantes $C_{1}$ y $C_{2}$, cuya influencia en la calidad de las soluciones es menor, nos encontramos en la misma situación cuando se analiza su efecto en la velocidad del algoritmo en el rango de valores utilizado. En este sentido, los resultados muestran como el valor de $C_{1}$ no tiene influencia en la velocidad del algoritmo, mientras que valores de $C_{2}$ en torno a 2 (valor más alto utilizado) realizan un menor número de evaluaciones de la función objetivo, aumentando así la velocidad del cálculo. El ahorro iterativo es mayor cuanto más compleja es la red objeto de estudio.

- La metodología basada en el algoritmo HS es en términos absolutos la que menos evaluaciones de la F.O realiza hasta alcanzar la solución definitiva, si bien tiene mayor dificultad para encontrar la solución mínima en redes complejas como Hanoi o R-9. En cuanto a la influencia de los parámetros de ajuste en la velocidad del algoritmo, el número de evaluaciones disminuye casi linealmente conforme aumenta el valor de la probabilidad HMCR (mayor velocidad), mientras que no guarda ninguna relación con el ajuste del PAR, de modo que este último parámetro no influye para nada en la velocidad del algoritmo.

- Por último, la optimización SFL tiene tres parámetros susceptibles de optimización cuyo valor puede relacionarse con el número de evaluaciones de la F.O que realiza el algoritmo. Así, para el número de saltos evolutivos (N), el número de evaluaciones realizadas es mayor (calculo más lento) cuanto más grande es el número de saltos evolutivos considerado, produciéndose un ahorro iterativo considerable en los valores más pequeños considerados para N. Del mismo modo, considerando únicamente el gasto computacional, los resultados muestran como el algoritmo es más rápido para valores del coeficiente acelerador (C) en torno a $1,75 \div 2$. La utilización de valores más grandes aumenta considerablemente el número de evaluaciones de la F.O, especialmente en casos más complejos como las redes de Hanoi o Joao Pessoa. Por último, la velocidad de cálculo del algoritmo es independiente de los valores dados al tamaño de submememeplex (Q), al menos en el rango de estudio considerado. 


\section{EFICIENCIA DE LOS MODELOS DE OPTIMIZACIÓN}

\subsection{Introducción}

El capitulo anterior realiza diversos análisis estadísticos que establecen relación entre el ajuste de los distintos parámetros de cálculo y la bondad de la solución obtenida en el diseño de distintas redes de distribución para cada técnica heurística. Así, tanto el análisis de parámetros como el análisis de población fundamentan lo buena o mala que es una determinada técnica en función de la capacidad del método para obtener una solución de mínimo coste o lo que se considera una buena solución de diseño.

Contrariamente, el análisis de velocidad trata de poner de manifiesto la existencia de otros factores que se deben tener en cuenta, como es el coste computacional asociado a la manipulación de estos parámetros. En este sentido, el número de evaluaciones de la función objetivo que realiza cada técnica antes de proporcionar la solución final en cada simulación es la forma que se tiene para determinar si una técnica es más o menos rápida.

La eficiencia es un nuevo concepto en la aplicación de métodos heurísticos a la resolución de problemas complejos. Este trabajo define la eficiencia como una herramienta matemática que permite relacionar la calidad de la solución obtenida con el esfuerzo computacional que realiza un determinado algoritmo heurístico antes de encontrar la solución de diseño definitiva. La eficiencia es la relación directa entre el número de mínimos/buenas soluciones y el número de evaluaciones de la función objetivo que realiza el algoritmo con cada método y configuración de parámetros, de modo que cuanto más alto resulta este valor numérico mayor es la eficiencia del algoritmo.

Así, el índice de eficiencia se fundamenta en la relación entre calidad de la solución y velocidad de resolución del algoritmo. Para relacionar ambos conceptos se crean dos índices de rendimiento, uno asociado a la calidad de la solución y otro asociado a la velocidad con la que trabaja el algoritmo. El cociente de ambos es lo que conocemos como eficiencia.

$$
E=\frac{\eta_{\text {calidad }}}{\eta_{\text {velocidad }}}
$$




$$
\begin{gathered}
\eta_{\text {calidad }}=\frac{n^{\mathrm{o}} \text { mínimos o } n^{\mathrm{o}} \text { buenas soluciones }}{n^{\mathrm{o}} \text { simulaciones }} \\
\eta_{\text {velocidad }}=n^{\mathrm{o}} \text { ev.función objetivo }
\end{gathered}
$$

El $\eta_{\text {calidad }}$ relaciona el número de mínimos/buenas soluciones que se obtiene con el total de repeticiones que se realiza para una determinada combinación de parámetros. Por su parte, el $\eta_{\text {velocidad }}$ se identifica con el número de evaluaciones de la función objetivo realizadas en cada simulación del problema. Si se relaciona este $\eta_{\text {velocidad }}$ con la totalidad de posibles soluciones distintas que tiene el problema de diseño es posible hacerse una idea de la cantidad de cálculos que ahorra este tipo de técnicas. Así, el número de posibles soluciones que puede tener un determinado problema depende tanto de la naturaleza del propio problema como del número de incógnitas que nos planteemos resolver. Así, en el diseño óptimo de redes de agua, donde se considera el diámetro de cada tubería como incógnita del problema el número total de combinaciones que se puede dar entre las distintas variables de decisión es:

$n^{\mathrm{o}}$ posibl. soluciones $=\left(n^{\mathrm{o}} \text { diámetr. gama }\right)^{n^{\mathrm{o}} \text { tuberias }}=n^{\mathrm{o}}$ tuberías $\cdot\left(\log n^{\mathrm{o}}\right.$ diametr. gama $)(6.4)$

El índice de eficiencia (E) da una idea de la calidad de la simulación realizada, de modo que cuanto mayor es este número mejor es la relación entre calidad de la solución y recursos empleados para obtenerla. Este índice de eficiencia representa una forma neutra de comparar los algoritmos de optimización en base a distintos criterios.

Por simplicidad de cálculo, el índice de eficiencia se muestra como un índice adimensional para cada una de las redes de distribución diseñadas en este trabajo. Así, para cada metodología, combinación de parámetros y red se ha calculado un índice de eficiencia dimensional (número de mínimos o buenas soluciones por evaluación de la F.O realizada).

Este índice de eficiencia se expresa de un modo proporcional. El objetivo es proporcionar una medida más intuitiva, por lo que cada uno de los índices resultantes se divide por el mayor de todos los obtenidos en una determinada red. Así, en cada red de distribución, la mejor combinación del mejor método tendrá un índice de eficiencia de valor uno. De este modo, valores de eficiencia cercanos a uno estarán próximos a la combinación más eficiente en una determinada red, mientras que los valores más alejados de 1 representan metodologías menos eficientes.

Para cada una de las redes de abastecimiento se analizan dos índices de eficiencia. El primero de ellos está basado en los distintos parámetros de ajuste que tiene cada una de las técnicas evolutivas empleadas y el segundo de ellos analiza el tamaño de población inicial con el que 
trabaja cada algoritmo de optimización. Los siguientes apartados muestran los resultados de eficiencia obtenidos en cada caso.

\subsection{Eficiencia de los modelos de optimización en la red de Hanoi}

Los valores de eficiencia obtenidos en la red de Hanoi para cada metodología de optimización dejan a dos de estas técnicas muy por encima del resto. De este modo, cuando se consideran criterios de eficiencia, las técnicas de optimización basadas en los algoritmos APG y SFLA son muy superiores al resto.

Entre estas dos técnicas, APG consigue el mejor valor de eficiencia entre todos los ajuste de parámetros realizados, por lo que todos los estudios de eficiencia relativos se realizan en base a esta técnica de optimización, ya sea de cara a la obtención de la solución mínima de diseño $(6,081$ millones de um) o a la obtención de un conjunto de buenas soluciones $(<6,263$ millones um). Así, la combinación más eficiente se obtiene para un tamaño constante de 100 individuos, una probabilidad de mutación de un $3 \%$ y una probabilidad de cruce de un $90 \%$. Este ajuste tiene un valor de eficiencia igual a 1 y representa la combinación más eficiente entre todas las simulaciones realizadas para la red de Hanoi cuando se pretende obtener la mejor solución posible.

En el caso de evaluar la eficiencia en la obtención de un conjunto de buenas soluciones de diseño, el APG también resulta ser la técnica más adecuada, con la salvedad de que en este caso no es necesaria la utilización de poblaciones iniciales tan elevadas, puesto que emplear un menor número de individuos favorece la velocidad del proceso de optimización. Al disminuir la población inicial del algoritmo estamos disminuyendo el número de óptimos de diseño, se sigue obteniendo un conjunto de soluciones que entran dentro de la definición de buena solución de diseño.

Los siguientes subapartados analizan con detalle los resultados de eficiencia para cada uno de los métodos heurísticos ensayados. La eficiencia en cada caso será mayor cuanto más se aproxime al valor de la unidad.

\subsubsection{Algoritmo Pseudogenético}

Para cualquiera de los algoritmos heurísticos propuestos es posible realizar análisis de eficiencia en función de todos los parámetros de cálculo susceptibles de ajuste. La figura 6.1 muestra la eficiencia del algoritmo genético en la red de Hanoi según los parámetros de optimización estudiados, es decir, la probabilidad de cruce y la probabilidad de mutación. La figura permite establecer de manera definitiva cuál es el ajuste óptimo de cálculo teniendo en 
cuenta tanto la bondad del resultado como el tiempo de cálculo que se emplea para llegar a él.

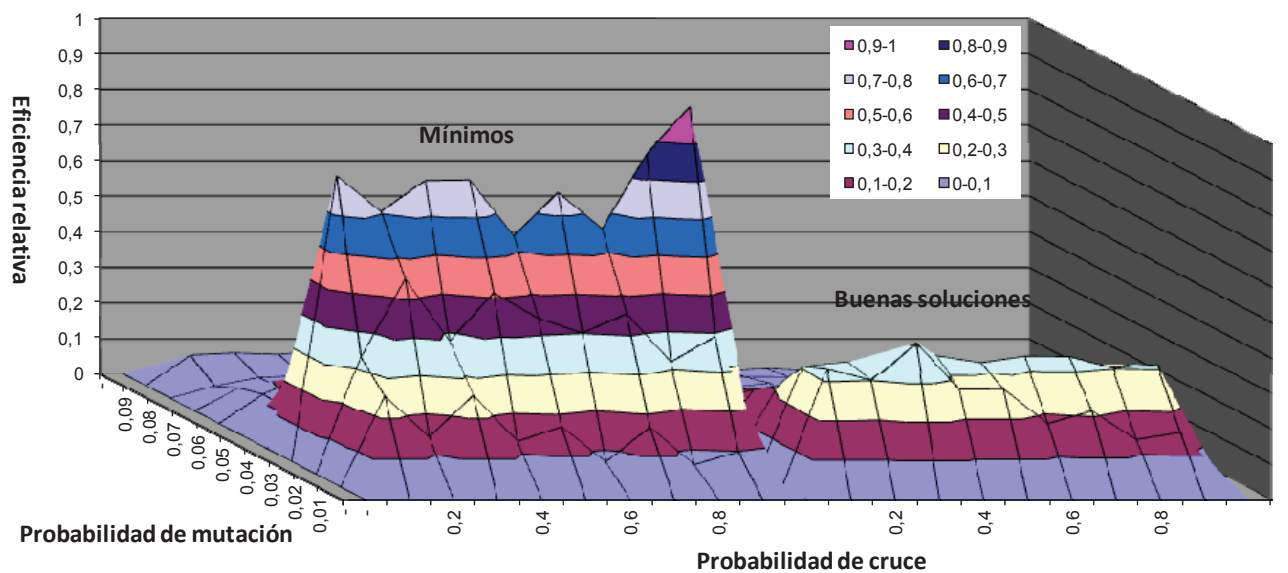

Figura 6.1. Análisis de eficiencia según mutación y cruce en la red de Hanoi para el APG

La figura muestra con claridad como una probabilidad de mutación en torno al 3\% trabaja de un modo más eficiente que el resto de opciones. La combinación de esta probabilidad de mutación con una probabilidad de cruce de un $90 \%$ da un resultado de eficiencia relativa igual a 1 , y representa la combinación más eficiente de diseño para la red de Hanoi entre todos los métodos estudiados. Con este ajuste de de mutación, los valores de eficiencia están por encima de 0,65 para cualquier probabilidad de cruce. En este caso, la combinación crucemutación más eficiente coincide con la mejor combinación cuando se consideraba únicamente la probabilidad de encontrar un buen resultado de diseño. De hecho, el gráfico es muy similar al mostrado cuando se estudiaba la optimización de parámetros, confirmando una probabilidad de mutación en torno al 3\% como óptima en el diseño de la red de Hanoi.

El lado izquierdo de la figura 6.1 representa la eficiencia relativa en la obtención de buenas soluciones de diseño para la red de Hanoi. En este caso, los valores tan pequeños de eficiencia relativa obtenidos son debidos al tamaño de población utilizado, que es constante y de 100 individuos. Tal como se aprecia en la figura 6.2, que analiza la eficiencia según el tamaño de población, cuando el objetivo es la obtención de un conjunto de buenas soluciones el algoritmo trabaja mucho mejor con poblaciones pequeñas, lo que refleja de nuevo la importancia de elegir bien el rango de trabajo de los distintos parámetros en función de cuál es el objetivo de diseño que se persigue.

Así, el estudio de eficiencia también puede ser aplicado al tamaño de población. De este modo, tomando como valor fijo la probabilidad óptima de mutación se dispone de una serie de simulaciones donde se varía tan sólo el tamaño de población y la probabilidad de cruce. La figura 6.2 muestra el estudio de eficiencia en estas condiciones, donde el objetivo es 
demostrar si el aumento de evaluaciones de la función objetivo que se produce al aumentar la población inicial del algoritmo compensa a nivel de resultados.

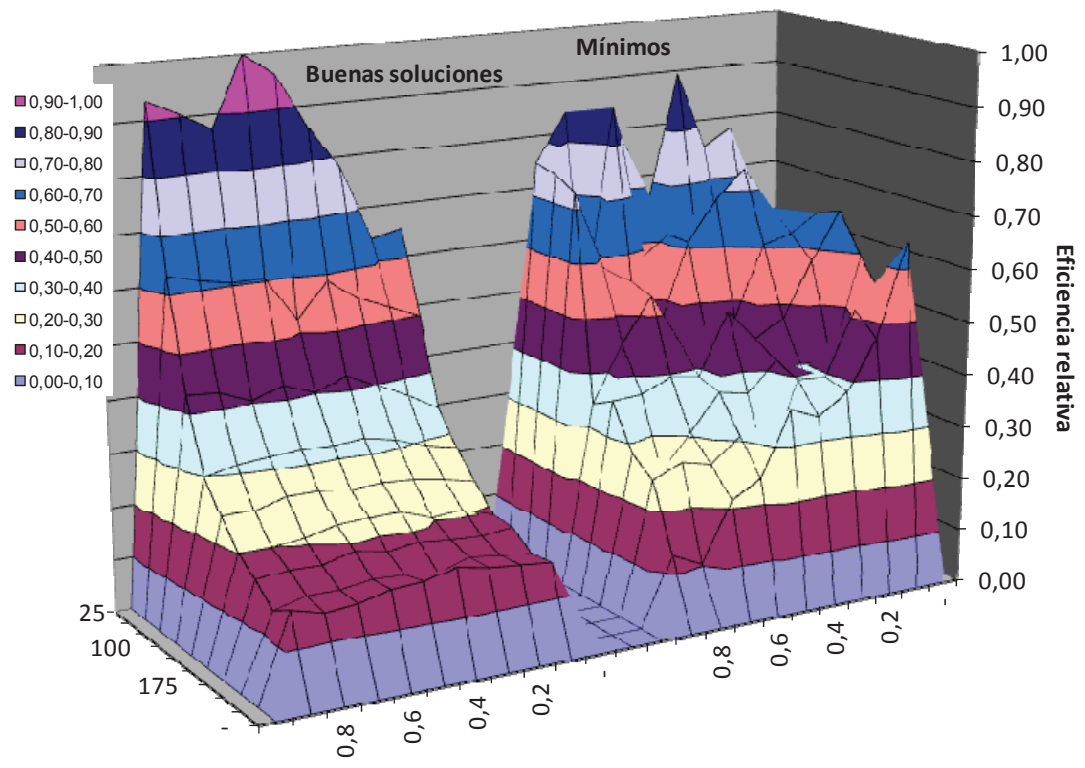

Figura 6.2. Análisis de eficiencia según cruce y población en la red de Hanoi para el APG

El estudio de eficiencia que relaciona la población inicial del algoritmo y la probabilidad de cruce permite sacar nuevas conclusiones más allá de las obtenidas en 5.3.1.1, donde conforme aumentaba el tamaño de la población también lo hacía la probabilidad de obtener el valor mínimo de diseño. El estudio de eficiencia descarta las poblaciones grandes como las más eficientes, puesto que el coste computacional adicional que requiere este aumento en la población del algoritmo no compensa la mejora obtenida. Del mismo modo, poblaciones por debajo de 50 individuos tienen los peores ratios de eficiencia, puesto que no son capaces de alcanzar prácticamente en ninguna ocasión el valor mínimo de diseño, por lo que quedan muy penalizadas.

De los datos proporcionados por la figura, el estudio de eficiencia para el APG muestra como tamaños de población de entre 50 y 75 individuos son los más eficientes, puesto que obtienen un mayor número de mínimos por evaluación de la función objetivo.

No obstante, si el objetivo es la obtención de un conjunto de buenas soluciones de diseño, sin que importe en exceso la obtención de la solución mínima de diseño, el tamaño inicial de población del APG puede reducirse hasta los 25 individuos, siendo éste el tamaño de población más eficiente, puesto que el aumento de velocidad conseguido compensa ampliamente un ligero empeoramiento de los resultados, tal como muestra el gráfico de la izquierda en la figura 6.2. 
La probabilidad de cruce se confirma como un parámetro de menor influencia en el caso de la red de Hanoi, puesto que para probabilidades de cruce entre un 10 y un $90 \%$ no se aprecian diferencias significativas si se comparan con la que ejercen los otros dos parámetros. No obstante, los resultados generales sí parecen mostrar cierta mejora con probabilidades de cruce más elevadas, por lo que siempre que sea posible se aconseja utilizar probabilidades de cruce por encima del 50\%.

De este modo, considerando el análisis de eficiencia, la tabla 6.1 muestra el mejor ajuste posible en el algoritmo APG para los parámetros de cálculo cuyo valor depende del usuario:

\begin{tabular}{|c|c|c|c|}
\hline \multicolumn{2}{|c|}{ PARÁMETROS } & Obtención de mínimas soluciones & Obtención de buenas soluciones \\
\hline Prob. de cruce & $\mathrm{P}_{\mathrm{c}}$ & $>50 \%$ & - \\
\hline Prob. de mutación & $\mathrm{P}_{\mathrm{m}}$ & $3 \%$ & $3 \%$ \\
\hline Tamaño de población & & $50-75$ individuos & 25 individuos \\
\hline
\end{tabular}

Tabla 6.1. Ajuste óptimo de parámetros APG en la red de Hanoi considerando la eficiencia de elección

\subsubsection{Algoritmo PSO modificado}

Los distintos análisis estadísticos realizados en el capitulo anterior evidencian dificultades para el algoritmo PSO cuando se trata de encontrar la solución de mínimo coste en problemas de diseño más complejos. Así, en el caso de la red de Hanoi, el algoritmo PSO consigue alcanzar la solución mínima de coste 6,081 millones de um, pero sólo un $1 \%$ del total de simulaciones realizadas conseguían esta solución.

La escasa repetibilidad del algoritmo PSO en la búsqueda de la solución óptima provocó que el análisis estadístico de soluciones se centrara en la obtención de buenas soluciones de diseño, entendiendo por estas últimas las que no superan en más de un $3 \%$ a la solución de mínimo coste. Con esta premisa, el filtro de resultados en función de los distintos parámetros determinó que el ajuste del límite de velocidad $\left(\mathrm{V}_{\text {lim }}\right)$ y la probabilidad de despiste $\left(\mathrm{P}_{\text {desp }}\right)$ tenían mayor importancia en la mejora de los resultados de diseño. Así, considerando como criterio de ajuste la probabilidad de encontrar la mejor solución posible, el análisis estadístico determinaba una $\mathrm{V}_{\text {lim }}$ en torno a 0,2. Esta limitación implica que entre iteración e iteración, un determinado conducto no podrá cambiar el valor de su diámetro más allá de un $20 \%$ del total de variables (diámetros) disponibles.

La probabilidad de despiste representa el otro parámetro crítico de ajuste en esta técnica. Su función es la de crear diversidad, puesto que desvía un determinado número de pájaros hacia posiciones aleatorias del espacio de soluciones. Para la red de Hanoi se determinó que un ajuste de $P_{\text {desp }}$ entre el 10 y el $20 \%$ aumentaba la probabilidad de obtener mejores soluciones.

Por último, la técnica de diseño basada en el algoritmo PSO permite el ajuste de dos constantes de cálculo llamadas $C_{1}$ y $C_{2}$. El análisis de parámetros en Hanoi determinó que el 
ajuste de dichas constantes puede considerarse como no crítico, puesto que la bondad de los resultados no se ve alterada, por lo que es posible seguir las recomendaciones generales dadas por distintos autores, que aconsejan la utilización de valores en torno a 2 para ambas.

Todas las decisiones anteriores se tomaban considerando la probabilidad de obtener la mejor solución posible de diseño. No obstante, es posible considerar la configuración del algoritmo tomando como criterio de elección la velocidad del mismo. En este caso, el análisis de velocidad realizado en 5.4 determina como el proceso de optimización es más rápido cuanto mayor es $\mathrm{V}_{\mathrm{lim}}$. Del mismo modo, el aumento de $\mathrm{P}_{\text {desp }}$ provoca una ralentización del cálculo, puesto que se envía un mayor número de pájaros aleatorios a posiciones inexploradas del espacio de soluciones, lo que aumenta el tiempo de convergencia del algoritmo.

Respecto a las constantes de cálculo $C_{1}$ y $C_{2}$, el análisis de velocidad determinaba como conclusión más lógica el no tener en cuenta criterios de velocidad para la elección del mejor valor de $C_{1}$, puesto que no se apreciaba ninguna tendencia lo suficientemente clara. En el caso de $\mathrm{C}_{2}$, la conclusión era opuesta, de modo que la tendencia general del algoritmo PSO es realizar un menor número de evaluaciones de la función objetivo cuando el valor numérico de $\mathrm{C}_{2}$ es mayor.

El análisis de eficiencia combina ambos estudios, de modo que trata de encontrar una solución de compromiso entre velocidad de cálculo y capacidad de encontrar la mejor solución posible. Los valores de eficiencia considerados tienen, por simplicidad de cálculo, un valor relativo a la metodología de diseño más eficiente para cada red de diseño. En el caso de la red de Hanoi, el mejor método de optimización resulta ser el APG, por lo que todos los valores de eficiencia están referidos al mejor ajuste posible de parámetros en APG, cuyo valor de eficiencia es 1 y que define la eficiencia máxima en la red de Hanoi. Cuanto más cerca estén los valores de eficiencia de 1 mejor será el desempeño del algoritmo PSO.

La figura 6.3 muestra el gráfico de eficiencia considerando los dos parámetros más determinantes en la optimización PSO, como son el límite de velocidad de la partícula $\left(\mathrm{V}_{\text {lim }}\right)$ y la probabilidad de despiste $\left(\mathrm{P}_{\text {desp }}\right)$. En este caso, el análisis se centra sólo en la obtención de buenas soluciones de diseño, puesto que la repetibilidad de la mínima solución en la red de Hanoi es escasa. 


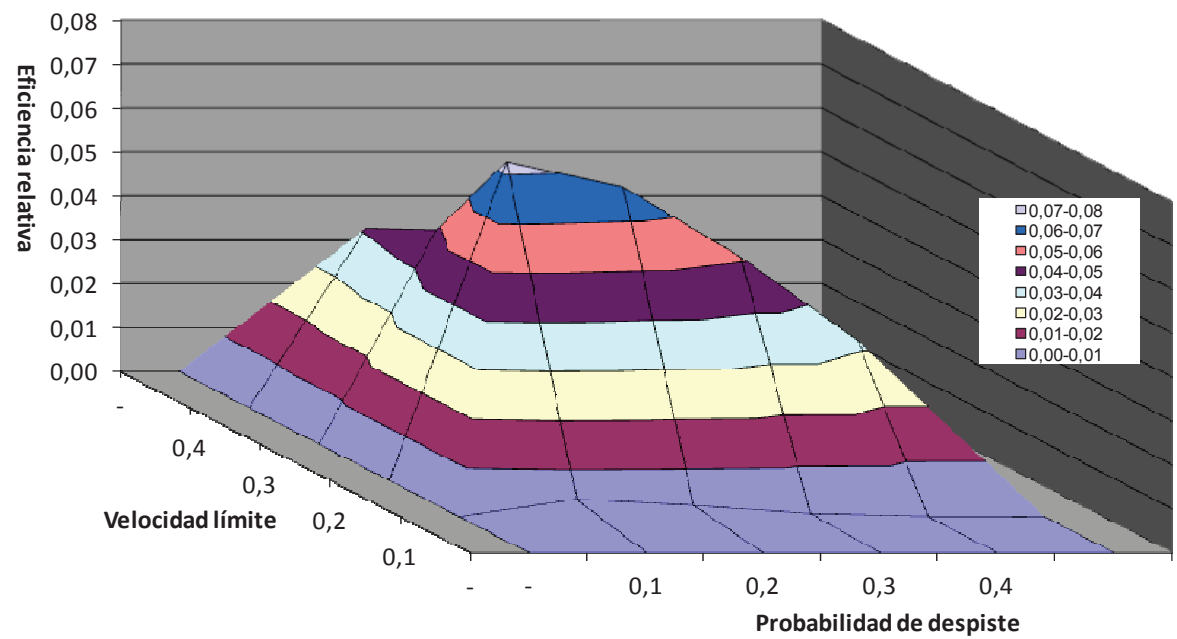

Figura 6.3. Análisis de eficiencia según $V_{\text {lim }}$ y $P_{\text {desp }}$ en la red de Hanoi para PSO modificado

El análisis local de eficiencia muestra claramente como el punto de trabajo óptimo para la red de Hanoi se encuentra para un límite de velocidad del $20 \%$ y una probabilidad de despiste del $10 \%$. Esta configuración identifica claramente la zona de máxima eficiencia en la optimización PSO. La probabilidad de despiste aumenta la eficiencia del algoritmo conforme disminuye su valor, puesto que realiza un menor número de evaluaciones para conseguir resultados muy similares, siendo ésta la principal diferencia con el estudio de parámetros realizado en 5.1, donde probabilidades de despiste entre el 10 y el $30 \%$ conseguían resultados muy similares.

Considerando un enfoque global acerca de la eficiencia del algoritmo PSO modificado en la red de Hanoi, los valores de eficiencia obtenidos son extremadamente bajos, por lo que aparentemente no es una técnica adecuada para un problema de este tipo. Así, PSO obtiene el rango de eficiencia más bajo entre todas las técnicas estudiadas con mucha diferencia, independientemente del ajuste de parámetros realizado.

El análisis de la eficiencia respecto de las constantes $C_{1}$ y $C_{2}$ no aporta mayor información, puesto que en este caso, la mejora obtenida al utilizar un determinado valor $u$ otro es prácticamente imperceptible de modo global, puesto que los índices de eficiencia obtenidos están todos por debajo de 0,05. El cuadro completo de eficiencia en función de las constantes $C_{1}$ y $C_{2}$, conteniendo todos los valores posibles para $V_{\lim }$ y $P_{\text {desp }}$ viene dado por la figura 6.4. 


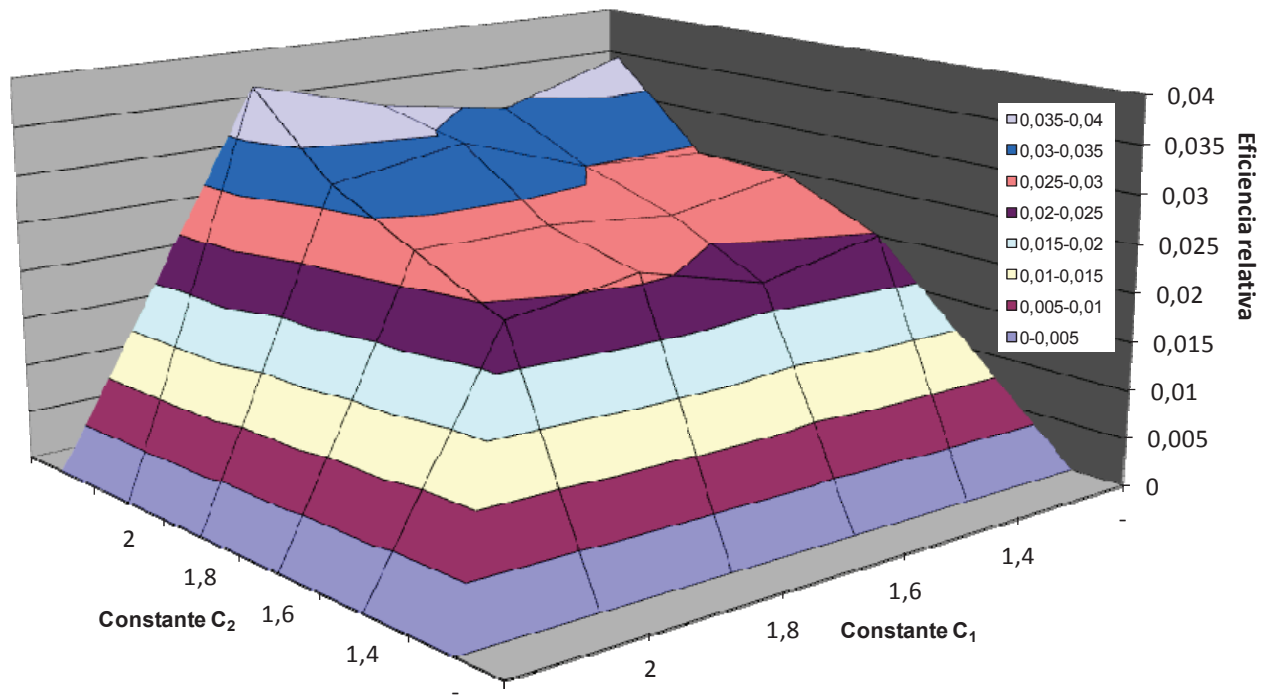

Figura 6.4. Análisis de eficiencia según $C_{1}$ y $C_{2}$ en la red de Hanoi para PSO modificado

Si consideramos tan sólo un criterio local que analice el algoritmo PSO, la conclusión es que el valor de $C_{1}$ es indiferente en el desempeño del algoritmo en este caso, mientras que la eficiencia del algoritmo es mayor para valores de $C_{2}$ en torno a 2. Este aumento en la eficiencia cuando $C_{2}$ es mayor viene dado por el menor número de evaluaciones que realiza el algoritmo cuando $C_{2}$ es más grande, obteniendo aún así resultados muy similares en cuanto a calidad de la solución.

Una vez determinada la influencia de los parámetros de ajuste propios de la optimización PSO tan sólo resta el análisis de eficiencia referido al número de individuos que intervienen en el proceso de optimización. Para ello se mantienen constantes todos los parámetros de ajuste excepto el tamaño de población del algoritmo, que varía entre 25 y 225 individuos. En este caso, las simulaciones que contiene la figura 6.5 son realizadas con la mejor combinación posible para $\mathrm{P}_{\text {desp }} \mathrm{Y} \mathrm{V}_{\text {lim }}$ considerando la calidad de las soluciones, por lo que la repetibilidad de la solución mínima de diseño aumenta lo suficiente como para considerar también su análisis de eficiencia. 


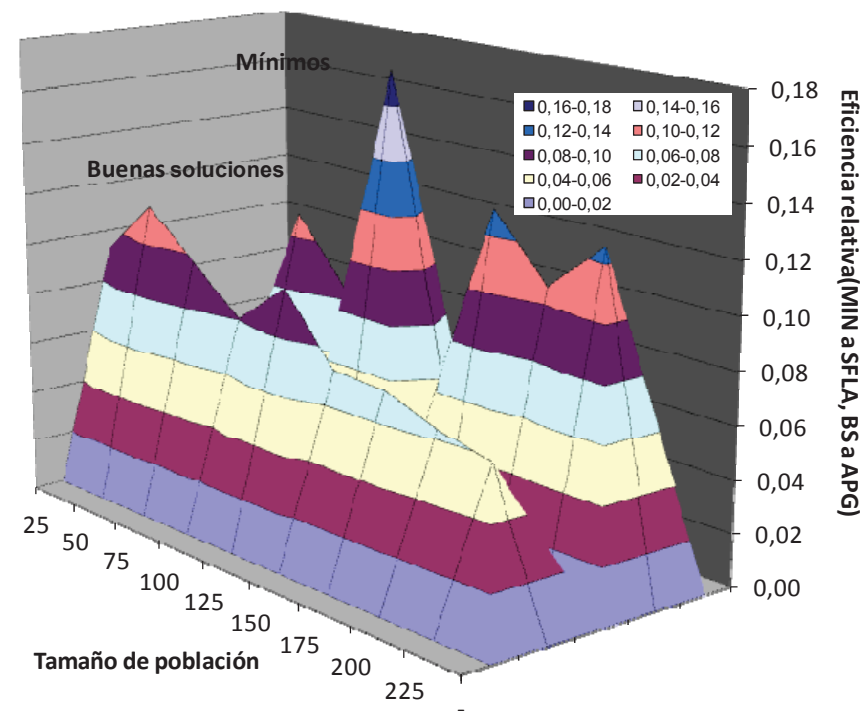

Figura 6.5. Análisis de eficiencia según población en la red de Hanoi para PSO modificado

La primera conclusión que se puede tomar de la representación es que considerar el mejor ajuste posible de parámetros permite mejorar los resultados obtenidos por el algoritmo PSO modificado. Pese a ello, la eficiencia de esta técnica de optimización en la red de Hanoi es claramente inferior al resto de técnicas que considera este trabajo.

Centrándonos en el análisis local, el gráfico de eficiencia muestra como las poblaciones más pequeñas son adecuadas para obtener un conjunto de buenas soluciones próximas al óptimo de diseño. En este sentido, poblaciones entre 50 y 125 individuos obtienen un índice de eficiencia similar, que resulta superior a los mayores tamaños de población.

Si se considera como criterio de eficiencia la búsqueda del óptimo de diseño, con un coste de 6,081 miles de um, los valores obtenidos aclaran pocas cosas, puesto que más que una tendencia se obtienen picos de eficiencia aislados. En este caso, el máximo de eficiencia se registra para una población de 125 individuos, con un índice de eficiencia de 0,17. No obstante, pese a la irregularidad de los resultados, es posible apreciar cierta mejora en los tamaños de población más grandes, donde la mayoría de tamaños considerados superan el 0,1 de eficiencia.

El estudio de eficiencia considerando el número de individuos que intervienen en el proceso finaliza el análisis de la red de Hanoi. La conclusión principal que se deriva es que el algoritmo PSO modificado es inferior a otras técnicas heurísticas tratadas en este trabajo si consideramos criterios de eficiencia. La siguiente tabla resume el rango óptimo de trabajo 
que debe considerarse en el diseño óptimo de la red de Hanoi mediante el algoritmo PSO modificado:

\begin{tabular}{|c|c|c|c|}
\hline \multicolumn{2}{|c|}{ PARÁMETROS } & Obtención de mínimas soluciones & Obtención de buenas soluciones \\
\hline Velocidad límite & $\mathrm{V}_{\lim }$ & 0,2 & 0,2 \\
\hline Prob. de despiste & $\mathrm{P}_{\text {desp }}$ & 0,1 & 0,1 \\
\hline Constante 1 & $\mathrm{C}_{1}$ & $1,4-2$ & $1,4-2$ \\
\hline Constante 2 & $\mathrm{C}_{2}$ & 2 & 2 \\
\hline Número individuos & & $>125$ & $50-125$ \\
\hline
\end{tabular}

Tabla 6.2. Ajuste óptimo de parámetros PSO en la red de Hanoi considerando la eficiencia

\subsubsection{Algoritmo Harmony Search}

El ajuste de parámetros en la red de Hanoi mediante el algoritmo HS mostraba dos situaciones opuestas en función del ajuste del PAR considerado. Así, el análisis demostraba que una mala elección del PAR provoca la no convergencia del algoritmo hacia soluciones factibles de diseño. Para valores del PAR superiores a 0,5 el algoritmo no es capaz de encontrar soluciones factibles, mientras que para valores inferiores a 0,5 la diferencia entre distintos valores es despreciable desde un punto de vista numérico. Dados los resultados, la definición inicial del PAR como parámetro de optimización resultaba poco conveniente, por lo que se consideró más adecuado definirlo como parámetro de convergencia.

Esta situación provoca que la optimización de parámetros en HS quede reducida a determinar cuál es el ajuste óptimo para la probabilidad HMCR. De este modo, el análisis realizado en 5.2 concluye que ajustar la probabilidad HMCR alrededor de 0,9-0,92 aumenta la probabilidad de obtener mejores soluciones en la red de Hanoi.

Si se toma en consideración el análisis de velocidad en HS, la conclusión era que este modelo de optimización realiza, en general, un menor número de evaluaciones de la función objetivo en comparación con el resto de métodos heurísticos estudiados.

Profundizando en este análisis respecto a los parámetros de ajuste del algoritmo, es posible establecer relación entre el número de evaluaciones de la función objetivo hasta encontrar la solución definitiva y el valor de la probabilidad HMCR, de modo que el cálculo es más costoso conforme HMCR es más pequeño. El mismo análisis respecto al parámetro de convergencia PAR determina que la velocidad de cálculo del algoritmo no es afectada por los distintos valores que pueda tomar este ajuste, por lo que únicamente es necesario tenerlo en cuenta de acuerdo a utilizar valores que converjan hacia soluciones factibles.

La relación entre ambos análisis se establece a través del análisis de eficiencia, de modo que se facilite la toma de decisiones de compromiso cuando hay que elegir entre calidad de solución y velocidad de cálculo. Inicialmente se muestra una representación de la eficiencia en función de la probabilidad HMCR y el ajuste del PAR cuando el objetivo es encontrar un conjunto de buenas soluciones de diseño por debajo de 6,263 millones de um. Los valores de 
eficiencia pueden considerarse como relativos, puesto que son referenciados en base a la combinación más eficiente entre todos los algoritmos utilizados, en este caso el algoritmo APG. La eficiencia será mayor cuanto más se aproxime a la unidad.

El análisis de eficiencia se realiza tan sólo en función de la probabilidad de encontrar un conjunto de buenas soluciones inferiores a un determinado valor, en este caso, 6,263 millones de um. Esta determinación se toma debido a la escasa repetibilidad que muestra el algoritmo HS cuando se trata de encontrar la solución mínima en la red de Hanoi, determinada en 6,081 millones de um. En este sentido, HS se encuentra en la misma situación que el algoritmo PSO modificado.

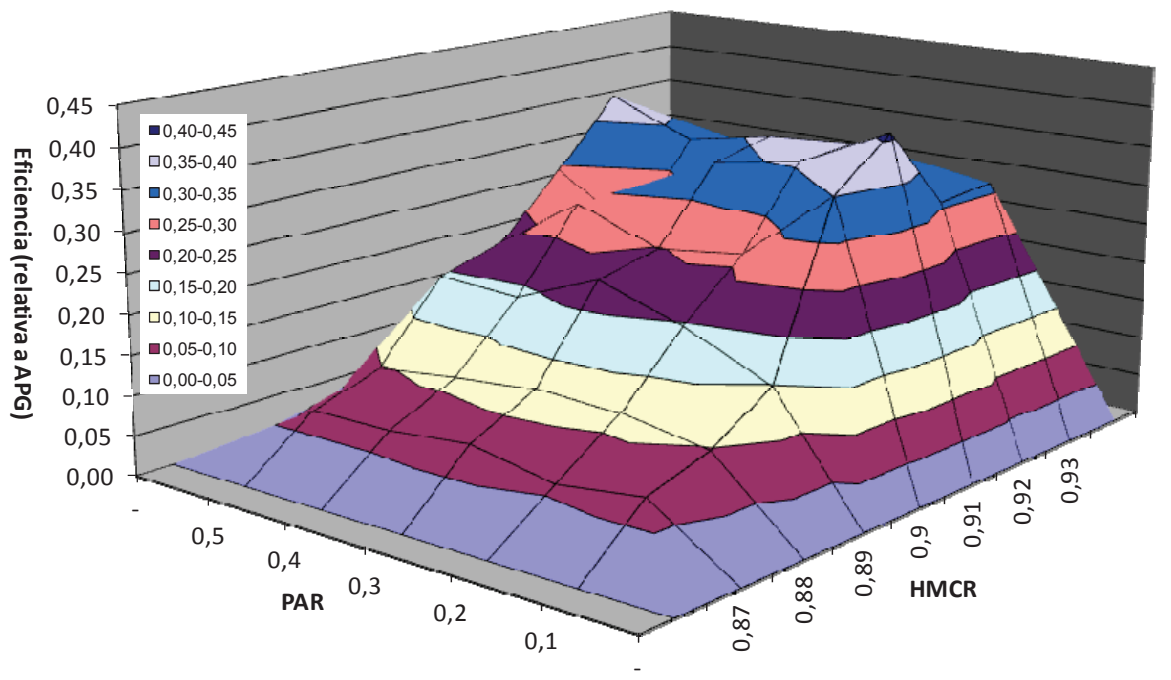

Figura 6.6. Análisis de eficiencia según HMCR y PAR en la red de Hanoi para algoritmo HS.

Considerando la eficiencia en la red de Hanoi en términos globales, los resultados obtenidos por el algoritmo HS pueden considerarse como discretos, puesto que su mejor zona de cálculo tiene valores en torno a 0,4 para la eficiencia relativa, bastante alejados tanto del APG como de SFLA, técnicas que podemos considerar como referencia en esta red. No obstante, el rendimiento que proporciona HS se encuentra bastante por encima del algoritmo PSO modificado en lo que a obtención de buenas soluciones se refiere.

Centrando el análisis alrededor de la propia optimización HS, la figura 6.7 muestra como existe una zona de eficiencia máxima para una probabilidad HMCR en torno a 0,91-0,92. En esta zona se combina la máxima probabilidad de obtener una buena solución en la red de Hanoi con una de las zonas más veloces dentro del algoritmo HS, puesto que el número de evaluaciones de la función objetivo disminuye cuanto mayor es la probabilidad HMCR considerada. 
Respecto al ajuste del PAR, que se ha definido como parámetro de convergencia, el gráfico de eficiencia confirma que la diferencia entre tomar un ajuste $u$ otro apenas es perceptible, puesto que su efecto tanto en la mejora de resultados como en la velocidad del algoritmo es mínimo. No obstante, el punto de máxima eficiencia en la búsqueda de buenas soluciones se obtiene para un PAR de 0,1, por lo que la recomendación respecto de este ajuste es tomarlo lo más pequeño posible, puesto que además de garantizar la convergencia del algoritmo se da la circunstancia de que es la zona de eficiencia máxima.

El número de individuos que intervienen en el proceso de optimización también es susceptible de análisis. Ya se ha nombrado anteriormente que el tratamiento que recibe la población del algoritmo HS es diferente del resto de técnicas, puesto que en este caso tan sólo se realiza una simulación por iteración. Aún así, el número de evaluaciones de la función objetivo hasta encontrar la solución definitiva es distinto según el tamaño de la memoria inicial que se considere, puesto que facilita o dificulta la entrada de una nueva solución en la memoria del algoritmo. Así, la figura 6.7 muestra la eficiencia relativa en HS para poblaciones comprendidas entre los 30 y los 135 individuos.

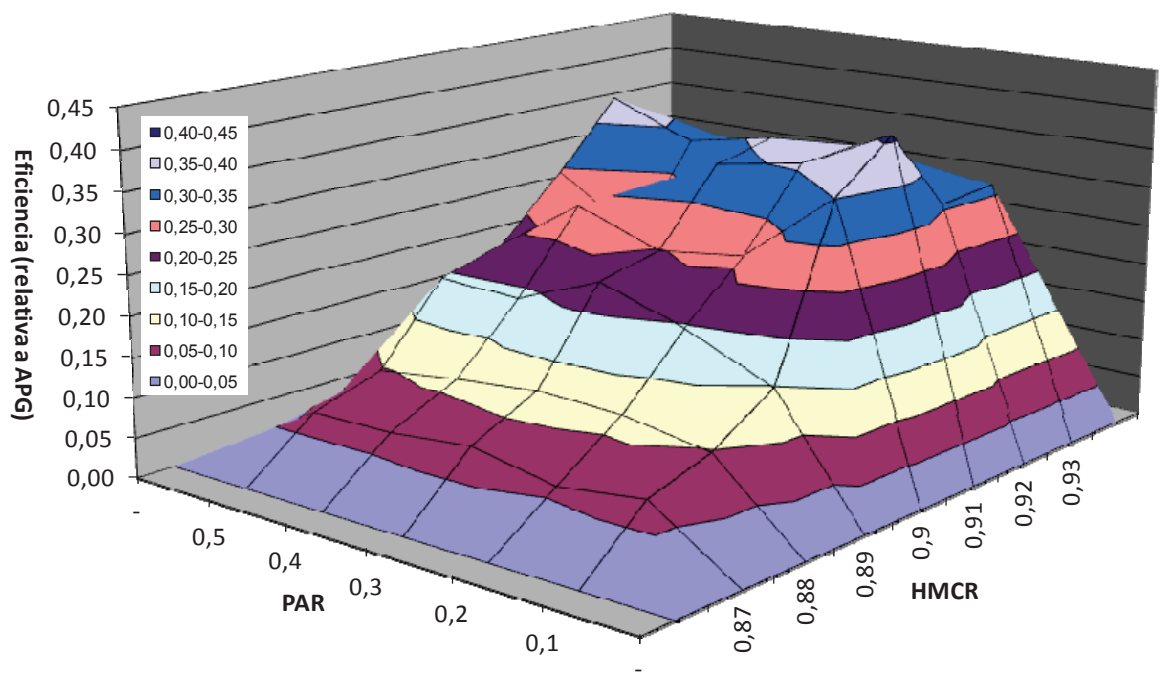

Figura 6.7. Análisis de eficiencia según población en la red de Hanoi para algoritmo HS

En la obtención de un conjunto de buenas soluciones de diseño inferiores a un valor dado, (6,263 millones de um), las poblaciones más pequeñas se muestran mucho más eficientes que las poblaciones grandes. Esto es debido al gran ahorro iterativo que provocan las poblaciones pequeñas en este caso. Así, la zona de eficiencia máxima del algoritmo HS está establecida en una población de 30 individuos, puesto que poblaciones más pequeñas tienen ya demasiadas dificultades para encontrar buenas soluciones, por lo que quedan penalizadas. 
Una vez evaluados los distintos parámetros puede afirmarse que la técnica de optimización basada en el algoritmo HS no es la más adecuada en la red de Hanoi si lo que se pretende es obtener con eficiencia la solución óptima de diseño. No obstante, HS es capaz de proporcionar un conjunto de buenas soluciones con resultados aceptables, aunque por debajo de otras técnicas de optimización más potentes como APG o SFLA. La tabla inferior muestra la zona de eficiencia máxima definida por el algoritmo HS en el diseño óptimo de la red de Hanoi:

\begin{tabular}{|c|c|c|c|}
\hline \multicolumn{2}{|c|}{ PARÁMETROS } & $\begin{array}{c}\text { Obtención de mínimas } \\
\text { soluciones }\end{array}$ & $\begin{array}{c}\text { Obtención de buenas } \\
\text { soluciones }\end{array}$ \\
\hline Probabilidad HMCR & HMCR & - & $0,9-0,92$ \\
\hline Ajuste pitchrate & PAR & - & $0,05-0,15$ \\
\hline Número individuos & Pop & - & 30 \\
\hline
\end{tabular}

Tabla 6.3. Ajuste óptimo de parámetros HS en la red de Hanoi considerando la eficiencia.

\subsubsection{Algoritmo SFL}

El algoritmo de optimización SFL es uno de los más potentes en cuanto a optimización se refiere. Por ello, el ajuste reviste mayor complejidad, puesto que son cinco los parámetros susceptibles de optimización.

Este proceso de ajuste, considerando como criterio de elección la probabilidad de obtener la mejor solución posible se lleva a cabo en 5.2 sobre una muestra de 26000 simulaciones realizadas para la red de Hanoi. El algoritmo SFL se muestra muy capaz en la obtención de la solución mínima de diseño, puesto que en sus mejores zonas de cálculo es el método que mayor número de mínimos obtiene, con probabilidades de éxito superiores al $15 \%$. Así, una combinación de parámetros dada por un número de saltos evolutivos (N) superior a 23,75, un tamaño de submemeplex (Q) cercano a 1 y un coeficiente acelerador (C) en torno a 2 puede considerarse como óptima en el proceso de obtención de la solución óptima de diseño.

Respecto al estudio de velocidad, el análisis se centra en la relación existente entre los parámetros relacionados con la naturaleza de los saltos evolutivos ( $N, Q$ y $C$ ) y el número de evaluaciones de la función objetivo hasta encontrar la solución definitiva. Así, en el caso de $Q$, los resultados no muestran una relación definida entre este parámetro y la velocidad, puesto que se producen distintos saltos. No obstante, los otros dos parámetros sí tienen una relación clara con el número de iteraciones que realiza el algoritmo. Así, el análisis del coeficiente acelerador concluía que el número de evaluaciones realizadas de la función objetivo disminuye en gran medida conforme aumenta el valor de $\mathrm{C}$ hasta llegar a valores cercanos a 1,75-2, momento en el que el número de evaluaciones realizadas vuelve a subir y el aumento de $\mathrm{C}$ no garantiza una búsqueda más rápida de la solución por parte del algoritmo. Por último, el coste computacional aumenta conforme lo hace el número de saltos evolutivos 
programados $(\mathrm{N})$, circunstancia que es perfectamente lógica, puesto que se está aumentando el número de cálculos realizados en cada iteración del algoritmo.

El cálculo de eficiencia permite la toma de decisiones considerando criterios de calidad y velocidad de modo conjunto. Las tres figuras mostradas a continuación representan la eficiencia del algoritmo SFLA en función de los parámetros de ajuste N, Q y C. La eficiencia representada es un valor relativo, puesto que son valores referidos al punto de eficiencia máxima en la red de Hanoi, obtenido mediante el APG. Este punto de eficiencia máxima tiene valor 1 y lo cerca o lejos que se encuentre la eficiencia del algoritmo SFL de la unidad determinará lo bueno que es el algoritmo en esta red.

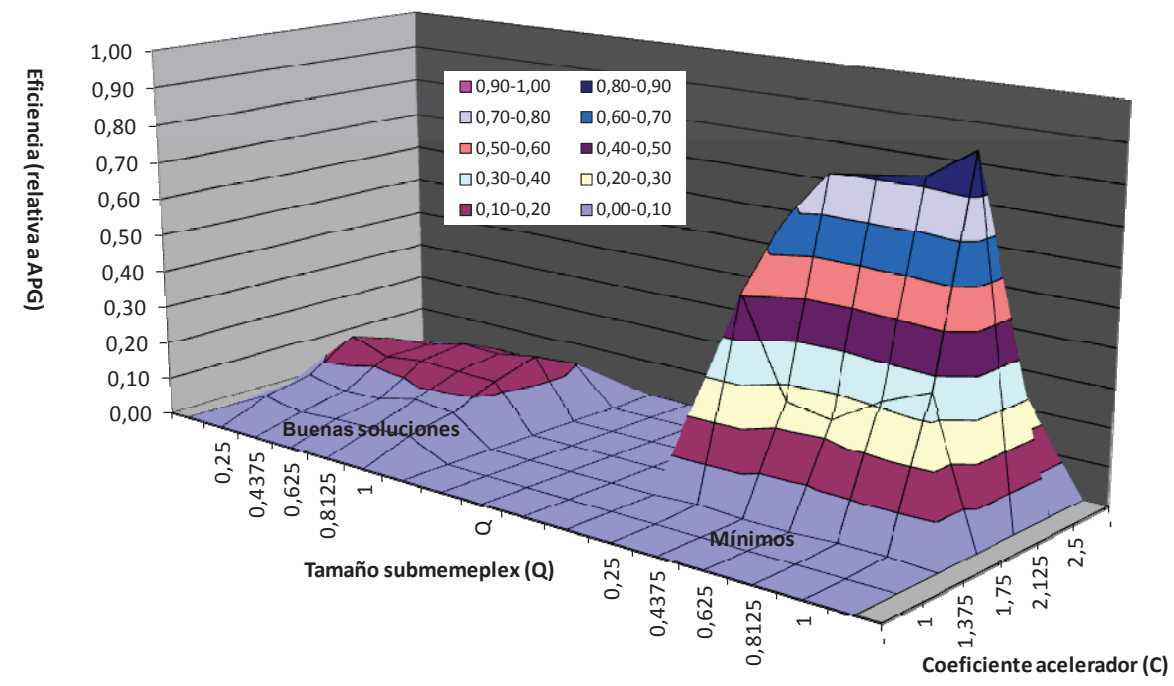

Figura 6.8. Análisis de eficiencia según tamaño submemeplex (Q) y coeficiente acelerador (C) para la red de Hanoi 


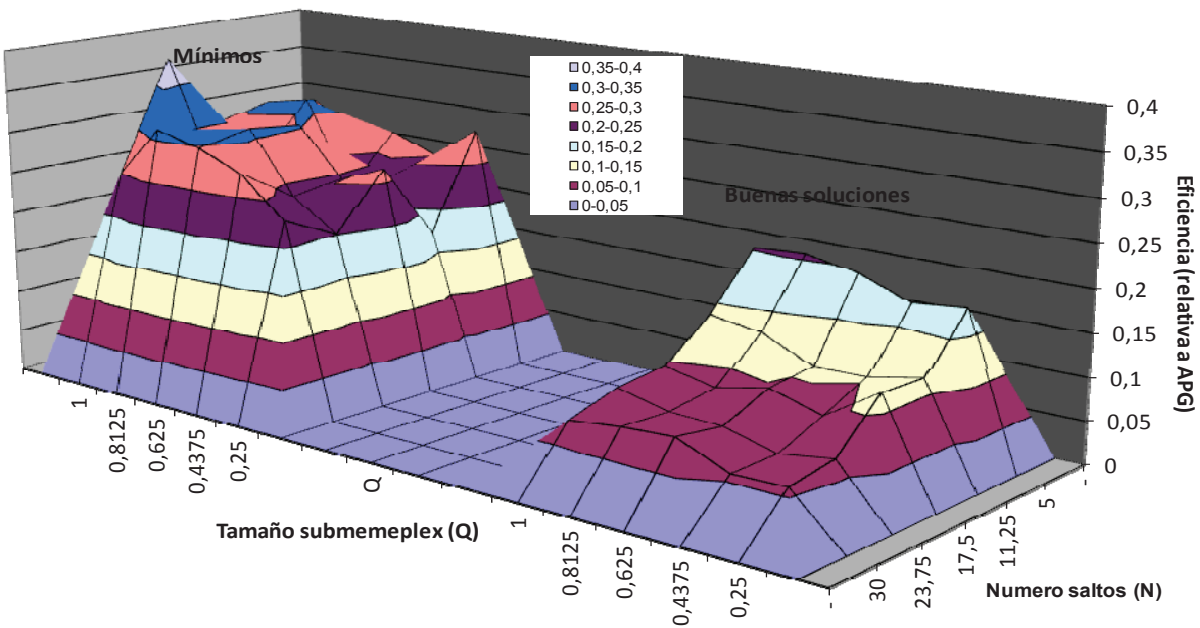

Figura 6.9. Análisis de eficiencia según tamaño submemeplex (Q) y número de saltos (N) para la red de Hanoi

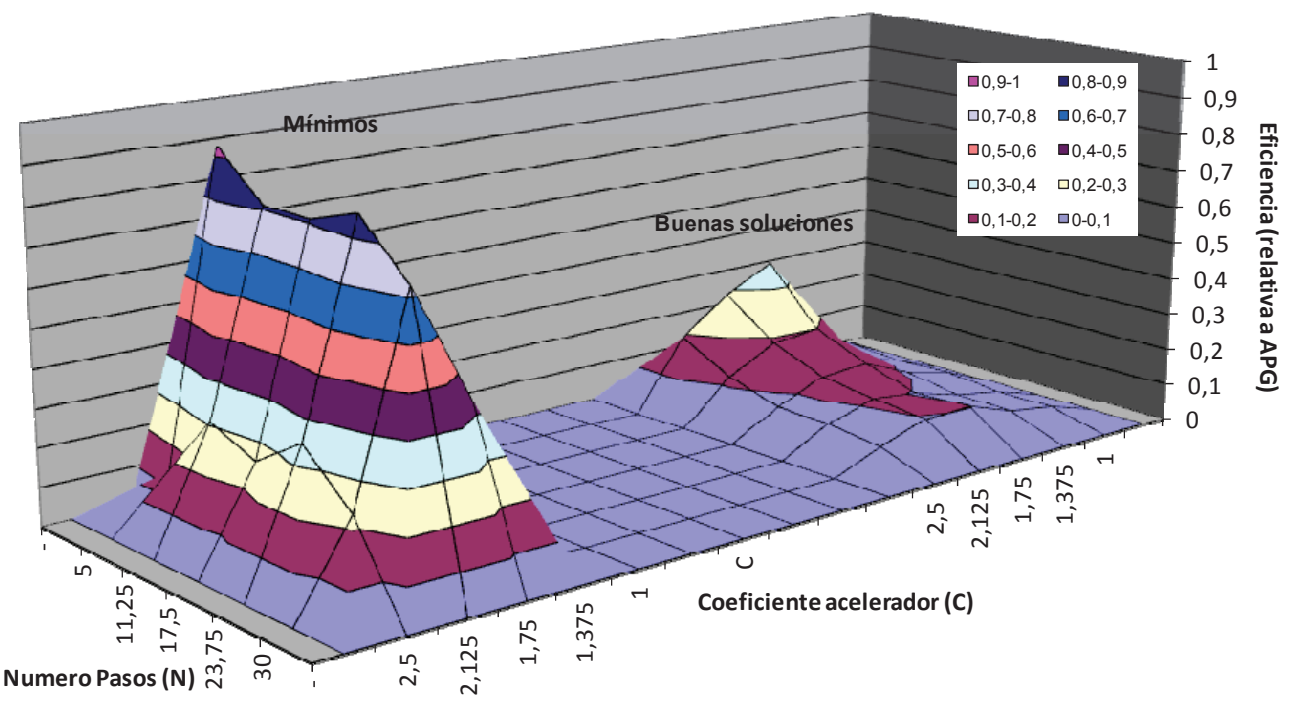

Figura 6.10. Análisis de eficiencia según número de saltos $(N)$ y coeficiente acelerador (C) para la red de Hanoi

El análisis de los resultados obtenidos en el diseño de la red de Hanoi muestra como el algoritmo SFL es más eficaz cuando se trata de encontrar la solución mínima del problema de diseño que cuando se trata de encontrar soluciones próximas a este óptimo. Esta diferencia se refleja con claridad en las representaciones realizadas en las figuras 6.8, 6.9 y 6.10, donde los gráficos de eficiencia de obtención de mínimas soluciones son mucho más altos. Este hecho tiene su fundamento en el número de evaluaciones que realiza la función objetivo en 
cada iteración del algoritmo SFL, superior a cualquier otra técnica. Este mayor número de iteraciones permite una mayor exploración del espacio de soluciones, mejorando progresivamente la solución de diseño, pero aumentando el tiempo de cálculo del algoritmo.

Estas representaciones tratan de reflejar la importancia del ajuste de parámetros en los resultados obtenidos. Así, en el caso del coeficiente acelerador, las figuras 6.8 y 6.10 muestran como un ajuste para $\mathrm{C}$ en torno a 2 maximiza el buen hacer del algoritmo, dando como resultado valores de eficiencia cercanos a 1. El ajuste de este parámetro no admite ningún tipo de discusión, especialmente en la obtención de mínimas soluciones, puesto que un ajuste de $\mathrm{C}$ superior o inferior a 2 disminuye rápidamente la eficiencia del algoritmo. El mejor ajuste de eficiencia coincide con las recomendaciones que se obtenían en los análisis de ajuste para la obtención de la mejor solución posible y velocidad, cuantificando de un modo adimensional la diferencia con el resto de valores de $\mathrm{C}$ testeados.

Las figuras 6.9 y 6.10 relacionan el número de saltos evolutivos con la eficiencia. Para $\mathrm{N}$, las figuras muestran como la eficiencia del algoritmo es algo mayor cuando el número de saltos evolutivos es pequeño. Este resultado es inverso al que mostraba el análisis de parámetros cuando se tenía como objetivo la obtención de la mejor solución posible. La diferencia fundamental entre ambos estudios radica en la penalización que imponen los grandes valores de $\mathrm{N}$ a la velocidad del algoritmo, puesto que provocan tal incremento del tiempo de cálculo que no compensa la mejora introducida en la probabilidad de obtener la solución mínima.

Esta diferencia se remarca aún más cuando se analiza la eficiencia en la obtención de buenas soluciones de diseño, puesto que la eficiencia del algoritmo en zonas con un ajuste de $\mathrm{N}=5$ es el doble que en zonas con valores de $\mathrm{N}$ en torno a 30. Del mismo modo, comparado con el APG, cabe destacar la disminución drástica que sufre la eficiencia de SFL en la obtención de buenas soluciones, penalizada por la gran cantidad de recursos que utiliza este algoritmo. En este sentido, para $\mathrm{N}=5$, que identifica el mejor ajuste para la red de Hanoi, los valores de eficiencia apenas alcanzan 0,30, muy lejos de la referencia que proporciona el APG.

Por último, en el rango de ajuste considerado para el tamaño de submemeplex (Q), el algoritmo SFL se muestra más eficiente conforme aumenta el valor de $Q$, alcanzando el máximo de eficiencia para $Q=1$, ya sea en la obtención de mínimas o buenas soluciones. La mejora producida conforme aumenta el tamaño de submemeplex no es lo suficientemente grande como para considerar el ajuste de este parámetro como crítico, pero sí que se produce de un modo constante, por lo que para la red de Hanoi es posible concluir que el ajuste óptimo de $Q$ está en torno a 1.

En este sentido, el coeficiente acelerador (C) resulta el parámetro más crítico en lo que a eficiencia se refiere para la red de Hanoi, puesto que de su correcta elección depende en gran medida la probabilidad de éxito que vaya a tener el algoritmo. 
Los datos de eficiencia proporcionados hasta el momento incluyen aquellos parámetros que tienen relación con la naturaleza de los saltos evolutivos. No obstante, el ajuste que realiza el usuario incluye dos parámetros más, relacionados en este caso con el número de individuos que intervienen en el proceso evolutivo. Estos dos parámetros son el número de memeplexes (m) y el número de ranas por memeplex ( $n$ ), siendo el producto de ambos el número total de partículas que intervienen en el proceso de optimización.

En este caso, el análisis de eficiencia se realiza a partir de una tanda de simulaciones que mantiene constantes los otros tres parámetros $(\mathrm{Q}, \mathrm{C}$ y $\mathrm{N})$, variando el ajuste de $\mathrm{m}$ y $\mathrm{n}$ entre 10 y 30, de modo que se estudian tamaños de población comprendidos entre los 100 y los 900 individuos. Los valores utilizados para $\mathrm{Q}, \mathrm{C}$ y $\mathrm{N}$ son los que definen la zona óptima de cálculo cuando se considera tan sólo la probabilidad de obtener la mejor solución posible. Así, la figura 6.11 representa la eficiencia relativa del algoritmo respecto de APG, técnica de mejor rendimiento en la red de Hanoi:

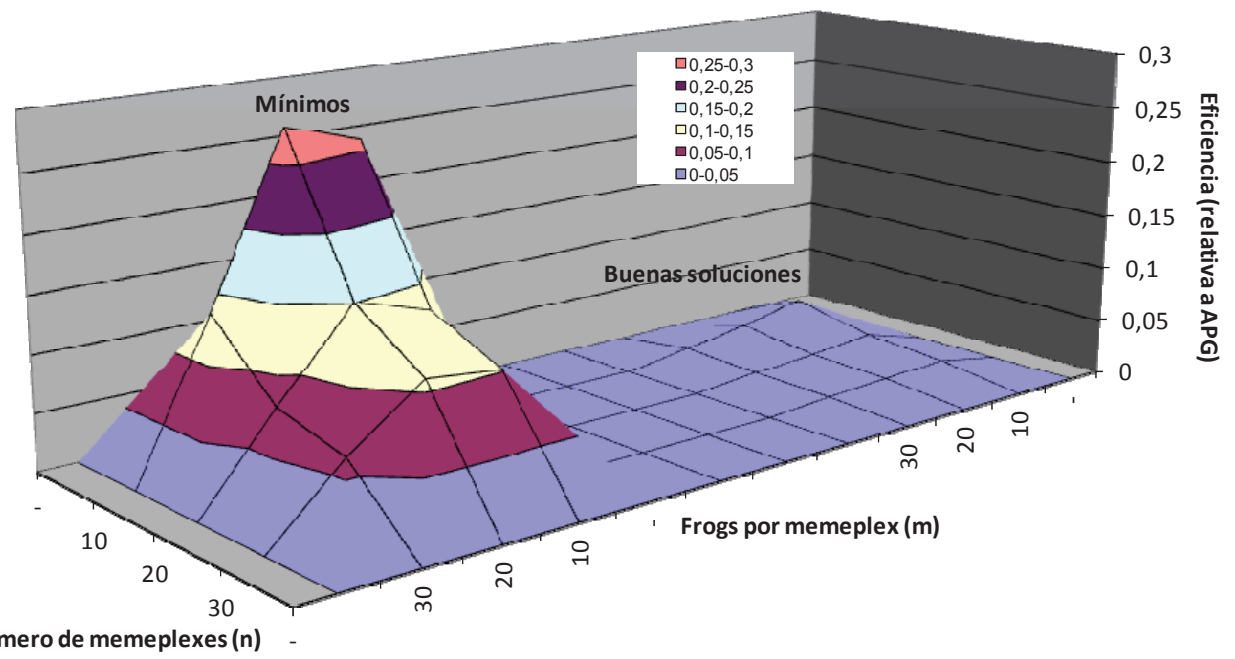

\section{Figura 6.11. Ajuste óptimo de $m$ y $n$ para algoritmo SFL en la red de Hanoi considerando la eficiencia}

Analizando de modo independiente cada uno de los dos parámetros que determinan la población del algoritmo, la figura muestra con claridad como el algoritmo es mucho más eficiente cuando el número de memeplexes es 10. Así, para n superior a 10 la eficiencia del algoritmo disminuye progresivamente, independientemente del valor que tome $\mathrm{m}$.

En el caso del número de ranas por memeplex, los resultados de eficiencia son muy parecidos para valores entre 10 y 20, disminuyendo drásticamente la eficiencia para m superior a 20. 
La conclusión general es que la eficiencia del algoritmo es mejor cuanto menor es el tamaño total de la población considerada, puesto que en todos los casos se da la circunstancia de que los peores resultados se obtienen cuando $m$ ó $n$ toman valores superiores a 20. Esta situación de baja eficiencia se produce porque el número de evaluaciones de la función objetivo realizadas con tamaños de población grandes se dispara en el algoritmo SFLA, provocando grandes penalizaciones en el cálculo de la eficiencia.

Tal como muestra la figura 6.11, la eficiencia del algoritmo SFLA en esta tanda de simulaciones ofrece valores muy cercanos a cero. La principal causa de este resultado es que todas las simulaciones que incluye la figura se realizan con $\mathrm{N}=30$, que unido a los grandes tamaños de población considerados provocan un aumento superlativo del número de evaluaciones realizadas en EPANET, lo que ralentiza el cálculo hasta un punto donde el aumento de mínimos/buenas soluciones producido no compensa los recursos empleados. El análisis de eficiencia respecto de $\mathrm{N}$ que mostraban las figuras 6.9 y 6.10 ya advertía que el algoritmo es mucho más eficiente para valores de $\mathrm{N}$ en torno a 5.

A la vista de los resultados obtenidos relacionando calidad de la solución y velocidad del algoritmo es posible concluir que la herramienta de optimización basada en SFLA es adecuada en la red de Hanoi cuando el objetivo de diseño es la obtención de la solución mínima, puesto que es lo suficientemente potente como para encontrar soluciones óptimas aún en un espacio de soluciones tan extenso como el que plantea la red de Hanoi. No obstante, si el problema de diseño no requiere únicamente de mínimas soluciones, sino que un conjunto de buenas soluciones cercanas al óptimo cumple el objetivo de diseño, los resultados de eficiencia muestran que otras técnicas permiten obtener los mismos resultados en mucho menos tiempo. Así, para la obtención de buenas soluciones tanto el APG como HS se encuentran muy por encima del algoritmo SFL.

El análisis de la eficiencia según el tamaño de población del algoritmo completa el estudio de todos los parámetros de ajuste dependientes del usuario en SFLA. La tabla 6.4 resume las conclusiones que se derivan del análisis de eficiencia realizado para la red de Hanoi, de modo que el rango de ajuste proporcionado combina la probabilidad de obtener la mejor solución con el menor gasto computacional posible.

\begin{tabular}{|c|c|c|c|}
\hline \multicolumn{2}{|c|}{ PARÁMETROS } & $\begin{array}{c}\text { Obtención de mínimas } \\
\text { soluciones }\end{array}$ & $\begin{array}{c}\text { Obtención de buenas } \\
\text { soluciones }\end{array}$ \\
\hline Tamaño submemeplex & $\mathrm{Q}$ & 1 & 1 \\
\hline $\begin{array}{c}\text { Número saltos } \\
\text { evolutivos }\end{array}$ & $\mathrm{N}$ & 5 & 2,125 \\
\hline $\begin{array}{c}\text { Coeficiente de } \\
\text { aceleración }\end{array}$ & $\mathrm{C}$ & 2,125 & 10 \\
\hline Ranas por memeplex & $\mathrm{m}$ & $10-20$ & 10 \\
\hline Número memeplexes & $\mathrm{n}$ & 10 & 5 \\
\hline
\end{tabular}

Tabla 6.4. Ajuste óptimo de parámetros SFL en la red de Hanoi considerando la eficiencia. 


\subsection{Eficiencia de los modelos de optimización en la red de Nueva York}

El análisis de eficiencia realizado en este caso concluye que el método que mejor se adapta a las características de la red es el algoritmo de optimización Harmony Search. En apartados anteriores ya se ha visto que HS tiene hasta tres parámetros cuya configuración depende del usuario, como son el tamaño de la memoria del algoritmo (población), la probabilidad HMCR y el ajuste del PAR. La mejor combinación para estos tres parámetros considerando como criterio de elección la eficiencia del algoritmo corresponde a un tamaño de memoria de 100 individuos, una probabilidad HMCR igual a 0,92 (tanto por uno) y un ajuste del PAR de 0,05. Esta combinación de parámetros toma valor 1 en el estudio de eficiencia relativa de la red de los túneles de Nueva York y representa la mejor combinación posible entre todos los métodos estudiados.

Las siguientes líneas muestran con detalle el estudio de eficiencia realizado para cada una de las metodologías heurísticas, ya sea en la obtención de soluciones mínimas para el problema de optimización, o de buenas soluciones (sobrecoste de hasta un 3\% respecto de la solución mínima). Cabe recordar que el índice de eficiencia relativa será mejor cuanto más se acerque a la unidad.

\subsubsection{Algoritmo Pseudogenético}

El análisis de eficiencia se basa en relacionar la probabilidad de encontrar una mínima/buena solución del problema con el esfuerzo computacional realizado hasta conseguirla, es decir, el número de evaluaciones de la función objetivo necesarias hasta alcanzar la solución del problema.

En la red de Hanoi, el APG se mostraba como el algoritmo más eficiente en el tratamiento de dicha red. En la red de los túneles de Nueva York, los recursos que pone en marcha el APG se antojan excesivos para un problema de menor complejidad como el de la red de los túneles de Nueva York. Así, si bien la probabilidad de encontrar una mínima solución para el problema es similar a la que obtiene el algoritmo HS, éste último lo hace con muchas menos evaluaciones de la función objetivo, por lo que encuentra la solución del problema en menos tiempo. Este hecho se ve reflejado en la figura 6.12, que muestra los valores de eficiencia relativa obtenidos para la red de los túneles de Nueva York en función de los operadores genéticos de mutación y cruce: 


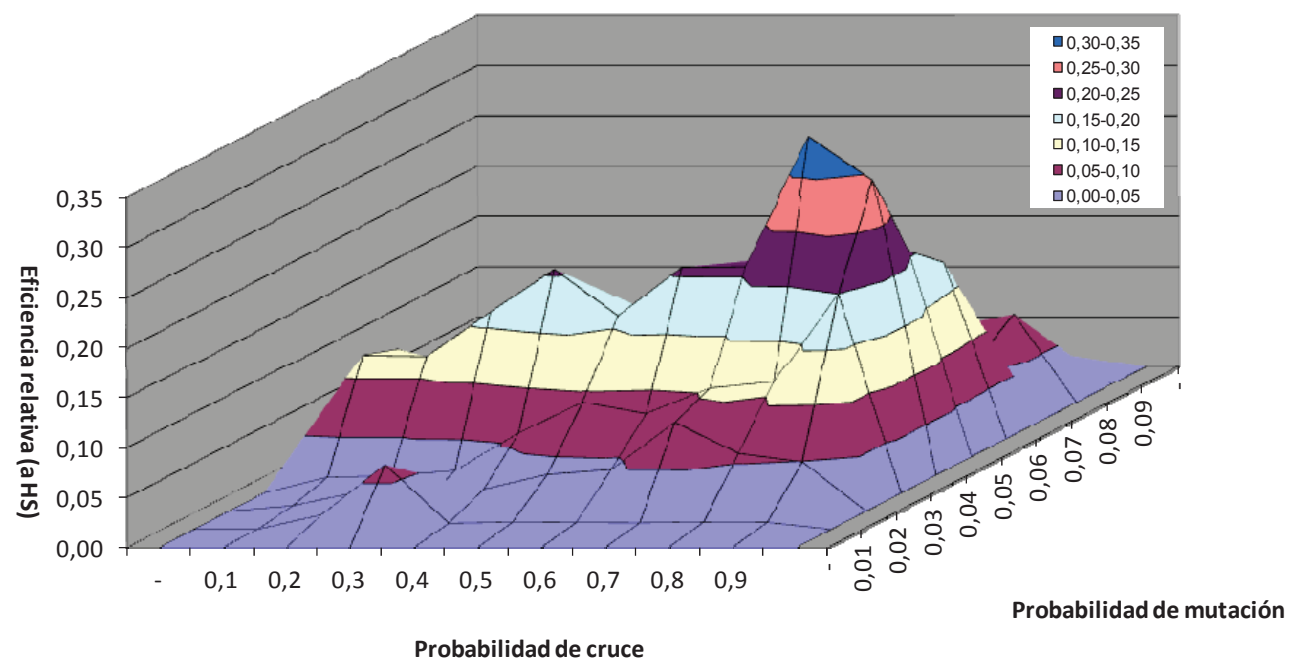

Figura 6.12. Análisis de eficiencia según mutación y cruce en la red de NY para el APG.

Los datos representados en la figura muestran como la zona más eficiente en la optimización por APG corresponde a probabilidades de mutación en torno al 4-5\% y probabilidades de cruce superiores al $60 \%$. Al igual que ocurría en la red de Hanoi, la zona de mayor eficiencia coincide con la zona que representa la mayor probabilidad de encontrar mínimas soluciones de diseño.

No obstante, si se atiende a los valores numéricos de eficiencia, es evidente que el algoritmo APG está muy lejos del algoritmo HS, puesto que la mejor zona de trabajo en APG apenas alcanza 0,3 como valor de eficiencia relativa. En el caso de considerar como criterio de eficiencia la obtención de buenas soluciones, los resultados incluso empeoran, puesto que la eficiencia relativa del APG alcanza como máximo 0,22 , lo que supone un grado de eficiencia casi 5 veces menor que el algoritmo HS.

Si se mantienen constantes los operadores genéticos es posible aplicar el criterio de eficiencia al tamaño de población. Las figuras 6.13 y 6.14 muestran la eficiencia relativa del algoritmo para un rango de población que se mueve entre 25 y 225 individuos. La tanda de simulaciones objeto de estudio toma para los operadores genéticos el valor más adecuado teniendo en cuenta únicamente la probabilidad de encontrar una mínima solución del problema. Así, la mutación toma valores entre 0,03 y 0,04, mientras que el cruce toma valores por encima de 0,6 . 


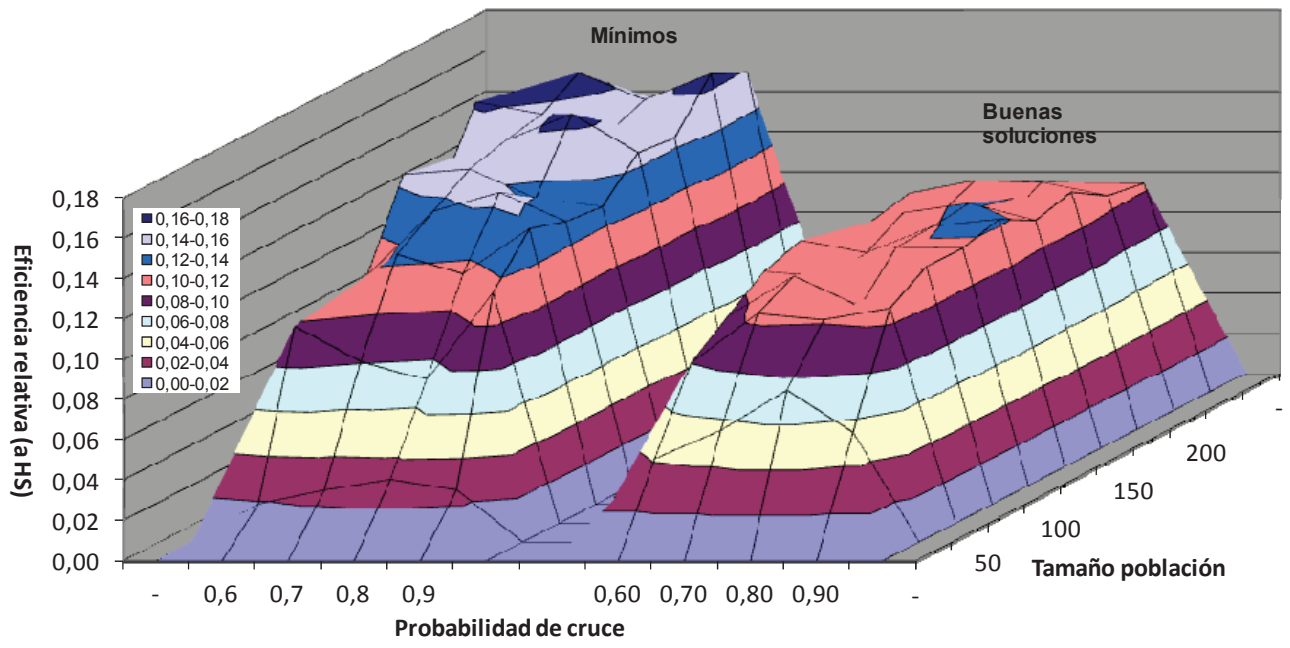

Figura 6.13. Análisis de eficiencia según población y cruce en la red de NY para el APG.

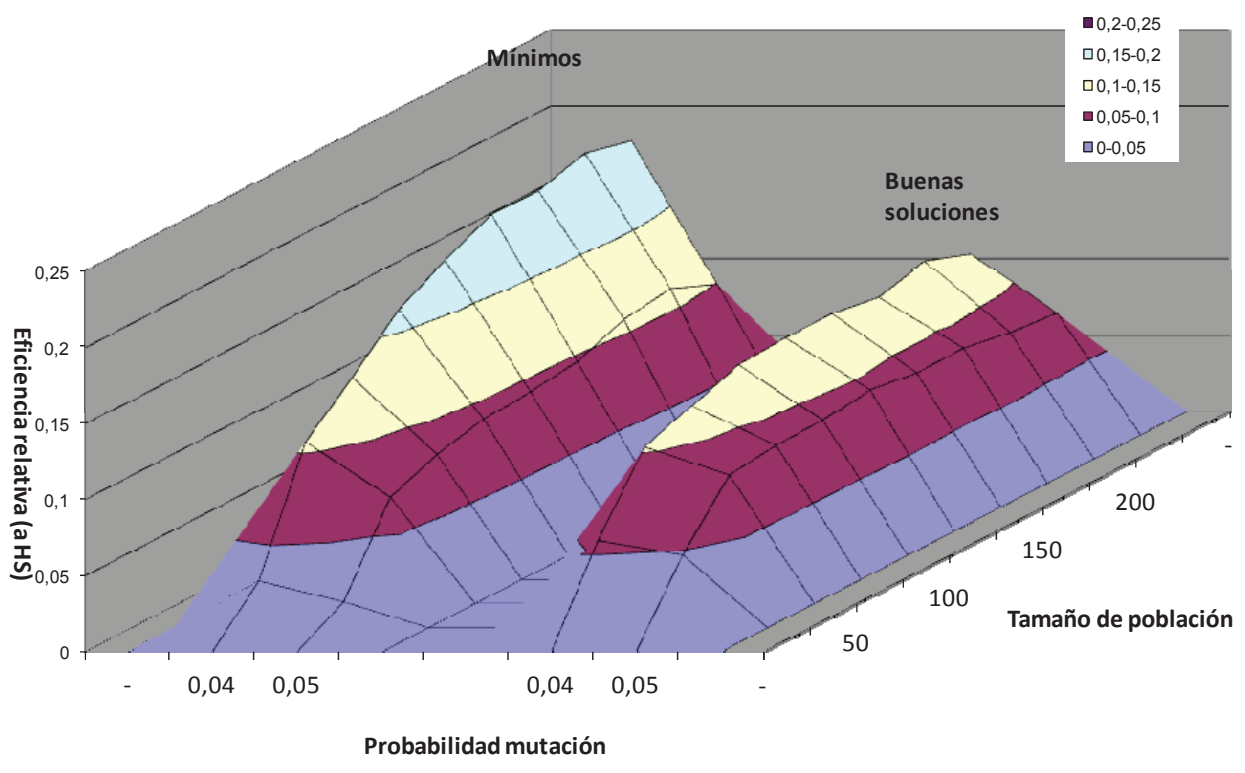

Figura 6.14. Análisis de eficiencia según mutación y cruce en la red de NY para el APG.

Anteriormente ya se ha estudiado la relación entre el tamaño de la población genética y la probabilidad de encontrar mínimas soluciones de diseño. La principal conclusión obtenida era que cuanto mayor era el tamaño de la población mayor era también la posibilidad de obtener una mejor solución, de modo que los resultados mejoraban progresivamente sin llegar a alcanzar un máximo en el rango estudiado. 
El estudio de eficiencia que relaciona la población inicial del algoritmo con los operadores genéticos permite tomar nuevas conclusiones. Así, la figura 6.13 permite comprobar como el APG tiene sus peores zonas de eficiencia para las poblaciones más pequeñas, pero a partir de cierto número de individuos, las diferencias entre unas poblaciones y otras son imperceptibles. En este sentido, si se considera la búsqueda de mínimos los resultados nos muestran que a partir de 100 individuos los valores de eficiencia son muy similares para probabilidades de cruce de entre un 60 y un $90 \%$.

Del mismo modo, la figura 6.14, que relaciona el tamaño de población con la probabilidad de mutación, sigue las mismas directrices en cuanto a la eficiencia del algoritmo, alcanzándose un máximo de población a partir del cual ésta no mejora. En este caso, poblaciones por debajo de 150 individuos provocan una menor eficiencia del algoritmo, mientras que entre 150 y 225 individuos es indiferente el tamaño de población que se utilice, puesto que la eficiencia es prácticamente constante para este intervalo de población. Respecto al operador genético de mutación, los gráficos de eficiencia confirman una probabilidad de mutación del $4 \%$ como óptima para la red de Nueva York.

Considerando el concepto de buena solución, el grado de eficiencia del APG no solo no mejora, sino que incluso empeora, puesto que los valores de eficiencia relativa apenas llegan a 0,15 . No obstante, cabe destacar que cuando el objetivo es encontrar tan sólo un conjunto de buenas soluciones es posible rebajar el número de individuos que entran en juego en el proceso de optimización sin temor a que descienda la eficiencia del APG. Así, tamaños de población entre 50 y 225 individuos muestran valores de eficiencia muy similares, por lo que no parece un parámetro de cálculo del que haya que preocuparse excesivamente si el objetivo es únicamente encontrar un conjunto de buenas soluciones.

En el caso de APG, cabe destacar que no hay que confundir pequeños valores de eficiencia con ningún tipo de incapacidad del APG en la red de Nueva York, puesto que por ejemplo, para una población de 225 individuos el APG consigue más de un $80 \%$ de buenas soluciones de diseño. El problema del APG en este caso radica en la cantidad de recursos que emplea, puesto que realiza un número excesivo de evaluaciones de la función objetivo para un problema de menor dificultad, por lo que queda muy penalizado respecto al algoritmo HS. Se puede concluir que para problemas más sencillos, con un menor número de mínimos locales que compliquen la búsqueda del óptimo, parece mucho más adecuado el uso de técnicas como Harmony Search, que realiza tan sólo una evaluación de la función objetivo en cada iteración.

Una vez evaluados los criterios de eficiencia considerados, cabe concluir que el APG no representa la técnica más adecuada para un problema de las características de la red de los túneles de Nueva York. No obstante, el estudio de eficiencia permite definir un rango de 
trabajo óptimo tanto para los operadores genéticos como para el tamaño de población con el que debe trabajar el algoritmo, que queda definido como:

\begin{tabular}{|c|c|c|c|}
\hline \multicolumn{2}{|c|}{ PARÁMETROS } & Obtención de mínimas soluciones & Obtención de buenas soluciones \\
\hline Prob. de cruce & $\mathrm{P}_{\mathrm{c}}$ & $>60 \%$ & $>60 \%$ \\
\hline Prob. de mutación & $\mathrm{P}_{\mathrm{m}}$ & $4 \%$ & $4 \%$ \\
\hline Tamaño de población & $\mathrm{Pop}$ & $>150$ individuos & $>50$ individuos \\
\hline
\end{tabular}

Tabla 6.5. Ajuste óptimo de parámetros APG en la red de los túneles de Nueva York considerando la eficiencia.

\subsubsection{Algoritmo PSO}

El análisis de parámetros realizado en 5.2 para el diseño de la red de los túneles de Nueva York aplicando el algoritmo PSO obtenía la solución de mínimo coste como la solución más repetida. Así, sobre un total de 25600 simulaciones, hasta un 13,35\% de ellas obtenía la óptima solución de diseño, con un coste de 38,642 millones de um. El filtro de resultados a través de los distintos parámetros de ajuste determinaba que el límite de velocidad de las partículas $\left(V_{\text {lim }}\right)$ y la probabilidad de despiste $\left(P_{\text {desp }}\right)$ eran los parámetros más críticos, de modo que su correcto ajuste prácticamente duplicaba la probabilidad de obtener la mínima solución del problema.

Así, el límite de velocidad que mejor funciona considerando únicamente la probabilidad de obtener la mejor solución estaba en torno a 0,4, lo que equivale a permitir un salto máximo de seis diámetros dentro de la gama utilizada, que consta de de 15 posibilidades distintas. En cuanto a la probabilidad de despiste, los resultados mejoraban considerablemente cuando se consideran probabilidades en torno al $10 \%$, puesto que valores inferiores provocan búsquedas incompletas y convergencias demasiado tempranas, mientras que valores superiores aumentan demasiado el factor aleatorio del método. Esta última situación se produce porque conforme se aumenta $\mathrm{P}_{\text {desp }}$ disminuyen los pájaros que siguen al líder que está en la mejor posición.

Por otro lado, si se considera la velocidad con la que calcula el algoritmo PSO, el análisis de velocidad muestra como conforme aumenta la velocidad límite de una determinada partícula disminuye el número de evaluaciones realizadas, puesto que se alcanzan antes los extremos de la gama de diámetros, acelerando la convergencia del algoritmo. Del mismo modo, al aumentar la probabilidad de despiste crece el número de evaluaciones realizadas, puesto que se envían más pájaros a explorar nuevas posiciones del espacio de soluciones sin importar la posición del líder.

El estudio de eficiencia relaciona el número de mínimos/buenas soluciones obtenidas con el número de evaluaciones realizadas que se requieren para conseguirlas. Obviamente, la situación ideal radica en obtener las mejores soluciones con el menor esfuerzo posible. La figura 6.15 relaciona ambos conceptos, puesto que representa la eficiencia del algoritmo PSO 
en la obtención de mínimas y buenas soluciones (3\%) de diseño. El valor de eficiencia proporcionado es relativo al método que se muestra como más eficiente en el diseño de la red de los túneles de Nueva York, es decir, el algoritmo Harmony Search.

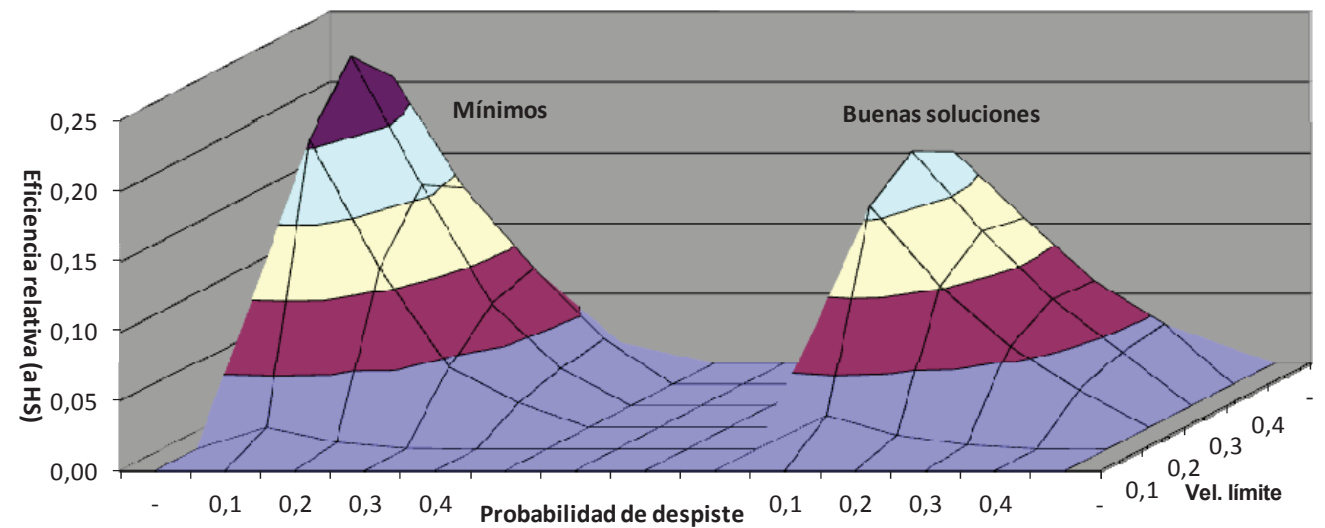

Figura 6.15. Análisis de eficiencia según $V_{\text {lim }}$ y $P_{\text {desp }}$ en la red de los túneles de NY para PSO modificado

El análisis de los resultados de eficiencia permite tomar varias conclusiones de importancia. Así, analizando los resultados de un modo local la conclusión es clara, y es que probabilidades de despiste en torno al $10 \%$ son las óptimas para la red de Nueva York, puesto que además de ser las que mejores soluciones obtienen considerando únicamente el coste de diseño también son las más eficientes. Tanto el análisis de mínimas soluciones como el de buenas soluciones muestran con claridad como la eficiencia del algoritmo baja rápidamente conforme aumenta la probabilidad de despiste. Sin embargo, si se centra el análisis en la velocidad límite de vuelo que puede tomar un pájaro, es decir, el número de diámetros que puede saltar en una única iteración dentro de la gama considerada, los resultados de eficiencia muestran como las diferencias entre utilizar valores entre 0,2 y 0,4 son pequeñas, mientras que para la red de Nueva York se descarta completamente límites de velocidad por debajo de 0,2, con un índice de eficiencia prácticamente nulo.

Considerando un enfoque más general de la eficiencia respecto al resto de métodos, cabe destacar como para la red de Nueva York, el algoritmo PSO obtiene valores de eficiencia cercanos al APG y supera ampliamente al algoritmo SFL. Este hecho es destacable, puesto que para redes más complejas, como puede ser la red de Hanoi o la red de Joao Pessoa, el algoritmo PSO está muy por debajo en cuanto a eficiencia a estas dos técnicas, que suben considerablemente cuanto más compleja es la red.

Por otro lado, los resultados obtenidos en el análisis de parámetros para $C_{1}$ y $C_{2}$ minimizan la importancia de ambas respecto a $P_{\text {desp }} \circ \mathrm{V}_{\text {lim }}$. La conclusión general respecto a ambas era que valores en torno a 1,8-2 mejoran ligeramente la probabilidad de obtener una mejor solución, 
pero no representaban en ningún caso un parámetro crítico para el sistema de optimización, puesto que en el rango estudiado las diferencias no eran considerables. En cuanto al número de cálculos realizados en EPANET por el algoritmo PSO, el estudio de velocidad no era capaz de establecer ningún tipo de relación entre $C_{1}$ y el número de evaluaciones realizadas por el algoritmo, pero sí que existía una cierta tendencia del algoritmo a realizar un menor número de cálculos cuando el valor numérico de $C_{2}$ era mayor. La figura 6.16 muestra la eficiencia del algoritmo en base a ambas constantes. Esta representación contiene todas las simulaciones realizadas, incluyendo todos los valores de $V_{\lim } \mathrm{Y} \mathrm{P}_{\text {desp }}$. De nuevo se muestran valores relativos al algoritmo HS, que se muestra como la mejor técnica de diseño para la red de Nueva York.

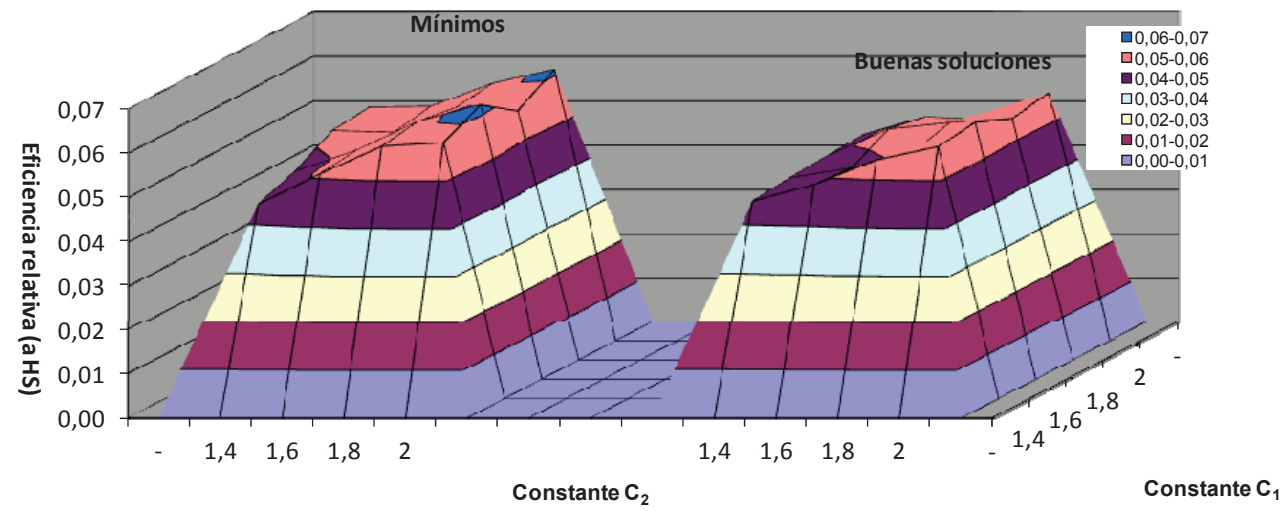

Figura 6.16. Análisis de eficiencia según $C_{1}$ y $C_{2}$ en la red de los túneles de NY para PSO modificado.

La representación muestra como la eficiencia del algoritmo es ligeramente mayor para valores de $C_{1}$ y $C_{2}$ más elevados. No obstante, la diferencia en el rango considerado para ambas constantes es del orden de 0,01 puntos de eficiencia entre los mejores y los peores valores. Así, el estudio de eficiencia confirma las recomendaciones dadas en la bibliografía, que aconsejan la utilización de valores en torno a 1,8 - 2 para ambas constantes, pero a la vez muestra como la elección de estos valores no puede ser considerada como una decisión crítica dentro del proceso de diseño.

Por último se analizan los valores de eficiencia en función del número de individuos que entran en el proceso de optimización. Así, partiendo de una configuración de parámetros constante para $V_{\text {lim, }}, P_{\text {desp }}, C_{1}$ y $C_{2}$ se analiza la eficiencia del algoritmo en base a distintos tamaños de población. Los resultados para la obtención de mínimas y buenas soluciones se muestran en la figura 6.17 . 


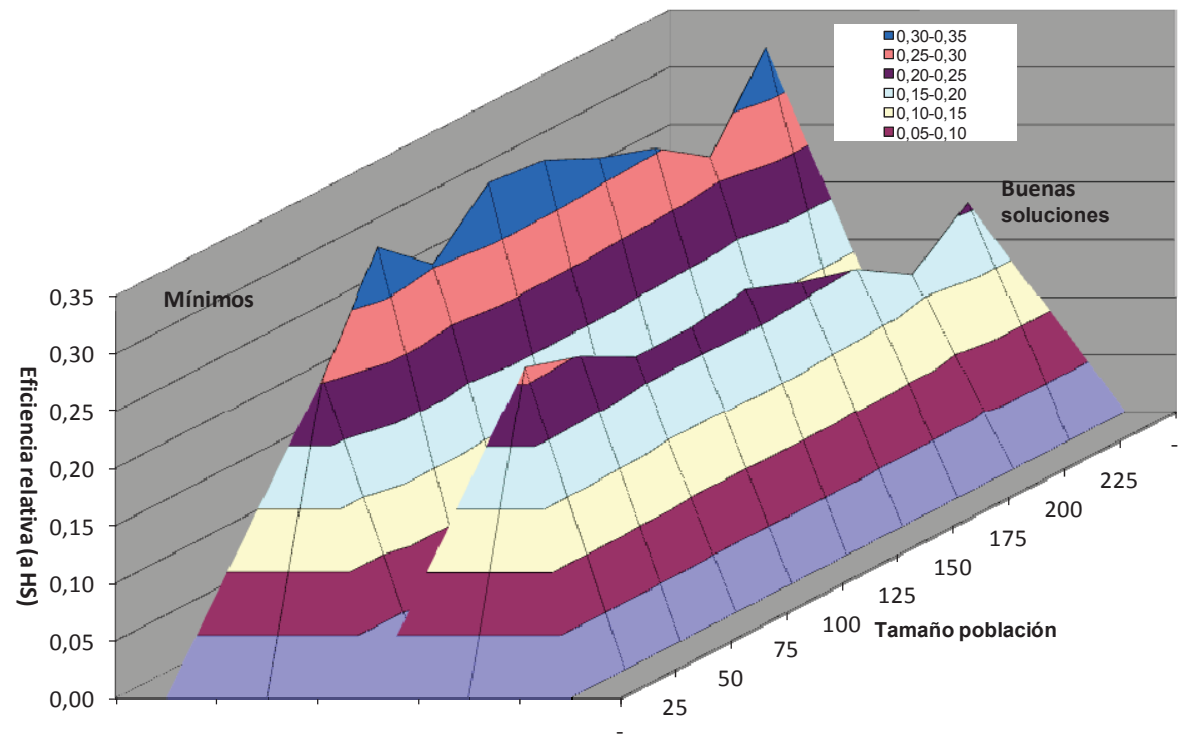

Figura 6.17. Análisis de eficiencia según tamaño de población en la red de los túneles de NY para PSO modificado

Considerando la obtención de mínimas soluciones de diseño en la red de Nueva York, los resultados muestran como para poblaciones superiores a 25 individuos se tienen valores de eficiencia en torno a 0,3-0,35. Así, en el rango comprendido entre 50 y 225 individuos no es posible determinar ninguna tendencia que haga preponderar un determinado número de individuos sobre otro.

Ampliando el campo de estudio a la eficiencia en la obtención de buenas soluciones los resultados muestran como si bien los valores de eficiencia relativa disminuyen respecto a la obtención de mínimos, sí que se aprecia cierta tendencia, de modo que cuanto menor es el número de individuos involucrados mayor es el valor de eficiencia relativa para la red de Nueva York.

Así, una vez estudiados los criterios de eficiencia relativos a los distintos parámetros, se puede concluir que el algoritmo PSO mejora sus prestaciones en la red de Nueva York respecto a otras redes más complejas, si bien no alcanza valores aceptables de eficiencia, puesto que queda muy lejos de los resultados obtenidos por Harmony Search en esta misma red. No obstante, es posible definir un rango de trabajo óptimo basado en las mejores condiciones de trabajo que muestra PSO en esta red, que queda definido como: 


\begin{tabular}{|c|c|c|c|}
\hline \multicolumn{2}{|c|}{ PARÁMETROS } & Obtención de mínimas soluciones & Obtención de buenas soluciones \\
\hline Velocidad límite & $\mathrm{V}_{\lim }$ & $30 \%$ & $30 \%$ \\
\hline Prob. de despiste & $\mathrm{P}_{\text {desp }}$ & $10 \%$ & $10 \%$ \\
\hline Constante 1 & $\mathrm{C}_{1}$ & $1,8-2$ & $1,8-2$ \\
\hline Constante 2 & $\mathrm{C}_{2}$ & $1,8-2$ & $1,8-2$ \\
\hline Número individuos & $\mathrm{Pop}$ & $50-225$ & 50 \\
\hline
\end{tabular}

Tabla 6.6. Ajuste óptimo de parámetros para el algoritmo PSO modificado en la red de los túneles de Nueva York considerando la eficiencia.

\subsubsection{Harmony Search}

Para la red de Nueva York, el algoritmo HS representa la referencia, puesto que obtiene los valores de eficiencia más altos. La siguiente figura muestra la eficiencia del algoritmo en función de la probabilidad HMCR y del ajuste del PAR

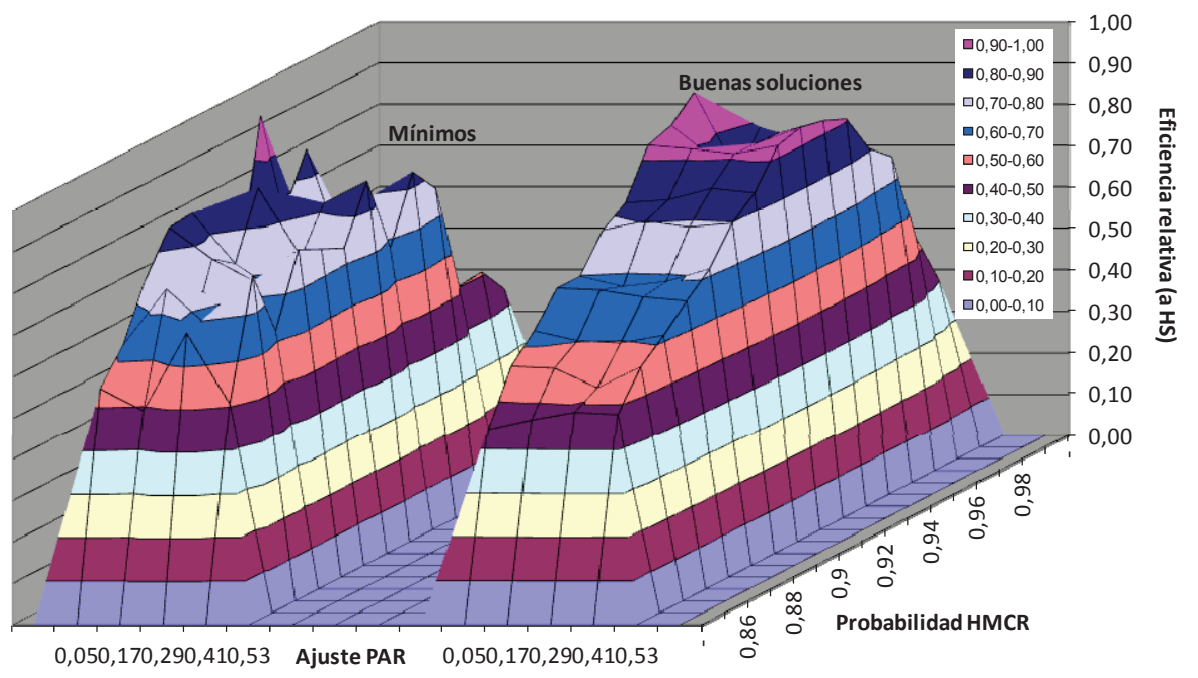

Figura 6.18. Análisis de eficiencia según HMCR y PAR en la red de los túneles de NY para algoritmo HS.

Los valores de eficiencia muestran como la optimización HS está muy por encima de las restantes técnicas de optimización en la red de Nueva York en casi todo el rango estudiado. De este modo, para probabilidades HMCR entre 0,85-0,95 y ajustes del PAR por debajo de 0,50 el $100 \%$ de las configuraciones tienen valores de eficiencia por encima de 0,5 , lo que prácticamente dobla la eficiencia en el resto de métodos de optimización estudiados.

Analizando los resultados de un modo local, la relación entre calidad de la solución y velocidad combina como zona de de máxima eficiencia los resultados obtenidos en análisis anteriores. Así, el estudio de parámetros concluye que la probabilidad de obtener mejores soluciones era mayor conforme disminuía el valor de la probabilidad HMCR, pero a la vez, el 
estudio de velocidad advertía que el considerar probabilidades HMCR más pequeñas aumenta el tiempo de cálculo del algoritmo. El estudio de eficiencia ayuda a tomar una decisión de compromiso entre la probabilidad de obtener una mejor solución y el tiempo que queremos emplear en obtenerla.

Así, el rango de trabajo que se puede definir como de eficiencia máxima en la red de Nueva York corresponde a probabilidades HMCR entre 0,92 y 0,95 aproximadamente, puesto que es la zona donde mejor se combina calidad y velocidad. En cuanto al ajuste del PAR, que toma únicamente sentido como parámetro de convergencia, la representación de eficiencia demuestra que su valor tampoco altera excesivamente los resultados siempre que permita la convergencia del algoritmo. La recomendación final respecto a este parámetro es que se tomen siempre valores lo suficientemente bajos como para garantizar la obtención de soluciones factibles de diseño. En este sentido, ajustes entre 0,05 y 0,15 se estiman como óptimos, puesto que son suficientemente bajos para garantizar convergencia y además se da la circunstancia de que el máximo de eficiencia se obtiene en un ajuste PAR de 0,05, tanto en el análisis de mínimos como en el de "buenas soluciones" de diseño.

El último parámetro de ajuste es el tamaño de memoria, o lo que es lo mismo, el número de individuos que componen la población inicial del algoritmo. De este modo, la figura 6.19 muestra los valores de eficiencia obtenidos para un intervalo de población entre 45 y 225 individuos.

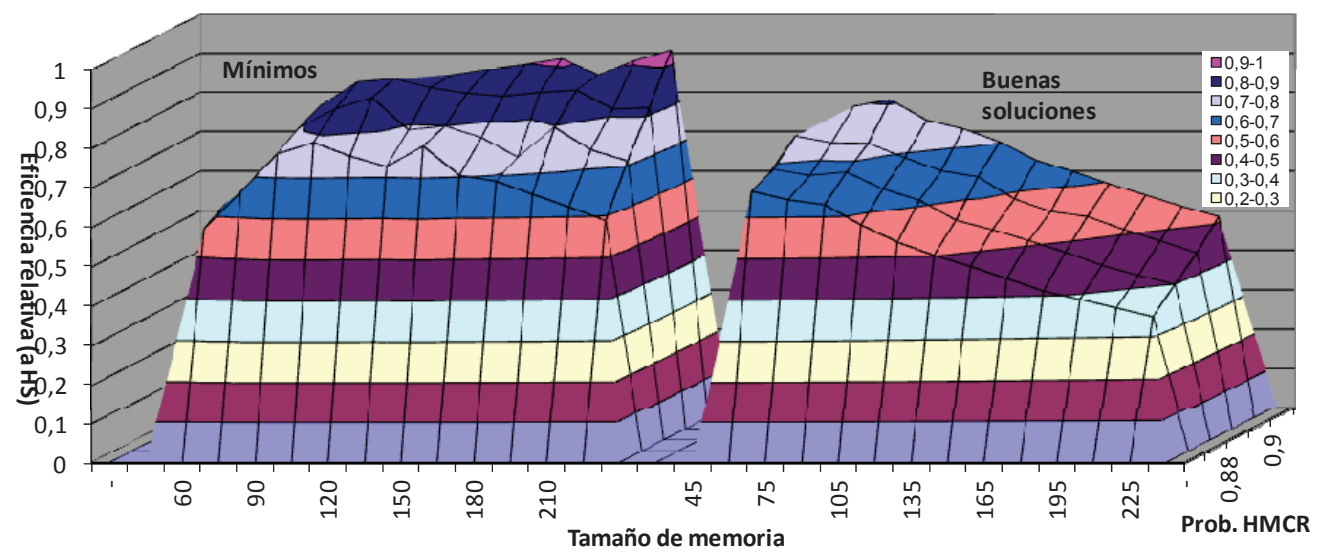

Figura 6.19. Análisis de eficiencia según tamaño de memoria en la red de los túneles de NY para algoritmo HS.

La figura 6.19 muestra la conveniencia de ajustar el número de individuos a los objetivos de diseño que se tengan para la red. De este modo, las poblaciones más grandes se muestran más eficientes a la hora de obtener la solución de mínimo coste para la red. Así, la representación del criterio de eficiencia en la obtención de mínimas soluciones muestra como 
conforme crece el número de individuos involucrados en el proceso de optimización aumenta ligeramente el valor de la eficiencia, alcanzando su máximo para una población de 225 individuos.

Por otro lado, si no existe necesidad de encontrar la solución de mínimo coste, sino que basta con la obtención de un conjunto de buenas soluciones cercanas al óptimo, las poblaciones más pequeñas se muestran más eficientes que las más grandes, de modo que entre 60-90 individuos bastan para encontrar un conjunto de soluciones próximas al óptimo con un gasto computacional mínimo.

El resumen de todo el análisis de eficiencia realizado para la red de Nueva York se muestra en la tabla 6.7. Dicha tabla muestra el rango de trabajo óptimo que debe ser considerado cuando se utiliza el procedimiento de diseño basado en HS, ya sea para la obtención de la solución mínima de diseño o para la obtención de un conjunto de soluciones próxima a ésta.

\begin{tabular}{|c|c|c|c|}
\hline \multicolumn{2}{|c|}{ PARÁMETROS } & $\begin{array}{c}\text { Obtención de mínimas } \\
\text { soluciones }\end{array}$ & $\begin{array}{c}\text { Obtención de buenas } \\
\text { soluciones }\end{array}$ \\
\hline Probabilidad HMCR & HMCR & $0,92-0,95$ & $0,92-0,95$ \\
\hline Ajuste pitchrate & PAR & $0,05-0,15$ & $0,05-0,15$ \\
\hline Número individuos & Pop & $200-225$ & $60-90$ \\
\hline
\end{tabular}

Tabla 6.7. Ajuste óptimo de parámetros para el algoritmo HS en la red de los túneles de Nueva York considerando la eficiencia.

\subsubsection{Algoritmo SFL}

El algoritmo de optimización SFL es probablemente el más complejo cuando se trata de decidir la mejor configuración posible. Esto es debido a que hasta cinco parámetros de ajuste necesitan definición, lo que complica sobremanera la puesta en marcha del proceso de optimización sin cierto conocimiento previo de la técnica.

El análisis estadístico de resultados en función de los distintos parámetros de ajuste se realiza en 5.2, sobre un total de 26000 simulaciones distintas para la red de Nueva York. Cuando se tiene en cuenta únicamente la capacidad del algoritmo para obtener la solución mínima de diseño el algoritmo SFL se muestra como el más efectivo de todos, puesto que la probabilidad de éxito en las mejores zonas de cálculo se encuentra en torno al 70\%, cifra que ninguno de los restantes algoritmos es capaz de alcanzar. En estas condiciones, la mejor combinación de parámetros viene dada por un tamaño de submemeplex (Q) de 0,44 , un número de saltos evolutivos (N) superior a 23,75 y un coeficiente acelerador (C) de 1,75.

Respecto al estudio de velocidad, el análisis realizado en 5.4 se centra en la influencia que ejercen los parámetros relacionados con la naturaleza de los saltos evolutivos (N, Q y C). Los resultados obtenidos para la red de Hanoi son extrapolables a los obtenidos en la red de Nueva York, aunque requieren ciertos matices. Así, en este caso, el tamaño del submemeplex 
(Q) sí que parece ejercer cierta influencia en la velocidad del algoritmo, de modo que se realiza un menor número de evaluaciones conforme aumenta el tamaño de submemeplex. En cuanto a los otros dos parámetros, el comportamiento es muy similar, con la salvedad de que en el caso del coeficiente acelerador (C), el utilizar valores superiores a 2 no aumenta el número de evaluaciones realizadas, sino que queda estable.

Las figuras inferiores muestran los valores de eficiencia relativa obtenidos en función de los tres parámetros de ajuste que guardan relación con la naturaleza de los saltos evolutivos. Estos valores de eficiencia se muestran de modo adimensional, de manera que el valor máximo de eficiencia es igual a 1.

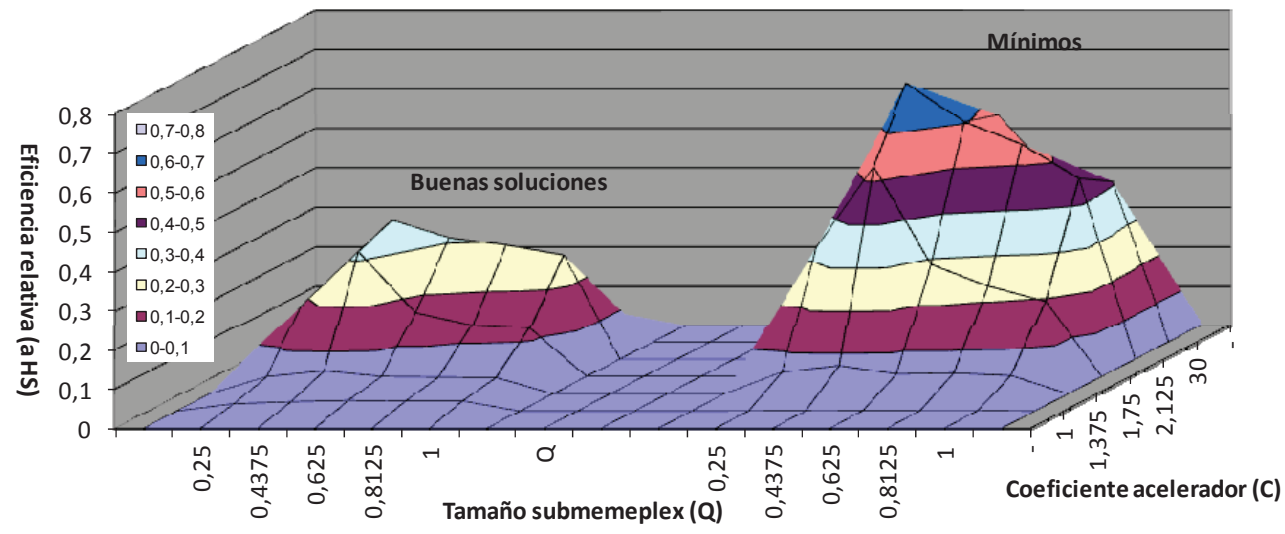

Figura 6.20. Análisis de eficiencia según tamaño submemeplex (Q) y coeficiente acelerador (C) para la red de Nueva York.

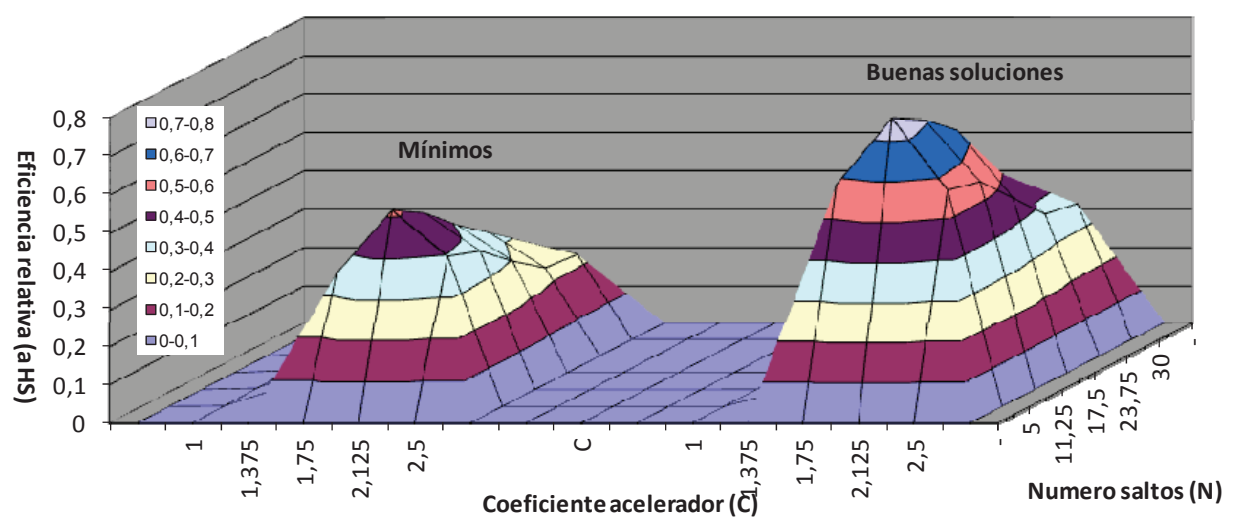

Figura 6.21. Análisis de eficiencia según coeficiente acelerador (C) y número de saltos (N) para la red de Nueva York. 


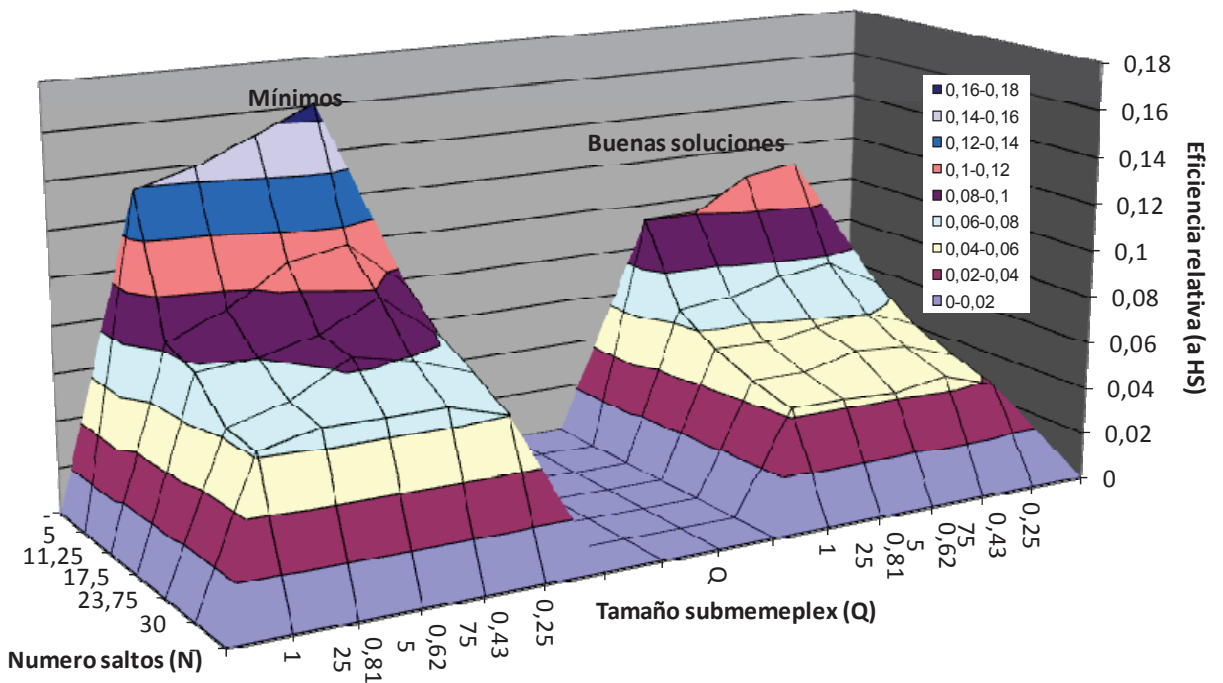

Figura 6.22. Análisis de eficiencia según tamaño submemeplex (Q) número de saltos (N) para la red de Nueva York.

El algoritmo SFL se muestra mucho más eficiente cuando el objetivo es encontrar soluciones mínimas de diseño, puesto que el mayor número de evaluaciones de la función realizadas por esta técnica frente a otras se ve recompensado con un mayor número de óptimos de diseño. En este sentido, la representación de la eficiencia en función de los distintos parámetros de ajuste muestra una diferencia considerable entre la obtención de soluciones mínimas y la obtención de buenas soluciones de diseño.

Del mismo modo, las distintas representaciones reflejan la importancia de una correcta elección de valores para cada parámetro de cálculo, puesto que la eficiencia es muy diferente en función del ajuste elegido. Así, en el caso del coeficiente acelerador (C), los valores de eficiencia muestran como un valor en torno a 2 es el ajuste más adecuado en este caso, puesto que todas las representaciones en función de $\mathrm{C}$ y otro parámetro obtienen el pico de eficiencia alrededor de este valor. En este caso, la recomendación derivada del análisis de eficiencia se encuentra muy próxima a los resultados obtenidos en el análisis de parámetros y en el de velocidad, puesto que ambos ya recomendaban valores en torno a 2 para el coeficiente de aceleración.

Considerando el análisis de eficiencia respecto del número de saltos recomendable se da el caso contrario. Así, el análisis de parámetros determinaba que la probabilidad de encontrar una solución mínima de diseño aumentaba proporcionalmente con el número de saltos permitidos por iteración. Sin embargo, el algoritmo es mucho más eficiente cuanto menor es el número de saltos realizados en cada iteración del algoritmo. Así, en el rango considerado, los valores de eficiencia más altos se obtienen para $\mathrm{N}$ igual a 5 , de modo que conforme 
aumenta $\mathrm{N}$ disminuye la eficiencia de forma muy considerable, tal como se puede apreciar en las figuras 6.21 y 6.22 .

Esta disminución tan drástica de la eficiencia se produce porque la mejora obtenida en calidad de la solución al aumentar el número de saltos por iteración no compensa el notable incremento de evaluaciones realizadas por el algoritmo. Así, considerar un ajuste de 30 saltos por iteración provoca que el algoritmo realice el triple de iteraciones que cuando se consideran tan sólo 5 saltos.

Por último, en el rango considerado, tamaños de submemeplex en torno a 0,4 son los que obtienen el pico de eficiencia. En este caso, las figuras 6.20 y 6.22 , que representan la eficiencia relativa en función de $Q$ y el resto de parámetros, muestran como el máximo de la función de eficiencia se encuentra en $Q=0,44$. En este caso, el valor óptimo de eficiencia es coincidente con el ajuste recomendado en 5.2 cuando se tiene en cuenta únicamente la probabilidad de obtener la mejor solución posible. Este tamaño de submemeplex no es la combinación más rápida si hablamos en términos de velocidad pero sí representa la solución de compromiso que relaciona los términos de calidad de la solución con velocidad del algoritmo.

Una vez definida la combinación más eficiente para el grupo de parámetros que podemos relacionar con la naturaleza de los saltos en SFLA es posible ampliar el estudio de eficiencia e introducir también el número de individuos con el que trabaja el algoritmo. Es conveniente recordar que el tamaño de la población en SFLA viene definido por dos parámetros, el número de memeplexes $(m)$ y el número de ranas por memeplex $(n)$. De este modo, manteniendo constante el ajuste para $\mathrm{Q}, \mathrm{C}$ y N , la figura 6.23 representa la eficiencia relativa en función de $m$ y $n$.

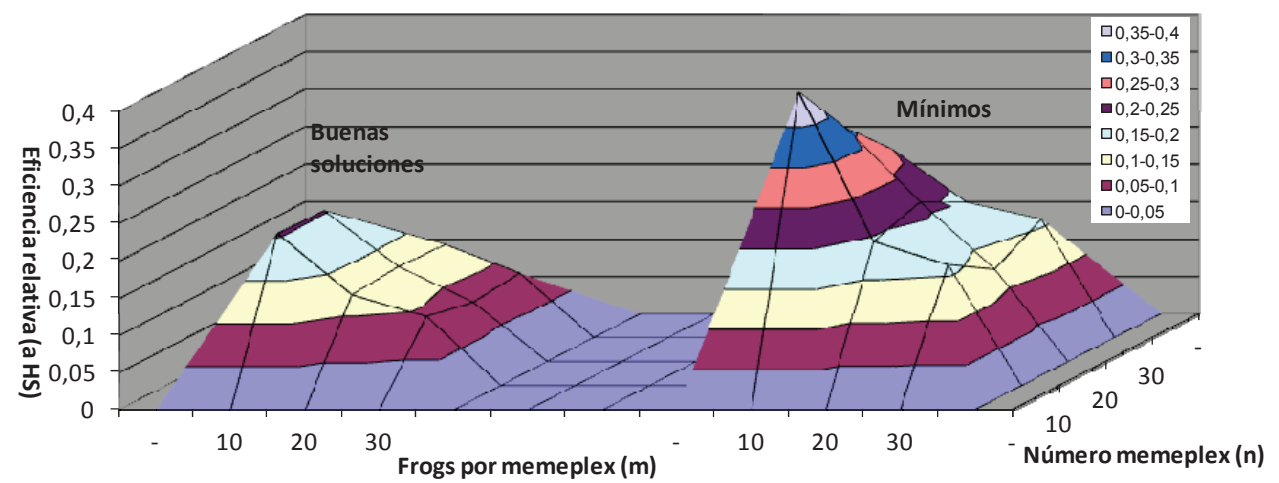

Figura 6.23. Análisis de eficiencia según tamaño de población $(m \times n)$ para la red de Nueva York. 
La figura muestra de modo claro como el algoritmo es más eficiente cuanto menor es el tamaño de la población. Así, la combinación más eficiente corresponde a 100 individuos (10x10), tanto para la obtención de mínimas soluciones como para la obtención de buenas soluciones de diseño.

Por otro lado, si se analiza de modo independiente el número de memeplexes (n) y el número de ranas que contiene cada memeplex $(\mathrm{m})$, los resultados en la red de Nueva York muestran como $\mathrm{m}$ resulta más crítico que $\mathrm{n}$ cuando se considera como criterio de análisis la eficiencia del algoritmo. Así, la eficiencia disminuye de modo considerable cuando se aumenta el número de ranas por memeplex, mientras que la disminución es mucho más suave al aumentar el número de memeplexes manteniendo constante $\mathrm{m}$. En este sentido, cuando el objetivo del problema es obtener un conjunto de buenas soluciones de diseño, el rango de ajuste óptimo para el número de memeplexes puede ampliarse hasta 20 , puesto que la eficiencia del algoritmo no se ve comprometida.

Una vez analizados los distintos parámetros cuyo valor depende del usuario en el algoritmo SFL, la siguiente tabla representa el mejor ajuste posible para el diseño óptimo de la red de los túneles de Nueva York considerando el análisis de eficiencia de este apartado. Esta tabla proporciona un rango óptimo de cálculo que combina la probabilidad de obtener la mejor solución posible con un coste computacional adecuado.

\begin{tabular}{|c|c|c|c|}
\hline \multicolumn{2}{|c|}{ PARÁMETROS } & $\begin{array}{c}\text { Obtención de mínimas } \\
\text { soluciones }\end{array}$ & $\begin{array}{c}\text { Obtención de buenas } \\
\text { soluciones }\end{array}$ \\
\hline Tamaño submemeplex & $\mathrm{Q}$ & 0,44 & 0,44 \\
\hline $\begin{array}{c}\text { Número saltos } \\
\text { evolutivos }\end{array}$ & $\mathrm{N}$ & 5 & 5 \\
\hline $\begin{array}{c}\text { Coeficiente de } \\
\text { aceleración }\end{array}$ & $\mathrm{C}$ & 2 & 2 \\
\hline Ranas por memeplex & $\mathrm{m}$ & 10 & 10 \\
\hline Número memeplexes & $\mathrm{n}$ & 10 & $10-20$ \\
\hline
\end{tabular}

Tabla 6.8. Ajuste óptimo de parámetros para el algoritmo SFL en la red de los túneles de Nueva York.

\subsection{Eficiencia de los modelos de optimización en la red R-9 de Joao Pessoa}

La red de Joao Pessoa es el sistema de abastecimiento urbano más grande de cuantos se abordan en este trabajo, y es por ello que los análisis en torno a esta red se realizan en base a la obtención de un conjunto de soluciones cercanas a la solución mínima absoluta, puesto que ésta carece de repetibilidad. El trazado de la red consta de 61 nudos de consumo, conectados entre si a través de 72 conducciones, realizándose la alimentación del sistema mediante un depósito de cabecera de altura conocida. 
La gama de diámetros considerada para la resolución del sistema de abastecimiento consta de 10 tamaños distintos, entre 100 y $600 \mathrm{~mm}$ de diámetro. La relación entre el número de conducciones a diseñar y las posibilidades de diseño existentes para cada una de estas conducciones ofrece un campo de soluciones para la red con $10^{72}$ posibles escenarios, que confirma a la red de Joao Pessoa como el sistema más complejo de cuantos se abordan en este trabajo.

La metodología de diseño con mayor ratio de eficiencia para la red R-9 de Joao Pessoa es el algoritmo HS. Este resultado aparentemente puede parecer sorpresivo, puesto que en redes complejas, algoritmos más potentes como APG o SFL se han mostrado más eficientes. En este caso, la propia complejidad del problema provoca una escasa repetibilidad de la solución mínima independientemente de la metodología estudiada, con lo que el análisis de resultados se realiza tan sólo respecto a la obtención de buenas soluciones de diseño, con un coste mínimo para la red de 192,366 millones de um, que con un margen del 3\% eleva la consideración de buena solución de diseño hasta 198,136 millones de um. Este margen es lo suficientemente amplio como para que la rapidez de la técnica basada en HS compense un mayor coste medio, pero dentro de los límites establecidos.

Bajo esta premisa, el ajuste de parámetros en HS que representa la zona de máxima eficiencia para el diseño de la red de Joao Pessoa viene dado por un tamaño de población de 100 individuos, con una probabilidad HMCR de 0,96 y un ajuste del PAR en torno a 0,3. Esta combinación tiene un valor de 1 en cuanto a eficiencia del algoritmo cuando se trata de conseguir un grupo de soluciones que no excedan en más de un $3 \%$ la solución mínima del algoritmo, por lo que los valores de eficiencia proporcionados en cada metodología toman como referencia esta combinación.

La metodología que sigue el estudio de eficiencia en esta red es similar a los apartados anteriores, analizando con detalle cada uno de los métodos heurísticos, considerando tanto el estudio general de la eficiencia, que permite comparar unos métodos con otros, como el estudio local, que permite determinar la zona de eficiencia máxima en cada algoritmo.

\subsubsection{Algoritmo Pseudogenético}

El análisis de eficiencia para la red de Joao Pessoa sigue el procedimiento general utilizado para todas las redes de distribución ensayadas, con la particularidad de que en este caso tan sólo se considera la probabilidad de encontrar un conjunto de buenas soluciones de diseño, debido a la escasa repetibilidad de la solución mínima.

En este sentido, el análisis de parámetros determina que probabilidades de mutación en torno al 1-3\% aumentan el porcentaje de buenas soluciones de diseño cuando el límite queda establecido en 198,137 millones de um. No obstante, probabilidades de mutación en torno al 
$1 \%$ consiguen un coste medio de diseño menor, por lo que si se disminuye el coste límite del concepto de buena solución también lo hace el rango óptimo de mutación.

Respecto a la probabilidad de cruce, este parámetro no se mostraba determinante cuando el límite de buena solución de diseño quedaba establecido en un 3\%, aunque de modo similar a como ocurría con la mutación, la disminución de la tolerancia de diseño provocaba una disminución en el porcentaje de éxito para probabilidades de cruce inferiores al 50\%. Esta situación provoca que la probabilidad de cruce determinada como óptima se encuentre en torno al $50-60 \%$.

Por último, la velocidad del algoritmo en la resolución de la red de Joao Pessoa sigue las directrices generales de comportamiento del APG, es decir, conforme crece la probabilidad de mutación lo hace también el número de evaluaciones, por lo que disminuye la velocidad. Por su parte, la probabilidad de cruce no sigue ningún tipo de tendencia respecto a la velocidad del algoritmo, por lo que la conclusión era que la configuración de este parámetro no afecta la velocidad.

La figura 6.24 representa la eficiencia en función de las probabilidades de cruce y mutación. Los valores de eficiencia que muestra la figura tienen un valor adimensional relativo al mayor valor de eficiencia conseguido entre todas las posibles configuraciones de todos los métodos disponibles.

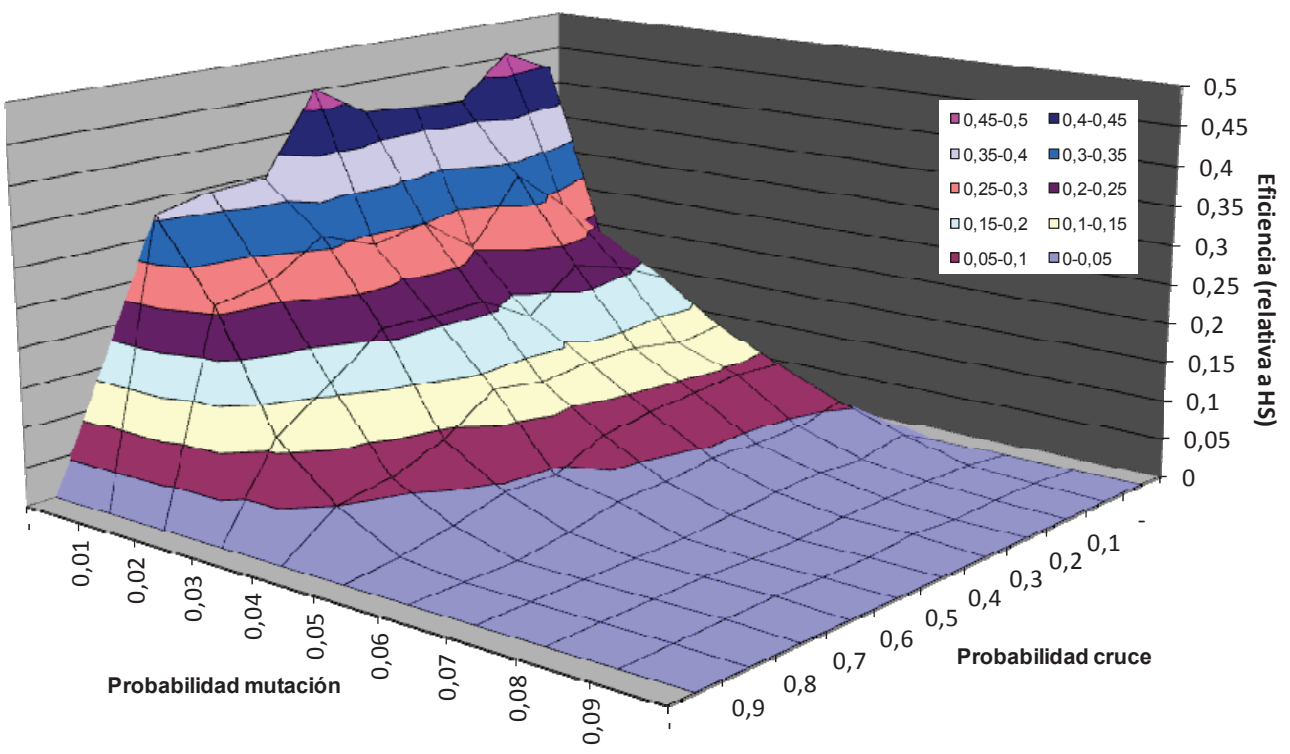

Figura 6.24. Análisis de eficiencia según mutación y cruce en la red R-9 de Joao Pessoa para el APG. 
En términos locales, los resultados obtenidos muestran como la eficiencia del APG es mucho mayor cuanto menor es la probabilidad de mutación. En este sentido, el gráfico de eficiencia limita aún más la zona óptima de trabajo que se obtenía cuando se tenía en cuenta tan sólo la probabilidad de obtener soluciones con un límite del 3\% sobre el mínimo absoluto.

Del mismo modo, la figura muestra como dentro del concepto definido de buena solución, probabilidades de cruce entre el 10 y el $60 \%$ aumentan la eficiencia del algoritmo en la isolínea de mutación que define la zona de máxima eficiencia en este caso. No obstante, este comportamiento no es común en todas las isolíneas de mutación, por lo que sería erróneo definir un rango de eficiencia máxima tan amplio para la probabilidad de cruce. De este modo, analizando con detalle todas las isolíneas de mutación sí que se observa que la zona de máxima eficiencia en cada caso se encuentra en torno a un cruce del $50-60 \%$, aunque las diferencias derivadas del operador de cruce son mucho menores que las del operador de mutación.

Considerando de un modo global la eficiencia obtenida por el APG, cabe destacar que su zona de máxima eficiencia se sitúa en valores cercanos a 0,5, bastante alejados de la unidad. Pese a ello, la técnica de optimización basada en el algoritmo APG es la más eficiente tras el algoritmo HS, que lidera en cuanto a términos de eficiencia el proceso de diseño de la red de Joao Pessoa cuando se atiende a la obtención de buenas soluciones con un límite del 3\% de sobrecoste.

Una vez definida la zona de máxima eficiencia de los operadores genéticos es posible incluir dentro del estudio de eficiencia diferentes tamaños de población, con el objetivo de determinar hasta cuanto es posible aumentar el tamaño de población sin comprometer con ello la velocidad del algoritmo. De este modo, la siguiente figura muestra la eficiencia relativa del algoritmo cuando se mantiene constante la probabilidad de mutación en un $1 \%$, utilizando probabilidades de cruce entre $50-60 \%$ y variando el número de individuos que intervienen en el proceso entre 25 y 225 individuos. 


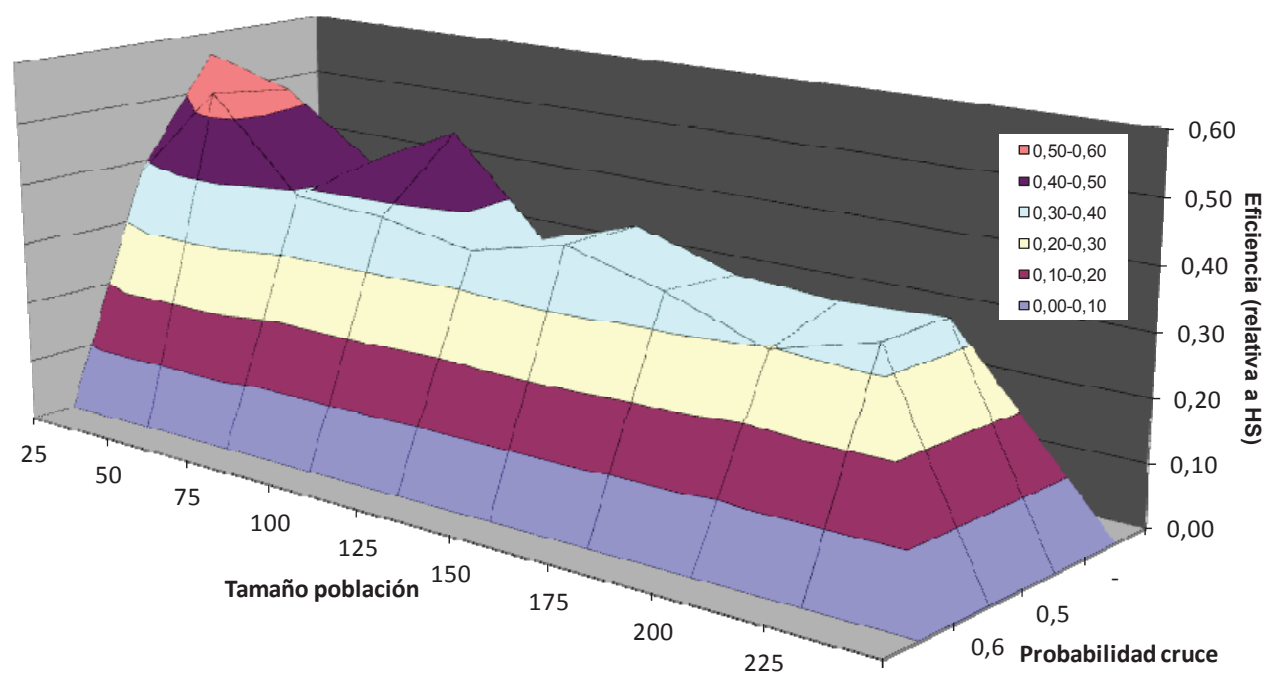

Figura 6.25. Análisis de eficiencia según población y cruce en la red de Joao Pessoa para el APG.

La representación acerca de la obtención de buenas soluciones en función del número de individuos que interviene en el proceso muestra como la eficiencia del APG disminuye proporcionalmente con el tamaño de la población. Así, una población entre 25 y 50 individuos constituye lo que podría denominarse zona de máxima eficiencia, puesto que obtiene una eficiencia cercana a 0,6. Este tamaño de población, combinado con el mejor ajuste posible para los operadores genéticos de mutación y cruce, mejora ligeramente los resultados obtenidos en la 6.24, situando la eficiencia del APG algo más cerca del algoritmo HS, referencia en esta red.

Las conclusiones derivadas del análisis de eficiencia respecto del número de individuos que debe intervenir en el proceso de optimización son inversas a las obtenidas cuando se estudiaba la relación entre el número de buenas soluciones y el tamaño de población. Así, el número obtenido de buenas soluciones aumentaba conforme también lo hacía era el tamaño de población considerado. No obstante, el aumentar el número de individuos del APG conlleva una ralentización del proceso, que en el caso de la red de Joao Pessoa es lo suficientemente grande como para que no compense la mejora producida en la obtención de buenas soluciones, tal como muestran los resultados de eficiencia.

Tras la evaluación de los distintos parámetros de ajuste en función de la eficiencia del algoritmo parece claro que un límite del $3 \%$ sobre la mejor solución posible es lo suficientemente amplio en este caso como para una técnica potente como APG se vea penalizada frente al algoritmo HS, que tiene una menor capacidad para encontrar mejores soluciones, pero que lo hace con muchos menos recursos. En este sentido, considerar un 
menor margen respecto del mínimo para entrar dentro de la definición de buena solución probablemente favorecería a técnicas más potentes como APG y SFLA frente a HS, así que en este caso la eficiencia depende probablemente del objetivo del problema.

No obstante, en las condiciones consideradas, la siguiente tabla muestra la zona de eficiencia máxima que puede definirse para la red de Joao Pessoa:

\begin{tabular}{|c|c|c|c|}
\hline \multicolumn{2}{|c|}{ PARÁMETROS } & Obtención de mínimas soluciones & Obtención de buenas soluciones \\
\hline Prob. de cruce & $P_{c}$ & - & $50-60 \%$ \\
\hline Prob. de mutación & $P_{m}$ & - & $1 \%$ \\
\hline Tamaño de población & $P_{o p}$ & - & $25-50$ individuos \\
\hline
\end{tabular}

Tabla 6.9. Ajuste óptimo de parámetros para APG en la red R-9 de Joao Pessoa.

\subsubsection{Algoritmo PSO modificado}

En todas las redes propuestas el algoritmo PSO ha tenido dificultades de diseño para encontrar la solución de mínimo coste en los sistemas de mayor tamaño. Así, cuando se analizaba la probabilidad de obtener un conjunto de buenas soluciones en función del ajuste de parámetros, el algoritmo PSO modificado ya mostraba carencias en este tipo de problemas, puesto que tan sólo algo más de un $10 \%$ del total de simulaciones realizadas conseguían el objetivo.

El filtro de soluciones que se realizó ajustando los distintos parámetros mejoraba los resultados, de modo que en la mejor zona de ajuste la probabilidad de encontrar una buena solución del problema aumentaba hasta el $25 \%$, todavía lejos de los resultados ofrecidos por otras técnicas como APG o SFLA. Esta zona de ajuste óptimo cuando se considera la probabilidad de obtener una buena solución toma un límite para la velocidad de las partículas del $20 \%$ y una probabilidad de despiste del $10 \%$. El correcto ajuste de estos dos parámetros, considerados críticos en la optimización PSO casi triplica la probabilidad de obtener una buena solución.

Respecto a la velocidad del algoritmo, el análisis para la red de Joao Pessoa sigue las mismas directrices generales ya comentadas para el algoritmo PSO modificado. Así, conforme aumenta el límite de velocidad en el que se mueve una partícula disminuye el número de evaluaciones realizadas, acelerándose la convergencia del algoritmo. En sentido contrario, cuando se aumenta la probabilidad de despiste crece el número de evaluaciones realizadas, y con ello el tiempo de convergencia del algoritmo.

La eficiencia representa una solución de compromiso entre calidad de la solución y velocidad del algoritmo. Para el análisis de la red de Joao Pessoa con el algoritmo PSO modificado, los valores de eficiencia relativa son referidos al algoritmo HS, que resulta ser la metodología más eficiente, y cuyo mejor ajuste posible toma valor 1. En este sentido, las siguientes figuras 
muestran como la eficiencia del algoritmo PSO modificado resulta muy baja en todo el rango de operación utilizado.

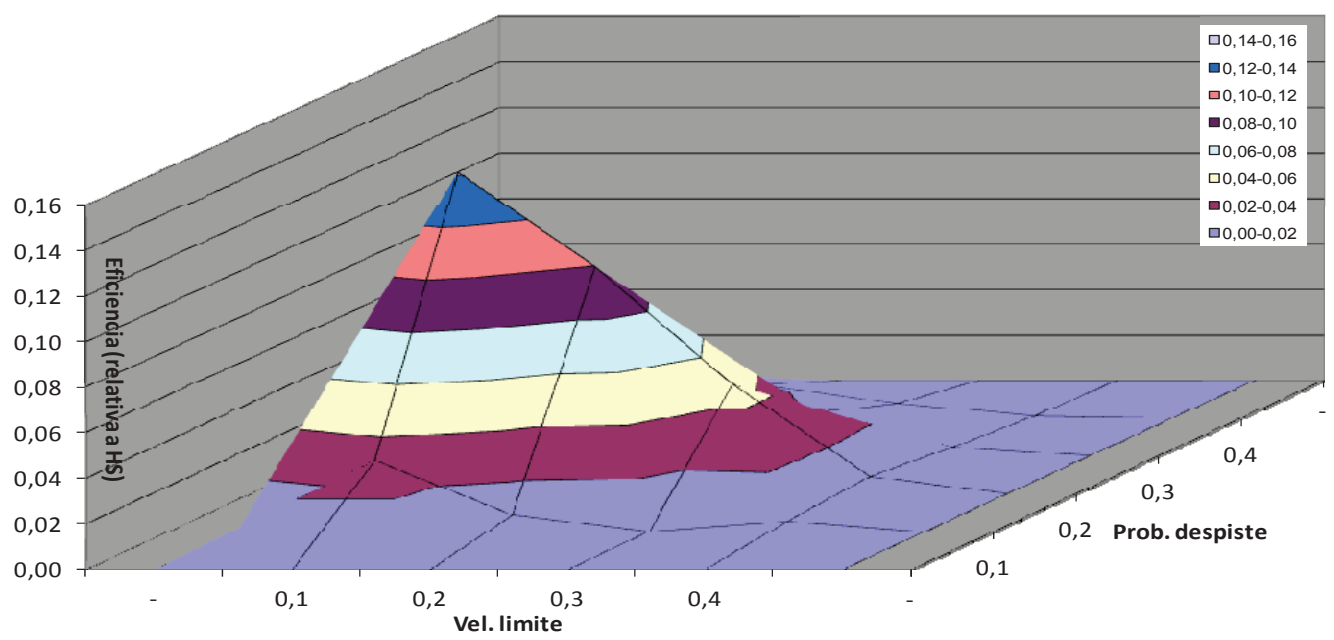

Figura 6.26. Análisis de eficiencia según $V_{\text {lim }}$ y $P_{\text {desp }}$ para la red $R-9$ de Joao Pessoa

Considerando sólo un ajuste local, la figura muestra unos resultados de eficiencia para el algoritmo PSO muy similares a los que se obtenían para la red de Hanoi en 6.2.2. Así, la eficiencia del algoritmo disminuye conforme crece la probabilidad de despiste, puesto que el número de evaluaciones realizadas crece para conseguir resultados similares. En este sentido, el análisis de eficiencia prioriza el utilizar una $P_{\text {desp }}$ alrededor del $10 \%$, en contraste con los resultados que proporcionaba el análisis de parámetros de 5.2, donde probabilidades de despiste hasta el $20 \%$ eran consideradas como óptimas en la obtención de buenas soluciones.

En cuanto a la velocidad límite de la partícula, el valor de máxima eficiencia queda establecido claramente en torno al $20 \%$, que en este caso equivale a limitar el salto dentro de la gama de diámetros a 2 unidades, puesto que la gama consta de 10 tamaños distintos.

Observando la eficiencia desde un punto de vista comparativo con el resto de técnicas es evidente que la optimización PSO no es adecuada para el diseño de la red de Joao Pessoa, puesto que la zona de máxima eficiencia tiene un valor de 0,15 , valor muy alejado del resto de técnicas que se analizan en este trabajo. Se da la circunstancia además que fuera de esta zona los resultados se empobrecen todavía más, con valores inferiores a 0,1 en el resto de zonas.

La inclusión en el análisis de eficiencia de las constantes $C_{1}$ y $C_{2}$ no mejora los resultados obtenidos, puesto que la mejora resultante de variar estos dos parámetros es prácticamente imperceptible, puesto que como ya se ha visto en el resto de redes, no representan un parámetro crítico en la optimización PSO. Así, el cuadro completo de eficiencia en función de 
las constantes $C_{1}$ y $C_{2}$, que incluye todos los posibles valores de $V_{\lim }$ y $P_{\text {desp }}$, muestra una eficiencia bajísima, con valores por debajo de 0,05 en todos los casos, por lo que no se considera de interés su representación.

Determinada la eficiencia del algoritmo en función de $\mathrm{V}_{\text {lim }}, \mathrm{P}_{\text {desp }}$ y las constantes tan sólo resta la inclusión del tamaño de población como variable de cálculo. Así, manteniendo estos cuatro parámetros constantes y utilizando el mejor ajuste posible para la obtención de buenas soluciones se varía el tamaño de la bandada entre 25 y 225 individuos. Los valores de eficiencia relativa obtenidos respecto al algoritmo HS son mostrados en la figura 6.27.

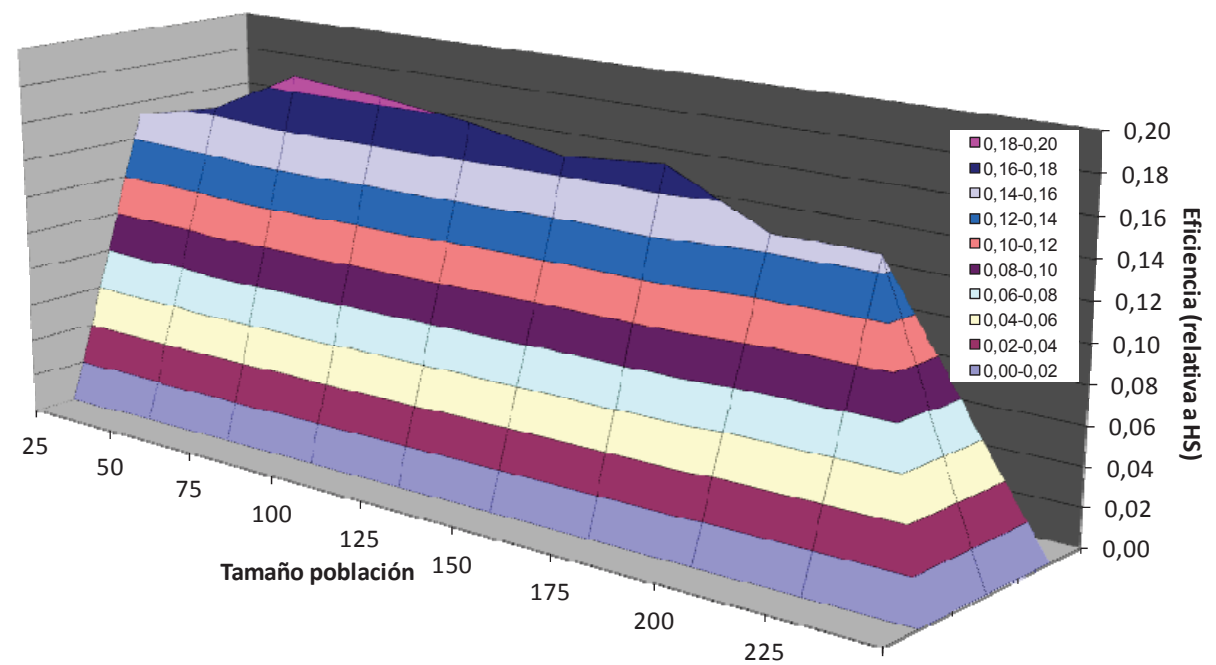

Figura 6.27. Análisis de eficiencia según tamaño de población para la red $R-9$ de Joao Pessoa

La utilización del mejor ajuste posible en cuatro de los cinco parámetros mantiene la eficiencia relativa del algoritmo en torno a $0,15 \div 0,2$ para todos los tamaños de población utilizados. Esta ligera mejora no evita que PSO siga siendo la peor técnica en el análisis de la red de Joao Pessoa entre todas las estudiadas, puesto que obtiene los ratios de eficiencia más bajos.

Centrando el análisis en el tamaño de población, los datos reflejan como poblaciones en torno a 75-100 individuos obtienen una eficiencia algo más alta, si bien la diferencia en la red de Joao Pessoa no es tan grande como en otros casos, puesto que todo el rango de población estudiado tiene una eficiencia comprendida entre 0,15 y 0,2 .

El análisis de eficiencia relativa considerando la población del algoritmo cierra el análisis estadístico para la red de Joao Pessoa. La conclusión final en esta red es que el algoritmo PSO modificado se queda corto cuando se trata de redes complejas, quedando a la cola de todos 
los métodos de optimización empleados en cuanto a eficiencia se refiere. No obstante, es posible la definición de un ajuste óptimo para esta técnica en función de la eficiencia del algoritmo, que viene dado en la siguiente tabla:

\begin{tabular}{|c|c|c|}
\hline \multicolumn{2}{|c|}{ Parámetros de ajuste } & Obtención de buenas soluciones \\
\hline Velocidad límite & $\mathrm{V}_{\lim }$ & 0,2 \\
\hline Prob. de despiste & $\mathrm{P}_{\text {desp }}$ & 0,1 \\
\hline Constante 1 & $\mathrm{C}_{1}$ & $1,4-2$ (no crítico) \\
\hline Constante 2 & $\mathrm{C}_{2}$ & $1,4-2$ (no crítico) \\
\hline Número individuos & Pop & $75-100$ \\
\hline
\end{tabular}

Tabla 6.10. Ajuste óptimo de parámetros para PSO modificado en la red R-9 de Joao Pessoa.

\subsubsection{Algoritmo Harmony Search}

Tanto en la red de Nueva York como en la red de Hanoi, una elección incorrecta del ajuste del pitchrate (PAR) provoca la no convergencia del algoritmo hacia soluciones factibles de diseño. En este sentido, los resultados demuestran que siempre que el algoritmo consiga una solución factible, el ajuste del PAR no tiene mayor influencia en el resultado, por lo que se define este parámetro como de convergencia y no de optimización. Para la red de Joao Pessoa se utiliza esta experiencia previa y no se consideran probabilidades de PAR superiores a 0,5 .

De este modo, la optimización de la técnica HS en lo que a un ajuste de parámetros se refiere queda reducida a determinar cuál es la influencia de la probabilidad HMCR en los resultados obtenidos. En este sentido, el ajuste de parámetros determina para la red de Joao Pessoa un ajuste óptimo de probabilidad HMCR en torno a 0,95-0,96. Para estos valores, la probabilidad de encontrar una buena solución de diseño en la red de Joao Pessoa esta en valores cercanos al $20 \%$.

Así, desde un punto de vista puramente cuantitativo en cuanto a número de buenas soluciones obtenidas, el algoritmo HS se mostraba inferior a APG y SFLA. No obstante, en cuanto a velocidad de cálculo, el algoritmo HS realiza un menor número de iteraciones respecto a otras técnicas más potentes, lo que sin duda le favorece cuando se habla de eficiencia del algoritmo. En este sentido, el número de evaluaciones de la función objetivo es menor cuanto menor es el parámetro de ajuste HMCR.

La figura 6.28 muestra la eficiencia del algoritmo HS en la obtención de buenas soluciones para la red de Joao Pessoa en función de la probabilidad HMCR y el ajuste del pitchrate. Entre todas las metodologías utilizadas, HS obtiene la eficiencia más alta en el diseño de esta red, por lo que el gráfico contiene el valor 1 de eficiencia para la pareja de valores (HMCR=0,96, $\operatorname{PAR}=0,3)$. 


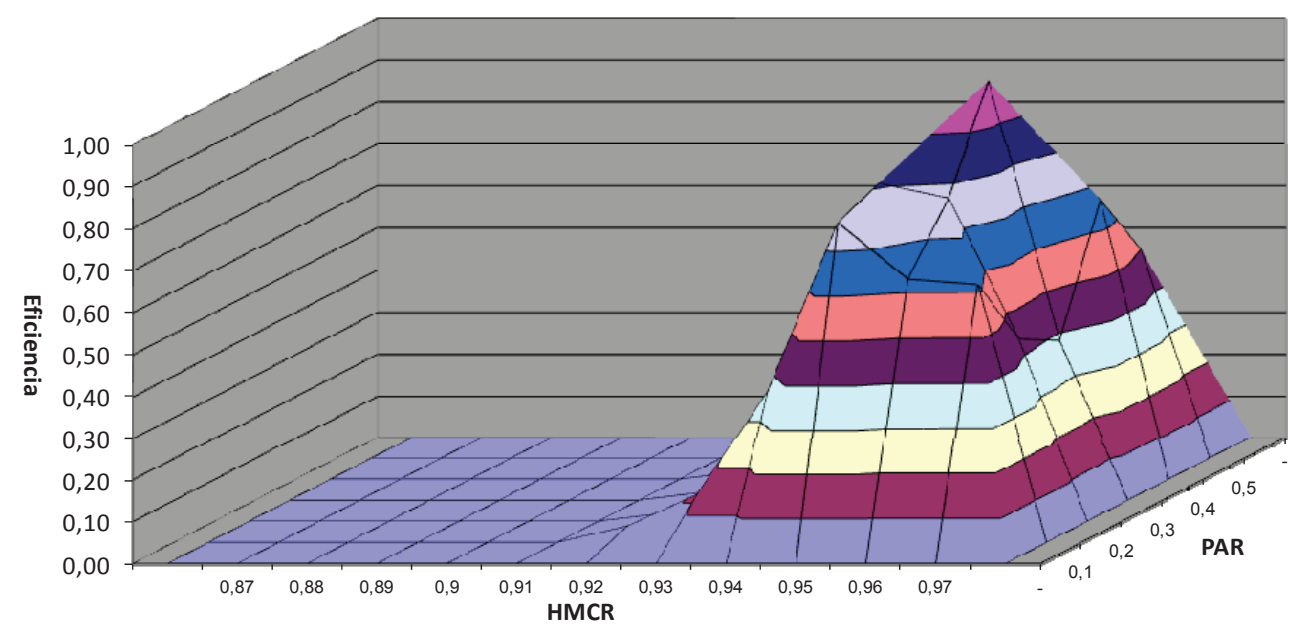

Figura 6.28. Análisis de eficiencia según HMCR y PAR para la red R-9 de Joao Pessoa

Tal como se puede apreciar en la figura, la eficiencia del algoritmo crece conforme aumenta el valor de la probabilidad HMCR. En este sentido destaca el contraste con probabilidades HMCR por debajo de 0,92 , donde el algoritmo no consigue ningún resultado que pueda considerarse como "buena solución" de diseño, por lo que la eficiencia es cero.

A la vista de los resultados, la zona de máxima eficiencia para la red de Joao Pessoa se mueve en torno a una probabilidad HMCR de 0,95-0,96. En toda esta zona, la eficiencia del algoritmo se mueve en valores cercanos a 0,8 , los cuales resultan muy superiores a los obtenidos por el resto de técnicas, puesto que el $A P G$, que sería la segunda técnica en cuanto a eficiencia, se mueve en torno a una eficiencia de 0,5.

Respecto al ajuste del PAR, considerado parámetro de convergencia y no de optimización, éste debe tener un valor lo suficientemente bajo como para asegurar la obtención de soluciones factibles. En este sentido, todas las simulaciones realizadas en la red de Joao Pessoa han proporcionado soluciones factibles, puesto que dada la experiencia previa acumulada en el análisis de las redes de Hanoi y Nueva York se decidió eliminar ajustes para el PAR por encima de 0,5. La figura muestra como no existe relación entre eficiencia del algoritmo y ajuste del PAR, aunque se recomienda utilizar ajustes pequeños para el PAR, a fin de asegurar la convergencia del proceso de optimización.

Obviamente, la mejor combinación posible de parámetros entre todas las técnicas considerando el criterio de eficiencia está contenida en las simulaciones realizadas con el algoritmo HS. Así, para una probabilidad HMCR de 0,96 y un ajuste del PAR de 0,3 se obtiene el valor de eficiencia más alto entre todos los calculados para la red de Joao Pessoa, por lo que se le asigna valor 1 . Las restantes combinaciones de parámetros y metodologías se realizan de modo comparativo a este valor. 
Para finalizar el análisis de parámetros se introduce la eficiencia en función del tamaño de memoria del algoritmo. Para ello se utilizan una serie de simulaciones con un tamaño de población comprendido entre los 15 y los 135 individuos, con una probabilidad HMCR que varía entre 0,88 y 0,92 y un ajuste del PAR constante que asegura la convergencia del algoritmo. La eficiencia del algoritmo en estas condiciones se muestra en la figura inferior:

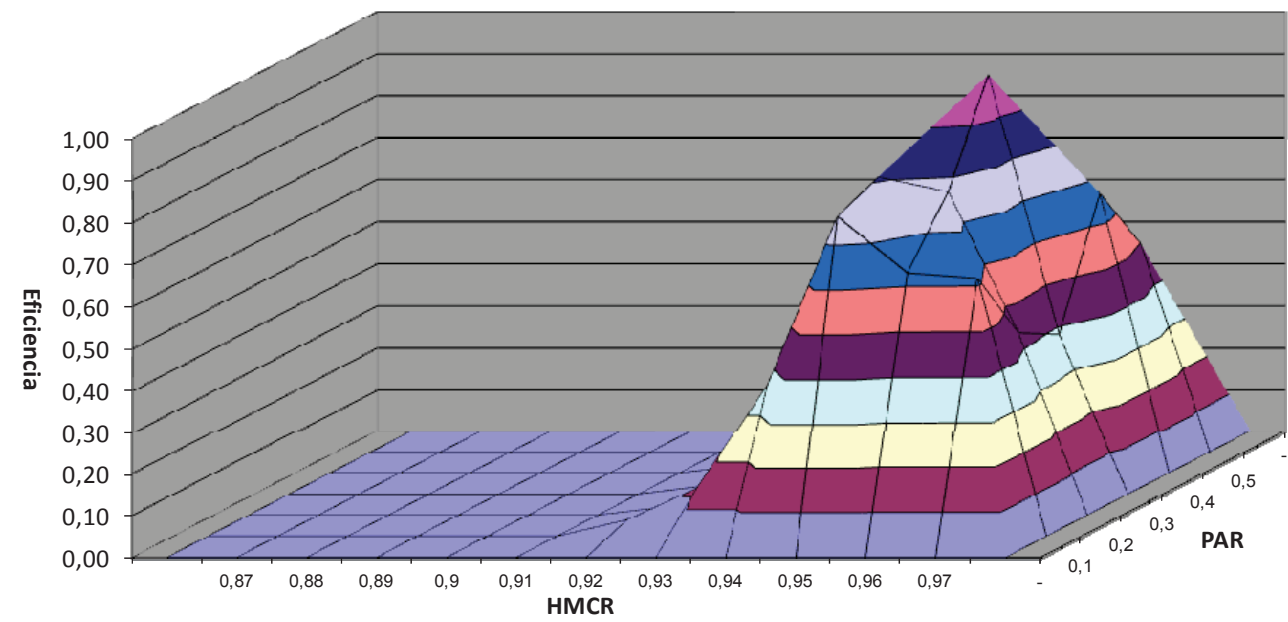

Figura 6.29. Análisis de eficiencia según tamaño de población para la red $R-9$ de Joao Pessoa

Los resultados muestran como la eficiencia en términos generales disminuye cuanto mayor es el tamaño de la memoria considerado, confirmando la tendencia general que ya se observó en el resto de redes. En este sentido, la zona de máxima eficiencia se encuentra para un tamaño de memoria alrededor de 30 individuos, aunque hay que tener en cuenta que 30 parece el límite en cuanto a mínima población, puesto que tamaños de población tan pequeños tienen una dificultad extrema en la búsqueda de buenas soluciones de diseño, por lo que disminuyen la eficiencia del algoritmo.

En cuanto a la probabilidad HMCR, la figura es consecuente con los resultados que mostraba la figura 6.28, de modo que conforme aumenta la probabilidad HMCR se obtiene una eficiencia mayor del algoritmo en la obtención de buenas soluciones. Cabe destacar que para probabilidades HMCR inferiores a 0,92 el algoritmo tiene una eficiencia de cero, puesto que en todas las simulaciones realizadas no se obtiene ningún resultado que pueda entrar dentro del concepto de buena solución definido.

El principal motivo por el que HS domina sobre el resto de técnicas en términos de eficiencia radica en la mayor velocidad a la que calcula respecto del resto de técnicas. Así, el porcentaje de buenas soluciones que obtiene para una red tan compleja como la de Joao Pessoa es muy inferior a otras técnicas más potentes como APG o SFLA, pero es tal la diferencia en cuanto a 
tiempo de cálculo que cuando se relacionan ambos conceptos ninguna de las anteriores puede superar al algoritmo HS.

A partir del estudio de eficiencia de este apartado, la siguiente tabla muestra el rango de operación para el algoritmo HS cuando se quiere conseguir la máxima eficiencia en el diseño de la red de Joao Pessoa.

\begin{tabular}{|c|c|c|}
\hline \multicolumn{2}{|c|}{ PARÁMETROS } & Obtención de buenas soluciones \\
\hline Probabilidad HMCR & HMCR & $0,95-0,96$ \\
\hline Ajuste pitchrate & PAR & $<0,3$ \\
\hline Número individuos & Pop & $30-45$ \\
\hline
\end{tabular}

Tabla 6.11. Ajuste óptimo de parámetros para HS en la red R-9 de Joao Pessoa.

\subsubsection{Algoritmo SFL}

La metodología de optimización basada en el algoritmo SFL es una de las más potentes cuando se trata de obtener la mejor solución posible, pero a la vez requiere de un mayor conocimiento por parte del usuario, puesto que hasta 5 parámetros requieren del ajuste por parte del usuario.

En este sentido, las simulaciones realizadas en 5.1 para la red de Joao Pessoa obtienen un $55 \%$ de soluciones con un coste inferior a 198,137 millones de um, que entraban dentro del concepto de buena solución definida para esta red. El análisis estadístico en función del ajuste para cada parámetro elevaba esta cifra hasta prácticamente el $80 \%$, siendo el algoritmo SFL la técnica que consigue mejores soluciones teniendo en cuenta únicamente el coste final. En estas condiciones, el mejor ajuste posible para los distintos parámetros venía dado por un coeficiente acelerador (C) alrededor de 1,75-2,25 y un número de pasos evolutivos (N) de 30, mientras que dentro del rango estudiado, el tamaño de submemeplex (Q) no ejercía influencia en la obtención de una mejor solución, por lo que puede estar comprendido entre 0,25 y 1 .

Por otro lado, si se considera el número de evaluaciones de la función objetivo que se realizan en cada simulación, el análisis realizado en 5.3 demuestra que el comportamiento de las redes de Hanoi y Joao Pessoa era similar, debido a la mayor complejidad de ambas respecto a las redes de Nueva York y Go-Yang. Así, para Q el análisis realizado no pudo demostrar ningún tipo de relación entre éste parámetro y la velocidad con la que calcula el algoritmo.

Contrariamente, los otros dos parámetros que guardan relación con la naturaleza de los saltos evolutivos sí influyen en la velocidad de cálculo en función del valor que tomen. Así el número de evaluaciones de la función objetivo disminuye conforme aumenta el valor de C hasta valores cercanos a 1,75-2, donde se produce un punto de inflexión. Del mismo modo, el número de evaluaciones de la función también es menor cuanto más pequeño es el número de saltos evolutivos que se programa en cada iteración. 
La eficiencia relaciona los conceptos de calidad y velocidad. Así, las siguientes figuras muestran la eficiencia del algoritmo SFL en el diseño óptimo de la red de Pessoa en función del ajuste de los distintos parámetros. Los valores de eficiencia mostrados son relativos y adimensionales, y se muestran en tanto por uno respecto de la mejor combinación posible entre todos los métodos estudiados, correspondiente al algoritmo HS.

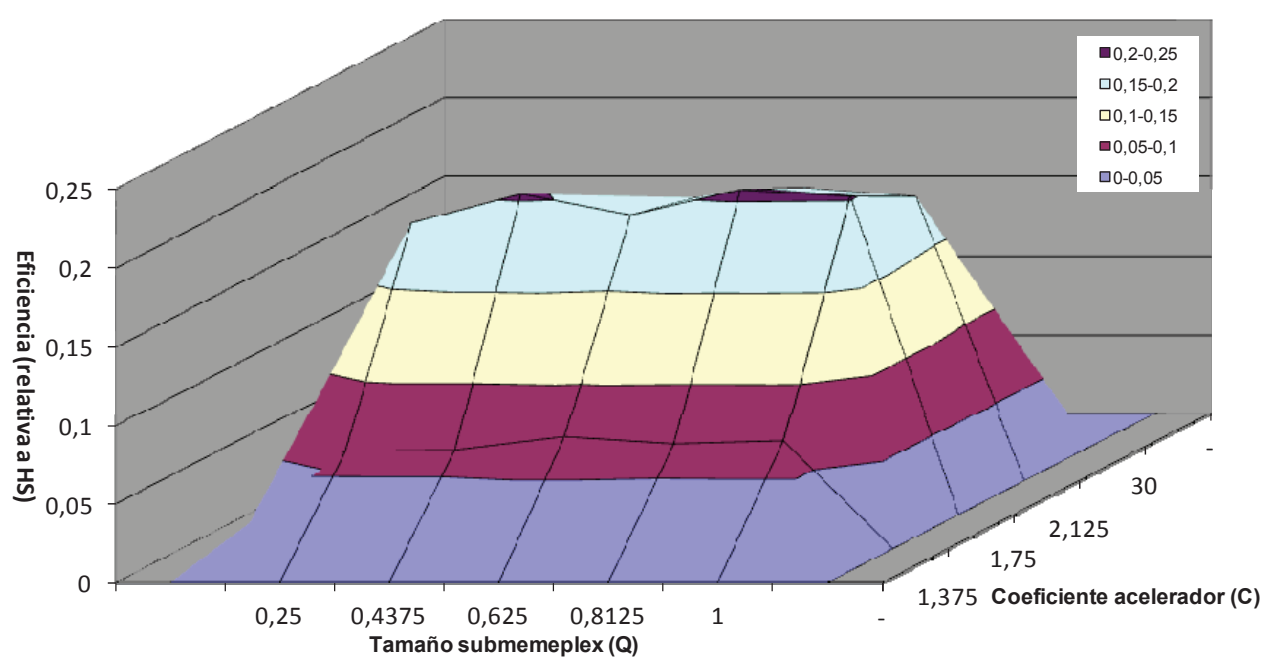

Figura 6.30. Análisis de eficiencia según tamaño submemeplex (Q) y coeficiente acelerador (C) para la red de Joao Pessoa

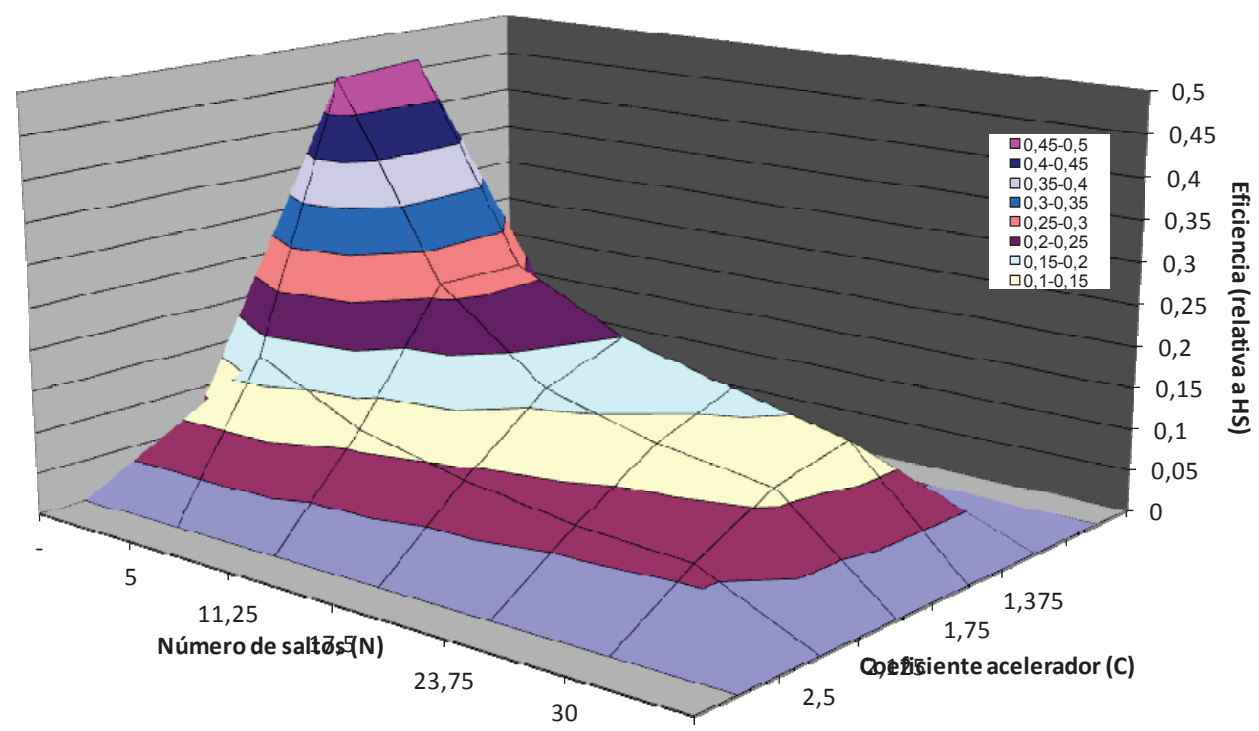

Figura 6.31. Análisis de eficiencia según número de saltos ( $N$ y y coeficiente acelerador (C) para la red de Joao Pessoa 


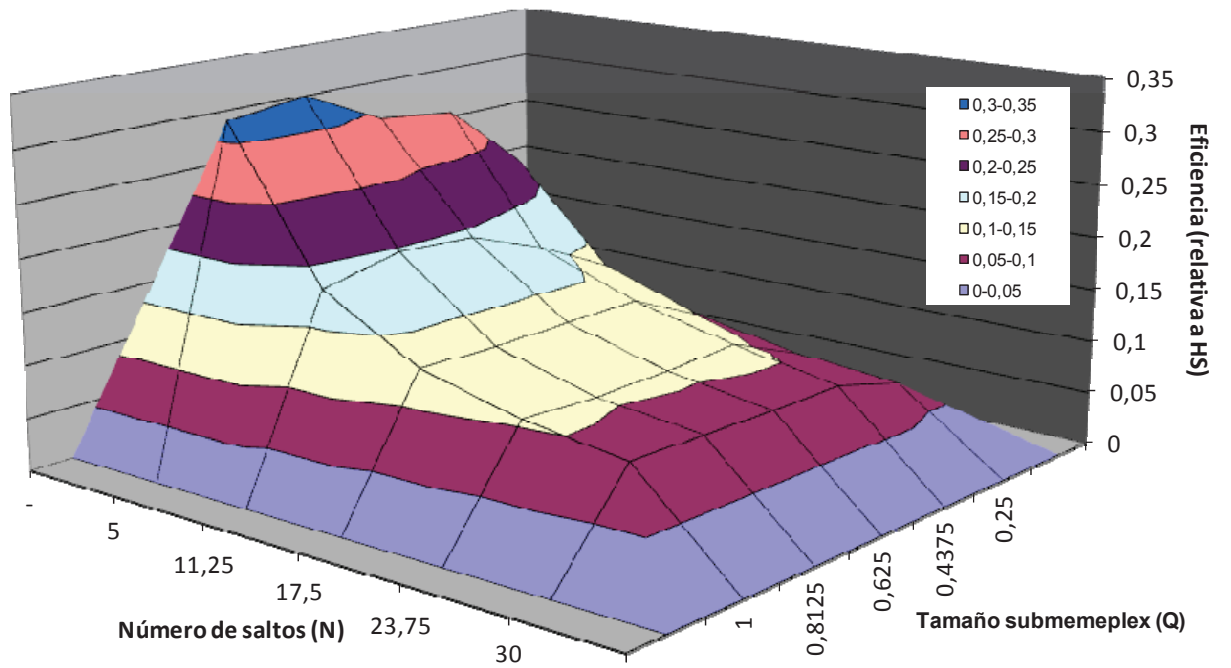

Figura 6.32. Análisis de eficiencia según tamaño submemeplex (Q) y número de saltos (N) para la red de Joao Pessoa

En todos los análisis realizados hasta ahora, el algoritmo SFL se ha mostrado más eficiente en la búsqueda de soluciones óptimas, puesto que la gran cantidad de evaluaciones de la función objetivo que realiza una simulación con este algoritmo favorece una exploración amplia del espacio de soluciones. No obstante, cuando el objetivo del problema de diseño se reduce a la búsqueda de lo que se considera buena solución de diseño sin necesidad de encontrar el mínimo absoluto, la eficiencia del algoritmo se ha visto reducida, puesto que el despliegue de recursos que realiza SFL se antoja excesivo.

El tamaño de la red de Joao Pessoa, así como la amplia gama de diámetros utilizada en su diseño, provoca que el campo de posibles soluciones sea el más amplio de todas las redes testeadas por este trabajo. Aparentemente, las características de la red de Joao Pessoa son favorables a la realización de un diseño con un algoritmo como SFL antes que por otras técnicas menos potentes como HS. No obstante, tanto el elevado coste de diseño como la propia complejidad de la red de Joao Pessoa provocan que la repetibilidad del número de mínimas soluciones sea lo bastante pequeño como para considerar únicamente un estudio de buenas soluciones próximas a este mínimo, y es en ese punto, donde otras técnicas como HS toman ventaja.

Así, todas las figuras que analizan la eficiencia del algoritmo SFL toman valores de eficiencia referidos a los obtenidos por HS, teniendo como objetivo el reflejar la importancia del ajuste de parámetros en la eficiencia del algoritmo, tanto de un modo local (propios parámetros SFL) como de un modo global respecto al resto de técnicas. De este modo, las figuras 6.30, 6.31 y 6.32 muestran la eficiencia del algoritmo en función del ajuste determinado por el usuario 
para los tres parámetros que guardan relación con la naturaleza de los saltos evolutivos de la optimización SFL.

Así, para el coeficiente acelerador (C), las figuras 6.30 y 6.32 muestran como la eficiencia del algoritmo es mucho mayor cuando $C$ se encuentra en torno a 1,75-2,25. Fuera de este rango, la eficiencia del algoritmo disminuye drásticamente, tanto para valores superiores como inferiores, por lo que el ajuste determinado no admite ningún género de dudas en cuanto a eficiencia se refiere. En este caso, el ajuste de C para la eficiencia del algoritmo coincide con las recomendaciones dadas en los análisis para la obtención de la mejor solución posible y la velocidad.

Por otro lado, si se presta atención a la evolución de la eficiencia con el número de saltos evolutivos programados, las figuras 6.31 y 6.32 muestran con claridad como la eficiencia del algoritmo es mayor conforme disminuye el número de saltos evolutivos. Este comportamiento es común en todas las redes, puesto que para todos los casos mostrados disminuye la eficiencia conforme aumenta el valor de $\mathrm{N}$, debido a la penalización que supone para la velocidad del algoritmo el utilizar un número elevado de saltos evolutivos.

Analizando los valores de eficiencia de modo local, los resultados muestran como la eficiencia del algoritmo en zonas con un ajuste de $\mathrm{N}=5$ es prácticamente cuatro veces la obtenida en zonas con ajustes de $\mathrm{N}$ en torno a 30. Del mismo modo, si analizamos la eficiencia obtenida de modo más general, comparando con el resto de metodologías, los resultados muestran como el algoritmo SFL está lejos de HS en cuanto a eficiencia del algoritmo, puesto que las mejores zona de ajuste para SFL apenas alcanza eficiencia en torno a 0,5, valores alejados de los obtenidos mediante HS.

En cuanto a la comparación con el resto de técnicas, la zona de máxima eficiencia del algoritmo SFL queda a la altura de la zona de máxima eficiencia del APG, sin diferencias significativas entre ambas técnicas, mientras que resulta muy superior al algoritmo PSO, que se muestra claramente como la peor de todas las técnicas testeadas en la red de Joao Pessoa.

El último parámetro relacionado con la naturaleza de los saltos es el tamaño de submemeplex (Q). Este parámetro representa el menos crítico entre todos los que tienen posibilidad de ajuste, puesto que la eficiencia en el rango considerado varía mínimamente entre unos valores y otros. Pese a ser el menos crítico en términos absolutos, $Q$ es representa el parámetro más complejo cuando se trata de definir reglas generales, puesto que para cada una de las redes analizadas se han obtenidos conclusiones diferentes. En el caso particular que representa la red de Joao Pessoa, cualquier ajuste considerado por encima de 0,4 se considera óptimo hablando en términos de eficiencia, puesto que las diferencias son mínimas. 
Del mismo modo, es posible analizar la eficiencia en función del número de individuos que intervienen en el proceso evolutivo. Tal como se ha visto en otras redes, SFL incluye dos parámetros de ajuste que identifican el número de individuos que van a intervenir en el proceso de optimización. Estos parámetros son el número de memeplexes $(\mathrm{m})$ y el número de ranas por memeplex $(n)$, resultando el producto de ambos la población del algoritmo.

La eficiencia en base a la población del algoritmo se analiza con una tanda de simulaciones que mantiene constantes $Q, C$ y $N$, variando tan sólo el ajuste de $m$ y $n$ entre 10 y 30, de modo que se analizan poblaciones comprendidas entre 100 y 900 individuos. Los valores utilizados para Q, C y N son los definidos en 5.1 como zona óptima de cálculo cuando se considera la probabilidad de obtener la mejor solución posible. En estas condiciones, la figura 6.33 representa la eficiencia relativa del algoritmo SFL en función de $\mathrm{m}$ y $\mathrm{n}$.

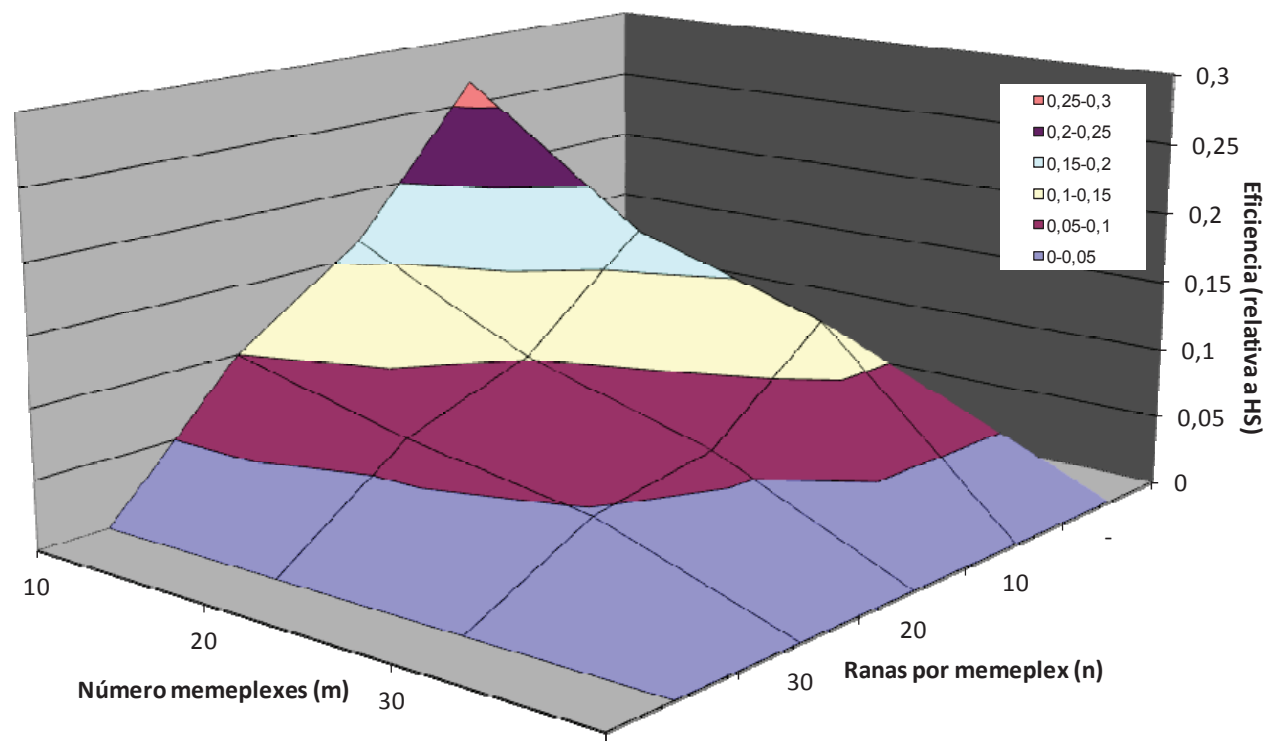

Figura 6.33. Análisis de eficiencia según número de memeplexes $(m)$ y ranas por memeplex (n) en la red R-9 de Joao Pessoa

El análisis de eficiencia respecto del tamaño de población con el que trabaja el algoritmo sigue las mismas directrices que en el resto de redes, de modo que la eficiencia es mayor cuanto menor es el número de individuos involucrados en el proceso de optimización.

Si se analiza de modo independiente el número de memeplexes (n) y el número de ranas contenidas por cada memeplex $(\mathrm{m})$, los resultados muestran como la eficiencia del algoritmo disminuye con el aumento de cualquiera de los parámetros, por lo que en este caso, la eficiencia del algoritmo se debe asociar sólo al tamaño global de la población, y no al modo en el que esté distribuida. De este modo, la combinación más eficiente corresponde a un 
tamaño de población total de 100 individuos, equivalente a tomar 10 ranas por memeplex y un número total de memeplexes de 10.

Como resumen del análisis realizado, la siguiente tabla muestra el mejor ajuste posible para cada uno de los parámetros del algoritmo SFL considerando criterios de eficiencia. La tabla proporciona una zona que podemos considerar como de máxima eficiencia, combinando la probabilidad de obtener la mejor solución posible con un coste computacional óptimo para la red R-9 de Joao Pessoa.

\begin{tabular}{|c|c|c|}
\hline \multicolumn{2}{|c|}{ PARÁMETROS } & Obtención de buenas soluciones \\
\hline Tamaño submemeplex & $\mathrm{Q}$ & $>0,4$ \\
\hline Número saltos evolutivos & $\mathrm{N}$ & 5 \\
\hline Coeficiente de aceleración & $\mathrm{C}$ & $1,75-2,25$ \\
\hline Ranas por memeplex & $\mathrm{m}$ & 10 \\
\hline Número memeplexes & $\mathrm{n}$ & 10 \\
\hline
\end{tabular}

Tabla 6.12. Ajuste óptimo de parámetros para algoritmo SFL en la red R-9 de Joao Pessoa.

\subsection{Eficiencia de los modelos de optimización en la red de Go-Yang}

La red de Go-Yang constituye el problema de diseño de mayor simplicidad entre los abordados. Así, el tamaño de la red, la gama de diámetros escogida y la restricción de presión considerada para el buen funcionamiento de la misma no plantean gran complejidad de diseño para los algoritmos evolutivos, por lo que tal como se vio en apartados anteriores, el número de mínimos obtenidos en este problema de diseño es el más numeroso de entre todas las redes analizadas. Así, la solución de mínimo coste en la red de Go-Yang es coincidente en todos los métodos y de valor 177.009,54 um.

El trazado de la red de Go-Yang consta de 22 nudos y 30 tuberías, que se distribuyen en 7 mallas, y cuya alimentación se realiza por medio de una bomba desde un depósito de cota fija situado a 71 metros. La gama de diámetros considerada para la resolución del problema de diseño tiene 8 tamaños distintos, entre 80 y $350 \mathrm{~mm}$. La relación entre tamaño de red y gama de diámetros permite determinar cuántos escenarios posibles tiene la red, siendo en este caso $8^{30}$ posibles soluciones de diseño.

La metodología de diseño que obtiene la mejor eficiencia en la red de Go-Yang es el algoritmo APG. En este caso, la mayor simplicidad de la red respecto a otras lleva asociada una mayor repetibilidad de la solución mínima en técnicas potentes como APG o SFL, siendo la velocidad con la que se alcanza dicha solución el principal factor diferenciador en cuanto a eficiencia se refiere. 
En este sentido, SFL ofrece una probabilidad muy alta de encontrar la solución mínima de diseño, superando el $90 \%$ en determinadas zonas de ajuste, pero el mayor gasto computacional la penaliza frente al APG cuando éste último utiliza pequeñas poblaciones de individuos.

En este caso, y dada la alta repetibilidad obtenida en la búsqueda de la mínima solución no se va a considerar el concepto de buena solución para estudiar la eficiencia del algoritmo, puesto que prácticamente en todas las metodologías se obtiene un $100 \%$ de probabilidad cuando se trata de encontrar soluciones que no superen el óptimo del sistema en más de un $3 \%$.

La metodología que sigue el estudio de eficiencia en esta red es similar a los apartados anteriores, analizando con detalle cada uno de los métodos heurísticos, considerando tanto el estudio general de la eficiencia, que permite comparar unos métodos con otros, como el estudio local, que permite determinar la zona de eficiencia máxima en cada algoritmo.

\subsubsection{Algoritmo Pseudogenético}

El análisis de parámetros para la red de Go-Yang utilizando el APG determinaba que probabilidades de mutación en torno al 2-3\% resultan las más adecuadas cuando se trata de encontrar el mayor número de óptimos de diseño sin considerar otros criterios de análisis. Respecto a la probabilidad de cruce, el ajuste óptimo resultaba más amplio, puesto que combinando probabilidades de cruce menores al $70 \%$ con el ajuste de mutación referido la probabilidad de encontrar la mínima solución de diseño era cercana al 50\%.

En términos de velocidad, el APG resuelve el problema de diseño con menor número de evaluaciones de la función objetivo cuanto más pequeño es el ajuste de mutación empleado. En cuanto a la probabilidad de cruce, las simulaciones realizadas no muestran ningún tipo de relación entre el ajuste de este parámetro y la velocidad del algoritmo.

La figura 6.34 muestra la eficiencia del APG en la red de Go-Yang según el ajuste realizado, considerando como parámetros variables las probabilidades de cruce y mutación, manteniendo constante la población del algoritmo y con un valor de 100 individuos. La interpretación de la figura permite establecer el mejor ajuste teniendo en cuenta tanto la bondad del resultado como el número de evaluaciones realizadas hasta llegar a la solución final. 


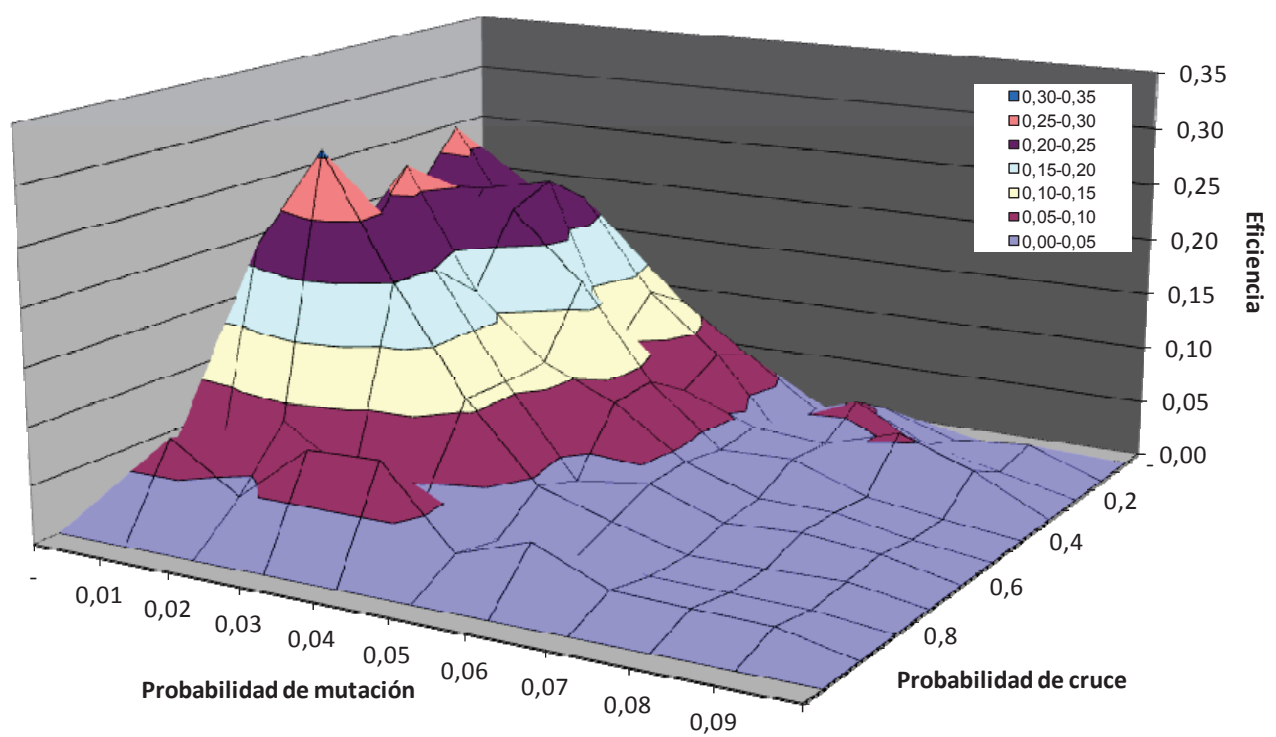

Figura 6.34. Análisis de eficiencia según mutación y cruce en la red de Go-Yang para el APG.

El gráfico de eficiencia ofrece resultados similares a los obtenidos en el resto de redes. Así, en términos locales, los resultados obtenidos demuestran que el APG es más eficiente en probabilidades pequeñas de mutación, puesto que no sólo se obtienen mejores soluciones desde un punto de vista económico, sino que además el número de evaluaciones medias realizadas es más menor, por lo que el algoritmo calcula más rápido.

A lo largo de esta tesis se comprueba como la eficiencia depende en gran medida del ajuste de mutación considerado, puesto que los diferentes análisis estadísticos demuestran que es el parámetro crítico en el APG. No obstante, pese a que su relevancia se mayor, es conveniente no obviar el ajuste de la probabilidad de cruce cuando se evalúa la eficiencia del algoritmo. Así, para la red de Go-Yang, los resultados muestran como el algoritmo obtiene, en términos generales, pequeñas mejora de eficiencia para probabilidades de cruce entre el $20 \mathrm{y}$ el $70 \%$. En este sentido, lo que se podría denominar como zona de máxima eficiencia del APG para la red de Go-Yang corresponde con una probabilidad de mutación del $2 \%$ y una probabilidad de cruce del $70 \%$.

Analizando los valores numéricos de eficiencia obtenidos llama la atención el hecho de que apenas superes el 0,3 en la mejor zona de cálculo, cuando anteriormente se ha comentado que el APG consigue los mejores valores de eficiencia para la red de Go-Yang. Esto es debido a que los cálculos representados en la figura 6.34 se realizan con una población constante de 100 individuos, que en este caso no corresponde con el tamaño de población más eficiente. La figura inferior representa la eficiencia del algoritmo en función del número de individuos que intervienen en el proceso de optimización. Para ello, se considera un rango de estudio 
con tamaños de población entre 25 y 225 individuos, mientras que los operadores genéticos considerados son los óptimos considerando como criterio la obtención de la mejor solución posible (ver apartado 5.2)

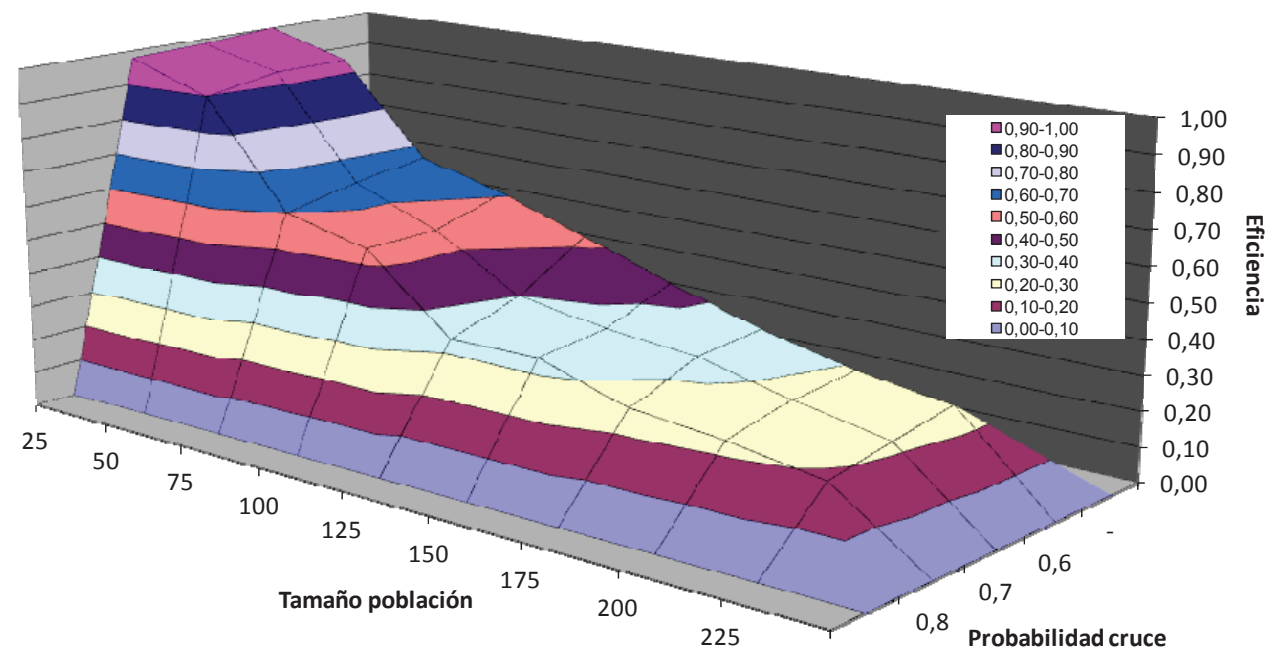

Figura 6.35. Análisis de eficiencia según tamaño de población en la red de Go-Yang para el APG.

Los resultados muestran con claridad como el APG es más eficiente cuando se consideran tamaños de población pequeños. Este tipo de comportamiento, con diferencias tan acusadas entre distintos tamaños de población se ve reforzado cuando el número total de posibles soluciones no es excesivamente elevado. Este es el caso de la red de Go-Yang, que entre los casos estudiados es el que posee un menor número de combinaciones considerando tamaño de la red y gama de diámetros utilizada, por lo que no requiere grandes tamaños de población para encontrar la mínima solución. Así, para este caso particular, cuanto mayor es el número de individuos que intervienen en el proceso de optimización más se ralentiza el cálculo de modo innecesario, por lo que disminuye la eficiencia en términos generales.

Así, para la tipología de la red de Go-Yang, la zona de máxima eficiencia en cuanto al tamaño de población está en torno a los 25 individuos, que corresponde con el menor tamaño de población considerado. Estos resultados están en consonancia con lo visto en el resto de redes, aunque en el resto de casos poblaciones de 25 individuos se antojaban insuficientes, quedando la zona de máxima eficiencia entre 50 y 75 individuos. La mayor simplicidad de la red de Go-Yang es la causa de que poblaciones menores de 50 sean capaces de encontrar con suficiencia las mejores soluciones con menos evaluaciones de la función objetivo.

Finalmente, la zona de eficiencia máxima para el APG cuando se aborda el diseño óptimo de la red de Go-Yang viene dado en la tabla 6.13: 


\begin{tabular}{|c|c|c|}
\hline \multicolumn{2}{|c|}{ PARÁMETROS } & Obtención de mínimas soluciones \\
\hline Prob. de cruce & $P_{c}$ & $0,2-0,7$ \\
\hline Prob. de mutación & $P_{m}$ & 0,02 \\
\hline Tamaño de población & $P_{0}$ & 25 \\
\hline
\end{tabular}

Tabla 6.13. Ajuste óptimo de parámetros para el APG en la red de Go-Yang.

\subsubsection{Algoritmo PSO}

Los análisis previos realizados en la red de Go-Yang utilizando el algoritmo PSO modificado obtienen como solución de mínimo coste el mismo valor que el resto de metodologías, con un coste de instalación de 177.009 um. El ajuste de parámetros determinaba que la probabilidad de encontrar la mínima solución dependía fundamentalmente del límite de velocidad de las partículas $\left(\mathrm{V}_{\text {lim }}\right)$ y de la probabilidad de despiste $\left(\mathrm{P}_{\text {desp }}\right)$, de modo que un ajuste de ambos en torno a 0,1 permitía obtener más de un $15 \%$ de soluciones óptimas en las simulaciones realizadas.

Respecto al ajuste de parámetros, los resultados obtenidos por el algoritmo PSO modificado en la red de Go-Yang son similares al resto de redes, con dos parámetros cuyo ajuste tiene gran influencia sobre la probabilidad de encontrar una mejor solución y otros dos cuya influencia es mucho menor, como son las constantes $C_{1}$ y $C_{2}$, encargadas de otorgar un mayor o menor peso a la búsqueda local y global del algoritmo. Para $C_{1}$, el algoritmo mejora ligeramente sus resultados conforme aumentamos su valor hasta 2 , mientras que en el caso de $C_{2}$ el algoritmo mantiene estables sus resultados en un rango comprendido entre 1,6 y 2 .

En cuanto a velocidad del algoritmo, los análisis realizados sobre la red de Go-Yang siguen la misma línea general que el resto de simulaciones, con un menor número de evaluaciones de la función objetivo para límites de velocidad mayores, de modo que se acelera la convergencia del algoritmo.

Considerando el tamaño de población, el algoritmo PSO modificado en la red de Go-Yang no ofrece grandes diferencias respecto de lo comentado en otras redes, de modo que conforme aumenta el tamaño de población aumenta el número de mínimos obtenidos, al mismo tiempo que la cantidad de recursos empleados. El análisis de eficiencia que se realiza a continuación determina si las mejoras conseguidas en cuanto a probabilidad de obtener una mejor solución compensa el esfuerzo computacional que requiere este tipo de configuraciones.

La figura 6.36 muestra la eficiencia del algoritmo en base a los distintos valores considerados para el límite de velocidad de la partícula y la probabilidad de despiste. En la red de Go-Yang, 
todos los valores de referencia son referidos al APG, que resulta ser la metodología más eficiente cuando trabaja con tamaños de población pequeños.

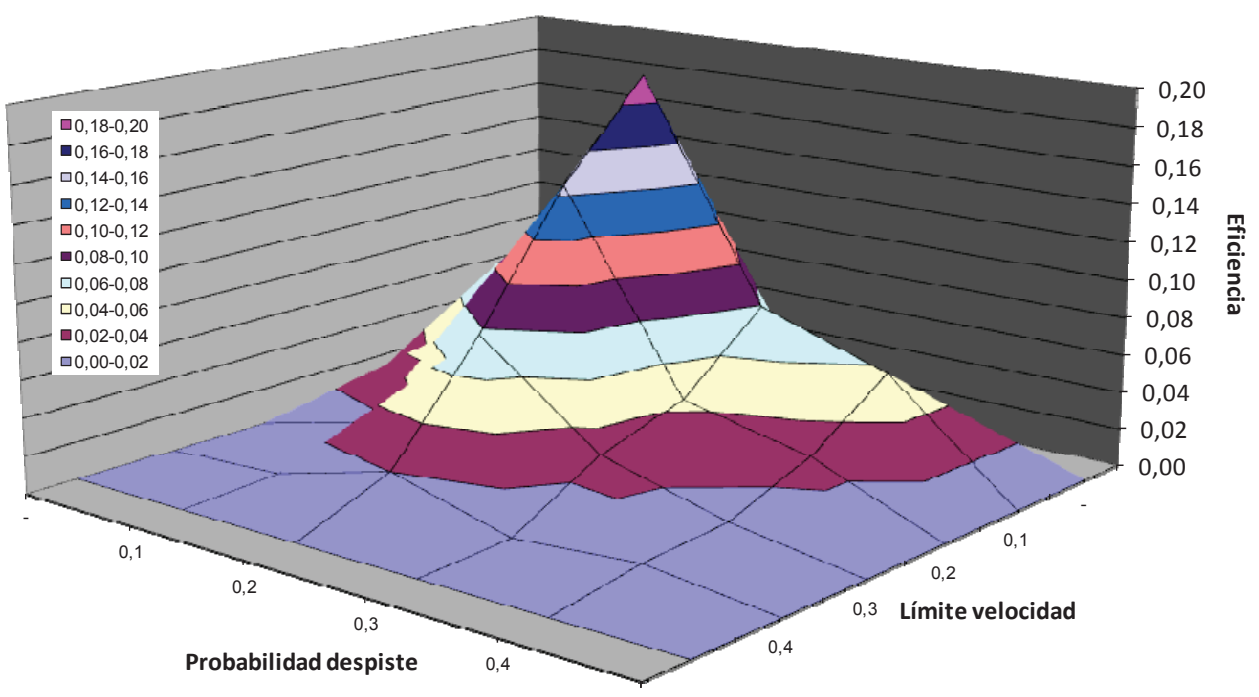

Figura 6.36. Análisis de eficiencia según $V_{\text {lim }}$ y $P_{\text {desp }}$ para la red de Go-Yang

Los resultados de eficiencia en Go-Yang son prácticamente idénticos a los obtenidos en el resto de redes, lo que va a permitir sacar conclusiones generales acerca del comportamiento del algoritmo PSO modificado como herramienta de diseño de redes de distribución. De este modo, la eficiencia del algoritmo alcanza su valor más alto cuando la probabilidad de despiste es del $20 \%$, disminuyendo con celeridad si se aumenta dicha probabilidad. En este sentido, los resultados de eficiencia no coinciden con el análisis de parámetros realizado (5.1) ni con el análisis de velocidad (5.4), sino que la eficiencia del algoritmo viene dada por una combinación de ambos estudios.

Respecto al límite de velocidad que debe imponerse a la partícula, la eficiencia del algoritmo es muy superior cuando éste se encuentra en torno al $10 \%$, lo que en este caso equivale a limitar el salto dentro de la gama de diámetros a 1 unidad como máximo, puesto que la gama consta de 10 diámetros distintos.

La zona de eficiencia máxima del algoritmo alcanza valores en torno a 0,2, que obviamente quedan muy lejos del valor unidad. Comparativamente al resto de técnicas es evidente que la optimización PSO no es la más apta, puesto que se encuentra lejos de los resultados proporcionados por el resto.

Respecto a la influencia en el análisis de las constantes de peso $C_{1}$ y $C_{2}$, la situación es la misma que en el resto de análisis, puesto que ninguna de estas constantes se muestra determinante en el grado de eficiencia conseguido por el algoritmo en su búsqueda de la 
mejor solución. No obstante, los valores más altos testeados para ambas constantes mejoran ligeramente los resultados de eficiencia, aunque en ningún caso se pueden considerar como determinantes, por lo que no se ha estimado de interés su representación, ya que la diferencia entre el peor y el mejor caso para ambas constantes es inferior a 0,05.

El único parámetro restante de análisis es el número de pájaros que entran en juego en la población inicial del algoritmo. Así, utilizando el mejor ajuste posible para los cuatro parámetros restantes obtenido en el apartado 5.2 se realizaron simulaciones con distintos tamaños de población entre 25 y 225 individuos. La figura inferior representa los valores de eficiencia relativos obtenidos respecto del APG:

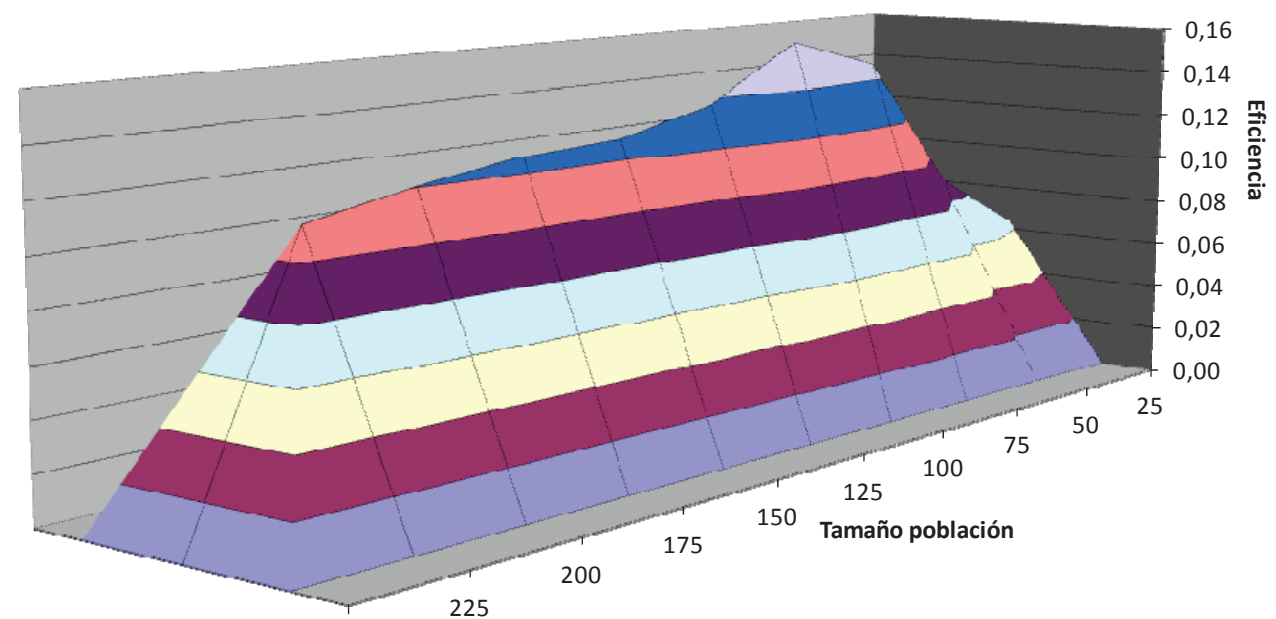

Figura 6.37. Análisis de eficiencia según tamaño de población para la red de Go-Yang

Tal como viene siendo la tónica general en todas las técnicas y redes, el aumento del tamaño de población para conseguir mejores soluciones no es la opción más adecuada cuando se toma como criterio de selección la eficiencia. De este modo, la figura muestra como una vez alcanzado un tamaño de población lo suficientemente alto como para garantizar una exploración completa del espacio de soluciones la eficiencia del algoritmo tiende a disminuir conforme aumenta el tamaño de la población cuando se mantienen constantes el resto de parámetros.

En este sentido, el tamaño óptimo para la población inicial del algoritmo corresponde en este caso con unos 75-100 individuos, disminuyendo la eficiencia de modo progresivo para valores superiores. En esta zona de eficiencia máxima, la eficiencia relativa del algoritmo sigue en torno a 0,15-0,2, resultados que están en consonancia con el análisis de eficiencia realizado para los restantes parámetros, puesto que el tamaño de población constante utilizado era de 100 individuos. 
El análisis de eficiencia acerca del número de individuos que intervienen en el proceso de optimización cierra el análisis estadístico del algoritmo PSO en la red de Go-Yang. Tal como ocurre en el resto de redes, la capacidad del algoritmo PSO modificado se queda escasa cuando se comparan sus resultados con otras metodologías de optimización. Pese a ello, el ajuste óptimo del método para la red de Go-Yang en función de la eficiencia viene dado en la siguiente tabla:

\begin{tabular}{|c|c|c|c|}
\hline \multicolumn{2}{|c|}{ PARÁMETROS } & Obtención de mínimas soluciones & Obtención de buenas soluciones \\
\hline Velocidad límite & $\mathrm{V}_{\lim }$ & 0,2 & 0,2 \\
\hline Prob. de despiste & $\mathrm{P}_{\text {desp }}$ & 0,1 & 0,1 \\
\hline Constante 1 & $\mathrm{C}_{1}$ & 2 (no crítico) & 2 (no crítico) \\
\hline Constante 2 & $\mathrm{C}_{2}$ & $1,6-2$ (no crítico) & $1,6-2$ (no crítico) \\
\hline Número individuos & Pop & $75-100$ & $75-100$ \\
\hline
\end{tabular}

Tabla 6.14. Ajuste óptimo de parámetros para el algoritmo PSO modificado en la red de GoYang.

\subsubsection{Algoritmo Harmony Search}

Los distintos análisis realizados acerca de la calidad de las soluciones de diseño que obtiene el algoritmo HS determinan que entre los parámetros susceptibles de ajuste por el usuario, los únicos que tienen influencia en el coste final de la solución son la probabilidad HMCR y el tamaño de población inicial del algoritmo. El último parámetro de ajuste, denominado PAR, se ha mostrado en todas las redes como un parámetro de convergencia, y en función de la experiencia previa se determinó que su valor debe ser inferior a 0,5.

En el resto de redes analizadas, la elección del mejor ajuste de parámetros en el algoritmo HS consiste en ajustar la probabilidad HMCR y el tamaño de población en función de la calidad de la solución obtenida. Para la red de Go-Yang, el análisis de parámetros realizado en el apartado 5.1 determina que no hay un ajuste de la probabilidad HMCR que permita mejorar los resultados de diseño, por lo que el estudio de eficiencia cobra especial importancia.

En el caso del tamaño de población, las conclusiones eran similares, de modo que no se obtenían grandes variaciones en los resultados aplicando distintos tamaños de población. Así, el diseño óptimo de la red de Go-Yang mediante algoritmo HS es el único donde la optimización de parámetros no mejoraba sustancialmente los resultados obtenidos en relación a la calidad de la solución.

Respecto al análisis de velocidad, este caso sigue las directrices generales observadas en todas las redes, de modo que el algoritmo es más rápido cuanto mayor es la probabilidad HMCR, mientras que el ajuste del PAR no afecta de ninguna manera a la velocidad del algoritmo. En cuanto al tamaño de población, el algoritmo HS sigue la tendencia general, de modo que el número de evaluaciones realizadas hasta la convergencia del cálculo es mayor para poblaciones iniciales más numerosas. 
El análisis de eficiencia relaciona todos estos conceptos. De lo expuesto hasta el momento, parece lógico pensar que si no hay un rango específico en cada parámetro de ajuste que permita asegurar una mejora en la calidad, la combinación más eficiente va a ser aquella que realice el menor número de evaluaciones de la función objetivo obteniendo similares resultados. Los valores de eficiencia mostrados en la figura, en base unidad, son referidos al algoritmo APG, que representa la metodología más eficiente en este caso. La siguiente figura muestra la eficiencia del algoritmo en función de la probabilidad HMCR y del ajuste del PAR.

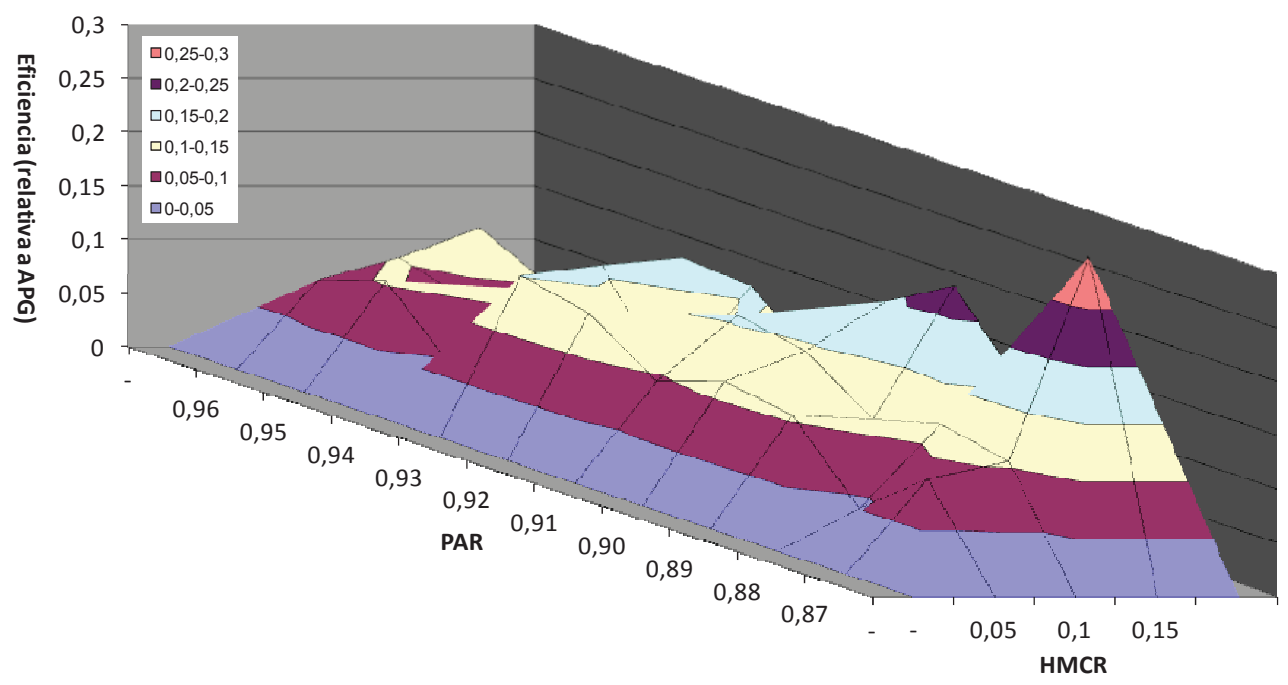

Figura 6.38. Análisis de eficiencia según HMCR y PAR para la red de Go-Yang

El análisis de eficiencia de la red de Go-Yang determina que el algoritmo HS está muy lejos del algoritmo APG en lo que a eficiencia se refiere. La zona de máxima eficiencia en este caso apenas alcanza un valor de 0,3 y ni siquiera hay una zona de ajuste clara que mantenga constante este valor, sino que es una zona de máxima eficiencia puntual que simplemente puede deberse a una distribución estadística.

Así, si se analiza la eficiencia del algoritmo de modo local para el algoritmo HS, el análisis no muestra una tendencia clara respecto de cuál es el mejor ajuste posible en este caso, puesto que si bien la zona de máxima eficiencia se produce para una probabilidad HMCR $=0,87$ y un $P A R=0,15$, el pico de eficiencia es aislado. No obstante, sí que parece que la eficiencia del algoritmo es algo mayor en la zona que corresponde a un ajuste del PAR en torno a 0,15 , lo que supone una excepción al comportamiento general de este parámetro, que en el resto de redes tan sólo tiene relación con la convergencia del algoritmo.

Pese a esta aparente tendencia se antoja difícil el elegir una zona de máxima eficiencia en este caso, puesto que la representación no muestra zonas completas con un mejor 
funcionamiento, sino picos puntuales que obtienen diferencias en la eficiencia que localmente parecen mucho más altos de lo que realmente son en términos generales. De este modo, considerando tanto el análisis del resto de redes como éste propio, la recomendación más sensata es considerar un ajuste del PAR que se encuentre en torno a 0,15, de modo que se garantice la convergencia del algoritmo y se aumente la eficiencia del algoritmo a la hora de obtener la mejor solución posible.

En el ajuste del HMCR, el algoritmo parece ser más eficiente cuando la probabilidad de este parámetro es baja (dentro del rango considerado), pese a que no puede considerarse este ajuste como crítico de cara al funcionamiento del algoritmo. Es por ello que parece conveniente el ampliar la zona que se puede considerar como de máxima eficiencia, estimándose ésta en torno a probabilidades HMCR entre 0,87 y 0,92.

Por último se aborda el análisis de eficiencia considerando el número de individuos que componen la población inicial del algoritmo. La muestra utilizada en este caso corresponde a simulaciones realizadas para tamaños de población entre 15 y 135 individuos, modificando dicho tamaño de 15 en 15. Teniendo en cuenta que este es el único caso donde la optimización de parámetros no permitía la mejora de la solución en cuanto a calidad, se consideró un rango amplio tanto para la probabilidad HMCR como para el ajuste del PAR. Así, la probabilidad HMCR está comprendida entre 0,87 y 0,93, mientras que el ajuste del PAR se ajusta entre 0,05 y 0,15. Este rango de trabajo se aproxima al ajuste de parámetros óptimo del resto de redes. La eficiencia del algoritmo según el tamaño de la memoria en estas condiciones se muestra en la figura 6.39.

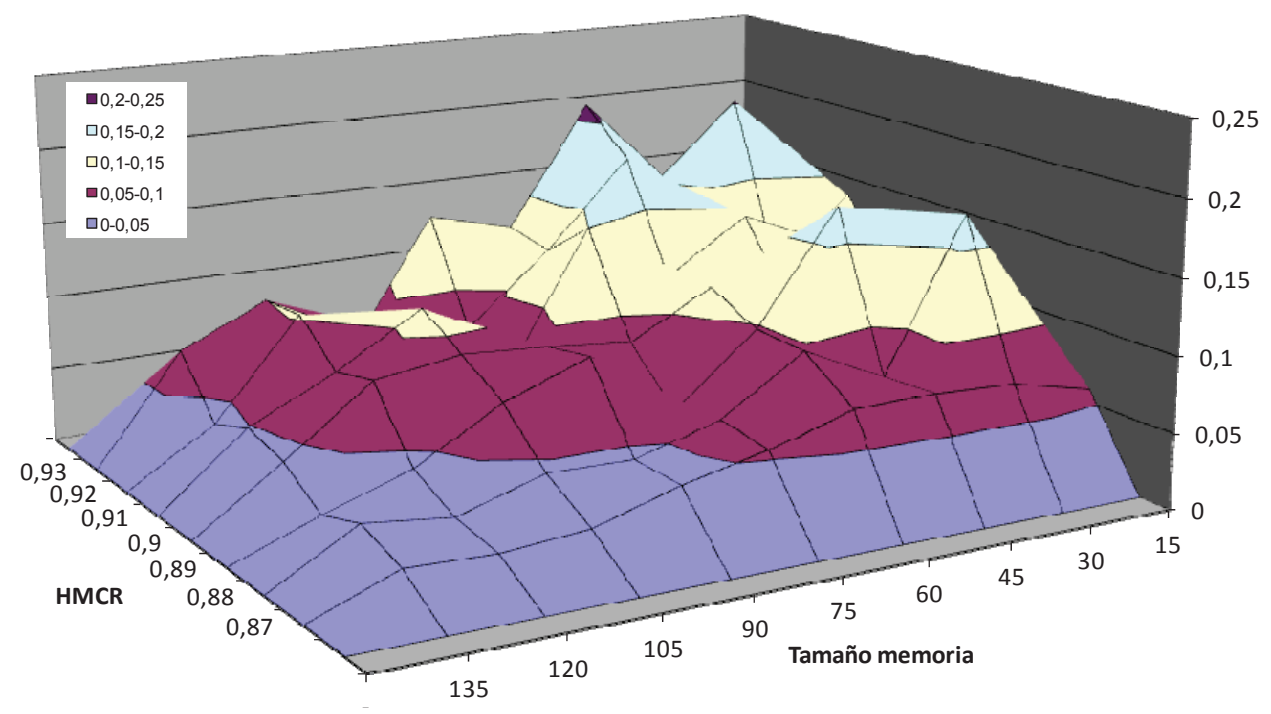

Figura 6.39. Análisis de eficiencia según tamaño de memoria para la red de Go-Yang. 
El algoritmo HS en la red de Go-Yang sigue la misma línea que en todos los casos anteriores, de modo que el algoritmo se muestra siempre más eficiente para poblaciones pequeñas, siempre y cuando el tamaño sea lo suficientemente grande como para evitar convergencias tempranas que caigan en mínimos locales. La red de Go-Yang es un caso sencillo, por lo que la zona que puede considerarse como de eficiencia máxima es bastante amplia, aproximadamente entre 15 y 45 individuos no representan grandes diferencias en cuanto a valores de eficiencia.

Cabe recordar que la mayor virtud del algoritmo HS es la velocidad con la que es capaz de proporcionar buenas soluciones de diseño, si bien esa rapidez va en detrimento de la probabilidad de encontrar la mínima solución de diseño, que es menor cuando se utiliza esta técnica. Considerando únicamente el criterio de elección basado en la eficiencia del algoritmo, la siguiente tabla muestra el mejor ajuste posible en el diseño óptimo de la red de Go-Yang.

\begin{tabular}{|c|c|c|}
\hline \multicolumn{2}{|c|}{ Parámetros de ajuste } & Obtención de mínimas soluciones \\
\hline Probabilidad HMCR & HMCR & $0,87-0,93$ \\
\hline Ajuste pitchrate & PAR & $\cong 0,15$ \\
\hline Número individuos & Pop & $15-45$ \\
\hline
\end{tabular}

Tabla 6.15. Ajuste óptimo de parámetros para el algoritmo HS en la red de Go-Yang.

\subsubsection{Algoritmo SFL}

Ya se ha visto en anteriores ejemplos la potencia de cálculo del algoritmo SFL en lo que a optimización se refiere. La propia complejidad del algoritmo, que requiere de cinco parámetros de ajuste provoca que no sea el más adecuado cuando se trata de resolver redes sencillas. Para la red de Go-Yang, el ajuste realizado en 5.2 sobre una muestra de 10000 simulaciones y la probabilidad de obtener la mejor solución posible, determinaba que la mejor zona de cálculo era capaz de obtener la mínima solución para el problema de diseño en alrededor del $65 \%$ de las simulaciones realizadas. El mejor ajuste posible considerando únicamente la posibilidad de obtener esta mínima solución correspondía a un coeficiente acelerador (C) en torno a 1,375 y 30 saltos evolutivos (N) por iteración. En cuanto al tamaño de submemeplex $(\mathrm{Q})$, el estudio no arrojaba ninguna conclusión y parecía indiferente su valor dentro del rango estudiado.

En cuanto a la velocidad del algoritmo, el comportamiento del algoritmo HS en la red de GoYang es prácticamente idéntico al que ya se veía en la red de Nueva York. Así, el tamaño del submemeplex (Q) ejerce cierta influencia en la velocidad del algoritmo, de modo que se realiza un menor número de evaluaciones conforme aumenta el tamaño de submemeplex. En cuanto al coeficiente acelerador, considerando únicamente el gasto computacional valores en torno a 1,75-2 son los que menos evaluaciones de la función objetivo realizan. Por último, el 
caso más claro tiene que ver con el número de saltos evolutivos, donde la convergencia del algoritmo es más lenta cuanto mayor es el número de saltos evolutivos.

De similar modo a como se ha procedido en el resto de casos, las figuras $6.40,6.41$ y 6.42 muestran la eficiencia del algoritmo SFLA en función de los distintos parámetros de ajuste para la red de Go-Yang. Los valores de eficiencia que se representan son relativos, puesto que están referidos al punto de eficiencia máxima en la red de Go-Yang, que corresponde a la zona de máxima eficiencia obtenida con el algoritmo APG.

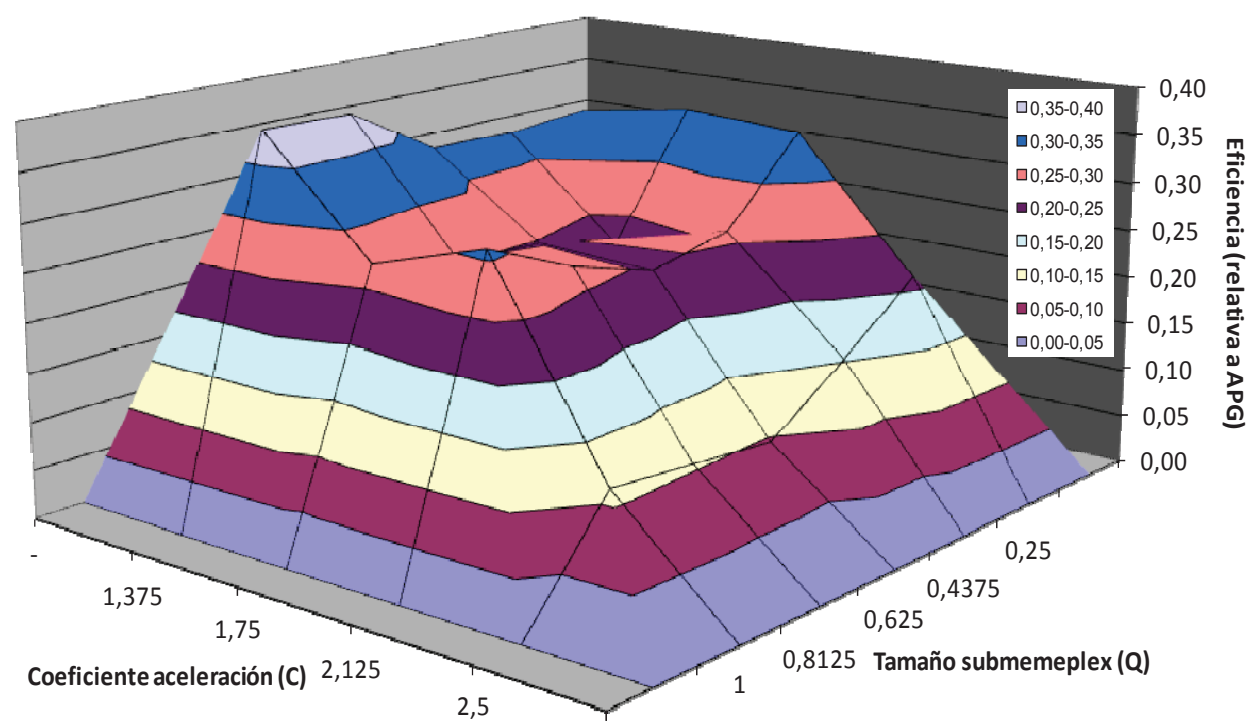

Figura 6.40. Análisis de eficiencia según tamaño submemeplex (Q) y coeficiente acelerador (C) en la red de Go-Yang 


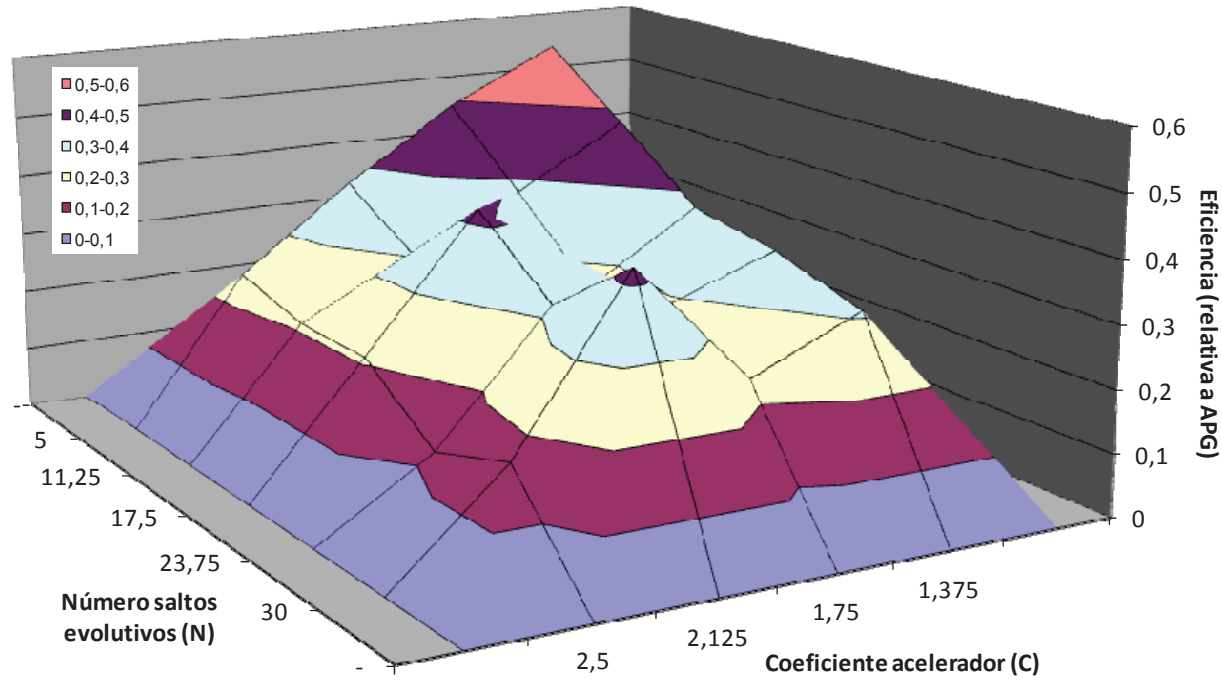

Figura 6.41. Análisis de eficiencia según número de saltos evolutivos $(\mathrm{N})$ y coeficiente acelerador (C) en la red de Go-Yang

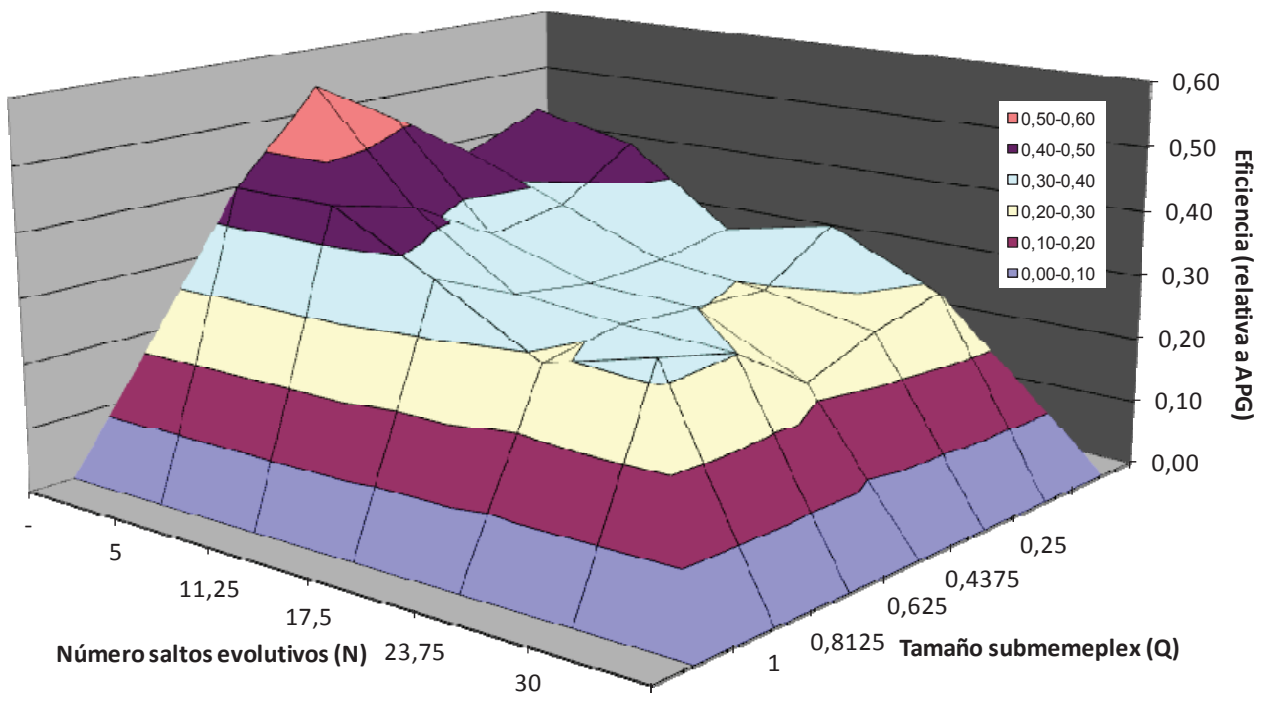

Figura 6.42. Análisis de eficiencia según tamaño submemeplex (Q) y número de saltos evolutivos ( $N$ ) en la red de Go-Yang.

El algoritmo SFL representa siempre la mejor opción cuando se trata de conseguir la mejor solución posible, siempre y cuando no importe demasiado el tiempo que tarde en conseguirla. Así, en el diseño de la red de Go-Yang es el algoritmo de optimización que mayor número de mínimos consigue, pero sin embargo no es el más eficiente, puesto que la 
cantidad de recursos que necesita el algoritmo SFL se antoja excesiva para una red de este tipo.

Así, las figuras 6.40, 6.41 y 6.42, que analizan la eficiencia del algoritmo SFL muestran el campo de eficiencia relativo referido al algoritmo APG, siendo su principal cometido reflejar el ajuste más eficiente en función del valor de los distintos parámetros que guardan relación con la naturaleza de los saltos evolutivos.

La evolución de la eficiencia en función del valor del coeficiente acelerador (C) puede determinarse a partir de las figuras 6.40 y 6.41, que relaciona este parámetro con los $\mathrm{N}$ y $\mathrm{Q}$. En este caso, ambas figuras son coincidentes respecto a la conclusión acerca del mejor ajuste para $C$, puesto que en ambos casos se aprecia como la eficiencia del algoritmo es mayor cuanto menor es el valor de C. El ajuste del coeficiente acelerador en función de la eficiencia del algoritmo es coincidente con el ajuste del mismo cuando se busca la mejor solución posible, recomendando en ambos casos un valor para $C$ de 1,375. Los valores de eficiencia obtenidos para la red de Go-Yang priman la mejora obtenida en el coste final de diseño sobre la velocidad del algoritmo, puesto que HS es mucho más rápido para valores de $\mathrm{C}$ superiores.

Respecto del número de saltos evolutivos (N), la conclusión es la misma que en el resto de redes analizadas, de modo que cuanto mayor es $\mathrm{N}$ menor es la eficiencia del algoritmo, puesto que la mejora conseguida en el valor de diseño no compensa la alta cantidad de recursos que exige el aumento de N. No obstante, la diferencia en la red de Go-Yang entre utilizar valores de $\mathrm{N}$ pequeños o grandes es algo menor que en otras redes, puesto que la facilidad con la que se encuentra el mínimo de diseño evita que el cálculo se prolongue demasiado. En este sentido, frente a otras redes, donde la eficiencia del algoritmo era hasta cuatro veces mayor utilizando $\mathrm{N}=5$ en lugar de $\mathrm{N}=30$, en Go-Yang ni siquiera se dobla el valor de la eficiencia entre un valor de $\mathrm{N}$ y otro.

Por último, el tamaño de submemeplex (Q), que hasta ahora se ha mostrado como el ajuste menos crítico entre los distintos parámetros, sigue en esa línea en las simulaciones realizadas para la red de Go-Yang. La definición de un ajuste óptimo para $Q$ en el rango considerado es una tarea compleja, puesto que en cada una de las redes se han obtenido resultados distintos, que impiden establecer una tendencia clara. Así, en el caso particular de la red de Go-Yang la diferencia en los resultados obtenidos entre unos valores de $Q$ y otros no sigue ninguna tendencia, siendo similares todos ellos, con algún que otro altibajo debido a la propia estadística. En función de la experiencia previa en otras redes, la recomendación más lógica es utilizar valores de $Q$ por encima de 0,5, pero únicamente porque las zonas de máxima eficiencia se localizan en este rango, no representando en ningún caso una decisión crítica para el buen funcionamiento del algoritmo en una red de tipología similar a Go-Yang. 
Si se analiza la eficiencia del algoritmo SFL respecto del resto de técnicas, los resultados sitúan al algoritmo SFL como la técnica más eficiente, exceptuando al APG cuando este último utiliza poblaciones muy pequeñas. Del mismo modo, el algoritmo SFL se muestra superior en casi todo el rango estudiado al algoritmo HS, puesto que tiene mayor facilidad para encontrar la solución mínima de diseño y muy superior al algoritmo PSO modificado, que nuevamente resulta ser la técnica que peor se adapta al problema.

En realidad, si se compara la eficiencia del algoritmo SFL con la del APG cuando ambos tienen una población de 100 individuos, la eficiencia del primero es mayor en términos generales, pero en una red tan sencilla como la de Go-Yang, la utilización de una población de individuos en torno a 50 es suficiente para que el APG multiplique su eficiencia.

El número de individuos que intervienen en el proceso de optimización viene dado por el número de memeplexes $(\mathrm{m})$ y el número de ranas por memeplex $(\mathrm{n})$, resultando el producto de ambos la población inicial del algoritmo. Para el algoritmo SFL, el número de individuos mínimo que se considera es de 100 unidades, lo que inicialmente le deja en desventaja frente a otras técnicas en una red con tan pocos mínimos locales y posibilidades de diseño como GoYang.

Así, la eficiencia en base a la población del algoritmo se realiza manteniendo constantes $Q, C$ y $\mathrm{N}$ y alternando los valores de $\mathrm{m}$ y $\mathrm{n}$ entre 10 y 30 , de modo que se analizan tamaños de población inicial de entre 100 y 900 individuos. Los valores constantes que se consideran para $\mathrm{Q}, \mathrm{C}$ y $\mathbf{N}$ eran los considerados en 5.2 como zona óptima de cálculo cuando se considera únicamente la posibilidad de conseguir la mejor solución posible. La eficiencia relativa del algoritmo según estas condiciones iniciales de cálculo viene dada por la figura: 


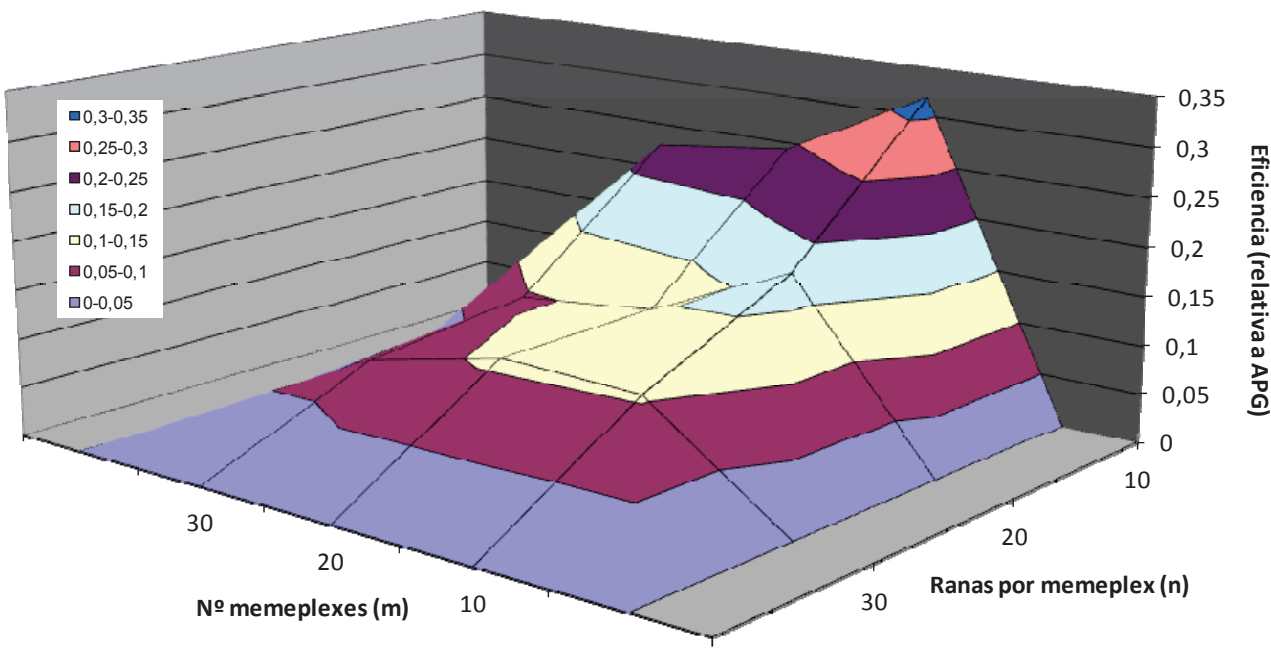

Figura 6.43. Análisis de eficiencia $n \div$ memeplexes $(m)$ y ranas por memeplex $(n)$ en la red de Go-Yang.

La figura 6.43 muestra con claridad como la eficiencia del algoritmo es mucho mayor cuanto menor es la población inicial del algoritmo. En este caso, incluso podría afirmarse con total seguridad que poblaciones más pequeñas que las consideradas serían incluso más eficientes, puesto que en una red de esta sencillez la calidad de la solución sería similar y el gasto computacional mucho menor. Normalmente, en todos los casos existe un número mínimo de individuos del cual no se puede bajar, puesto que dificultaría la búsqueda, provocando la caída del proceso en mínimos locales, pero en este caso, y a tenor de los resultados proporcionados por el resto de metodologías, 100 individuos es una población considerable y todo hace presagiar que poblaciones más pequeñas todavía mejorarían la eficiencia del algoritmo.

El resumen de todo el proceso de optimización según la eficiencia del algoritmo viene dado por la tabla inferior, donde se proporciona el mejor ajuste posible para cada parámetro del algoritmo SFL considerando como único criterio el de la eficiencia. Los valores dados en esta tabla componen lo que podemos considerar como zona de máxima eficiencia del algoritmo SFL para la red de Go-Yang dentro del rango de cálculo considerado:

\begin{tabular}{|c|c|c|}
\hline \multicolumn{2}{|c|}{ PARÁMETROS } & Obtención de buenas soluciones \\
\hline Tamaño submemeplex & $\mathrm{Q}$ & $>0,5$ \\
\hline Número saltos evolutivos & $\mathrm{N}$ & 5 \\
\hline Coeficiente de aceleración & $\mathrm{C}$ & 1,375 \\
\hline Ranas por memeplex & $\mathrm{m}$ & 10 \\
\hline Número memeplexes & $\mathrm{n}$ & 10 \\
\hline
\end{tabular}

Tabla 6.16. Ajuste óptimo de parámetros según eficiencia para el algoritmo SFL en la red de Go-Yang. 


\subsection{Aplicaciones basadas en el análisis de eficiencia}

El análisis de eficiencia en los distintos modelos de optimización pretende evitar que un usuario poco experimentado obtenga poco rendimiento de este tipo de aplicaciones por su propio desconocimiento. Así, tomando como referencia las conclusiones derivadas del análisis estadístico se plantean ahora una serie de aplicaciones prácticas que aprovechan las recomendaciones proporcionadas por el análisis de eficiencia.

De este modo, se consideran las recomendaciones derivadas del análisis de eficiencia respecto del mejor ajuste de parámetros en cada modelo de optimización para la resolución de dos nuevos problemas de optimización.

La primera aplicación considera el diseño de una pequeña red de distribución, necesaria para el abastecimiento de una nueva urbanización. Dicha red debe incorporarse a la red general de un municipio más grande, por lo que realmente se trata de un problema de ampliación. El ejemplo muestra todo el proceso realizado partiendo únicamente de la topología de la red

El segundo de los problemas planteados considera un criterio de fiabilidad para la resolución de las redes de diseño resueltas en este trabajo. El objetivo es asegurar el abastecimiento a unas condiciones determinadas bajo un escenario de rotura de una conducción. Así, se aplican las configuraciones más eficientes para cada modelo de optimización a un problema más complejo y que requiere mayor tiempo de cálculo.

Las tablas $6.17,6.18,6.19$ y 6.20 muestran el ajuste recomendado para cada uno de los modelos de optimización analizados considerando el análisis de eficiencia del apartado anterior. Estos valores representan ajustes eficientes en los parámetros de cada metodología y son los utilizados para la resolución de los ejemplos de aplicación propuestos en este apartado. La misma filosofía puede aplicarse para la resolución de otros problemas de optimización que no considera esta tesis.

\begin{tabular}{|c|c|c|}
\hline \multicolumn{2}{|c|}{ PARÁMETROS } & Obtención de mínimas soluciones \\
\hline Prob. de cruce & $\mathrm{P}_{\mathrm{c}}$ & 0,5 \\
\hline Prob. de mutación & $\mathrm{P}_{\mathrm{m}}$ & $0,02-0,03-0,04$ \\
\hline Tamaño de población & & 50 \\
\hline
\end{tabular}

Tabla 6.17. Ajuste óptimo de eficiencia en el algoritmo APG.

\begin{tabular}{|c|c|c|}
\hline \multicolumn{2}{|c|}{ PARÁMETROS } & Obtención de mínimas soluciones \\
\hline Velocidad límite & $\mathrm{V}_{\lim }$ & 0,2 \\
\hline Prob. de despiste & $\mathrm{P}_{\text {desp }}$ & 0,1 \\
\hline Constante 1 & $\mathrm{C}_{1}$ & 2 \\
\hline Constante 2 & $\mathrm{C}_{2}$ & 2 \\
\hline Número individuos & & $75-225$ \\
\hline
\end{tabular}

Tabla 6.18. Ajuste óptimo de eficiencia en el algoritmo PSO. 
6. Eficiencia de los modelos de optimización

\begin{tabular}{|c|c|c|}
\hline \multicolumn{2}{|c|}{ Parámetros de ajuste } & Obtención de mínimas soluciones \\
\hline Probabilidad HMCR & HMCR & $0,92-0,95$ \\
\hline Ajuste pitchrate & PAR & 0,15 \\
\hline Número individuos & & 50 \\
\hline
\end{tabular}

Tabla 6.19. Ajuste óptimo de eficiencia en el algoritmo HS.

\begin{tabular}{|c|c|c|}
\hline \multicolumn{2}{|c|}{ PARÁMETROS } & Obtención de buenas soluciones \\
\hline Tamaño submemeplex & $\mathrm{Q}$ & 0,4 \\
\hline Número saltos evolutivos & $\mathrm{N}$ & 5 \\
\hline Coeficiente de aceleración & $\mathrm{C}$ & 2 \\
\hline Ranas por memeplex & $\mathrm{m}$ & 10 \\
\hline Número memeplexes & $\mathrm{n}$ & 10 \\
\hline
\end{tabular}

Tabla 6.20. Ajuste óptimo de eficiencia en el algoritmo SFL.

\subsubsection{Aplicación a la ampliación de una red de trazado real.}

El proyecto de la red de Noja representa la ampliación de una red de distribución ya construida, que surge de la necesidad de abastecimiento de una nueva urbanización, cuya red se tiene que añadir a la ya existente.

En este caso, al ser tan sólo proyecto de ampliación no es necesario el diseño de la red completa, sino tan sólo el de la parte que corresponde a la nueva red construida. El problema queda reducido al dimensionado de los diámetros de la ampliación, de modo que se cumplan los requerimientos mínimos de presión, que en este caso serán de 25 mca.

Toda la información relacionada con la topología de la red, como puede ser la longitud de las conducciones, la ubicación de los distintos elementos, etc se obtiene de planos digitalizados. Como resultado se obtiene un mapeado de toda la red de distribución, que incluye cotas de todos los puntos singulares de la misma, como son nudos, válvulas, depósitos, etc. La figura 6.44 representa la representación digital organizada en capas, entre las que se incluye la red de distribución de agua actual remarca en azul.

Con toda la información disponible es necesario reorganizarla de tal modo que pueda ser introducida en un programa de análisis. En este caso, los diámetros de las conducciones fueron introducidos en el mapa a través del programa AIGUA, que permite relacionar un programa CAD con una base de datos Access. De este modo se consigue vincular elementros gráficos y alfanuméricos, generando una base de datos que podrá ser tratada de cara a la creación de un fichero inp que pueda utilizarse en EPANET. 


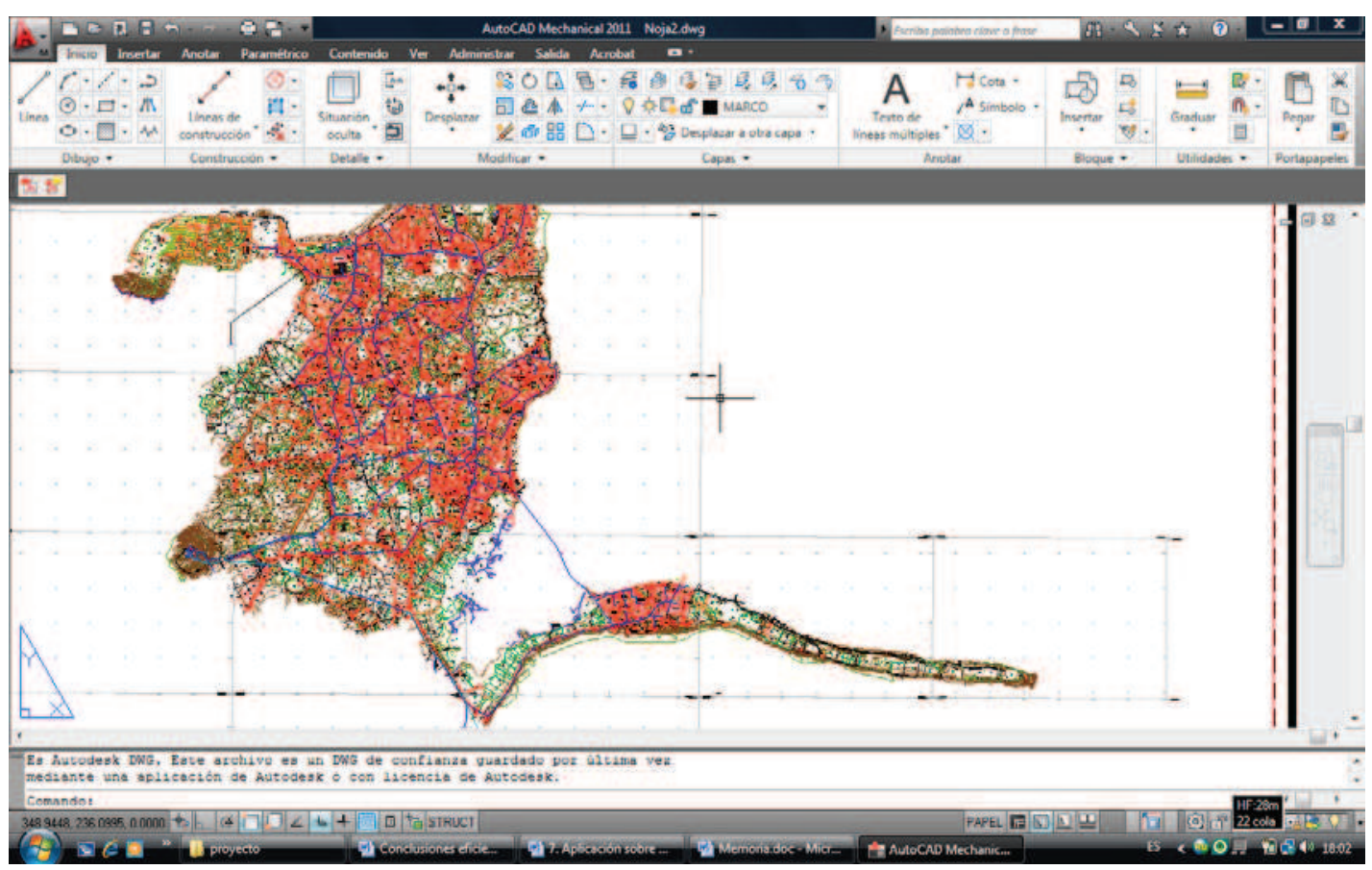

Figura 6.44. Topología CAD para la red de Noja

El archivo inp permite el análisis de la red en el estado actual, así como predecir el funcionamiento de la misma en escenarios futuros. La figura 6.45 muestra la red original del municipio sin ninguna modificación. El programa EPANET permite realizar la simulación de la red, de modo que a partir de los diámetros de las conducciones y el consumo en cada nudo es posible saber cuál es el caudal circulante por cada una de las conducciones, así como la presión en cada uno de los nudos.

La información que se tiene de la red original comprende todos los datos topográficos de la red, donde se muestra el trazado de las conducciones, los diámetros y secciones, así como el perfil de cada tramo y detalles de los aliviaderos, pozos, depósitos y demás elementos singulares. La red de Noja tiene un tamaño considerable, de modo que es conveniente la simplificación de la misma, a fin de reducir el proceso de optimización posterior en la medida de lo posible. 


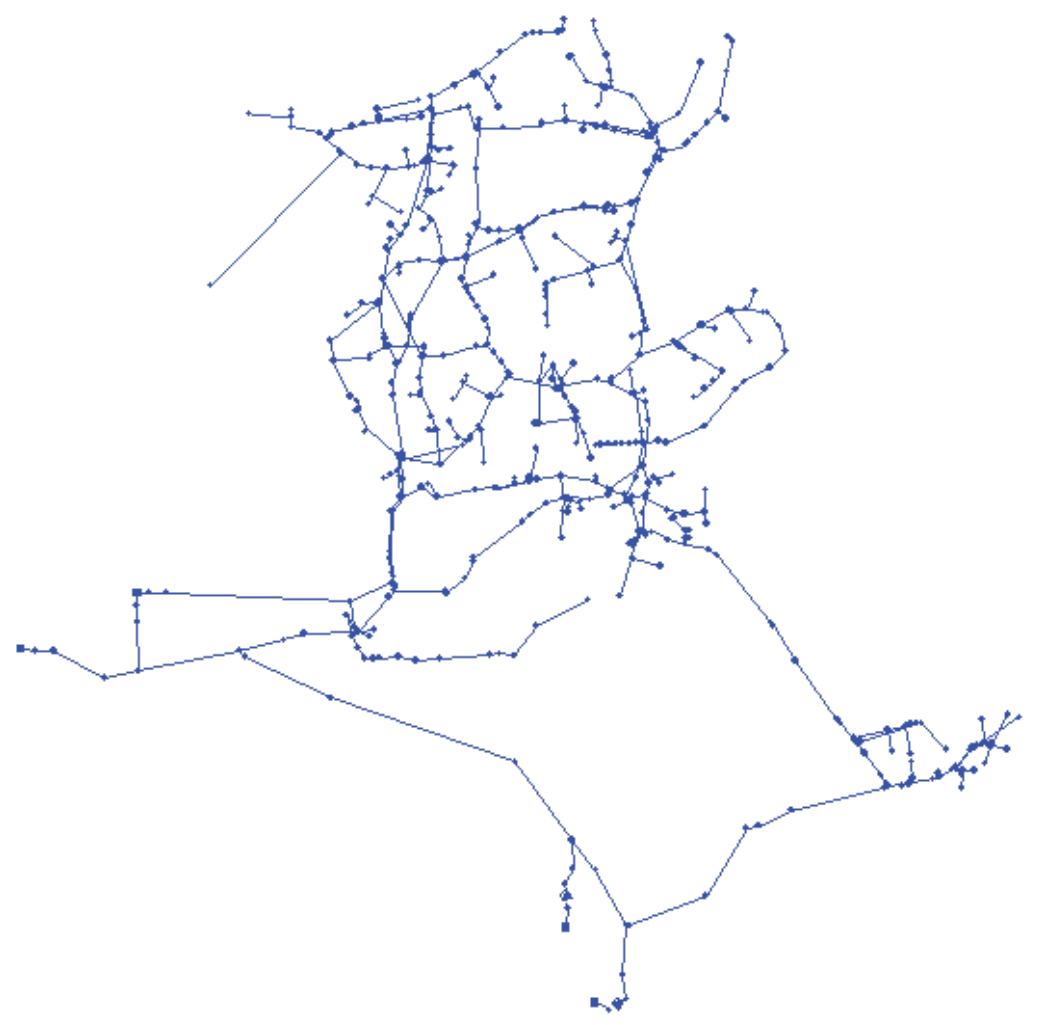

Figura 6.45. Red de distribución de agua en Noja

Es posible realizar una esqueletización de la red original, en una simplificación que elimina las ramificaciones, dejando únicamente el esqueleto mallado de la red de distribución. Esta simplificación se realiza acumulando los caudales circulantes de cada ramificación en el nudo de partida de la red mallada correspondiente. Este artificio permite la simplificación de la red, permitiendo una mayor velocidad de cálculo en el diseño de la red con los distintos algoritmos evolutivos.

La red existente cumple las restricciones de presión mínima en todos los nudos de carga, puesto que todos ellos mantienen una presión de servicio por encima de 25 mca. A dicha red hay que añadir el diseño realizado para la nueva urbanización, teniendo en cuenta que los requisitos de presión mínima se deben seguir cumpliendo. La figura 6.46 muestra la red simplificada, así como el perfil de ampliación que es necesario realizar para el abastecimiento de la nueva urbanización: 


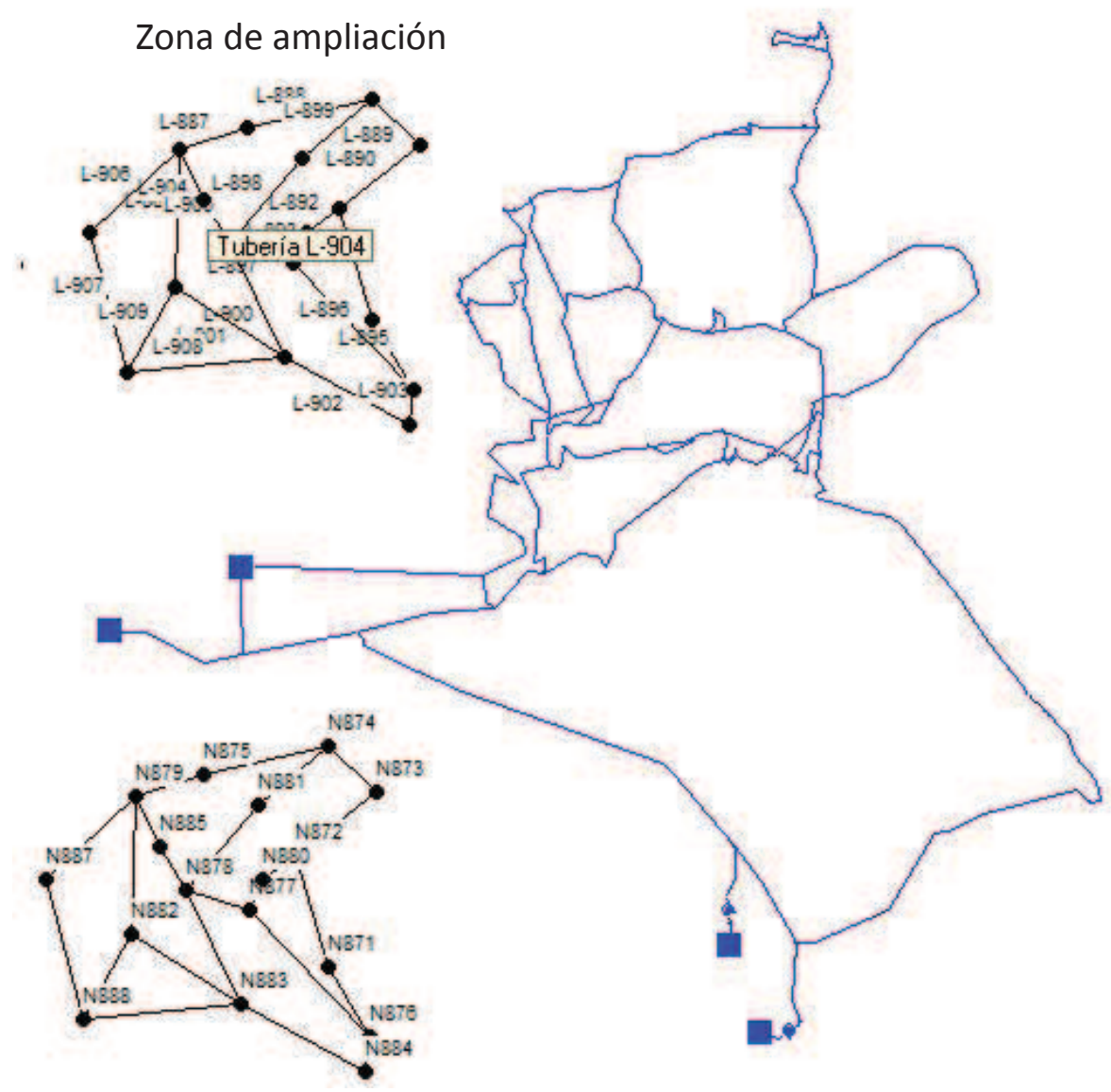

Figura 6.46. Red simplificada de distribución en Noja con el proyecto de ampliación

La ampliación correspondiente a la nueva urbanización puede conectarse por un solo punto, de manera que se cargara todo el caudal desde un único nudo, de modo que la conexión quedara realizada a través de una red ramificada, lo que simplificaría el cálculo sobremanera. Así, tras realizar una estimación del consumo que va a tener la nueva urbanización se cargó a la red en el punto marcado en la figura 6.46 un caudal de $25 \mathrm{l} / \mathrm{s}$, que se añade al caudal que ya circulaba en dicho nudo antes de realizar el proyecto de ampliación de la red.

Inicialmente se supone para todas las conducciones de la zona de ampliación el diámetro máximo de la gama con la que se va a trabajar, que será de $250 \mathrm{~mm}$. La siguiente tabla muestra con detalle los resultados obtenidos y se resaltan en sombreado los puntos que no cumplen las presiones mínimas tras la simulación: 
6. Eficiencia de los modelos de optimización

\begin{tabular}{|c|c|c|c|c|c|c|c|}
\hline Id & $\begin{array}{l}\text { Altura } \\
\text { (mca) }\end{array}$ & $\begin{array}{c}\text { Presión } \\
\text { (mca) }\end{array}$ & Demanda (I/s) & Id & $\begin{array}{l}\text { Altura } \\
\text { (mca) }\end{array}$ & $\begin{array}{c}\text { Presión } \\
\text { (mca) }\end{array}$ & Demanda (I/s) \\
\hline P1 & 67,995 & 0 & $-139,733$ & N61 & 50,121 & 26,121 & 0 \\
\hline P2 & 62,97 & 0 & $-24,847$ & N62 & 48,967 & 24,967 & 0 \\
\hline P3 & -20 & 0 & 0 & N63 & 45,307 & 23,929 & 1,149 \\
\hline P4 & -20 & 0 & 0 & N64 & 45,511 & 24,467 & 0,616 \\
\hline N1 & 44,91 & 31,473 & 2,409 & N65 & 50,01 & 25,509 & 0,648 \\
\hline N2 & 46,166 & 35,468 & 0 & N66 & 52,079 & 28,4 & 0,645 \\
\hline N3 & 49,07 & 26,284 & 6,055 & N67 & 59 & 59 & 0 \\
\hline N4 & 48,967 & 25,008 & 3,068 & N68 & 59,159 & 54,898 & 0 \\
\hline N5 & 48,967 & 24,967 & 0 & N69 & 45,053 & 31,656 & 0 \\
\hline N6 & 48,85 & 25,678 & 2,466 & N70 & 45,314 & 31,916 & 0 \\
\hline N7 & 48,858 & 25,759 & 0 & N71 & 49,227 & 26,624 & 0,74 \\
\hline N8 & 45,736 & 25,496 & 0,811 & N72 & 48,967 & 24,96 & 0 \\
\hline N9 & 46,169 & 31,221 & 0 & N73 & 48,967 & 24,96 & 0 \\
\hline N10 & 51,058 & 27,222 & 0 & N74 & 50,124 & 25,548 & 4,13 \\
\hline N11 & 52,761 & 28,93 & 0 & N75 & 48,977 & 24,4 & 0 \\
\hline N12 & 53,019 & 28,677 & 0 & N76 & 48,853 & 25,707 & 0 \\
\hline N13 & 52,99 & 26,828 & 0 & N77 & 48,855 & 25,709 & 0 \\
\hline N14 & 51,091 & 26,399 & 0,874 & N78 & 45,76 & 25,544 & 0 \\
\hline N15 & 51,899 & 28,697 & 0,333 & N79 & 45,821 & 25,605 & 0,646 \\
\hline N16 & 54,334 & 31,633 & 1,339 & N80 & 46,27 & 26,963 & 0 \\
\hline N17 & 50,266 & 24,45 & 1,307 & N81 & 46,495 & 27,188 & 8,241 \\
\hline N18 & 49,719 & 25,866 & 0,661 & N82 & 46,168 & 31,782 & 0 \\
\hline N19 & 50,218 & 24,538 & 2,827 & N83 & 46,169 & 31,783 & 0 \\
\hline N20 & 43,758 & 17,87 & 0,485 & N84 & 46,061 & 30,885 & 0,313 \\
\hline N21 & 50,241 & 26,241 & 3,862 & N85 & 46,168 & 30,992 & 0 \\
\hline N22 & 50,32 & 27,927 & 0,847 & N86 & 46,175 & 31,092 & 1,688 \\
\hline N23 & 52,016 & 31,511 & 1,462 & N87 & 46,171 & 31,089 & 0 \\
\hline N24 & 51,948 & 29,48 & 0 & N88 & 50,732 & 26,872 & 0 \\
\hline N25 & 51,796 & 31,257 & 0 & N89 & 48,978 & 25,119 & 1,962 \\
\hline N26 & 51,353 & 30,527 & 0 & N90 & 50,52 & 26,626 & 0 \\
\hline N27 & 50,886 & 31,844 & 0,703 & N91 & 49,822 & 25,928 & 0,547 \\
\hline N28 & 51,713 & 31,204 & 1,562 & N92 & 50,293 & 26,465 & 0 \\
\hline N29 & 51,413 & 30,78 & 1,956 & N93 & 43,767 & 19,961 & 0 \\
\hline N30 & 51,926 & 29,251 & 0,55 & N94 & 43,758 & 19,952 & 0 \\
\hline N31 & 51,924 & 30,034 & 0,31 & N95 & 53,018 & 28,587 & 0 \\
\hline N32 & 54,2 & 33,2 & 1,777 & N96 & 49,719 & 25,592 & 0,66 \\
\hline N33 & 55,944 & 34,899 & 3,456 & N97 & 50,21 & 24,526 & 0,269 \\
\hline N34 & 59,786 & 34,636 & 0 & N98 & 50,209 & 26,209 & 0 \\
\hline N35 & 59,159 & 55,082 & 0 & N99 & 50,21 & 26,21 & 0 \\
\hline N36 & 48,902 & 29,902 & 2,341 & N100 & 52,744 & 28,444 & 0,162 \\
\hline N37 & 48,878 & 29,747 & 3,363 & N101 & 51,944 & 29,527 & 0 \\
\hline
\end{tabular}




\begin{tabular}{|c|c|c|c|c|c|c|c|}
\hline N38 & 48,954 & 24,878 & 0 & $\mathrm{~N} 102$ & 51,713 & 31,554 & 0 \\
\hline $\mathrm{N} 39$ & 50,223 & 27,955 & 1,12 & $\mathrm{~N} 103$ & 51,311 & 30,56 & 0 \\
\hline $\mathrm{N} 40$ & 48,211 & 24,693 & 11,439 & $\mathrm{~N} 104$ & 51,35 & 30,599 & 0 \\
\hline $\mathrm{N} 41$ & 50,918 & 28,505 & 0,285 & $\mathrm{~N} 105$ & 48,888 & 29,929 & 0 \\
\hline $\mathrm{N} 42$ & 50,918 & 30,065 & 2,361 & $\mathrm{~N} 106$ & 48,893 & 29,934 & 0 \\
\hline $\mathrm{N} 43$ & 50,918 & 33,531 & 1,781 & $\mathrm{~N} 107$ & 48,87 & 30,326 & 0 \\
\hline $\mathrm{N} 44$ & 50,931 & 39,665 & 1,901 & $\mathrm{~N} 108$ & 48,871 & 30,328 & 0 \\
\hline $\mathrm{N} 45$ & 51,163 & 47,575 & 1,426 & $\mathrm{~N} 109$ & 48,873 & 30,272 & 0 \\
\hline $\mathrm{N} 46$ & 59 & 53,742 & 0 & $\mathrm{~N} 110$ & 48,873 & 30,272 & 0 \\
\hline $\mathrm{N} 47$ & 49,253 & 38,019 & 0,467 & $\mathrm{~N} 111$ & 48,896 & 29,978 & 1,271 \\
\hline $\mathrm{N} 48$ & 49,722 & 24,018 & 4,207 & $\mathrm{~N} 112$ & 48,897 & 29,979 & 0 \\
\hline $\mathrm{N} 49$ & 67,995 & 0 & $-139,733$ & $\mathrm{~N} 113$ & 48,944 & 29,944 & 0 \\
\hline $\mathrm{N} 50$ & 62,97 & 0 & $-24,847$ & $\mathrm{~N} 114$ & 48,932 & 29,932 & 1,1 \\
\hline $\mathrm{N} 51$ & -20 & 0 & 0 & $\mathrm{~N} 115$ & 48,956 & 24,909 & 0,881 \\
\hline $\mathrm{N} 52$ & -20 & 0 & 0 & $\mathrm{~N} 116$ & 48,954 & 24,907 & 0 \\
\hline $\mathrm{N} 53$ & 43,771 & 30,071 & 1,4 & $\mathrm{~N} 117$ & 49,909 & 35,802 & 2,823 \\
\hline $\mathrm{N} 54$ & 43,771 & 28,271 & 2,3 & $\mathrm{~N} 118$ & 50,221 & 28,016 & 1,938 \\
\hline $\mathrm{N} 55$ & 43,761 & 21,761 & 1,4 & $\mathrm{~N} 119$ & 50,918 & 28,491 & 0 \\
\hline N56 & 43,763 & 19,463 & 1,3 & $\mathrm{~N} 120$ & 50,918 & 28,491 & 0 \\
\hline N57 & 43,767 & 19,767 & 26,081 & $\mathrm{~N} 121$ & 55,737 & 51,755 & 0 \\
\hline N58 & 43,763 & 25,763 & 1,4 & $\mathrm{~N} 122$ & 55,95 & 51,969 & 0,682 \\
\hline $\mathrm{N} 59$ & 43,76 & 19,76 & 2,1 & $\mathrm{~N} 123$ & 58,508 & 51,508 & 0,778 \\
\hline N60 & 43,761 & 19,261 & 1,7 & & & & \\
\hline
\end{tabular}

Tabla 6.21. Simulación de la red de Noja conectando la zona de ampliación a través de un solo punto de conexión.

El análisis de la red en estas condiciones determina la existencia de nudos donde no se cumple la presión mínima de servicio exigida para el buen funcionamiento de la red, por lo que será necesario realizar la ampliación de la red por dos puntos diferentes, distribuyendo así los caudales, y justificando de esta manera la aplicación de metodologías evolutivas para la optimización económica del diseño. Así, hasta un total de 19 puntos en la red tienen presiones por debajo de 25 mca. Este resultado justifica la conexión de la nueva red a través de dos puntos, convirtiendo el proyecto de ampliación en un sistema mallado, de modo que queda justificada la utilización de metodologías heurísticas que permitan la resolución del problema de diseño. Las siguientes tablas muestran con detalle la topología de la zona de ampliación.

\begin{tabular}{|c|c|c||c|c|c|}
\hline N. nudo & Cota $(\mathbf{m})$ & $\mathbf{Q}(\mathbf{l} / \mathbf{s})$ & N.nudo & Cota $(\mathbf{m})$ & $\mathbf{Q}(\mathbf{l} / \mathbf{s})$ \\
\hline 871 & 19 & 1,1 & 880 & 13,7 & 1,4 \\
\hline 872 & 10 & 1,7 & 881 & 15,5 & 2,3 \\
\hline 873 & 10,8 & 12,82 & 882 & 22 & 1,4 \\
\hline 874 & 13,5 & 2 & 883 & 24,3 & 1,3 \\
\hline 875 & 16 & 1,4 & 884 & 24 & 1,081 \\
\hline
\end{tabular}


6. Eficiencia de los modelos de optimización

\begin{tabular}{|c|c|c||c|c|c|}
\hline 876 & 23,5 & 0,8 & 885 & 18 & 1,4 \\
\hline 877 & 14,8 & 1,2 & 887 & 24 & 2,1 \\
\hline 878 & 16 & 1,7 & 888 & 24,5 & 1,7 \\
\hline 879 & 20 & 1,6 & & & \\
\hline
\end{tabular}

Tabla 6.22 Datos de los nudos de conexión para la zona de ampliación de la red de Noja.

\begin{tabular}{|c|c|||c|c|}
\hline Línea & Longitud $(\mathbf{m})$ & Línea & Longitud $(\mathbf{m})$ \\
\hline 886 & 333 & 899 & 218 \\
\hline 887 & 171 & 900 & 305 \\
\hline 888 & 304 & 901 & 311 \\
\hline 889 & 157 & 902 & 339 \\
\hline 890 & 246 & 903 & 80 \\
\hline 891 & 283 & 904 & 131 \\
\hline 892 & 97 & 905 & 124 \\
\hline 893 & 81 & 906 & 295 \\
\hline 895 & 194 & 907 & 347 \\
\hline 896 & 156 & 908 & 377 \\
\hline 897 & 156 & 909 & 235 \\
\hline 898 & 266 & & \\
\hline & & & \\
\hline
\end{tabular}

Tabla 6.23. Longitud de las líneas en la zona de ampliación de la red de Noja.

En este caso, la gama de diámetros propuesta tiene un diámetro máximo de $250 \mathrm{~mm}$, mientras que el material elegido para la nueva obra fue un PE de alta densidad, cuyo detalle de tamaño y precio se muestra en la siguiente tabla:

\begin{tabular}{|c|c|c|}
\hline No diámetro & Diámetro (mm) & Coste (€) \\
\hline 0 & 50 & 3,3 \\
\hline 1 & 63 & 4,77 \\
\hline 2 & 75 & 6,91 \\
\hline 3 & 90 & 10,23 \\
\hline 4 & 110 & 13,26 \\
\hline 5 & 125 & 16,52 \\
\hline 6 & 140 & 21,68 \\
\hline 7 & 160 & 27,39 \\
\hline 8 & 180 & 33,76 \\
\hline 9 & 200 & 57,74 \\
\hline
\end{tabular}

Tabla 6.24 Gama de diámetros utilizada en el proyecto de ampliación de la red de Noja.

La presión mínima que se le va a exigir a la red es de 25 mca, por lo que todos los nudos de la nueva red deben cumplir dicha restricción. El tamaño reducido de la red nos permite cierta agilidad de cálculo, puesto que los diámetros calculados son tan sólo veintitrés. El diseño de la ampliación utilizando métodos funcionales da los siguientes resultados: 


\section{DISEÑO SIN FIABILIDAD}

Método 1: Diámetros Mínimos: Corrección por Pendiente

problema resuelto en 72 iteraciones

47295,55€

Método 3: Pendiente Económica aplicada a todos los nudos

problema resuelto en 63 iteraciones

46099,19€

Método 3: Pendiente Económica aplicada a los defectos

problema resuelto en 43 iteraciones

33.104,0 um

\section{Tabla 6.25 Coste de diseño para el proyecto de ampliación de Noja mediante métodos funcionales.}

En el caso de la red de Noja, el problema es original, por lo que no es posible comparar el diseño con otros autores, siendo el único patrón de comparación posible los resultados de diseño que dan métodos funcionales como los mostrados en la tabla superior.

No obstante, el objetivo en este caso no es comparar los resultados con otros investigadores, sino poner en práctica las conclusiones derivadas del estudio de eficiencia, aplicando a las distintas metodologías los ajustes que se han determinado como más eficientes en cada caso. En las condiciones de funcionamiento dadas, la mejor solución obtenida por cualquier método evolutivo tiene un coste económico de 29.695,37 um. Los diámetros correspondientes a dicha solución son para cada uno de los tramos los siguientes:

\begin{tabular}{|c|c||c|c|}
\hline Línea & $\mathbf{D}(\mathbf{m m})$ & Línea & $\mathbf{D}(\mathbf{m m})$ \\
\hline 886 & & & 75 \\
\hline 887 & 50 & 899 & 125 \\
\hline 888 & 75 & 900 & 75 \\
\hline 889 & 90 & 901 & 160 \\
\hline 890 & 140 & 902 & 180 \\
\hline 891 & 110 & 903 & 140 \\
\hline 892 & 63 & 904 & 140 \\
\hline 893 & 90 & 905 & 110 \\
\hline 895 & 50 & 906 & 110 \\
\hline 896 & 63 & 907 & 125 \\
\hline 897 & 180 & 908 & 50 \\
\hline 898 & 180 & 909 & \\
\hline & 63 & & \\
\hline
\end{tabular}

Tabla 6.26. Solución de diseño para el proyecto de ampliación de Noja mediante algoritmos evolutivos.

Las cuatro técnicas ensayadas permiten obtener la solución mostrada en la tabla 6.26. La aplicación de técnicas evolutivas a este caso de ampliación permite mejorar sustancialmente los resultados que obtienen las técnicas funcionales de diseño. Así, metodologías como la basada en los diámetros mínimos o la basada en la pendiente económica resultan más caras, 
superando en más de un $50 \%$ el coste de diseño que proporcionan las distintas metodologías heurísticas. Entre las técnicas funcionales, la mejor de todas ellas es la que se basa en la pendiente económica aplicada a los defectos, y aún así el coste proporcionado por dicha técnica es un $11 \%$ superior.

Para cada una de las técnicas evolutivas tratadas en este trabajo se ha realizado una batería de 1500 simulaciones, utilizando como ajuste para los distintos parámetros el rango determinado como de mayor eficiencia en cada caso. En este sentido, la siguiente tabla muestra a modo resumen los resultados obtenidos:

\begin{tabular}{|c|c|c|c|c|}
\hline Coste & APG & PSO & HS & SFLA \\
\hline $\begin{array}{c}\text { Solución mínima } \\
\text { (29.695 um) }\end{array}$ & $9,06 \%$ & $0,13 \%$ & $8,59 \%$ & $4.86 \%$ \\
\hline $\begin{array}{c}\text { Buena solución } \\
\text { (<30.586 um) }\end{array}$ & $63,86 \%$ & $10,60 \%$ & $68,77 \%$ & $73.86 \%$ \\
\hline
\end{tabular}

Tabla 6.27. Probabilidad de obtener una mínima/buena solución en la red de Noja.

Tres de los cuatro modelos de optimización empleados funcionan adecuadamente en la búsqueda de buenas soluciones de diseño para la red de Noja, puesto que APG, PSO y SFLA superan en todos los casos el $60 \%$ de probabilidad de encontrar una buena solución de diseño. La excepción a este buen comportamiento en los modelos de optimización desarrollados se encuentra en el algoritmo PSO, donde apenas un $10.60 \%$ de las simulaciones realizadas obtienen lo que se podría considerar una buena solución del problema.

En cuanto a la obtención de mínimas soluciones de diseño, tanto APG como HS bordean el $10 \%$ de probabilidad de éxito, prácticamente doblando al algoritmo SFL. Esta es una situación poco habitual, ya que prácticamente en todos los casos planteados durante este trabajo es el algoritmo SFL el que obtiene un mayor número de soluciones mínimas. No obstante, cuando se considera el límite de buena solución es el algoritmo que mejores resultados obtiene, puesto que un $73.86 \%$ de las simulaciones realizadas entran dentro de esta definición.

\subsubsection{Aplicación a la fiabilidad de una red de distribución.}

La disponibilidad de un recurso tan importante como el agua es fundamental para el desarrollo normal de la vida, hasta el punto de que los sistemas de abastecimiento y distribución son infraestructuras de vital importancia en las ciudades. Por este motivo, el diseño de redes de distribución de aguas urbanas se debe afrontar de modo que el abastecimiento de agua potable a una determinada población pueda garantizarse durante las 24 horas del día.

De modo general, es posible enunciar el objetivo principal de un servicio de agua como la satisfacción de todas las demandas de consumo, con la presión adecuada y al mínimo coste. De acuerdo a esta definición, el funcionamiento adecuado de una red de distribución puede ser valorado en términos de fiabilidad. 
Obviamente es inevitable el sufrir fallos en distintos componentes del sistema, por lo que en la medida de lo posible es necesaria la introducción de medidas operativas y de diseño que permitan hacer la red algo menos vulnerable a dichos fallos, de modo que el servicio de abastecimiento pueda garantizarse bajo escenario de fallo de alguno de los componentes del sistema.

La gran cantidad de fallos diferentes que pueden producirse en una red de distribución constituye posiblemente la mayor fuente de dificultades teóricas y prácticas a la hora de establecer de un modo apropiado y comprensible una serie de medidas de fiabilidad que puedan ser usadas en el diseño práctico de una RDA. La fiabilidad representa un factor explicito en el diseño y operación de RDA, siendo la existencia de redes malladas un ejemplo de ello. Así, la presencia de mallas añade fiabilidad y redundancia al sistema, puesto que proporciona un exceso de capacidad y caminos alternativos para suministrar agua ante el fallo de un componente del sistema.

Tradicionalmente, el diseño de redes malladas de distribución de agua ha entrado en confrontación con las metodologías de diseño económico, puesto que de algún modo, los requisitos de fiabilidad y redundancia en este tipo de redes son opuestos a los requisitos de dimensionado económico. No obstante, es posible incluir en el proceso de optimización ciertos requisitos que hacen de la red mallada una red fiable, al menos en lo que a la rotura de una conducción se refiere.

La bibliografía proporciona multitud de definiciones distintas acerca de lo que considera fiabilidad. En este trabajo, se va a considerar como fallo del sistema el que los caudales asociados a las demandas no lleguen a suministrarse o bien que dichos caudales se suministren a una presión inferior al mínimo aceptado o especificado para una determinada red. Así, el sistema se considera fiable cuando es capaz de seguir cumpliendo las restricciones definidas de presión y caudal aún en el caso de que alguna de las conducciones de la red tenga una rotura.

Bajo este escenario, la utilización de técnicas heurísticas permite un manejo adecuado de la función objetivo y las restricciones del problema, que se complementan con el concepto de fiabilidad considerado en este trabajo. Así, el coste de fiabilidad formará parte de la función objetivo, integrándose como un sumando más, de modo que quede impuesto un coste de penalización de fiabilidad, lo suficientemente grande como para que soluciones que no cumplan los valores umbrales impuestos para el buen funcionamiento de la red queden descartadas.

De este modo, las líneas siguientes muestran los resultados de diseño obtenidos para las redes de Hanoi, Nueva York, R-9 de Joao Pessoa y Go-Yang cuando se considera el concepto de fiabilidad. De idéntico modo a como se procedía cuando se consideraba el diseño sin 
fiabilidad, inicialmente se muestra el resultado de diseño obtenido por distintos métodos de diseño funcional. Posteriormente se muestran los resultados alcanzados por los distintos algoritmos evolutivos, utilizando en cada metodología el ajuste de parámetros que se ha determinado como óptimo en el análisis de eficiencia.

\subsubsection{Red de Hanoi}

Los problemas asociados a una posible falta de suministro por una rotura parcial en alguna de las tuberías de la red quedan soslayados al introducir el concepto de fiabilidad de la red en el diseño. La siguiente tabla muestra los resultados obtenidos con métodos funcionales en el diseño de la red de Hanoi cuando se incluye la fiabilidad por rotura de una tubería como una restricción de diseño.

\begin{tabular}{|l|}
\hline DISEÑO CON FIABILIDAD \\
\hline No se puede romper Línea_1 \\
No se puede romper Línea_10 \\
No se puede romper Línea_11 \\
No se puede romper Línea_12 \\
No se puede romper Línea_2 \\
No se puede romper Línea_20 \\
No se puede romper Línea_21 \\
No se puede romper Línea_22 \\
No se puede romper Línea_3 \\
No se puede romper Línea_4 \\
No se puede romper Línea_5 \\
\hline Método 1: Diámetros Mínimos: Corrección por Pendiente \\
problema resuelto en 3899 iteraciones \\
9.825.547,0€ \\
\hline Método 2: Diámetros Máximos \\
problema resuelto en 2051 iteraciones \\
9.825.547,0€ \\
\hline Método 3: Pendiente Económica aplicada a todos los nudos \\
problema resuelto en 3995 iteraciones \\
10.276.010,0€ \\
\hline Método 4: Pendiente Económica aplicada a los defectos \\
problema resuelto en 3899 iteraciones \\
9.825.547,0€ \\
\hline
\end{tabular}

Tabla 6.28. Coste de diseño obtenido para la red de Hanoi utilizando metodologías no heurísticas considerando criterios de fiabilidad.

Cabe destacar que algunas de las líneas de la red no es posible romperlas en el caso de considerar un diseño que incluya el concepto de fiabilidad. Esto es debido a que si se rompe una de estas líneas la red de distribución no cumple en ningún caso las presiones mínimas exigidas para el sistema. Así, la primera columna muestra todas las conducciones cuya rotura imposibilita de modo absoluto el funcionamiento normal de la red de distribución, no cumpliéndose en ningún caso las restricciones de diseño impuestas para la gama de diámetros considerada. 
Obviamente, el diseño de la red sin fiabilidad realizado en el capítulo 5 para la red de Hanoi tiene un menor coste, pero no ofrece ninguna garantía de suministro en caso de rotura. En este caso el mejor resultado obtenido es coincidente en tres de los cuatro métodos utilizados, con un valor de 9,825 millones de um.

El objetivo perseguido en esta aplicación es doble. Así, por un lado se pretende mejorar el diseño realizado en apartados anteriores añadiendo seguridad en suministro y por otro se presente poner en práctica las conclusiones obtenidas para las distintas técnicas heurísticas en el estudio de eficiencia. Para ello se han realizado 500 simulaciones para cada uno de los modelos de optimización que se han aplicado en este trabajo. El ajuste de parámetros utilizado en cada caso ha sido el definido en el apartado anterior como el más eficiente. Así, en estas condiciones de funcionamiento, la mejor solución obtenida es coincidente en todos los modelos de optimización ensayados, con un coste económico de 9,036 millones de um. Los diámetros correspondientes tanto a la solución sin fiabilidad realizada en el apartado 4 como a la solución con fiabilidad que ensaya esta aplicación se muestran en la tabla siguiente:

\begin{tabular}{|c|c|c|c|c|c|}
\hline Línea & $\begin{array}{c}\text { Solución evolutivos } \\
\text { sin fiabilidad }\end{array}$ & $\begin{array}{c}\text { Solución } \\
\text { evolutivos con } \\
\text { fiabilidad }\end{array}$ & Línea & $\begin{array}{c}\text { Solución } \\
\text { evolutivos sin } \\
\text { fiabilidad }\end{array}$ & $\begin{array}{c}\text { Solución } \\
\text { evolutivos con } \\
\text { fiabilidad }\end{array}$ \\
\hline 1 & 1016 & 1016 & 18 & 609.6 & 1016 \\
\hline 2 & 1016 & 1016 & 19 & 508 & 1016 \\
\hline 3 & 1016 & 1016 & 20 & 1016 & 1016 \\
\hline 4 & 1016 & 1016 & 21 & 508 & 508 \\
\hline 5 & 1016 & 1016 & 22 & 304.8 & 304.8 \\
\hline 6 & 1016 & 1016 & 23 & 1016 & 1016 \\
\hline 7 & 1016 & 1016 & 24 & 762 & 1016 \\
\hline 8 & 1016 & 1016 & 25 & 762 & 1016 \\
\hline 9 & 1016 & 1016 & 26 & 508 & 1016 \\
\hline 10 & 762 & 1016 & 27 & 304.8 & 1016 \\
\hline 11 & 609.6 & 702 & 28 & 304.8 & 1016 \\
\hline 12 & 609.6 & 702 & 29 & 406.4 & 702 \\
\hline 13 & 508 & 1016 & 30 & 304.8 & 609.6 \\
\hline 14 & 406.4 & 1016 & 31 & 304.8 & 508 \\
\hline 15 & 304.8 & 1016 & 32 & 406.4 & 406.4 \\
\hline 16 & 304.8 & 1016 & 33 & 406.4 & 508 \\
\hline 17 & 406.4 & 1016 & 34 & 609.6 & 508 \\
\hline $\begin{array}{c}\text { Coste } \\
\text { (millones um) }\end{array}$ & & & & 6,081 & 9,036 \\
\hline
\end{tabular}

Tabla 6.29. Solución de diseño para la red de Hanoi considerando fiabilidad en la red de distribución

Cuando se diseña la red de distribución de modo fiable, hasta 20 de las 31 conducciones deben ser instaladas con un diámetro mayor del requerido cuando el diseño carece de fiabilidad en las conducciones. Esta consideración encarece la instalación, pero permite que la red sea capaz de suministrar los caudales demandados a la presión requerida aún con una 
rotura en la red. La diferencia entre diseñar con o sin fiabilidad en este caso es de un $50 \%$ en lo que a coste total de la red se refiere.

Si se compara el coste del diseño con fiabilidad utilizando modelos de optimización basados en algoritmos evolutivos con el coste obtenido por medio de métodos funcionales, los resultados confirman lo expuesto anteriormente, y es que el diseño utilizando algoritmos evolutivos resulta más económico, puesto que permite una mayor exploración del espacio de soluciones. En este caso, el ahorro es de más de un $8 \%$ respecto de la mejor solución dada por un método funcional.

Estadísticamente, la utilización del ajuste de parámetros más eficiente aumenta la obtención de mínimas soluciones. La tabla inferior muestra el porcentaje de mínimas/buenas soluciones obtenido para cada uno de los modelos de optimización que utiliza este trabajo:

\begin{tabular}{|c|c|c|}
\hline Modelo de optimización & $\begin{array}{c}\text { Mínimas soluciones (9,032 miles } \\
\text { um) }\end{array}$ & $\begin{array}{c}\text { Buenas soluciones (<9,307 miles } \\
\text { um) }\end{array}$ \\
\hline APG & $60,2 \%$ & $100 \%$ \\
\hline PSO modificado & $68,2 \%$ & $99,8 \%$ \\
\hline HS & $3,2 \%$ & $60,2 \%$ \\
\hline SFLA & $62 \%$ & $100 \%$ \\
\hline
\end{tabular}

Tabla 6.30. Probabilidad de obtener una mínima/buena solución en la red de Hanoi considerando criterio de fiabilidad

Los resultados obtenidos certifican la importancia del ajuste de parámetros, puesto que utilizando estos modelos de optimización de modo eficiente los resultados experimentan importantes mejoras. Así, tres de los cuatro modelos de optimización empleados obtienen la mínima solución en más de un $60 \%$ de las simulaciones realizadas. Del mismo modo, si se considera el concepto de buena solución de diseño con un margen del 3\% sobre el coste mínimo, la probabilidad de éxito aumenta el $100 \%$ en APG y SFLA y $99.8 \%$ en el caso del algoritmo PSO modificado.

La excepción al buen funcionamiento general de los modelos de optimización en el diseño fiable de la red de Hanoi está en el algoritmo HS, que apenas consigue la solución mínima en el 3,2\% del total de simulaciones realizadas. No obstante, si se considera el concepto de buena solución, los resultados del modelo mejoran hasta el 60,2\% del total de simulaciones realizadas. Estos resultados son consecuentes con los resultados que se obtenían en el análisis sin fiabilidad, puesto que el algoritmo HS ofrecía sus peores resultados en el diseño de la red de Hanoi.

\subsubsection{Red de Nueva York}

Del mismo modo que en el caso anterior se muestra el coste de diseño obtenido para la red de los túneles de Nueva York cuando se considera la fiabilidad del sistema en caso de tener 
una rotura en la red de distribución. Inicialmente, la tabla muestra los resultados obtenidos con los métodos funcionales descritos anteriormente:

\begin{tabular}{|l|}
\hline DISEÑO CON FIABILIDAD \\
\hline No se puede romper Línea_17a \\
No se puede romper Línea_18a \\
\hline Método 1: Diámetros Mínimos: Corrección por Pendiente \\
Número de Simulaciones: 759 \\
294.146.500.0 um \\
\hline Método 2: Diámetros Máximos \\
Número de Simulaciones: 1606 \\
294.146.500.0 um \\
\hline Método 3: Pendiente Económica aplicada a todos los nudos \\
Número de Simulaciones: 2295 \\
294.146.500.0 um \\
\hline Método 4: Pendiente Económica aplicada a los defectos \\
Número de Simulaciones: 3300 \\
294.146.500.0 um \\
\hline
\end{tabular}

Tabla 6.31. Coste de diseño obtenido para la red de Nueva York utilizando metodologías funcionales considerando criterio de fiabilidad.

La solución para el problema de ampliación de la red de Nueva York es la misma en todos los métodos funcionales cuando se consideran condicionantes de fiabilidad del sistema. La consideración de posibles escenarios de fallo en alguna de las tuberías de la red provoca un encarecimiento considerable, puesto que el coste definitivo de instalación se multiplica por cuatro respecto a la solución más económica que ofrecía el método de diámetros mínimos.

Tal como se realiza en el caso de la red de Hanoi, es posible ajustar la función objetivo del algoritmo de optimización de modo que considere criterios de fiabilidad. Considerando en este caso fiabilidad del sistema como funcionamiento normal de la red de abastecimiento aún en el caso de producirse una rotura. Para estas condiciones, los distintos algoritmos heurísticos empleados proporcionan una mejor solución de diseño de 68.786 miles de um, inversión que supone menos de un $25 \%$ del coste proporcionado por cualquiera de los métodos clásicos funcionales de diseño que muestra la tabla 6.31.

Al igual que en el resto de redes, el ajuste empleado para cada modelo de optimización es el más eficiente de acuerdo a las conclusiones obtenidas en el apartado 6, realizando para cada metodología 500 simulaciones. La solución de diámetros correspondiente viene dada en la tabla inferior:

\begin{tabular}{|c|c|c|c|c|c|}
\hline Línea & $\begin{array}{c}\text { Solución } \\
\text { evolutivos sin } \\
\text { fiabilidad }\end{array}$ & $\begin{array}{c}\text { Solución } \\
\text { evolutivos } \\
\text { con fiabilidad }\end{array}$ & Línea & $\begin{array}{c}\text { Solución } \\
\text { evolutivos sin } \\
\text { fiabilidad }\end{array}$ & $\begin{array}{c}\text { Solución } \\
\text { evolutivos } \\
\text { con fiabilidad }\end{array}$ \\
\hline 1 & 0 & 180 & 12 & 0 & 0 \\
\hline 2 & 0 & 156 & 13 & 0 & 0 \\
\hline 3 & 0 & 144 & 14 & 0 & 0 \\
\hline 4 & 0 & 0 & 15 & 0 & 156 \\
\hline
\end{tabular}


6. Eficiencia de los modelos de optimización

\begin{tabular}{|c|c|c|c|c|c|}
\hline 5 & 0 & 0 & 16 & 96 & 48 \\
\hline 6 & 0 & 0 & 17 & 96 & 96 \\
\hline 7 & 144 & 144 & 18 & 84 & 72 \\
\hline 8 & 0 & 0 & 19 & 72 & 96 \\
\hline 9 & 0 & 0 & 20 & 0 & 60 \\
\hline 10 & 0 & 0 & 21 & 72 & 96 \\
\hline 11 & 0 & 0 & & & \\
\hline $\begin{array}{c}\text { Coste } \\
\text { (millones um) }\end{array}$ & & & & 38,812 & 68,786 \\
\hline
\end{tabular}

Tabla 6.32. Solución de diseño para la red de Nueva York considerando fiabilidad en la red de distribución

Si se compara el tamaño de las distintas conducciones cuando se diseña sin y con fiabilidad, resulta que hasta 9 de los 11 diámetros que requieren modificación son distintos. Como es natural, el coste de la instalación es mayor que cuando el diseño es realizado sin garantizar el suministro en caso de rotura, siendo en este caso el sobrecoste de aproximadamente 30 millones de um. Esto quiere decir que en el caso de querer asegurar la red de los túneles de Nueva York frente a una rotura, la inversión inicial será un $77 \%$ más costosa.

Si se compara el coste de diseño obtenido mediante los modelos de optimización evolutivos con el obtenido por métodos funcionales, la diferencia es muy grande a favor de los algoritmos evolutivos, puesto que ninguno de los métodos funcionales considerados ha encontrado una solución fiable por debajo de 294,146 millones de um, coste que supera en más de cuatro veces el estimado por los algoritmos evolutivos.

Todas las simulaciones realizadas con cada una de las metodologías evolutivas consideran el ajuste determinado como el más eficiente. La siguiente tabla muestra la probabilidad de éxito obtenida por cada uno de los modelos de optimización teniendo en cuenta que se han realizado 500 simulaciones en cada caso:

\begin{tabular}{|c|c|c|}
\hline Modelo de optimización & $\begin{array}{c}\text { Mínimas soluciones (9,032 } \\
\text { miles um) }\end{array}$ & $\begin{array}{c}\text { Buenas soluciones (<9,307 } \\
\text { miles um) }\end{array}$ \\
\hline APG & $2,4 \%$ & $25,6 \%$ \\
\hline PSO modificado & $2 \%$ & $13,6 \%$ \\
\hline HS & $0 \%$ & $0 \%$ \\
\hline SFLA & $28,4 \%$ & $36,6 \%$ \\
\hline
\end{tabular}

Tabla 6.33. Probabilidad de obtener una mínima/buena solución en la red de Nueva York considerando criterio de fiabilidad

Cabe destacar la poca repetibilidad obtenida para la mínima solución en la mayoría de las técnicas, pese a utilizar en todos los casos el ajuste de parámetros más eficiente. El único de los modelos de optimización que funciona aceptablemente bien es el basado en el algoritmo SFL, que obtiene la solución mínima el $28.4 \%$ de las simulaciones realizadas. Considerando el concepto de buena solución de diseño, los distintos algoritmos evolutivos aumentan la 
probabilidad de éxito, si bien destacan sobremanera los resultados obtenidos por el algoritmo HS, que no obtienen ninguna buena solución en las 500 simulaciones realizadas.

\subsubsection{Red R-9 de Joao Pessoa}

La red R-9 de Joao Pessoa es la más grande de todas cuanto se analizan en este trabajo, por lo que la probabilidad de que se dé un fallo en alguna de las conducciones de la red es mayor que en otros casos.

La metodología de diseño empleada hasta el momento para calcular la red de Joao Pessoa no contemplaba ningún escenario de rotura, por lo que si ocurriera cualquier incidencia que obligara a cerrar cualquiera de los conductos de la red no quedaría garantizado el suministro en las condiciones demandadas. Para evitar este tipo de incidencia es posible incluir el concepto de fiabilidad en un determinado escenario, de manera que el proceso de diseño garantice el suministro aún en el caso de una rotura en una tubería de la red. Del mismo modo que en el resto de casos, la tabla inferior muestra el coste determinado mediante una serie de métodos funcionales cuando se considera el diseño de la red bajo un escenario de fiabilidad por rotura:

\begin{tabular}{|l|}
\hline DISEÑO CON FIABILIDAD \\
\hline No se puede romper Línea_1 \\
No se puede romper Línea_8 \\
\hline Método 1: Diámetros Mínimos: Corrección por Pendiente \\
problema resuelto en 724 iteraciones \\
302.490.200 um \\
\hline Método 2: Diámetros Máximos \\
problema resuelto en 1385 iteraciones \\
303.856.600 um \\
\hline Método 3: Pendiente Económica aplicada a todos los nudos \\
problema resuelto en 2010 iteraciones \\
339.150.300 um \\
\hline Método 4: Pendiente Económica aplicada a los defectos \\
problema resuelto en 2981 iteraciones \\
339.671.600 um
\end{tabular}

Tabla 6.34. Coste de diseño obtenido por distintos métodos funcionales para Joao Pessoa.

El coste de instauración de la red crece considerablemente cuando se quiere asegurar el suministro aún en condiciones de rotura, de modo que la inversión se ve incrementada en más de un $50 \%$ por término medio. La solución de menor coste entre los métodos funcionales considerados la consigue el método basado en los diámetros mínimos, con 302,490 millones de um. Al igual que en el resto de redes, la solución de diseño es mejorada económicamente cuando se utilizan metodologías heurísticas. No obstante, esta red presenta una particularidad respecto a las demás, y es que la solución mínima obtenida no es coincidente en todos los métodos, siendo el algoritmo SFL el que proporciona el menor coste en el diseño de la red R-9 de Joao Pessoa. Así, la mejor solución obtenida tiene un coste de 288,646 millones de um, aunque esta solución carece de repetibilidad y se obtiene tan sólo una vez, 
por lo que no se puede ni siquiera plantear que sea el óptimo de diseño para la red cuando se considera fiabilidad en la misma.

El resto de técnicas no son capaces de alcanzar la solución proporcionada por el algoritmo SFL, pero todas obtienen resultados de diseño mejores que el dado por las técnicas funcionales. Así, el APG obtiene una mejor solución de 288,754 millones de um, el algoritmo PSO modificado tiene como mejor solución 293,304 millones de um y el algoritmo HS obtiene la solución más alta entre los algoritmos evolutivos con un coste de 293,854 millones de um.

Cuando se realiza el diseño utilizando los distintos algoritmos evolutivos y considerando fiabilidad para la red de distribución, el menor coste obtenido es 183,567 millones de um. Esta solución se obtiene con cualquiera de los cuatro modelos de optimización propuestos. La utilización de algoritmos evolutivos mejora el diseño realizado por métodos funcionales, si bien en este caso la mejora no es tan elevada, debido a la tipología de la red. De igual modo al resto de casos se han realizado 500 simulaciones con cada metodología, utilizando siempre el ajuste determinado como más eficiente en el apartado 6. La tabla inferior muestra la mejor solución obtenida tanto si se considera fiabilidad para la red como si no.

\begin{tabular}{|c|c|c|c|c|c|}
\hline Línea & $\begin{array}{c}\text { Solución } \\
\text { evolutivos sin } \\
\text { fiabilidad }\end{array}$ & $\begin{array}{l}\text { Solución SFL con } \\
\text { fiabilidad }\end{array}$ & Línea & $\begin{array}{c}\text { Solución } \\
\text { evolutivos sin } \\
\text { fiabilidad }\end{array}$ & $\begin{array}{l}\text { Solución SFL con } \\
\text { fiabilidad }\end{array}$ \\
\hline 1 & 600 & 600 & 37 & 100 & 200 \\
\hline 2 & 500 & 600 & 38 & 100 & 250 \\
\hline 3 & 450 & 600 & 39 & 100 & 200 \\
\hline 4 & 450 & 500 & 40 & 100 & 250 \\
\hline 5 & 100 & 600 & 41 & 100 & 100 \\
\hline 6 & 300 & 600 & 42 & 100 & 100 \\
\hline 7 & 400 & 600 & 43 & 100 & 100 \\
\hline 8 & 400 & 600 & 44 & 100 & 100 \\
\hline 9 & 400 & 500 & 45 & 100 & 100 \\
\hline 10 & 400 & 300 & 46 & 100 & 100 \\
\hline 11 & 400 & 350 & 47 & 100 & 100 \\
\hline 12 & 100 & 200 & 48 & 100 & 100 \\
\hline 13 & 100 & 400 & 49 & 100 & 100 \\
\hline 14 & 100 & 350 & 50 & 100 & 100 \\
\hline 15 & 100 & 400 & 51 & 150 & 150 \\
\hline 16 & 100 & 150 & 52 & 150 & 200 \\
\hline 17 & 100 & 100 & 53 & 100 & 100 \\
\hline 18 & 100 & 100 & 54 & 100 & 100 \\
\hline 19 & 100 & 150 & 55 & 100 & 150 \\
\hline 20 & 150 & 150 & 56 & 100 & 150 \\
\hline 21 & 200 & 150 & 57 & 150 & 200 \\
\hline 22 & 100 & 150 & 58 & 100 & 200 \\
\hline 23 & 100 & 100 & 59 & 100 & 150 \\
\hline 24 & 100 & 100 & 60 & 100 & 150 \\
\hline 25 & 100 & 150 & 61 & 100 & 150 \\
\hline 26 & 150 & 150 & 62 & 100 & 150 \\
\hline 27 & 350 & 250 & 63 & 100 & 150 \\
\hline 28 & 350 & 250 & 64 & 100 & 150 \\
\hline 29 & 200 & 200 & 65 & 100 & 150 \\
\hline
\end{tabular}




\begin{tabular}{|c|c|c|c|c|c|}
\hline 30 & 100 & 250 & 66 & 150 & 200 \\
\hline 31 & 100 & 250 & 67 & 100 & 100 \\
\hline 32 & 250 & 200 & 68 & 100 & 100 \\
\hline 33 & 250 & 200 & 69 & 100 & 100 \\
\hline 34 & 150 & 150 & 70 & 100 & 150 \\
\hline 35 & 150 & 200 & 71 & 100 & 100 \\
\hline 36 & 100 & 200 & 72 & 100 & 100 \\
\hline $\begin{array}{c}\text { Coste } \\
\text { (millones um) }\end{array}$ & & & & 192.366 & 288.646 \\
\hline
\end{tabular}

Tabla 6.35. Solución de diseño para la red R-9 de Joao Pessoa considerando fiabilidad en la red de distribución.

En este caso, considerar la fiabilidad implica un gasto adicional en el diseño de prácticamente 100 millones de um, que representa una cifra más que considerable. Comparando ambos diseños puede comprobarse que hasta 45 de las 72 conducciones experimentan un cambio en su dimensionado, aunque no en todos los casos aumenta el tamaño de la tubería.

Pese a que la solución mínima no tiene ninguna repetibilidad todos los algoritmos consiguen un conjunto amplio de buenas soluciones cuyo coste medio está por debajo del obtenido por los distintos métodos funcionales. En este sentido, la siguiente tabla el porcentaje de buenas soluciones obtenido por cada metodología, considerando como coste límite 297,305 millones de um, valor correspondiente al $3 \%$ de sobrecoste de la solución mínima absoluta. El número total de simulaciones realizadas con cada modelo de optimización fue de 500.

\begin{tabular}{|c|c|c|}
\hline Modelo de optimización & Mínima solución (millones um) & $\begin{array}{c}\text { Buenas soluciones (<297.305 } \\
\text { millones um) }\end{array}$ \\
\hline APG & 288,754 & $71,6 \%$ \\
\hline PSO modificado & 293,304 & $3 \%$ \\
\hline HS & 293,854 & $2,8 \%$ \\
\hline SFLA & 288,646 & $85,2 \%$ \\
\hline
\end{tabular}

Tabla 6.36. Probabilidad de obtener una mínima/buena solución en la red $R-9$ de Joao Pessoa considerando criterio de fiabilidad.

Los resultados de la tabla muestran claramente como APG y SFL son metodologías de optimización claramente superiores en este caso, puesto que ambas tienen una probabilidad de encontrar una buena solución del problema por encima del 70 \%. Estos resultados están en el mismo orden de los obtenidos cuando se realizaba el análisis de la red sin considerar la fiabilidad, puesto que APG y SFL son más potentes en redes más complejas, encontrando mejores resultados aún a costa de consumir algo más de recursos.

Ninguno de los otros dos modelos de optimización puede considerarse adecuado en el análisis de este caso, puesto que ambos obtienen resultados muy por debajo de APG o SFL, no pasando en ningún caso del $3 \%$ de probabilidad de obtener una buena solución. 


\subsubsection{Red de Go-Yang}

Tal como se realiza en el resto de redes ensayadas, es posible realizar un diseño alternativo de la red que garantice la funcionalidad del sistema de distribución en caso de padecer una rotura en la red. Los resultados de diseño obtenidos a través de métodos funcionales son los siguientes:

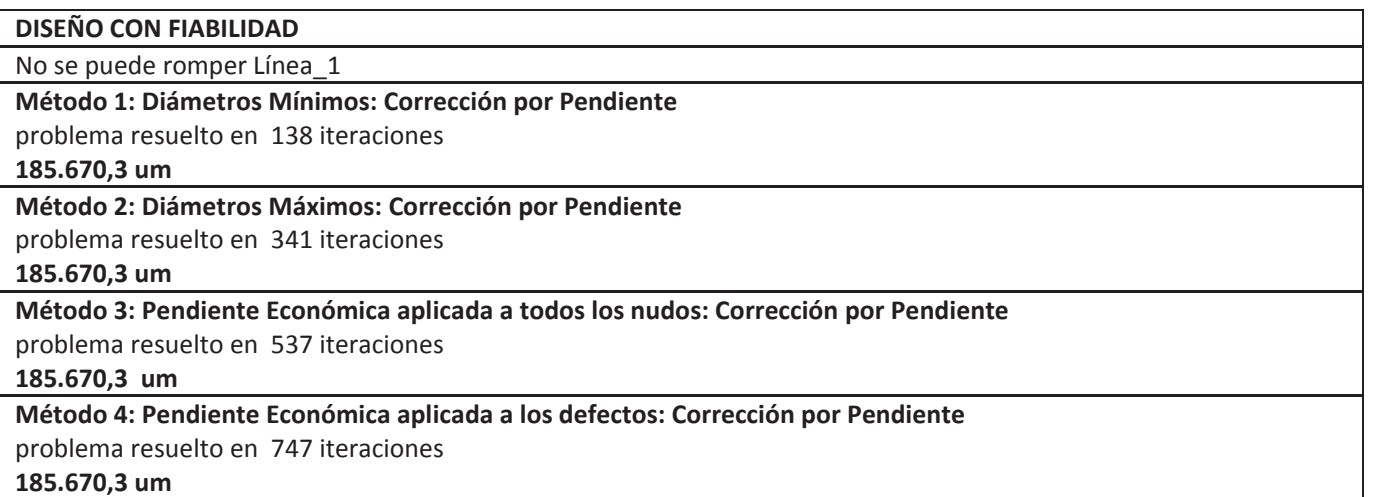

\section{Tabla 6.37. Coste de diseño obtenido por distintos métodos funcionales para la red de Go-} Yang considerando fiabilidad del sistema.

Cuando se considera la fiabilidad del sistema como parte del proceso de diseño todos los métodos funcionales consiguen la misma solución, con un coste asociado de 185670,3 um. Como es lógico, el coste de instauración de la red crece al considerar la fiabilidad del sistema, pero la diferencia en este caso no es tan considerable como en el resto de redes vistas anteriormente, de modo que en la red de Go-Yang asegurar el suministro en caso de rotura tan sólo supone un coste adicional del $4,77 \%$.

Cuando se realiza el diseño utilizando los distintos algoritmos evolutivos y considerando fiabilidad para la red de distribución, el menor coste obtenido es 183567,4 um. Esta solución se obtiene con cualquiera de los cuatro modelos de optimización propuestos. Al igual que en el resto de redes, la utilización de algoritmos evolutivos mejora el diseño realizado por métodos funcionales, si bien en este caso la mejora no es tan elevada, debido a la tipología de la red. De igual modo al resto de casos se han realizado 500 simulaciones con cada metodología, utilizando siempre el ajuste determinado como más eficiente. La tabla 6.38 muestra la mejor solución obtenida tanto si se considera fiabilidad para la red como si no.

\begin{tabular}{|c|c|c|c|c|c|}
\hline Línea & $\begin{array}{c}\text { Solución } \\
\text { evolutivos sin } \\
\text { fiabilidad }\end{array}$ & $\begin{array}{c}\text { Solución } \\
\text { evolutivos con } \\
\text { fiabilidad }\end{array}$ & Línea & $\begin{array}{c}\text { Solución } \\
\text { evolutivos sin } \\
\text { fiabilidad }\end{array}$ & $\begin{array}{c}\text { Solución } \\
\text { evolutivos con } \\
\text { fiabilidad }\end{array}$ \\
\hline 1 & 150 & 200 & 16 & 80 & 150 \\
\hline 2 & 150 & 125 & 17 & 80 & 80 \\
\hline 3 & 125 & 150 & 18 & 80 & 80 \\
\hline 4 & 125 & 125 & 19 & 80 & 100 \\
\hline 5 & 100 & 80 & 20 & 80 & 125 \\
\hline
\end{tabular}




\begin{tabular}{|c|c|c|c|c|c|}
\hline 6 & 80 & 100 & 21 & 80 & 80 \\
\hline 7 & 80 & 80 & 22 & 80 & 125 \\
\hline 8 & 80 & 125 & 23 & 100 & 100 \\
\hline 9 & 80 & 80 & 24 & 80 & 80 \\
\hline 10 & 80 & 100 & 25 & 80 & 80 \\
\hline 11 & 80 & 80 & 26 & 80 & 125 \\
\hline 12 & 80 & 80 & 27 & 100 & 100 \\
\hline 13 & 80 & 150 & 28 & 80 & 80 \\
\hline 14 & 80 & 150 & 29 & 80 & 80 \\
\hline 15 & 80 & 150 & 30 & 80 & 100 \\
\hline Coste (um) & & & & $177.009,5$ um & $183.567,4$ um \\
\hline
\end{tabular}

Tabla 6.38. Solución de diseño para la red de Go-Yang considerando fiabilidad en la red de distribución.

Pese a que la diferencia económica entre ambas soluciones no es elevada en términos porcentuales, lo cierto es que 16 de las 30 conducciones experimentan un cambio en el diámetro a instalar, siendo este cambio a un diámetro superior en todas los casos excepto dos. El coste total de instalación no experimenta una gran subida debido a que la gama de materiales considerada para las conducciones no experimenta grandes incrementos de precio en los diámetros considerados como solución del problema.

En la red de Go-Yang, los cuatro modelos de optimización evolutivos que trata este trabajo son capaces de encontrar la misma solución mínima de diseño cuando se considera la fiabilidad para el sistema de distribución. La siguiente tabla muestra la probabilidad de éxito obtenida para cada una de estas técnicas en la obtención de mínimas/buenas soluciones. El número total de simulaciones realizado en cada caso es de 500 repeticiones, utilizando en cada caso el ajuste de parámetros más eficiente.

\begin{tabular}{|c|c|c|}
\hline Modelo de optimización & $\begin{array}{c}\text { Mínimas soluciones (9,032 miles } \\
\text { um) }\end{array}$ & $\begin{array}{c}\text { Buenas soluciones (<9,307 miles } \\
\text { um) }\end{array}$ \\
\hline APG & $4,8 \%$ & $100 \%$ \\
\hline PSO modificado & $1,8 \%$ & $100 \%$ \\
\hline HS & $0,4 \%$ & $100 \%$ \\
\hline SFLA & $7,8 \%$ & $100 \%$ \\
\hline
\end{tabular}

Tabla 6.39. Probabilidad de obtener una mínima/buena solución en la red de Go-Yang considerando criterio de fiabilidad.

Como viene siendo habitual en todas las redes, APG y SFLA son los modelos de optimización que mejores resultados obtienen en lo que a búsqueda de la mínima solución se refiere, aunque en este caso, la repetibilidad es escasa, puesto que el mejor resultado es obtenido por el algoritmo SFL, con apenas un 7,8\% de probabilidad de encontrar el mínimo. No obstante, todas las técnicas son capaces de ofrecer un alto porcentaje en cuanto a obtención de buenas soluciones se refiere, puesto que todas obtienen un $100 \%$ de efectividad en este aspecto. 


\section{CONCLUSIONES Y DESARROLLOS FUTUROS}

\subsection{Conclusiones}

En el desarrollo de la presente tesis se han estudiado distintas metodologías de diseño de redes de agua, basadas todas ellas en la aplicación de algoritmos de optimización evolutivos. El estudio de cada una de estas metodologías se orienta hacia la obtención de modelos generales de diseño que permita la obtención de la mejor solución posible en el menor espacio de tiempo, de modo que como consecuencia del trabajo realizado han podido establecerse distintas fronteras de aplicación para cada una de ellas.

El capitulo 2 establece una serie de principios básicos a considerar cuando se aborda el diseño óptimo de redes de agua. En este sentido, existen multitud de modelos cuando se pretende abordar el diseño de redes hidráulicas, cada uno de los cuales trata de conseguir un determinado estado hidráulico para la red en función de los objetivos marcados en cada caso.

Las distintas metodologías aplicadas en este trabajo obtienen el dimensionado hidráulico de la red, de modo que se cumplan unas determinadas condiciones de servicio en la misma, como son criterios de presión de servicio, velocidad, etc. Estas restricciones deben cumplirse en las condiciones más desfavorables de servicio, por lo que habitualmente se utilizan modelos de régimen permanente.

A lo largo del capítulo se repasan distintas metodologías de diseño, algunas de las cuales se fundamentan tan sólo en variables de naturaleza hidráulica, mientras que otras incluyen en su formulación variables de naturaleza económica. Dentro de estas últimas se sitúan los distintos algoritmos evolutivos que muestra este trabajo y el capítulo 2 trata de mostrar con claridad todas las ventajas que presentan este tipo de técnicas frente a otras.

Dada su complejidad, la introducción de este tipo de técnicas está asociada al desarrollo de los ordenadores, por lo que su utilización es relativamente reciente. Las ventajas de este tipo de técnicas son evidentes, puesto que permite la búsqueda de soluciones más allá de los mínimos locales que suelen alcanzar las técnicas de diseño basadas únicamente en criterios hidráulicos. Este tipo de técnicas de optimización permite ampliar el campo de búsqueda, y por tanto, la capacidad de encontrar mejores soluciones. 
Los algoritmos evolutivos abarcan distintas técnicas de optimización, cuya característica común es la evolución de una primera solución aleatoria del problema hacia posiciones más ventajosas dentro del espacio de soluciones. La versatilidad de estas técnicas permite su utilización en todo tipo de procesos de optimización relacionados con la ingeniería del agua, pero hasta el momento no existía ningún trabajo que permitiera comparar estas técnicas entre si, a fin de evaluar cual es la más adecuada para cada proceso de optimización.

Esta tesis ha analizado en profundidad algunas de estas técnicas evolutivas, seleccionando una serie de ejemplos de aplicación a partir de los cuales se sacan distintas conclusiones acerca de la utilización de estas técnicas en procesos de diseño de redes de distribución de agua.

Así, del análisis de los ejemplos estudiados puede establecerse una serie de conclusiones generales relativos a la comparación entre los resultados de diseño obtenidos por una serie de métodos funcionales y los obtenidos por los distintos métodos evolutivos que ensaya este trabajo.

En este sentido, el capítulo 4 de este trabajo aborda la resolución de distintos problemas de diseño en redes de agua. Algunos de estos problemas de optimización son muy populares en la bibliografía, habiendo sido abordados con anterioridad por otros investigadores, por lo que hay suficientes criterios de comparación tanto con metodologías funcionales como con metodologías basadas en algoritmos evolutivos de otros autores. Este es el caso de los problemas de diseño de la red de Hanoi y de la red de los túneles de Nueva York.

Además de estas dos redes, el capitulo 4 aborda el diseño de las redes de Go-Yang y Joao Pessoa, que si bien no tienen tantas referencias en la bibliografía, también se tiene cierto patrón de comparación con los autores que las presentan. Estos son los casos de la red de GoYang (Geem, 2001) y la red R-9 de Joao Pessoa (Pimentel, 2009). Del análisis de diseño óptimo en estas redes se toman las siguientes conclusiones generales:

- Cualquiera de las metodologías evolutivas ensayadas obtiene en todas las redes al menos una solución que mejora económicamente el diseño de la red obtenido por cualquiera de los métodos funcionales ensayados. Todas las soluciones de diseño obtenidas por cualquier metodología cumplen una serie de restricciones de diseño, ya sea de presión mínima, velocidad mínima, etc.

- La mejora obtenida no es un parámetro fijo, sino que depende sobretodo de la tipología de la red. Normalmente, cuanto más grande y complejo es el diseño de la red mayor es la diferencia económica entre diseñar con métodos funcionales o métodos evolutivos. Así por ejemplo, en el caso de la red R-9 de Joao Pessoa, el ahorro obtenido utilizando un algoritmo evolutivo frente al mejor de los métodos 
funcionales (LEHNSNET) es de apenas un 3.65\%, pero en un caso tan complejo y grande como éste supone un ahorro de 9,25 millones de um. Sin embargo, en una red de menor tamaño y mayor sencillez de diseño, como puede ser la red de GoYang, el 3\% de ahorro obtenido al diseñar mediante metodologías evolutivas tan sólo supone 5500 um.

- Entre todas las redes ensayadas, el mayor porcentaje de ahorro obtenido utilizando algoritmos evolutivos se da en la red de los túneles de Nueva York, donde el proyecto de rehabilitación tiene un coste inferior en un $6,7 \%$ al ofrecido por la mejor de las técnicas funcionales. De los análisis realizados puede estimarse que el ahorro derivado de utilizar algoritmos evolutivos en el diseño de redes de agua está entre un 3 y un $7 \%$ respecto a la mejor técnica funcional en cada caso.

- En las redes de Hanoi, Nueva York, R-9 de Joao Pessoa y Go-Yang todos los modelos de optimización desarrollados en este trabajo alcanzan la misma solución mínima a excepción del algoritmo de optimización basado en el recocido simulado. Los resultados obtenidos por este algoritmo evolutivo son sustancialmente peores que los del resto, motivo por el que se descartó incluir este modelo en análisis más profundos.

- El diseño de redes mediante algoritmos heurísticos no sólo permite la obtención de mínimas soluciones, sino que permite obtener un conjunto de posibles soluciones del problema que en ocasiones se encuentran muy cercanas al óptimo. Es por ello que es posible definir el concepto de "buena solución" del problema como aquella que por lo cercana que está al óptimo de diseño también puede ser válida. A lo largo de esta tesis se ha definido el concepto de buena solución como toda aquella que no supera en más de un $3 \%$ al coste mínimo obtenido para una determinada red.

La única desventaja de los algoritmos evolutivos frente a otras metodologías de diseño es la necesidad de tener ciertos conocimientos previos que permitan ajustar correctamente los distintos parámetros de cada una de estas técnicas, reduciendo en lo posible el factor aleatorio que arrastra de forma intrínseca la propia formulación de estos modelos de optimización. En este sentido, la mayor carga de trabajo en esta tesis se encuentra focalizada en el análisis estadístico realizado para cada uno de los modelos de optimización propuestos, con el objetivo de obtener unas reglas básicas de configuración que permitan la utilización de este tipo de modelos con total confianza. Del mismo modo, este tipo de análisis permite la toma de decisiones en cuanto a cuál puede ser la técnica más adecuada en el dimensionado de redes de agua.

Cada metodología de diseño tiene sus propios parámetros de ajuste, que determinan en cada caso un modelo de comportamiento en la búsqueda del óptimo del sistema. El capítulo 5 de 
la tesis ha analizado individualmente todos los modelos evolutivos de optimización desarrollados, tomando distintos criterios de análisis que permitan la toma de decisiones en cuanto a cual es la mejor opción posible para el diseño de redes de distribución de agua.

Así, el apartado 5.1 determina el ajuste óptimo para cada uno de los parámetros cuyo valor tiene que ser introducido en el proceso de diseño, de forma que la probabilidad de encontrar la mínima solución para el problema de diseño sea lo más elevada posible. En este análisis se mantiene constante el número de individuos con el que trabaja cada uno de los algoritmos y se realiza un barrido de simulaciones variando el ajuste del resto de parámetros en cada una de las metodologías. Este tipo de análisis estadístico, donde sólo se tiene en cuenta la obtención de la mejor solución posible es lo que se ha denominado "análisis de parámetros".

Los resultados derivados de las simulaciones muestran como los modelos de optimización basados en APG y SFL son superiores en la obtención de soluciones mínimas de diseño. Ambos modelos se muestran como herramientas potentes de diseño una vez quedan ajustados correctamente los distintos parámetros de cálculo asociados en cada caso. En la obtención de la mejor solución posible, los modelos de optimización basados en PSO y HS tienen muchas dificultades a la hora de encontrar la solución mínima de diseño, y en términos generales también obtienen un conjunto de buenas soluciones inferior a los obtenidos por APG y SFL.

Así, si bien todos los modelos de optimización desarrollados son capaces de encontrar la mínima solución en algún caso, APG y SFL obtienen la mayor repetibilidad de ésta con gran diferencia sobre los otros dos modelos. La excepción a esta regla general se produce en la red de los túneles de Nueva York, donde las características de diseño que requiere esta red favorecen de algún modo al algoritmo HS, que obtiene la mayor probabilidad de obtención de la solución mínima en este caso.

Si se analizan los resultados en función de las redes analizadas, la principal conclusión es que la repetibilidad de mínimas soluciones en cada caso depende de en gran medida de la propia red cuyo diseño se quiere realizar. En este sentido, la red R-9 de Joao Pessoa es la más compleja de todas las analizadas, puesto que tanto el tamaño de la misma como la gama de diámetros considerada para su resolución son lo suficientemente grandes como para que la repetibilidad de mínimas soluciones sea la más pequeña en todas las metodologías diseño utilizadas, puesto que el número de mínimos locales que tiene el diseño de la red dificulta la convergencia hacia una única solución.

En el lado opuesto se encuentra la red de Go-Yang, con un número inferior de conductos a dimensionar y una gama de diámetros que permite una convergencia relativamente sencilla hacia la misma solución óptima. La totalidad de modelos de optimización utilizados obtienen la mayor repetibilidad de mínimas soluciones en este caso. 
En la repetibilidad de una determinada solución de diseño juega un papel clave el ajuste dado a los distintos parámetros en cada una de las metodologías, hasta tal punto de que una incorrecta elección de los distintos parámetros puede provocar que el modelo de optimización parezca inservible a la hora de afrontar un determinado diseño. Las conclusiones derivadas del análisis de parámetros para cada una de las técnicas cuando sólo se tiene en cuenta la posibilidad de obtener la mejor solución posible son:

- El algoritmo APG tiene dos parámetros susceptibles de ajuste, llamados tradicionalmente operadores genéticos. En todas las simulaciones realizadas con este modelo de optimización, el operador genético de mutación se muestra como el más crítico, puesto que de su correcta elección va a depender la bondad de las soluciones obtenidas. En este sentido, probabilidades de mutación entre un 2 y un $4 \%$ aumentan considerablemente el porcentaje de obtener una mejor solución. Respecto al operador genético de cruce, éste tiene una influencia mucho menor en la bondad de los cálculos obtenidos, si bien probabilidades de cruce superiores al $50 \%$ favorecen ligeramente los resultados de diseño en términos generales, aunque no es una mejora apreciable en todas las redes analizadas.

- El modelo de optimización desarrollado con el algoritmo PSO contiene 4 parámetros de ajuste: el límite de velocidad de vuelo de una determinada particula $\left(V_{\text {lim }}\right)$, las constantes $C_{1}$ y $C_{2}$ y la probabilidad de despiste $\left(P_{\text {desp }}\right)$. Los tres primeros se incluyen dentro de la formulación original de PSO mientras que $P_{\text {desp }}$ se incorpora en el modelo desarrollado para esta tesis como una medida adicional que permite aumentar la diversidad de soluciones.

En todas las simulaciones llevadas a cabo, $\mathrm{V}_{\text {lim }}$ y $\mathrm{P}_{\text {desp }}$ resultan ser los parámetros cuyo ajuste podemos considerar crítico en la obtención de la mejor solución posible. $V_{\lim }$ determina el tamaño del salto que se puede dar dentro de la gama de diámetros considerada entre dos iteraciones consecutivas. La conclusión respecto a este parámetro es que limitar la velocidad entre un 10 y un 30\% respecto del número de posibles diámetros favorece la convergencia hacia mejores soluciones.

Por su parte, la $\mathrm{P}_{\text {desp }}$ introduce un factor aleatorio necesario para crear diversidad durante el proceso de optimización, evitando así convergencias demasiado tempranas del algoritmo. Su introducción en la formulación del algoritmo mejora claramente los resultados obtenidos, pero conviene evitar su abuso, puesto que conforme aumenta el valor de este parámetro también lo hace la parte aleatoria del algoritmo. Las simulaciones realizadas determinan que $\mathrm{P}_{\text {desp }}$ en torno al $10 \%$ son ideales en todas las redes analizadas, disminuyendo drásticamente el rendimiento del modelo de optimización en valores inferiores y superiores. 
Por último, el valor de las constantes $C_{1}$ y $C_{2}$ tiene relación con el peso que se otorga a las búsquedas global y local dentro del proceso de optimización. El valor de ambas es quizá el menos controvertido de todos los estudiados, puesto que en la bibliografía se pueden encontrar múltiples referencias que aconsejan la utilización de valores entre 1,8 y 2 para dichas constantes. Las simulaciones realizadas confirman estos valores, si bien dentro del rango de ajuste considerado $\left(1<\mathrm{C}_{1}<2,1<\mathrm{C}_{2}<2\right)$ no se aprecian grandes diferencias, resultando mucho más crítica la correcta configuración de $V_{\lim } \mathrm{Y} \mathrm{P}_{\text {desp }}$.

- La optimización basada en el algoritmo HS permite la libre configuración de dos parámetros, llamados probabilidad HMCR y ajuste del PAR. En términos de robustez, el algoritmo HS es más sensible que el resto de metodologías tratadas, puesto que una elección errónea en el ajuste de los parámetros provoca la no convergencia del algoritmo hacia soluciones factibles. En este sentido, ajustes del PAR por encima de 0,5 no permiten la obtención de soluciones factibles de diseño en ningún caso.

Una vez obtenida la convergencia, el análisis de los resultados determina que la influencia del ajuste del PAR en los mismos es nula, por lo que la principal conclusión respecto a este parámetro es que resulta ser únicamente de convergencia, por lo que la recomendación es utilizar valores lo suficientemente bajos en todos los casos como para asegurar la misma.

Respecto a la probabilidad HMCR se hace difícil elegir unos valores óptimos generales considerando el rango de trabajo utilizado, puesto que para cada una de las redes se obtenía una zona óptima ligeramente distinta. Es por ello que se emplazó la elección de la zona óptima a la evaluación de otros factores de decisión, como la velocidad del algoritmo o la población del mismo.

- El modelo de optimización basado en el algoritmo SFL es, junto al APG, el más potente de todos los métodos utilizados cuando se considera únicamente la probabilidad de obtener la mejor solución posible. La búsqueda de la mejor configuración para el buen funcionamiento de esta metodología es complicada, puesto que hasta 5 parámetros requieren de ajuste antes de realizar el proceso de optimización, si bien dos de ellos tienen relación con el tamaño de población del algoritmo.

No obstante, tal como ocurre en otras metodologías, no todos los parámetros de ajuste tienen la misma importancia en el proceso de optimización. Así, las simulaciones realizadas en las distintas redes muestran como el número de submemeplexes (Q) es el parámetro menos sensible cuando se considera tan sólo el 
resultado final de diseño. Así, en el rango de trabajo considerado (0,25-1), la elección de un valor $u$ otro es indiferente.

En el lado opuesto en cuanto a importancia se encuentra el parámetro de aceleración (C), donde se puede afirmar con rotundidad que valores comprendidos entre 1,75 y 2,25 mejoran ampliamente el desempeño del algoritmo, obteniendo un coste medio inferior en la totalidad de las redes de benchmarking tratadas en esta tesis.

Por último, las simulaciones realizadas demuestran que la consideración de un mayor número de pasos evolutivos (N) favorece la obtención de mejores soluciones hasta en un $15 \%$. Sin embargo, la elección de grandes valores de $\mathrm{N}$ ralentiza el cálculo, por lo que lo significativa o no que resulta esta diferencia hay que buscarla en el análisis de eficiencia.

Tal como puede apreciarse en las líneas superiores, cada uno de los modelos de optimización desarrollados en esta tesis depende de una serie de parámetros cuyo ajuste óptimo requiere de un amplio trabajo estadístico. Cada una de las técnicas tiene sus propios parámetros y es complejo compararlos entre sí. En este sentido, el tamaño de la población con la que se inicia el proceso de optimización es el único parámetro común en todas las metodologías evolutivas, por lo que su estudio se abordó de modo independiente en el apartado 5.3 de esta tesis.

En términos generales, la utilización de un mayor número de individuos favorece la obtención de mejores soluciones, puesto que aumenta el número de evaluaciones de la función objetivo y aumenta la exploración del espacio de soluciones. Sin embargo, cuanto más grande es la población mayor es el tiempo de convergencia empleado por el algoritmo. La mejora producida al emplear poblaciones más grandes no tiene una forma lineal, sino que a partir de determinados tamaños de población la mejora producida apenas es apreciable, por lo que es necesario tomar soluciones de compromiso entre mejora de la solución y tiempo de cálculo.

La propia complejidad de la red también tiene mucho que ver en este aspecto, puesto que en casos donde la red no es excesivamente compleja no tiene sentido el utilizar grandes poblaciones de individuos, puesto que no se obtiene ninguna mejora. Este es el caso de la red de Go-Yang, donde todos los algoritmos evolutivos empleados obtienen una alta probabilidad de encontrar el mínimo aún en las poblaciones más pequeñas ensayadas.

La importancia a la hora de elegir el tamaño de población es mayor en redes más complejas, puesto que utilizar pocos individuos en este tipo de redes provoca convergencias demasiado tempranas, ya que el número de mínimos locales es mayor y cuesta más salir de ellos. En este aspecto, no se aconseja la utilización de poblaciones menores de 50 individuos en ninguna de las metodologías evolutivas ensayadas. 
Ya se ha nombrado que habitualmente la utilización de poblaciones grandes conlleva una ralentización del cálculo, puesto que el número de evaluaciones de la función objetivo tiende a ser mayor al intervenir más individuos en el proceso de optimización. En el ámbito de aplicación en el que se mueve un método heurístico, el término "velocidad" se refiere precisamente al número de evaluaciones de la función objetivo que realiza el algoritmo de cálculo antes de encontrar la solución final del problema y este tipo de análisis es el abordado en 5.4. Así, este apartado relaciona el número de evaluaciones realizadas con el ajuste de los distintos parámetros en cada uno de los algoritmos analizados, obteniéndose las siguientes conclusiones:

- En términos generales para el APG, el número de evaluaciones de la función objetivo hasta que se produce la convergencia es menor en los valores más bajos del operador genético de mutación. Así, cuanto mayor es el valor de este parámetro menor es la velocidad del algoritmo. Por otro lado, la irregularidad del número de evaluaciones realizadas en función de la probabilidad de cruce impide sacar conclusiones acerca de la relación de este operador con la velocidad del algoritmo, por lo que la conclusión más plausible es que la probabilidad de cruce no tiene una influencia directa en el número de evaluaciones realizadas ni por tanto, en la velocidad con la que calcula el APG.

La excepción a la regla general se encuentra cuando el tamaño, y por tanto, la complejidad de la red no es muy elevada. En este tipo de redes, la búsqueda del óptimo en el espacio de soluciones es más sencilla, debido a que el número de posibles soluciones y de mínimos locales es menor. Esta situación simplifica el proceso de búsqueda, de modo que la diferencia entre utilizar unas probabilidades de cruce/mutación u otras no afecta tanto a la velocidad del algoritmo, puesto que todas las combinaciones posibles son capaces de resolver rápidamente el problema.

- En el caso del algoritmo PSO, el número de evaluaciones de la función objetivo crece conforme aumenta la probabilidad de despiste que se le da a una determinada partícula. Es importante recordar que este operador se introduce dentro del modelo precisamente para aumentar el número de evaluaciones y evitar convergencias tempranas. No obstante, hay que tener cuidado, puesto que un aumento en exceso del número de iteraciones podría disminuir la eficacia del algoritmo, por lo que se hace necesario buscar soluciones de compromiso que fijen el punto óptimo de este parámetro. El estudio de eficiencia ayuda a tomar este tipo de decisiones.

De igual manera, si se considera el límite de velocidad de vuelo de una partícula entre iteración e iteración se observa como conforme disminuye este operador aumenta el número de evaluaciones de la función objetivo. 
Por último, en el caso de las constantes $C_{1}$ y $C_{2}$, ambas ejercen una influencia algo menor en la velocidad del algoritmo. En este sentido, los análisis realizados determinan que el valor de $C_{1}$ no tiene ninguna influencia en la velocidad del algoritmo, mientras que valores de $\mathrm{C}_{2}$ en torno a 2 (valor más alto utilizado) realizan un menor número de evaluaciones de la función objetivo, aumentando así la velocidad del cálculo. Este ahorro iterativo es mayor cuanto más compleja es la red objeto de estudio.

- En términos absolutos, la metodología de optimización basada en HS es la que menos evaluaciones de la función objetivo realiza hasta converger a una solución definitiva, por lo que se puede decir que es el más rápido de los modelos de optimización desarrollados. Por ejemplo, en la red de Hanoi, mientras APG, PSO o SFL no realizan menos de 50000 evaluaciones de la función objetivo, el modelo basado en HS realiza un máximo de 25000 evaluaciones en la configuración más lenta de todas las testeadas.

Si se analiza la influencia que tienen el ajuste de los distintos parámetros de optimización HS, el análisis determina que el número de evaluaciones de la función objetivo disminuye de modo casi lineal conforme aumenta el valor de la probabilidad HMCR, de modo que el algoritmo trabaja más rápido cuanto mayor es el valor de éste parámetro.

Respecto al ajuste del PAR, el análisis respecto a la influencia de los parámetros en la calidad de la solución ya dejaba entrever que este operador ejercía sólo funciones de convergencia. El análisis de velocidad confirma esta teoría, puesto que utilizar un ajuste del PAR u otro no afecta de ninguna manera a la velocidad con la que el algoritmo converge a la solución final.

- En el caso de la optimización SFL, el análisis de velocidad se centra en la influencia que ejercen los parámetros relacionados con la naturaleza de los saltos evolutivos, que son el número de saltos evolutivos (N), el tamaño de submemeplex (Q) y el coeficiente acelerador (C).

Así, respecto al número de saltos evolutivos, el coste computacional es mayor conforme aumenta el número de saltos evolutivos programados. De hecho, el ahorro iterativo que se produce para valores pequeños de $\mathrm{N}$ es bastante considerable, $\mathrm{y}$ dicho ahorro es mayor cuanto más compleja es la red, hasta el punto de que en la red de Joao Pessoa la configuración con $\mathrm{N}=5$ realiza tan sólo el $20 \%$ de las simulaciones realizadas por el algoritmo cuando $\mathrm{N}=30$.

En cuanto al coeficiente acelerador (C), si se tiene en cuenta solamente el gasto computacional, el análisis estadístico concluye que valores en torno a 1,75-2 son los 
que menos evaluaciones de la función objetivo realizan en términos generales, por lo que aumentan la velocidad de cálculo del algoritmo. Si se toman en cuenta casos particulares más complejos, como Hanoi o Joao Pessoa, dar valores más altos a $\mathrm{C}$ aumenta el gasto computacional.

Por último, la asignación de distintos valores al tamaño de submemeplex (Q) no deja entrever ningún tipo de relación entre este valor y la velocidad con la que calcula el algoritmo.

Hasta este punto, la tesis realizó diversos análisis estadísticos que establecen relación entre el ajuste de los distintos parámetros de cálculo y la bondad de la solución obtenida en el diseño de distintas redes de distribución para cada técnica heurística. Del mismo modo, el análisis de velocidad ponía de manifiesto la existencia de otros factores a tener en cuenta, como es el coste computacional asociado a la manipulación de estos parámetros. El análisis de eficiencia abordado en el capítulo 6 es la fórmula que permite relacionar todos los criterios que se deben tener en cuenta cuando se considera el diseño óptimo de redes con algoritmos evolutivos.

En este sentido, la mayoría de los modelos de optimización planteados funcionan aceptablemente en cuanto a eficiencia se refiere, de modo que la elección de uno u otro depende en gran medida tanto del objetivo requerido de diseño como de las características de la propia red. El análisis de eficiencia permite la toma de decisiones en cuanto a la elección de una determinada técnica en el diseño de redes de distribución, así como cual será el mejor ajuste posible en cada caso sin necesidad de realizar de nuevo un análisis estadístico completo.

Así, cuando el problema de diseño es complejo y se pretende obtener la solución mínima de diseño, las técnicas de optimización más potentes son las basadas en Algoritmos Genéticos (AG) y Algoritmos SFL. Estas dos metodologías son las que consiguen mayor repetibilidad en la obtención de la solución óptima para todas las redes ensayadas, lo que no quiere decir que sean las más eficientes en todas las redes.

En ese sentido, el algoritmo SFL es en todos los casos el que consigue mayor repetibilidad en la obtención de la solución óptima de diseño cuando se configura correctamente, pero tiene un alto gasto computacional, así como un proceso de ajuste complejo, que requiere de la optimización de 5 parámetros de cálculo. Es por ello que para redes de pequeño tamaño o problemas donde no sea necesario obtener la solución óptima de diseño puede resultar una opción no prioritaria, puesto que en esas condiciones existen otras técnicas que proporcionan una mayor eficiencia que el algoritmo SFL. 
Una de estas técnicas es el APG, basada en un Algoritmo Genético tradicional pero con algunas modificaciones que permiten su mejora y que ya se detallaron en el capítulo 3 de este trabajo. El APG representa una buena opción tanto para redes complejas como para redes más simples cuando se busca la solución óptima de diseño. Así, tanto para la red de Hanoi, como para la red de Go-Yang ha resultado ser la técnica más eficiente en la búsqueda de la solución óptima de diseño, superando ligeramente los resultados que obtiene el algoritmo SFL en ambos casos, aunque con un menor esfuerzo a la hora de determinar cuál es la zona de mayor eficiencia, puesto que el APG tan sólo requiere del ajuste de 3 parámetros por parte del usuario.

En los casos de Nueva York y Joao Pessoa el APG se ve superado por el algoritmo HS, obteniendo resultados similares al algoritmo SFL y superando ampliamente al algoritmo PSO en lo que a eficiencia se refiere. Tal como se ha mencionado, la eficiencia de un algoritmo de optimización tiene mucho que ver con la propia complejidad de la red, así como de los objetivos de diseño que se planteen.

Así, la principal característica del algoritmo HS es la velocidad con la que converge hacia soluciones factibles, siendo en todos los casos el algoritmo que menos evaluaciones de la función objetivo realiza hasta encontrar la solución definitiva en cada iteración. Esto representa una ventaja, pero también arrastra un inconveniente, y es la dificultad que tiene este algoritmo para obtener repetibilidad cuando se trata de encontrar la solución de mínimo coste. No obstante, en ocasiones, especialmente en redes muy grandes, no es necesario encontrar la solución más barata posible, sino un conjunto de soluciones cercanos a ésta y es en esta situación donde el algoritmo HS adquiere valor, puesto que ese conjunto de soluciones lo encuentra generalmente en un menor espacio de tiempo.

Por ejemplo, la red R-9 de Joao Pessoa consta de 61 conductos a diseñar bajo ciertas condiciones de funcionamiento. El coste mínimo para la red en las condiciones de operación definidas es de 192,366 millones de um y dicha solución no tiene repetibilidad con ninguna de las técnicas, puesto que es una solución entre $10^{61}$ posibilidades, con multitud de mínimos locales. Ante esta tesitura, encontrar rápidamente un conjunto de soluciones que no obtengan ese coste de diseño, pero sí un resultado cercano a él resulta de mucho interés.

A la capacidad para encontrar buenas soluciones sin un excesivo coste computacional se añade la ventaja de contar con tan sólo dos parámetros de optimización que requieran ajuste, puesto que el tercero de ellos, el ajuste del PAR, se ha demostrado que cumple funciones de convergencia y no de optimización.

En el lado opuesto en cuanto a eficiencia dentro de las técnicas de optimización tratadas se encuentra el algoritmo PSO modificado, que obtiene resultados muy inferiores al resto de técnicas en todas las redes, siendo siempre la metodología menos eficiente en todas las 
simulaciones realizadas. Los siguientes apartados resumen para cada una de las técnicas utilizadas las conclusiones derivadas de esta tesis:

\subsubsection{Algoritmo Pseudogenético (APG)}

La metodología de optimización basada en algoritmos genéticos se muestra como la más robusta de entre todas las propuestas, puesto que independientemente del ajuste considerado para cualquiera de sus tres parámetros de optimización es capaz de obtener soluciones factibles para el problema de diseño planteado. Esta capacidad del APG representa una ventaja importante respecto a otras técnicas, donde la optimización de parámetros no es sólo requerida para la mejora de resultados, sino también para la propia convergencia del algoritmo.

En este sentido, la robustez del APG permite que cualquier configuración en los parámetros de cálculo sea capaz de resolver un determinado problema de optimización, por lo que no se requiere de ningún tipo de experiencia previa para resolver un determinado diseño. No obstante, el ajuste de parámetros permite la mejora en la búsqueda del óptimo, ya sea en la propia calidad de la solución o en los recursos que consume el APG al realizar la simulación. La combinación de calidad y velocidad es lo que conocemos por eficiencia y el estudio realizado en este trabajo demuestra que el APG es uno de los algoritmos más eficientes cuando se trata de encontrar el óptimo de diseño para una determinada red de distribución de agua.

La eficiencia del APG es especialmente buena cuando se trata de encontrar la solución de coste mínimo para una determinada red. Dentro de los operadores genéticos que requieren un determinado ajuste, el que tiene una mayor influencia en la eficiencia del algoritmo es el operador genético de mutación. De hecho, dados los resultados obtenidos puede considerarse el valor del operador de mutación como el más crítico de todos los que envuelven la metodología genética, hasta el punto de que un mal ajuste de este operador desemboca en un empeoramiento superlativo de resultados para las redes más complejas. En términos generales puede concluirse que asumiendo probabilidades de mutación en torno al 2-4\% vamos a tener la seguridad de estar trabajando en el mejor rango posible para éste parámetro de optimización, puesto que todas las redes de distribución analizadas se mueven en torno a estos valores. Respecto a este operador genético, la influencia entre buscar la solución óptima de diseño o simplemente una solución cercana a ésta es inexistente, puesto que el ajuste óptimo es el mismo.

En cuanto al operador genético de cruce, el análisis de eficiencia demuestra como el ajuste de éste parámetro no es tan crítico como en el caso del operador de mutación. En este sentido, y sin despreciar la mejora en términos generales que se obtiene en la eficiencia para probabilidades de cruce que se encuentren por encima del $50 \%$ en todas las redes analizadas, 
es posible afirmar que el algoritmo es capaz de encontrar mínimas/buenas soluciones en todas las redes independientemente del ajuste del operador de cruce.

Por último, el análisis de eficiencia en cuanto a la población inicial con la que trabaja el algoritmo determina un número variable de individuos en función del objetivo de diseño planteado. Así, en la determinación del coste mínimo de diseño para una determinada red es aconsejable el utilizar poblaciones algo superiores, en torno a 50-75 individuos en términos generales. Este tamaño de población no va a proporcionar el óptimo de eficiencia en el 100\% de las redes, pero garantiza un alto grado de eficiencia en cualquier caso.

Contrariamente al resto de operadores genéticos, el ajuste del tamaño de población en función de la eficiencia varía en función de los objetivos de diseño. Así, cuando la obtención de un conjunto de buenas soluciones el número de individuos que intervienen en el proceso de optimización puede ser algo menor. El estudio de eficiencia determina en todas las redes que poblaciones en torno a 25-50 individuos son las más eficientes, puesto que garantizan la obtención de un conjunto de buenas soluciones con un bajo coste computacional. No es aconsejable tomar tamaños de población más pequeños de 25 individuos, puesto que la calidad de la solución se resiente lo suficiente como para no compensar el ahorro computacional derivado.

\subsubsection{Algoritmo PSO}

El algoritmo PSO fue diseñado originalmente para la optimización de variables continuas, y adaptado posteriormente a la optimización de variables discretas, como puede ser la elección de un determinado tamaño de diámetro en una red de distribución de agua. Esta formulación original del algoritmo PSO no resultaba de interés en el problema de optimización que trata este trabajo, debido a que el algoritmo converge de un modo demasiado temprano hacia los extremos del espacio de soluciones, obteniéndose unos costes de diseño que podían considerarse como malos de modo comparativo al resto de metodologías.

Debido a estas limitaciones, el algoritmo con el que se trabaja es un PSO modificado, donde se introdujo un nuevo parámetro, denominado probabilidad de despiste $\left(P_{\text {desp }}\right)$, que aumentaba la exploración del espacio de soluciones, evitando convergencias demasiado tempranas del algoritmo. Pese a estas modificaciones, el desempeño del algoritmo PSO en la optimización de redes de distribución ha resultado muy inferior al resto de técnicas utilizadas, puesto que la eficiencia del algoritmo PSO modificado queda muy penalizada al encontrar en términos generales un menor número de mínimos/buenas soluciones aún en el mejor ajuste de los distintos parámetros de optimización.

En este sentido, el algoritmo PSO resulta ser la peor técnica en todas las redes que analiza este trabajo, con resultados de eficiencia muy alejados del resto de metodologías salvo en la red de los túneles de Nueva York, donde obtiene resultados cercanos al APG, pero inferiores a 
los algoritmo HS y SFL. Así, independientemente de los objetivos de diseño planteados, el algoritmo PSO no representa en ninguno de los casos planteados la mejor opción.

Considerando la eficiencia del algoritmo en función del ajuste de parámetros realizado existe una diferencia clara en cuanto a la importancia relativa de unos parámetros y otros en cuanto al buen funcionamiento del algoritmo PSO modificado. Así, tanto $\mathrm{V}_{\lim }$ como $\mathrm{P}_{\text {desp }}$ representan dos parámetros críticos en cuanto a eficiencia del algoritmo se refiere, siendo su correcta configuración de vital importancia en los resultados obtenidos. En este sentido, los resultados en todas las redes son concluyentes, de modo que la velocidad límite de una determinada partícula debe estar en torno al 20-30 \% del número de valores que puede tomar la variable de decisión, mientras que la probabilidad de despiste es aconsejable que se encuentre en torno al $10 \%$ del total de partículas que intervienen en el proceso de optimización.

En el caso de la velocidad máxima con la que se mueve una determinada partícula, teniendo en cuenta que en este trabajo la variable de decisión es el diámetro a instalar en una determinada tubería, el límite aconsejado implica que por ejemplo para una gama de diez diámetros, la $\mathrm{V}_{\lim }$ a la que tendrían que volar los pájaros sería $\mathrm{V}_{\lim }=(-2,2)$, que implicaría un máximo salto de 2 diámetros dentro de la gama entre dos iteraciones consecutivas.

En cuanto a la probabilidad de despiste que se asigna a una determinada partícula y que le libera de seguir al líder en una determinada iteración, los resultados concluyen que si bien la utilización de este parámetro aumenta el espacio de búsqueda del algoritmo, el utilizar porcentajes más allá del $10 \%$ provoca que la búsqueda sea cada vez más aleatoria. El estudio de eficiencia determina claramente como $\mathrm{P}_{\text {desp }}$ en torno al $10 \%$ proporcionan los mejores resultados.

Por otro lado, el ajuste de las constantes $C_{1}$ y $C_{2}$ se concluye que es de importancia menor, al menos en el rango estudiado, puesto que la influencia en la eficiencia del algoritmo es mucho menor que en los parámetros mencionados anteriormente. De este modo, la bibliografía recomienda en términos generales valores en torno a $1,8 \div 2$ para estas dos constantes, siendo la conclusión de este trabajo la misma. No obstante, el valor de estos dos parámetros no puede considerarse crítico, puesto que el utilizar valores más pequeños de los mencionados no ejerce una influencia decisiva en la eficiencia del algoritmo PSO modificado.

En último lugar, el análisis de eficiencia en cuanto al tamaño de la bandada inicial con la que se va a producir el proceso de optimización determina, de similar modo a como operaba el APG, que el tamaño más adecuado considerando como criterio de elección la eficiencia del algoritmo dependerá de cuales sean los objetivos de diseño planteados. Así, si el objetivo de diseño es la recopilación de un conjunto de buenas soluciones para una determinada red el tamaño de población a considerar será algo menor que si se requiere la obtención de la mejor solución posible de diseño. 
En este sentido, los análisis realizados sugieren que para la obtención de un conjunto de buenas soluciones el algoritmo PSO es más eficiente cuando trabaja con tamaños de población comprendidos entre 50 y 125 individuos, siendo aconsejable realizar el ajuste en función de la complejidad de la propia red. Así, para redes más complejas, tipo Hanoi o Joao Pessoa es conveniente ajustar hacia 125 individuos, mientras que para redes de menor dificultad como Nueva York o Go-Yang será suficiente con utilizar poblaciones cercanas a los 50 individuos.

El tamaño de población deberá ser algo mayor si se trata de aumentar la probabilidad de obtener la mínima solución de diseño. En este caso es aconsejable el trabajar con poblaciones en torno a 100-125 individuos en todos los casos, independientemente de la dificultad de la red de distribución.

La conclusión final respecto del algoritmo PSO modificado es que pese a estas recomendaciones en cuanto al ajuste de los distintos parámetros, las características del algoritmo no se ajustan completamente al problema de diseño planteado, por lo que es conveniente la utilización de otras metodologías de optimización tratadas en este trabajo.

\subsubsection{Algoritmo SFL}

La metodología basada en el algoritmo SFL es probablemente la más potente si se tiene en cuenta únicamente la capacidad de obtener la solución de mínimo coste en el diseño de una determinada red de distribución. Pese a ello, la cantidad de recursos computacionales consumidos por éste algoritmo lo sitúan en un nivel similar al APG en cuanto a eficiencia en cuanto a obtención de soluciones óptimas se refiere.

No obstante, los requerimientos computacionales del método provocan que la metodología disminuya su eficiencia cuando se considera únicamente la capacidad de obtener un conjunto de buenas soluciones de diseño, puesto que metodologías como APG ó HS son superiores en este aspecto, puesto que consiguen resultados similares con un menor número de evaluaciones de la función objetivo.

SFL tiene además una dificultad adicional, y es la necesidad de ajustar cinco parámetros de cálculo, cuya influencia es fundamental en la búsqueda de la mejor solución posible de diseño para una determinada red. Tres de estos parámetros se encuentran asociados a la naturaleza de los saltos evolutivos en cada iteración del algoritmo, mientras que los otros dos representan el número de individuos que intervienen en el proceso de optimización, lo que se conoce comúnmente como población inicial del algoritmo.

De igual modo que ocurría en el APG, el SFL es un algoritmo robusto, capaz de obtener soluciones convergencia hacia soluciones factibles de diseño prácticamente con cualquier 
ajuste en los distintos parámetros de cálculo, pero un ajuste correcto de los mismos favorece enormemente la obtención de mejores soluciones y el aumento de la eficiencia del algoritmo.

De este modo, el análisis de eficiencia demuestra que, dentro del rango estudiado, cuanto menor es el número de saltos evolutivos $(\mathrm{N})$ mayor es la eficiencia del algoritmo, puesto que utilizar valores elevados de $\mathrm{N}$ aumenta el número de evaluaciones de la función objetivo hasta el punto de no compensar la posible mejora en el resultado final. Este resultado es coincidente en todas las redes, de modo que la conclusión final respecto de este parámetro es que un valor $\mathrm{N}=5$ es el óptimo en el problema de optimización que se plantea, no siendo descartable la utilización de valores más bajos, puesto que en el rango estudiado éste era el valor más pequeño.

Respecto al coeficiente acelerador, cuyo rango de estudio está comprendido entre 1 y 2,5 , el análisis de eficiencia descarta los valores en los extremos del intervalo como los más apropiados en la optimización SFL. Así, la conclusión respecto de este parámetro es que un valor en torno a 2 aumenta en términos generales la eficiencia del algoritmo, comprobándose este hecho en tres de las cuatro redes consideradas. La única excepción es la red de Go-Yang, donde el algoritmo es más eficiente para $C=1,375$, pero aún en este caso los valores de eficiencia son buenos en torno a 2, por lo que parece lógico elegir este valor como óptimo de eficiencia en cuanto al coeficiente acelerador se refiere.

El último parámetro que guarda relación con la naturaleza de los saltos evolutivos es el tamaño del submemeplex (Q). En términos generales, este parámetro puede considerarse como el menos crítico en cuanto a la eficiencia del algoritmo SFL, puesto que los resultados son razonablemente buenos independientemente del valor de $Q$, al menos en el rango de estudio considerado, que comprende valores entre cero y uno. No obstante, la eficiencia del algoritmo se ve ligeramente mejorada en todas las redes cuando el algoritmo trabaja con valores superiores a 0,4 , por lo que la recomendación final acerca del tamaño de submemeplex será utilizar un ajuste de $Q$ superior a este valor.

En cuanto a la población inicial del algoritmo, determinada por el número de memeplexes ( $\mathrm{n}$ ) y el número de ranas por memeplex $(\mathrm{m})$, los resultados son coincidente en todas las redes, siendo el algoritmo más eficiente cuanto menor es el tamaño de población total considerado. Así, para todas las redes, la combinación entre $m$ y $n$ más pequeña posible, con un total de 100 individuos (10x10) involucrados en el proceso de optimización es la más eficiente.

En términos generales se ha comprobado que todos los algoritmos tienen el punto de trabajo óptimo en tamaños de población de 100 individuos como máximo, por lo que cabe la posibilidad de que en el caso del algoritmo SFL, poblaciones en torno a 50-75 individuos podrían incluso mejorar la eficiencia del algoritmo SFL. 


\subsubsection{Algoritmo HS}

La metodología de optimización basada en el algoritmo HS resulta ser una técnica muy eficiente cuando no es requisito indispensable obtener repetibilidad en la solución mínima de diseño para una determinada red. Así, esta técnica es muy eficiente en la obtención de un conjunto de buenas soluciones próximas al óptimo de diseño, puesto que la convergencia del algoritmo es más temprana en términos generales, ya que en cada iteración realiza únicamente una evaluación de la función objetivo, independientemente de la población inicial del algoritmo.

Esta característica provoca que el algoritmo HS sea el más rápido en cuanto a convergencia de todos los algoritmos de optimización estudiados en este trabajo, pero como contrapartida disminuye la repetibilidad de mínimos de diseño, puesto que HS tiene menor capacidad de exploración. Es por ello que en redes de diseño más complejas, como Hanoi o Joao Pessoa, el número de soluciones óptimas obtenidas por el algoritmo HS es mucho menor que el obtenido por otras técnicas más potentes como APG o SFL. Sin embargo, cuando se aplica el concepto de "buena solución" del algoritmo, que agrupa soluciones de diseño que como máximo sean un 3\% más caras que la solución mínima, el algoritmo HS mejora sus prestaciones sobremanera, situándose como una de las técnica más eficientes.

La metodología de optimización basada en el algoritmo HS suma otra desventaja frente a técnicas como APG o SFL, y es la robustez del algoritmo. De este modo, HS no es capaz de proporcionar soluciones factibles en todo el rango de ajuste que se puede dar a sus parámetro de cálculo, por lo que al igual que ocurría en el algoritmo PSO original, una muy mala elección de parámetros puede impedir la convergencia del algoritmo. El análisis estadístico de soluciones realizado permite solucionar este problema, pero es algo a tener en cuenta en esta técnica de optimización.

Así, el parámetro de convergencia que hay que tener en cuenta en la optimización HS es el ajuste del PAR. Los resultados obtenidos en las redes analizadas demuestran que ajustes del PAR por encima de 0,5 no convergen hacia soluciones factibles. Del mismo modo, el análisis estadístico de soluciones demuestra que este parámetro es sólo de convergencia, y no de optimización, de modo que siempre que se obtenga convergencia, este parámetro no afecta a la eficiencia del algoritmo. Es por ello que la conclusión respecto del ajuste PAR es que basta con garantizar la convergencia del algoritmo, por lo que se recomienda utilizar valores del PAR entre 0,05 y 0,3 indistintamente.

Dejando de lado el ajuste de la convergencia, la bondad de las soluciones de diseño en HS viene determinada por el ajuste de la probabilidad HMCR y por el tamaño de la memoria del algoritmo (población inicial). La probabilidad HMCR determina si el valor de cada variable de decisión en una determinada iteración es elegido entre los valores que esa misma variable de decisión ya tiene en otras partituras de la memoria o es tomado de fuera. En este sentido, el 
ajuste exacto de la probabilidad HMCR es distinto en cada una de las redes de distribución simuladas, pero en términos generales el resultado de diseño resulta bonificado para probabilidades altas del HMCR, siendo el óptimo de eficiencia HMCR más alto cuanto mayor es el tamaño de la red que se considera. La conclusión final respecto a este parámetro es considerar valores entre el 90 y el $95 \%$, puesto que este rango contiene el ajuste óptimo del HMCR en todas las redes de distribución consideradas por este trabajo.

Por último, la eficiencia del algoritmo HS en función de la población inicial que se considera para el proceso de optimización sigue la misma línea que en el resto de técnicas, de modo que tamaños de población pequeños resultan más eficientes, siempre que este número sea lo bastante grande como para garantizar diversidad en las soluciones y evitar convergencias demasiado tempranas. Así, en términos generales, todas las redes obtienen la eficiencia máxima para tamaños de memoria entre 30 y 45 individuos, salvo la red de Nueva York, donde se produce una excepción, creciendo la eficiencia del algoritmo con el tamaño de población, sin que se llegue a alcanzar un punto de inflexión, tal como ocurre en las restantes redes.

Una vez analizado el término de eficiencia para los distintos algoritmos evolutivos, el apartado 6.7 toma como referencia los resultados de eficiencia obtenidos para el planteamiento y resolución de dos nuevos problemas de optimización, detallados a continuación:

- Inicialmente se aborda el proyecto de ampliación de una red real situada en el municipio de Noja. La aplicación de las configuraciones óptimas considerando criterios de eficiencia hace que los modelos de optimización basados en APG, SFLA y HS obtengan en todos los casos más de un $60 \%$ de probabilidad de obtener una buena solución. El algoritmo PSO queda en este caso por detrás del resto de técnicas, puesto que tan sólo obtiene un $10 \%$ de buenas simulaciones, en consonancia con los estudios anteriores, que la situaban como la peor técnica.

Respecto de la probabilidad de encontrar la mínima solución, los resultados son susceptiblemente mejores que cuando no se considera ningún tipo de optimización de parámetros, puesto que tanto el APG como el HS obtienen cifras cercanas al $10 \%$ de obtención de óptimos, quedando el algoritmo SFL ligeramente por detrás, con un $6 \%$.

- Los distintos modelos de optimización desarrollados pueden modificarse de modo que sea posible considerar conceptos como el de fiabilidad. Así, en esta tesis se considera que el sistema es fiable cuando es capaz de seguir cumpliendo las restricciones definidas de presión y caudal aún en el caso de que alguna de las conducciones de la red tenga una rotura. 
De este modo se aplican para las redes de Hanoi, Nueva York, Joao Pessoa y Go-Yang las configuraciones definidas como más eficientes en cada uno de los modelos de optimización y se diseñan todas las redes considerando la fiabilidad del sistema en caso de existir una rotura en la conducción. La aplicación directa de las configuraciones determinadas en esta tesis como de máxima eficiencia permite tener la confianza de que el algoritmo va a converger en todos los casos, proporcionando los mejores resultados posibles.

Así por ejemplo, en la red de Hanoi, los modelos de optimización basados en APG, PSO y SFL consiguen más de un $60 \%$ de mínimas soluciones y un $100 \%$ de las simulaciones realizadas entran dentro del concepto de "buena solución". El algoritmo HS tiene dificultad para encontrar la solución mínima (3,2\%), pero más del $60 \%$ de simulaciones pueden considerarse como buena solución del problema. En el resto de redes los resultados no son tan impresionantes pero sí que están muy por encima de los que se obtenían antes de realizar ningún tipo de optimización con los parámetros del sistema.

La conclusión final de esta tesis es que las técnicas de optimización basadas en algoritmos evolutivos resultan de suma utilidad cuando se trata de optimizar la resolución de problemas en redes de agua. Del mismo modo, hay que destacar que una correcta elección de los parámetros de los que dependen este tipo de técnicas ayuda sobremanera a mejorar los resultados obtenidos por este tipo de metodología, minimizando el factor aleatorio que por definición acompaña a los algoritmos. Esta tesis define un nuevo concepto en lo que a técnicas evolutivas se refiere, la eficiencia, y lo aplica con éxito a los distintos problemas planteados.

Como resumen de las principales conclusiones de la tesis en cuanto a la eficiencia de los algoritmos de optimización estudiados, las tablas 7.1, 7.2, 7.3 y 7.4 muestran el ajuste recomendado para cada uno de los modelos de optimización. Estos valores representan ajustes eficientes en los parámetros de cada metodología y representan un buen punto de partida a la hora de afrontar un nuevo diseño mediante metodologías evolutivas.

\begin{tabular}{|c|c|c|}
\hline \multicolumn{2}{|c|}{ PARÁMETROS } & Obtención de mínimas soluciones \\
\hline Prob. de cruce & $\mathrm{P}_{\mathrm{c}}$ & 0,5 \\
\hline Prob. de mutación & $\mathrm{P}_{\mathrm{m}}$ & $0,02-0,03-0,04$ \\
\hline Tamaño de población & & 50 \\
\hline
\end{tabular}

Tabla 7.1. Ajuste óptimo de eficiencia en el algoritmo APG. 


\begin{tabular}{|c|c|c|}
\hline \multicolumn{2}{|c|}{ PARÁMETROS } & Obtención de mínimas soluciones \\
\hline Velocidad límite & $\mathrm{V}_{\lim }$ & 0,2 \\
\hline Prob. de despiste & $\mathrm{P}_{\text {desp }}$ & 0,1 \\
\hline Constante 1 & $\mathrm{C}_{1}$ & 2 \\
\hline Constante 2 & $\mathrm{C}_{2}$ & 2 \\
\hline Número individuos & & $75-225$ \\
\hline
\end{tabular}

Tabla 7.2. Ajuste óptimo de eficiencia en el algoritmo PSO.

\begin{tabular}{|c|c|c|}
\hline \multicolumn{2}{|c|}{ Parámetros de ajuste } & Obtención de mínimas soluciones \\
\hline Probabilidad HMCR & HMCR & $0,92-0,95$ \\
\hline Ajuste pitchrate & PAR & 0,15 \\
\hline Número individuos & & 50 \\
\hline
\end{tabular}

Tabla 7.3. Ajuste óptimo de eficiencia en el algoritmo HS.

\begin{tabular}{|c|c|c|}
\hline \multicolumn{2}{|c|}{ PARÁMETROS } & Obtención de buenas soluciones \\
\hline Tamaño submemeplex & $\mathrm{Q}$ & 0,4 \\
\hline Número saltos evolutivos & $\mathrm{N}$ & 5 \\
\hline Coeficiente de aceleración & $\mathrm{C}$ & 2 \\
\hline Ranas por memeplex & $\mathrm{m}$ & 10 \\
\hline Número memeplexes & $\mathrm{n}$ & 10 \\
\hline
\end{tabular}

Tabla 7.4. Ajuste óptimo de eficiencia en el algoritmo SFL.

\subsection{Desarrollos futuros}

Debido a la versatilidad de los algoritmos de optimización heurísticos, numerosos investigadores han aplicado con éxito este tipo de técnicas a la resolución de todo tipo de problemas en infinidad de campos, entre los que se incluye la optimización del diseño en redes de agua. No obstante, hasta la fecha no existían técnicas que permitieran la comparación entre todas estas metodologías más allá del resultado final obtenido, por lo que se hacía complicado determinar qué técnica podía ser más adecuada para cada problema.

Este trabajo desarrolla el concepto de eficiencia en la aplicación de algoritmos evolutivos a la optimización del diseño en redes de agua, que permite determinar que algoritmo funciona mejor en base tanto al resultado económico obtenido como a la velocidad de cálculo del algoritmo. No obstante, los resultados alcanzados en esta tesis no pueden ser considerados como universales, puesto que están basados en tan sólo cuatro redes de distribución. Las siguientes líneas repasan algunos aspectos donde se considera necesario profundizar en el conocimiento del problema: 
- Mejora de los modelos de optimización propuestos. Evidentemente, cualquiera de las metodologías desarrolladas en esta tesis puede ser mejorada, puesto que siempre es posible introducir modificaciones en los algoritmos de optimización, de cara a mejorar el buen hacer de los mismos. Sin duda, esta es una de las grandes ventajas que ofrecen los algoritmos evolutivos, que resultan muy versátiles a la hora de introducir modificaciones en la programación de los mismos.

- Validez de los criterios de eficiencia en otros problemas de optimización. Los resultados obtenidos acerca de la configuración más eficiente en cada algoritmo de optimización no pueden ser considerados como universales, si bien resultan un buen punto de partida a la hora de afrontar el diseño de otras redes de distribución de agua o el análisis de otros problemas de optimización.

- Estudio de nuevas metodologías de optimización. Los cinco algoritmos de optimización desarrollados en esta tesis no son únicos, sino que existen numerosas metodologías en la bibliografía basadas en algoritmos evolutivos. Esta tesis ha estudiado en profundidad las metodologías que ha considerado más importantes y con mayor capacidad de desarrollo, pero sería un error no considerar la posibilidad de abordar en un futuro el desarrollo de otros algoritmos evolutivos que puedan mejorar los resultados ya existentes.

- Planteamiento de nuevos problemas de optimización relacionados directamente con el diseño de redes de distribución de agua. En este sentido, el diseño realizado en esta tesis tan sólo contempla el dimensionamiento de las conducciones de la red de distribución de agua, cumpliendo una serie de restricciones de velocidad y presión. Sin embargo, es posible introducir nuevos criterios de diseño, como podría ser la optimización del bombeo o la fiabilidad del sistema de distribución de agua.

En la misma línea, sería interesante el desarrollo de modelos de optimización basados en algoritmos evolutivos que permitan la resolución de otros problemas relacionados con la hidráulica, como podría ser la realización de modelos de rehabilitación en conducciones, la determinación de caudales no controlados o la detección de fugas en los sistemas a presión.

Estas son algunas de las líneas de investigación que pueden abordarse en relación directa con el problema de optimización que aborda esta tesis, que es el diseño de redes de agua. No obstante, la versatilidad de los algoritmos evolutivos en cuanto a la resolución de cualquier problema de optimización permitiría aprovechar muchas de las conclusiones obtenidas para abordar otros problemas que no tienen que tener nada que ver con la temática que nos ocupa. 
Por último, cabe destacar que en este momento se están adaptando los modelos de optimización desarrollados y las conclusiones derivadas de esta tesis con el objetivo de participar en la batalla mundial de diseño de redes de agua (The Battle of the Water Networks II), enmarcada dentro de las actividades del 140 simposio de análisis de redes de distribución de agua que tendrá lugar en Australia durante septiembre de 2012. Para este caso, los algoritmos son adaptados al diseño de funciones multiobjetivo, puesto que no sólo es necesario tener en cuenta criterios de diseño sino también criterios de calidad. 


\section{BIBLIOGRAFÍA}

Abadie, J.; Carpentier, J. (1969). "Generalization of the Wolfe reduced gradient method to the case of nonlinear constraints". In R. Fletcher (Ed.), Optimization (pp. 37-47). New York: Academic Press.

Ackley, D.H.(1987). “A Connectionist Machine for Genetic Hillclimbing”. Kluwer Academic Publishers, Boston, Massachusetts.

Afshar, M.H (2006). "Application of a Genetic Algorithm to Storm Sewer Network Optimization". Scientia Iranica, Vol 13, no 3, pp 234-244.

Afshar, M.H (2006). "Improving the efficiency of ant algorithms using adaptative refinement: Application to storm water network design". Advances in Water Resources, Vol 29, pp 1371-1382.

Alperovits, E; Shamir, U (1977). "Design of Optimal Water Distribution Systems". Water Resource Research, Vol 12, no 6, 885-900.

Baker, J.A. (1987) "Reducing Bias and Inefficiency in the Selection Algorithm".In John J. Grefenstette, editor, Genetic Algorithms and Their Applications: Proceedings of the Second International Conference on Genetic Algorithms, pp 14-22. Lawrence Erlbaum Associates, Hillsdale, New Jersey, July.

Booker, L.B. (1982). "Intelligent Behavior as an Adaptation to the Task Environment". PhD thesis, Logic of Computers Group, University of Michigan, Ann Arbor, Michigan.

Brindle, A. (1981). "Genetic Algorithms for Function Optimization". PhD thesis, Departmentof Computer Science, University of Alberta, Edmonton, Alberta.

Caruana, R; Schaffer, J.D (1988). "Representation and Hidden Bias: Gray vs. Binary Coding for Genetic Algorithms". Proceedings of the Fifth International Conference on Machine Learning, pp 132-161, San Mateo, California.Morgan Kauffman Publishers.

Cerny, V. (1985). "Thermodynamical approach to the travelling salesman problema: an efficient simulation algorithm". Journal of Optimization Theory and Applic, Vol 45, pp 41-55. 
Clerc, M; Kennedy, J. (2002). "The particle swarm - explosion, stability, and convergence in a multidimensional complex space. IEEE Trans. Evolutionary Computation, Vol 6(1), pp 58-73,

Cross, Hardy. "Analysis of flow in networks of conduits or conductors". University of Illinois Bulletin No. 286. November 1936.

Cunha, M.C; Sousa, J (1999). "Water distribution networks design optimization: simulated annealing approach". Journal of Water Resources Planning and Management. July/August 1999, pp $215-221$.

De Jong, A.K. (1975). An Analysis of the Behavior of a Class of Genetic Adaptive Systems. PhD thesis, University of Michigan.

Dowsland, K; Adenso, B. (2001). "Diseño de heurísticas y fundamentos del Recocido Simulado". Inteligencia Artificial, n으, pp 34-52.

Duan, N; Mays, L; Lansey, K. (1990). "Optimal reliability-based design of pumping and distribution systems". ASCE Journal of Hydraulic Engineering, Vol 116(2), pp 249268.

Duan, Q; Sorooshian, S; Gupta, V. (1994). "Optimal use of the SCE - UA global optimization method for calibrating watershed models". Journal of Hydrology, Vol 158, pp. 265284.

Eiger, G.; Shamir, U.; Ben-Tal, A (1994) “Optimal design of water distribution systems". Water Resource Research, Vol 30, № 9, pp 2637-2646.

Eusuff, M.M., Lansey, K.E. (2006). “Shuffled frog leaping algorithm: a memetic meta-heuristic for combinatorial optimization. Engineering Optimization, 38 (2), pp. 129-154.

El-Baharawy, A; Smith, A. (1985). "Application of MINUS to Water Collection and Distribution Network" . Civil Enginnering Systems, Vol. 2, pp 38-49.

Engelhardt, M.O., Savic, D.A., Walters, G.A. (1999). "Using genetic algorithms to optimise water distribution system rehabilitation". 9th International MIRCE Symposium on System Operational Effectiveness, Knezevic, J., U.D Kumar and C. Nicholas (eds.), Woodbury, UK.

Farmani, R; Matthew, R.G.S; Javadi, A.A. (1999). "Discrete optimisation of water distribution networks using genetic algorithms". Proceedings of the 1999 International Conference on Computing and Control for the Water Industry, Exeter University, August, pp 427-436. 
Formiga, K. (1999). "Metodologia de Otimização de Redes Malhadas Através da Programação Não Linear". Dissertação de Mestrado; UFPB, CCT, Departamento de Engenharia Civil, CampinaGrande-PB. 158 p.

Fraser, Alexander S.; Burnell, D. "Computer Models in Genetics". McGraw-Hill, New York, 1970.

Fuertes, Garcia Sierra, Iglesias, Lopez, Martinez, Perez (2002). “Modelación y diseño de redes de abastecimiento de agua". Grupo Mecánica de Fluidos. Dep. Ingeniería Hidráulica y Medio Ambiente

Fujiwara, O., and Khang, D. B. (1987). "A two-phase decomposition method for optimal design of looped water distribution networks." Water resources research, Vol 23, no6, pp 977-982.

Fujiwara, O., Khang, D.B (1990) "A two phase decomposition method for optimal design of looped water distribution network". Water resources research, Vol 26, no 4, pp 539549.

Geem, Zong Woo (2001). "Optimal cost design of water distribution networks using harmony search". Environmental Planning and Management Program. John Hopkins University.

Gessler, J. (1985). "Pipe Network Optimization by Enumeration”. Computer Applications in Water Resources (Proceedings of the Speciality Conference), Ed H.C Torno, 572-590.

Gilbert; Syswerda(1989). "Uniform Crossover in Genetic Algorithms". Proceedings of the Third International Conference on Genetic Algorithms, pages 2-9, San Mateo, California. Morgan Kaufmann Publishers.

Golberg, D.E; Hsing Kuo, C (1987) ). “Genetic Algorithms in Pipeline Optimization”. Journal of Computing in Civil Engineering, Vol. 1, no 2, 148-141.

Gomes, H; Formiga, KTM (2001). “PNL2000: Método prático de dimensionamento econômico de agua". Revista Brasileira de Recursos Hídricos. Porto Alegre, ABRH Vol 6 (4), pp 91-108

Gomes, H; Marques, S.T; Oliveira, P; Menezes, M (2009). "Optimal dimensioning model of water distribution systems". ISSN 0378-4738, Water SA, Vol 35, pp 421-432.

Goulter, I. G., and Morgan, D. R. (1985). "An integrated approach to the layout and design of water distribution systems." Civil Engineering Systems, Vol 1 (2), pp 104-113. 
Goulter, I.C.; Coals, A.V. (1986). "Quantitative Approaches to Reliability Assessment in Pipe Networks". Journal Transportation Engineering, Vol 112, no 3, pp 287-301.

Goulter, I. (1995). "Analytical and simulation models for reliability analysis in water distribution systems." Improving efficiency and reliability in water distribution systems, E.Cabrera and A. F. Vela, eds., Kluwer Academic, London, pp 235-266.

Granados, A. (1990). "Infraentructuras de Regadios - Redes Colectivas de Riego a Presión". Servicio de publicación de E.T.S.I. de Caminos de la Universidad Politécnica de Madrid, España.

Halhal, D.; G.A. Walters; D.A. Savic; D. Ouazar, (1999). "Scheduling of Water Distribution System Rehabilitation using Structured Messy Genetic Algorithms". Evolutionary Computation, Vol. 7, no 3, pp 311-329.

Holland, John H. "Adaptation in Natural and Artificial Systems". University of Michigan Press, Ann Arbor, Michigan, 1975.

Holland, J. (1992). “Algoritmos Genéticos”. Revista Investigación y Ciencia. № 192, pp. 38-45

Iglesias, P.L (2003). "Desarrollo de una herramienta para modelación de sistemas de abastecimiento de agua utilizando sistemas de información geográfica y algoritmos genéticos (MAGIAS)". Memoria del Proyecto de Investigación no DPI2003-02676 del Ministerio de Ciencia y Tecnología (España).

Iglesias, P.L (2001). “Modelo general de análisis de redes hidráulicas a presión en régimen transitorio". Tesis Doctoral - Dpto. Ingeniería Hidráulica y Medio Ambiente. Universidad Politécnica de Valencia.

Iglesias, P.L, Lopez, P.A, Lopez, G., Martinez, F.J, (2004) "EPANET 2.0vE. Manual de usuário". Ed. Grupo Multidisciplinar de Modelación de Fluidos Universidad Politécnica de Valencia, 246 pág.

Iglesias, P.L; Lopez, P.A; Martinez, F.J; Perez, R. (2002). “Dimensionado económico de impulsiones mediante algoritmos genéticos". II Seminario Hispano Brasileño sobre Planificación, Proyecto y Operación de Redes de Abastecimiento de Agua. Valencia, 10-12 diciembre, 2002.

Iglesias, P.L; Mora, D; Fuertes, V; Martinez, F.J (2006). “Análisis estadístico de soluciones de diseño de Redes de Abastecimiento de Agua mediante Algoritmos Genéticos". XXII Congreso Latinoamericano de Hidráulica. Ciudad Guayana. Venezuela. 
Jin, Y-X., Cheng H.Z et al. (2007). "New discrete method for particle swarm optimization and its application in transmission network expansion planning." Electric Power Systems Research Vol 77 (3-4), pp 227-233.

Karmeli, D.; Gadish, Y; Meyers, S. (1968), "Design of Optimal Water DistributionNetworks", Journal of the Pipeline Division (ASCE), Vol. 94, PL1, pp. 1-10.

Kennedy J., Eberhart R. (1995). "Particle Swarm Optimization". Proceedings of the IEEE international conference on neural networks, Perth, Australia, pp 1942-1948.

Kessler, A., and U. Shamir (1989). "Analysis of the linear programming gradient method for optimal design of water supply networks." Water Resources Research, Vol 25 (7), pp 1469-1480, doi:10.1029/WR025i007p01469.

Kessler, A; Shamir, U. (1997). "Decomposition technique for optimal design of water suplí systems". Engineering Optimization, Vol 17, no 1, pp 1-19.

Kirkpatrick, S., Gellat, C.D., Vecchi, M.P. (1983). "Optimization by simulated annealing". Science, Vol 220, pp 671-680.

Lancey, K.E; Mays, L. (1989). “Optimal design of water distribution system design,” ASCE Journal of Hydraulic Engineering, Vol 115(10), pp 1401-1418.

Lancey, K.E; Duan, N; Mays, L.W; Tung, Y.K. (1989). "Water Distribution System Under Uncertainties". Journal of Water Resources Planning and Management, ASCE, Vol. 115, No. 5, pp 630-644.

Leal, A.F. (1995). "Estudo comparativo de métodos de otimização de redes malhadas pressurizadas". Dissertação de Mestrado em Engenharia Civil. Campina Grande: UniversidadeFederal da Paraíba, 1995. $141 \mathrm{p}$

Liang, Lou Y; Thompson, Rusell G; Young, David M (2004). "Optimising the design of sewer networks using genetic algorithms and tabu search". Engineering, Construction and Architectural Management, Vol 121 № 2, pp 101-112.

Mahamed G.H. Omran, Mehrdad Mahdavi (2008). "Global-best harmony search". Applied Mathematics and Computation, no 198, pp 643-656.

Mahdavi, M; Fesanghary, M; Damangir, E (2007) “An improved harmony search algorithm for solving optimizatin problems". Applied Mathematics and Computation, no 188, pp 1567-1579. 
Matías, A (2004). “Etapas en el diseño de redes distribución de agua mediante algoritmos genéticos". III Seminario hispano-brasileño sobre Planificación, Proyecto y Operación de Redes de Abastecimiento de Agua. Valencia.

Mays, Larry W; Wenzel, Harry G (1976). “Optimal Design of Multilevel Branching Sewer Systems". Water Resource Research, Vol 12 n 5, 913-917.

Mays, Larry W; Chie Yen, Ben (1975). "Optimal Cost Design of Branched Sewer Systems". Water Resource Research, Vol 11 № 1, pp 37-47.

Metropolis, N.; Rosenbluth, A. W.; Rosenbluth, M.; Teller, A. H.; Teller, E.(1953). "Equation of State Calculations by Fast Computing Machines." J. Chem. Phys. Vol 21, pp 10871092.

Mora, D (2006). "Ampliación de la red de abastecimiento de Noja mediante la utilización de Algoritmos Genéticos". Proyecto Final de Carrera - Dpto. Ingeniería Hidráulica y Medio Ambiente. Universidad Politécnica de Valencia.

Mora, D; Iglesias, P.L; Fuertes, V; Martinez, F.J (2006). “Metodología para diseño y ampliación de redes de abastecimiento mediante Algoritmos Genéticos". XII Congreso Internacional de Ingeniería de Proyectos. Valencia. España

Morley, MS; Atkinson, RM; Savic, DA; Walters, GA. (2001). “GAnet: genetic algorithm platform for pipe network optimisation". Advances Engeneering Software, vol 32, no. 6, pp 467-475.

Murphy, L.J, Simpson, A.R, Dandy, G.C. (1993) "Pipe network optimization using an improved genetic algorithm". Res. Rep no R109, Department of Civ. and Envir. Engrg, University of Adelaide, Australia.

Murtagh, B.A.; Saunders, M.A. (1987). "MINOS 5.1 User's Guide. Systems Optimization Laboratory". Department of Operations Research, Stanford University.

Newell, A, J.C. Shaw, H.A. Simon (1962). "The processes of creative thinking". H.E. Gruber, G. Terrell, and M. Wertheimer, editors, Contemporary approaches to creative thinking, pp 63-119. Atherton Press, New York.

Quindry, G., Brill, E. D., Liebman, J., and Robinson, A. (1979) "Comments on 'Design of Optimal Water Distribution Systems' by Alperovits and Shamir," Water Resources Research, Vol. 15, No. 6, Dec. pp 1651-1654. 
Reca, J; Martinez, C.; Gil, R; Baños (2008). "Application of several meta-heuristic Techniques to the Optimization of Real Looped Water Distribution Networks". Water Resources Manage 22, pp 1367-1379.

Reed, J., R. Toombs, and Nils Aall Barricelli. (1967) "Simulation of biological evolution and machine learning". Journal of Theoretical Biology, Vol 17, pp 319-342.

Rossman, L.A., (1997). "EPANET 2.0 User's manual". Ed. Drinking Water Research Division. Risk Reduction Engineering Laboratory. Environmental Protection Agency.

Salgado, R., (1988). "Computer modelling of water distribution networks using the gradient method". PhD Thesis. Civil Engineering Department. University of Newcastle-upon-tyne.

Savic, D.A y Walters, G.A (1997). "Genetic Algorithms for Least-Cost Design of water Distribution Systems". Journal of Water Resources Planning and Management, Vol $125, \mathrm{n} \div 2$, pp $67-77$

Schaake, J.C., and Lai, D. (1969). "Application to Water Distribution Network Design". Report 116, Hydrodynamics. Linear Programming and Dynamic Programming. Laboratory, Department of Civil Engineering, MIT, Cambridge, MA.

Silva, R. C. A. (1997). "Otimização de Redes Ramificadas A través do Método da Programação NãoLinear". UFPB, CCT, Departamento de Engenharia Civil, Campina Grande-PB; 1997. $148 \mathrm{p}$

Shi, Y., Eberhart, R. (1998). "Parameter selection in particle swarm optimization”. Proceedings of the Seventh Annual Conference on Evolutionary Programming, pp 591-600.

Shi, Y., Eberhart, R. (1998). "A modified particle swarm optimizer". Proceedings of the IEEE international conference on evolutionary computation, pp 69-73.

Shi, Y., Eberhart, R. (2001)“Fuzzy adaptative particle swarm optimization”. Proceedings of the IEEE international conference on evolutionary computation, pp 101-106.

Su, Y.C; Mays, L.W; Duan, N; Lansey, K.E. (1987“). "Reliability-Based Optimization Model for Water Distribution Systems". Journal of Hydraulic Engineering, ASCE, Vol 114, № 12.

Tang, Wilson H; Mays, Larry W; Chie Yen, Ben (1975). “Optimal Risk-Based Design of Storm Sewer Networks". Journal of the Environmental Engineering Division, June 1975, 381-398. 
Todini, E., Pilati, S., (1987). "A gradient algorithm for the analysis of pipe networks". Proceedings International Conference on Computer Applications for Water Supply and Distribution. Leucester, Politechnic, 8-10 september.

Wang, Q.J (1991). "The Genetic Algorithm and Its Application to Calibrating Conceptual Rainfall-Runoff Models". Water Resources Research, Vol 27. no 9, pp 2467-2471 


\section{ANEXO. CONCLUSIONS AND FUTURE DEVELOPMENTS}

\subsection{Conclusions}

In the development of the doctoral thesis there have been studied different methods of design of water networks, based all of them in the application of evolutionary optimization algorithms. The study of each one of these methodologies is aimed to obtaining general design models which allow obtain the best possible solution in the shortest space of time. As a result of the research we have been settled for any technique of optimization different borders of application.

Chapter 2 provides a set of basic principles to consider when addressing the optimal design of water networks. In this sense, there are many models when trying to approach the design of hydraulic networks, each seeking to achieve a certain state in the water network based on the objectives set in each case.

The different methodologies used in this thesis obtained the hydraulic dimensioning of the network, fulfilling certain conditions of service, as are criteria for pressure, velocity, etc... These restrictions must be met in the most unfavorable conditions in which it will operate the water network, so commonly used steady-state models.

Along the chapter different methodologies of design are reviewed, some of which are based only on variables of hydraulic nature, whereas others include in the formulation variables of economic nature. The evolutionary algorithms are in the latter group. Thus, the chapter 2 tries to show with clarity all the advantages that present this type of techniques opposite to others.

Because of its complexity, the introduction of these techniques is associated with the development of computers, so its use is relatively recent. The advantages of this type of techniques are evident, since they allow the search of solutions beyond the local minimums that usually reach the techniques of design solely based on hydraulic criteria. This type of optimization techniques allows to expand the field search, and therefore, the capacity to find better solutions. 
Evolutionary algorithms include different optimization techniques, which common characteristic is the evolution of a first random solution of the problem towards more profitable positions inside the space of solutions. The versatility of these techniques allows its use in all types of processes related to engineering optimization in water networks, but so far there was no work comparing these techniques, in order to evaluate which is most suitable for each process optimization

This thesis has analyzed in detail some of these evolutionary techniques, selecting different application examples, making conclusions about the use of these techniques in process design of water distribution networks.

Thus, from the proposed benchmarking networks, it may take a number of general conclusions concerning the comparison between the results obtained by different design methods derived from functional and evolutionary methodologies tested in this doctoral thesis.

In this sense, the chapter 4 shows the resolution of different problems of design in water distribution networks. Some of these problems of optimization are very popular in the literature, having being realized previously by other researchers. It is possible to compare the own results with those of other authors, already be with functional methodologies or with methodologies based on evolutionary algorithms. This is the case of the Hanoi network problem and the New York tunnels problem.

In addition to these two networks, Chapter 4 raises the design of Go-Yang network and Joao Pessoa network. These networks do not have so many references in the literature, but also has some standard of comparison with other authors. These are the cases of the design problems Go-Yang (Geem, 2001) and Joao Pessoa (Pimentel, 2009). Analysis of optimal design in these networks take the following general conclusions:

- Any of the tested evolutionary methods obtains in all networks at least one solution which improves economically design of the network obtained by any of the functional methods tested. All design solutions obtained by any method satisfy the design constraints, either minimum pressure, minimum velocity, etc.

- The improvement is not a fixed parameter, but depends mainly on the type of water network. Typically, the larger and more complex the network design greater the economic gap between functional design methods or evolutionary methods. For example, in the case of the Joao Pessoa network, the saving obtained by using an evolutionary algorithm against best functional methods (LEHNSNET) is barely $3.65 \%$, but in one case as complex and large as it saves um 9.25 million um. However, in a 
network of smaller and greater simplicity of design, such as Go-Yang network, a 3\% saving represents only 5500 um.

- Among all the networks tested, the highest percentage of savings obtained with evolutionary algorithms is given in the network of tunnels in New York, where the rehabilitation project will cost $6.7 \%$ lower than that offered by the best functional technique. In general, it is possible to estimate savings between 3 and $7 \%$ in the design of water networks when using evolutionary methods rather than traditional functional methodologies.

- All developed optimization models reach the same minimum solution in Hanoi, New York, Joao Pessoa and Go-Yang design problems, except for the optimization algorithm based on simulated annealing. The results obtained by the latter methodology are substantially worse than the rest. For this reason was discarded include this model in subsequent analyzes.

- Water networks design by heuristic algorithms not only allows to obtain minimal solutions, but leads to a set of possible solutions that mostly are very close to optimal. Therefore it is possible to define the concept of "good solution" of the problem as one that does not exceed $3 \%$ over the minimum cost obtained for a given network

The only disadvantage of evolutionary algorithms compared to other design methodologies is the need to have certain knowledge to properly adjust the various parameters of each of these techniques, reducing where possible the random factor inherently associated with the formulation of these optimization models. In this sense, the most laborious part of this thesis was to perform a statistical analysis for each of the proposed optimization models, in order to obtain a basic configuration rules that allow the use of such models with confidence. Similarly, this type of analysis allows decisions about what may be the most appropriate technique in the design of water networks.

Each methodology has its own optimization setting parameters that determine in each case a model of behavior in the search for the optimal design solution. Chapter 5 analyzes individually all the evolutionary developed models, taking different criteria of analyses that allow to decide for which it is the best option for the design of water distribution networks.

Moreover, section 5.1 determines the optimum setting for each of the parameters whose value must be introduced in the design process, so that the probability of finding the problem's minimal solution of design would be as high as possible. This first analysis uses a constant number of individuals in all the algorithms, changing the setting of the rest parameters in each of the methodologies. This type of statistical analysis, which only considers obtain the best possible solution is what has been named " analysis of parameters". 
The simulation results show how optimization models based on APG and SFL are superior in achieving minimum design solutions. Both models are powerful tools of design when setting in parameters of adjustment is appropriate. On obtaining the best possible solution, the models of optimization based on PSO and HS have many difficulties at the moment of finding the minimal solution of design, and in general terms also they obtain a minor number of good solutions to the obtained ones for APG and SFL.

Thus, while all optimization models developed are able to find the minimal solution in some cases, APG and SFL obtain better repeatability than HS and PSO. The exception to this general rule occurs in the New York tunnels problem, where the design features required by this network favoring the HS algorithm, which obtains the highest probability of obtaining the minimum solution in this case.

If the results are analyzed in terms of networks, the main conclusion is that the repeatability of "minimal solutions" in each case depends mainly on the network itself. In this sense, the network R-9 in Joao Pessoa is the most complex of all analyzed, because both the size as the diameter range are large enough so that the repeatability of "minimal solutions" is the smallest of all water networks tested, since the number of local minima makes the convergence towards a single solution more difficult.

On the opposite side we find the network of Go-Yang, with a smaller number of pipes to design and a diameter range which allows a relatively simple converging towards the same optimal solution. In this case, all optimization models get their best results in repeatability of "minimal solutions".

The repeatability of a "minimal solution" design is influenced mainly by the parameters settings done in each optimization methodology, to the point that an incorrect choice of different parameter values can cause the optimization model does not find economic solutions useful for the design problem. Conclusions about the analysis of parameters for each of the techniques when only takes into account the possibility of obtaining the best possible solution are:

- The APG algorithm has two parameters subject to adjustment, traditionally called genetic operators. In all simulations with this model of optimization, the genetic operator of mutation is the most critical setting, since its correct choice will depend on the goodness of the solutions obtained. In this sense, mutation probabilities between 2 and $4 \%$ greatly increase the percentage of obtaining better solutions. Regarding the crossover genetic operator, it has less influence on the goodness of design calculations made, but crossover probabilities over $50 \%$ slightly better results overall, although not a significant improvement on all networks analyzed. 
- The optimization model developed with the PSO algorithm contains four setting parameters: the velocity limit flight of a given particle $\left(V_{\text {lim }}\right)$, the constants $C_{1}$ y $C_{2}$ and the "confusion probability" $\left(P_{\text {desp }}\right)$. The first three are included in the original formulation of PSO, while $P_{\text {desp }}$ is incorporated into the model developed for this doctoral thesis as an additional parameter that increases the diversity of solutions.

In all simulations performed, $\mathrm{P}_{\text {desp }}$ and $\mathrm{V}_{\lim }$ represent the parameters whose setting we consider critical to get the best possible solution. $V_{\text {lim }}$ determines the step size that can be given within the range of diameters considered between two consecutive iterations. The conclusion on this parameter is that velocity limits between 10 and $30 \%$ from the number of possible diameters favors convergence to better solutions.

For its part, the $\mathrm{P}_{\text {desp }}$ introduces a random factor needed to create diversity during the optimization process, avoiding earlier convergence of the algorithm. The introduction of this parameter in the formulation of the algorithm improves the results, but its use should be prevent, since increasing its value also increases the randomness with which optimizes the algorithm. Statistical analyzes determined that "likelihood of confusion" about $10 \%$ are ideal in all analyzed networks, dramatically decreasing performance optimization model in upper and lower values.

Finally, the value of the constants $C_{1}$ and $C_{2}$ is related to the weight given to global and local searches within the optimization process. The value of both is perhaps the least controversial of all the studies, since in the literature we find numerous references that advise the use of values between 1.8 and 2 for these constants. The study confirms these values, although within the adjustment range considered $\left(1<\mathrm{C}_{1}\right.$ $<2,1<\mathrm{C}_{2}<2$ ) there were no major differences.

- The HS-based optimization allows free configuration of two parameters, called Harmony Memory Considering Rate (HMCR) and Pitch Adjustment Rate (PAR). In terms of robustness, the algorithm HS is more sensitive than other methods discussed, since a wrong choice in the setting of the parameters causes deflection towards feasible solutions. In this regard, PAR settings above 0.5 not allow obtaining design feasible solutions in any case.

Once the convergence to a feasible solution, the analysis of the results found that the influence of PAR adjustment in obtaining "minimal solutions" is zero, so the main conclusion regarding this parameter is it only affects the convergence of the algorithm, so the recommendation is to use sufficiently low values in all cases to assure the convergence. 
Regarding HMCR, it is difficult to choose optimal values generally considered the working range used, since the optimum working range is different in all water systems tested. For this reason, it is not possible to define an optimal zone based on these data, putting off to choice the other decision factor's evaluation such as algorithm velocity or the population's size.

- The optimization model based on the SFL algorithm is, together with APG, the most powerful of all methods used when considering only the probability of obtaining the best possible solution. The search for the best settings for optimum performance of this method is complicated, because it contains 5 parameters that require adjustment before the optimization process, although two of them are related to population size of the algorithm.

Nevertheless, as it happens in other methodologies, not all the setting parameters have the same importance in the process of optimization. Thus, the results on the water networks determine the number of submemeplexes (Q) is the least sensitive parameter when considering only the end result of design. In the considered working range (0.25-1), the choice of one value or another is irrelevant.

On the opposite side, the parameter of acceleration (C) can be considered as critical in a correct configuration for SFL algorithm. In this sense, we can state categorically that values between 1.75 and 2.25 greatly improve the performance of the algorithm, obtaining a lower average cost in all benchmarking networks discussed in this thesis.

Finally, the results in the simulations show that the consideration of a greater number of evolutionary steps (N) favors the obtaining of better solutions up to $15 \%$.

Each of the optimization models developed in this thesis depends on a number of parameters that best setting requires a comprehensive statistical work. Each methodology has its own parameters and compare them is complex. In this sense, the size of the population which starts the optimization process is the only parameter common to all evolutionary methodologies, so it study addressed independently in section 5.3 of this thesis.

In general terms, the use of a greater number of individuals favors the obtaining of better solutions, since it increases the number of evaluations of the objective function and increases exploration of the solution space. However, the larger the population the greater the convergence time used by the algorithm. The improvement produced by using larger populations do not have a linear form, but from certain population sizes produced little improvement is seen, therefore it is necessary to choose between the improvement of the solution and the computation time. 
The network topology also has much to do in this respect, as in cases where the network is not overly complex makes no sense to use large populations of individuals, since it does not get any improvement. This is the case of the network of Go-Yang, where all evolutionary algorithms have a high probability of finding the minimum even in the smallest populations tested.

The importance in choosing the population size is greater in more complex networks, since small populations used in this type of network convergence results too early. This is because the number of local minima is larger and more difficult to get out of them. In this regard, it is not advisable to use smaller populations of 50 individuals in any of the tested evolutionary methods.

Usually, the use of large populations leads to a slowdown in the calculation, since the number of evaluations of the objective function tends to be higher than most individuals involved in the optimization process. The scope in which it moves a heuristic method, the term "speed" refers precisely to the number of objective function evaluations performed by the calculation algorithm before finding the final solution of the problem. This type of analysis is done in Section 5.4. Thus, this section lists the number of evaluations with the adjustment of the parameters in each of the algorithms analyzed, yielding the following conclusions:

- Overall for the APG, the number of objective function evaluations until convergence occurs is lower for small mutation probabilities. Thus, the higher is the value of this parameter, the lower is the velocity algorithm. Moreover, the irregularity in the number of evaluations based on the crossover probability prevent from taking conclusions about the relation of this operator with the velocity of the algorithm, so the most plausible conclusion is that the probability of crossover does not have a direct influence on the number of evaluations.

The exception to the general rule is when the size, and therefore, the complexity of the network is not very high. In such networks, the search for the optimum in the solution space is simpler, because the number of potential solutions and local minimum is smaller. This simplifies the search process, so the difference when using different probabilities of crossover/mutation does not affect the velocity of the algorithm, since all the possible combinations are able to quickly resolve the problem.

- For PSO algorithm, the number of evaluations of the objective function grows with increasing the "confusion probability" that is given to a particular particle. It is important to remember that this operator is introduced into the model precisely to increase the number of evaluations and avoid early convergence. However, we should be careful, since an excessive increase in the number of iterations may 
decrease the effectiveness of the algorithm, so it is necessary to seek compromise solutions that set the optimum for this parameter. The efficiency study helps in making such decisions.

Similarly, considering the velocity limit flight of a particle between iteration and iteration, as is observed at lower values of this operator increases the number of evaluations of the objective function.

Finally, in the case of the constants $C_{1}$ and $C_{2}$, both have less influence on the speed of the algorithm. In this sense, the analyzes determined that the value of $C_{1}$ has no influence on the velocity of the algorithm, while $C_{2}$ values around 2 (highest value used) perform fewer evaluations of the objective function, increasing the calculation velocity. This iterative savings is greater the more complex the network under study.

- In absolute terms, the optimization methodology based on HS is the least objective function evaluations performed to converge to a final solution, so it can be said to be the fastest of the developed optimization models. For example, the network of Hanoi, while APG, SFL and PSO do not perform less than 50000 evaluations of the objective function, the HS-based model makes a maximum of 25000 evaluations on the slowest setting of all tested.

If we analyze the influence of setting parameters of HS optimization, the analysis determines that the number of evaluations of the objective function decreases almost linearly with increases as the value of HMCR, so the faster the algorithm works the higher the value of this parameter.

As for the Pitch Adjustment Rate (PAR), the analysis regarding the influence of the quality parameters of the solution determined that the operator only performs functions of convergence. The velocity analysis confirms this theory, since using different PAR settings does not affect in any way to the velocity with which the algorithm converges to the final solution.

- In the case of SFL optimization, velocity analysis focuses on the influence of parameters related to the nature of evolutionary leaps, which are the number of evolutionary steps $(\mathrm{N})$, the size of submemeplex $(\mathrm{Q})$ and coefficient accelerator (C).

Thus, considering the number of evolutionary steps, the method is slower the greater the number of scheduled evolutionary steps. In fact, the iterative savings occurs for small values of $\mathrm{N}$ is quite considerable, and the savings are greater the more complex is the network, to the point that in Joao Pessoa network configuration with $\mathrm{N}=5$ done just $20 \%$ of the simulations performed by the algorithm when $\mathrm{N}=30$. 
As for the accelerator coefficient (C), if one considers only the computational effort, statistical analysis concludes that values around 1.75 to 2 are the least objective function evaluations made in general terms, so that increase the calculation velocity of the algorithm. Taking into account more complex individual cases, such as Hanoi or Joao Pessoa networks, giving higher values to $\mathrm{C}$ increases the computational effort.

Finally, assigning different values to the size of submemeplex (Q) does not indicate any relationship between this value and the velocity of optimization proccess.

At this point, the thesis made several statistical analyzes that establish the relation between the setting of the different parameters and goodness of the solution obtained in the design of different distribution networks for each heuristic technique. Similarly, velocity analysis revealed the existence of other factors to consider, such as computational cost associated with the manipulation of these parameters. The efficiency analysis discussed in Chapter 6 is the formula that relates all the criteria that must be taken into account when considering the optimal design of networks with evolutionary algorithms.

In this sense, most of the optimization models function acceptably concerning efficiency, so the choice of one or another depends largely on both the required design objective and the characteristics of the network itself. The objective of efficiency analysis is to help taking the best decision in each case and what would be the best fit in each case without requiring again a full statistical analysis.

Thus, when the design problem is complex and the main objective is to obtain the minimum solution of design, the more powerful optimization techniques are those based on genetic algorithms (GA) and SFL algorithms. These two methods are getting better repeatability in obtaining the optimal solution for all networks tested, which does not mean they are the most efficient in all networks.

The SFL algorithm is in all cases the one with greater repeatability in obtaining the optimal design when properly configured, but requires a high computational effort and a complex adjustment process, which requires 5 parameters optimization calculation. That is why for small networks or problems where it is not necessary to obtain the optimal design may be an option, but not a priority. This is because for simpler problems there are other techniques that provide greater efficiency than the SFL algorithm.

One such technique is the APG, based on a traditional genetic algorithm but with some modifications detailed in Chapter 3 of this thesis. The APG is a good option for complex networks to simpler networks when looking for the optimal design solution. So much for the 
network of Hanoi, and the network of Go-Yang has proved the most efficient technique in finding the optimal solution design, slightly better results obtained by the SFL algorithm in both cases. On the other hand, the correct configuration of APG requires only 3 parameters adjustment, which is an advantage over the SFL algorithm.

In cases of New York and Joao Pessoa, the APG is less efficient than the HS algorithm, with similar results to the SFL algorithm. The PSO algorithm is the worst efficiency obtained with very difference. As mentioned, the efficiency of an optimization algorithm has to do with the complexity of the network, as well as raised design objectives.

Thus, the main feature of the HS algorithm is the velocity with which converges to feasible solutions, being in all cases the algorithm less objective function evaluations performed to find the final solution. This represents an advantage, but also carries a problem. This is the difficulty for this algorithm to get repeatability when it comes to finding the least cost solution. However, at times, especially in very large networks, it is not necessary to find the cheapest possible solution, but a set of solutions close to it, and it is in this situation where the HS algorithm has value, since the set of solutions as generally found in a shorter time.

For example, the network R-9 of Joao Pessoa has 61 pipes to design. The minimum cost for the network in the defined operating conditions is 192.366 millions um. This solution has not repeatability with any of the techniques, since it is a solution between $10^{61}$ possibilities, with many local minima. Given this situation, find a set of superior solutions to design minimum cost, but close to it would be interesting.

The ability to find good solutions without excessive computational cost is the main advantage of the HS algorithm. Furthermore, this method has the advantage of having only two setting parameters, since the third of them, the Pitch Adjustment Rate, has been shown that performs functions of convergence and no optimization.

On the opposite side in terms of efficiency is the modified PSO algorithm, which gets the worst results in all networks. This methodology is less efficient in all simulations. The following paragraphs summarize the conclusions about each technique used:

\subsubsection{PseudoGenetic Algorithm (APG)}

The optimization methodology based on genetic algorithms is shown as the most robust of all the proposals, because regardless of the setting considered for any of the three optimization parameters, is able to obtain feasible solutions for the design problem. This ability of APG represents an important advantage over other techniques, where the parameter optimization is not only required to improve results, but also for the convergence of the algorithm itself. 
In this sense, the robustness of the APG allows any configuration parameters calculation would be able to solve a given optimization problem, so it would not require any previous experience to solve a given design. However, setting parameters allows improvement in the search for optimal, either in the quality of the solution itself or in the resources consumed by the APG to perform the simulation. The combination of quality and velocity is what is known as efficiency; the study in this paper shows that the APG is one of the most efficient algorithms when it comes to finding the optimum design for a given water distribution network.

The efficiency of APG is especially good when it comes to finding the lower cost solution for a given network. Within the genetic operators that require a certain adjustment. The one that hat the greater influence on the efficiency of the algorithm is the genetic operator of mutation. In fact, considering the results it can be said that the mutation probability is the most critical of all the methodology involving genetics. A poor fit of this operator leads to a worsening results for more complex networks. Overall we can conclude that mutation probabilities assuming about $2-4 \%$ we will have the security of working in the best possible range for this parameter optimization, since all the analyzed distribution networks move around these values.

For the crossover genetic operator, the efficiency analysis shows how the adjustment of this parameter is not as critical as in the case of the mutation operator. In this respect, and valuing the slight improvement obtained in the efficiency of crossing probabilities that are above $50 \%$ on all networks analyzed, it can be said that the algorithm is able to find minimum/good solutions regardless of the setting crossover operator.

Finally, analysis of the efficiency in the initial population that employs the algorithm determines a variable number of individuals depending on the design goal. Thus, in determining the minimum cost design for a given network is advisable to use higher populations, around 50-75 individuals in general. The population size will not provide optimum efficiency at $100 \%$ of the networks, but ensures a high degree of efficiency in any case.

Contrary to other genetic operators, adjusting the size of population in terms of efficiency varies depending on the design goals. So, when obtaining a set of good solutions is sufficient, the number of individuals involved in the optimization process may be somewhat less. The efficiency study determined that populations around 25-50 individuals are the most efficient in all analyzed networks, as they guarantee obtaining a set of good solutions with low computational cost. It is not advisable to take smaller population sizes of 25 individuals, since the quality of the solution suffers not enough to compensate for computational savings derivative. 


\subsubsection{PS0 Algorithm}

The PSO algorithm was originally designed to optimize continuous variables, and subsequently adapted to the optimization of discrete variables, such as the choice of a certain size in diameter in a water distribution network. The original formulation of PSO algorithm was not of interest in the optimization problem discussed in this thesis, because the algorithm converges in a way too early for the ends of the solution space, resulting in design costs could be considered bad for comparison to other methodologies.

Due to these limitations, the methodology developed is a modified PSO algorithm, which introduces a new parameter, called Confusion Probability $\left(P_{\text {desp }}\right)$, which increased the exploration of the solution space, avoiding too early convergence of the algorithm. Despite these changes, the performance of PSO algorithm in the optimization of distribution networks has been very inferior to other techniques, since the efficiency of the modified PSO algorithm is highly penalized to find overall fewer minimum/good solutions even in the best fit of the different optimization settings.

In this sense, the PSO algorithm turns out to be the worst technique in all water networks studied, with an efficiency much lower than other methods except in the New York tunnels design problem, where it obtained results close to APG, but lower than the algorithm HS and SFL. Thus, regardless of design objectives, the PSO algorithm is not in any of the cases presented the best option.

Considering the efficiency of the algorithm depending on the setting of parameters there is a clear difference regarding the relative importance of some parameters and others to keep the modified PSO algorithm in working order. Thus, $P_{\text {desp }}$ and $V_{\text {lim }}$ are two critical parameters in terms of efficiency of the algorithm is concerned. In this sense, the results on all networks are quite categorical, so that the velocity limit of a given particle should be around $20-30 \%$ of the number of values that can take the decision variable, while the "confusion probability" is advisable that is about $10 \%$ of particles involved in the optimization process.

In the case of the maximum velocity with which a given particle moves, taking into consideration that in this work the decision variable is the diameter to be installed in a certain pipe, the recommended limit implies for example for a range of ten diameters the $V_{\text {lim }}$ at which particles have to move would $\mathrm{V}_{\text {lim }}=(-2,2)$, which would break up two diameters within the range between two consecutive iterations.

As for the confusion probability that is assigned to a given particle, which releases follow the leader in a given iteration, the results conclude that while the use of this parameter increases the search space of the algorithm, using percentages exceeding $10 \%$ causes the search is increasingly randomly. The study clearly identified as Pdesp efficiency around $10 \%$ provide the best results. 
Moreover, the adjustment of the constants $C_{1}$ and $C_{2}$ is less important, at least in the range studied, as the influence on the efficiency of the algorithm is much lower than in the above parameters. Thus, the literature generally recommended values around $1.8 \div 2$ for these two constants, and so it does the conclusion of this study. However, the value of these two parameters can not be considered critical, since using smaller values of the above does not have a decisive influence on the efficiency of the modified PSO algorithm.

Finally, the efficiency analysis in the size of the initial population to start the process of optimization determines, in a similar way to the APG, the right size as a criterion of choice considering the efficiency of the algorithm depends on which design goals are presented. Thus, if the design goal is to collect a set of good solutions for a given network the size of population to be considered will be somewhat less than if required to obtain the best possible design.

In this respect, the analysis suggests that for obtaining a good set of solutions, the PSO algorithm is more efficient when working with population sizes between 50 and 125 individuals. It is advisable to perform the settings depending on the complexity of their own network. Thus, for more complex networks, such as Hanoi or Joao Pessoa should be adjusted to 125 individuals, while for networks more easily as New York or Go-Yang will have to use populations close to 50 individuals.

Population size should be somewhat larger to increase the probability of obtaining the minimum design solution. In this case it is advisable to work with populations around 100-125 individuals in all cases, regardless of the difficulty of the distribution network.

The final conclusion regarding the modified PSO algorithm is that despite these recommendations for the setting of various parameters, characteristics of the algorithm is not conform completely to the water distribution design problem, so it is advisable to use other optimization methodologies treated in this work.

\subsubsection{SFL Algorithm}

The methodology based on the SFL algorithm is probably the most powerful if it is considered only the ability to obtain the least cost solution in the design of a particular distribution network. Nevertheless, as many computing resources consumed by this algorithm makes is at a level similar to APG in terms of efficiency.

However, the computational requirements of the algorithm leads to reductions in efficiency when considering only the ability to obtain a set of good design solutions, so as APG or HS methods are superior in this aspect, since they get similar results with a fewer objective function evaluations.SFL also has an additional difficulty, and is the need to setting five design parameters, whose influence is crucial in finding the best economical design for a given 
network. Three of these parameters are associated with the evolutionary nature of the leaps in each iteration, while the other two represent the number of individuals involved in the optimization process, which is commonly known as initial population of the algorithm.

Like the PseudoGenetic Algorithm, the algorithm SFL is a robust method, capable of obtaining convergence towards feasible solutions design with any setting in the various parameters. Howewer, a correct adjustment greatly favors the obtaining of better solutions and increased efficiency of the algorithm.

Thus, the efficiency analysis shows that, within the range studied, the lower the number of evolutionary steps $(\mathrm{N})$ the greater the efficiency of the algorithm, since on having used high values of $\mathrm{N}$ it increases so much the number of iterations that the possible improvement does not compensate in the final result. This result is coincidental in all the networks, so that the final conclusion with regard to the number of steps is that a value $\mathrm{N}=5$ is the ideal one in the problem of optimization, not being descartable the utilization of lower values, since in the studied range this one was the smallest value.

Considering the accelerator coefficient whose study range is between 1 and 2.5, the efficiency analysis discards the values at the ends of the interval as appropriate. This way, the conclusion respect of this parameter is that a value around 2 increases in general terms the efficiency of the algorithm. This situation is given in three of four considered water networks. The only exception is Go-Yang's network, where the algorithm is more efficient for $\mathrm{C}=1,375$, but yet at this case the values of efficiency are good around 2, for what it seems to be logical to choose this value as ideally of efficiency for the accelerating coefficient.

The last parameter relates to the nature of evolutionary steps is the size of submemeplex (Q). In general terms, this parameter can be regarded as less critical in terms of efficiency of the algorithm SFL, since the results are reasonably good regardless of the $Q$ value, at least in the range of study considered, comprising values between zero and one. However, the efficiency of the algorithm is slightly improved in all networks when the algorithm use values greater than 0.4 . So, the final recommendation regarding the size of submemeplex is to use a higher $Q$ setting this value.

As for the initial population of the algorithm, determined by the number of memeplexes $(n)$ and the number of frogs memeplex $(\mathrm{m})$, results are coincident in all networks, being more efficient algorithm the smaller the size of the population. Thus, for all networks, the combination of $\mathrm{m}$ and $\mathrm{n}$ as small as possible, with a total of 100 individuals (10x10) involved in the optimization process is more efficient. 
In general terms it was found that all algorithms have a working range in 100 individuals maximum, so it might be possible that in the case of SFL algorithm, around 50-75 populations individuals may even improve the efficiency of SFL algorithm.

\subsubsection{HS Algorithm}

The optimization methodology based on the HS algorithm is a very efficient when it is not required to obtain repeatability in minimum design solution for a given network. Thus, this technique is very efficient in obtaining a set of "good solutions" near the optimum design, since the convergence of the algorithm is earlier in general terms. HS performs only a calculation of the objective function by iteration, regardless of the initial population of the algorithm, and this is the main cause of fast convergence.

This feature makes the HS algorithm be the fastest in convergence of all optimization algorithms studied in this work, but in return decreases the repeatability of minimal design solutions, since HS is less able to scan. Therefore, in more complex networks such as Hanoi or Joao Pessoa, the number of optimal solutions obtained by the HS algorithm is much lower than that obtained by other techniques more potent as APG or SFL. However, when applying the concept of "good solution" of the algorithm, which includes design solutions that are at most $3 \%$ more expensive than the minimum solution, the HS algorithm greatly improves its performance, ranking among the most efficient techniques.

The optimization methodology based on the HS algorithm adds another disadvantage compared to techniques such as APG or SFL, and it is the robustness of the algorithm. So, HS is not able to provide feasible solutions in the full range of setting parameters. Thus, as occurred in the original PSO algorithm, a very poor election of parameters can prevent convergence of the algorithm. Statistical analysis made solutions can solve this problem, but it's something to consider in this optimization technique.

Thus, the convergence parameter to take into account in the optimization HS is the pitch adjustment rate (PAR). The results show in the networks analyzed that pitch adjustment rates above 0.5 do not converge to feasible solutions. Similarly, the statistical analysis shows that PAR is only a convergence parameter. Thus, once the convergence is obtained, this parameter does not affect the efficiency of the algorithm. That is why the conclusion regarding the PAR adjustment is enough to guarantee the convergence of the algorithm, so it is recommended to use PAR values between 0.05 and 0.3 either.

Regardless of convergence, the goodness of the HS design solutions is determined by setting the HMCR and the memory size of the algorithm (initial population). The probability HMCR determines whether the value of each decision variable in a given iteration is chosen from the values that the same decision variable have already in other chains of memory or is taken out. In this regard, adjusting the probability HMCR is different in each of the simulated distribution 
networks, but in general the design result better with high probabilities of HMCR. The final conclusion on this parameter considers values between 90 and $95 \%$, since this range contains the optimal setting HMCR in all distribution networks considered in this work.

Finally, the efficiency of HS algorithm based on the initial population that is considered for the optimization process follows the same line as in other techniques, so that small population sizes are more efficient. However, it must be beared in mind that this number should be large enough to ensure diversity and avoid convergence solutions too early. Thus, in general, all networks to obtain the maximum efficiency of memory sizes between 30 and 45 individuals, unless the network in New York, where an exception occurs, increasing the efficiency of the algorithm with the population size, without come to reach a point of inflection, as in the other networks.

Analyzed the term of efficiency for different evolutionary algorithms, Section 6.7 uses the efficiency results obtained for the approach and resolution of two new optimization problems, detailed below:

- Initially it is solved the project of extension of a real water network placed in Noja's municipality. The application of the ideal configurations considering criteria of efficiency makes the models of optimization based on APG, SFLA and HS obtain in all the cases more $60 \%$ of probability to obtain a good solution. The algorithm PSO stays in this case behind the rest of methodologies, since only obtains $10 \%$ of good simulations, in agreement with the previous studies, which were placing it as the worst algorithm.

Respect of the probability of finding the minimal solution, the results are better than when it are not considered to be any type of optimization of parameters, since both the APG and the HS obtain probabilities near to $10 \%$ of obtaining the minimum, staying the algorithm SFL lightly behind, with $6 \%$.

- Different optimization models developed can be modified so that it is possible to consider concepts such as reliability. Thus, this thesis considers the system is reliable when it is able to remain within the constraints defined (pressure and flow) even in the event that any of the lines on the network has a break.

Thus, we will apply to networks of Hanoi, New York, Joao Pessoa and Go-Yang defined settings to be more efficient in each of the optimization models. Subsequently all the networks are designed considering the reliability of the system if there is a break in any pipe. Direct application of configurations determined in this thesis as the highest efficiency can be confident that the algorithm will converge in all cases, providing the best possible results. 
For example, in the Hanoi network, optimization models based on APG, PSO and SFL get over $60 \%$ of minimal solutions and $100 \%$ of the design results fall within the concept of "good solution". The HS algorithm has difficulty finding the minimum solution (3.2\%), but more than $60 \%$ of simulations can be considered as a good solution. In the rest of the networks are not as impressive results but they are far above those obtained before any optimization of system parameters.

The final conclusion of this thesis is that the optimization techniques based on evolutionary algorithms are very useful when trying to optimize the resolution of problems in water systems. Similarly, it must be stressed that a correct choice of parameters of each technique helps greatly to improve the results obtained by such methods, minimizing the random factor that accompanies the algorithms definition. This thesis defines a new concept as far as regards evolutionary techniques, efficiency, and successfully applied to various.

To summarize the main conclusions of the thesis as to the efficiency of optimization algorithms studied, tables 7.1, 7.2, 7.3 and 7.4 show the recommended setting for each of the optimization models. These values represent adjustments efficient parameters of each methodology and represent a good starting point when we make a new design using evolutionary methods.

\begin{tabular}{|c|c|c|}
\hline \multicolumn{2}{|c|}{ PARAMETERS } & Obtaining minimal solution \\
\hline Crossover probability & $\mathrm{P}_{\mathrm{c}}$ & 0,5 \\
\hline Mutation probability & $\mathrm{P}_{\mathrm{m}}$ & $0,02-0,03-0,04$ \\
\hline Population size & & 50 \\
\hline
\end{tabular}

Tabla 7.1. Optimal Efficiency Adjustment in APG.

\begin{tabular}{|c|c|c|}
\hline \multicolumn{2}{|c|}{ PARAMETERS } & Obtaining minimal solution \\
\hline Limited velocity & $\mathrm{V}_{\lim }$ & 0,2 \\
\hline Confusion probability & $\mathrm{P}_{\text {desp }}$ & 0,1 \\
\hline Constant 1 & $\mathrm{C}_{1}$ & 2 \\
\hline Constant 2 & $\mathrm{C}_{2}$ & 2 \\
\hline Population size & & $75-225$ \\
\hline
\end{tabular}

Tabla 7.2. Optimal Efficiency Adjustment in PSO.

\begin{tabular}{|c|c|c|}
\hline \multicolumn{2}{|c|}{ PARAMETERS } & Obtaining minimal solution \\
\hline Probability HMCR & HMCR & $0,92-0,95$ \\
\hline Pitchrate Adjustment & PAR & 0,15 \\
\hline Population size & & 50 \\
\hline
\end{tabular}

Tabla 7.3. Optimal Efficiency Adjustment in HS. 


\begin{tabular}{|c|c|c|}
\hline \multicolumn{2}{|c|}{ PARAMETERS } & Obtaining minimal solution \\
\hline Submemeplex size & $\mathrm{Q}$ & 0,4 \\
\hline Evolutive steps & $\mathrm{N}$ & 5 \\
\hline Acceleration coefficient & $\mathrm{C}$ & 2 \\
\hline Frogs memeplex & $\mathrm{m}$ & 10 \\
\hline Memeplexes number & $\mathrm{n}$ & 10 \\
\hline
\end{tabular}

Tabla 7.4. Optimal Efficiency Adjustment in SFL algorithm

\subsection{Future Developments}

Due to the versatility of heuristic optimization algorithms, several researchers have successfully applied these techniques to solving all kinds of problems in many fields, among which include design optimization in water networks. However, until today there were no techniques to compare all these methods beyond the final result, so it was difficult to determine which technique might be more appropriate for each problem.

This thesis develops the concept of efficiency in the application of evolutionary algorithms to optimize the design of water networks, which determines which algorithm works best based on both the economic result obtained as the calculation velocity of the algorithm. However, the results in this thesis can not be considered as universal, since they are based on only four water distribution networks. The following lines go over some areas where it is considered necessary to study in depth the understanding of the problem:

- Improved optimization models proposed. Obviously, any of the methodologies developed in this thesis can be improved, since it is always possible to modify the optimization algorithms. No doubt this is one of the great advantages of evolutionary algorithms, which turn out to be very versatile at the moment of introducing modifications in the programming of the same ones.

- Validity of the criteria of efficiency in other optimization problems. The results obtained on the most efficient configuration at each optimization algorithm can not be considered as universal, but are a good starting point at the moment of confronting the design of other water distribution networks or analysis of other problems optimization.

- VStudy of new optimization methodologies. The five optimization algorithms developed in this thesis are not unique, but there are many methodologies in the literature based on evolutionary algorithms. This thesis has studied the methodologies considered more important and more capable of development, but it would be a mistake not to consider the possibility of approaching in a future the 
development of other evolutionary algorithms that could improve the already existing results.

- Approach of new optimization problems directly related to the design of water distribution networks. In this sense, the design made in this thesis provides only for the sizing of the pipe from the water distribution network, meeting velocity and pressure constraints. However, it is possible to introduce new design criteria, as could be the optimization of pumping stations or the reliability of the water distribution system.

In the same line, it would be interesting to develop optimization models based on evolutionary algorithms that allow the resolution of other problems related to hydraulics, as might be the modeling of pipeline rehabilitation, the uncontrolled flow determination or detection leaks in pressurized systems.

These are some of the lines of research directly related to the optimization problem addressed in this thesis. However, the versatility of evolutionary algorithms in terms of solving any optimization problem would take advantage of many of the conclusions obtained for other problems that do not have to have anything to do with the subject matter.

Finally, note that at this time are adapting the optimization models developed, using the conclusions of this thesis, in order to participate in the global battle for water network design (The Battle of the Water Networks II), located within the activities of the 14th symposium of analysis of water distribution networks to be held in Australia in September 2012. For this case, the algorithms are adapted to the design of multiobjective functions, since it is only necessary to consider the design criteria but also quality criteria.

Por último, cabe destacar que en este momento se están adaptando los modelos de optimización desarrollados y las conclusiones derivadas de esta tesis con el objetivo de participar en la batalla mundial de diseño de redes de agua (The Battle of the Water Networks II), enmarcada dentro de las actividades del 14 simposio de análisis de redes de distribución de agua que tendrá lugar en Australia durante septiembre de 2012. Para este caso, los algoritmos son adaptados al diseño de funciones multiobjetivo, puesto que no sólo es necesario tener en cuenta criterios de diseño sino también criterios de calidad. 


\section{ANEXO. CONCLUSÕES E DESENVOLVIMENTOS FUTUROS}

\section{Conclusões}

No desenvolvimento desta tese temos estudado diferentes métodos de dimensionamento de redes de água, tudo com base na aplicação de algoritmos de otimização evolucionária. 0 estudo de cada uma dessas metodologias destina-se a obtenção de modelos gerais de dimensionamento, que produzem a melhor solução possível possível no mais curto espaço de tempo, assim que como um resultado do trabalho tenham sido estabelecidos para a implementação fronteira vário cada um deles.

O Capítulo 2 fornece um conjunto de princípios básicos a serem considerados quando se trata do dimensionamento otimizado de sistemas pressurizados de distribuição de água. Neste sentido, há muitos modelos ao tentar abordar o projeto de redes hidráulicas, cada qual procura atingir um determinado estado da rede hidráulica com base nos objectivos definidos em cada caso.

As várias metodologias utilizadas neste trabalho obtido o dimensionamento hidráulico da rede, de modo como para atender certas condições de serviço, como são critérios para velocidade, pressão, etc. Essas restrições devem ser atendidas nas condições mais desfavoráveis de serviço, de modo que comumente usados modelos de estado estacionário.

O capítulo analisa diferentes metodologias de dimensionamento, algumas das quais são baseadas apenas em variáveis de natureza hidráulica, enquanto outras variáveis incluídas na formulação de natureza econômica. Entre estes últimos são colocados diferentes algoritmos evolucionários mostrado neste trabalho e capítulo 2 tenta mostrar claramente todas as vantagens oferecidas por estas técnicas em detrimento de outras.

Dada a sua complexidade, a introdução de estas técnicas está associado com o desenvolvimento de computadores, portanto, seu uso é relativamente recente. As vantagens destas técnicas são evidentes, uma vez que permite a busca de soluções para além mínimos locais normalmente até técnicas de dimensionamiento com base exclusivamente em critérios hidráulicos. Este tipo de técnicas de otimização permite ampliar o campo de pesquisa e, portanto, a capacidade de encontrar soluções melhores. 
Algoritmos evolucionários incluem diversas técnicas de otimização, cuja característica comum é a evolução de uma solução inicial aleatória de o problema em posições mais vantajosas no interior do espaço de soluções. A versatilidade dessas técnicas pode ser usado em todos os tipos de processos relacionados com a otimização de engenharia da água, mas até agora não havia trabalho para a comparação de estas técnicas uns com os outros, a fim de avaliar qual é o mais adequado para cada processo de otimização.

Esta tese analisou em profundidade algumas dessas técnicas evolucionárias, selecionando uma série de exemplos de aplicação a partir do qual conclusões diferentes podem ser sobre a utilização destas técnicas no processo de dimensionamento de redes de distribuição de água.

Assim, a análise dos exemplos pode estabelecer um número de conclusões gerais sobre a comparação entre os resultados obtidos por métodos funcionais e aqueles obtidos por aplicação de métodos evolucionários.

Nesse sentido, o Capítulo 4 do presente artigo aborda a resolução de problemas no dimensionamento de redes de água. Alguns desses problemas de otimização são muito populares na literatura, tendo sido abordados anteriormente por outros pesquisadores, de forma que há muitas soluções para permitir a comparação de resultados. Este é o caso dos problemas de projeto de rede de Hanói e da rede de túneis em Nova York.

Além destas duas redes, o Capítulo 4 aborda a resolução de redes de Go-Yang e João Pessoa, que, embora não muitas referências na literatura, também tem algum padrão de comparação com os autores presentes. Estes são os casos da rede de Go-Yang (Geem, 2001) e R-9 da rede de João Pessoa (Pimentel, 2009). Análise de projeto ideal nestas redes, tendo as seguintes conclusões gerais:

- Todas as metodologias evolutiva obter, pelo menos, uma solução que melhora a economicamente melhor solução de o obtido por um método funcional. Todas as soluções de projeto obtido por qualquer metodologia atende a uma série de restrições de projeto, seja de pressão mínima, velocidade mínima, etc.

- A melhora não é um parâmetro fixo, mas depende principalmente do tipo de rede. Normalmente, o maior e mais complexo é o projeto da rede maior é o fosso económico entre os métodos de desenho funcional ou métodos evolucionários. Por exemplo, se a rede R-9 de João Pessoa, a economia do uso de um algoritmo evolutivo com melhores métodos funcionais (LEHNSNET) é de apenas 3,65\%, mas em um caso tão complexo e grande como ele salva hum 9,25 milhões um. No entanto, em uma rede de tamanho menor e simplicidade do dimensionamento, tais como a rede de Go-Yang, 3\% de economia alcançada através de abordagem evolutiva para projetar é apenas 5500 um. 
- Entre todas as redes testadas, o maior percentual de economia obtido utilizando algoritmos evolutivos é dada na rede de túneis em Nova York, onde o projecto de reabilitação vai custar $6,7 \%$ menor do que o oferecido pelas melhores técnicas funcionais. Da análise pode-se estimar que a economia de uso de algoritmos evolutivos no projeto de redes de água está entre 3 e $7 \%$ sobre a melhor técnica funcional em cada caso.

- Todos os modelos de otimização desenvolvidos neste trabalho alcançar a solução mínima para todas as redes de distribuição de água. A única exceção é o algoritmo de otimização baseado em Simulated Annealing. Os resultados deste algoritmo evolutivo são substancialmente piores do que o resto, por incluir este modelo foi descartada na análise posterior.

- O dimensionamento de rede por algoritmos heurísticos não só permite a obtenção de soluções mínimas, mas leva a um conjunto de possíveis soluções para o problema que às vezes estão muito próximas do ideal. É por isso que é possível definir o conceito de "boa solução" do problema, que é tão perto do melhor dimensionamento também pode ser válido. Ao longo deste trabalho que definiu o conceito de solução boa como qualquer um que não exceda em mais de $3 \%$ com custos mínimos obtidos para uma determinada rede.

A única desvantagem de algoritmos evolucionários em comparação com outras metodologias de dimensionamento é a necessidade de ter algum conhecimento prévio que permitem corretamente ajustar os vários parâmetros de cada uma dessas técnicas, reduzindo sempre que possível o fator aleatório que se arrasta na formulação desses modelos de otimização. Nesse sentido, a maior carga de trabalho nesta tese está focada em a análise estatística para cada um dos modelos de otimização propostos, a fim de obter algumas regras básicas de configuração que permitem o uso de tais modelos com confiança. Da mesma forma, este tipo de análise permite que as decisões quanto ao que pode ser a técnica mais adequada no dimensionamento das redes de água.

Cada metodologia de projeto tem suas próprias parâmetros de ajuste que determinam em cada caso, um modelo de comportamento na busca de melhor desempenho do sistema. Capítulo 5 da tese analisou individualmente todos os modelos desenvolvidos de otimização evolutiva, utilizando diferentes critérios de análise para tomada de decisão sobre qual é a melhor opção para o dimensionamento de redes de distribuição de água.

Assim, secção 5.1 determina a configuração ideal para cada parâmetro cujo valor tem de ser introduzida no processo de dimensionamento, de modo que a probabilidade de encontrar a solução mínima para o problema é o mais alto possível. Nesta análise, mantendo constante o número de indivíduos que trabalham com cada um dos algoritmos e verifica as simulações 
variando o ajuste de outros parâmetros em cada uma das metodologias. Este tipo de análise estatística que leva em conta apenas a obtenção a melhor solução possível é o que é chamado de "parâmetros de análise".

Os resultados das simulações mostram como modelos de otimização baseado em APG e SFL são superiores em alcançar soluções de dimensionamento mínimo. Os dois modelos são ferramentas poderosas se a definição dos parâmetros é feita corretamente. Na obtenção da melhor solução possível, com base em modelos de otimização PSO e HS têm muitas dificuldades para encontrar o dimensionamento da solução mínima, e em geral também terá um conjunto de boas soluções do que aquelas obtidas pelo APG e SFL.

Assim, enquanto todos os modelos de otimização desenvolvidos são capazes de encontrar a solução mínima em alguns casos, APG e SFL repetibilidade obter o máximo dele, de longe, ao longo dos outros dois modelos. A exceção a essa regra geral ocorre na rede de túneis em Nova York, onde as caracteristicas de dimensionamento exigidas por esta rede, de alguma forma favorecer o algoritmo de HS, que obtiver o maior probabilidade de se obter a solução mínima neste caso.

Se analisarmos os resultados com base nas redes analisadas, a principal conclusão é que as soluções de repetibilidade baixos em cada caso depende muito da sua própria rede cujo dimensionamento é para ser realizado. Neste sentido, a rede R-9 de João Pessoa é o sistema mais complexo de todos os analisados. Tanto o tamanho dele como a faixa de diâmetros de inclusão para a sua resolução são o suficiente grandes para que a repetibilidade de soluções mínimas é o menor em todas as metodologias de projeto utilizadas.

No lado oposto encontra-se a rede de Go-Yang, com um menor número de tubulação para dimensionamento e uma gama de diâmetros que permite uma convergência relativamente simples em direção a mesma solução óptima. Todos os modelos de otimização usados obtido o maior número de soluções mínimas no caso em apreço.

Uma escolha incorreta de os parâmetros pode causar o modelo de otimização parece inútil para abordar um dimensionamento particular. As conclusões a partir da análise de parâmetros para cada uma das técnicas quando um considera só a possibilidade de obtenção de a melhor solução disponível:

- O algoritmo de APG tem dois parâmetros sujeitos a ajustes, tradicionalmente chamados operadores genéticos. Em todas as simulações com este modelo de otimização, o operador genético de mutação é mostrado como o mais crítico, desde a sua escolha correta vai depender da bondade de as soluções obtidas. Neste sentido, as probabilidades de uma mutação do entre um 2 e um $4 \%$ aumentar consideravelmente o percentual de obtenção de uma solução melhor. Quanto ao 
operador de cruzamento genético, tem muita menos influência sobre a bondade dos cálculos feitos. No entanto, provavelmente superior a 50\% cruzar ligeiramente favorecendo os resultados do projeto em termos gerais.

- O modelo de otimização desenvolvido com o algoritmo PSO contém 4 parâmetros ajustáveis: o limite de velocidade de uma partícula $\left(V_{\lim }\right)$, a $C_{1}$ e $C_{2}$ constantes ea probabilidade de esquecimento $\left(P_{\text {desp }}\right)$. $O$ três primeiro são incluídos na formulação original da PSO, enquanto $\mathrm{P}_{\text {desp }}$ está incorporada no modelo desenvolvido para essa tese como uma medida adicional que aumenta a diversidade de soluções.

Em todas as simulações realizadas, $V_{\text {lim }}$ e $P_{\text {desp }}$ e os parâmetros mais importantes são definidas em obter a melhor solução possível. $V_{\text {lim }}$ determina o tamanho do passo que pode ser dado dentro do intervalo de diâmetros considerados entre duas iterações consecutivas. A conclusão sobre este parâmetro é a de que o limite de velocidade entre 10 e $30 \%$ favorece a convergência para soluções melhores.

Pela sua parte, o $P_{\text {desp }}$ introduz um factor aleatório necessário para criar diversidade durante o processo de otimização, evitando assim convergências demasiado precoces de o algoritmo. A sua introdução em a formulação de o algoritmo melhora claramente os resultados, mas deve evitar que o seu abuso, uma vez que com o aumento do valor deste parâmetro também faz parte aleatória do algoritmo. As simulações determina que o $P_{\text {desp }}$ deve ser cerca de $10 \%$ para todas as redes analisadas, diminuindo drasticamente modelo de otimização de desempenho em valores superiores e inferiores.

Finalmente, o valor da constantes $C_{1}$ e $C_{2}$ está relacionado com o peso dado às pesquisas globais e locais dentro do processo de otimização. $O$ valor de ambos é talvez o menos polêmico de todos os estudos, uma vez que na literatura encontramos várias referências que aconselham o uso de valores entre 1,8 e 2 para essas constantes. Simulações confirmar esses valores, embora dentro da faixa de ajuste considerado $\left(1<\mathrm{C}_{1}<2,1<\mathrm{C}_{2}<2\right)$ não houve grandes diferenças, resultando em muito mais críticas as configurações corretas de $V_{\text {lim }}$ e $P_{\text {desp }}$.

- O algoritmo de otimização baseado no HS permite a configuração livre de dois parâmetros, chamados HMCR probabilidade e ajuste PAR. Em termos de robustez, o HS algoritmo é mais sensível do que o resto de metodologias tratadas. Uma escolha errada na configuração do parâmetro faz com que a convergência do algoritmo não é soluções viáveis. Neste sentido, as configurações de PAR acima de 0,5 não permitem a obtenção de soluções de dimensionamento factíveis em qualquer caso.

Uma vez obtido o convergência, análise dos resultados determina que a influência de ajusta PAR em o mesmo é nil, de modo que o principal conclusão em relação a este 
parâmetro é que ele ser exclusivamente de convergência, de modo a recomendação é para usar valores baixos em todos os casos como para garantir o mesmo.

No que respeita à HMCR probabilidade é difícil escolher valores ótimos geralmente considerados o intervalo de trabalho utilizado, uma vez que para cada uma das redes tenho uma zona ideal ligeiramente diferente. É por isso que a escolha foi colocado na óptima para a avaliação de fatores de decisão de outros tais como a velocidade do algoritmo ou o povo dos mesmos.

- O modelo de otimização baseado no SFL algoritmo é, com a APG, o mais poderoso de todos os métodos utilizados quando se considera apenas a probabilidade de obter a melhor solução possível. A busca dos melhores ajustes para o bom funcionamento desta metodologia é problemática, dado que até 5 parâmetros requerem ajuste antes de o processo de otimização, embora dois deles estão relacionados ao tamanho da população do algoritmo.

No entanto, como ocorre em outras metodologias, nem todos os parâmetros de ajustamento têm a mesma importância no processo de otimização. Assim, as simulações mostram sobre as redes como o número de submemeplexes (Q) é o parâmetro menos sensível quando considerando-se apenas o resultado final de seu dimensionamento. Assim, na gama de Trabalho considerou (0,25-1), a escolha de um valor ou outro é irrelevante.

No lado oposto em importância é o parâmetro de aceleração (C), onde ele pode ser afirmado categoricamente que valores entre 1,75 e 2,25 melhorar significativamente o desempenho do algoritmo, a obtenção de um custo média, menos em todos os redes de benchmarking discutido nesta tese.

Por último, as simulações mostram que a consideração de um maior número de passos evolucionários (N) ajuda a obter melhores soluções em até $15 \%$. No entanto, a escolha de grandes valores de $\mathrm{N}$ retarda o cálculo, de modo que significativa ou não que os resultados dessa diferença deve ser buscada na análise de eficiência

Como pode ser visto nas linhas superiores, cada um dos modelos de otimização desenvolvidos nesta tese depende de uma série de parâmetros cuja óptima ajustamento requer um trabalho amplo estatístico. Cada uma das técnicas tem os seus próprios parâmetros e compará-los é complexa. Neste sentido, o tamanho da população com o qual iniciar o processo de otimização é o único parâmetro comum a todas as metodologias evolutivas, de modo que seu estudo dirigido de forma independente no ponto 5.3 desta tese.

Em termos gerais, o uso de um número maior de indivíduos favores a obtenção de soluções melhores, uma vez que aumenta o número de avaliações da função objetivo e aumenta a 
exploração do espaço de solução. No entanto, o maior a população maior o tempo de convergência usada pelo algoritmo. A melhoria produzidos pelo emprego de populações maiores não tem uma forma linear, mas a partir de tamanhos determinados a melhoria produzida é dificilmente perceptível, por isso é necessário para ter em soluções de compromisso entre a melhoria da solução e tempo de computação.

A própria complexidade da rede também tem muito a fazer a este respeito, como nos casos em que a rede não é excessivamente complexa, não faz sentido usar grandes populações de indivíduos. Este é o caso da rede de Go-Yang, onde todos os algoritmos evolucionários obter uma alta probabilidade de encontrar o mínimo até mesmo nas menores populações testadas.

A importância na escolha do tamanho da população é maior em redes mais complexas, uma vez que pequenas populações causando convergência demasiado cedo, pois o número de mínimos locais é maior e custos mais fora delas. A este respeito, não é aconselhável a utilização de populações menores de 50 indivíduos de em qualquer um dos métodos testados evolucionários.

O uso de grandes populações leva a uma desaceleração no cálculo, uma vez que o número de avaliações da função objetivo tende a ser maior do que a maioria dos indivíduos envolvidos no processo de otimização. $O$ âmbito em que se move um método heurístico, a "velocidade" termo refere-se precisamente o número de avaliações da função objetivo realizadas pelo algoritmo de cálculo antes de encontrar a solução final do problema e este tipo de análise é o abordado no ponto 5.4. Bem, o presente número se relaciona o número de avaliações conduzidas com que adapta os vários parâmetros em cada um dos algoritmos analisados, obtendo-se as seguintes conclusões:

- No geral para a APG, o número de avaliações da função objetivo até que a convergência ocorre é mais baixa para valores mais baixos de operador de mutação genética. Assim, o maior é o valor de este parâmetro menor a velocidade de algoritmo. Além disso, a a irregularidade do número de avaliações de acordo com o cruzamento impede tirar conclusões sobre a relação deste operador com a velocidade do algoritmo, de modo a conclusão da mais plausível é que a probabilidade de cruzamento não tem uma influência direta sobre o número de avaliações realizadas, nem, por conseguinte, na velocidade com a qual calcula o APG.

A exceção à regra geral é encontrado quando o tamanho, e, portanto, complexidade a rede não é muito elevado. Neste tipo de redes, a busca a partir de óptimo em o espaço de solução é mais simple, porque o número de possíveis soluções e mínimos locais é mais baixa. Isso simplifica o processo de busca, de modo que a diferença entre usar probabilidades de cruzamento / mutação ou não afeta a velocidade do algoritmo, uma vez que todas as combinações possíveis são capazes de rapidamente resolver o problema. 
- Para o algoritmo PSO, o número de avaliações da função objetivo cresce com probabilidade crescente de confusão que é dado a uma partícula em particular. É importante para se lembrar que este operador é introduzido no modelo precisamente para aumentar o número de avaliações e evitar a convergência precoce. No entanto, ser cuidadoso, uma vez que um aumento em um excesso de o número de iterações pode diminuir a eficácia do algoritmo, por isso, é necessário buscar soluções de compromisso que fixados o óptimo para este parâmetro. O estudo de eficiência ajuda na tomada de tais decisões.

Da mesma forma, considerando o limite de velocidade de vôo de uma partícula entre iteração e iteração pode ver como este operador aumenta com a diminuição do número de avaliações da função objetivo.

Finalmente, no caso de o constantes $C_{1}$ e $C_{2}$, tanto exercer uma influência um pouco menos em a velocidade de algoritmo. Neste sentido, o analisa determinou que o valor de $C_{1}$ não tem nenhuma influência sobre a velocidade do algoritmo, enquanto os valores de $\mathrm{C}_{2}$ ao redor de 2 (valor mais alto usado) realizar avaliações em menor número de da função objetivo, aumentando bem a velocidade do cálculo. Esta poupança é maior a mais complexa de rede o sob estudo.

- Em termos absolutos, metodologia de otimização baseada em HS realiza avaliações da função objetivo menos a convergir para uma solução final, para que possa ser dito ser o mais rápido dos modelos de otimização desenvolvidos. Por exemplo, a rede de Hanói, enquanto o APG, SFL PSO ou não executam menos de 50000 avaliações da função do objectivo, o modelo HS-baseado faz um máximo de 25000 avaliações sobre a configuração mais lenta de toda a testada.

Se analisar a influência de ajustar os vários parâmetros do HS optimização, a análise determina que o número de avaliações da função objectivo diminui quase linearmente com o aumento como o valor da probabilidade HMCR, de modo que o algoritmo funciona mais mais rápido quanto maior o valor deste parâmetro.

No que diz respeito o ajustamento do PAR, a análise sobre a influência dos parâmetros sobre a qualidade da solução, e deu a entender que dispunha de apenas este capacidades de convergência do operador. Análise de velocidade confirma esta teoria, pois um PAR uso ajuste ou outro não afeta de forma alguma com a velocidade com que o algoritmo converge para a solução final.

- No caso de otimização de SFL, análise de velocidade centra-se em a influência dos parâmetros relacionados com a natureza de saltos evolutivos, que são o número de 
saltos evolutivos ( $\mathrm{N}$ ), o tamanho do submemeplex (Q) e o acelerador de coeficiente (C).

Portanto, com respeito ao número de saltos evolutivos, o custo computacional é mais elevado como o número de saltos evolutivos. Na verdade, a economia iterativa ocorre para valores pequenos de $\mathrm{N}$ é bastante considerável, e as poupanças são maior é a mais complexa for a rede, para o ponto de que, em rede R-9 a configuração com N = 5 feito apenas $20 \%$ das simulações realizadas pelo algoritmo de quando $\mathrm{N}=30$.

Quanto ao coeficiente de acelerador (C), se se leva em conta apenas os gastos, a análise estatística concluiu que os valores de cerca de 1,75-2 geralmente executar um número menor de avaliações da função objectivo, para aumentar a velocidade de cálculo do algoritmo. Tendo em conta casos mais complexos individuais, como Hanoi ou R-9, dando valores mais elevados de $\mathrm{C}$ aumenta a despesa computacional.

Finalmente, atribuindo valores diferentes para o tamanho de submemeplex (Q) não deixa qualquer tipo de relacionamento entre este valor e, a velocidade com a qual calcula o algoritmo.

Neste ponto, a tese feita estatística de várias análises que estabelecer o elo entre o ajustamento dos parâmetros de projeto vários e da bondade da solução obtida no dimensionamento de das redes de distribuição diferentes para cada técnica heurística. Da mesma forma, análise de velocidade revelou a existência de outros fatores para ter em conta, como é o custo computacional associado à manipulação de esses parâmetros. A análise de eficiência discutida no Capítulo 6 é a fórmula que relaciona todos os critérios que devem ser levados em conta quando se considera o melhor projeto de redes com algoritmos evolucionários.

Nesse sentido, a maioria dos modelos de otimização de posou operar aceitavelmente em matéria de eficiência refere-se, de modo que a escolha de um ou de outro depende em grande parte tanto o dimensionamento como objetivo exigido com as características da rede em si. A análise de eficiência permite a tomada de decisão quanto à escolha de uma determinada técnica na concepção de redes de distribuição, e que será o melhor ajuste possível em cada caso, sem ter que realizar novamente uma análise estatística completa.

Assim, quando o problema de projeto é complexo e busca a solução de dimensionamento mínimo, as técnicas de otimização mais poderosas são baseadas em algoritmos genéticos (GA) e algoritmos SFL. Esses dois métodos são cada vez melhor repetibilidade na obtenção da solução ótima para todas as redes testadas, o que não significa que eles são os mais eficientes em todas as redes. 
Nesse sentido, o algoritmo de SFL é em todos os casos a um com uma maior repetibilidade na obtenção de o desenho óptimo quando devidamente configurado, mas tem uma alta sobrecarga computacional e um processo de ajustamento complexo. É por isso que para redes pequenas ou problemas onde não é necessário para obter o melhor projeto pode ser uma opção não uma prioridade, uma vez que essas condições existem outras técnicas que proporcionam uma maior eficiência do que o algoritmo SFL.

Uma dessas técnicas é a APG, baseada em um algoritmo genético tradicional, mas com algumas modificações que permitem a melhoria e já detalhado no capítulo 3 deste trabalho. A APG é uma boa opção para redes complexas para redes mais simples quando se olha para a solução de dimensionamento ideal. Assim muito para a rede de Hanói, e da rede de Go-Yang revelou-se a técnica mais eficiente em encontrar o dimensionamento da solução óptima, superando ligeiramente os resultados obtidos pelo algoritmo de SFL em ambos os casos, embora com uma menos esforço quando da determinação da área de maior eficiência, uma vez que a APG requer apenas 3 parâmetros de ajustamento pelo usuário.

No caso de Nova York e João Pessoa APG é superada pelo algoritmo de HS, resultados semelhantes para o algoritmo de SFL e o algoritmo de PSO superando longe como a eficiência está em causa. Como mencionado, a eficiência de um algoritmo de otimização tem muito a ver com a complexidade da rede, bem como objetivos de projeto que surgem.

Assim, a principal característica do algoritmo de HS é a velocidade com a qual converge para soluções viáveis, sendo em todos os casos o melhor nesta área. Isto representa uma vantagem, mas também traz um inconveniente, ea dificuldade para este algoritmo para obter repetibilidade quando se trata de encontrar a solução de menor custo. Entretanto, às vezes, especialmente em redes muito grandes, é necessário para você, encontrar a solução mais barata possível, mas um conjunto de soluções fechar a ele tem valor em esta situação, uma vez que o conjunto de soluções é encontrado geralmente em um espaço menor de tempo.

Por exemplo, a rede R-9 de João Pessoa é composto de 61 tubulaçãos ao projeto sob determinadas condições operacionais. O custo mínimo para as condições operacionais de rede é definido 192,366 milhões de um e esta solução não tem repetibilidade com qualquer uma das técnicas, uma vez que ele é uma solução entre $10^{61}$ possibilidades, com muitos mínimos locais. Dada esta situação, encontrar rapidamente um conjunto de soluções que não recebem o custo do projeto, mas um resultado próximo a ele é de muito interesse.

A capacidade de encontrar boas soluções sem custo computacional excessivo é adicionado a vantagem de ter apenas dois parâmetros de ajuste que exigem ajuste, desde o terceiro, o ajuste do PAR foi mostrado para atender funções de otimização de convergência e não. 
No lado oposto em termos de eficiência em as técnicas de otimização discutidos é o modificado algoritmo de PSO que obtém resultados muito mais baixos do que as outras técnicas em todas as redes, a metodologia sendo sempre menos eficiente em todas as simulações. As seções a seguir resumem cada uma das técnicas utilizadas as conclusões desta tese:

\section{Algoritmo Pseudogenético (APG)}

A metodologia de otimização baseada em algoritmos genéticos é mostrado como o mais robusta de todas as propostas, porque, independentemente da configuração considerado para qualquer um dos três parâmetros de otimização é capaz de obter soluções factíveis para o problema de dimensionamento. Esta habilidade do APG representa uma vantagem importante sobre outras técnicas, onde a otimização de parâmetro não é apenas necessárias para melhorar resultados, mas também para a convergência do algoritmo em si.

Neste sentido, a robustez da APG permite que qualquer cálculo dos parâmetros de configuração é capaz de resolver um problema de otimização dado, para que ele não exige qualquer experiência anterior para resolver um desenho ou modelo dado. No entanto, o ajustamento de parâmetros permite a melhoria na prossecução de óptima, quer sob a própria qualidade de a solução ou em os recursos que ele consome o APG quando realizar a simulação. A combinação de qualidade e velocidade é o que é conhecida pela eficiência e de estudo em este artigo mostra que o APG é um dos algoritmos mais eficientes quando se trata de encontrar o dimensionamento óptimo para uma dada rede de distribuição de água.

A eficiência da APG é especialmente bom quando se trata de encontrar a solução de menor custo para uma determinada rede. Dentro dos operadores genéticos que exigem uma certa adaptação, que tem uma maior influência sobre a eficiência do algoritmo é o operador genético de mutação. Na verdade, dado os resultados obtidos podem ser considerados o valor do operador de mutação como o mais crítico de todos que envolvem a metodologia genética, até o ponto em que um ajuste pobre deste operador esvazia em um superlativo piora dos resultados para redes mais complexas. Em geral, podemos concluir que as probabilidades de mutação assumindo cerca de $2-4 \%$, teremos a segurança de trabalhar na faixa melhor possível para esta otimização de parâmetros, já que todas as redes de distribuição analisados mover em torno destes valores. Sobre este operador genético, a influência entre pesquisar o desenho óptimo ou apenas boa esta está faltando, uma vez que o melhor ajuste é o mesmo.

Como para o operador de cruzamento genético, a análise de eficiência mostra como o ajuste deste parâmetro não é tão crítica como no caso de o operador de mutação. A este respeito, e sem negligenciar a melhoria global obtido em a eficiência de cruzar probabilidades que estão acima de $50 \%$ em todas as redes analisadas, ele pode ser dito que o algoritmo é capaz de 
encontrar soluções de mínimos / boa em todas as redes, independentemente da configuração do operador cruzamento.

Por último, a análise de eficiência como para a população inicial com a qual ele funciona o algoritmo determina um número variável de indivíduos em função do objetivo do projeto. Assim, na determinação do concepção custo mínimo para uma dada rede é aconselhável a utilização de populações um pouco mais elevados, em torno de 50-75 pessoas em geral. 0 tamanho da população não irá fornecer uma ótima eficiência a 100\% das redes, mas garante um elevado grau de eficiência em qualquer caso.

Contrariamente ao que outros operadores genéticos, o ajustamento do tamanho da população em função da eficiência varia dependendo dos objetivos de dimensionamento. Assim, quando a obtenção de um conjunto de boas soluções o número de indivíduos envolvidos no processo de otimização pode ser um pouco menos. O estudo de eficiência determinou que todas as populaçãos em torno de redes de 25-50 indivíduos são os mais eficientes, uma vez que garantem a obtenção de um conjunto de boas soluções com baixo custo computacional. Não é aconselhável fazer exame de tamanhos menores de população de 25 indivíduos, uma vez que a qualidade da solução se ressente o suficiente para não compensar o derivado de poupança computacional.

\section{Algoritmo PSO}

O algoritmo de PSO foi originalmente projetado para otimizar as variáveis contínuas, e, posteriormente, adaptado para a otimização de variáveis discretas, tais como a escolha de um determinado tamanho de diâmetro em uma rede de distribuição de água. Esta formulação original da algoritmo de PSO não era de interesse em o problema de otimização discutido neste trabalho, porque o algoritmo converge em uma maneira demasiado cedo para os extremos de o espaço de solução, resultando em custos de dimensionamento poderia ser considerado ruim por comparação com outras metodologias.

Devido a essas limitações, o algoritmo com o qual ele trabalha é um PSO modificado, que introduziu um novo parâmetro, chamado probabilidade de esquecimento $\left(P_{\text {desp }}\right)$, que aumentou a exploração do espaço de soluções, evitando convergência muito cedo do algoritmo. Apesar destas mudanças, o desempenho do PSO algoritmo na otimização das redes de distribuição tem sido muito inferior a outras técnicas, uma vez que a eficiência do algoritmo PSO modificado é altamente penalizado, uma vez que é muito difícil obter soluções mínimas/boas.

Neste sentido, o algoritmo PSO acaba por ser a pior técnica em todo este trabalho analisa as redes com resultados de eficiência distantes de outras metodologias, exceto na rede de túneis em Nova York, onde obteve resultados próximos a APG, mas mais baixo do que o algoritmo de HS e SFL. Bem, independentemente de o conjunto de metas de 
dimensionamento, o algoritmo de PSO não representar, no qualquer um dos casos suscitavam a melhor opção.

Considerando-se a eficiência do algoritmo, dependendo da definição de parâmetros de lá é uma distinção clara feita para estabelecer a importância relativa de alguns parâmetros e outros com relação ao bom funcionamento do algoritmo de PSO modificado. Assim, $\mathrm{P}_{\text {desp }}$ e $\mathrm{V}_{\text {lim }}$ representam dois parâmetros críticos para a eficiência do algoritmo está em causa, sendo a configuração correta de vital importância para os resultados. Neste sentido, os resultados em todas as redes são inconclusivos, de modo que a velocidade limite de uma dada partícula deve ser em torno de $20-30 \%$ do número de valores que podem tomam a variável de decisão, enquanto que a probabilidade de confusão é aconselhável que está em torno de $10 \%$ de partículas totais envolvidas no processo de otimização.

No caso de velocidade máxima, com que se move para uma dada partícula, tendo em conta que, em deste trabalho, a variável de decisão é o diâmetro de instalar em um tubo de dado, o limite implica que, para exemplo para uma gama de dez diâmetros, o $\mathrm{V}_{\lim }$ a que teria de voar dos partículas seria $V_{\lim }=(-2,2)$, o que implicaria um salto máximo de 2 diâmetros dentro do intervalo entre duas iterações consecutivas.

A probabilidade de confusão que é atribuído a uma partícula particular e libera do seguir o líder em uma determinada iteração, os resultados concluir que enquanto o uso de este parâmetro aumenta o espaço de busca do algoritmo, utilizando-se percentuais além de $10 \%$ faz com que a pesquisa a ser cada vez mais aleatório. $O$ estudo identifica como $P_{\text {desp }}$ em torno de $10 \%$ fornecem os melhores resultados do eficiência.

Por outro lado, o ajustamento da constantes $C_{1}$ e $C_{2}$ concluir-se que é de menor importância, pelo menos em da faixa estudada, uma vez que a influência sobre a eficiência do algoritmo é muito menor do que em os parâmetros mencionados anteriormente. Assim, a literatura recomenda, em termos gerais valores cerca de $1,8 \div 2$ para estas duas constantes, sendo a conclusão deste trabalho o mesmo. No entanto, o valor de estes dois parâmetros não pode ser considerado crítico, uma vez que o uso de valores menores de o exposto acima não exercer uma influência decisiva sobre a eficiência do algoritmo de PSO modificado.

Em último lugar, a análise de eficiência em relação à dimensão do população inicial com a qual ela irá produzir o processo de otimização determina, em forma semelhante a como operou o APG, que o critério de tamanho mais apropriado de escolha depende dos objetivos do projeto são apresentados. Assim, se o objetivo do projeto é reunir um conjunto de boas soluções para uma determinada rede do tamanho da população a ser considerado será um pouco menos do que se for necessário para obter o melhor projeto possível.

Neste sentido, o analisa realizada sugerem que, para a obtenção de um conjunto de boas soluções o algoritmo de PSO é mais eficiente quando estiver trabalhando com tamanhos 
populacionais entre 50 e 125 indivíduos, sendo no entanto aconselhável fazer o ajuste dependendo da complexidade do próprio rede. Assim, para redes mais complexas, Hanoi ou R-9 tipo deve ser ajustada para 125 indivíduos, enquanto que para redes com mais facilidade como Nova York ou Go-Yang terá de usar cidades próximas a 50 indivíduos.

O tamanho da população deve ser um pouco mais elevado se se trata de aumentar a probabilidade de uma solução mínima de dimensionamento. Neste caso é aconselhável para trabalhar com populações em torno de 100-125 indivíduos em todos os casos, independentemente de dificuldade da rede de distribuição.

A conclusão final sobre o modificado algoritmo PSO é que, apesar destas recomendações para o ajuste de vários parâmetros, características do algoritmo não é conformar completamente ao problema de projeto, por isso é aconselhável a utilização de metodologias de otimização de outros tratados neste trabalho.

\section{Algoritmo SFL}

A metodologia baseada no algoritmo de SFL é provavelmente o mais poderoso, se um considera apenas a capacidade de obter a solução de menor custo no dimensionamento de uma rede de distribuição em particular. No entanto, a quantidade de recursos computacionais deste algoritmo está localizado a um nível semelhante ao APG na eficiência em termos de soluções óptimas

No entanto, os requisitos computacionais do método faz com que o método de diminuir a sua eficiência quando se considera apenas a capacidade de obter um conjunto de soluções de bom dimensionamento, metodologias como a APG ou SH são superiores neste aspecto, uma vez que obter resultados semelhantes com avaliações menos função objetivo.

SFL também tem uma dificuldade adicional, ea necessidade de estabelecer cinco parâmetros de projeto, cuja influência é crucial para encontrar o melhor dimensionado possível para uma determinada rede. Três destes parâmetros estão associados à natureza da saltos evolutivos em cada iteração do algoritmo, enquanto os outros dois representam o número de indivíduos que intervêm no processo de otimização, o que é comumente conhecido como população inicial o algoritmo.

Assim como aconteceu no APG, a SFL é um algoritmo robusto, capaz de obter soluções convergentes para projetar soluções viáveis para praticamente qualquer configuração dos vários parâmetros de cálculo, mas um ajuste adequado dos mesmos favorece fortemente a obtenção de melhor soluções e crescentes a eficácia do algoritmo.

Assim, a análise de eficiência mostra que dentro da faixa estudada, o menor o número de saltos evolutivos $(N)$ que o uma maior eficiência o do algoritmo, uma vez que eles usam altos 
valores de $\mathrm{N}$ aumenta o número de avaliações da função objetivo até ao ponto de não compensando o possível melhora na o resultado final. Este resultado é coincidente em todas as redes, de modo que a conclusão final em relação a este parâmetro é a de que um valor de $\mathrm{N}=5$ é o óptimo em o problema de otimização que surge, não sendo governado para fora a utilização de valores mais baixos, uma vez que na gama estudada era o menor valor.

No que diz respeito o acelerador de coeficiente, cuja gama de estudo é entre 1 e 2,5, a análise de eficiência descarta os valores nas extremos como o mais apropriado em otimização de SFL. Assim, a conclusão sobre este parâmetro é a de que um valor em torno de 2 aumenta eficiência global do algoritmo e encontrei este em três das quatro redes considerados. A única exceção é a rede de Go-Yang, onde o algoritmo é mais eficiente para $C=1,375$, mas mesmo neste caso, os valores de eficiência são boas em torno de 2, então parece lógico para escolher esse valor como uma ótima eficiência em relação ao coeficiente de acelerador se refere.

O último parâmetro está relacionado com a natureza de saltos evolutivos submemeplex é o tamanho de (Q). Em termos gerais, este parâmetro pode considerado como o, pelo menos crítico sobre o algoritmo de eficiência SFL, uma vez que os resultados são razoavelmente bom independentemente do valor de $Q$, pelo menos, na gama de estudo considerou, compreendendo valores entre zero e um. No entanto, a eficiência de algoritmo é ligeiramente melhorada em todas as redes quando o algoritmo trabalha com os valores acima de 0,4 , de modo que a recomendação final sobre o tamanho de submemeplex irá usar uma configuração de $Q$ mais elevado do que este valor.

No que diz respeito a população inicial o algoritmo, determinada pelo número de memeplexos (n) e o número de rãs por memeplexo $(m)$, os resultados são coincidentes em todas as redes, sendo o algoritmo mais eficiente quanto menor o tamanho da população. Assim, para todas as redes, a combinação de $m$ e $n$ tão pequeno quanto possível, com um total de 100 indivíduos (10x10) envolvidas no processo de otimização é mais eficiente.

Em termos gerais tem provado que todos os algoritmos têm o ponto ótimo de trabalho em tamanhos de população de 100 indivíduos como máximo, de modo que se encaixa a possibilidade de que, no caso de algoritmo de SFL, as populações em torno de 50-75 indivíduos poderia até mesmo melhorar a eficiência do SFL algoritmo.

\section{Algoritmo HS}

A metodologia de otimização baseada no algoritmo de HS acaba por ser uma técnica muito eficiente quando não é necessária para obter repetibilidade na solução de dimensionamento mínimo para uma determinada rede. Assim, esta técnica é muito eficiente na obtenção de um conjunto de boas soluções estreitas para dimensionamento ótimo, uma vez que a convergência de o algoritmo mais antigo é em termos gerais, uma vez que em cada iteração 
realiza apenas uma avaliação de função objectivo, independentemente população inicial de o algoritmo.

Esta característica faz com que o algoritmo de HS é o mais rápido na convergência de todos os algoritmos de otimização estudados neste trabalho, mas em contrapartida diminui a repetibilidade mínimos de dimensionamento, uma vez que HS é menos capaz de explorar. É por isso que em redes de dimensionamento mais complexos, como Hanoi ou João Pessoa, o número de soluções ótimas obtidos pelo algoritmo de HS é muito mais baixa do que a obtida por outras técnicas mais potentes como APG ou SFL. Contudo, ao aplicar o conceito de "boa solução" do algoritmo, que inclui soluções de dimensionamento que são mais de $3 \%$ mais caro do que a solução mínima, o algoritmo HS melhora seu desempenho, classificando como um dos mais eficiente.

A metodologia de otimização baseada no algoritmo HS acrescenta uma outra desvantagem em comparação com técnicas como o AG ou SFL, e a robustez do algoritmo. Assim, HS não é capaz de fornecer soluções viáveis em toda a gama de ajuste que pode dar a seu cálculo parâmetro, portanto, como ocorreu em o algoritmo de PSO original, uma escolha muito pobre de parâmetros pode impedir que convergência do algoritmo. A análise estatística feita podem resolver este problema, mas é algo a considerar nesta técnica de otimização.

Assim, o parâmetro de convergência que deve ser levado em conta na Otimizando o HS é o ajuste do PAR. Os resultados mostram que as redes analisadas configurações de PAR acima de 0,5 não convergirem para soluções viáveis. Da mesma forma, a análise estatística de soluções de mostra que este parâmetro é apenas de convergência, e não de otimização, de modo a que, desde que obtenham a convergência, este parâmetro não afeta a eficácia do algoritmo. É por isso que a conclusão acerca da adaptação PAR é suficiente para garantir a convergência do algoritmo, por isso é recomendado o uso de valores PAR entre 0,05 e 0,3 também.

Deixando de lado o ajuste de convergência, a bondade de soluções de dimensionamento em HS é determinado ajustando o HMCR probabilidade e pelo tamanho da memória do algoritmo (população inicial). O HMCR probabilidade determina se o valor de cada variável de decisão em uma determinada iteração é escolhido a partir dos valores que a variável de decisão mesmo é já em outras partes da memória, ou for tomada para fora. Neste sentido, o ajuste exato da HMCR probabilidade é diferente em cada uma das redes de distribuição de simulados, mas em termos gerais o resultado do projeto é subsidiado para altas probabilidades de HMCR. A conclusão final sobre este parâmetro é considerar valores entre 90 e 95\%, pois essa faixa contém a HMCR configuração ideal em todas as redes de distribuição considerados neste trabalho.

Finalmente, o HS eficácia do algoritmo em função de a população inicial de que é considerado para o processo de otimização segue a mesma linha do que no resto de técnicas, de modo a 
que tamanhos populacionais pequenos são mais eficientes, desde que número este como grande o suficiente para assegurar a diversidade e evitar soluções de convergência muito cedo. Assim, em termos gerais, todas as redes a eficiência máxima obtida tamanhos de memória entre 30 e 45 indivíduos, exceto a rede de Nova York, onde uma exceção ocorre, crescendo a eficácia do algoritmo com o tamanho da população, sem ser alcances chegar a um ponto de inflexão, como ocorre em as redes restantes.

Depois de analisar o termo de eficiência para diferentes algoritmos evolucionários, ponto 6.7 resultados de eficiência utliza para a abordagem e resolução de dois problemas de otimização novo, detalhado abaixo

- Inicialmente, o projeto de expansão trata de uma verdadeira rede no município de Noja. A aplicação de configurações de ideal considerando critérios de eficiência faz com que os modelos de otimização baseado em APG, SFLA, e HS obtido em todos os casos probabilidade de mais de $60 \%$ de obtenção de uma boa solução. $O$ algoritmo PSO, neste caso, está por trás das outras técnicas, já que apenas $10 \%$ obtiveram boas simulações, de acordo com estudos anteriores, que a colocou como a pior técnica.

No que diz respeito a probabilidade de encontrar a solução mínimo de pedido, os resultados são sensitivamente melhor do que quando ele não é considerado qualquer tipo de parâmetros de otimização, uma vez que tanto o APG e do SH obter probabilidade perto de $10 \%$ para se obter óptima, deixando o algoritmo de SFL um pouco atrás, com $6 \%$.

- Modelos de otimização desenvolvidos pode ser modificado de modo que é possível considerar conceitos tais como a confiabilidade. Assim, esta tese considera o sistema é confiável quando ele é capaz de permanecer dentro dos constrangimentos definidos de pressão e fluxo de até mesmo em o evento de que qualquer das linhas sobre a rede tem uma pausa.

Isto se aplica a redes de Hanoi, Nova York, R-9 e Yang Go-definidos ajustes para ser mais eficiente em cada um dos modelos de otimização e todas as redes são projetadas considerando a confiabilidade do sistema em caso de quebra na condução. A aplicação direta de configurações determinadas nesta tese como a mais alta eficiência pode estar confiante de que o algoritmo irá convergir em todos os casos, proporcionando os melhores resultados possíveis.

Por exemplo, na rede de Hanoi, modelos de otimização baseado em APG, PSO e obter SFL mais de um mínimo de $60 \%$ e soluções $100 \%$ das simulações são abrangidas pelo conceito de "boa solução". O algoritmo de HS tem dificuldade em encontrar a solução mínima (3,2\%), mas mais do que $60 \%$ de simulações pode ser considerado como uma boa solução. No resto do as redes não são tão resultados 
impressionantes mas eles estão muito acima aqueles obtidos antes de qualquer otimização dos parâmetros do sistema.

A conclusão final desta tese é que as técnicas de otimização baseadas em algoritmos evolucionários são muito úteis quando se tenta otimizar a resolução de problemas nos sistemas de água. Similarmente, é digno de nota que uma escolha correta de parâmetros para os quais estas técnicas dependem grandemente ajudar a melhorar os resultados obtidos por esta metodologia, minimizando o factor aleatório que acompanha a definição algoritmos. Esta tese define um novo conceito na medida em que respeita técnicas evolucionárias, eficiência e aplicada com sucesso a diversos problemas.

Para resumir as principais conclusões a tese quanto à eficiência de algoritmos de optimização estudados, tabelas 7,1, 7,2, 7,3 e 7,4 mostram a configuração recomendada para cada um dos modelos de optimização. Estes valores representam ajustes de parâmetros eficientes de cada metodologia e representam um bom ponto de partida ao fazer um novo desenho usando métodos evolutivos.

\begin{tabular}{|c|c|c|}
\hline \multicolumn{2}{|c|}{ PARÃMETROS } & Obtenção de soluções minimas \\
\hline Prob. de cruzamento & $\mathrm{P}_{\mathrm{c}}$ & 0,5 \\
\hline Prob. de mutação & $\mathrm{P}_{\mathrm{m}}$ & $0,02-0,03-0,04$ \\
\hline Tamanho da populaçao & & 50 \\
\hline
\end{tabular}

Tabla 7.1. Best-fit eficácia do algoritmo APG.

\begin{tabular}{|c|c|c|}
\hline \multicolumn{2}{|c|}{ PARÃMETROS } & Obtenção de soluções minimas \\
\hline Limite de velocidade & $\mathrm{V}_{\lim }$ & 0,2 \\
\hline Prob. de esquezimento & $\mathrm{P}_{\text {desp }}$ & 0,1 \\
\hline Constante 1 & $\mathrm{C}_{1}$ & 2 \\
\hline Constante 2 & $\mathrm{C}_{2}$ & 2 \\
\hline Tamanho da populaçao & & $75-225$ \\
\hline
\end{tabular}

Tabla 7.2. Best-fit eficácia do algoritmo PSO.

\begin{tabular}{|c|c|c|}
\hline \multicolumn{2}{|c|}{ PARÃMETROS } & Obtenção de soluções minimas \\
\hline Probabilidade HMCR & HMCR & $0,92-0,95$ \\
\hline Ajuste pitchrate & PAR & 0,15 \\
\hline Tamanho da populaçao & & 50 \\
\hline
\end{tabular}

Tabla 7.3. Best-fit eficácia do algoritmo HS.

\begin{tabular}{|c|c|c|}
\hline \multicolumn{2}{|c|}{ PARÃMETROS } & Obtenção de soluções minimas \\
\hline Tamanho submemeplex & $\mathrm{Q}$ & 0,4 \\
\hline Número saltos evolutivos & $\mathrm{N}$ & 5 \\
\hline Coeficiente de aceleraçao & $\mathrm{C}$ & 2 \\
\hline Rãs memeplexo & $\mathrm{m}$ & 10 \\
\hline Tamanho da populaçao & $\mathrm{n}$ & 10 \\
\hline
\end{tabular}

Tabla 7.4. Best-fit eficácia do algoritmo SFL. 


\section{Desenvolvimentos futuros}

Devido à versatilidade de algoritmos de otimização heurísticos, vários pesquisadores têm aplicado com sucesso destas técnicas para a resolução de todos os tipos de problemas em muitos campos, entre os quais incluem a otimização do projeto de redes de água. No entanto, até à data não existiam técnicas para a comparação entre esses métodos para além do resultado final, por isso era difícil de determinar qual a técnica poderá ser mais adequado para cada problema.

Este documento desenvolve o conceito de eficiência na aplicação de algoritmos evolutivos para otimizar o projeto de redes de água, que determina qual algoritmo funciona melhor com base em ambos o resultado econômico obtido como a velocidade de cálculo do algoritmo. No entanto, os resultados em esta tese não pode ser considerado como universal, uma vez que eles são baseados em apenas quatro redes de distribuição. As linhas a seguir passar por cima de algumas áreas em que se considere necessário para aprofundar a compreensão do problema:

- Modelos para a otimização do proposto. Obviamente, qualquer um de as metodologias desenvolvidas nesta tese pode ser melhorado, uma vez que é sempre introdução de eventuais alterações os algoritmos de otimização, a fim de melhorar a habilidade de o mesmo. Sem dúvida esta é uma das grandes vantagens de algoritmos evolucionários, que são muito versáteis quando as alterações na programação deles.

- Validade dos critérios de desempenho em outros problemas de otimização. Os resultados obtidos sobre a configuração mais eficiente em cada algoritmo de otimização não pode ser considerado como universal, mas são um bom ponto de partida para abordar o projeto de redes de água de distribuição ou outros de análise de outros problemas otimização.

- A investigação sobre novos métodos de otimização. Os cinco algoritmos de otimização desenvolvidos nesta tese não são únicos, mas existem muitas metodologias na literatura baseada em algoritmos evolutivos. Esta tese estudou as metodologias consideradas mais importantes e mais capaz de desenvolvimento, mas seria um erro não considerar tratar no desenvolvimento futuro de outros algoritmos evolucionários que podem melhorar os resultados existentes.

- Abordagem de problemas de otimização novos diretamente relacionados com a concepção de redes de distribuição de água. Neste sentido, o projeto feito nesta tese prevê apenas o dimensionamento da tubulação da rede de distribuição de água, atendendo a uma série de restrições à velocidade e pressão. No entanto, é possível introduzir os critérios de projeto novas, como poderia ser o de otimização de bombeamento ou a confiabilidade do sistema de distribuição de água. 
No mesmo sentido, seria interessante desenvolver modelos de otimização baseados em algoritmos evolucionários que permitem a resolução de outros problemas relacionados ao sistema hidráulico, como poderia ser o modelo de recuperação do tubulaçãoes, a determinação do fluxo descontrolado ou detecção de vazamentos em sistemas pressurizados.

Finalmente, note que neste momento estão a adaptar os modelos de otimização desenvolvidos e as conclusões desta tese, a fim de participar na batalha global para o projeto de rede de água (A Batalha da Água Redes II), sob dentro das atividades do simpósio 14 de análise de redes de distribuição de água a ser realizada na Austrália em setembro de 2012. Para este caso, os algoritmos são adaptados para o dimensionamento de funções multiobjetivo, uma vez que não só é necessário considerar os critérios de dimensionamento, mas também critérios de qualidade. 